
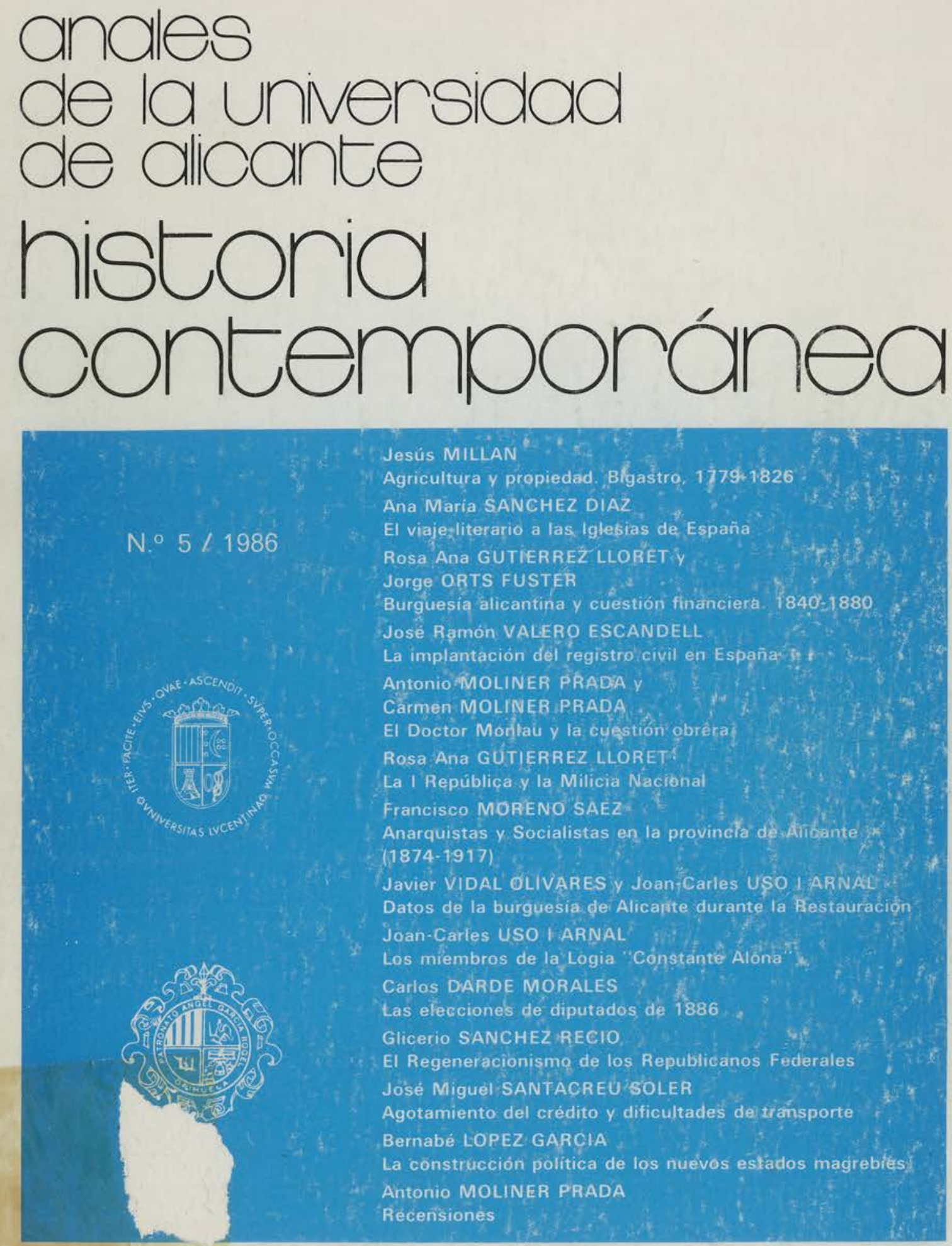

DEPARTAMENTO DE HISTORIA CONTEMPORANEA

UNIVERSIDAD DE ALICANTE

PATRONATO "ANGEL GARCIA ROGEL". ORIHUELA

CAJA DE AHORROS DE ALICANTE Y MURCIA 

anales

de la universidad

de allcante.

nistoria

contemporánea 


\section{ANALES DE LA UNIVERSIDAD DE ALICANTE HISTORIA CONTEMPORANEA}

Director: Salvador FORNER MUÑOZ

Secretario: José Miguel SANTACREU SOLER

Vocales: Concepción FERNANDEZ-CORDERO AZORIN Rosa Ana GUTIERREZ LLORET

Francisco MORENO SAEZ Glicerio SANCHEZ RECIO

\section{SECRETARIADO DE PUBLICACIONES UNIVERSIDAD DE ALICANTE \\ CAJA DE AHORROS DE ALICANTE Y MURCIA}




\section{andes \\ de la universidad de allicante. \\ nistoria \\ contemporánea}



Agricultura y propiedad de la tierra en la colonización señorial. Bigastro 1779-1826, por Jesús MILLAN.

El viaje literario a las Iglesias de España: una empresa ilustrada de los hermanos Villanueva en la primera mitad del siglo XIX, por Ana María SANCHEZ DIAZ.

La burguesía alicantina y la cuestión financiera. 1840-1880, por Rosa Ana GUTIERREZ LLORET y Jorge ORTS FUSTER.

La implantación del registro civil en España (problemas de utilización en estudios demográficos), por José Ramón VALERO ESCANDELL.

El Doctor Pere Felip Monlau y la cuestión obrera, por Antonio MOLINER PRADA y Carmen MOLINER PRADA.

La I República y la Milicia Nacional: organización del Batallón de Voluntarios de la República de Alicante, por Rosa Ana GUTIERREZ LLORET.

Anarquistas y Socialistas en la provincia de Alicante (1874-1917), por Francisco MORENO SAEZ.

Datos básicos para la reconstrucción histórica de la burguesía de Alicante durante la Restauración, por Javier VIDAL OLIVARES y Joan-Carles USO I ARNAL.

Aproximación al estudio cuantitativo y socio-profesional de los miembros de la Logia "Constante Alona» de Alacant, por JoanCarles USO I ARNAL.

Las elecciones de diputados de 1886, por Carlos DARDE MORALES.

El Regeneracionismo de los Republicanos Federales, por Glicerio SANCHEZ RECIO.

Agotamiento del crédito y dificultades de transporte (dos problemas de las relaciones comerciales republicanas entre particulares durante la guerra civil española 1936-1939), por José Miguel SANTACREU SOLER.

La construcción política de los nuevos estados magrebíes, por Bernabé LOPEZ GARCIA.

Recensiones, por Antonio MOLINER PRADA.

Memorias de licenciatura: resúmenes de las memorias de licenciatura leídas en el Departamento de Historia Contemporánea de la Universidad de Alicante. 



\section{AGRICULTURA Y PROPIEDAD DE LA TIERRA EN LA COLONIZACION SEÑORIAL BIGASTRO, (1779-1826) JESUS MILLAN Universidad de Valencia.}

La importancia de la expansión del espacio agrícola durante el siglo XVIII en el País Valenciano ha sido puesta de relieve repetidamente. Con menor frecuencia, sin embargo, se ha tratado de relacionar este desarrollo de la agricultura con la evolución de la sociedad que lo protagonizaba. Un estudio de este tipo no puede limitarse a la evolución de las producciones agrarias, sino que debe fijarse especialmente en las estructuras sociales y en la dinámica económica que impulsa. Problemas como la forma en que se desarrolló el capitalismo en el campo valenciano o el debate sobre el relativo retraso industrial no pueden afrontarse sin tener en cuenta la manera en que se extendió la agricultura, los grupos sociales que resultaron beneficiados y las estructuras productivas y de mercado que se derivaron de ello. La contraposición de hipótesis interpretativas en estos terrenos hace más interesantes los intentos de cuantificación, aunque se refieran a casos singulares.

El extremo sur del País Valenciano fue un territorio de colonización por excelencia durante el siglo XVIII' '. Frecuentemente esta colonización fue realizada mediante la fórmula de la fundación de señorios de jurisdicción alfonsina. En general, el procedimiento abarca una vertiente económica y un aspecto político. Por un lado se trataba de rentabilizar fincas anteriormente poco explotadas mediante el asentamiento de un cierto número de colonos. Pero, en realidad, el procedimiento estaba lejos de ser una mera operación económica. El promotor de la colonizaciớn recibía un cierto ámbito de poder jurisdiccional sobre el lugar recién fundado. Ello le permitía privatizar determinadas esferas de poder público, por debajo de un municipio realengo o de otro señor superior. Tras la supresión de los fueros valencianos en 1707 se impuso de hecho la interpretación de que las competencias superiores del municipio realengo habian desaparecido. Por más que, teóricamente al menos, se mantuviese vigente la posibilidad de recurrir a los tribunales reales, lo cierto es que una jurisdicción menor, pero inmediata y determinante sobre la vida de los colonos, se transfería a las manos privadas del señor. En el caso de Bigastro, el acta fundacional reservaba al Cabildo catedral el nombramiento de los cargos municipales, la autorización y presidencia de las asambleas vecinales y el visto bueno para los acuerdos del concejo del lugar (caps. 8, 12). Los vecinos no podrían acudir

1 ALBEROLA ROMA, A., 1984. GIMENEZ LOPEZ, E., 1981. RUIZ TORRES, P., 1979. MILLAN, J., 1984, pp. 98-112, 176-196. 
a ningún otro juez y quedaban sometidos a la discrecionalidad del Cabildo para dictar nuevas ordenanzas (caps. 34 y 36). Como veremos, los canónigos usaron esta facultad en temas como la cosecha de seda o el avecindamiento de nuevos colonos. Todo ello sin necesidad de recurrir a expedientes - como las concesiones gubernatorio nomine- que de hecho asimilaban estos señoríos a los de mero y mixto imperio. Así, en el señorío de Benejúzar, fundado como alfonsino en el siglo XVII, la justicia, designada por el señor, regulaba en el XVIII, desde los juegos de cartas y las horas nocturnas en que podían pasear por la calle los vecinos casados hasta las penas con que se castigaba el acceso al soto señorial. En varias ocasiones impuso penas de destierro por intentos de violación o por disputas derivadas del canto de coplas satíricas a horas intempestivas. Por ello me parece dudoso afirmar, como hace A. Gil Olcina, que la jurisdicción alfonsina no suponía «la suplantación de la justicia real, sino una acción complementaria de policía de pequeños núcleos». De ser así, idéntico cometido hubieran podido cumplir los diputados rurales designados por el municipio realengo, pero es elocuente que cuando la ciudad de Orihuela, hacia 1730, ofreció esta posibilidad - que respetaba el dominio directo de los señores sobre la tierralos señores y las autoridades reales la desecharan rápidamente ${ }^{2}$. Los señores alfonsinos, por tanto, no sólo deseaban conservar sus títulos sobre la tierra sino, de modo muy especial, ejercer también un poder político autónomo y no una mera delegación de funciones por parte de un poder central superior.

La colonización también es característica de un comportamiento económico especial por parte de los señores. En la corona de Castilla se fue haciendo manifiesto a lo largo del siglo XVIII que muchos propietarios importantes preferían mantener buena parte de sus tierras sin cultivar o dedicadas a una agricultura extensiva. Por el contrario, en el caso de la colonización alfonsina en el País Valenciano quienes disponían de la tierra - bien en dominio consolidado o bien en dominio útil- prefirieron emprender la fundación de un lugar y el asentamiento de colonos: un proceso que fue aconsejado casi siempre en vano para otras zonas de España ${ }^{3}$. Por tanto, la colonización señorial viene a llamar la atención sobre una peculiar estructura social en la que estos dueños de la tierra debian ennoblecerse precisamente por medio de una

${ }^{2}$ GIL OLCINA, A., 1983, p. 42. Sobre el problema de la jurisdicción de los señoríos alfonsinos y la ciudad realenga de Orihuela en el siglo XVIII, MILLAN, J., 1984, pp. 288-297. La carta de fundación del lugar de Bigastro en ARV, Escribanías de Cámara, 1816, n: 97, fs. 129 v.- 143. Los datos de Benejúzar proceden de AMBE, Libros capitulares y Causas criminales, ss. XVIII y XIX. Vid. ALBEROLA ROMA, A., 1984, pp. 418-421. 1978.

${ }^{3}$ Cfr. Millan, J., 1984. LlUCH, E., 1973. AMALRIC, J.P., 1983. ARTOLA, M., 
puesta en cultivo más intensa de su patrimonio.

Por otra parte, esta opción afectaba al conjunto de la sociedad, al introducir en los circuitos de acceso a la tierra nuevas superficies hasta entonces poco disponibles o totalmente marginadas de la agricultura. ¿De qué modo se producía esta influencia en la dinámica social? A primera vista, cabría sospechar una relación favorable al campesinado, dada la mayor afluencia de tierras dispuestas para el cultivo. Sin embargo, esta primera tendencia teórica no explica la complejidad real de los resultados en ningún proceso de colonización. Con frecuencia, los terrenos colonizados por sus propietarios habían estado anteriormente al alcance de los usos de la población campesina. La colonización no significaba, pues, un simple acceso a nuevas tierras, sino, muchas veces, su entrega a los colonos en otras condiciones, bajo pactos filtrados y dispuestros por la propiedad y la jurisdicción privada del señor. Esta circunstancia desvirtúa, naturalmente, muchas de las consecuencias favorables que de otro modo debiera haber tenido para el campesinado el proceso colonizador.

En el caso del Bajo Segura, Gil Olcina ${ }^{4}$ ha señalado la pervivencia hasta el siglo $X X$ de grandes propiedades nobiliarias en municipios originados por la colonización señorial durante el siglo XVIII. El hecho se contrapone a la suerte seguida por otros señoríos valencianos, cuya propiedad territorial acabó por desvanecerse en la práctica durante el siglo XIX. ¿Cómo se explica la evolución seguida por estos señoríos? No creo que su menor extensión territorial - lo que siempre es algo relativo - explique por sí sola la trayectoria a favor de la consolidación del dominio en manos del señor. Ni tampoco la escrupolosidad en una gestión que no difería tanto de la de los señores baronales que disponían de derechos menos rentables. En realidad, en el primer caso se trataba de operaciones de colonización conducidas por la iniciativa señorial que era también, no hay que olvidarlo, la del propietario de la tierra en el momento de la fundación. Es cierto que la necesidad de atraer colonos podía jugar a favor del campesinado, pero, por otra parte, la lógica y el alcance de los asentamientos campesinos no respondían a la propia necesidad del labrador, sino a los intereses del titular del señorío. Así, el señor podía conceder fórmulas de asentamiento más o menos favorables a los colonos o reservarse parte de la tierra en dominio consolidado, siempre en función de la urgencia del proyecto agrícola y de la fuerza negociadora de los colonos. Esta, cuando la propiedad privada los excluía de la tierra, tendía a ser escasa. Todo ello se daba en coyunturas históricas cambiantes. A fines del siglo XVII la colonización señorial se vio obligada a conceder a los nuevos pobladores

${ }^{4}$ GIL OLCINA, A., 1979, pp. 158-161. 
el dominio útil de buena parte del territorio. No obstante, pese a la renovada presión demográfica que vivía la comarca, la viabilidad de las colonizaciones por entonces fué muy precaria. En ello debió influir la abundancia de tierras disponibles y la salvaguarda que los fueros prestaban a muchas práticas campesinas, amparadas por los derechos de la ciudad realenga de Orihuela ${ }^{5}$.

Posteriormente la colonización cambió de signo. Tras la Guerra de Sucesión y la supresión de los fueros valencianos (1707), los señores necesitaron cada vez emnos ceder el dominio útil a fin de atraer colonos. Al generalizarse la privatización de la tierra en la comarca, los campesinos hubieron de aceptar condiciones progresivamente más inestables. De ahí la aparición de grandes propiedades cuyo dominio útil no fue entregado por los señores a los campesinos. A fin de cuentas, la explotación agraria sólo requería la enfiteusis en ciertas circunstancias y los terrenos poseídos en dominio consolidado por el señor pudieron ser objeto de explotación mediante otras fórmulas renovables tempralmente. «Estas propiedades sólo en parte son llevadas por sus dueños y lo demás está repartido entre un número mayor o menor de renteros», observaba a comienzos del siglo $X X$ una junta ministerial ${ }^{6}$. Ya desde el siglo XVli los señores se habían reservado en muchos caso el dominio pleno, pero habian fragmentado la explotación entre numerosos arrendatarios. De nuevo era la misma economía campesina, pero sometida a situaciones más precarias que la enfiteusis, lo que servía para cultivar la tierra. Por tanto, la colonización señorial valenciana, ni siquiera en estos caso más tardíos, no se resolvía en la franca desposesión del campesinado y el empleo de mano de obra asalariada. Esta diferencia entre gran propiedad y pequeña explotación separa el caso del Bajo Segura del modelo andaluz o la conocida «vía prusiana».

El caso a que se refiere este trabajo responde escasamente a la asimilación a que se ha podido hacer entre gran propiedad y señorios de jurisdicción alfonsina en el sur valenciano. En Bigastro a diferencia de otros cásos próximos, parece haberse distribuido toda la tierra en enfiteusis. Situado a unos $5 \mathrm{Kms}$. de Orihuela, con una posición favorable

${ }^{5}$ Es significativo que la primera solicitud del Cabildo para obtener la jurisdicción alfonsina en Bigastro fuese rechazada por el procurador patrimonial, Jaume Roig, alegando falta de pruebas. El mismo Jaume Roig había amparado las reclamaciones de la ciudad de Orihuela contra el segregacionismo del señor de Jacarilla, que impedía las prácticas comunales de los vecinos. Este pleito había sido ganado por la ciudad en 1697 y en 1699 el municipio oriolano se planteó la posibilidad de requerir el apoyo del procurador patrimonial contra nuevas privatizaciones del marqués de Rafal. MILLAN, J., 1981 y 1984, p. 118. ARV, Escribanías de cámara, 1816, n: 97, fs. 91 ss. (22-IX y 15-XII-1701).

${ }^{6}$ Cit. GIL OLCINA, A., 1983, p. 49. 
en la huerta del Bajo Segura y caracterizado por la enfiteusis, este pequeño señorío eclesiástico parecería especialmente adecuado para el desarrollo de la prosperidad campesina. Sin embargo, contrariamente a lo que se ha supuesto a veces de forma mecánica, ni la división de dominios y los censos fijos en metálico garantizaron la propiedad del campesinado, ni el resultado del proceso colonizador fue el fortalecimiento económico y la acumulación a favor de los cultivadores directos. Sin duda, el estudio de un único caso resulta poco explicativo de la evolución de un conjunto sometido a circunstancias diversas, pero el examen de la trayectoria de un lugar puede arrojar alguna luz sobre algunas suposiciones y debates actuales en torno a la estructura social y económica del campo valenciano contemporáneo?.

\section{UNA PROFUNDA TRANSFORMACION DEL CULTIVO}

El lugar de Bigastro fue fundado como señorío de jurisdicción alfonsina por el Cabildo catedral de Orihuela en 1701. El hecho se inscribe en la colonización señorial que resurgía a finales del siglo XVII, en coincidencia con la recuperación demográfica y la reactivación del comercio. La finalidad del Cabildo era incrementar el cultivo -y consiguientemente las rentas - de diversas fincas que habian pasado a su poder. Las descripciones de estas propiedades no son siempre precisas o coincidentes pero, al menos, nos sirven para darnos una idea de la distribución de cultivos antes de la colonización ${ }^{8}$, según se observa en el cuadro adjunto.

En conjunto, unas 256 hectáreas en la zona sur oriental de la huerta próxima a la ciudad de Orihuela y, por tanto, contigua a núcleo fundamental de expasión demográfica. La zona de agricultura más intensiva en la huerta oriolana había sido tradicionalmente el sudoeste de la ciudad y esta situación periférica de Bigastro hasta entonces se acusa en el tamaño de las propiedades y en el peso del secano y la tierra sin arbolado. 1985.

${ }^{7}$ GIL OLCINA, A., 1979. ROMERO GONZALEZ, J., 1983. RUIZ TORRES, P.,

${ }^{8}$ CANALES, G., 1981. También he utilizado ARV, Escribanías de cámara 1816, n. 97 , fs. 91 ss. 


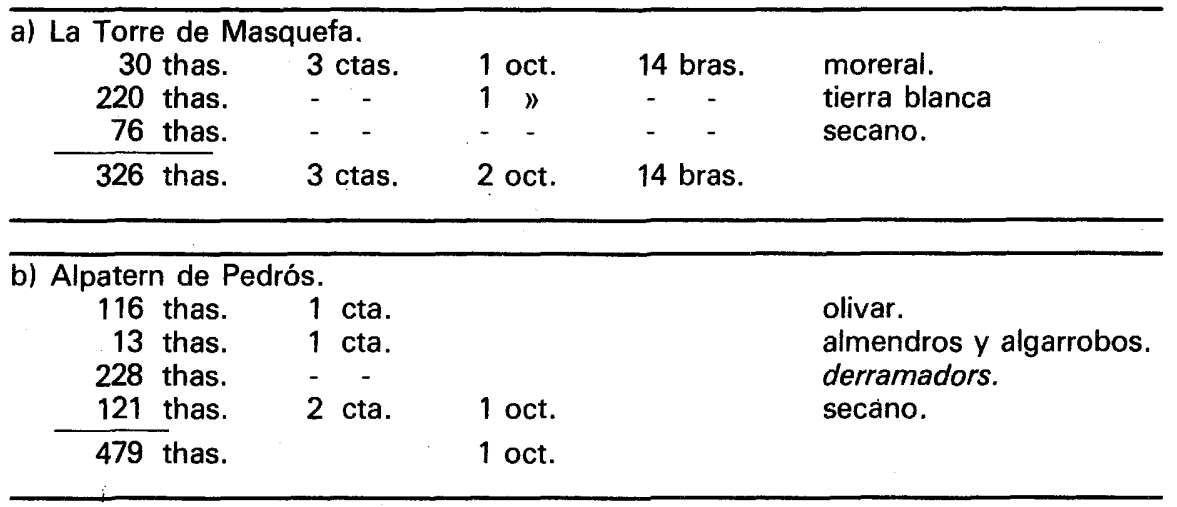

c) Heredad de D. Juan Ferrández de Mesa.

18 thas. 1 cta. viña.

528 thas. - - blanca regadio.

293 thas. 2 ctas. secano.

839 thas. 3 ctas.

ch) Heredad de Ginés Aniorte.

195 thas.

d) Heredad de D. Arnaldo Rosell y Roca.

$\begin{aligned} 112 & \text { thas. } \\ 128 \text { thas. } & \text { secano y olivar. } \\ 68 \text { thas. } & \text { moreral y olivar. }\end{aligned}$

En conjunto, unas 256 hectáreas en la zona sur oriental de la huerta próxima a la ciudad de Orihuela y, por tanto, contigua a núcleo fundamental de expansión demográfica: La zona de agricultura más intensiva en la huerta oriolana había sido tradicionalmente el sudoeste de la ciudad y esta situación periférica de Bigastro hasta entonces se acusa en el tamaño de las propiedades y en el peso del secano y la tierra sin arbolado.

La estrategia del Cabildo fue, no ceder estas fincas por separado a diversos arrendatarios, sino agruparlas para establecer una colonización conjunta del territorio. ¿Cómo se llegó a la decisión de fundar un lugar y repartir el dominio útil de la tierra? El criterio no se adoptó sin indagaciones: seis canónigos fueron comisionados «per a que fasen totes les diligencies convenients per a veure si convindrà fer un lloch». La actitud final debe entenderse dentro de la lógica seguida en aquella coyuntura económica. Por aquellos años el Cabildo mostraba un especial interés por extender el cultivo de sus fincas, incorporando a la labranza 
las zonas incultas adyacentes. Para ello utilizaba bien el trabajo de sus arrendatarios - a quienes comprometía en los contratos y subvencionaba a veces después-, bien sus propios recursos en casos especiales. La premura por poner la tierra en cultivo parece ser lo determinante y a ello se supeditaba la forma concreta de explotación que se introduciria. Algún ejemplo parece sugerir que el interés por labrar las propiedades no era ajeno, en realidad, a la polémica sobre el aprovechamiento de los terrenos incultos, recientemente renovada por entonces:

"Que es llaure lo tros de terra que està inculta que és part de Matarredona ...y que es ferme de dret sobre dit tros de terra, y que es veja si lo pot llaurar lo arrendador de Matarredona, y si no que correga lo gasto per conte del Capítol llaurant de present promptament un bancalı ${ }^{9}$.

De este modo, la distribución del dominio útil en Bigastro, lejos de contemplarse como un gesto ajeno al cálculo económico, parece estrechamente relacionada con el interés por aumentar la renta de la tierra en las condiciones demográficas y políticas dominantes en aquel momento. La forma concreta que adoptó la colonización del territorio de Bigastro debía suponer, además del posible afán de prestigio social que otorgaba el señorío, la desconfianza en que los arrendatarios disponibles pudiesen mejorar notablemente las fincas y hacerlas más rentables a corto plazo. Por otra parte, el Cabildo decidió emprender la fundación del lugar en 1697: el mismo año en que la ciudad realenga de Orihuela habia logrado la recuperación parcial de los usos comunales sobre las tierras incultas del término. Si se trataba de evitar esta amenaza, el imperativo de la roturación debía hacerse por una vía rápida que sólo el asentamiento de muchos colonos era capaz de asegurar ${ }^{10}$.

Las tierras que los canónigos se disponian a colonizar no se hallaban exactamente en una condición de baldías o. abandonadas, pues el olivar e incluso la morera tenían ya una presencia notable. Había, sin embargo, una cierta extensión de secanos y zonas marginales al regadío que vienen a reproducir el problema habitual de los yermos contiguos a las tierras roturadas. Se trataba de elevar el nivel de intesificación del cultivo, extendiendo el modelo que era normal entonces en un

\footnotetext{
${ }^{9}$ ACO, Dietari, 1692-1707, fs. 175 v., 192 v. Otro ejemplo en sentido similar (f. 208): "Que es informe si Sebastián Vargas tè cultivades les quaranta tafulles que tè arrendades... y si constàs haver cumplit ab la obligació ab que se li arrendaren, que se li preste a dit Bargues dos cafisos de forment per a que sembre dites terrers, fent obligació de restituhirlo per a lo mes de juliol de 1699 y donnant fermansa». Agradezco las facilidades dadas por J. Sánchez Portas para la consulta de estos fondos.

${ }^{10}$ Sobre el problema de los pastos y las dificultades para obtener el derecho a vallar los de los particulares, MILLAN, J., 1984, pp. 112-115.
} 
sector restringido de la huerta de Orihuela. No se trataba, por tanto, de'una colonización para poner en cultivo tierras abandonadas, como haría con sus propiedades, por ejemplo, el convento de la Merced - «no las puede cultivar, de las cuales no percibe utilidad alguna»" ${ }^{1-}$, sino de una intesificación mayor del cultivo que contrasta con la tendencia a la explotación extensiva (cultivo al tercio, auge de la ganadería) que se imponía por entonces en muchas zonas de la corona de Castilla $^{12}$. Los canónigos oriolanos, por el contrario, obligaron a los colonos a plantar en el plazo de cuatro años, so pena de comiso, 6 tahúllas $(0,7$ has.) de viña, olivar, moreral o frutales. Dado que los colonos iniciales eran 16, estos cultivos, que en los momentos fundacionales de la colonización sólo ocupaban como mucho el 18,7 por 100 de la superficie, se incrementarían, según los planes del Cabildo, en el plazo de cuatro años casi una cuarta parte más: un 23 por 100 de la tierra vendría así a estar ocupado por estas plantaciones.

Vale la pena destacar que, en términos relativos, la superficie de Bigastro no era especialemente grande. Las fincas reunidas por el $\mathrm{Ca}$ bildo constituían una extensión pequeña comparada con las dehesas y cortijos de Salamanca, Extremadura, La Mancha o Andalucía durante el siglo XVIII, cuya extensión con mucha frecuencia cuadruplica por lo menos la disponible en Bigastro. Dentro de la comarca del Bajo Segura Bigastro queda bastante lejos de las casi 2.200 has. colonizadas mediante enfiteusis por las Pías Fundaciones o de las 1.500 que, a fin del setecientos, se apropiaría el señor de Algorfa. Se incluye, por el contrario, entre un cierto número de operaciones colonizadoras como las de Formentera ( 369 has.), la de los jesuitas en el Campo de Salinas (289 has.) y, probablemente, la del contiguo lugar de Molins, realizada muy poco antes ${ }^{13}$.

El lugar fundado por los canónigos ocupa un lugar destacado en la demografía de la comarca durante el siglo XVIII. Según los datos censales habría crecido a una tasa del 3,09 por 100 acumulativo al año entre 1716 y 1794 , lo que lo coloca a la cabeza de las poblaciones del Bajo Segura. A ello ha debido contribuir en la primera mitad del siglo una natalidad particularmente alta, así como el estímulo de la tierra fértil distribuida en enfiteusis. El crecimiento se hizo mucho más lento en la segunda mitad del siglo y, por último, entre 1794 y 1827 los datos censa-

1 Cit. BERNABE GIL, D., 1982, pp. 139-140.

12 GARCIA FERNANDEZ, J., 1979.

${ }^{13}$ BERNABE GIL, D., 1982, pp. 139-141. Hubo establecimientos de fincas menos extensas, ya sin originar señoríos alfonsinos. Cfr. CABO ALONSO, A., 1979 y 1983. GARCIA FERNANDEZ, J., 1979. 
les suponen sólo un aumento del 0,56 por 100 anual. La serie parroquial de bautismos muestra un rápido auge que llega a doblar las cifras iniciales en menos de 30 años (1727-1756); luego tiene lugar un bache que no se supera hasta $1772-76$ y los altibajos, acompañados de alzas en los matrimonios, se prolongan en 1791 a $1832{ }^{14}$.

Según los cabreves del Cabildo este incremento demográfico tan notable no se refleja en la expansión de la superficie cultivada. Entre 1715 y 1722 los canónigos distribuyeron en enfiteusis unas 268 has. Las tierras cabrevadas en 1779 eran 291,3 has. y en 1826 unas 264 has. De este modo, sólo cabe admitir ligeros cambios: un 8,7 por 100 más en 1779 y un 1,5 por 100 menos en 1826, siempre respecto al terrazgo inicial. ¿Cómo se puede explicar esta superficie casi estática en presencia de un aumento de población tan notable? Cabría suponer que los cabreves no incluyeran todas las tierras labradas del lugar, pero hay que señalar que no aparecen referencias a tierras no sometidas al dominio directo del Cabildo. Es cierto que los censos agrarios actuales vienen a señalar como superficie labrada en Bigastro el doble de la que aparece en los cabreves ${ }^{15}$. Dejando de lado la posible alteración de los término municipales, la diferencia respecto a estas cifras debe radicar en las tierras que no podian explotarse con las técnicas anteriores y que, por tanto, no eran de hecho cultivables. Por consiguiente, si todo el aumento de población ha gravitado sobre una superficie prácticamente invariable, ¿cabe hablar de un «ciclo estático» en este proceso de colonización? La ampliación de la superficie cultivada no es el único dato a tener en cuenta, sino que se debe considerar la evolución de los cultivos sobre esta superficie casi idéntica a lo largo del tiempo. Para observarlo he elaborado los cuadros 1 y 2.

El resultado de la colonización no puede ser considerado simplemente como un callejón sin salida o como una "expansión estática». A todas luces la agricultura de Bigastro se ha alterado profundamente, no en virtud de la ampliación de la labranza a nuevas tierras, sino a partir de cambios importantes en los cultivos mantenidos en las tierras del señorío. Para empezar, algo más del 52 por 100 de la tierra era de rega-

${ }^{14}$ MILLAN, J., 1984 pp. 143-144, 154-156, 160, 373-376.

${ }^{15}$ Las concesiones iniciales en ARV, Escribanias de cámara, 1816, n? 97. Las fuentes para 1770 y 1826 son ACO, Cabreve original del lugar de Bigastro. Año 1779, n: 1.374; Hijuela de Bigastro, n. 1.379. Mientras que en el primer caso se trata de un cabreve levantado en aquel año, la segunda fuente consiste en una lista de enfiteutas, elaborada antes de la Guerra de Independencia, en la que se han ido introduciendo anotaciones posteriores sobre enajenaciones y herencias. Estas anotaciones alcanzan hasta 1826, aunque hay alguna rectificación de 1827. Para elaborar esta fuente he omitido todas las partidas rectificadas y he tomado en consideración sólo las anotaciones que aparecen vigentes hasta la fecha más avanzada. Tampoco he utilizado los datos sobre el dominio útil de las casas. 


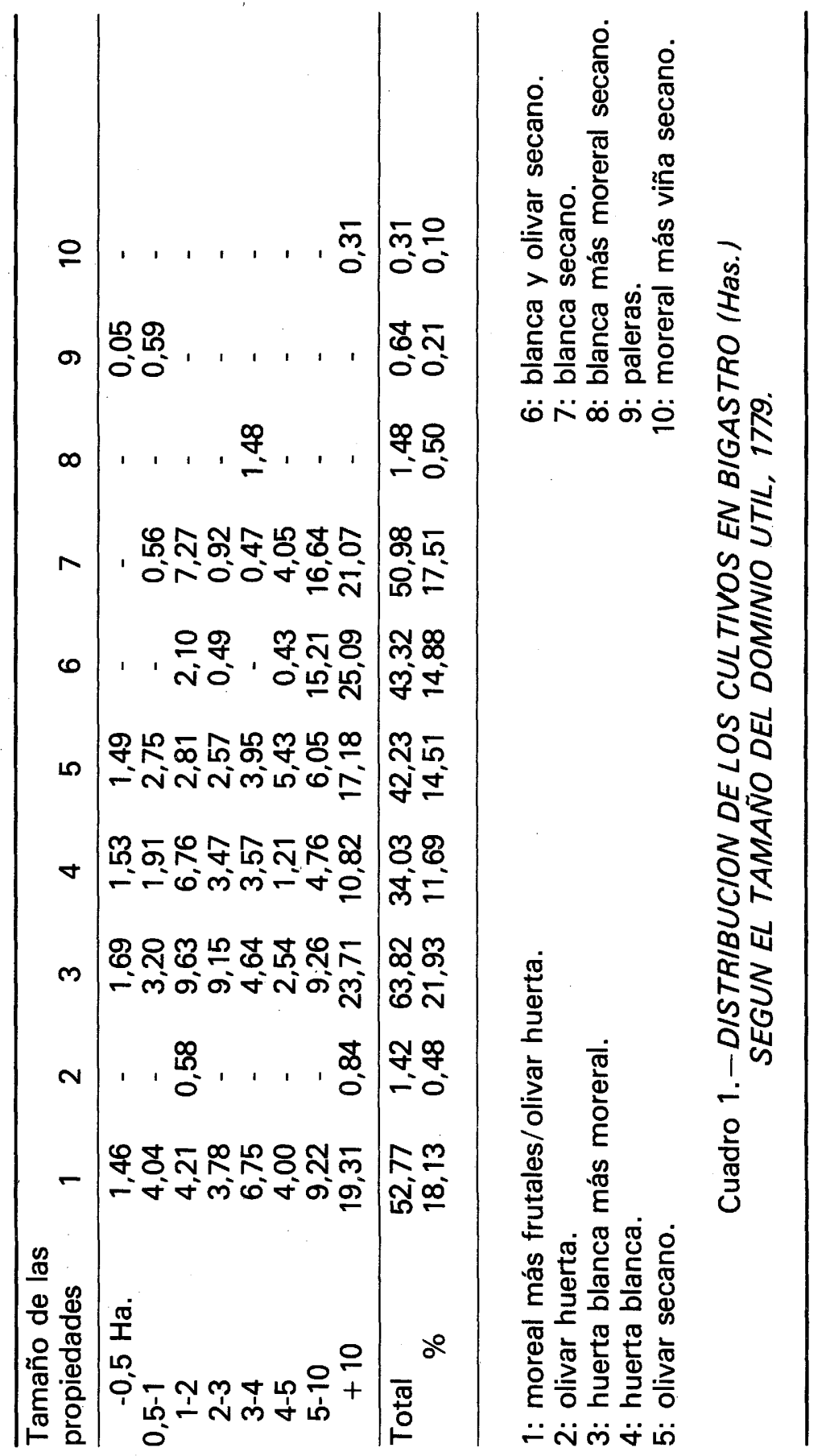




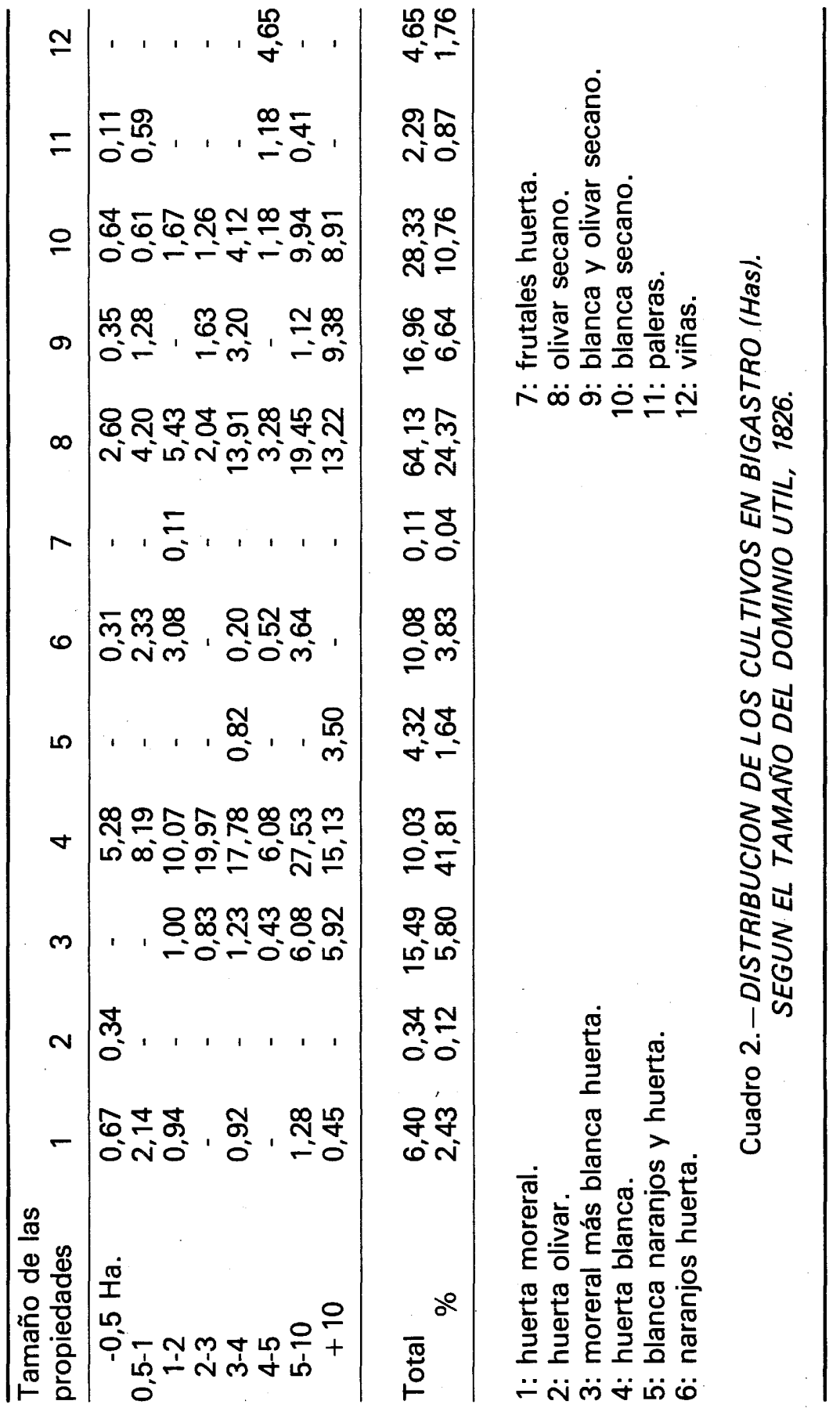


dío en 1779 y en 1826, pese a la notable crisis arrastrada desde hacía décadas, este porcentaje avanza hasta el 56 por 100, aunque quizás ello se explique por el abandono parcial del secano. En cualquier caso, la proporción de regadío sitúa a Bigastro entre los términos más dedicados a la agricultura de huerta del País Valenciano. Los porcentajes de regadío en la superficie cultivada quedaban por lo normal lejos del 50 por 100 en la mayoría de los municipios valencianos del siglo XVIII ${ }^{16}$. Este hecho sin duda colocaba a Bigastro en una posición muy ventajosa para emprender un rumbo especial de progreso agrícola: no la expansión territorial impulsada por la presión de los habitantes, sino un sustancial cambio de cultivos.

En 1779 la tierra cultivada que incluía moreral, frutales, olivar o viña representa el 70,5 por 100 del total. Esto supone que el programa de intensificación del cultivo planeado por la señoría al iniciar la colonización se ha cumplido con creces. Pero aún más importante es observar el panorama agrario hacia 1826. Por un lado, el porcentaje dedicado a arbolado se mantiene en un nivel alto, aunque inferior: el 46,4 por 100 del dominio útil cultivado. Tras varias décadas de crisis a veces profundas, el paisaje agrario se ha reorientado en el señorío. Sobre todo, naturalmente, en favor de los cultivos anuales, y así la tierra blanca de regadío ha pasado de ser casi el 12 por 100 en 1779 a ocupar un 42 por 100 en 1826. Probablemente el hecho debe interpretarse, al menos en parte, como un cierto regreso a la agricultura de subsistencia, obligado por la crisis de importantes cultivos comerciales. Pero no únicamente. La tierra blanca puede estar dedicada a cereales, pero también a hortalizas o cáñamo. $Y$, en todo caso, merece la pena considerar que la tierra blanca en el secano, lejos de aumentar - como cabría imaginar dentro de un esquema en que la crisis de subsistencias empuja hacia tierras marginales-, se ha reducido muy considerablemente. Estos datos indican que la respuesta a la crisis inicial del siglo XIX, al menos a la altura de 1826, ha sido en esta colonización señorial más flexible de lo que cabría sospechar según una hipótesis de campesinos pobres, obligados a mantener el cultivo tan sólo en función de su propia subsistencia. El moreral, que en 1779 está presente en el 40,6 por 100 de las tierras, ha perdido rápidamente su anterior hegemonía y en 1826 no llega al 8 por 100. El olivar, el otro gran cultivo comercial de las décadas finales del siglo XVIII, también se ha visto sustituido en el regadío y se ha desplazado hacia el secano. En cambio, en 1826 aparece una mayor espe-

${ }^{16}$ Tomo el dato del trabajo de P. RUIZ TORRES, «El País Valenciano en el siglo XVIII», en Homenaje a P. Vilar. La España del siglo XVIII. Crítica, Barcelona, 1986. 
cialización de cultivos, con menor presencia de los asociados y, fundamentalmente, ha surgido una extensión apreciable de huertos de frutales y de naranjos que, en conjunto ocupan cerca del 6 por 100 de la superficie. El hecho es destacable porque supone una rápida respuesta a la recuperación del tráfico exterior de cítricos, que se había hundido décadas atrás y sin contar con el estímulo de las exenciones oficiales ${ }^{17}$. La viña en el secano también ha crecido, a partir de unos niveles ínfimos, hasta rozar el 2 por 100 de la tierra cultivada. Tan sólo el aumento de las paleras se podría interpretar en función de una agricultura marginal vinculada a la subsistencia de una población empobrecida.

La agricultura de Bigastro experimentó grandes transformaciones durante el siglo XVIII que convirtieron su territorio en un importante dominio de la morera hasta situarse, pese a su reducida extensión, entre los principales núcleos sederos de la comarca ${ }^{18}$. Este hecho debe llevar a reconsiderar la hipótesis, sostenida por Gil Olcina ${ }^{19}$, de que «la enfiteusis, régimen de tenencia muy apto para propiciar la colonización de tierras abandonas y conquista de nuevos espacios agrícolas, no era en cambio, el régimen de tenencia que iba a reclamar una agricultura de marcada orientación comercial que tenía por base una fuerte acumulación de trabajo y elevados gastos de cultivon. El caso de Bigastro, por el contrario, parece mostrar que la subsistencia de los enfiteutas se apoyaba en una agricultura diversificada e intensiva que dependía, en muy buena parte, de la comercialización de las cosechas. Esta orientación fue la que, siguiendo las directrices señoriales, desarrollaron los colonos de Bigastro, hasta el punto que la agricultura del lugar dependía claramente de la morera. No se puede afirmar que la relación entre agricultura comercial y de autoconsumo no ha haya transformado, decisivamente, a favor de la primera. Pero, por otra parte, este cambio agrario ha debido necesitar de importantes inversiones de trabajo para

${ }^{17}$ En la década de 1820 se recuperan los niveles de exportación naranjera de fines del siglo XVIII, interrumpidos por los transtornos derivados de las guerras con Francia. ABAD GARCIA, V., 1984, pp. 20, 50-52. FONTANA, J., 1970, p. 13. En 1829 una real orden eximió del pago del diezmo a los naranjos que se plantaran en terrenos que no se hubiesen roturado en las últimas tres décadas, ARV, Real Acuerdo, I. 124, f. 279.

${ }^{18}$ En 1740, que fue un año de escasa cosecha, declaró 890 libras de seda, situándose muy cerca de otros municipios de la comarca que disponían de una superficie mayor. Es significativo también que Benejúzar, otro señorío de origen alfonsino fundado en el siglo XVII, aparezca en primer lugar, exceptuando Orihuela, el mismo año, MILLAN, J., 1984, p. 258.

19 1980, pp. 187-188. La función de la enfiteusis a este respecto debe depender más bien de la finalidad y el contexto socioeconómico en que se realice la colonización. Cfr. FRANCH BENAVENT, R., 1982, pp. 257-271. 
ser alcanzado, primero, y conservado después hasta la altura de 1779. En ausencia de una expansión territorial importante, es esta honda transformación del cultivo lo que ha debido absorber en gran medida el aumento demográfico que tuvo lugar, de forma tan destacada, en el señorío.

Al mismo tiempo, esta intensificación del cultivo muestra que, era posible realizar importantes transformaciones agrícolas con el mismo nivel tecnológico imperante. El problema para realizar esta transformación debía residir ante todo, no en nuevas técnicas, sino en obtener el volumen de trabajo necesario. En Bigastro esto fue posible mediante la enfiteusis. Por ello, si bien muchos pequeños campesinos fueron los autores de la intesificación del cultivo, esto no significa que pudieran hacerlo con sus propios recursos únicamente. Había que financiar, no sólo la introducción de nuevas plantaciones, sino el mismo mantenimiento de la mano de obra hasta que se pudieran recoger y vender las cosechas. Para muchos, probablemente, esta posibilidad estaba fuera de su alcance y hubieron de recurrir a otros medios ajenos de financiación. De esta forma, por más que la colonización aparezca dominada por la enfiteusis, en realidad, su dinámica abría paso forzosamente a la penetración del capital. Esta aparece reflejada de diversas formas en la organización del señorío. El Cabildo se reservó al fundar el lugar la preferencia a la hora de cobrar en las tierras y frutos de sus vasallos "sos pechos, y lo demés que li deuràn per rahó de préstamos o qualsevol contracte» (art. 41). La documentación se refiere a la existencia de un pósito, sobre el que el Cabildo tenía cargado un censo, que probablemente concediera préstamos a los vecinos y que, a comienzos del siglo XIX, registraba grandes atrasos ${ }^{20}$. Un papel fundamental debió cumplir en este terreno todo lo relativo al comercio de la seda. Todos estos canales de penetración del capital no han podido dejar de afectar a la misma propiedad de los enfiteutas sobre la tierra.

\section{LA DESIGUALDAD EN LA PROPIEDAD.}

La fundación del lugar de Bigastro supuso una opción especial sobre la propiedad. En 1701 las tierras que poseían los canónigos fueron entregadas en enfiteusis, preferentemente, a «els criats y llauradors de Capítol ${ }^{2{ }^{2}}$. Suponía, por tanto, la entrega de tierras en dominio útil a quienes hasta entonces no eran propietarios. Los desposeidos venian así a alcanzar un cierto grado, no por subordinado menos significativo, de propiedad. ¿Cómo es posible entender esta opción de los dueños

\footnotetext{
${ }^{20}$ ARV, Escribanías de cámara, 1816, n: 97, f. 185.

${ }^{21}$ ACO, Dietari, 1692-1707, fs. 262 v., 277.
} 
de la tierra a comienzos del siglo XVIII? ¿Hasta qué punto pesó en la resolución del Cabildo un cálculo de las ventajas de la colonización así establecida frente a otras fórmulas alternativas? El hecho de que toda la tierra se distribuyese en enfiteusis, a diferencia de otras colonizaciones contemporáneas, puede mover a pensar en la existencia de compromisos no puramente económicos a la hora de establecer la forma de colonización. Pero otros datos restan mucha importancia a este aspecto. Es más que dudoso que la cesión de dominio útil fuese una forma involucionista de proseguir la explotación agrícola en la zona. Dadas las prioridades de los rentistas, el potencial económico de los arrendatarios existentes y los costes de la mano de obra asalariada, la sustitución del arrendamiento por la enfiteusis fue en muchas ocasiones una operación basada en el cálculo económico a comienzos del siglo XVIII. La misma perentoriedad del Cabildo a la hora de exigir mejoras en los cultivos a corto plazo no es precisamente un indicio de absentismo señorial. No hay que olvidar tampoco que, tras la entrada de las tropas borbónicas en 1706, el Cabildo, al observar un cultivo inadecuado por parte de los colonos y notables atrasos en el pago, no tuvo inconveniente en embargar los bienes de los morosos y emprender una nueva distribución de los lotes ${ }^{22}$.

Con todo, parece que el Cabildo sostenía una preferencia teórica por hacer compatible este criterio de rentabilidad indudable con el mantenimiento de la pequeña propiedad generalizada. Asi la carta fundacional prohibió a los colonos vender las casas o las tierras por separado, «de forma que per ningun pretexte, accident ni causa es puixen deixar de tenir ad minus la mitat de la sort juntament amb la casa, ni la casa es puixa separar de dites thafulles» (art. 29).

¿Hasta qué punto se ha mantenido este esquema durante el siglo posterior a la colonización? Algunas fuentes dan la impresión de que Bigastro estaba caracterizado, en efecto, por la pequeña explotación campesina. «Es un vecindario de más de cien vecinos la mayor parte arraigados, y los demás jornaleros», se informaba en $1751^{23}$. Los establecimientos iniciales y los cabreves de 1779 y 1826 (cuadros 3-5) nos permiten contrastar esta opinión.

${ }^{22}$ CANALES, G., 1981. Ya en 1698 el Cabildo disponía que sus enfiteutas cabrevaran y que, en caso de impago, se les comisase el dominio útil, ACO, Dietari, 1692-1707, f. 217 v.

${ }^{23}$ ARV, Real Acuerdo, 1751, f. 636. 
La evolución del índice de concentración de Gini fue la siguiente:.

$$
\begin{array}{r}
1715-22 .-0,293 \\
1779 .-0,607 \\
1826 .-0,616
\end{array}
$$

En el aspecto de la propiedad el carácter inicial de la colonización aparece también profundamente trastornado. Los establecimientos de comienzos de siglo se hacen sobre todo en favor de un núcleo de enfiteutas que reciben entre 5 y 10 hectáreas. Son ellos más de la mitad de los colonos y reciben una porción algo mayor del dominio útil. Las diferencias iniciales entre los colonos, aunque existentes sin duda, no son muy marcadas. Unos cincuenta años después la polarización entre los enfiteutas es ya muy clara. La propiedad más pequeña, de menos de una hectárea, se ha fragmentado mucho y presenta a casi la mitad de los colonos. En el otro extremo, los escasos dueños de más de 10 has. controlan casi la mitad del término. El panorama de 1826, sin dejar de significar un ligero avance en la concetración de la propiedad, no supone un paso decisivo en este proceso. Los dueños de más de 10 has. han perdido en control sobre la superficie total, pero lo han ganado los enfiteutas de escalones inmediatamente inferiores, entre 5 y 10 , 4 y 5 y 3 y 4 has. Por otra parte, continúa aumentando el peso de los muy pequeños colonos. No se prolonga el proceso hacia la formación

\begin{tabular}{|c|c|c|c|c|c|c|}
\hline & \multicolumn{5}{|c|}{$\%$} & \multirow[b]{2}{*}{ Acumul. } \\
\hline & Enfit. & $\%$ & Acumul. & Has. & $\%$ & \\
\hline$-0,5$ Has. & 1 & 2,63 & 2,63 & 0,4 & 0,14 & 0,14 \\
\hline $0,5-1$ & 2 & 5,26 & 7,89 & 2,0 & 0,74 & 0,88 \\
\hline $1-2$ & 1 & 2,63 & 10,52 & 1,6 & 0,59 & 1,47 \\
\hline $2-3$ & 3 & 7,89 & 18,41 & 8,2 & 3,06 & 4,53 \\
\hline $3-4$ & 2 & 5,26 & 23,67 & 7,37 & 2,75 & 7,28 \\
\hline $4-5$ & 3 & 7,89 & 31,56 & 14,10 & 5,26 & 12,54 \\
\hline $5-10$ & 21 & 55,26 & 86,82 & 153,38 & 57,27 & 69,81 \\
\hline-10 & 5 & 13,15 & 99,97 & 80,75 & 30,15 & 99,96 \\
\hline \multirow[t]{2}{*}{ Total } & 38 & \multicolumn{5}{|c|}{267,8} \\
\hline & \multicolumn{6}{|c|}{$\begin{array}{c}\text { Cuadro 3. - DISTRIBUCION DEL DOMINIO UTIL } \\
\text { SEGUN LOS ESTABLECIMIENTOS INICIALES. } \\
\text { BIGASTRO, } 1715-1722\end{array}$} \\
\hline
\end{tabular}
de grandes posesiones del dominio útil, pero aumenta el peso de las propiedades medias y se fragmentan mucho las más pequeñas. 


\begin{tabular}{ccccrrr}
\hline & Enfit. & $\%$ & Acumul. & \multicolumn{1}{c}{ Has. } & \multicolumn{1}{c}{$\%$} & $\begin{array}{c}\% \\
\text { Acumul. }\end{array}$ \\
\hline$-0,5$ Has. & 24 & 24 & 24 & 6,30 & 2,16 & 2,16 \\
$0,5-1$ & 18 & 18 & 42 & 13,06 & 4,48 & 6.64 \\
$1-2$ & 22 & 22 & 64 & 33,38 & 11,46 & 18,10 \\
$2-3$ & 9 & 9 & 73 & 20,41 & 7,00 & 25,10 \\
$3-4$ & 6 & 6 & 79 & 20,89 & 7,17 & 32,27 \\
$4-5$ & 4 & 4 & 83 & 17,68 & 6,07 & 38,34 \\
$5-10$ & 9 & 9 & 92 & 61,18 & 21,00 & 59,34 \\
-10 & 8 & 8 & 100 & 118,37 & 40,63 & 99,97 \\
\hline Total & 100 & \multicolumn{5}{c}{291,3} \\
\multicolumn{7}{c}{ Cuadro 4. DISTRIBUCION DEL DOMINIO UTIL } \\
\end{tabular}

\begin{tabular}{|c|c|c|c|c|c|c|}
\hline & Enfit. & $\%$ & $\begin{array}{c}\% \\
\text { Acumul. }\end{array}$ & Has. & $\%$ & $\begin{array}{c}\% \\
\text { Acumul. }\end{array}$ \\
\hline $\begin{array}{c}-0,5 \text { Has. } \\
0,5-1 \\
1-2 \\
2-3 \\
3-4 \\
4-5 \\
5-10 \\
-10\end{array}$ & $\begin{array}{r}43 \\
29 \\
18 \\
10 \\
12 \\
4 \\
10 \\
4\end{array}$ & $\begin{array}{r}33,07 \\
22,30 \\
13,84 \\
7,69 \\
9,09 \\
3,03 \\
7,69 \\
3,07\end{array}$ & $\begin{array}{l}33,07 \\
55,37 \\
69,21 \\
76,90 \\
85,99 \\
89,02 \\
96,71 \\
99,78\end{array}$ & $\begin{array}{l}10,47 \\
20,00 \\
22,34 \\
25,75 \\
42,22 \\
17,35 \\
69,47 \\
56,53\end{array}$ & $\begin{array}{r}3,96 \\
7,57 \\
8,46 \\
9,75 \\
15,98 \\
6,56 \\
26,29 \\
21,40\end{array}$ & $\begin{array}{r}3,96 \\
11,53 \\
19,99 \\
29,74 \\
45,73 \\
52,30 \\
78,59 \\
99,99\end{array}$ \\
\hline \multirow[t]{2}{*}{ Total } & 130 & & & 264 & & \\
\hline & \multicolumn{5}{|c|}{$\begin{array}{c}\text { Cuadro 5. - DISTRIBUCION DEL DOMINIO UTIL } \\
\text { EN BIGASTRO, } 1826\end{array}$} & \\
\hline
\end{tabular}

Con todo, esta información sólo nos habla de la distribución de la tierra entre los dueños del dominio, pero no nos dice nada sobre el peso de la población desposeída. Su cálculo no resulta sencillo. El censo de Floridablanca de 1787 da la cifra de 988 habitantes para Bigastro. La clasificación por profesiones en este caso es escasamente útil, pues incluye 36 labradores, 10 jornaleros, 12 artesanos, 11 criados, 1 cura y 1 sacristán. En total, 69 vecinos. Es prácticamente imposible ajustar esta clasificación por oficios de los cabezas de familia al número de habitantes que arroja el censo. De modo que sólo cabe concluir que la tabla de profesiones está mal confeccionada y no es posible extraer de ella una hipótesis sobre el volumen de población jornalera. 
Por su parte, el cabreve de 1779 presenta 86 enfiteutas avencidados en el lugar. ¿Qué cantidad de habitantes cabe atribuir a este número de vecinos? Incluso teniendo en cuenta la alta tasa de natalidad que caracterizó a Bigastro hasta mediados de siglo, no parece lógico hacer corresponder esta cifra con más de 500 habitantes. Puesto que los censos de 1769 y 1787 remiten a una cota próxima a los 1.000 habitantes se puede estimar que para 1779 entre el 40 y el 50 por 100 de la población carecía de todo derecho sobre la tierra del lugar. La hipótesis viene confirmada por un vecindario de 1787 que parece relacionado con el censo de Floridablanca y que da la cifra de 185 vecinos. Aplicando los datos del cabreve de ocho años antes, el 53,5 por 100 de los vecinos carecería de tierras en el término ${ }^{24}$.

La hipótesis de un grado de desposesión elevado para la segunda mitad del siglo XVIII se sustenta también en otros datos. El malestar por los precios de las subsistencias, que acabó reflejándose en Bigastro en el estadillo de un motín el 16 de abril de 1766 , es una buena prueba de la dependencia del mercado de un gran sector de la población. Según el Cabildo, el motín se debía a que «se avian introducido gentes avecindandose en el, no teniendo tierras, de cuyo producto puedan mantenerse, ni assi mismo oficio con que subenir a sus necesidades». Recuperando por un momento su inclinación teórica por la pequeña propiedad, el Cabildo dió instrucciones a la justicia del lugar para «que en adelante no permitan avecindarse en dicho pueblo a persona que no tenga bienes, $u$ oficio de que mantenerse ${ }^{25}$. En la práctica no se tomó ninguna medida efectiva y la tendecia a la concentración continuó desfigurando el reparto inicial de la tierra. Una década después el Cabildo se limitó a deplorar que las continuas enajenaciones del dominio útil que realizaban los colonos fuesen a favor de compradores forasteros, lo que se estimaba irremediable si querían "salir de los apremios con que estan conminados al pago de sus créditos» ${ }^{26}$. Sería esta actuación de los especuladores urbanos lo que más contribuiría a la desposesión campesina. El Cabildo catedral de Orihuela, a diferencia de otros señores eclesiásticos, se abstuvo de intervenir para consolidar su dominio, aunque el tema se suscitó en 1792 sin hallar eco entre los canónigos ${ }^{27}$. Tan sólo hacia 1820 el Cabildo cambió de actitud y se de-

${ }^{24}$ CASTELLO TRAVER, J.E., 1978. El vecindario de 1787 en AMO, Libro capitu- lar, 1787, fs. 60-61 v.

${ }^{25}$ ACO, Actas capitulares, 1765-1767, fs. 400-401.

${ }^{26}$ Id., 1777-1779, 7-VIII-1777.

${ }^{27}$ MILLAN, J., 1984, pp. 378-379. En Redován, en cambio, los dominicos, señores del lugar, trataron de consolidar parte del dominio, BERNABE GIL, D., 1982, p. 166. Otro ejemplo en PESET, M. et alii, 1981 y ANDRES ROBRES, F., 1980. 
cidió a comisar el dominio útil de los enfiteutas morosos. Por este sistema en 1831 un 8 por 100 del término le pertenecía ya por completo ${ }^{28}$.

El padrón de 1826, al no señalar la residencia de los enfiteutas, impide hacer cálculos, aunque sean aproximativos, sobre el grado de desposesión de los vecinos. He procurado, sin embargo obtener algunos datos a través de otras fuentes coetáneas. Para ello he utilizado un Padrón de vecinos de Bigastro arreglado a los libros de la parroquia del mismo año 1822, realizado por el cura párroco ${ }^{22}$. Este padrón arroja un total de 195 vecinos, lo que podria inducir a pensar en un cierto ocultamiento, si tenemos en cuenta que el Diccionario de Miñano de 1827 señala 231 y Cavanilles en 1794 ya había dado la cifra de 201 vecinos. Contando, pues, con estas posibles deficiencias se puede observar que el padrón de 1822 clasifica como jornaleros a los 105 vecinos, es decir, el 53,8 por 100 del total. ¿Resulta fiable esta clasificación como índice de carencia del dominio útil? Para tratar de comprobarlo he comparado la relación de enfiteutas de 1826 con el padrón de vecinos de cuatro años antes. Por desgracia, la comparación resulta demasiado insegura muchas veces, debido a la falta del segundo apellido de los enfiteutas o por ser imposible de identificar en una $u$ otra fuente. Con un alto grado de certeza sólo he podido identificar 36 vecinos, lo que es un porcentaje excesivamente reducido para extraer conclusiones. Sin embargo, hay un aspecto que resulta digno de consideración: en 8 casos los enfiteutas en cuestión eran clasificados por el vecindario como jornaleros. En todos estos casos disponían de parcelas mínimas y sólo uno de ellos supera - escasamente 10,57 has.) - la media hectárea. El dato, en realidad, resulta muy poco preciso, pero puede sustentar el criterio de corregir a la baja el volumen de jornaleros que señala el vecindario de 1822. O dicho de otro modo: se podría sospechar que el porcentaje de desposeídos, al ser inferior al 53,8 no aumentó entre lo calculado para 1779 y 1826 . Pero esta hipótesis no podría mantenerse sin dilucidar antes el grado de ocultamiento que sufre el padrón de 1822, ya que esto puede alterar las conclusiones:

De todas formas, lo que resulta patente es que la figura jurídica de la enfiteusis no era ninguna garantía de defensa de la pequeña propiedad campesina. A. Gil Olcina ha señalado que la disolución de la propiedad señorial en el País Valenciano y su sustitución por la pequeña propiedad rural se explica por la difusión de la enfiteusis en los señorios valenciano ${ }^{30}$. La generalización de este argumento, sin embargo, re-

${ }^{28}$ ACO, Mayordomia, 1831, fs. 11-13.

${ }^{29} \mathrm{AMB}$, Documentos varios, 1811-1850. Agradezco las faciliades dadas por José J. Moya, alcalde de Bigastro, para la consulta de este archivo.

30 1980 , p. 188. 
sulta poco convincente. Por un lado, la enfiteusis no era un dato originario, sino que es preciso explicar las razones de su introdución cuando los señores disponian de otras alternativas cuyas ventajas no ignoraban. Esto sucedió en gran parte de los señoríos valencianos tras la expulsión de los moriscos en 1609, pero también en los lugares de colonización como sucede en Bigastro. Por otra parte, a veces parece olvidarse que la enfiteusis, aunque ofrece oportunidades para la estabilidad de sus beneficiarios, no impide en absoluto la enajenación del dominio útil por medio de venta e, incluso, que en tal caso la señoría directa dispone de preferencia para consolidar de nuevo el dominio. Así, el mantenimiento de la propiedad campesina, que no debe confundirse con el mantenimiento de la enfiteusis, se explica principalmente, allí donde se haya producido, no por una figura jurídica que no obstaculiza la enajenación del dominio, sino por la capacidad de los colonos para resistir las exacciones señoriales, fiscales y crediticias y conservar su tierra. En definitiva, por la estructura social de los colonos, su capacidad de presión a la hora de fijar los establecimientos y para beneficiarse de la intesificación del cultivo. Dada la naturaleza de los colonos de Bigastro, su dependencia del crédito y su escasez de medios propios (en 1787 habia 24 pares de labor para 36 labradores), la enfiteusis no supuso un freno a la concentración de la propiedad. Con frecuencia se tiende a confundir enfiteuta con campesino, pero muchos de los registrados en los cabreves de Bigastro y, desde luego, los más importantes no respondian a este esquema. La gran propiedad podía reproducirse sin trabas en forma de dominio útil concentrado en pocas manos $y$, en este sentido, la figura de la enfiteusis es compatible con la génesis de la gran propiedad. Que las cosas hayan sido de otra manera no se puede explicar, por tanto, por la forma jurídica de tendencia, sino que habrá que acudir a explicaciones más complejas.

En 1779 el 14 por 100 de los propietarios eran forasteros y controlaban el 25,4 por 100 del dominio útil. Los enfiteutas con título de don eran el 8 por 100 y controlaban un 22,6 por 100 de la tierra. En 1826 esta última categoría de enfiteutas pasa a suponer el 15,4 por 100 y le corresponde el 31,2 por 100 de la tierra. El examen de los principales dueños del dominio útil revela grados destacables de concentración de la propiedad, según se detalla en el cuadro adjunto.

Puede que muchos enfiteutas fuesen a la vez arrendatarios en el realengo bajo la hipoteca de su dominio útil.

La presencia de enfiteutas urbanos, sobre todo de la ciudad de Orihuela, es un dato común con otros señoríos valencianos, asentados en un terreno fértil y no sometidos a partición de frutos, como ha estudia- 
1. Herederos de D. Francisco Mesples, de Orihuela.

Has. \%

2. Blas Lorente, Bigastro.

$26,65 \quad 9,14$

$24,14 \quad 8,28$

3. D. Luis Valdelomar, administrador de rentas de tabaco, Orihuela.

$13,10 \quad 4,49$

$12,73 \quad 4,37$

$11,94 \quad 4,09$

4. Josefa Abellán, Bigastro. $\quad 88,56 \quad \frac{4,09}{30,40}$

5. José Perales, id.

1826.

1. D. Manuel Villanueva

2. José Rubio y Josefa

Fuentes

3. Manuel y María Martínez

4. D. Ruperto Estor y Cía

5. D. Fco. Morales y Da Ma

Teresa Mesples

$\begin{array}{rr}22,89 & 8,66 \\ 12,26 & 4,64 \\ 10,83 & 4,09 \\ 10,54 & 3,98 \\ \frac{9,65}{66,17} & \frac{3,65}{25,04}\end{array}$

do J. Romero ${ }^{31}$. Llama, en cambio, la atención la ausencia de la nobleza titulada, que tanto peso tenía en toda la comarca y, en especial, en el término realengo de Orihuela. Por otro lado, la comparación entre 1779 y 1826 muestra, junto al aumento del número de enfiteutas acomodados y generalmente urbanos, una cierta disgregación de los más importantes patrimonios forjados hacia 1779. Las primeras fortunas en 1826 pertenecen a vecinos del lugar que ejercerán en él una destacada actividad social y política, como sucede ante todo con D. Manuel Villanueva Torregrosa ${ }^{32}$. Los especuladores urbanos - un grupo que incluye agricultores con capital como Francisco López Campillo, rentistas de abolengo tradicional como los Maseres, o comerciantes, prestamistas y administradores como los Sorzano, Estor, Maisonnave, Arnaldo o Díe-- se hacen sentir principalmente en el control de fincas medianas y pequeñas.

\section{LAS POSIBILIDADES DE ACUMULACION $Y$ LA PRESION DEL CAPITAL.}

¿Cómo se debe entender este asalto parcial a la deteriorada comu-

31 1983, pp. 143-152.

${ }^{32}$ MILLAN, J., 1984, pp. 391-392. Sobre las características de algunos de estos nuevos propietarios, MILLAN, J., 1984 (a), pp. 107-114. 


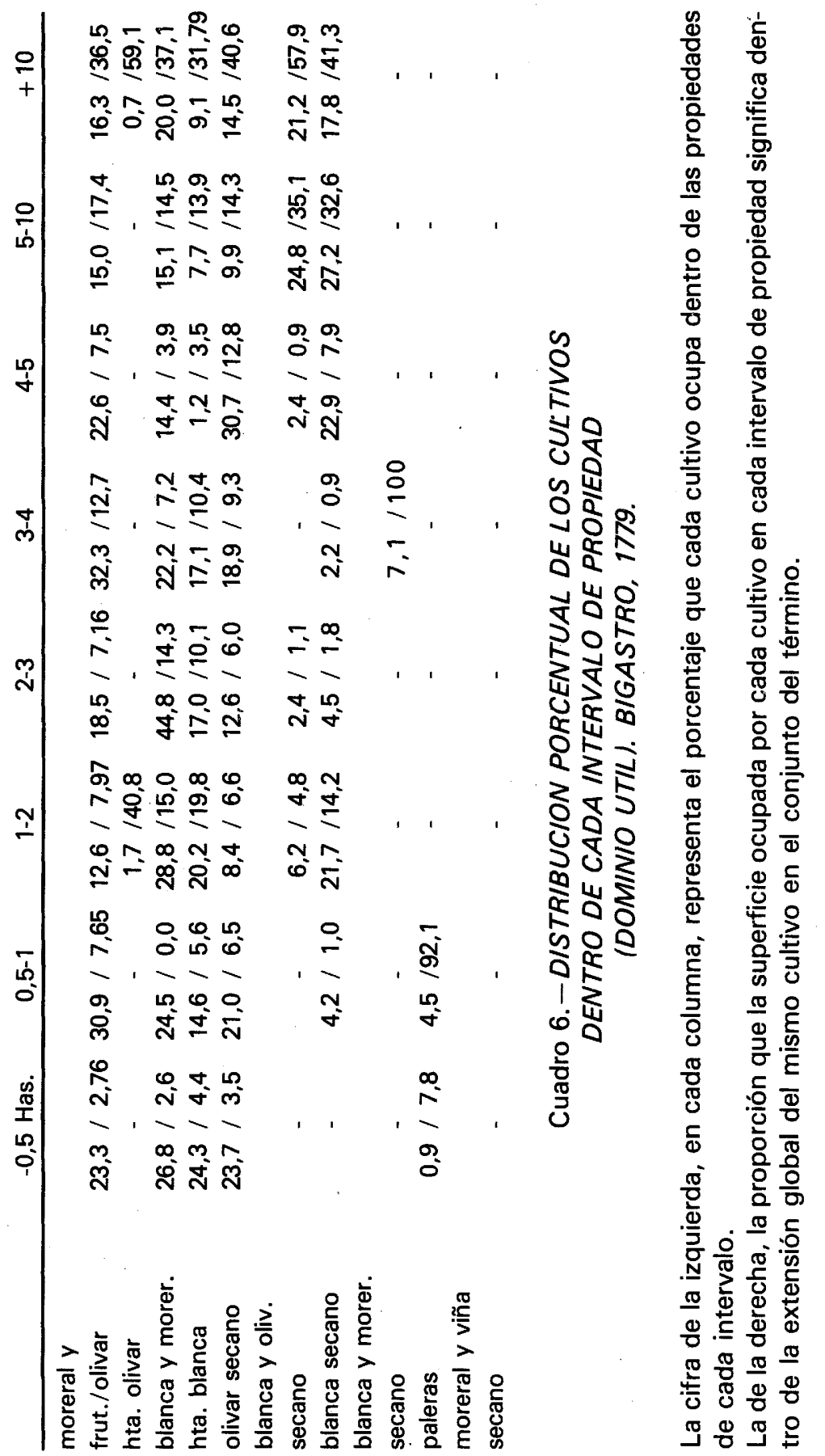




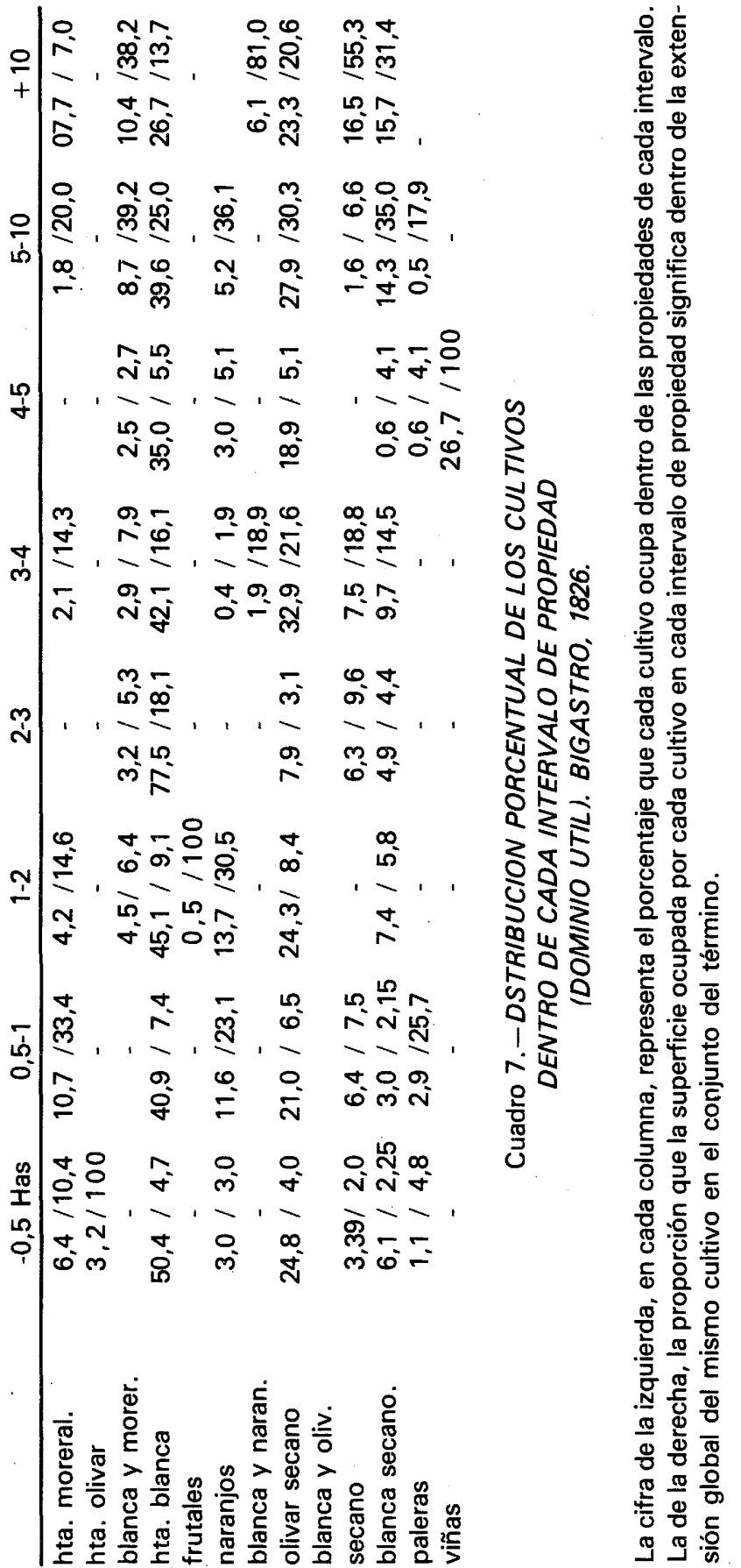


nidad campesina? ¿Puede interpretarse el hecho de que no haya un avance espectacular de la concentración de la propiedad en 1826 como una recomposición de la economía de los pequeños enfiteutas? Teóricamente, la estructura de las cargas señoriales no debia ser un obstáculo para ello, puesto que no incluian partición de frutos. Como se deriva de los siguientes cuadros, elaborados para los años 1779 y 1826, el peso fundamental de los ingresos señoriales en Bigastro venía determinado por los censos fijos en metálico ${ }^{33}$ :

\begin{tabular}{|c|c|c|c|}
\hline Año 1779. & & $\%$ & \\
\hline $\begin{array}{l}\text { Arrendamiento moreral } \\
\text { Corral de ganado } \\
\text { Pensión del pósito } \\
\text { Pilón de carnicería } \\
\text { Horno } \\
\text { Almazara } \\
\text { Tienda y panadería } \\
\text { Censos enfitéuticos }\end{array}$ & $\begin{array}{rl}20 & \mathrm{~L} . \\
15 & \mathrm{~L} . \\
9 & \mathrm{~L} . \\
10 & \mathrm{~L} . \\
138 & \mathrm{~L} . \\
85 & \mathrm{~L} . \\
10 \mathrm{~L} & \mathrm{~L} . \\
1.531 \text { L. 14s. } 5 / 6\end{array}$ & 2s. $2 \mathrm{~d}$ & $\begin{array}{r}19,34 \\
77,56\end{array}$ \\
\hline Total ingresos & 1.742 L. $16 \mathrm{~s} .2$ 5/6d. & & \\
\hline
\end{tabular}

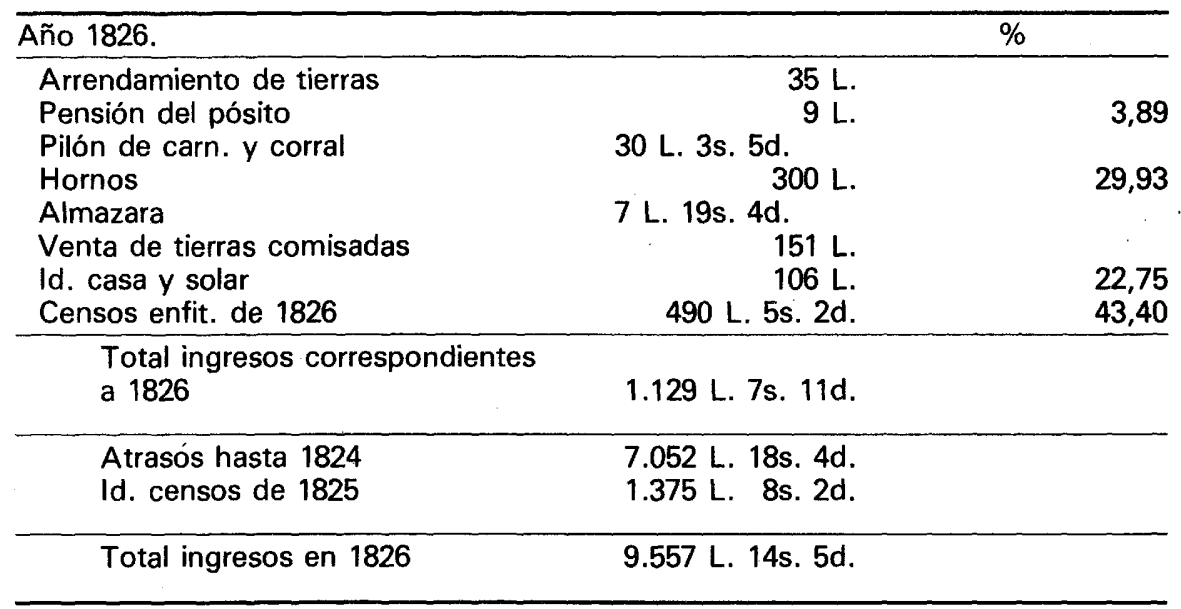

En ambos casos los censos en metálico son la parte fundamental de los ingresos. Ni siquiera los grandes atrasos en el cobro, registrados en 1826, pueden ocultar este hecho. Incluso el mayor peso relativo de las regalías viene compensado por la dificultad de mantener algunas de ellas, como sucede con la tienda y la almazara.

${ }^{33}$ Los datos proceden de ACO, 1.367 y 1.378-a. 
¿Cómo explicar en estas circunstancias la impresión general de la escasa capacidad económica de la mayoría de los vecinos y su dependencia de la señoría? El mismo Cabildo, haciendo la apología de su conducta en el lugar, suscitó el tema en 1816. Debido «a la feracidad de las tierras de Bigastro, situación, calidades y aumentos naturales de las mismas y a lo módico de las pensiones establecidas es indudable que si el Cabildo hubiese conservado el dominio útil de las expresadas propiedades y las hubiese dado por arriendo le producirían anualmente diez veces más de lo que percibe por ellas $\|^{34}$. Los cabreves de 1779 y 1826 corroboran la impresión de unos censos inmóviles. Ya al hacer los establecimientos a comienzos del XVIII el Cabildo había fijado una gama muy amplia de censos, según la calidad de la tierra, que iban desde los 5 dineros por tahúlla en el secano a los 30 sueldos en el caso del moreal de regadío. En los cabreves aparece como novedad la tierra censida a razón de 40 sueldos por tahúlla, tanto de olivar como blanca huerta, sobre todo en la partida de Bailesa. El monto global de los censos percibidos por la señoría tan sólo presenta ligeras oscilaciones: $1.402 \mathrm{li}$ bras en 1747, 1.351 en $1779,1.368$ en 1803 o 1.356, que le correspondía cobrar al Cabildo en 1826, son cifras que remiten a la estabilidad a largo plazo de la principal fuente de ingresos señoriales. En general, pues, la evolución de los censos ha sido nula. En función de esta circunstancia el abogado del Cabildo calculaba así, en 1816, la renta por tahúlla que iba a parar a los dueños del dominio útil:

\begin{tabular}{|c|c|c|}
\hline Cultivo (tha.) & Censos & Renta del enfiteuta \\
\hline $\begin{array}{l}\text { Huerta blanca } \\
\text { Campa blanca }\end{array}$ & $\begin{array}{l}9-15 \text { sueldos } \\
5-9 \text { dineros }\end{array}$ & $\begin{array}{l}3,5 \text { Libras }-8 \mathrm{~L} \text {. } \\
2 \mathrm{~L} \text {. en las } 100 \text { thas. mejores } \\
1 \mathrm{~L} \text {. en } 20 \text { thas. inferiores }\end{array}$ \\
\hline $\begin{array}{l}\text { Olivar huerta y } \\
\text { campo }\end{array}$ & 5 din. -6 sueld. & 3 L. -20 L. \\
\hline
\end{tabular}

Este cálculo - en el que curiosamente no se tiene en cuenta la tiera moreral- , aunque probablemente tendencioso en sus apreciaciones, apoya lo que cabría imaginar en principio: los censos fijos en metálico deberían haber dejado un amplio margen de acumulación en manos de los enfiteutas. Sin embargo, en el caso de Bigastro no ha sido esta la norma. ¿Cómo cabe explicar esta evolución? No es fácil dar una res-

${ }^{34}$ Un perito que actuaba como testigo del Cabildo declaró que los arrendamientos de tierras de similar calidad estaba en 3 libras por tahúlla $\left(1.185 \mathrm{~m}^{2}\right)$ y fueron aumentando hasta las 16 libras. ARV, Escribanías de cámara, 1816, n. 97, fs. 486, 676 v. 
puesta a este interrogante, pero la distribución de cultivos según el tamaño de las propiedades de los enfiteutas puede proporcionar algunas orientaciones (cuadros 6 y 7 ).

En 1779 el grueso de las pequeñas propiedades - las menores de 3 has. - está dominado por cultivos comerciales. La morera rebasa casi siempre la mitad de la superficie y el olivar - en explotaciones exclusivas, es decir, casi nunca asociado a la tierra en blanco- mantiene un grado de presencia importante, entre el 8 y el 24 por 100. Por último hay que recordar la notable variedad de posibilidades (cereal / hortalizas / cáñamol de la tierra blanca. De este modo, las pequeñas propiedades no están dedicadas a cultivos directos de subsistencia, sino a producciones que, dada su demanda comercial, hagan viable la pequeña propiedad. Siempre cabe discutir que las pequeñas propiedades correspondieran o no a enfiteutas campesinos y esto alteraría la interpretación del papel de estos cultivos. Pero, según el cabreve, los enfiteutas con título de don dueños de menos de 3 has. apenas poseían un 8 por 100 de las propiedades inferiores a esa superficie. Por tanto, la propiedad de quienes se titulaban don - fueran rentistas, especuladores urbanos o agricultores acomodados - influye muy poco en las posesiones de menos de 3 has. En gran medida, pues, al referirnos a estas propiedades pequeñas estamos hablando de los campesinos entendidos convencionalmente. Esta vinculación a la agricultura comercializada no puede entenderse simplemente como una especialización ventajosa para los agricultores. Este tipo de agricultura requería un cierto volumen de inversión $\mathrm{y}$, sobre todo, pasar a depender para el propio consumo de los mecanismos del mercado. Es más que probable que la mayoria de los pequeños colonos no hayan podido financiar el cultivo intensivo ni su propio consumo hasta la obtención de las cosechas y, por esta vía, ha podido ir avanzando la pérdida progresiva del dominio útil.

Algunos datos relativos a la seda parecen sustentar esta hipótesis. En 1725, cuiando aún se estaban distribuyendo los lotes a los enfiteutas, el Cabildo ordenó la instalación de tornos e hiladores que trabajasen la seda de Bigastro «conviniendo en todo el arrendador de dicho lugar». En 1776 Da Ma Teresa Casaus, viuda de D. Francisco Mesples, solicitó del Cabildo que no permitiese «hilar la seda fuera de la Casa de la Señoría». Los canónigos, en consecuencia, ordenaron "que todas las noches se lleve a la casa de la Señoría la seda que hilaren todos los vezinos de Bigastro». La conexión entre una agricultura en crecimiento y el comercio de la seda, tal vez pasando por los mecanismo del crédito, debió ser una de las grandes vías de acumulación en el $\mathrm{Ba}$ jo Segura durante el siglo XVIII. La actividad de Pedro y Vicente Miravete, comerciantes oriolanos, era descrita asi en 1731: "comersian y man- 
tienen tienda pública de mercader la de más crédito en esta, asiendo empleos considerables en seda, y otras cosas, además de la gruesa hasienda que posehen $)^{35}$. En el caso de Bigastro cabe sospechar un interés preferente de la señoría y de sus administradores de derechos por controlar la seda de los colonos, quizás como garantía del pago de sus deudas, adelantos para la labranza o para el pago de contribuciones. En este contexto no es de extrañar que los primeros propietarios del dominio útil en 1779 resulten ser $D^{a}$. Ma Teresa Casaus y los herederos de D. Francisco Mesples, comerciante, prestamista y administrador del Cabildo. La colonización señorial favorecía así la acumulación de una cierta burguesía comercial y usuraria que, entre otros negocios, gestionaba las empresas agrarias de los terratenientes y acababa por participar en el control de la tierra.

La gran propiedad en 1779 está dedicada, en cambio, a cultivos de secano, sobre todo con una fuerte presencia del olivar. Las propiedades de quienes tienen el título de don ofrecen una estructura dominada por las diversas formas de moreral (un 56,6 por 100 ), lo que podría interpretarse como presencia de antiguas parcelas de pequeños colonos que recientemente han cambiado de manos.

En 1826 esta estructura se ha alterado sustancialmente. Las propiedades de menos de 3 has. - que han pasado a ser más de tres cuartas partes del total- consisten en más de la mitad de su superficie en huerta blanca. Una parte sustancial, próxima al 25 por 100 , se dedica al olivar de secano. El moreral ha sido sustituido de un modo muy intenso, pero conserva aún cierta importancia entre las propiedades menores. La gran propiedad también ofrece un notable peso de la huerta blanca, pero ya menor que en los tramos inferiores. La primacía aquí es discutida por el olivar y la tierra blanca de secano. También aparecen proporciones significativas de moreral y blanca en el regadío. En cambio, el aspecto más innovador, la aparición del naranjo, es un fenómeno vinculado a la pequeña propiedad, aunque no de modo exclusivo.

Sin embargo, esta nueva distribución de cultivos no puede intrepetarse según los mismos esquemas de 1779. En 1826 casi el 40 por 100 de las propiedades de menos de 3 has. pertenecen a enfiteutas con título de don $y$, consiguientemente, no pueden entenderse como sustento directo de la economía familiar campesina. Siete de los catorce enfiteutas que tenían naranjos disponian de ese título y a ellos les per-

${ }^{35}$ Los datos sobre la seda en Bigastro en ACO, Libro de acuerdos capitulares, 1723-1726, f. 188. Dietario, 1732-1741, f. 657. Libro de acuerdos capitulares, 1772-1776, 15-V-1776. La última cita procede de AMO, Libro capitular, 1731, f. 80. D. Francisco Mesples pujó por las tierras que fueron de los jesuitas en Orihuela tras su expulsión, MILLAN, J., 1984, p. 356. 
tenecía más del 77 por 100 de la tierra plantada de huerto. Tres de ellos tenian el apellido Mesples ${ }^{36}$.

No puedo pretender interpretar esta evolución, pero sí hacer algunas hipótesis que puedan ajustarse a ella. Hasta mediados del siglo XVIII los colonos, provistos de escasos medios pero protagonistas de una elevada natalidad, debieron verse afectados tanto por el coste de la intensificación del cultivo como por la fragmentación de las explotaciones ocasionada por las herencias. La salida para hacer frente a los múltiples pagos a que había que responder como resultado del esfuerzo colonizador se halló en la práctica de cultivos comerciales - la morera y el olivar - que permitieran soportar las cargas. Pero las fluctuaciones del mercado o los declives de la productividad arrojaban a la insolvencia a muchas pequeñas explotaciones endeudadas. Es lo que parece haber sucedido en las décadas de 1760 y 1770 , época que D. Francisco Mesples se hizo con un importante número de parcelas. Posteriormente los años de la Guerra de Independencia y de la epidemia de 1811 y 1812 supusieron otro momento de enajenaciones, como sucede en los casos de D. Manuel Villanueva Torregrosa o D. Ruperto Estor y Cía.

Pero esta nueva oleada de adquisiciones por parte de quienes no eran campesinos no ha resultado en un mayor grado de monopolio de la tierra hacia 1826. Una de las causas puede estar en que la necesidad de obtener una rentabilidad de estas tierras tal vez obligara a los compradores del dominio útil - incapaces de introducir la explotación directa - a tolerar la continuidad en la tierra del antiguo enfiteuta, ahora bajo otro título. Su imposibilidad para recuperar la rentabilidad a corto plazo pudo llevar a tolerar el auge del cereal y la pérdida del arbolado. Es posible que, en estas condiciones, muchos colonos expropiados tuviesen opción a recuperar el dominio útil, sobre todo en el caso de las ventas a carta de gracia. Pero, por otra parte, la misma crisis general de la agricultura debió estimular las inversiones en tierra de los sectores más dinámicos de la sociedad urbana que trataban de diversificar riesgos. Esta demanda adicional de tierras tal vez permitió desprenderse de parte del dominio útil a quienes lo habian acumulado a costa de los campesinos en el siglo XVIII pero ahora se veían alcanzados por los problemas. Es esta competencia por la tierra que procede de la ciudad

${ }^{36} \mathrm{D}$. Pedro Mesples, seguramente el mismo que en 1826 detentaba el dominio útil de unas 6 has. en Bigastro, se caracterizó por su conducta política moderada a partir de 1835. Formó parte del Ayuntamiento que se negó en 1836 a adherirse a la proclamación de la Constitución de 1812 y, al igual que otros burgueses reaccionarios como Matías Sorzano, dueño de 4,3 has. en Bigastro, se abstuvo en 1840 de adherirse al pro nunciamiento progresista de ese año, AMO, Acuerdos del Ayuntamiento, 1840-1841., fs. 138 v. ss. 
$y$, en menor medida de algunos ricos enfiteutas locales lo que ha protagonizado las facetas más novedosas de la transformación agraria, aunque no haya hecho avanzar gran cosa la concentración de la propiedad. El campesinado, en cambio, proseguía sumido en una situación incierta, definida por la fragmentación de sus explotaciones y el coste de la transformación de los cultivos caducos.

\section{CONSIDERACION FINAL: LAS DOS FASES DELA ESPECIALIZACION AGRICOLA.}

En Bigastro, ni el reparto inicial de lotes enfitéuticos de forma bastante equitativa ni la presencia de una cierta inclinación de principio por la pequeña propiedad bastaron para evitar la amplia disgregación de la comunidad campesina. La colonización, lejos de multiplicar las unidades de cultivo autosuficientes y asegurar la autonomía del enfiteuta a la hora de organizar el cultivo, multiplicó los lazos de vinculación con el mercado, tanto por el lado de la comercialización de las cosechas como por el de la mercantilización de la subsistencia campesina. La intesificacion del cultivo avanzó mucho y se logró sobre un terreno que no experimentó cambios apreciables en su extensión. En conjunto, triunfó una especialización agraria que mantuvo a una población muy dinámica.

La colonización de Bigastro aparece como una operación de desarrollo agrícola que, pese a revestirse con la fórmula de la enfiteusis, favoreció extraordinariamente las relaciones de mercado y la penetración del capital. Esta especialización agraria, que descansaba sobre la seda en el siglo XVIII pero que se reconvertiría hacia los críticos y el cáñamo en el primer cuarto del XIX, no redundó, sin embargo, en la diversificación de la economía del lugar ni, en general, del conjunto de la comarca. El padrón de 1822 recoge un número escaso de artesanos, entre los que predominan los dedicados al transporte:

\begin{tabular}{|c|c|c|c|c|c|c|c|}
\hline $\begin{array}{l}\text { Arrieros } \\
\text { Carreteros } \\
\text { Mulero }\end{array}$ & $\begin{array}{l}6 \\
3 \\
1\end{array}$ & $\begin{array}{l}\text { Tejedores } \\
\text { Sastre }\end{array}$ & $\begin{array}{l}2 \\
1\end{array}$ & $\begin{array}{l}\text { Aperadores } \\
\text { Herreros } \\
\text { Molinero }\end{array}$ & $\begin{array}{l}2 \\
2 \\
1\end{array}$ & $\begin{array}{l}\text { Albañiles } \\
\text { Carpintero } \\
\text { Sangradores }\end{array}$ & $\begin{array}{l}2 \\
1 \\
3\end{array}$ \\
\hline
\end{tabular}

Por entonces el municipio informaba en el mismo sentido ${ }^{37}$ :

"En este pueblo se encuentran dos hornos concegiles de pan cocer, dos telares de seda, un médico que se mantiene con sus propiedades, porque la utilidad de su facultad es muy limitada, dos tiendas de

${ }^{37}$ AMO, Actas de Ayuntamiento, de Bigastro, 28-1X-1822. Una situación similar se puede registrar en Benjúzar: en 1780 aparecen 42 arrieros y carreteros, pero sólo 11 tejedores de lienzos. 
comestibles con muy cortos surtidos, dos erreros miserables, un desdichado barbero y dos carteros de bueyes que aunque suelen salir al tragin se ayudan con parte de la agricultura para haber subsistir».

La falta de desarrollo de la manufactura en la zona no puede imputarse, sencillamente, a una agricultura autárquica o regida por la lógica campesina de Chajanov ${ }^{38}$. En general, la hipótesis de una fuerte presión señorial que reduciría la demanda y frenaría el avance agrícola durante el XVIII, mantenida por R. Aracil, M. García Bonafé , T. Carnero y J. Palafox, resulta muy difícil de sostener. Con independencia de que la realidad parece haber sido otra, habría que recordar que el «empobrecimiento» genérico del campesinado no explica necesariamente la reducción del mercado interior sino que, como señalaba Lenin, puede ser un factor del desarrollo capitalista. A la luz de lo que muestran las investigaciones recientes, creo que habría que dirigir la atención hacia la estructura de la oferta de mano de obra - teóricamente disponible, pero pocas veces contratada-, las formas de acceso a la explotación de la tierra y las peculiaridades de una demanda de manufacturas que aumentó sin concentrarse en una reducida cúpula señorial. En efecto, los campesinos enfiteutas no practicaban la agricultura que convenía a sus necesidades, sino la que les venía impuesta por su dependencia del mercado y su obligación de satisfacer diversos tipos de cargas. Tampoco puede afirmarse que la presión señorial eliminara los excedentes del campesino, puesto que, como he tratado de probar, esa carga se mantuvo casi inmóvil entre la fundación del lugar y el primer cuarto del siglo $X I X^{39}$. El hecho es destacable por cuanto, exceptuando las Pías Fundaciones, la partición de frutos no se daba en las zonas regables de señorio del Bajo Segura. Por otra parte, las rentas derivadas de la transformación agraria protagonizada por los colonos, lejos de concentrarse en el titular del señorío, debieron beneficiar a círculos sociales más

${ }^{38}$ ARACIL, R. et alii, 1983, p. 94.

${ }^{39}$ ARACIL, R. y GARCIA BONAFE, M., 1984, pp. 455, 458. Los argumentos de Lenin en LENIN, V.I., 1974, pp. 27 ss. Según la interpretación de J. PALAFOX y T. CARNERO, 1982, pp. 21-23 y J. PALAFOX, 1984, pp. 298-299, y 1985, p. 341, la fuerte presión señorial habria impedido superar el nivel de subsistencia de la población, diversificar el consumo y utilizar productivamente sus excedentes. La agricultura del XVIII sería extensiva y vinculada al aumento de la población. En cambio, la producción para el mercado sólo aumentaría significativamente a partir de inicios del siglo XIX. Las investigaciones de los últimos años, sin embargo, no permiten sustentar estos presupuestos, cuando nos muestran la naturaleza jurisdiccional de muchos derechos señoriales o la limitación de los censos en metálico en casos muy significativos, por no hablar de la problemática de las zonas de realengo. Para una discusión de estos temas RUIZ TORRES, P., 1985 y su trabajo citado en la nota 16. 
amplios. Intermediarios comerciales y prestamistas urbanos fueron piezas básicas en el desarrollo de la colonización, llegaron a hacerse con una parte muy significativa del dominio útil $y$, por tanto, también ellos debieron percibir una parte importante del excedente obtenido en esta empresa agrícola.

El caso del señorío de Bigastro es tanto el de una excepcional introducción de la agricultura comercial como el de un claro atraso de la industria. Las dos características - un atraso industrial que no es explicable por la pobreza agrícola - caracterizan a la economía valenciana, según parece, hasta las décadas centrales del siglo XIX. No se trata, por tanto, de que la industrialización sólo haya contado con incentivos a partir de un proceso agrícola localizable teóricamente por las mismas fechas. Hay que considerar, por el contrario, que la renovación agrícola era bastante anterior, había sido incluso muy importante durante el XVIII y, pese a ello, el crecimiento industrial hubo de esperar hasta la década de 1860 para empezar a hacerse notar. Por eso la relación entre la expansión agrícola y el desarrollo industrial aparece escindida en dos fases que requieren un tratamiento distinto ${ }^{40}$.

La intesificación y comercialización de los cultivos, así como la desposesión campesina, aunque estuvieron presentes durante el siglo XVIII, no redundaron en incentivos industriales. Pero la razón no se halla en la existencia de una sociedad rural ajena al mercado y sumida en niveles de subsistencia por la presión señorial, sino en mecanismos diferentes y más complejos. Las relaciones de mercado no dejaron de crecer a lo largo de todo este tiempo. En Bigastro, por ejemplo, la señoría arrendó la tienda y taberna del lugar por unas 140 libras en 1747 pero, pese a la rebaja de derechos dictada en 1766, lo hizo por 321 en 1803, por 581 en 1805 y por 560 en 1810. En la ciudad de Orihuela se detecta un crecimiento del comercio local a partir de finales de la década de 1730. En 1776 se informaba de los comerciantes que «todos los años aumentan su gremio de individuos». Unos diez años atrás se había autorizado

${ }^{40}$ MALUQUER DE MOTES, J., 1984. Sobre las relaciones entre la intesificación agrícola y la industria rural catalana, TORRAS, J., 1984. En cuanto a las relaciones entre la especialización agrícola y el desarrollo industrial británico, JONES, E.L., 1974, y MENDELS, F., 1980. El desarrollo agrícola del siglo XIX no continuó el ritmo de expansión naranjera inicialmente mostrado por el Bajo Segura. Por otro lado, tampoco repercutió favorablemente para la industria de la misma comarca, auque si en otras próximas. El problema estriba, por tanto, en hallar las peculiaridades de la especialización agrícola del siglo XVIII que, en lugar de favorecer una especialización industrial semejante o propiciar encadenamientos como los que se dieron en otras zonas, se redujo a acentuar el carácter rural de los núcleos urbanos próximos. 
el mercado semanal y la instalación de tiendas de comestibles en las partidas rurales ${ }^{41}$. Pero esta innegable vinculación con el comercio se hacía de un modo especial. Los campesinos que, al igual que sucedia por entonces en Cataluña, obtenían dinero por sus cosechas mercantilizadas, no supusieron un incentivo ni para la formación de un artesanado propio ni para la difusión de la industria doméstica en el área local. Los efectos de la seda valenciana durante el siglo XVIII - seda consumida en gran parte por la industria catalana ${ }^{42}$ - no son semejantes en absoluto a los que supuso la exportación del aguardiente para el mercado interior catalán en la misma época. Tampoco tuvo efectos comparables a los que, a largo plazo, acabó representando la difusión de los cítricos en el País Valenciano desde los últimos años del siglo $X \mid X^{43}$.

La expansión agrícola del siglo XVIII supuso intesificación del cultivo, dependencia del capital y desposesión campesina, pero no tuvo repercusiones favorables a la industria: carente de impulsos industriales, fue una ruralización basada en el comercio y desarrollada en detrimento de las economías urbanas anteriormente establecidas, antes de que la nueva ocupación del espacio y la expansión de la labranza se precipitasen de modo irreversible. En este sentido, la expansión rural del siglo XVIII supuso un corte con respecto a la situación anterior y a las débiles estructuras industriales existentes al inicio del proceso no salieron fortalecidas como resultado sino que, por el contrario, caminaron hacia su desaparición. La nueva ampliación del mercado que supuso la colonización de las tierras fue capitalizada por el comercio exterior de productos manufacturados y por la industrialización de otras zonas que experimentaban por entonces, como sucedió en Cataluña, un tipo de desarrollo diferente ${ }^{44}$.

La segunda fase de esta evolución de la agricultura valenciana tuvo un carácter muy distinto. La industria se desarrollaría desde mediados del siglo XIX en determinadas comarcas sobre la base de esta es-

${ }^{47}$ Los datos de la tienda en ACO, 1.367 y 1.368-a. Sobre el comercio oriolano, AMO, Libro capitular, 1736, fs. 20, 334. Id. 1766, fs. 39 v. - 41. MILLAN, J., 1984, p. 338.

${ }^{42}$ FERRER i ALOS, LI., 1984, p. 54. TORRAS i RIBE, J., 1979, p. 32.

${ }^{43}$ TOMAS CARPI, J.A., 1976. PALAFOX, J., 1984, pp. 301-302. Hay que insistir en que la vinculación con el mercado europeo de la gricultura valenciana no era una novedad del siglo XIX, como se da a entender en este último trabajo de J. Palafox. Existía desde bastante atrás, pero, lejos de mostrar siempre un efecto favorable a la industria, se impuso en ocasiones en detrimento de las manufacturas existentes. La inserción en el mercado internacional es una historia más entrecortada y contiene ocasiones frustradas, cfr., p.e., NADAL, J., 1985 o, en general, SENGHAAS, D., 1985.

${ }^{44}$ MALUQUER DE MOTES, J., 1984. 
pecialización rural que, anteriormente, había mostrado su unilateral carácter agrícola. Los encadenamientos industriales, que no se produjeron entonces, se dieron favorablemente para ciertas comarcas bajo el estímulo de los críticos. Las razones para este desigual comportamiento necesitarán aún de más investigaciones sobre sus mecanismos peculiares en cada coyuntura histórica. 


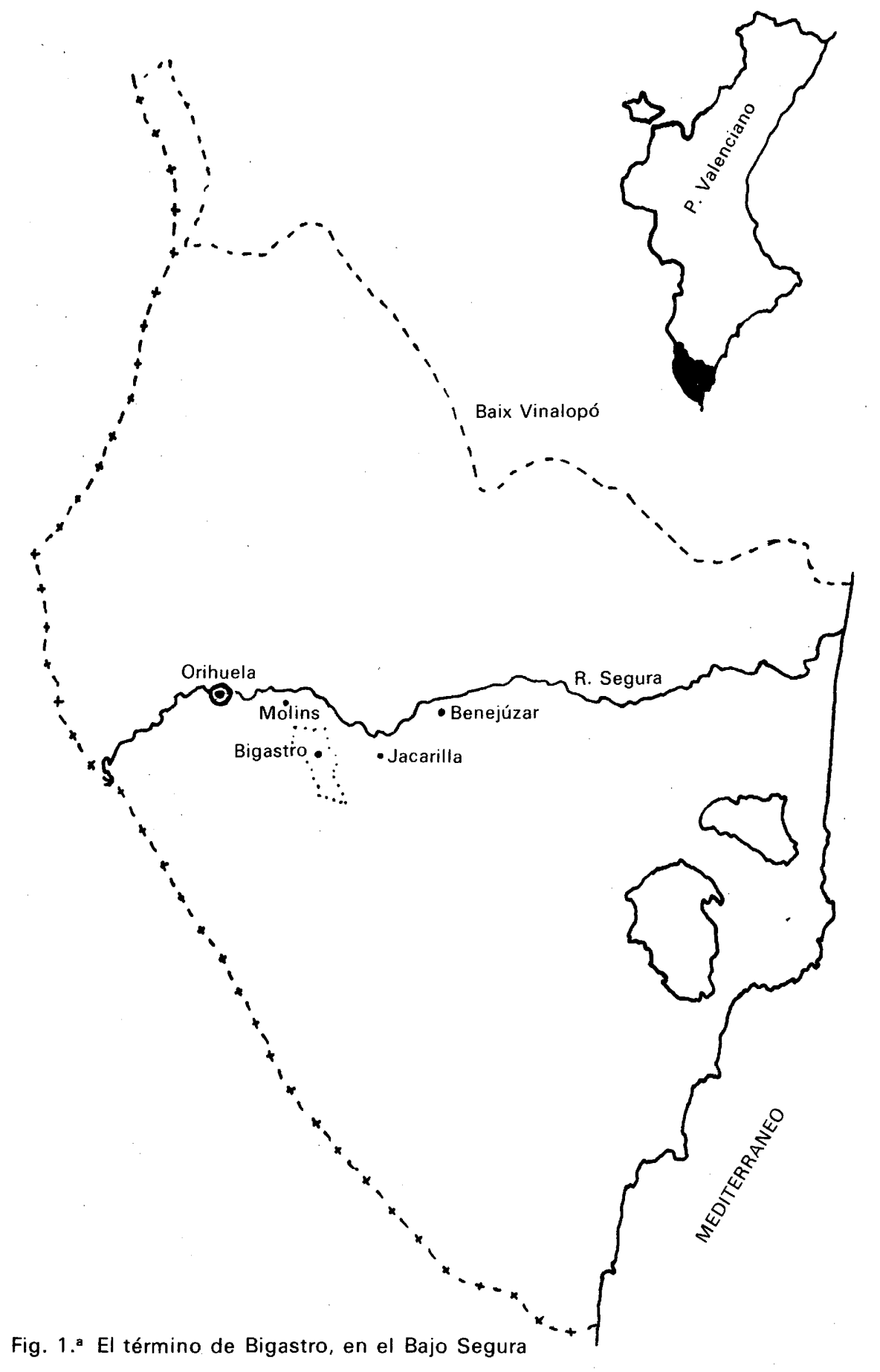


$\%$ Superficie
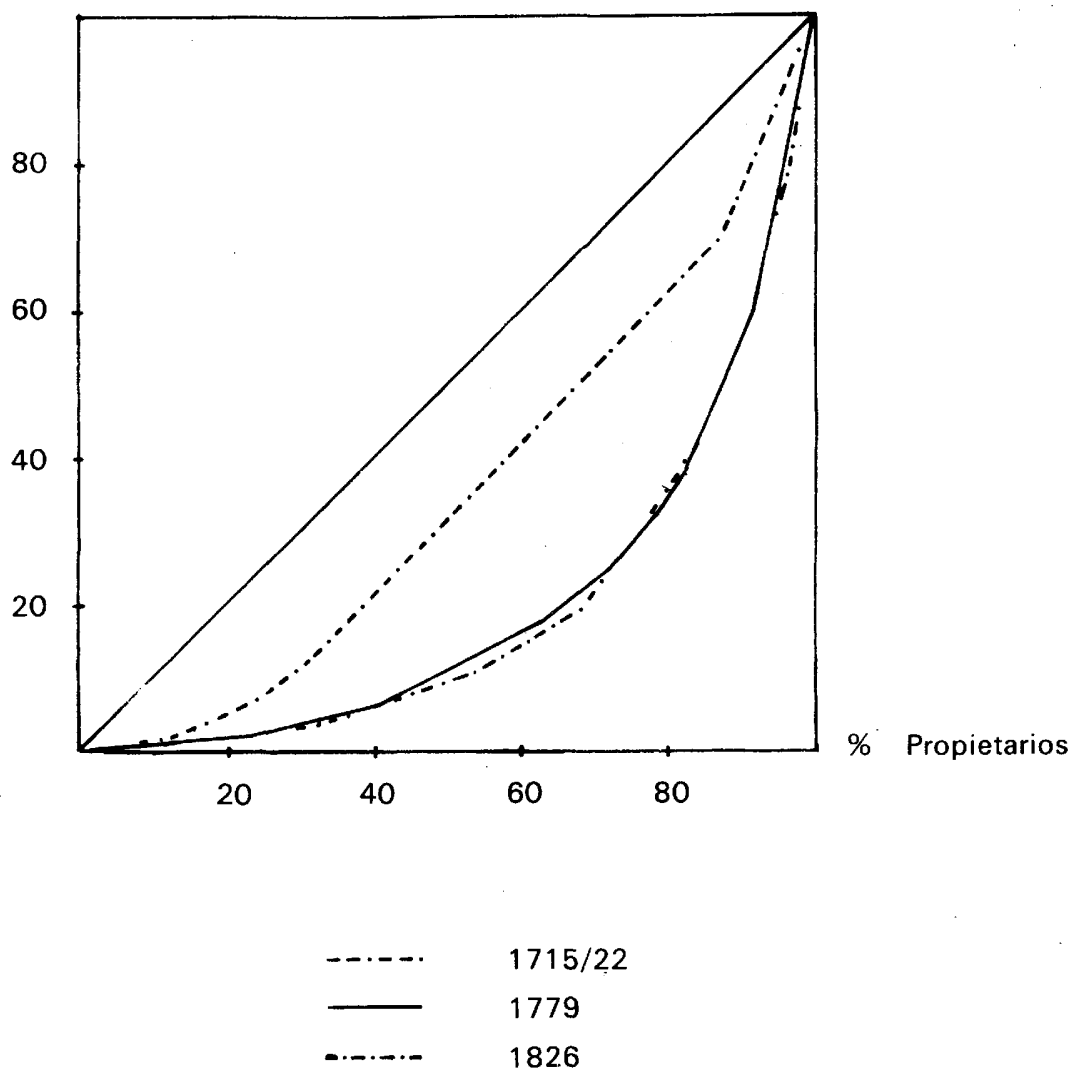

Fig. Curvas de concentración de' Lorenz

Bigastro, $1715 / 22$ a 1826 
REFERENCIAS:

ACO: Archivo Catedral de Orihuela.

AMB: Archivo Municipal de Bigastro.

AMBE: Archivo Municipal de Benejúzar.

AMO: $\quad$ Archivo Municipal de Orihuela.

ARV: $\quad$ Archivo del Reino de Valencia.

Abad García, V., 1984: Historia de la naranja (1781-1939). Comité de Gestión de la Exportación de Frutos Cítricos, Valencia, 1984.

Alberola Romá, A., 1984: Jurisdicción y propiedad de la tierra en Alicante (ss. XVII y XVIII). Ayuntamiento y Universidad de Alicante, Alicante 1984.

Amalric, J.P., 1983: "La part des seigneurs dans la province de Salamanque au XVIII-e. siècle», en Congreso de historia rural. Siglos XV al XIX. Casa de Velázquez y Universidad Complutense, Madrid, 1983; pp. 711-725.

Andrés Robres, F., 1980: «La detracción de la renta agraria en los señoríos del Colegio de Corpus Christi durante el siglo XVII», Estudis, no. 8 (1979-80), pp. 193-222.

Aracil, R. y García Bonafé, M., 1984: «De los Borbones a la Restauración» en Historia de los pueblos de España, dirigida por M. Barceló. Los antiguos territorios de la Corona de Aragón. Aragón, Baleares, Cataluña, País Valenciano. Argos Vergara, Barcelona, 1984; pp. 452-473.

Aracil, R. et alii, 1983: «Els estudis d'història agrària al País Valencià», en Primer Col.loqui d'història agrària. Ins. Alfons el Magnànim, Valencia, 1983; pp. 79-117.

Artola, M. et alii, 1978: El latifundio. Propiedad y explotación, ss. XVIIIXX. Ministerio de Agricultura, Madrid, 1978.

Bernabé Gil, D., 1982: Tierra y sociedad en el Bajo Segura (1700-1750). Universidad de Alicante y Caja de Ahorros Provincial, Alicante, 1982.

Cabo Alonso, A., 1979: "Concentración de propiedad en el campo salmantino a mediados del siglo XVIII», en ANES ALVAREZ, G. et alii. La economía agraria en la historia de España. Propiedad, explotación, comercialización, rentas. En Alfaguara y Fundación J. March, Madrid, 1979; pp. 141-148.

Cabo Alonso, A., 1983: "Constantes hitóricas de gran propiedad en el campo extremeño», en Congreso de Historia rural. Siglos XV al XIX. Casa de Velázquez y Universidad Complutense, Madrid, 1983; pp. 173-185.

Canales, G., 1981: "Creación del señorío eclesiástico de Bigastro (1697-1715)», en La propiedad rústica en España y su influencia en la organización del espacio. Fac. de Filosofía y Letras 
de la Universidad de Alicante, 1981; pp. 65-73.

Ferrer i Alós, LI., 1984: "La formació de la nova burguesia al s. XVIII», L'Avenc, n. 70 (1984), pp. 52-56.

Fontana, J., 1970: «Colapso y transformación del comercio exterior español entre 1792 y 1827 . Un aspecto de la crisis en la economía del Antiguo Régimen en España», Moneda y crédito, n. 155 (1970), pp. 3-23.

Franch Benavent, R., 1980: «El régimen señorial del Convento de Aguas Vivas durante el siglo XVIII», Estudis, n. 8 (1979-80), pp. 223-271.

García Fernández, J., 1979: "Formas de explotación», en ANES ALVAREZ, G. et alii. - La economía agraría en la historia de España. Propiedad, explotación, comercialización, rentas. Ed. Alfaguara y Fundación J. March, Madrid, 1979; pp. 189-210.

Gil Olcina, A., 1979: La propiedad señorial en tierras valencianas. Del Cenia al Segura, Valencia, 1979.

Gil Olcina, A., 1983: "La propiedad de la tierra en los señoríos de jurisdicción alfonsina», en Congreso de historia rural. Siglos XV al XIX. Casa de Velázquez y Universidad Complutense, Madrid, 1983; pp. 35-51.

Giménez López, E., 1981: Alicante en el siglo XVIII: economía de una ciudad portuaría en el antinguo régimen. Inst. Alfonso el Magnánimo, Valencia, 1981.

Jones, E.L., 1974: "Los orígenes agrícolas de la industria», En Agricultura y desarrollo del capitalismo. A. Corazón, Madrid, 1974; pp. 303-341.

Lenin, V.I., 1974: El desarrollo del capitalismo en Rusia. El proceso de la formación de un mercado interior para la gran industria. Ariel, Esplugues de Llobregat, 1974.

Lluch, E., 1973: El pensament economic a Catalunya (1760-1840). Els orígens ideològics del proteccionisme i la presa de consciència de la burguesia catalana. Ed. 62. Barcelona, 1973.

Maluquer de Motes, J., 1984: "La revolució industrial a Catalunya», L'Avenc, n. 73 (1984), pp. 18-34.

Mendels, F., 1980: "Seasons and Regions in Agriculture and Industry During the Process of Industrialization», en POLLARD, S. (Ed.). - Region und Industrialisierung. Studien zur Rolle der Region in der Wirtschaftsgeschichte der letzten zwei Jahrhunderte. Vandenhoeck und Ruprecht, Göttingen, 1980; pp. 177-195.

Millán, J., 1981: «La ciudad y los señores. La crisis del realengo foral en el sur del País Valenciano", Estudis d'història contemporània del País Valencià, n. 2 (1981), pp. 63-97.

Millán, J., 1984: Rentistas y campesinos. Desarrollo agrario y tradicio- 
nalismo politico en el sur del País Valenciano. Inst. J. GilAlbert, Alicante, 1984.

Millán, J., 1984 (a): «Antiliberalisme, protesta i subordinació popular al sud del País Valencià. El tradicionalisme polític en el desenvolupament d'una agricultura intensiva», Recerques $\mathrm{n} .16$ (1984), pp. 95-118.

Nadal, J., 1985: «Un siglo de industrialización en España, 1833-1930» en La modernización económica de España 1830-1930, comp. de N. Sánchez Albornoz, Alianza Ed., Madrid, 1985; pp. 89-101.

Palafox, J., 1984: "La economía valenciana en los siglos XIX y XX», Papeles de economía española, n. (1984), pp. 298-308.

Palafox, J., 1985: «Exportaciones, demanda interna y crecimiento económico en el País Valenciano», en La modernización económica de España 1830-1930, comp. de N. Sánchez Albornoz. Alianza Ed., Madrid, 1985; pp. 319-343.

Palafox, J. y Carnero, T., 1982: "La economía del País Valenciano (1750-1936). Crecimiento sin industrialización», Información comercial española, n. 586 (1982), pp. 21-32.

Peset, M. et alii, 1981: "El señorío de Alfara del Patriarca, 1601-1845», Estudis d'història contemporània del País Valencià, no. 2 (1981), pp. 7-60.

Romero González, J., 1983: Propiedad agraria y sociedad rural en la España mediterránea. Los casos valenciano y castellano en los siglos XIX y XX. Ministerio de Agricultura, Pesca y Alimentación, Madrid, 1983.

Ruiz Torres, P., 1979: «Propiedad de la tierra y estructura de clases en el campo valenciano durante los siglos XVIII y XIX: los carrizales de Elx», Estudis d'història contemporània del País Valencià, n. 1 (1979), pp. 75-134.

Ruiz Torres, P., 1985: "Desarrollo y crisis de la agricultura en el País Valenciano a finales del antiguo régimen», en GARCIA SANZ, A. y GARRABOU, R. (eds.). - Historia agraria de la España contemporánea. 1. Cambio social y nuevas formas de propiedad (1800-1850). Crítica, Barcelona, 1985; pp. 347-379.

Senghaas, D., 1985: Aprender de Europa. Consideraciones sobre la historia del desarrollo. Alfa, Barcelona-Caracas, 1985.

Tomás Carpi, J. A., 1976: La economía valenciana: modelos de interpretación. F. Torres, Valencia, 1976.

Torras, J., 1984: «Especialización agrícola e industria rural en Cataluña en el siglo XVIII»., Revista de historia económica, n.3 (1984), pp. 113-127.

Torras i Ribé, J., 1979: La revolució industrial a la comarca d'Anoia $\mathrm{R}$. Dalmau, Barcelona, 1979. 


\title{
«EL VIAJE LITERARIO A LAS IGLESIAS DE ESPAÑA: UNA EMPRESA ILUSTRADA DE LOS HERMANOS VILLANUEVA EN LA PRIMERA MITAD DEL SIGLO XIX.'
}

\author{
ANA MARIA SANCHEZ DIAZ
}

\section{PLANTEAMIENTO}

"El Viaje Literario a las Iglesias de España», obra de gran empeño de los hermanos Villanueva, surgirá a partir de un plan de Joaquín Lorenzo Villanueva encaminado a escribir una obra titulada «De antiquis Hispanae Eclesia ritibus», para el que ganó un cierto apoyo gubernativo.

Pretendía esclarecer cuestiones relativas a la disciplina y liturgia tardorromana, visigótica y medieval, dado el atraso en que se encontraban estos estudios en España. Los regalistas más entusiastas, que estaban detrás del proyecto, aspiraban a legitimar así sus aspiraciones de una iglesia nacional autóctona y diferenciada respecto a los módulos uniformadores introducidos en la Península por los cluniacenses con Alfonso VII de Castilla-León en el siglo XIII, y generalizados en la siguiente centuria para todo el orbe católico por los papas Gregorio VIl e Inocencio III $^{2}$.

Presentado al Gobierno a comienzos de 1802 el proyecto de la obra y una memoria de los auxilios necesarios para la empresa, se decide que Fray Jaime Villanueva, hermano y colaborador de Joaquín Lorenzo, emprendiera un viaje a las distintas iglesias de España para recoger los materiales necesarios. El viaje nace, pues, con un objetivo ritual, pasando después a asumir otro tipo histórico y literario.

«El Viaje Literario» vino a ser una obra maestra, cuya utilización es aún hoy indispensable para el conocimiento de la historia eclesiástica española desde el mundo tardorromano hasta el momento actual.

${ }^{1}$ Resumen de la Tesis de Licenciatura que, bajo la dirección del Dr. Juan Bta. Vilar, fue leida en la Facultad de Letras de la Universidad de Murcia en 9 de julio de 1985.

${ }^{2}$ A Joaquín Lorenzo Villanueva sobre todo preocupó hondamente la necesidad de un regreso a las mejores tradiciones de la Iglesia española, a su juicio descuajadas por un romanismo arrivista. En este sentido se pronunciará ya en 1794 en sus «Cartas eclesiásticas del Dr. Joaquín Lorenzo Villanueva al Dr. Guillermo Diaz Luzezedi... Madrid. Imp. Real. 1794. Cuarenta años más tarde, al final de sus días, volverá sobre el tema en la lejana Irlanda: Ibernia Phomicea, seu Phoenicum in Ibernia incolatus, ex ejus priscarium coloniarum nominibus et carum idolatrico cultu demostratio. Dublín, Tip. R. Graisberry. 1831. Villanueva trazará aquí la similitud entre los casos español e irlandés, privados ambos de sus esencias propias por patrones impuestos desde Roma. 
Su importancia es comparable a la "España Sagrada» del padre Enrique Flórez de Setién, escrita en el segundo tercio del siglo XVIII, si bien los datos que aporta el erudito valenciano, aunque no alcanzan la totalidad del ámbito nacional, superan la obra citada por su mayor rigor y actualidad.

\section{EXENCIONES Y PRIVILEGIOS EN FAVOR DE LOS HERMANOS VILLANUEVA. ASPECTOS FINANCIEROS Y PROTECCION REAL A LA EMPRESA.}

La empresa encomendada a los hermanos Villanueva en 1802 es considerada desde el primer momento como propia del Gobierno, debiendo éste subsanar determinadas dificultades que pudieran entorpecer la labor investigadora de aquellos. Se podría calificar de «protección» el interés que tanto Carlos IV, como su hijo Fernando VII demuestran en repetidas ocasiones por el buen fin del proyecto, aunque la situación política y económica por la que atraviesa la España de la época distaba de facilitar un proyecto de este empeño.

Cabe destacar en honor de la más estricta justicia el destacado papel asumido po Godoy al propiciar el impulso inicial que posibilitó la edición. Tal protección fue dispensada directamente y a través de su pariente el ministro Ceballos.

Aunque la posteridad ha preferido disociar al no simpre justamente vilipendiado Príncipe de la Paz, de esta y otras honrosas empresas relacionadas con la difusión en nuestro país de las letras, las artes, las ciencias y la cultura en general, lo cierto es que el propio valido, muchos años después, desde su destierro en Francia, al hacer el balance de su gestión en unas memorias justificativas, recordará ${ }^{3}$ que en el campo de las ciencias eclesiásticas hacia 1802-1803 eran numerosas las obras que, bajo su omnipotente patrocinio, se publicaban en España. Entre ellas recordará los escritos de autores luego malditos, como el buen obispo Felix Amat, o los hermanos Villanueva, tachados después injustamente por una censura oscurantista como jansenistas por el sólo hecho de oponerse - en el plano secular - a los abusos de la corte de Roma.

La crítica histórica más reciente, con toda objetividad, situará a los hermanos Villanueva y a su obra conjunta en el lugar destacado que les corresponde, dentro del mundo cultural de los tiempos de Carlos

${ }^{3}$ Vid. PRINCIPE DE LA PAZ, Memorias. Edición y estudio preliminar de Carlos Seco Serrano. B.A.E., t. LXXXVIII, p. 373; MURIEL, Andrés: Historia de Carlos IV. Edición y estudio preliminar de C. Seco Serrano. B.A.E. CXV, ps. 215-217. 
IV y Fernando VII ${ }^{4}$. «EI Viaje Literario» merece desde luego figurar entre las obras señeras, cuya publicación legitima la justa reivindicación de Godoy por Carlos Seco ${ }^{5}$ como protector y difusor de las luces en España.

Exenciones y privilegios reales facilitarán la labor de Jaime Villanueva en diferentes aspectos: conmutación de los años de lectura en la cátedra de teología por los muchos dedicados a su investigación, franqueo de archivos y bibliotecas eclesiásticas y pasaporte especial para su desplazamiento a la Francia napoleónica, obteniendo al propio tiempo del ministro del Interior francés toda clase de facilidades para que pudiese visitar cuantos archivos, bibliotecas o museos considerara necesario. En esta ocasión, nuestro investigador - que era religioso dominico-, gozó de un privilegio especial, como era el poder vestir el traje de presbitero secular, por expreso deseo del rey y con la correspondiente licencia del vicario general de los dominicos en España ${ }^{6}$. No era para menos, si se piensa que la secularización introducida en Francia en ambientes eclesiásticos durante la Revolución, en considerable medida subsistía con Bonaparte?

Desde el punto de vista económico, la financiación del «Viaje Literario", considerado como propiedad del Estado, se extiende a dos vertientes: una, a cubrir los gastos derivados de los desplazamientos, adquisición de libros, pago de escribientes, ect., y otra a la edición y publicación de la obra, que se mandará imprimir a la Imprenta Nacional, por cuenta del erario público.

De los documentos utilizados ${ }^{8}$ se deduce que los hermanos Villanueva gozaron de una subvención estatal de 12.000 reales anuales desde 1802 a 1814, cantidad a todas luces escasa y no siempre cobrada con puntualidad. La época más difícil fue sin duda la comprendida entre los años 1808 y 1812, coincidiendo con la guerra peninsular. En ese tiempo y por razones obvias, la Hacienda pública deja de abonar la do-

${ }^{4}$ Vid, por ejemplo: CORONA BARATECH, Carlos: Revolución y reacción en el reinado de Carlos IV. Madrid, 1957.

${ }^{5}$ SECO, Introducción al PRINCIPE DE LA PAZ, Memorias... p: XLIV ss.

${ }^{6}$ A.H.N. Consejos. Leg. 11.317², Exp. 1. "El Viaje Literario a las Iglesias de Españal, del prólogo de J. Villanueva.

7 DANSETTE, Adrien: Histoire religieuse de la France Contemporaine. París, Flammarion. 1965, ps. 127-222. Vid. también sobre la incidencia del Concordato de 1800 sobre el clero francés: HASQUIN, Hervé: Histoire de la laícité, Bruxelles. Ed. La Reinaissance du Livre. 1979. ps. 25-26.

${ }^{8}$ AHN. Consejos. Leg. 11.317². Exp. 1: «El Viaje Literario a las Iglesias de Españà, del prólogo de J. Villanueva. 
tación establecida y fray Jaime tendrá que recurrir a la ayuda económica de sus hermanos en religión.

En la etapa comprendida de 1814 a 1820 , el Gobierno parece olvidar la existencia de Villanueva, retirado a Valencia. Aprovechando la restauración de las libertades en el Trienio constitucional, las gestiones que realiza en favor de la edición de su obra vuelven a interesar al Gobierno, que reducirá la ayuda financiera al «Viaje Literario» a 6.000 reales, con los que el dominico tendrá que cubrir además gastos de escribientes y de impresión en su ciudad natal.

\section{RECOPILACION DE FUENTES POR JAIME VILLANUEVA. SUS VIAJES POR LOS ARCHIVOS DE LOS OBISPADOS DE CATALUÑA, VALENCIA, MALLORCA Y SEVILLA.}

Resueltos los problemas previos suscitados por el proyecto de los hermanos Villanueva, en buena parte por las relaciones y capacidad gestora de Joaquín Lorenzo, en 25 de julio de 1802, Jaime Villanueva recibe un oficio del ministro don Pedro Ceballos ${ }^{9}$, a quién previamente se había interesado en la empresa, por el cual era comunicada a don Joaquín Lorenzo Villanueva la autorización real para escribir una «Historia dogmática de los antiguos ritos y ceremonias de nuestra Iglesia».

Como quiera que Jaime Villanueva, de acuerdo con sus hermanos, decidiese iniciar sus trabajos en su tierra natal, bien provisto de dineros, marchó a Valencia a mediados de octubre de 1802. Nos consta que en 20 de ese mes se encontraba ya en la urbe mediterránea. Previamente había sido cursada una orden a todos los conventos valencianos para que le fuesen franqueados sus archivos, dando por supuesto que los establecimientos dependientes del clero secular deberían hacer lo mismo.

Malos momentos eran aquellos para emprender trabajos de investigación en los fondos archivísticos eclesiales, por el recelo suscitado en amplios sectores de la Iglesia española, por la velada desamortización que de sus bienes venía desarrollando Godoy desde 1794 - ocupación de beneficios eclesiásticos vacantes, impuesto del $15 \%$ sobre adquisición de bienes raices por la Iglesia, liquidación de temporalidades de los expulsados jesuitas... etc. ${ }^{10}-$, política llamada a culminar en la obtención de un breve pontificio - 12 diciembre 1806-, en virtud del cual Pio VII facultaba al monarca español a enajenar «la

\footnotetext{
${ }^{9}$ Ibídem: Oficio - 25 de julio 1802- de don Pedro Ceballos a Joaquín Lorenzo Villanueva.

10 TOMAS Y VALIENTE, Francisco: "El marco político de la desamortización de España». Barcelona. Ariel. 1971. ps. 38-43.
} 
séptima parte de los predios pertenecientes a las iglesias, monasterios, conventos, comunidades, fundaciones y otras cualesquiera personas eclesiásticas, incluso los bienes patrimoniales de las cuatro órdenes $\mathrm{Mi}$ litares y la de San Juan de Jerusalén" ". Todo ello al objeto de aliviar la desesperada situación de las finanzas reales, situación agravada en los últimos años por causa de las interminables contiendas con el Reino Unido, y en particular con la República Francesa y Napoleón, empresa esta última que por su carácter de semicruzada contrarrevolucionaria, merecia toda la aprobación y apoyo de la Santa Sede.

Ante estas dificultades, que no auguraban precisamente feliz éxito para su trabajo, Jaime Villanueva decidirá con buen criterio adoptar una actitud franca y transparente, proponiendo a los dueños de los archivos trabajar siempre en presencia de canónigos y archiveros, presentando a los interesados los resultados de sus investigaciones, al objeto de tranquilizarlos en el sentido de no haber nada en ellas que pudiera perjudicarles. De esta forma conseguirá tener acceso a todos los archivos eclesiásticos $y$, aunque no estaba autorizado para ello, extenderá su labor a otros de carácter civil.

En Valencia va a permanecer hasta el 24 de febrero de 1803, en que pasa a Segorbe, pero en mayo regresa a la capital regnícola, tan querida para él, trabajando en la cartuja de Porta-Coeli; en los monasterios jerónimos de Murta y Coralva; en el de Aguas Vivas, de la orden de San Agustín; Valldigna, de la de San Bernardo, y en las colegiatas e iglesias de Játiva, Gandía, Onteniente y otras de menor importancia.

El deseo por parte del gobierno de que el estudio de los archivos eclesiásticos se generalizase a toda la Nación, hará que a principios de 1804, el fraile dominico reciba orden de viajar a Castilla, León, Asturias y Galicia. Frustrada esta idea a causa de una epidemia que asolaba parte de esas regiones, regresa a Valencia, donde asocia a la empresa a Ignacio Herrero, también religioso de la Orden de Predicadores, excelente paleógrafo que, en adelante, será el más firme apoyo con que contó el ilustre historiador valenciano.

A partir de este momento, el doctor Villanueva va a centrar sus trabajos en Cataluña, llegando a Tortosa en junio de 1804. Estudia los archivos de Peñíscola y Benifaza, y pasa a Tarragona en agosto del mismo año. Tiene problemas con el doctoral de la catedral, que le cierra el archivo durante trece días, teniendo que esperar a su muerte para poder tener acceso de nuevo a los documentos allí guardados.

En 18 de octubre, Villanueva pasará al monasterio de Santas Cruces, y desde allí, a los de Poblet, Escala-Dei y Escornalbón. Es la suya,

${ }^{11}$ Cfr. Ibídem, ps. 43-44. 
ante todo, una labor de transcriptor, realizada con minuciosidad preciosista, a la que cabría sumar sus esfuerzos para ordenar la documentación disponible, e incluso limpiar físicamente las vetustas instalaciones en que permanecía amontonada. También dedicará una parte de su tiempo a elaborar índices de los fondos.

Un año permanecerá en Barcelona, escudriñando y ordenando las bien provistas estanterías de los archivos del Carmen descalzo; la catedral; el Archivo Real, en donde extractará más de 160 documentos alfonsinos del siglo XIII; archivos parroquiales y conventuales, y los ubicados en los monasterios de Monserrat, San Jerónimo de Valedrón, Murta, Cartuja de Montalegre, San Miguel del Fay, San Cucufate del Vallés, Ferrara, etc.

En noviembre de 1805 sale para Vich - o Vique, como también se le menciona-, donde trabaja hasta el 29 de enero de 1806, fecha en que comienza sus investigaciones en el monasterio de Ripoll. Tras una breve estancia en la colegiata de San Juan de las Abadesas, regresa a Ripoll y, desde allí sube a la Cerdaña española, entrando el 1 de marzo en la villa de Puigcerdá.

Hasta junio se consagra al estudio de los fondos custodiados en Seo de Urgel, trabajando en el archivo de su catedral, al mismo tiempo que visita las colegiatas de Castelldó y Orgaña. A finales de dicho mes pasa a los monasterios de Gesú, de la orden de San Benito; Labaixo, de la de San Bernardo; Alzón, de la de San Benito, y el 29 de junio visita la villa de Tremp. En 8 de julio el infatigable viajero se dirige al antiguo monasterio de Mur y al día siguiente pasa a la colegiata de Ager y de alli a Roda. Sus recorridos resultan bastante más completos que el itinerario seguido varias décadas antes por el también benemérito Enrique Flórez en la fase de recogida de materiales para su «España Sagrada».

De estos viajes y continuas pesquisas y apuntes iba resultando «un gran cúmulo de noticias históricas que no podían tener lugar en la 'Colección diplomática', que se me encargaba; resolví no desaprovecharlas y escribir como viajero, que toca y vé los documentos originales, la historia de las Iglesias y monasterios» ${ }^{12}$.

De ésto se deduce el carácter rigurosamente científico que quiso dar a su obra apoyándola exclusivamente sobre un vasto elenco documental y bibliográfico, "porque ningún historiador merece ser creído sobre su palabra; y el lector tiene un derecho indisputable para pedir la razón de sus aserciones» ${ }^{13}$.

\footnotetext{
${ }^{12}$ AHN, Consejos, leg. $11.317^{2}$ : Declaraciones.... Op. cit.

${ }^{13}$ Ibídem.
} 
Desde agosto hasta diciembre de 1806 permanecerá en Lérida, dirigiéndose posteriormente a Cervera, Iborra, Calaf, Manresa, monasterio de Bages, Prats de Llusanés y Estany. De alli, por Vich, visitada por segunda vez, pasará a Gerona, trabajando en todos sus archivos desde el 13 de enero de 1807 hasta los primeros días de junio. Por esas fechas pasó a los monasterios de Breda, San Pedro Cercada, Amer, Bañolas y San Feliu de Crixols. En 4 de julio le vemos iniciar la consulta de los archivos de la colegiata de Ulla. Luego marchará al convento de Servitas de Nuestra Señora de Gracia, y antes de dejar el Ampurdán, su curiosidad intelectual le prescribirá una visita a las ruinas heleno-romanas de Ampurias y Castellón de Ampurias.

Transcurre el primer semestre de 1807 y en 11 de julio regresa a Gerona con objeto de preparar su viaje científico al Rosellón, Languedoc y Provenza, la antigua Galia Narbonense, en donde, con buena lógica, tanto los hermanos Villanueva como sus patrocinadores pensaban que podría hallarse abundante documentación referida a la historia eclesiástica de Cataluña ${ }^{14}$.

Autorizado por el Gobierno con un pasaporte especial y provisto de un despacho, facilitado por el ministro del Interior de Francia, en virtud del cual le serían franqueados archivos, bibliotecas y museos, Jaime Villanueva sale de Gerona en 5 de agosto de 1807, en dirección a Perpiñán, Narbone, Carcasone, Toulouse y otros puntos intermedios. Alli comprueba con honda decepción que todos los documentos habían sido destruidos durante la todavía reciente Revolución. El clérigo español pasa a París al objeto de visitar la naciente Biblioteca Nacional y tomar nota de todas las noticias referentes a libros raros y curiosos sobre España. Pronto percibe que cuantas fuentes llegan a su poder no guardan relación con la historia de Cataluña, por lo que recaba del Gobierno español autorización para emprender el regreso. Es así como en septiembre rinde viaje en Madrid. Aquí hará entrega del fruto de sus investigaciones a la Imprenta Nacional.

Apenas transcurridas unas semanas de corto respiro, cuando en los primeros días de octubre el incansable dominico reemprende en $\mathrm{Ca}$ taluña la búsqueda de fuentes útiles para su obra en la Colegiata de Vilabertrán, cercanías de Vilasacra, lugar a donde se había trasladado el monasterio de los benedictinos de San Pedro de Roda; archivos de la colegiata y monasterios de Besalú, y en Olot y Camprodón. Desde allí, vuelve por segunda vez a los monasterios de San Juan de las Abadesas y Ripoll, deteniéndose en este último desde el 24 de octubre hasta el 5 de noviembre.

14 lbídem. 
En su búsqueda exhaustiva de fuentes documentales recorre lugares como Portella, Berga, el monasterio benedictino de Serrates, Solsona y Cardona. Se presenta otra vez a los monasterios de Bages y Montserrat y regresa a Barcelona el 30 de noviembre. Enterado no sin alborozo del fallecimiento del doctoral de Tarragona, que le había impedido examinar los archivos catedralicios, pasa a esta ciudad el 24 de diciembre y aprovecha la ocasión para estudiar a voluntad los registros originales de los concilios provinciales. El 4 de enero de 1808 marcha a Balaguer y de aquí se dirigirá a Bellpuig de las Avellanas, en donde permanecerá por espacio de dos semanas. Con la consulta de este archivo dará por finalizado su trabajo en Cataluña.

Había concluido una etapa muy importante del ambicioso periplo científico proyectado e iniciado años antes ${ }^{15}$. De los resultados obtenidos el sabio eclesiástico valenciano dará cumplida cuenta al ministro Ceballos, en el curso de una entrevista mantenida con él en Aranjuez en 12 de marzo de 1808. Precisamente cinco días antes y en el mismo lugar donde habría de desarrollarse uno de los episodios de máxima trascendencia en nuestro devenir histórico ${ }^{16}$, el primer golpe de estado de nuestra Historia Contemporánea, modelo y anticipo de toda una serie de sucesos similares que, infortunadamente, se han venido repitiendo de forman intermitente hasta tiempos bien recientes.

Sin embargo, Jaime Villanueva no podía preveer el alcance para España y para el futuro de su propia obra de los acontecimientos que se avecinaban en España. Encontrándose en Madrid, sobreviene el golpe de estado de Aranjuez, la destitución de Godoy, la abdicación de Carlos IV, el efímero primer reinado de Fernando VII, la insidiosa ocupación francesa de la capital y el levantamiento del pueblo madrileño. Todo ello entre marzo y mayo de 1808. Con ocasión de los sucesos del 2 de mayo, su vida llega a correr peligro, de forma que opta por escapar a Valencia.

Se abre un paréntesis no cerrado hasta septiembre de 1809, y durante el cual es nombrado prior del convento dominico de Onteniente. En la fecha últimamente apuntada, la Junta Suprema Central, que desde Aranjuez había pasado a Sevilla, huyendo de la proximidad de las tropas francesas, le cursa una orden para que continúe sus investiga-

\footnotetext{
${ }^{15}$ No pocos detalles sobre los orígenes de la empresa y algunos curiosos detalles sobre su desarrollo los hallamos en VILLANUEVA, Joaquín Lorenzo: Vida Literaria de D. (...) Londres. Imp. A. Macintosh. 1825. Vol. I.

${ }^{16}$ Sobre el paradigmático "motín de Aranjuez» y sus efectos inmediatos, véase ARTOLA GALLEGO, Miguel: La España de Fernando VII, t. XXVI de la "Historia de España» dirigida por Menéndez Pidal. Introducción de C. Seco Serrano. Madrid. EspasaCalpe. 1968, ps. 5-14.
} 
ciones en los archivos de las provincias andaluzas todavía no ocupadas por el invasor. En 5 de octubre llega a la capital hispalense, e inicia sus trabajos en la Biblioteca Colombina - luego Archivo General de Indiasy en el archivo catedralicio. Encontrándose allí le sorprenderá la luctuosa batalla de Ocaña, en donde fue desarticulado por los franceses el dispositivo militar español, con el consiguiente descrédito y disolución final de la Junta Central, en tanto se inicia la invasión de Andalucía ${ }^{17}$. Una vez más Villanueva se verá obligado a poner tierra por medio. Precipitadamente sale de Sevilla en 25 de enero de 1810, dejando abandonados sus papeles ${ }^{18}$.

Transcurre medio año, tiempo en el que se afana en los trabajos de investigación y en la resolución de asuntos de su instituto, pero sin abandonar el reino valenciano. En esto llega de Cádiz el acuerdo de la Regencia, señalando la apertura de las sesiones de Cortes para el mes de agosto. Joaquín Lorenzo Villanueva ha sido elegido diputado por Valencia y se le ordena que se presente sin demora en la urbe gaditana. En compañía de su hermano Jaime, de un sobrino y un secretario, parten de San Felipe de Játiva en 26 de julio. Las epidemias y la inseguridad de los mares les obliga a detenerse unas semanas en Cartagena y Orihuela ${ }^{19}$, llegando a su destino a mediados de octubre de 1810, después de un periplo pródigo en interesantes sucesos, que conocemos en sus detalles por un memorable e interesantísimo dietario publicado luego por Joaquín Lorenzo ${ }^{20}$.

En Cádiz fray Jaime, ayudado de las influencias de su hermano y del buen predicamento de que disfrutaba el mismo como profesional competente y laborioso, fue designado redactor oficial del Diario de Sesiones de las Cortes, cargo que ocupó hasta 24 de junio de 1813 . No obstante, la Regencia le autoriza en 23 de diciembre de 1812 para que continúe sus investigaciones archivísticas en las provincias ya liberadas

${ }^{17}$ TORENO, conde de: Historia del levantamiento, guerra y revolución de España: Por el Excmo. Sr. (...). Precedida de la biografía del autor escrita por el Excmo. Sr. D. Leopoldo Augusto de Cueto, de la Academia Española. B.A.E., t. LXIV (Madrid, 1953), ps. 172-214.

${ }^{18} \mathrm{AHN}$, Consejos, leg. 11.317²: Prólogo ms. de Jaime Villanueva al «Viaje Literario a las Iglesias de España».

${ }^{19}$ VILAR, Juan Bta.: Aproximación a la Orihuela Contemporánea. Selección de textos. Prólogo de J.M. Cuenca Toribio. Murcia. Publ. Patronato «A. García Rogel» (Orihuela) 1982, t. I ps. 129-134.

${ }^{20}$ VILLANUEVA, Joaquín Lorenzo: Mi viaje a las Cortes, en «Memorias de tiempos de Fernando VII»). Edición y estudio preliminar de M. Artola. B.A.E. t. 98 (Madrid, 1957), ps. 3-440. 
de la presencia francesa. En Sevilla logra recuperar la documentación perdida tres años antes, y poco después, ante el peligro de una nueva epidemia de fiebre amarilla, el Gobierno le envía a Baleares.

De esta suerte, Jaime Villanueva emprende la última etapa de su "Viaje», embarcando en Cádiz en 10 de octubre de 1813. Tras un rápido estudio de los archivos de Mahón y Ciudadela, llega a Mallorca el 21 de diciembre. Allí permanecerá hasta el 29 de marzo de 1814, fecha en que regresa a Valencia.

Como resultado de esta última étapa, Jaime Villanueva escribirá su "Viaje a las islas Baleares» y el "Viaje a la Iglesia de Sevilla», que quedaría incompleto por las razones antes apuntadas.

\section{EDICION DE LOS VOLUMENES I-IV Y LA SUPUESTA AUTORIA DE JOAQUIN LORENZO}

El gran esfuerzo realizado por Jaime Villanueva en el exhaustivo examen de los archivos diocesanos y monacales de media España se va a plasmar en la pronta edición de los volúmenes iniciales del «Viaje Literario», que van a ver la luz entre 1803 y 1806.

No hay que olvidar, no obstante, que el ímprobo trabajo del viajero no habría alcanzado tan positivos resultados sin la acción paralela de su hermano Joaquín Lorenzo, al que puede considerarse como el gestor de la empresa por sus continuas relaciones con el monarca Carlos IV, con el privado Godoy y con el ministro Ceballos, encaminadas a la consecución de fondos para la financiación de la obra ${ }^{21}$ y del permiso real para su impresión y publicación ${ }^{22}$.

Cabría preguntarse si Joaquín Lorenzo consideraba más importante su labor gestora que la científico-especulativa de su hermano, habida cuenta de que la publicación de los cinco volúmenes iniciales la hace exclusivamente a su nombre. Realmente surge de él la idea de escribir una historia de los antiguos ritos de España y es él quien solicita del ministro Ceballos que Jaime sea asociado a la empresa. En cualquier caso el propio canónigo valenciano esclarece los detalles de esta singular colaboración ${ }^{23}$.

Podríamos considerar que en la primera etapa, la labor de los her-

${ }^{21}$ AHN, Consejos, leg. 11.317²: Carta de Joaquín Lorenzo Villanueva al ministro Ceballos. Madrid, 3 agosto 1802.

${ }_{22}$ Ibidem: Instancias de J.L. Villanueva al ministro Ceballos, marzo 1803, y a Carlos IV. Aranjuez, 25 marzo 1804.

${ }^{23}$ VILLANUEVA, J.L.: Vida literaria... Op. Cit., Vol I. 
manos Villanueva es complementaria, manteniéndose una continua relación epistolar entre ambos, mediante la cual Jaime informa puntualmente a su hermano de los descubrimientos científicos que realiza. Estas cartas, junto con los documentos inéditos que las acompañaban, son presentadas por Joaquín a Ceballos, ilustradas con notas y observaciones propias, lo que podría explicar el hecho de que los primeros volúmenes del "Viaje Literiario" se publicaran a su nombre.

El propio clérigo valenciano aduce como causa fundamental la censura eclesiástica que pesaba sobre él, aunque ésto no será obstáculo para que los volúmenes posteriores fuesen publicados con su rúbrica. De una forma u otra, el tiempo terminó clasificando la autoría real de los volúmenes iniciales. Muchos años después, cuando Manuel Godoy trace el balance retrospectivo de su gestión gubernativa en sús memorias, se congratulará de que en 1804 el «doctísimo fray Jaime Villanueva, llegaba ya al tercer tomo de su «Viaje Literario a las Iglesias de España», viaje y obras que se expendieron de Real Orden y a expensas del Gobierno» ${ }^{24}$.

Dejando a un lado los complejos motivos de la atribución exclusivista de Joaquín Lorenzo y centrándonos en el contenido de los tres tomos iniciales del "Viaje Literario», el mismo Jaime esquematiza la cuestión así: «El 1., después de una breve noticia de algunas antigüedades de Xátiva, trata de otras de la Ciudad de Valencia, de sus obispos, ritos, sínodos, códices y fiestas particulares. El $2^{\circ}$ continúa la misma materia, tratando especialmente del origen de las misas en el día de ánimas, de la fiesta de San Cristóbal, invasión del barrio de los Judíos en 1391, Códices de San Miguel de los Reyes, campana del Puig, y otras cosas antiguas. El $3^{\circ}$. contiene la historia de la Iglesia de Segorbe, catálogo documentado de sus obispos, sínodos, ritos, reliquias, etc.: trata del milagro de las fuentes de Osset, con muchas memorias para la vida del célebre D. Juan Bautista Pérez») ${ }^{25}$.

Estos tres volúmenes iniciales ${ }^{26}$, aparecidos en 1803 y 1804 bajo el nombre de Joaquín Lorenzo Villanueva, en cuanto a contenido se corresponden con el volumen VIII de la «España Sagrada» del P. Flórez,

${ }^{24}$ PRINCIPE DE LA PAZ, Memorias, op. cit. ps. 369-371.

${ }^{25}$ AHN, Consejos. Leg. 11.317²: Prólogo ms. de J. Villanueva Op. cit.

${ }^{26}$ VILLANUEVA, Joaquín Lorenzo: Viaje Literario a las Iglesias de España». Le publica con algunas observaciones Don (...), Capellán de honor y predicador de S.M., y rector de los Reales Hospitales General y de la Pasión de Madrid. Madrid. En la Imprenta Real. 1803-1804, 3 vols. 
donde se incluyen las iglesias de Valencia ${ }^{27}$ y Játiva ${ }^{28}$ entre las primitivamente sufragáneas de Toledo. Desde luego el «Viaje Literario» resulta ser muy superior en cuanto al marco espacial estudiado y sobre todo por la calidad y cantidad de las fuentes aportadas.

La finalidad que se propone el ilustre investigador valenciano es estudiar las diferencias existentes entre los ritos antiguos y los usados en su época. Se siente atraido por la gran variedad de aquellos, ya estudiados en su día, entre otros, por Martene, aunque éste sólo hace mención al mozárabe, prescindiendo de los que se practicaron desde su abolición hasta la introducción del breviario romano por San Pío $\mathrm{V}$ y el ritual de Pablo $V^{29}$. Llega a la conclusión de que a pesar de que, con la invasión de los godos en España, la liturgia romana queda anulada, sólo lo fue en su ceremonial externo y no en su propia identidad, de tal modo que obispos del siglo XVI aún seguían utilizando los antiguos ritos, creándose así una disconformidad de nuestra disciplina ritual con la romana.

Estas noticias, comunicadas por cartas a su hermano, de las cuales se incluyen diez en el primer volumen, siete en el segundo y nueve en el tercero, con un apéndice documental en cada uno de ellos, son ampliadas por Joaquín Lorenzo Villanueva con otras extraidas de las colecciones publicadas de nuestros concilios antiguos, de las decretales y cartas de sumos pontífices pertenecientes a España y de obra de los padres españoles ${ }^{30}$.

Tanto Flórez como Villanueva omiten toda referencia a la diócesis de Orihuela, en razón de su tardío establecimiento - 1564- sobre los territorios regnícolas dependientes hasta el momento de la mitra de Cartagena ${ }^{31}$.

Con los volúmenes IV-V, Villanueva abrirá la serie dedicada a Cataluña, comenzando por la diócesis tortosina, transitoria entre Valencia y el Principado. Estos volúmenes vieron la luz en 1805 y 1806 , siendo

${ }^{27}$ FLOREZ, Henrique: España Sagrada. Theatro Geographico-histórico de la lglesia de España. Tomo VIII: De las Iglesias Sufragáneas Antiguas de Toledo, Palencia, Setabi, Segovia, Segobriga, Valencia, Valeria y Urci, según su estado antiguo. Añádese el chronicón del Pacense, más exacto que en las ediciones anteriores. Segunda edición. Por el M.R.P.M. Fr. (...) Ex asistente General de las Provincias de España, Orden de San Agustín. Madrid. Por Don Antonio Sanz, Impresor del Rey nuestro Señor, y de su consejo. Años de MDCCLXIX, ps. 34-62.

${ }^{28}$ Ibídem, ps. 134-195.

${ }^{29}$ AHN, Consejos, leg. 11.317²: Prólogo ms. al "Viaje Literario» Op. cit.

30 VILLANUEVA, J.L: "Viaje Literario.... t. I. (Introducción sin páginas).

${ }^{31}$ Vid. VILAR, J.B.: Orihuela, una ciudad valenciana en la España Moderna. Prólogo de S. García Martínez. Murcia. Publ. Patronato «A. García Rogel» (Orihuela). 1981, vol. III, ps. $770-814$. 
celebrados con toda justicia como el más riguroso y documentado estudio de la historia eclesiástica publicado hasta el momento sobre el ámbito catalán, manteniendo todavía buena parte de su interés y vigencia.

\section{LOS HERMANOS VILLANUEVA DURANTE LA PRIMERA RESTAURACION FERNANDINA.}

La guerra de la Independencia, y la revolución política que conllevó, permitió a clérigos como los Villanueva, de ideas jansenistas en la medida en que abogaban por el desmantelamiento del aparato autoritario y coactivo eclesiástico, expresarse con mayor libertad. Como apunta J.A. Maravall ${ }^{32}$, sacerdotes que en el campo eclesiástico habian sido regalistas al decantarse contra el absolutismo religioso, necesariamente tenían que ser liberales, o cuando menos reformistas, en su rechazo del absolutismo político.

Joaquín Lorenzo Villanueva, cuya heterodoxia doctrinal hasta el momento no ha sido claramente establecida - mucho menos la de su hermano Jaime - ${ }^{33}$, será sin duda el más conspicuo y destacado representante del jansenismo español en su fase política. Así lo prueba su ejecutoria personal a partir de su destacada participación en las Cortes de Cádiz, sobre todo en la Comisión de Asuntos Religiosos, y por su intervención en las gestiones que precedieron y acompañaron a la imposición del juramento de la Constitución de 1812 a los eclesiásticos, frente al parecer contrario del clero más conservador agrupado en torno al obispo de Orense, sector este último que manifestaría sus tesis en un folleto anónimo - atribuido al mitrado Inguanzo ${ }^{34}-$ y cuya réplica precisamente fue encomendada a Villanueva.

El diputado valenciano se mostrará en todo momento firmemente católico, como lo evidencia sus reiteradas intervenciones en favor de la uniformidad religiosa recogida en el texto constitucional ${ }^{35}$, pero con

${ }^{32}$ Sobre los origenes y sentido del catolicismo liberal en España, en «Homenaje a Aranguren», Ediciones de la Revista de Occidente. Madrid. 1972, ps. 229-266.

${ }^{33}$ Esta cuestión es estudiada por Juan Bta. VILAR en su monografía de conjunto sobre el protestantismo español contemporáneo: Los origenes de la // Reforma en España (1812-1869). En preparación.

${ }^{34}$ Vid. CUENCA TORIBIO, José Manuel: D. Pedro de Inguanzo y Rivero (1764-1836), último primado del Antiguo Régimen. Pamplona, 1965. Vid. también CUENCA TORIBIO, Estudios sobre la Iglesia española en el siglo XIX. Madrid. Rialp. 1973, ps. $15-22$.

35 TIERNO GALVAN, Enrique: Leyes Politicas Españolas Fundamentales (1808-1936). Madrid. Tecnos. 1972, ps. 23-24. 
igual decisión propugnará por la reforma eclesiástica, por la convocatoria de un concilio nacional y por el reforzamiento de las atribuciones episcopales en detrimento de la omnipotente autoridad pontificia. En su famoso «Dictamen» ${ }^{36}$, leído en las Cortes en $1813^{37}$, Villanueva estimará que, sin detrimento del privilegiado trato que debía dispensarse a la religión católica por ser la de la inmensa mayoría de los españoles, en el futuro deberían contemplarse también los derechos de los disidentes. Para ello bastaba, a su juicio, con suprimir la Inquisición, aboliendo algunas de sus competencias y transfiriendo las restantes a los prelados en sus diócesis, y al propio Estado. Nos consta que estas ideas, aunque más matizadas, eran compartidas por fray Jaime Villanueva.

Habiéndose ganado la feroz inquina del sector tradicional del estamento social a que pertenecía ${ }^{38}$, el propio Villanueva referirá años más tarde la gigantesca operación montada por Fernando VII para la detención por sorpresa, arresto e irregular enjuiciamiento y condena de él y sus compañeros diputados de signo liberal ${ }^{20}$. El proceso ${ }^{40}$ seguido al infortunado canónigo, en relación con su participación en los sucesos políticos precedentes, se prolongó de forma penosa durante los años 1814 y 1815.

La revolución de 1820 sacó a Joaquín Lorenzo de la prisión y a su hermano de la oscuridad. El primero fue reelegido diputado por su provincia de origen, asumió un papel destacado en la política religiosa del trienio constitucional, se reafirmó en sus posturas regalistas de siempre, perfiló mejor su jansenismo intelectual y cuando fue designado embajador ante la Santa Sede y el pontífice se negó a recibir en sus estados a tan peligroso sujeto, Villanueva abogó por la ruptura con Roma y esbozó el proyecto de una Iglesia nacional, nominalmente sujeta al Papa, pero muy próxima al modelo anglicano ${ }^{41}$.

${ }^{3}$ DICTAMEN del Sr. Joaquín Lorenzo Villanueva, Diputado en Cortes por Valencia, acerca de la segunda proposición preliminar del proyecto de decreto sobre los Tribunales protectores de la Religión, leido en las sesiones del 20 y 21 de Enero, Cádiz, Imp. de D. García Campoy, 1813.

${ }^{37}$ El «Dictamen» fue prohibido por el Tribunal «in totum», aún cuando para quienes estaban autorizados a leer libros prohibidos. Vid. EDICTO del Santo oficio de la Inquisición. Madrid, 22 de julio 1815, 1 hj.

${ }^{38}$ ALCALA GALIANO, Antonio: Recuerdos de un anciano. Por el Excmo. Señor D. (...). Madrid. Luis Navarro, Editor. 1878, p. 210.

39 VILLANUEVA, Joaquín Lorenzo: Apuntes sobre el arresto de los vocales de Cortes, ejecutado en mayo de 1814, escrito en la cárcel de Madrid. Madrid. Imp. de las Cortes. 1820.

40 LASA IRAOLA, Ignacio: El proceso de Joaquín Lorenzo Villanueva, 1814-1815. "Cuadernos de Historia", IV (Madrid, 1973), ps. 29-82.

${ }^{41}$ Vid. VILLANUEVA, Vida Literaria... Op. cit. Véase también VILLANUEVA, Diputado: Nuevos apuntes del (...) sobre las cartas del Señor Alcalá Galiano. Madrid. Imp. de Mateo Repullés. 1821. 


\section{FERNANDO VII SE INTERESA POR EL "VIAJE LITERARIO». EDICION DE LOS VOLUMENES VI-X POR LA IMPRENTA NACIONAL. IMPRESION EN VALENCIA.}

El caos político-social y el desmantelamiento económico que sufre el país durante la guerra de la Independencia iban a marcar un compás de espera en la edición del "Viaje Literario», que se prolongaría hasta 1820.

En su esfuerzo por sacar adelante el "Viaje Literario», Jaime Villanueva practica gestiones cerca de don Agustín Argüelles, a la sazón ministro de la Gobernación durante el trienio constitucional. Le propone la posibilidad de que se pueda continuar la publicación en Valencia, con la consiguiente economía en los costos de edición pues «ubastaría que el Gobierno me consignase 6.000 reales anuales, con que acudir a los gastos precisos de copiantes, correctores, ect. $\rangle^{42}$.

La larga etapa de desconcierto intelectual y gubernativo por la que había atravesado España obligará al ministro a recabar información a la Academia de la Historia sobre los antecedentes del «Viaje Literario». Los informes que el secretario de dicha institución, don Diego Clemencín, envía al ministro Argüelles no pueden ser más positivos, alcanzando sus resultados a finales del año 1820, en que Fernando VII autorizará la impresión del volumen VI y siguientes de la obra que nos ocupa.

Otra cuestión que se va a suscitar al renaudar la publicación de los nuevos volúmenes de la obra de Villanueva es la relativa a la autoría de la misma, habida cuenta de que los cinco volúmenes primeros aparecen a nombre de Joaquín Lorenzo y no de Jaime, quien ahora considera "debe publicarse a nombre mío que soy el viajero» ${ }^{43}$. Sin embargo subsistían todavía ciertos problemas relativos a la censura de la orden de los dominicos, que el investigador valenciano pretende subsanar.

El problema queda zanjado cuando Fernando VII, en diciembre de 1820 ordena que se dispense a J. Villanueva de la censura que exigen los estatutos de su orden, mandato que será acatado sin reparos por el vicario general de los dominicos de Valencia. De esta suerte, los volúmenes $\mathrm{VI}$ al $X$ verán la luz desde marzo de 1821 hasta finales del mismo año. La edición se hace en Valencia en la imprenta Monfort, según deseos del propio autor.

La impresión de estos cinco volúmenes en Valencia se tradujo en sustantivo abaratamiento de los costes de edición. Además permitió al

${ }^{42}$ AHN. Consejos. Leg. $11.317^{2}$ : de la instancia de J. Villanueva a A. Argüelles, Valencia, 20 junio 1820 .

43 Ibídem. 
Estado reducir a 6.000 reales la pensión que venía pasando al autor, todo ello sin detrimento de la calidad en la impresión de la obra. Monfort, titular de una de las imprentas más profesionalizadas de provincias, realizó ciertamente un trabajo excelente. No sólo en cuanto al esmero de la edición ${ }^{44}$, sino por haberse servido de criterios de composición, papel e incluso caracteres tipográficos similares a los utilizados en los volúmenes iniciales.

A pesar del apoyo gubernamental, Jaime Villanueva asistirá con hondo pesar a la nueva suspensión de su obra a partir de abril de 1822. Esta nueva interrupción se prolongará durante largos años, de tal forma que nuestro historiador morirá sin haber visto concluida la edición total del "Viaje Literario».

Tres causas fundamentales podríamos apuntar para la comprensión del hecho: la crisis económica por la que atravesaba España, la primacía que los factores políticos adquirieron en esa época sobre cualesquiera otros en medio de un país sumido en un analfabetismo generalizado, y el fracaso final de la experiencia liberal, con el consiguiente exilio de los hermanos Villanueva. Los argumentos de éstos en favor de la continuación de la obra van a ser de escaso valor frente a los del director de la Imprenta Nacional, don Eugenio de Tapia, que hará ver la irrentabilidad económica de la empresa.

\section{LA DESAPARICION DE JAIME VILLANUEVA Y EL DESTINO DE SUS MANUSCRITOS.}

Jaime Villanueva muere en noviembre de 1824, en Londres, a donde había emigrado tras el restablecimiento en España del absolutismo monárquico (decreto de 1 de octubre de 1823). Como en otros muchos casos este auto-exilio fue una prudente decisión para escapar a la represión antiliberal que se perfilaba en el horizonte político, más dura que la de 1814.

La obra inédita de Jaime Villanueva seguiría una suerte azarosa después de la muerte de su autor. En el largo período transcurrido entre la emigración de 1824 y la Constitución de 1837, los manuscritos de Villanueva, que por cierto habían permanecido en Valencia confiados por el autor a su fiel colaborador Ignacio Herrero, quedan en el olvido. Son muchos los problemas de España - represión absolutista, la transición al liberalismo, la larga enfermedad de Fernando VII, la cuestión sucesoria, la guerra civil y la revolución liberal que se va a manifestar en todos

${ }^{44}$ VILLANUEVA, Jaime: Viaje Literario..., Valencia. Imp. Monfort Olivares. 1821, vols. $\mathrm{VI}-\mathrm{X}$. 
los órdenes de la vida española - para que se prestase atención al asunto que nos ocupa.

En septiembre de 1838, una vez restablecidas las libertades constitucionales en nuestra nación, Ignacio Herrero dará cumplida cuenta a la Academia de la Historia del tesoro documental que poseía. Esta noticia, aunque obtiene una grata acogida por parte de la citada institución, no alcanzará resultados positivos hasta un año más tarde, en que, informado de nuevo el ministro de la Gobernación, se inician unas minuciosas diligencias por parte de la Subsecretaría de este ministerio, que dan por resultado el hallazgo en su archivo de los antecedentes del «Viaje Literario». Este hecho suscitará honda alegría, pero al mismo tiempo motivará una gran preocupación por el futuro de los originales, ante las pretensiones de la Academia de la Historia de incluir los manuscritos del docto dominico en la "España Sagrada» del P. Flórez.

La defensa que Gobernación hace del "Viaje Literario» es contundente pues considera que "si la Academia de la Historia se halla animada del deseo de publicar aquellos manuscritos, ocasión tiene de hacerlo y de acreditar su celo; publíquense los manuscritos a nombre de su verdadero autor y como continuación de la obra de que forman parte $»^{45}$.

Tales declaraciones moverán al Gobierno en diciembre de $184^{\circ}$, solicitar del padre Herrero los documentos para ponerlos a disposici , de la Academia, dándose así inicio a una nueva etapa en la publicacic 7 del «Viaje Literario», en la que hay que destacar el decisivo apoyo del regente Espartero, recién llegado al poder - octubre 1840 - y que aparece en España como vivo símbolo del progresismo.

\section{EDICION DE LOS VOLUMENES FINALES}

Los trabajos de Ignacio Herrero dan como resultado que en febrero de 1841 se envie a Madrid el manuscrito del volumen XI, que comprendia cinco cartas, referidas a la Iglesia de Urgel, desde mediados del siglo XIII hasta principios del XVIII, con inclusión del episcopologio, cánones, volúmenes manuscritos, noticia de varios monasterios y colegiatas, historia detallada del monasterio de Bellpuig de las Avellanas y otras constituciones sinodiales de diferentes obispos de aquella catedral ${ }^{46}$.

${ }^{45} \mathrm{AHN}$, Consejos. Leg. 11.317²: de las recomendaciones de la subsecretaría de Gobernación al titular del Ministerio. Madrid, 16 diciembre, 1840.

${ }^{46}$ Ibídem: del oficio del jefe político de Valencia al ministro de la Gobernación, Valencia, 20 febrero, 1841. 
Tal como quedó el volumen, sus materiales se reagruparon en dos grandes capítulos o "cartas» y un extenso apéndice documental. La carta LXXXV recoge la parte final del epistologio urgellense, en tanto la siguiente reune un conjunto de materiales diversos bajo el título global de «Noticia de códices de cánones y otros manuscritos muy notables que se conservan en el archivo de la iglesia de Urgel». En cuanto al "Apéndice de documentos», es una selección de fuentes, donde se espigan para ofrecerlos al lector los documentos más relevantes a que se hace referencia en el texto.

De este volumen ${ }^{47}$ como de los dos siguientes hemos consultado sendas ediciones de $1850^{48}$ realizadas en la "Imprenta de la Real Academia de la Historia, a cargo de D. Celestino G. Alvarez, calle de S. Vicente Baja, núm. 74». Ignoramos si se trata de una reimpresión, o si por el contrario - como parece casi seguro - los materiales presentados por Herrero fueron retenidos diez años, hasta la estabilización política del pais al término de la regencia de Espartero en 1843, y la conquista del poder por el Partido Moderado al año siguiente, y en el que se mantendrian con continuidad por espacio de una década ${ }^{49}$, sumado a la propicia coyuntura económica, posibilitó la reanudación de tan magno empeño literario.

La transcripción del volumen XII se concluye en junio del mismo año. Dicho tomo comprendía 328 hojas de texto y 157 en 135 documentos justificativos. También en este caso la edición manejada por nosotros aparece fechada en 1850 y en la imprenta de la R. Academia de la Historia. Consta de ocho capítulos o cartas y un apéndice documental. El capítulo inicial cierra cuanto se refiere a la iglesia de Urgel. Los dos siguientes inciden sobre diferentes monasterios de la alta Cataluña - Castellbó, Orgaña, Tremp, Bellpuig de las Avellanas... etc - . Los cinco restantes se ocupan por entero de la iglesia de Gerona, su historia, ritos códices y otros fondos documentales. Algunos de los materiales aludidos se reproducen en un excelente apéndice documental ${ }^{50}$.

${ }^{47}$ VILLANUEVA, Jaime: Viaje Literario a las Iglesias de España. Su autor Don (...). Presbitero, individuo de la Academia de la Historia. Tomo XI: Viaje a Urgel. Publicado por la misma Academia. Madrid. Imprenta de la Real Academia de la Historia... 1850.

${ }^{48}$ Ejemplares consultados en la Sala de Manuscritos, Raros y Curiosos, B.N. de Madrid. Como la restante colección de esta obra procede del legado realizado por el eximio arabista Pascual de Gayangas a la Biblioteca Nacional.

${ }^{49}$ COMELLAS, José Luis: Los moderados en el poder. 1844-1854 Madrid. Escuela de Historia Moderna. 1970, p. 10 ss.

${ }^{50}$ VILLANUEVA, Viaje Literario... t. XII. Viaje a Gerona. Madrid. Imprenta de la Real Academia de la Historia. 1850. 
Tanto el volumen XIII como el XIV inciden también sobre la iglesia gerundense. El primero de los mencionados ${ }^{51}$, consta de un capítulo único - la carta n:95-, consistente en un "Catálogo de los obispos de Gerona», o lo que es lo mismo un episcopologio, por cierto muy bien documentado. EI XIV está formado por cuatro capítulos. Con el primero se concluye el episcopologio. El siguiente incide exclusivamente sobre la colegiata de San Félix, el tercero es una miscelánea de noticias diversas, el cuarto estudia los monasterios de la diócesis gerundense, a saber: San Salvador de Breda, San Pedro de Cercada, Sta. María de Amer, Sta. María de Rosas y S. Esteban de Bañolas. No se incluye apéndice documental ${ }^{52}$.

La desaparición de fray Ignacio Herrero acaecida a principios de 1844 , suscitó la gran preocupación tanto del Gobierno como de la Academia de la Historia, por el peligro que ello representaba para la conservación de los documentos que obraban en su poder.

Hay que destacar el decisivo interés de la máxima institución histórica del país por la obra de Jaime Villanueva y su apoyo para la edición de los volúmenes finales, responsabilidad que asumió años más tarde, dada la desastrosa situación financiera de la Imprenta Nacional y el desfavorable informe emitido por don Manuel Bretón de los Herreros, administrador de la misma.

En total fueron editados por la Academia de la Historia doce volúmenes. Diez de ellos completará el ciclo catalán, con particular referencia a la diócesis de Barcelona, Lérida y Tarragona ${ }^{53}$, con aportación de una impresionante información documentada.

Los dos últimos ${ }^{54}$ se referirán a las iglesias de Mallorca y Menorca, con especial incidencia sobre la primera, en relación con la cual aporta un elenco documental todavia hoy insustituible y de preceptiva consulta para cuantos se interesen por las islas Baleares, su historia, instituciones, arte y cultura.

Es de señalar el magno esfuerzo editorial que representó la cuidada edición de una mitad larga del «Viaje Literario» - 12 volúmenes sobre un total de 22- en sólo tres años. Es cierto que la Administración facilitó los medios necesarios, allanando los obstáculos económicos, pero

\footnotetext{
51 Ibídem, tomo XIII: Viaje a Gerona. Publicado por la misma Academia. Madrid. Imprenta de la Real Academia de la Historia. 1850.

${ }^{52}$ Ibídem, t. XIV: Viaje a Gerona. Madrid. Imp. de la R. Academia de la Historia. 1850.

${ }^{53}$ Ibídem, t. XV-XX, Madrid. 1850-1851... Op. cit.

${ }^{54}$ Ibídem, t. XXI-XXII. Madrid, 1852... op. cit.
} 
no por ello es menor el mérito de la Academia de la Historia al llevar a buen puerto, con esmero casi preciosista, una empresa de tal embergadura en un tiempo record.

\section{CONCLUSIONES}

Con nuestro estudio hemos tratado de dilucidar, siquiera en parte, cuantos problemas se relacionan con el «Viaje Literario» y con sus autores, personajes que sin duda habría que enmarcar en una etapa de la cultura española ubicable entre la llustración y el Romanticismo. Puede afirmarse con escaso riesgo de error que ambos eruditos, por nacer tardíamente,'son más bien personajes sietecentistas, circunstancia que repercutirá negatívamente en sus vidas, aunque sólo fuese por la incomprensión de sus contemporáneos.

En cuanto al proceso editorial estudiado, podemos concluir con el eximio historiador P. Fita, que el «Viaje Literario a las Iglesias de España» es una de las empresas de mayor empeño de cuantas han sido abordadas en tiempos modernos en el campo de la investigación histórica española ${ }^{55}$. Nos consideramos recompensados si de alguna forma hemos contribuido a su mejor conocimiento.

\section{ABREVIATURAS UTILIZADAS}

A.H.N.: $\quad$ Archivo Histórico Nacional (Madrid).

B.A.E.: Biblioteca de Autores españoles.

B.N.: Biblioteca Nacional (Madrid).

B.R.A.H.: Boletín de la Real Academia de la Historia.

${ }^{55}$ LESMES FRIAS, La correspondencia cientifica del $P$. Fita con sabios extranjeros. B.R.A.H. 


\section{BURGUESIA Y COMERCIO EN ALICANTE A MEDIADOS DEL SIGLO XIX.}

La actividad económica fundamental de la ciudad de Alicante en el siglo XIX era el comercio. Sus características de ciudad portuaria durante los siglos XVII y XVIII configuraron una actividad mercantil que alcanzó su máximo esplendor en la pasada centuria.

El desarrollo económico desde 1840 hizo conocer a la ciudad una etapa de prosperidad, puesta de manifiesto en un crecimiento de la población en relación con el paralelo incremento de la actividad agrícola y comercial. En concreto el volumen del tráfico portuario creció tan rápidamente que obligó a la burguesía local a interesarse por la realización de reformas y mejoras en las instalaciones del puerto desde los años cincuenta.

El comercio alicantino se especializó en la exportación de una serie de productos de las comarcas próximas entre los que destaca en primer lugar la producción de vinos, tanto de su huerta con el vino fondiIlón como de otras zonas vitícolas de la provincia. Seguían en importancia materias primas como las fibras vegetales, esparto y cáñamo, y la barrilla. Estas exportaciones que habian gozado de un tráfico de gran intensidad en épocas anteriores se veían ahora reducidas a consecuencia de las transformaciones que tuvieron lugar en la agricultura alicantina desde la mitad del siglo XIX.

Otros artículos de incidencia eran la almendra, el olivo y el algarrobo que junto con pequeñas partidas de sal provenientes de las salinas de Torrevieja y Guardamar completaban la exportación alicantina.

La importación de otro tipo de productos como los cereales y los salazones era también primordial desde el punto de vista comercial. Ambos artículos alimenticios eran de capital importancia para el consumo de la ciudad, teniendo en cuenta la deficitaria producción cerealista de las comarcas más cercanas y el alto precio del transporte de trigo de Castilla, incluso una vez construida la línea férrea con Madrid, y la gran demanda que tenían los salazones por ser uno de los principales integrantes del consumo popular. Además a través del puerto de Alicante se distribuían estos productos a las zonas interiores.

Es necesario destacar, también, el papel de la ciudad como centro distribuidor de ciertos productos coloniales y otras mercancías que aun- 
que no representan grandes cantidades en el volumen total de importaciones si tienen significación en relación con la estructura comercial y las fuentes de ingresos de la burguesía local. Estos productos, procedentes del comercio de cabotaje con otros puertos peninsulares como Cádiz o Málaga, llegaban a Alicante para ser luego distribuidos al interior de la península'.

La apertura del ferrocarril Madrid-Alicante en 1858 creó nuevas expectativas para el desarrollo del sector comercial. El tradicional comercio con Madrid que se realizaba por medio de carretas contaría desde este momento con un medio de transporte más rápido que daría mayor celeridad al tráfico y a las actividades comerciales con Castilla. A partir de entonces el ferrocarril se convertía junto con el puerto en el eje de la economia alicantina.

La construcción del ferrocarril y su orientación al transporte de mercancías alentó la creación de una infraestructura adecuada a las nuevas necesidades comerciales que se centró en la construcción de almacenes y depósitos de mercancías.

Como vemos, en esta coyuntura las perspectivas de la burguesía comercial no podían ser mejores. Pero el desarrollo del comercio chocaba con un problema, que se arrastraba desde los comienzos del siglo, la falta de circulación monetaria para realizar los intercambios. A lo largo de todo el siglo XIX se reflejaba esta dificultad, que se hará acuciante en la década de los cuarenta. En 1842 la Junta de Comercio de Alicante en una exposición elevada al Secretario de Estado y del Despacho de Gobernación se quejaba de la escasez de moneda española en el mercado y su sustitución por moneda francesa ${ }^{2}$. Por este motivo señalaba la necesidad de crear una casa de emisión de moneda en Alicante aprovechando las cinco fábricas de fundición que en ese mo-

\footnotetext{
' Consultando una documentación relativa al comercio de cabotaje entre varios puertos españoles en el Archivo Historico Nacional (A.H.N.), hemos comprobado que existía una estrecha conexión comercial entre Cádiz y Alicante que se concretaba en una serie de productos como el azúcar, el cacao, el añil, maderas preciosas, especias y tinturas que llegaban desde Cádiz en las barcas de cabotaje. A.H.N. Sección de Hacienda, leg. 3640.

${ }^{2}$ En 1847 El Mensajero, Boletín de la Compañía Alicantina de Fomento, se expresaba en el mismo sentido quejándose de la mayor circulación de los napoleones franceses (piezas de cinco francos) frente a la moneda española, lo que suponia dar a aquella moneda un valor intrínseco superior al legal y al correspondiente al peso de la pieza, además de recalcar que: «el gobierno que admite una moneda extranjera como nacional abdica en favor de otro gobierno extraño el derecho exclusivo que tiene de acuñar moneda admisible en el pais que administra, y si además le da un valor comparativamente más alto que el de la moneda nacional perjudica los intereses de sus subordinados favoreciendo a los de un país extraño...» El Mensajero, 14 de enero de 1847.
} 
mento funcionaban en la capital y los yacimientos minerales de Sierra Almagrera y de Cartagena. La casa de moneda serviría para aumentar la circulación monetaria y por tanto facilitaría los intercambios y fomentaría el comercio alicantino ${ }^{3}$.

No sólo la falta de circulación de moneda era una traba al desarrollo comercial sino también la falta de créditos para invertir en estos negocios. La burguesía alicantina conocía las interesantes iniciativas que en este sentido se habían dado en otros países europeos con la creación de sociedades crediticias. Gran parte de los comerciantes, aunque asentados en Alicante, eran de origen extranjero y actuaban como agentes de compañias comerciales de sus países de origen y estaban, por tanto, en contacto con las más innovadoras corrientes europeas del pensamiento económico y habian visto, gracias a su estrecha relación con estos países, los favorables resultados de tales entidades para el comercio. Así surgía la posibilidad de crear una entidad crediticia que contribuyera al fomento de los negocios mercantiles.

\section{LA PRIMERA INICIATIVA FINANCIERA: \\ LA COMPAÑIA ALICANTINA DE FOMENTO}

En 1846, en un contexto de expansión comercial se imponía la necesidad de crear un instrumento financiero que estuviera al servicio del desarrollo agrario y comercial, base de la economía alicantina. De la mano de una burguesía dinámica y emprendedora surgía la primera iniciativa financiera autóctona, la Compañía Alicantina de Fomento. Nacía en un entorno propicio para la creación de este tipo de instituciones pues ya se habian dado iniciativas similares en otros lugares de nuestra geografía y nacía esta sociedad con un marcado carácter local. Se hacía incidencia en que la entidad financiera respondiera a los intereses locales y provinciales y no fuese una nueva filial de un establecimiento foráneo:

«Muchas y diferentes son las asociaciones y empresas establecidas en la corte de poco tiempo a esta parte, y todas propagando del centro de España a las provincias sus dećantados ofrecimientos, han establecido los medios de operar, han nombrado sus representantes, han publicado sus estatutos (...). Pero basta decir, el que rara es la operación provechosa que éstas hayan realizado ni con particulares, ni con labradores ni con empresas, ni con establecimiento alguno y muchos los propietarios desengañados de las ilusiones que se les habían hecho concebir en los programas que con tanta difusión vieron la luz pública.

${ }^{3}$ Archivo Municipal de Alicante (A.M.A). Sala Histórica. Arm. 22, Leg. Indeterminado. Años 1840-43. 
Era preciso pues acudir con un remedio eficaz, dando una lección provechosa a las provincias que en el caso de ésta se encontrasen y establecer una compañía representada por sujetos interesados en la ventura y prosperidad del país; era necesario el que personal de conocida probidad, de no desmentida honradez, de arraigo, riquezas, instrucción y patriotismo, se encargasen de explotar los elementos de felicidad pública en beneficio del procomunal y no dominados por un interés mezquino de codiciosa especulación» ${ }^{4}$.

Surgía así en época temprana esta iniciativa financiera pero no sólo ligada a sectores de la burguesia comercial sino también a parte de la oligarquía agraria. El Consejo de Administración era una representación de ambas fracciones de la burguesía local. La agricultura, una vez desaparecidos los pósitos, necesitaba también unas posibilidades crediticias que más adelante se concretarían en la posibilidad de crear un Banco Agrícola ${ }^{5}$ destinado a facilitar los préstamos a labradores y hacendados, pero en este momento la Compañía Alicantina de Fomento se planteaba como una entidad crediticia dirigida tanto al sector agrícola como al comercial ${ }^{6}$.

La sociedad se creaba con un capital social de un total de 6 millones de reales representados por la emisión de 6.000 acciones nominales de 1.000 rs. cada una. Se fijaba a la compañía una duración de cincuenta años que se podría prorrogar a voluntad de los accionistas.

La idea de su fundación partió de un financiero madrileño, Pedro de Lara, que ya había estado vinculado a otros proyectos relacionados con la ciudad como el de la construcción del ferrocarril Madrid-Alicante?

${ }^{4}$ El Mensajero, 31 de diciembre 1846.

${ }^{5}$ El crédito agrícola fue uno de los temas que más preocupó en el siglo XIX a la burguesia local. En 1861 se intentó crear un Banco Agrícola que no llegó a ponerse en funcionamiento (Vid. Archivo de la Diputación Provincial de Alicante - ADPA Sección de Fomento, Leg. 501). En la década de los ochenta volvía a resurgir la iniciativa de la mano del Diputado alicantino Enrique Bushell, que presentó en noviembre de 1881 una proposición de ley para la creación de un Banco Agricola. Vid. BUSHELL, E. El crédito agrícola. Imp. Carratalá Gadea, Alicante. 1881.

${ }^{6}$ Asi constaba en sus objetivos. Véase El Mensajero, 31 de Diciembre de 1846.

7 Pedro de Lara fue el promotor de la llamada línea del Mediterraneo, que uniria Alicante con la Corte. Su proyecto, el primero que se presentó, recibió el apoyo de la corporación municipal de Alicante en 1843. Una vez que fue aprobado, el financiero madrileño animó la constitución de la sociedad Camino de Hierro de María Cristina, que sería la encargada de llevarlo a término. A pesar de que se llegaron a suscribir varias acciones, en mayo de 1845 el mismo Pedro Lara anunciaba la disolución de la sociedad en los salones del Consulado al haber obtenido Jose de Salamanca la concesión del ferrocarril de Madrid a Aranjuez. Véase A.M.A. Cabildos. 14 de noviembre de 1843. Boletín Oficial de la Provincia de Alicante (B.O.P.). 14 de Enero de 1844 y GINER PASTOR, J. El Ferrocarril Madrid-Alicante en el siglo XIX. Alicante, 1983 págs. 20 y 21. 
Los directivos de la nueva sociedad eran terratenientes y comerciantes. Entre los primeros destacaban miembros de la nobleza provinciana, propietarios de tierras en la Huerta y otras comarcas alicantinas, como el Marqués de Algorfa, el Barón de Finestrat, el Conde de CasasRojas y Miguel Pascual de Bonanza. Junto a ellos aparecen comerciantes que, en muchos casos también poseían tierras en la provincia, como Ramón Izquierdo, Angelo Cutayar y Francisco París ${ }^{8}$. Completaban el Consejo dos consejeros de provincia, Felipe Gil y J. Pedro Sanmartín, y un coronel de infantería, Lorenzo Novella, que además figuraban también en las listas de contribuyentes como propietarios.

Sus objetivos quedaron marcados desde el inicio de su constitución. En primer lugar la creación de una Caja de Ahorros y el facilitar el crédito a labradores y artesanos. Además, se hacía una declaración genérica de fomento de la riqueza pública de la provincia en todos sus ramos "agricultura, comercio, navegación e industria».

La sociedad gozó desde sus inicios de una buena acogida y contó con el apoyo institucional. Para ello se nombraron vocales supernumerarios de la Junta de Gobierno a destacadas personalidades del mundo de la política y las finanzas tales como Mariano Roca de Togores, Joś Antonio Ponzoa, José de Salamanca, Conde de Goyeneche, Juan A toine Zayas, José Aynat, Mariano Rebagliato, José Romero Giner y Fra:cisco Aynat ${ }^{9}$. Las expectativas que despertó en la burguesía comercial agrícola fueron muy halagueñas:

«El objetivo primordial de la Compañia Alicantina de Fomento, objeto en el más alto grado humanitario, y que sin duda ha de proporcionar inmensos bienes al país. Porque esta sociedad, contando con los recursos necesarios, alargará la mano al desventurado labrador para sacarlo del estado de miseria y abatimiento en que se encuentra, $y$ tendiendo la vista sobre nosotros mismos y a nuestro alrededor, dará un giro al comercio y movimiento a la descuidada industria; en aquel facilitando la exportación de los productos indígenas que no necesitamos, y la importación de los extraños, de que carecemos y en éste planteando los establecimientos que nuestra posición topográfica requiera y que los adelantos científicos del siglo actual están exigiendo ${ }^{10}$.

Su actividad se centró principalmente en la Caja de Ahorros que

${ }^{8}$ Todos ellos figuraban como los mayores contribuyentes de la capital en el año 1849. Véase Lista de Electores y elegibles para cargos municipales. Alicante, 1849.

${ }^{9}$ Todos ellos Diputados a Cortes por la provincia de Alicante El Mensajero, 10 de diciembre de enero 1846.

'10 Ibídem, 28 de enero de 1847. 
contó con un reglamento especial por el que se creaba una caja abierta a toda clase de personas aunque fijaba un tipo mínimo de imposición de 4 rv. con un interés del $4 \%$ anual. La creación de esta entidad estaba dentro del pensamiento filantrópico de la época, pero no hay que olvidar el carácter utilitarista y político que señala Clementina Ródenas:

La creació de Caixes d'Estalvis a partir dels anys quaranta del segle XIX, cal situar-la en el context de la difussió del pensament utilitarista després del retorn dels liberals emigrats d'Anglaterra i de França pero alhora cal no oblidar que llur èxit i propagació està vinculat al fet de considerar-les com a institucions essencialment anti-revolucionaries" " ".

Tenía también una vertiente moralizante. El obrero podía a través del ahorro conseguir un capital que le permitiera acceder a la propiedad:

«Como quiera que la propiedad sea el primer elemento de bienestar social, el primer medio de educación, así como la primera garantía de moralidad y de libertad, creemos que sería conseguir un inmenso y saludable resultado, el poder, a favor de una institución económica, extender a mayor número de hombres la posesión del capital mueble o inmueble...

...Convencidos de que éste es el mejor y más cómodo empleo que a sus economías pueden dar los artesanos labradores, sirvientes, y cuantos, en fin, viven del producto de su trabajo, opinamos que a todos los hombres que con firme y buena voluntad deseen la moralidad y el bienestar del pueblo cumple esforzarse por promover y generalizar en sus respectivas provincias esta útil institución.

Util, sí, por todos los conceptos; pues a las ventajas que ya hemos enumerado, tienen las Cajas de Ahorros la de ser una garantía moral contra la ociosidad y la depravación, que por lo regular absorbe una parte del salario de aquellos infelices dejándoles sólo en cambio estériles remordimientos, miseria y desesperación ${ }^{22}$.

Partiendo de este concepto del carácter utilitario y moralizante de la Caja de Ahorros, era su propósito extender estas instituciones a los pueblos más importantes de la provincia. Para ello el propio fundador de la Compañía Alicantina de Fomento, Pedro de Lara, se dedicó a recorrer las localides de Elche, Aspe, Monforte, Novelda, Elda, Petrel, Sax, Villena y Almansa, nombrando en cada una de ellas representantes que se encargarían de gestionar alli los intereses de la sociedad para en fechas posteriores proceder a la creación de sucursales de la Caja de Aho-

"RODENAS, C. Banca i industrialització. El cas Valencia. 1840-1880. Valencia 1878, pág. 231.

${ }^{12}$ EI Mensajero, 1 de junio de 1847. 
rros. Este ambicioso proyecto no pudo realizarse por el modesto capital que respaldaba a la Compañía.

Otra de las actividades que la Alicantina de Fomento puso en marcha, nada más establecerse, fue la creación de un seguro contra las quintas, que aseguraba a los suscritos el reemplazo del servicio en el ejército para lo que se debían abonar cuotas que iban aumentando de cantidad según fuese mayor la edad de los asegurados.

Al principio los promotores de la sociedad vieron sus esfuerzos coronados por el éxito pues nada más transcurridos nueve dias del anuncio de la sociedad en la Gaceta de Madrid se tuvo que cerrar la suscripción pues se habían solicitado cerca de 11.000 acciones. De su actividad posterior poco sabemos pues las referencias documentales son prácticamente nulas. Durante el año 1847 siguieron saliendo noticias en el Boletín Oficial de la Provincia referentes a la Compañía y El Mensajero siguió siendo subtitulado Boletín de la Compañia Alicantina de Fomento hasta enero de 1848. El Jefe Político de Alicante José Rafael Guerra escribía en su memoria del año 1848 que la sociedad tuvo que disolverse tras la promulgación de la ley de sociedades por acciones de enero de ese mismo año, que, regulada por reglamento en el mes de febrero, suspendia la autorización para crear tales sociedades ${ }^{13}$. Tal ley, que se debió al impacto de la crisis del 48 que la clase dirigente española atribuyó a la especulación y al liberalismo económico ${ }^{14}$, desanimó a los accionistas que dejaron de abonar el $5 \%$ que se les había pedido. En marzo de 1848 se reunían los accionistas en la sede la Alicantina de Fomento de la calle San Fernando ${ }^{15}$; probablemente en esa reunión se tomó la decisión de disolver definitivamente la sociedad pues desde ese momento no hemos encontrado ninguna referencia a sus actividades. Con su disolución finalizaba la primera experiencia financiera de los capitalistas alicantinos y habría que esperar a 1877 para que resurgiera un proyecto de este tipo con la creación de la Caja Especial de Ahorros de Alicante.

\section{LA CAJA ESPECIAL DE AHORROS DE ALICANTE.}

Las Cajas de ahorros y la ideología republicana.

Ya hemos apuntado que la creación de Cajas de Ahorro se inserta-

${ }^{13}$ RAFAEL GUERRA, JOSE. Memoria redactada por... Gefe Superior Político de Provincia de Alicante, en cumplimiento de lo dispuesto por el Sr. José M. del Castillo, inspector de la Administración Civil del Distrito, en sus oficios de 29 de julio y 1 y 14 de Septiembre últimos. Alicante 1848. Pág. 9.

14 TORTELLA CASARES, G. Los origenes del capitalismo en España Madrid. 1975. pág. 39.

${ }^{15}$ B.O.P. 24 de marzo de 1848. 
ba dentro de una línea de pensamiento filantrópico pues es indudable su conexión con entidades benéficas y filantrópicas. En sus primeros momentos aparecen indisolublemente unidas a los Montes de Piedad y en la mayoría de los casos la iniciativa de su creación partió de este tipo de instituciones. Por otra parte no podemos separar su aparición y desarrollo de las nuevas corrientes del pensamiento económico, del desarrollo del capitalismo, de la burguesía y del liberalismo en la España del siglo XIX. En palabras de Palacios Bañuelos hay que: «insistir en la vinculación de estas instituciones con la burguesía, recordando que esas cualidades típicas, propias de la mentalidad burguesa como orden, propiedad, seguridad, libertad, dinero, poder, ahorro, etc., acompañaron también a las Cajas de Ahorro en su nacimiento y evolución $)^{16}$.

En Alicante la iniciativa de fundación de la Caja Especial de Ahorros en 1877 fue protagonizada por un grupo de republicanos encabezados por Eleuterio Maisonnave, a los que luego se unieron otros representantes de la burguesía local con una adscripción política diferente, bien en el conservadurismo canovista, bien en el liberalismo sagastino. Esta circunstancia liga claramente al nacimiento de la Caja de Ahorros con la ideología republicana.

El fundamento ideológico que justificó la creación de la entidad, que se resumía en la máxima: «el ahorro del obrero es su redención social», recoge uno de los plantemientos del pensamiento social republicano, enlazando claramente con el utopismo español de las primeras décadas del ochocientos y con el programa de reformas económicas y sociales del federalismo pimargalliano. Ahorro y crédito fueron dos constantes en la ideología social del republicanismo español. Desde 1858, el principal teórico del federalismo, Francisco Pi y Margall elaboraba un pensamiento socioeconómico encaminado a unas reformas sociales que aboquen en una nueva sociedad donde todos los individuos tengan acceso a la propiedad. Desde este planteamiento hacia gran incidencia en el papel del crédito al obrero, que debía venir a través del Estado ${ }^{17}$.

Más tarde, en pleno sexenio revolucionario, se presentaba en la Asamblea federal de febrero de 1872 el Dictamen sobre bases económicas-sociales para mejorar las condiciones de las clases jornaleras, que, elaborado por una Comisión presidida por Pi y Margall, volvía a insistir en la necesidad de emancipar a las clases populares a través

${ }^{16}$ PALACIOS BAÑUelOS, L. Las Cajas de Ahorros en la Andalucia del siglo XIX. Madrid, 1977. págs. 46 y 47.

${ }_{17}$ Sobre los planteamientos de reforma económica y social en el republicanismo español en los años sesenta Vid. SANCHEZ-RECIO, G. «Los planteamientos socioeconómicos del Partido Democrático. La polémica entre Pí y Margall y Castelar en 1864». Saitabi XXVII, 1977. págs. 123-144. 
del crédito y la creación de entidades crediticias sobre nuevas bases ${ }^{18}$. Indudablemente el pensamiento social de Pi y Margall era mucho más profundo y reformista, al estar tan influenciado por el socialismo utópico y Proudhon, que el de los republicanos alicantinos que acometieron la creación de la Caja de Ahorros pero tampoco podemos negar que la justificación moral de su fundación, la importancia dada al ahorro y al crédito tuvieron su origen en la filosofía social del republicanismo federal. Por otra parte el republicanismo de talante moderado defendia también la creación de cajas de ahorros como medio de solventar la lucha de clases y evitar el conflicto social. En este planteamiento enlazaría claramente con las ideas de Mesonero Romanos que da a estas instituciones un carácter esencialmente antirrevolucionario ${ }^{19}$.

Estos presupuestos recogía el diario republicano posibilista de la capital El Graduador en su artículo de presentación de la Caja de Ahorros:

«Calcúlese el número de jornaleros que pueden haber en Alicante, y el tipo que, sin grandes esfuerzos y privaciones, puede buenamente ahorrar cada semana, y se verá que arroja una cantidad muy respetable, la cual por falta de cultura y por inexperiencia, absorbe lo superfluo, el vicio, mermando el escaso capital que alcanza a duras penas el trabajo.

Multiplíquese esta cantidad por las semanas del año, añadiéndose el interés correspondiente, que bien empleado este dinero ganaría, y digan nuestros lectores, si no es previsible semejante abandono y tan torpe desprendimiento en quienes no tienen casi que comer.

Ese capital bien empleado daría óptimos frutos, mejoría de las condiciones de la alimentación, de la habitación o del trabajo, acumularía, además de tantos beneficios generales, el interés compuesto, y daria a todos una noción más clara de lo que es la sociedad, apagando este lenitivo los odios de casta...

Por ésto deseamos que se establezca con buena suerte en Alicante la Caja de Ahorros, institución redentora de los débiles... ${ }^{x}$.

Creación y objetivos de la Caja Especial de Ahorros.

En 1858 se inaguraba la linea del ferrocarril Madrid-Alicante pro-

${ }^{18}$ Dictamen sobre bases económicas-sociales para mejorar las condiciones de las clases jornaleras (5 de marzo de 1872). Reproducido en TRIAS BEJARANO, J. Francisco Pi y Margall. Pensamiento Social. Madrid, 1968.

19 PALACIOS BAÑUELOS, L. op. cit. pág. 51.

${ }^{20}$ El Graduador, 7 de marzo de 1877. El subrayado es nuestro. 
movido por el financiero José de Salamanca, con ella se creaban nuevas posibilidades de inversión comercial y de desarrollo económico. En este contexto y coincidiendo con la puesta en funcionamiento de la línea férrea se creaba en Alicante una sucursal del Banco de España, que será junto con la abierta en Valencia la primera sucursal que funcionará en provincias. La instalación de esta sucursal a través de la que se canalizará prácticamente toda la circulación monetaria y la inversión de capital, dirigida sobre todo a los negocios mercantiles, retrasó la aparición de una entidad financiera autóctona. Además la politica restrictiva en materia de préstamos de la sucursal, dictada desde la sede central, creó un malestar en ciertos sectores de comerciantes y capitalistas alicantinos. En 1870, el diario republicano La República Española expresaba sus quejas en este sentido: "La sucursal del Banco que al establecerse en esta plaza hizo concebir las mejores esperanzas al comercio, ha venido a ser un estorbo para ese mismo comercio y un inconveniente para la creación de un Banco Local» ${ }^{21}$.

De esta manera se iría gestando un interés por crear una entidad financiera propia desde los años sesenta pero que se paralizó al iniciarse una coyuntura depresiva a mediados de la década. La crisis cuyos síntomas se evidenciaron hacia 1864 hizo impensable la creación de una entidad de este tipo. En Valencia, donde ya se habian dado iniciativas en este campo, la crisis de 1866 originaba el hundimiento de la banca autóctona ${ }^{22}$. Precisamente por esta razón se paralizó en 1863 un proyecto de creación de una Caja de Ahorros que llegó a ser presentado y aprobado por la Sociedad Económica de Amigos del País.

Una vez superada la crisis vuelve a plantearse el tema. Finalmente el proyecto se realizaría en 1877 con la creación de la Caja Especial de Ahorros de Alicante. En un principio la entidad solo combinaría las operaciones de Caja de Ahorros y Monte de Piedad, pero en los años siguientes iría ampliando el radio de sus actividades entrando en competencia con la sucursal del Banco de España. De hecho irá supliendo en cierta medida y en algún tipo de operaciones a esta sucursal cuya actuación durante el último tercio del siglo XIX, con la desviación de fondos monetarios a Madrid en la conceptualización de deudora de la sede central, originó una cierta desconfianza hacia la sucursal por parte de la burguesía local, que además vió rechazados todos sus intentos de conseguir de la dirección del Banco la elevación de categoria de la filial.

Para la apertura de la Caja Especial de Ahorros se constituía una

${ }^{21}$ La República Española, 23 de septiembre de 1870.

22 RODENAS, C. La Banca Valenciana: Una aproximació històrica. Valencia. 1982. págs. 37 y ss. 
sociedad anónima que en la escritura de fundación contaba con 30 socios, encabezados por Eleuterio Maisonave que fue, en realidad, el promotor del proyecto ${ }^{23}$. A su lado encontramos propietarios como el Barón de Finestrat, José Carlos de Aguilera, Clemente Miralles de Imperial. Comerciantes como Enrique Bushell, Federico Itier, Rigoberto Ferrer, Adolfo Faes y Carlos Sánchez Palacio, y profesionales como los médicos Manuel Ausó Monzó y Manuel Ausó Arenas, el arquitecto José Guardiola Picó y el abogado Jorge García Montaner. Gran parte de los socios fundadores y accionistas militaban en el republicanismo posibilista, de ahí la vinculación que establecemos entre el nacimiento de la Caja de Ahorros y el partido republicano que no anula el hecho de que a la iniciativa se sumasen otros miembros de la burguesía local que participaban de ideologías radicalmente distintas a la republicana.

La Caja Especial de Ahorros se constituía con un capital social de 25.000 pesetas representado por cien acciones de un valor nominal de 250 pesetas cada una de ellas. Maisonnave fue el encargado de elaborar la memoria de presentación y los estatutos, que él mismo defendió con entusiasmo ante una reunión de hombres de negocios en los Salones del Consulado de Alicante en la que se llegaron a cubrir el $80 \%$ de las acciones emitidas ${ }^{24}$.

Las acciones estaban muy repartidas. Los mayores accionistas, que no superaban las cinco acciones cada uno, fueron José G. Amérigo, Adolfo Faes, Leopoldo Laussat y Carlos Faes. Con cuatro acciones figuraban Anselmo Berguez, Clemente Miralles y José Carlos Aguilera. El resto de accionistas, a excepción de Alejandro A. García que poseía tres, compraron una o dos acciones ${ }^{25}$.

En los estatutos de la Caja Especial de Ahorros de Alicante se consideraban socios fundadores a los tenedores de las acciones que se emitieron para su fundación. Además en ellos se contemplaba la figura del socio copartícipe que podría ser el imponente de una cantidad superior a 1.000 pesetas y el industrial de «reconocida moralidad» que habiendo impuesto cualquier cantidad tuviese un tallér y presentase una relación de veinte o más imponentes ${ }^{26}$. La actividad de la Caja quedaba regu-

${ }^{23}$ Eleuterio Maisonnave, republicano posibilista e imbuido de planteamientos sociales reformistas, estuvo interesado desde muy joven por los temas financieros, probablemente por su vinculación familiar al mundo comercial. En 1862 escribía un artículo en El Bostezo, semanario que el mismo habia fundado, sobre los «Bancos de Giro». Reproducido en RICO GARCIA, M. y MONTERO PEREZ, A. Ensayo biográficobibliográfico de escritores de Alicante y su provincia. Alicante 1888.

${ }^{24}$ El Graduador, 13 de marzo de 1877.

${ }^{25}$ B.O.P. 18 y 19 de abril de 1877.

${ }^{26}$ Asi veremos como en las sucesivas memorias de la Caja desde su fundación van apareciendo socios coparticipes. Los primeros serán Jose Alvarez Coiñas y Francisco Carratalá Cernuda, que pasarán a esta categoria a finales de 1877. Memoria anual de la Caja Especial de Ahorros de Alicante, leída en la Junta General de Accionistas el 8 de diciembre de 1877. Establecimiento tipográfico de Costa y Mira. Alicante, 1877. 
lada por la Junta General de Accionistas, en la que se incluyen también los socios copartícipes, y el Consejo de Administración compuesto por quince socios fundadores que se renovará a mitad todos los años. Para el primer Consejo de Administración Eleuterio Maisonnave fue elegido presidente; José Bueno, abogado y catedrático, vicepresidente y el comerciante Juan Leach secretario, cargo que comportaba según los estatutos el de director-gerente de la sociedad. El resto del Consejo se compuso de doce miembros elegidos entre los accionistas de la institución ${ }^{27}$.

La Caja de Ahorros contó desde un principio con el apoyo de entidades oficiales como el Ayuntamiento y la Junta de Agricultura, Industria y Comercio. Esta última cedió parte de sus locales, de forma provisional, para la instalación de las primeras oficinas de la entidad que así pudo abrir sus puertas al público el 1 de julio, tres meses después de su constitución.

Los promotores de la Caja quisieron primar la importancia del ahorro y el crédito sobre las actividades del Monte de Piedad. En la memoria de fundación, Eleuterio Maisonnave criticaba esta institución partiendo de una doble consideración. En primer lugar los objetos empeñados en los Montes eran, en una gran parte de los casos, necesarios para la vida doméstica por ser ropas, colchones, abrigos, etc. Además el almacenamiento de objetos constituía una riqueza amortizada, un capital fuera de circulación y por lo tanto improductivo. Desde esta perspectiva Maisonnave llegaba a proponer la posibilidad de no crear un Monte de Piedad en beneficio de la opción de establecer una Asociación de Crédito al Trabajo ${ }^{28}$. Se incidía, pues, en un establecimiento que recogiera los ahorros y facilitara el crédito personal.

«La consagración del crédito personal al jornalero; el reconocimiento de su dignidad al trabajador, la circulación constante de la riqueza, sin que se acumule en ningún caso ni por ningún motivo; el mejoramiento moral y material de todas las clases; la inversión del ahorro en objetos útiles y reproductivos: he aquí lo que los hombres pensadores se han propuesto realizar; inspirándose en los sentimientos de la justicia que tanto distinguen a la generación presente, y lo que los filántropos, dejándose llevar de sus generosas aspiraciones, no podrán hacer jamás» ${ }^{20}$.

Como vemos se rechaza el pensamiento filantrópico en íntima co-

${ }^{27}$ B.O.P. de 19 de abril de 1877.

${ }^{28}$ Este planteamiento enlaza claramente con los propuestos por los republicanos en años anteriores y que hemos señalado en páginas precedentes.

${ }^{29}$ Memoria y estatutos para la creación de una Caja Especial de Ahorros en Alicante. Imp. Costa y Mira. Alicante 1877, pág. 7 y 8. 
nexión con los Montes de Piedad frente a la posibilidad de una institución de ahorro y crédito a las clases populares. Es una idea muy innovadora dentro del pensamiento económico que imbuía los presupuestos de creación de cajas de ahorros en esa época. Pero a pesar de estos planteamientos la situación social y económica del Alicante ochocentista, donde funcionaban casas de empréstito sobre alhajas y ropas con intereses que en algunos casos llegaban al $90 \%$ sobre las cantidades prestadas, aconsejaba la institucionalización de un Monte de Piedad, entidad más familiar entre las clases populares, que combinado con la caja de ahorros y los préstamos de garantía personal pudiese erradicar la usura e instrumentalizar el ahorro como medio de fomento de la riqueza. En este sentido en el artículo primero de los Estatutos se señala: "La Caja Especial de Ahorros de Alicante es un establecimiento destinado a recibir las economías de las personas laboriosas con el fin de hacerlas productivas y a facilitar el crédito personal a las clases obreras». Por eso se consignaban en las operaciones de la Caja, aparte de las normales de recibir imposiciones y dar dinero a préstamo sobre ropas, alhajas y otros objetos, la de hacer préstamos a los imponentes sobre su crédito personal. Pero para la obtención de estos préstamos, que no podían exceder las 1.500 pesetas al $6 \%$ de interés anual, el pet $:$ cionario tenía que estar al frente de algún establecimiento industric y ofrecer una garantía de las dos terceras partes del préstamo solicitado en imposiciones hechas por él mismo u otras personas. Así la concesión de préstamos y facilidades financieras creaba falsas expectativas en estos sectores de la población pues la mayoría de las veces el jornalero, el artesano o el pequeño comerciante no podía ofrecer más garantía personal que los objetos que tradicionalmente empeñaba, con lo cual los usureros y prestamistas no van a desaparecer de la sociedad alicantina.

Lógicamente estos presupuestos justificativos de la constitución de la Caja Especial de Ahorros encubrían el carácter financiero y especulativo de la operación al servicio, no de estas clases populares, sino de la propia burguesía y del capitalismo decimonónico.

\section{Evolución de la Caja Especial de Ahorros: 1877-1880}

El primer problema con que tendría que enfrentarse la entidad sería el de su credibilidad en determinados sectores de la población pues la práctica de la usura estaba tan arraigada que se podía producir un rechazo hacia la nueva institución. De ahí el esfuerzo que se impusieron los promotores para demostrar por medio de la prensa local y las memorias anuales de la entidad, a las que daban gran publicidad, que la Caja de Ahorros era una sociedad sólida que debía inspirar confianza 
y que sus beneficiarios iban a ser las clases más necesitadas.

Hemos explicado la creación de dos secciones dentro del establecimiento, la Caja de Ahorros propiamente dicha y la sección de préstamos que operaba a través del Monte de Piedad. La primera tenía como función recoger las imposiciones de los clientes y mantenerlas en depósito hasta que se produjera su reintegro. La Caja, de esta manera, siempre podría disponer de unos fondos, dependiendo su cuantía del mayor o menor número de imposiciones, para destinarlos al Monte de Piedad, el encargado de realizar los préstamos sobre alhajas y ropas.

En la evolución de las Cajas de Ahorros en el siglo XIX se podían plantear dos tipos de problemas en relación con la conjunción de la Caja de Ahorros y Monte de Piedad. Uno de ellos era el derivado de la insuficiencia de fondos en la sección de ahorros, que no podia en este caso allegar los recursos suficientes para hacer frente a las demandas del Monte. El otro se planteaba en una situación inversa; es decir, la incapacidad de la sección de préstamos para absorver el creciente volumen de imposiciones, produciéndose, de esta forma, un exceso de capital que podía llevar al fracaso a la entidad. De estos dos problemas que afectaron en mayor o menor medida a las Cajas de Ahorros en esta época, solo el segundo afectará a la entidad alicantina pues en los primeros años de su evolución fue recibiendo un creciente número de imposiciones que no pudieron ser absorvidas por las operaciones de préstamo del Monte, creando así un amplio excedente de capital que podía suponer un peligro para la propia existencia de la Caja. En 1880 el desfase era evidente, $y$ el Consejo de Administración se planteaba seriamente el problema:

«... a un desmedido aumento de imposiciones y desempeños, productores de grandes ingresos, no correspondiera un proporcional aumento de préstamos que dieran colocación a aquellos, ocasionando con ésto una existencia de capital inactivo, que en vez de ser útil y beneficioso a la sociedad, fuera causa de crecidos intereses que habría de pagar la misma ${ }^{30}$.

Como solución se proponía en la misma memoria bajar los tipos de interés que se pagaban en las operaciones de préstamos, que pasarán del $12 \%$ al $10 \%$ anual, y así, aumentando las facilidades, confiaban en un mayor volumen de petición de préstamos en el Monte de Piedad. También se sopesará la posibilidad de bajar el interés devengado por las imposiciones del $6 \%$ al $5 \%$. Un año más tarde el problema seguia planteado ya que no se había logrado la corrección del desfase. Para ello se acordó fijar un máximo en la cuota de imposición que tendría,

\footnotetext{
${ }^{30}$ Memoria anual de la Caja Especial de Ahorros de Alicante, leída en Junta General de Accionistas el 15 de enero de 1880. Est. Tipográfico de Costa y Mira, Alicante, 1880.
} 
lógicamente, un carácter fluctuante en razón del aumento o disminución de las sumas impuestas. El límite cuantitativo se fijaba para la primera imposición en 125 pesetas y 50 pesetas para las posteriores. Más tarde se bajarían aún más los máximos, quedando fijados en 50 pesetas la primera imposición y en 25 pesetas las restantes ${ }^{31}$. Junto a estas medidas de rebaja de los tipos de interés y fijación de cotas cuantitativas a las imposiciones se tomaron otras destinadas a buscar salidas al exceso de capital mediante la inversión en créditos hipotecarios sobre fincas, créditos sobre efectos comerciales y la compra de bienes inmobiliarios.

En los cuadros siguientes podremos ver como las dos secciones registraron en los primeros años, tras la fundación de la institución, un incremento manifiesto.

\section{CAJA DE AHORROS}

Balance de Operaciones (en pesetas)*

\begin{tabular}{ccccr}
\hline Años & n. imposiciones & Cantidades & $n^{0}$. reintegros & Cantidades \\
\hline 1877 & 1.317 & $31.494,50$ & 8 & $1.673,84$ \\
1878 & 2.788 & $57.894,38$ & 183 & $28.853,98$ \\
1879 & 2.545 & $75.370,62$ & 175 & $34.962,08$ \\
1880 & 2.549 & $55.039,89$ & 257 & $56.465,18$
\end{tabular}

Volumen medio anual en Ptas.

\begin{tabular}{ccc}
\hline Años & imposiciones & reintegros \\
\hline 1877 & 23,9 & 209,1 \\
1878 & 20,7 & 157,6 \\
1879 & 29,6 & 199,7 \\
1880 & 21,5 & 219,7
\end{tabular}

FUENTE: Memoria anual de la Caja especial de Ahorros de Alicante leída en Junta General de Accionistas de enero de 1889. Elaboración propia.

${ }^{31}$ Memoria anual de la C.E.A.A., leida en Junta General de Accionistas el 16 de enero de 1881. Est. Tipográfico Costa y Mira, Alicante, 1881. 


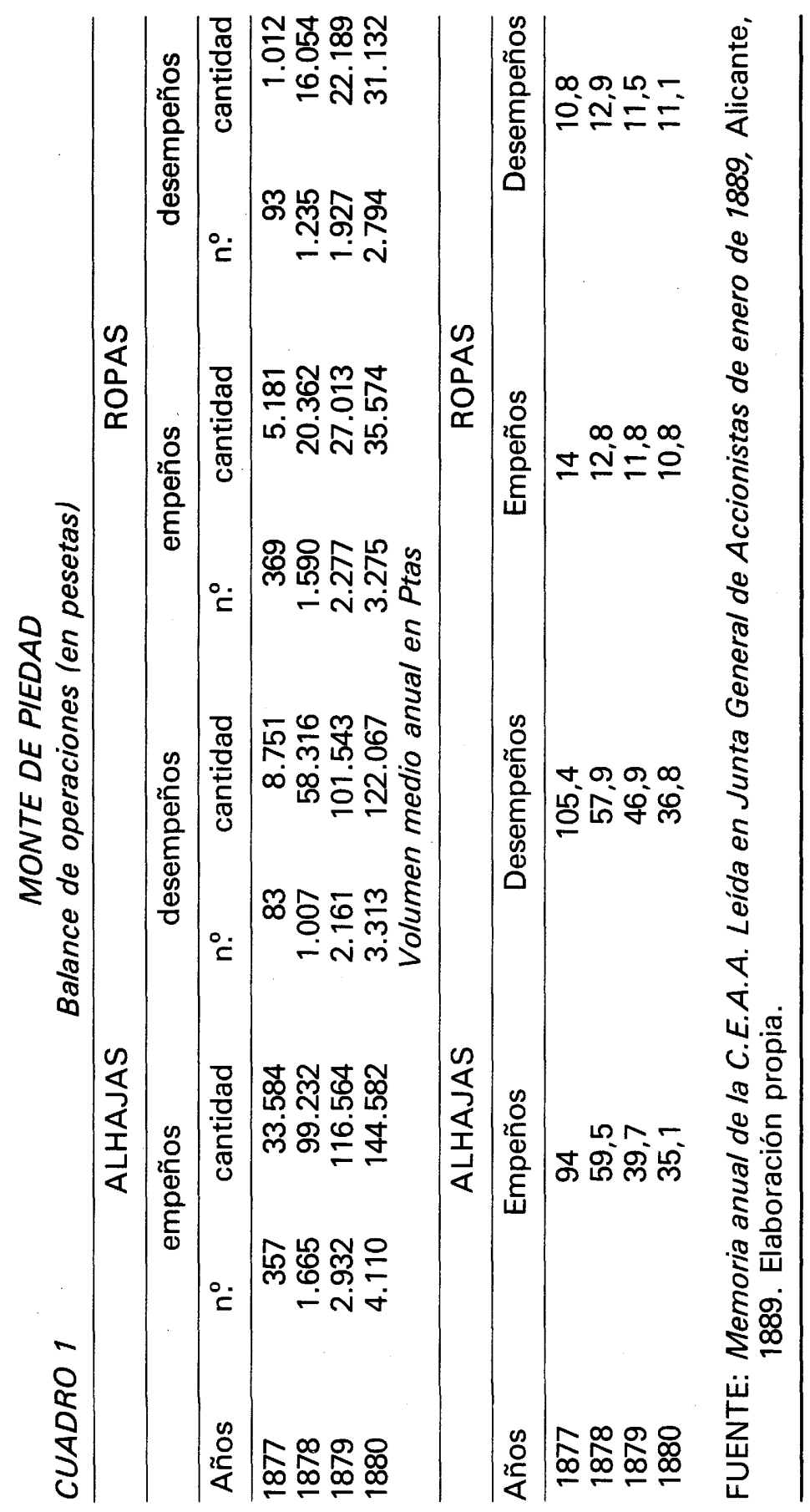


Según se observa en los cuadros anteriores tanto la Caja de Ahorros como el Monte de Piedad realizaron un interesante volumen de operaciones en los primeros años de su funcionamiento. Durante 1877 la cifra de operaciones en las dos secciones fue muy alta teniendo en cuenta que sólo funcionaron desde el 1 de julio, lo que demuestra que hubo una buena acogida por parte de la población alicantina. El Monte de Piedad experimentó una marcha ascendente en el número de empeños efectuados, crecimiento que es más relativo en el volumen de capital prestado como nos indica la disminución del volumen medio anual de las cantidades prestadas que pasó de 59 pesetas en 1878 a 35 pesetas en 1880 en el caso de préstamos sobre alhajas. A excepción del año 1878 en el que las cantidades prestadas sufrieron un aumento del orden del $295 \%$ con respecto al año anterior, lo que parece estar en relación con la quiebra en ese año de dos de las más importantes casas de comercio de la ciudad, Jose Bas y Hnos. y Cristóbal Pacheco e Hijo, que provocaron una crisis pasajera en el mundo comercial ${ }^{32}$, el volumen de capital prestado mantuvo una tónica de ascenso progresivo pero sin incrementos considerables lo que producirá, al contar la Caja de Ahorros con un aumento comparativamente mayor de los depósitos, el desfase entre el Monte y la Caja al que antes aludíamos. Por su parte la sección de ahorros también mostrará un crecimiento aceptable con un marcado retroceso en el año 1880, que parece estar relacionado con la medida de bajar el tipo de interés de las imposiciones para corregir el exceso de capital acumulado.

Interesa ahora tratar una cuestión de indudable importancia, el definir el tipo de cliente que acude al Monte y a la Caja. Con respecto a la primera sección es de utilidad conocer del total de préstamos efectuados los porcentajes de los que fueron sobre alhajas y de los realizados sobre ropas. Al contrario de lo que sucedió en otras Cajas de Ahorro españolas, donde los préstamos sobre ropas suponían sobre el total un porcentaje cercano al $80 \%{ }^{33}$, en la entidad alicantina los empeños sobre alhajas superarian en número a los de ropas con un porcentaje medio para los años 1878 a 1880 del $55 \%$ frente al $45 \%$ registrado por los efectuados sobre ropas. Esta circunstancia confirma nuestra hipótesis de que los principales beneficiarios de las operaciones de empeño del Monte fueron sectores de la burguesía y clases medias más que otros grupos sociales como asalariados o clases populares, a pesar de la propaganda que los directivos de la sociedad se hacían como benefactores de las clases jornaleras. La definición del cliente-tipo de la sección de ahorros no entraña dificultad en esos años pues en las memorias anua-

${ }^{32}$ A.D.P.A. Sección de Fomento. Leg. 125.

${ }^{33}$ Este sería, por ejemplo, el caso de la Caja de Ahorros y Monte de Piedad de Linares. Vid. PALACIOS BAÑUELOS, L. op. cit. pág. 261. 
les se detallan las profesiones de los impositores ${ }^{34}$. Ello nos ha permitido elaborar el cuadro adjunto:

Distribución de Impositores en categorías socioprofesionales.

\begin{tabular}{lrrrrrr}
\hline Profesiones & 1877 & \multicolumn{3}{c}{1878} & \multicolumn{3}{c}{1879} \\
\hline & impositores & $\%$ & impositores & $\%$ & impositores & $\%$ \\
\hline profesionales & & & & & & \\
labogados, inge- & & & & & & \\
nieros, médicos, & & & & & & \\
etc.) & 10 & 4,27 & 17 & 4,22 & 26 & 4,39 \\
Artesanos & 16 & 6,83 & 29 & 7,21 & 43 & 7,26 \\
Comerciantes & 7 & 2,99 & 12 & 2,98 & 20 & 3,37 \\
Empleados & 15 & 6,41 & 26 & 6,46 & 39 & 6,58 \\
Estudiantes & 1 & 0,42 & 7 & 1,74 & 29 & 4,89 \\
Jornaleros & 10 & 4,27 & 14 & 3,48 & 22 & 3,71 \\
Marineros & 1 & 0,42 & 3 & 0,74 & 5 & 0,84 \\
Militares & 4 & 1,70 & 5 & 1,24 & 5 & 0,84 \\
Servicios (pelu- & & & & & & \\
queros, músicos, & & & & & & \\
Cocheros, etc.) & 3 & 1,28 & 10 & 2,48 & 12 & 2,02 \\
Sirvientes & 15 & 6,41 & 33 & 8,20 & 46 & 7,77 \\
Propietarios & 4 & 1,70 & 10 & 2,48 & 11 & 1,85 \\
Cigarreras & & & 3 & 0,74 & 16 & 2,70 \\
Labradores & & & 1 & 0,24 & 1 & 0,16 \\
Varios & & & 2 & 0,48 & 6 & 1,09 \\
Señoras y niños & 148 & 63,24 & & & & \\
Sin profesión & & & 230 & 57,21 & 311 & 52,53 \\
\hline \multicolumn{1}{c}{ Totales } & 234 & & 402 & & 592 & \\
& & & & & &
\end{tabular}

FUENTE: Memorias anuales de las C.E.A.A. leídas en Juntas Generales de Accionistas el 8 de diciembre de 1877, el 8 de diciembre de 1878, y el 15 de enero de 1880. Elaboración propia.

Según reflejan estas cifras más de la mitad de los imponentes en los primeros años fueron señoras y menores de edad, el primer año con el $63,2 \%$ para situarse en los años siguientes dentro del epígrafe «sin profesión» con más del $50 \%$. Este hecho refleja la participación de la mujer en el ahorro, considerado desde ese momento como elemento

\footnotetext{
${ }^{34}$ Hasta el año 1879, después las profesiones de los clientes de la entidad se detallarian en las memorias de forma esporádica.
} 
indispensable de la economía doméstica. La mujer fue, en efecto, una de las principales usuarias de la Caja de Ahorros pero su integración en un grupo separado del resto de los impositores desvirtua el análisis sociológico de los impositores ya que no nos indica a que clase social pertenecian esas mujeres.

Dentro de la mitad restante destaca un grupo claramente adscrito a la burguesía y clase media local que integrado por comerciantes, propietarios y profesionales como abogados, médicos o ingenieros, alcanza el mayor número de impositores. Otros grupos como los artesanos, empleados y estudiantes también serán señalados clientes de la sección de ahorros y además manifestaran el crecimiento más importante.

Las clases asalariadas la utilizaron poco. Los jornaleros constituyen dentro de los clientes de la entidad un grupo escasamente significativo, lo que es lógico en una coyuntura de crisis pues no hay que ofvidar que en los años finales de los setenta se registraron altas tasas de emigración jornalera al norte de Africa y difícilmente podía ahorrar el jornalero que se veía obligado a emigrar para poder vivir. En contrapartida el sector del servicio doméstico surtió un importante número de los imponentes de estos años, hecho que parece estar relacionado con la indudable influencia y paternalismo que sobre los sirvientes ejercían sus señores.

Por último es necesario mencionar a las cigarreras que constituian uno de los grupos sociales más significativos de la ciudad. Sólo aparecen reflejados en las estadisticas a partir de 1878 pero con un mínimo porcentaje de participación ya que su capacidad de ahorro era también, como ocurría con los jornaleros, muy limitada o casi nula pues normalmente sus ingresos eran complementarios y necesarios para la economía familiar.

En conclusión, podemos decir que, por lo menos para los años estudiados, los principales clientes de la Caja Especial de Ahorros de Alicante, no fueron las clases asalariadas y jornaleras, como habian pretendido los promotores en la justificación de sus objetivos, sino sectores pertenecientes a una clase media, burguesía comercial, profesionales, e incluso a la pequeña burguesía local. 



\title{
LA IMPLANTACION DEL REGISTRO CIVIL EN ESPAÑA (PROBLEMAS DE UTILIZACION EN ESTUDIOS DEMOGRAFICOS)
}

\author{
JOSE RAMON VALERO ESCANDELL
}

Generalmente se considera que a partir de la realización por el Estado de censos periódicos de la población y de la instauración del Registro Civil por el que se obliga a la inscripción de todos aquéllos nacimientos, defunciones o matrimonios acaecidos a partir del 1 de enero de 1871, España penetra en una etapa moderna, estadística, en cuanto a estudios demográficos. Sin ánimo de negar esta idea, habría que matizarla, tanto en cuanto a los censos (posiblemente el de 1860 se realiza debido a la escasa fiabilidad del de 1857) como al Registro Civil. El presente artículo pretende, por un lado, estudiar los precedentes del Registro Civil en España y su posible aprovechamiento para los estudios demográficos de los años centrales del siglo XIX; por otro, estudiar, los problemas de implantación - y consiguiente fiabilidad de los datos-del Registro Civil en su primera década de funcionamiento. $Y$ todo ello, fundamentalmente, a través del estudio de dichos documentos en atguna población de nuestro País Valenciano.

Podríamos dividir el proceso de instauración del Registro Civil en España en tres etapas:

\section{A) HASTA LA DESAPARICION DEFINITIVA DEL REGIMEN SEÑORIAL.}

Evidentemente, la sociedad española antes de la desaparición del régimen señorial se organizaba en un Estado confesional (que sólo en contados años - como el Trienio Liberal - permitió una tímida libertad de cultos que en modo alguno puede compararse con una libertad religiosa entendida a la manera actual) y con una Iglesia Católica que, ya desde el Concilio de Trento, mantenía en las parroquias de todas las entidades de población, por pequeñas que estan fueran, un registro eclesiástico sistematizado; por ello, el Registro Civil, si bien aconsejable, no era imprescindible. Por otro lado, las escasas confrontaciones electorales celebradas se realizaron mediante sufragio censitario, lo que hacia utilizar para la obtención de las credenciales de elector una documentación eminentemente fiscal, no demográfica.

Posiblemente el precedente más antiguo de la preocupación del Estado por estos asuntos sea la Real Cédula del 21 de marzo de 1749 por la que Fernando VI encarga a los eclesiásticos que los libros de bautis- 


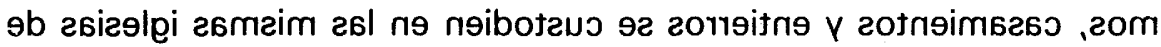

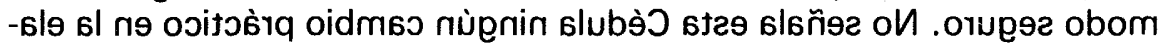

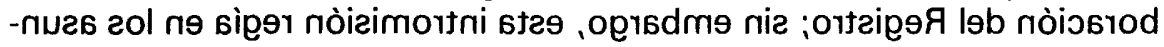

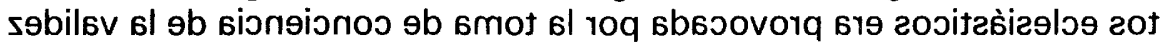

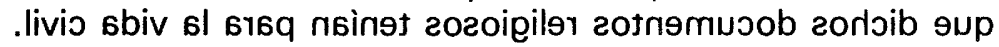

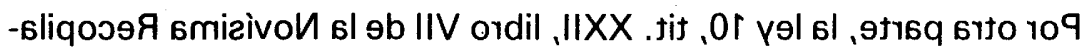

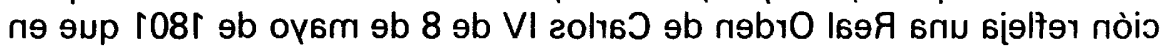

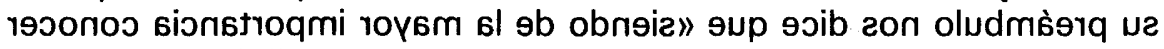

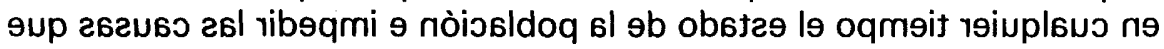

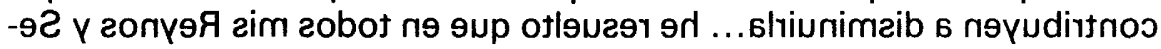

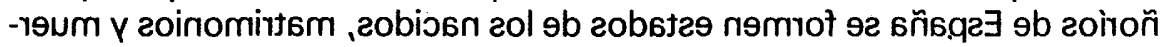

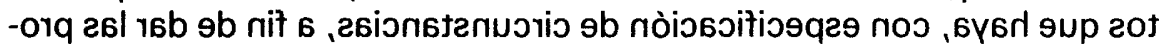

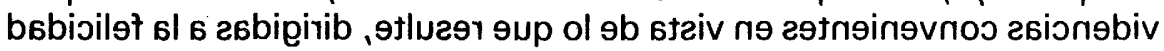

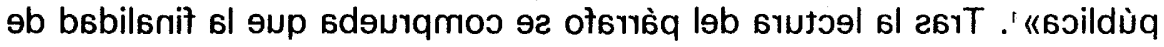
9b 6 l oniz livis orfeipgr onrobom nu r6rod6l9 $9 \mathrm{~b}$ 6l ofn6f 29 on n9bro 61

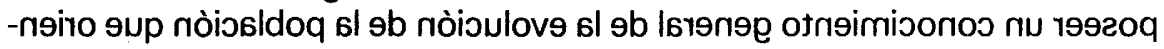

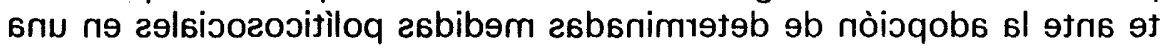

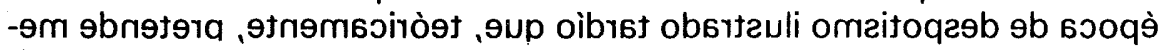

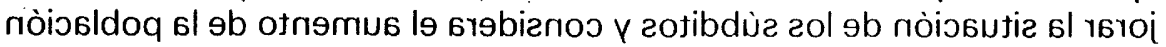

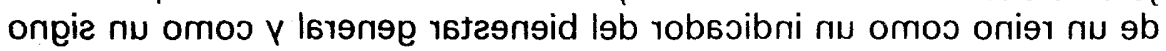
.Isiongtoq ss9upir ob

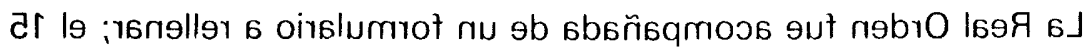

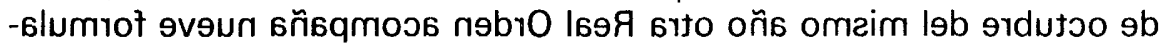

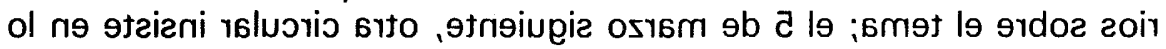

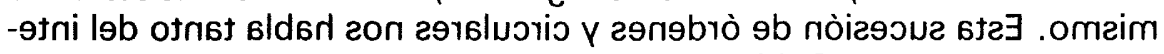
29bstlusitib 26l 9b omos sm9t ls onrof n9 onridod l9 roq obsıfeom 29̀1

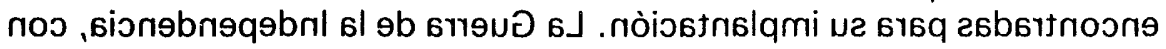

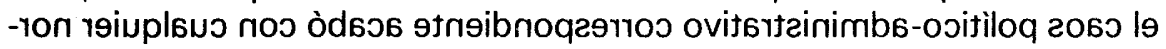
-mi obsiz6m9b sìne on 9up , obiouborq э219d6r 919ibuq эup nòiossilsm

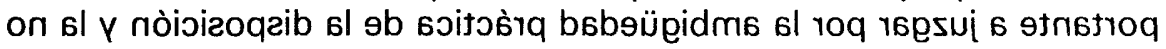

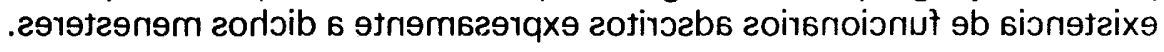

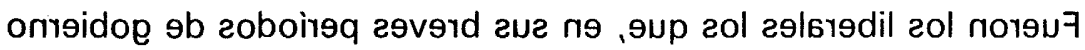

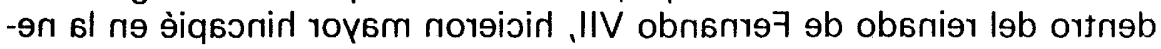

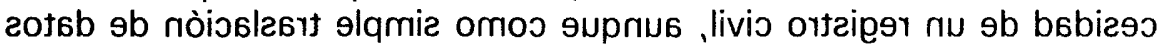

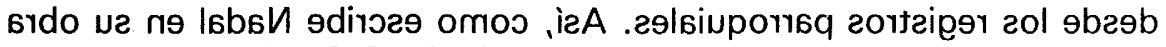

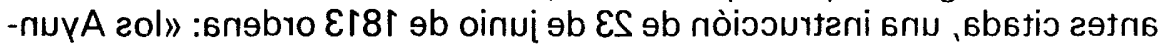

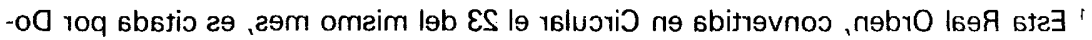

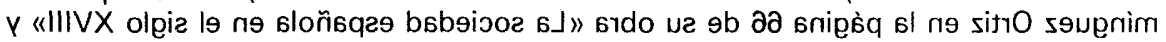

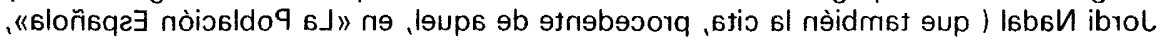

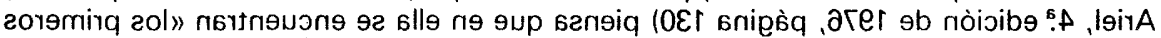
. «loñisqas livis ortaipgr lob zodeiţ 
tamientos enviarán al Jefe Político de la provincia cada tres meses una nota de los nacidos, casados y muertos en el pueblo, extendido por el cura o curas párrocos, con especificación de sexos y edades, de cuya nota conservará el Ayuntamiento un registro». Posteriormente, durante el Trienio Liberal, la Ley Municipal de 3 de febrero de 1823 establece - señal de que no se cumplían las disposiciones anteriores- un registro civil de nacimientos, casados y muertos. Al igual que anteriormente sucediera con la Guerra de la Independencia, el Manifiesto de los Persas y los Cien Mil Hijos de San Luis, respectivamente, restaron continuidad a los nuevos intentos.

Pese a que pudieran haberse realizado, lo cierto es que de los archivos municipales consultados - Elda, Villena, Ibi, Cullera,- ninguno cuenta con documentación sobre registros civiles de aquellos años. Del estudio de los catálogos de fondos de varios de nuestros archivos, sólamente en el de Denia ${ }^{2}$ aparece documentado un registro civil desde el 30-8-1821 al 17-7-1822, menos de un año, dentro del Trienio Liberal aunque previo a la Ley Municipal antes indicada. Sería interesante la realización de estudios sobre estos precedentes del registro civil durante el período liberal en aquellos lugares donde sea posible para comprobar la variedad de información, la correlación o no con los datos eclesiásticos, la continuidad de las series, la unidad o no del registro civil municipal en aquellos lugares con más de una parroquia; pero, por ahora, lo cierto es la escasa importancia documental de estos inicios del registro civil español.

\section{B) EL REGISTRO CIVIL ENTRE 1841-70.}

El primer intento serio y relativamente continuado de establecer un auténtico registro civil en España, pese a todos los defectos que podạmos achacarle, viene expresado por el Decreto de 24 de enero de 1841, nuevamente promulgado durante un período progresista, el de la regencia de Espartero. No es rara esta relación entre la voluntad de instaurar un auténtico registro civil y los períodos progresistas de nuestra historia si tenemos en cuenta dos circunstancias: el intento inherente en todo gobierno liberal-progresista de deslindar el poder civil y el religioso (acotando en lo posible la incidencia sociopolítica de la Iglesia Católica) y el monopolio que la jerarquía católica poseía en cuanto al control del estado civil y aún de la propia existencia de los ciudadanos.

2 J. Martí Muñoz: "Catálogo de documentación. Archivo de Denia» instituto de Estudios Alicantinos. 1981. Página 68. 
Entre los muchos fallos que dicho Decreto presentaba, y que a la larga harán fracasar definitivamente las experiencias de registro civil español de carácter administrativo - es decir, realizado por los ayuntamientos en lugar de por los juzgados como está establecido actualmente - , uno de los más importantes es el de no tratarse de un registro completo, válido para todo el territorio del Estado. El art. 1\% indica que «los Ayuntamientos de las capitales, de las cabezas de partido y de todos los pueblos que excedan de 500 vecinos, establezcan en sus Secretarías el Registro Civil». Evidentemente, todos los lugares de población no comprendidos en este artículo quedaban excluídos del Registro Civil, $y$ teniendo en cuenta la gran cantidad de pueblos que no llegaban a dicha población - de hecho, la mayoria de nuestros pueblos no llegaban a 500 vecinos, sobre 2.000 habitantes usando el coeficiente multiplicador 4 - un elevado porcentaje de la población española no se veía afectado por la medida y se debió acudir suplementariamente al registro eclesiástico.

Por contra, el art. $2^{\circ}$, que hablaba de formularios obligatorios e impresos para todos los ayuntamientos, muestra una clara voluntad de sistematización una amplia información demográfica. (Ver cuadro 1).

\section{CUADRO 1}

EJEMPLOS DE FORMULARIOS DEL REGISTRO CIVIL ADMINSITRATIVO (Según Decreto de 24-1-1841)

A) NACIMIENTOS.

Núm

Nacimiento de

El día

a la hora de

en la calle de

núm.

cuarto

Es hijo de

PADRES

PUEBLO DE SU NATURALEZA

PROVINCIA

Su profesión

Abuelos paternos

Abuelos maternos

Se bautiza en la parroquia de

B) DEFUNCIONES

Núm

de mil ochocientos cuarenta.

Hoy ha muerto

natural de

de edad de 
su estado

de profesión

Su enfermedad

Testamento

Vivia en

Se ha enterrado en

Padres

Pueblo de su naturaleza

Provincia

Su profesión

C) MATRIMONIOS

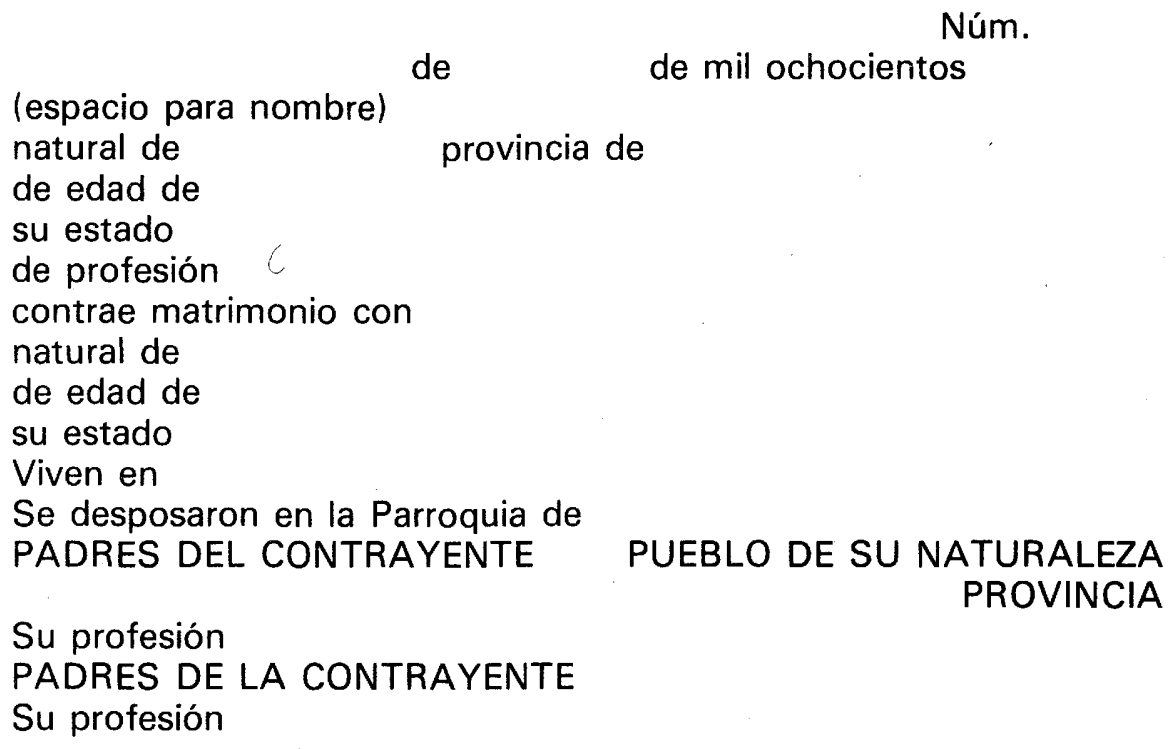

Por otra parte, como resultado de que en la práctica la Iglesia seguía siendo el único caso de referencia, el Decreto se entrometía claramente en los asuntos eclesiásticos y, por supuesto, seguían existiendo interferencias entre ambas instituciones. Según el art. 3. el Registro Civil se atribuía la prioridad en cuanto a nacimientos y defunciones: «...no podrán los curas bautizar ni enterrar sin que se les presente la papeleta del encargado del Registro Civil...» Al contrario, el art. 4\% invertía el orden en cuanto a matrimonios: «...los curas párrocos darán noticia circunstanciada y exacta al Registro Civil de los que se celebren cada día dentro de las veinticuatro horas siguientes: «La intromisión en el ámbito religioso se acrecienta en el art. 60: "Se arreglarán los párrocos a los modelos adoptados para los libros, a fin de que estos puedan llevarse con todas las circunstancias que se expresan". Si unimos a ello que el Decreto es de 24 de enero de 1841 y que a partir de su recibo en los ayuntamientos se debe mandar imprimir los libros, que cuando empie- 
cen a rellenarse deben incluir «todas las partidas cronológicamente colocadas desde el $1^{\circ}$ de Enero" (con la consiguiente solicitud de información sobre todas las inscripciones, como indica el art. 5\%), y si pensamos que no se amplía ningún tipo de personal dedicado al efecto en las Secretarías de los Ayuntamientos -y en muchos de ellos esta función representa un considerable trabajo-, el resultado práctico será que las parroquias siguen registrando los sucesos e informando de ellos periódicamente a los ayuntamientos. De hecho, la orden de 24 de mayo de 1845, época de gobierno moderado, derogaba varios artículos por las dificultades surgidas para su cumplimiento y dejaba de hecho el registro en manos de la Iglesia.

En la práctica los libros del registro civil fueron rellenados por la inmensa mayoría de los ayuntamientos obligados a ello. De los archivos antes indicados, no se conservan en el de Elda pero existen en Villena, Cullera e lbi; sabemos que las hojas de registro utilizadas en $\mathrm{Cu}$ llera fueron compuestas en la imprenta de José $M$. Ayoldí, sita en el número 5 de la calle de Caballeros de Valencia, y no estaban impresas expresamente para Cullera sino válidas para cualquier otra población española, lo que indica su uso masivo. Por el contrario, las hojas de inscripción de Villena están impresas exclusivamente para dicha ciudad. Es posible que no fuesen realizadas con una estricta continuidad: del archivo de Villena conservamos la práctica totalidad pero en Cullera sólo se conservan los libros de los años 1841-43 y 1850-63 mientras que en Ibi sólo aparecen actualmente ${ }^{3}$ los correspondientes a 1862-65, en un solo volumen.

Para su utilización como fuente documental, el interés de estos libros dependerá fundamentalmente de la conservación o pérdida de los libros parroquiales. En aquellos lugares donde, a causa fundamentalmente de la Guerra del 36, el archivo parroquial haya desaparecido, estos libros son una fuente demográfica vital; en aquellos donde la parroquia conserve su información, no serían imprescindibles, aunque debido a la sistematización de los formularios la lectura de las actas sea más fácil en los libros municipales.

En cuanto a la información contenida en las partidas, a pesar de los formularios, presentan multitud de lagunas. Así, en Cullera no aparecen en los libros de nacimientos ni la hora ni el domicilio familiar, ni la profesión del padre (por contra, en cuanto a legitimidad o no, parecen recrearse: "de legítimo enlace», "de legítimas nupcias», de "tála-

${ }^{3}$ Es posible que al realizarse el inventario, actualmente en proyecto, aparezca mayor información; este archivo es actualmente - noviembre de 1983- el más descuidado y desordenado que conozco. 
mo legítimo»); en las defunciones no aparece el domicilio; en los matrimonios no aparece la edad de los contrayentes, la profesión, el domicilio familiar o el pueblo de nacimiento de los padres. De hecho las partidas eran suministradas trimestralmente o anualmente por los párrocos locales y no aportan más información que la inserta en las partidas eclesiásticas, como he comprobado personalmente en varias inscripciones. Además, concediendo una alta fiabilidad a los registros parroquiales, los registros civiles se ajustan bastante a ellos luego pueden convertirse en una perfecta fuente sustitutoria alli donde sea preciso. (Ver cuadro 2 ?)

\section{CUADRO 2}

COMPARACION ENTRE EL REGISTRO CIVIL Y EL ECLESIASTICO CULLERA, $1857-63$

\begin{tabular}{|c|c|c|c|c|c|}
\hline & Año & R. Parroquial & R. Civil & Diferencia & \\
\hline \multirow[t]{8}{*}{ a) Nacimientos } & 1853 & 422 & 414 & 8 & \\
\hline & 1854 & 414 & 416 & -2 & \\
\hline & 1855 & 394 & 390 & 4 & \\
\hline & 1856 & 446 & 443 & 3 & \\
\hline & 1857 & 461 & 459 & 2 & \\
\hline & 1858 & 490 & 490 & $=$ & \\
\hline & 1859 & 428 & 421 & 7 & \\
\hline & $1853-59$ & 3.055 & 3.033 & 22 & $0,72 \%$ \\
\hline \multirow[t]{10}{*}{ b) Defunciones } & 1854 & 701 & 700 & & \\
\hline & 1855 & 246 & 249 & -3 & \\
\hline & 1856 & 394 & 391 & 3 & \\
\hline & 1857 & 287 & 288 & -1 & \\
\hline & 1858 & 251 & 244 & 7 & \\
\hline & 1859 & 301 & 308 & -7 & \\
\hline & 1860 & 387 & 380 & 7 & \\
\hline & 1861 & 267 & 265 & 2 & \\
\hline & 1862 & 260 & 259 & 1 & \\
\hline & $1854-62$ & 3.094 & 3.084 & 10 & $0,32 \%$ \\
\hline \multirow[t]{8}{*}{ c) Matrimonios } & 1857 & 111 & 109 & 2 & \\
\hline & 1858 & 89 & 82 & 7 & \\
\hline & 1859 & 105 & 101 & 4 & \\
\hline & 1860 & 94 & 94 & $=$ & \\
\hline & 1861 & 111 & 110 & 1 & \\
\hline & 1862 & 90 & 89 & 1 & \\
\hline & 1863 & 92 & 91 & 1 & \\
\hline & $1857-63$ & 692 & 676 & 16 & $2,36 \%$ \\
\hline
\end{tabular}

Fuente: Elaboración propia basada en los registros civiles del Archivo Municipal de Cullera y los libros de la Parroquia de los Santos Juanes de dicha ciudad. 
Como podemos comprobar, en la práctica la diferencia era mínima; puede deberse fundamentalmente a errores de inscripción, a diferencia de fechas en ciertos registros (es posible, ¿por qué no?, que en algún caso fuesen errores míos en el recuentol. De todos modos, la diferencia se da globalmente siempre a favor del registro parroquial y es mayor en los matrimonios y mínima en las defunciones. La explicación a esto puede darse en que en matrimonio entre gente de distinto pueblo, muchos se realizan en la parroquia de la novia (con lo que estarían registrados en los libros parroquiales) mientras que solian marchar a vivir al pueblo del novio (con lo que tal vez no se incluyesen en el registro civil municipal); por el contrario, las defunciones no se prestaban a tales problemas y los errores pueden ser únicamente de omisión o recuento.

Las inscripciones del registro civil municipal de Ibi son de mayor importancia documental por haber desaparecido el registro parroquial de la época, pero por eso mismo no podemos establecer entre ambos registros una comparación; de todas formas, debido a que también eran recogidos de los datos parroquiales cada cierto tiempo («está revisado y conviene con el libro sacramental ${ }^{4}$, se lee al principio de cada año) su fiabilidad sería muy similar a la de Cullera. La mayor dificultad estriba en que sólo conservamos la documentación de cuatro años. De ellos deducimos que no solían existir lagunas informativas en los formularios, salvo la no indicación de enfermedad causante de la muerte en las partidas del año 1862 y la no especificación de la legitimidad o ilegitimidad, posiblemente por no entender de qué se trataba: donde el formulario escribía "es hijo» para contestar legítimo o ilegítimo, el secretario escribia "de» y a continuación el nombre de los padres (o lo dejaba en blanco, en su casol.

En los registros de lbi existe al final del libro un resumen anual de los nacimientos, defunciones y casamientos con su correspondiente evolución mensual. Debido a que llevan impresos en su cabecera «Provincia de Alicante, partido de Ayuntamiento de " pienso que esos estadillos no fueron únicamente locales sino que representaban un intento de sistematizar el registro civil a nivel más general, interito inútil en tanto no se efectuaban registros de muchas localidades de la provincia. El más sencillo de dichos estadillos era el de nacimientos, que sólo incluía los datos de legitimidad, nacidos muertos y muertos antes de bautizarse, además del número de nacidos. Por el contrario el más complicado, con gran diferencia, era el de las defunciones que incluía diferencias por sexos, estado civil, naturaleza española o ex-

${ }^{4}$ Tanto esta como las demás frases entrecomilladas referentes a lbi están extraidas del libro Registro Civil del Archivo Municipal de Ibi. 
tranjera, si testaron y (por grupos) la edad de los fallecidos, la posición social y las causas ostensibles de fallecimientos; es curioso reflejar que en cuanto a las profesiones la de «profesores, médicos, abogados, eclesiásticos, curiales y toda ocupación facultativa» era sólo para varones y la de "ocupaciones domésticas» sólo para mujeres; por lo que respecta a las causas de fallecimiento reflejaban si la muerte natural era "con auxilio eclesiástico» o "repentina» y en cuanto a las muertes violentas, pese a ser un apartado no muy abundante, diferenciaban cinco subgrupos: heridas, asfixias, caidas, ahogados y suicidios. En cuanto a los matrimonios se especificaba únicamente el estado civil previo de ambos contrayentes y la edad (dividida en cuatro grupos: 15 a 25,25 a 35,35 a 50 y más de 50 años).

Otra característica original del registro civil ibense es que, en la cara opuesta al estadillo, el funcionario escribía los nacimientos, defunciones y matrimonios de cada año, comparándolos con los del anterior e indicando la causa que creía fundamental en la diferencia. Así, 1865 fue un mal año demográfico y hubo menos nacimientos y casamientos y más defunciones; el funcionario señalaba como causas del aumento de defunciones «la intenterancia del frío, pues en este pueblo no invadió el cólera», de los menores nacimientos "la ausencia de jornaleros en busca de trabajo» y de la escasez de bodas «la dificultad en las transaciones mercantiles» (sic.). Evidentemente, 1865 debió ser para Ibi un mal año a.todos los niveles.

\section{C) 1870: LA LEY PROVISIONAL DEL REGISTRO CIVIL.}

El actual Registro Civil español, al margen de cuestiones de detalle, viene rigiéndose por la Ley Provisional de Registro Civil de 17 de junio de 1870, decretada por las Cortes Constituyentes durante la regencia del general Serrano. Dicha ley se había hecho absolutamente imprescindible desde el momento en que la Constitución de 1869 garantizaba la libertad religiosa al pueblo español y, consiguientemente, dejaban de ser obligatorios los bautismos, entierros y bodas católicos; por tanto, ni los registros parroquiales iban a coincidir exactamente con la realidad - siempre ofrecerían cifras más o menos inferiores - ni era conveniente reproducir la interconexión anterior entre las instituciones civiles y católicas. Por ello, en junio de 1870 ya se establecía una ley con suficiente antelación para poder entrar en funcionamiento el 1 de enero de 1871 (recordemos que el decreto de 1841 fue dispuesto el 24 de enero con validez retroactiva desde el primero de mes) y unos días antes de entrar en funcionamiento - el 13 de diciembre - se añade un reglamento para su ejecución y cumplimiento. La Ley se caracteriza fundamentalmente por el traspaso de funciones desde los ayuntamientos a, 
los juzgados, dado el fracaso con que se habian saldado todos los intentos de establecer el registro mediante el sistema administrativo: este fracaso se reconocerá prácticamente cuando en las actas de matrimonio conste la fecha de inscripción de nacimiento del contrayente en el registro eclesiástico y no en el municipal; así, en la primera acta de matrimonio del Juzgado Municipal de Elda se lee que el primer contrayente estaba «inscrito de nacimiento en el Registro parroquial de esta Villa en diecisiete de julio de mil ochocientos cuarenta y cinco», fecha en que teóricamente debía estar funcionando el Registro Civil.

En cuanto a la información contenida en cada inscripción no parece ser que fuese mucho más completa que anteriormente, aunque de una parte se cumplía más a rajatabla y de otra era excesivamente prolija en detalles inútiles y farragosos, difícil de leer hasta que aparezcan impresas (lo que no sucede, al menos en lo concerniente a los nacimientos del Registro Civil de Elda, hasta bien avanzado 1880). Frente al registro municipal previo, la información de los nacimientos sólo amplía la mayoría de edad de los padres (no la edad) y la profesión de los abuelos aunque, eso sí, dan todo lujo de detalles del que efectúa el registro y de los testigos y circunstancias del propio documento; las defunciones no amplían detalle alguno de importancia demográfica y sí todos los que ofrecen validez al documento (quien registra, ante quién, testigos...). En los matrimonios la única innovación de importancia demográfica se refiere a los abuelos de ambos contrayentes, con expresión del estado civil (o difunto en su caso) y naturaleza; estamos ante el más complicado de los documentos, que enumera hasta las preguntas a los contrayentes, el lugar y fecha del matrimonio religioso y las circunstancias alusivas (publicación de edictos, posibles impedimentos) lo que hace que cada inscripción ocupe entre cinco y siete páginas.

Pese a lo que pudiera pensarse no acaban aquí los problemas en cuanto a la implantación del registro civil. Dice Nadal que «verdadero registro civil no lo hubo en España hasta la Ley Provisional del mismo» ${ }^{5}$ pero lo cierto es que tardó bastantes años más en realizarse de una manera mínimamente satisfactoria. Para comprobarlo vamos a realizar el estudio de los 10 primeros años de registro civil en el Juzgado Municipal de Elda, comparando sus datos extraídos con los obtenidos en el registro parroquial, aunque debemos indicar que en los archivos parroquiales no se conservan las partidas de defunción de dichos años ni las de bautismos de 1871-76. (Ver cuadro 3).

${ }^{5}$ Op. cit. pág. 130. 


\begin{tabular}{|c|c|c|c|c|c|}
\hline & $\begin{array}{l}\text { EVOLUC } \\
\text { ELDA, }\end{array}$ & $\begin{array}{l}\text { DE NACIMIENT } \\
\text {-80. COMPARAC }\end{array}$ & $\begin{array}{l}\text { Y DEFUNCI } \\
\text { N DE REGIST }\end{array}$ & $\begin{array}{l}\text { NES } \\
\text { OS }\end{array}$ & \\
\hline & Nacimientos & & Defunciones & Crec. V & etativo \\
\hline Año & R. Civil (A) & R. Parroquial (B) & R. Civil (C) & $A-C$ & $B-C$ \\
\hline 1871 & 107 & & 173 & -66 & \\
\hline 1872 & 112 & & 126 & -14 & \\
\hline 1873 & 136 & & 164 & -28 & \\
\hline 1874 & 146 & & 114 & 32 & \\
\hline 1875 & 106 & & 112 & -6 & \\
\hline 1876 & 117 & & 144 & -27 & \\
\hline 1877 & 96 & 176 & 106 & -10 & 70 \\
\hline 1878 & 105 & 161 & 103 & 2 & 58 \\
\hline 1879 & 81 & 181 & 90 & -9 & 91 \\
\hline 1880 & 82 & 179 & 97 & -15 & 82 \\
\hline
\end{tabular}

Fuente: Registro Civil del Juzgado Municipal de Elda y Libros de bautismos de la Parroquia de Santa Ana de Elda.

De la comparación se comprueban enormes diferencias de los nacimientos registrados en la parroquia y en el juzgado, en detrimento de este último; en los años de posible comparación, 1877 a 1880, no se registran civilmente más que el $52,2 \%$ de los bautizados lo que indica una nula fiabilidad del registro civil de la época para los estudios de carácter demográfico: la tasa de natalidad eldense utilizando los datos del registro civil sería similar a la de comienzos de los sesenta del presente siglo, lo cual es a todas luces incierto. Como el registro de defunciones es, por el contrario, bastante más fiable (nos daría una tasa de mortalidad para la época en torno al $28 \%$ ol siguiendo los datos del juzgado de la entonces villa presentaba un altísimo decrecimiento vegetativo en una época para la cual los registros parroquiales señalan un claro incremento. Sin que podamos atrevernos a afirmar que el Registro Civil inscriba la totalidad de las defunciones de la época, lo cierto es que la seriedad y publicidad que rodea las muertes, la presencia de un médico que certifica la defunción, el entierro que se realizaba escasas horas después y se desarrollaba con la concurrencia de una comitiva que atravesaba las calles del pueblo y era presidida por un sacerdote y la costumbre de dar parte a la autoridad hicieron posible que el registro de defunciones fuese el primero en normalizarse.

Todo lo contrario sucedió con el registro de los matrimonios. Sus datos, en los inicios, son absolutamente inservibles para estudios demográficos globales. Como muestra, comparemos los datos de los registros civil y eclesiástico (Ver cuadro 4). 


\begin{tabular}{|c|c|c|c|}
\hline \multicolumn{4}{|c|}{ CUADRO 4} \\
\hline \multicolumn{4}{|c|}{ NUMERO DE MATRIMONIOS. ELDA， 1871-1880. } \\
\hline Año & R. Civil & R. Parroquial & Diferencia \\
\hline 1871 & 9 & 23 & -14 \\
\hline 1872 & 15 & 50 & -35 \\
\hline 1873 & 11 & 39 & -28 \\
\hline 1874 & 63 & 46 & 17 \\
\hline 1875 & 52 & 25 & 27 \\
\hline 1876 & 12 & 36 & -24 \\
\hline 1877 & 6 & 32 & -26 \\
\hline 1878 & 1 & 35 & -34 \\
\hline 1879 & 2 & 34 & -32 \\
\hline 1880 & 5 & 36 & -31 \\
\hline $1871-80$ & 164 & 356 & -192 \\
\hline
\end{tabular}

Fuente: Registro Civil del Juzgado Municipal y Libro de matrimonios de la Parroquia de Santa Ana.

Como se puede comprobar, los matrimonios reflejados en las fuentes judiciales no representaban más que el $46 \%$ de los matrimonios religiosos durante el período comparado, lo que dificulta cualquier estudio de la nupcialidad de la década a través del registro civil. Pero además, mientras que durante casi todos los años los datos del registro civil son muy inferiores a los religiosos y en algunos casos casi nulos, otros años - como el 1875- los superan en mas del doble. Así, por ejemplo, en diciembre de 1875 se inscriben en el Juzgado la friolera de 33 uniones de parejas, más que durante los cinco años sucesivos; ello presupone que en el Juzgado aprovechaban posiblemente los meses de menor trabajo para realizar estas pesadísimas inscripciones y convocarian de algún modo a inscribirse a los casados en un período de tiempo amplio ${ }^{6}$.

De otra parte, los nacimientos y defunciones afectan a la propia esencia del individuo: comienzan a existir o desaparecen al margen de registrarse o no en juzgados o parroquias; los casamientos son diferentes: su esencia está en ser registrados («esos no están casados», dice la gente de los que no están inscritos). Por otra parte, en un período de libertad religiosa - salvo en el caso de que exista, como en España

${ }^{6}$ De hecho, en la primera acta el matrimonio religioso se celebró el 24 de Diciembre de 1870 . 
actualmente, una convalidación civil del acto religioso- el casamiento por un registro ni implica necesariamente validez o necesidad por el otro. Todo ello complicaba la eficacia del registro civil en una época donde la mentalidad consideraba el casámiento esencialmente como la unión de dos personas «ante el altar».

\section{CONCLUSION.}

La implantación del registro civil en nuestro país se produce a lo largo del siglo XIX y las principales disposiciones que lo desarrollan fueron promulgadas en las etapas políticamente innovadoras - liberales, progresistas, demócratas - que intentaron bien modernizar las bases del Estado; bien desplazar a la Iglesia Católica del control sobre la existencia de los ciudadanos.

Hasta 1840 no hay una sola tentativa seria que sustituya al registro eclesiástico; todas las disposiciones se redujeron a trasladar información de los datos parroquiales a las secretarías de los ayuntamientos.

El Decreto de 24-1-1841 fue el único precedente digno de importancia, con formularios sistematizados sobre los que apenas aportó innovación alguna la Ley Provisional de 1870. Sin embargo, algunos defectos técnicos como la retroactividad de la entrada en vigor, la no implantación en los pequeños municipios de dicha tarea y la interconexión con el registro eclesiástico (al que acabó subordinándose) frustaron esta última intentona de registro civil de carácter administrativo.

En 1870 la Ley Provisional de Registro Civil traslada las inscripciones de nacimientos, defunciones y matrimonios de los ayuntamientos a los juzgados, independizándose definitivamente de los registros parroquiales.

En cuanto a la utilización de los primeros datos del registro civil para los estudios demográficos, de los tímidos intentos del primer tercio del siglo apenas conservamos dato alguno; los derivados del decreto de 1841, al ser prácticamente los mismos que los parroquiales, sólo presentan un cierto interés cuando pueden suplir a los libros parroquiales desaparecidos. Los datos del Registro Civil a partir de 1871, que junto con los censos y padrones son la fuente esencial de los estudios demográficos modernos, presentan en los primeros años de implantación bastantes problemas de fiabilidad a causa de la gran cantidad de sucesos no registrados. 



\section{EL DOCTOR PERE FELIP MONLAU Y LA CUESTION OBRERA}

ANTONIO MOLINER PRADA

CARMEN MOLINER PRADA

Cataluña, pionera en las transformaciones industriales en nuestro país, vivió en primer lugar la problemática social que ésta planteaba. Fueron los médicos y también los economistas quienes más directamente se acercaron a estudiar las condiciones de vida y trabajo de los obreros algodoneros catalanes'. La obra del doctor Pere Felip Monlau se debe circunscribir en este contexto. Su descripción y denuncia de la situación de la clase obrera de Barcelona y de su cinturón industrial a mediados del siglo XIX es un documento histórico valiosísimo.

\section{NOTAS BIOGRAFICAS.}

La biografía de este polifacético personaje ha sido puesta de manifiesto extensamente por su hijo Josep Monlau Sala en su libro Relación de los estudios, grados, méritos, servicios y obras científicas y literarias del IImo. Sr. Dr. D. Pedro Felipe Monlau, publicado en Madrid en 1864². Por ello sólo señalaremos los aspectos más sobresalientes.

1 El estudio del urbanista Idelfonso Cerdá llega incluso a señalar el promedio de vida de los obreros barceloneses, según sus estimaciones realizadas entre los años 1837 a 1847. Las cifras no necesitan ningún comentario:

\begin{tabular}{lccc}
\hline & hombres & mujeres & promedio ambos sexos \\
clase rica $\ldots \ldots \ldots \ldots$ & 33,83 & 34,11 & 33,97 \\
clase menestral $\ldots \ldots$ & 25,41 & 24,90 & 25,15 \\
clase pobre o & & & \\
jornalera $\ldots \ldots \ldots \ldots$ & 19,68 & 27,43 & 23,55 \\
\hline
\end{tabular}

Cfr. Teoría general de la urbanización (Con un Apéndice Monografía estadística de la clase obrera de Barcelona en 1856. Madrid, 1867, 2 vols. Citado por IZARD, M. Industrialización y obrerismo. Las tres clases de vapor 1869-1913. Barcelona, 1973, pág. 84.

${ }^{2}$ Estudio en el que se han basado posteriormente los de COMENGE, L. La medicina en el siglo XIX. Apuntes para la historia de la cultura médica en España, Barcelona, 1914; LOPEZ PIÑERO, J. Ma y otros Medicina y sociedad en la España del siglo XIX. Madrid, 1964; CALVET I CAMARASA, J.M. «El pensament de Pere Felip Monlau», I Congrés Internacional d'Història de la Medicina Catalana, Barcelona, Montpellier, 1970, vol. IV; JUTGLAR, A. P.F. Monlau y J. Salraich. Condiciones de vida y trabajo obrero en España a mediados del siglo XIX. Anthropos, Barcelona, 1984 etc.

Una buena síntesis de su vida se encuentra en la Tesis de Licenciatura de la doctora C. MOLINER PRADA Pedro Felipe Monlau: Su aportación a la Higiene Española a través de El Monitor de la Salud (1858-64). Univ. Autónoma Madrid, Facultad de Medicina, 1983 (inédita). 
El doctor Pere Felip Monlau nació en Barcelona en 1808, iniciando sus estudios de humanidades (Gramática, Retórica, Poética y Filosofía) en el Seminario de Barcelona entre los años 1816-24. Posteriormente realizó estudios de Matemáticas y Cosmografía en la Real Academia de Ciencias Naturales de Barcelona; Física, Química y Botánica en la Junta de Comercio de Cataluña; enseñanza de idiomas, y los propios de la carrera médica en el Real Colegio de Medicina y Cirugía de Barcelona, obteniendo en 1831 el título de licenciado y dos años después el de doctor en medicina.

En 1828 inició también su fecunda carrera literaria que se extendió a lo largo de toda su vida.

La primera publicación sobre higiene, una de las materias en las que más destacó, data de 1832, titulada ¿El cólera morbo invadirá la España?, en la que expuso el método mejor para su prevención, insistiendo en la utilización de la desinfección.

En 1833 fue aceptado como socio numerario en la Real Academia de Ciencias Naturales y Artes de Barcelona, presentando a tal efecto en 1834 una Memoria sobre la necesidad de establecer prados artificiales en España.

Por estos años ocupó varios cargos como médico militar e hizo frente a la epidemia de cólera que sufrió Barcelona durante los años 1834-35.

En esta etapa de su vida le atrajo el mundo periodístico. Fue redactor de noticias extranjeras en EI Vapor, entre 1833 y 1835, y director político y literario de este diario de 1835 a 1836. Periódico que recogió varios artículos de Abreu, introductor del fourierismo en España, entre ellos el relacionado con el incendio de la fábrica Bonaplata por un grupo de obreros. Lo que motivó una seria república por parte de la burguesía catalana a través del periódico conservador El Guardia Nacional. Como ha escrito Antonio Elorza el citado artículo, que erróneamente aparecía como de tendencia sansimonia, copiado de El Grito de Carteya, intentaba llamar la atención de los capitalistas para que conocieran la situación de la clase obrera para mejorarla, y recíprocamente ésta obtener la benevolencia de aquéllos ${ }^{3}$.

A través de sus páginas Monlau difundió las ideas sansimonianas y la necesidad de una nueva Constitución ante el menguado Estatuto Real de 1834. En 1836 escribió ideas similares, bajo el seudónimo de José Andrew de Covert-Spring, en la revista El propagador de la liber$\operatorname{tad}^{4}$.

${ }^{3}$ ELORZA, A. El fourerismo en España. Madrid 1975, págs. XXII-XXIII.

${ }^{4}$ Según las investigaciones de Anna Ramspott y Jordi Maluquer de Motes, Covert-Spring, tradicionalmente identificado con un misterioso José Andrés de Fontcuberta, encubría en realidad al médico Pere Felip Monlau. Cfr. "Romanticisme i saint- 
Asi pues, en ambas publicaciones Monlau expuso la doctrina de Saint-Simon, aunque con cierta originalidad, y trató de promover un amplio movimiento industralista y socialista. Su alternativa política, al margen de los moderados y exaltados, estaba destinada a reforzar a las posiciones de la burguesía industrial y a constituir un nuevo Estado, capaz de desarrollar la industrialización y modernización del país. Desde el punto de vista social su objetivo se circunscribía a acabar con la gran propiedad y con el poder político de los terratenientes. En esta línea Monlau contó también con Antonio Ribot y Fontseré y Pedro Mata, influidos por Lamennais y Mazzini.

$Y$ cuando sus amigos intervinieron en el motín progresista-radical de 5 de enero de 1836, siendo detenidos Mata y Ribot, y deportados a Canarias Raull y Antonio Gironella, él permaneció al margen del conflicto y de sus consecuencias.

A finales de 1837 se trasladó a Francia por motivos políticos, estudiando en París, Lyon, Burdeos y Marsella, y después visitó Londres.

El propio Monlau hace referencia a estos años con estas palabras: "Lanzado en 1837 a Francia por una de aquellas oleadas tan frecuentes en los pueblos víctimas de la discordia civil, resolví aprovechar mi viaje forzado, estudiando algún ramo especial, para iniportar luego a mi patria conocimientos e ideas útiles y de provechosa aplicación (...). La saña de los partidos políticos me iba dando tiempo, y lo emplee en enterarme del estado de la instrucción pública en su conjunto ${ }^{5}$.

Al regresar a España en 1839, reemprende la publicación de El Constitucional, teniendo como colaboradores al médico Pedro Mata y a Antonio Ribot entre otros ${ }^{6}$. En esta etapa se declaró partidario del progresismo.

A partir de aquí su vida se orientó hacia la docencia, como profesor del Hospital Militar de Barcelona, donde ya había ejercido anteriormente, y de Geografía y Cronología en la Academia de Ciencias Naturales y Artes de la misma ciudad. En 1840 desempeñó la cátedra de Literatura e Historia en la Universidad de Barcelona y dirigió el Semanario Popular de Ciencias, Agricultura y Artes.

\footnotetext{
simonisme a Catalunya en temps de revolució» (1835-37), Recerques, 6 (1976), Apèndix, págs. 87-91; Sobre la difusión de la ideología sansimoniana a través de Monlau ver el capt. II de la obra de J. Maluquer de Motes, El socialismo en España (1833-1868), Barcelona 1977, págs. 97 y s.

${ }^{5}$ MONLAU I ROCA, P.F. De la Instrucción pública en Francia. Ensayo sobre su estado en 1838 y 1839. Barcelona, 1840, págs. 1 y 2.

${ }^{6}$ CALVET I CAMARASA, J.M. o.c. págs. 281-304.
} 
En 1841 publicó una memoria sobre el derribo de las murallas de la ciudad de Barcelona, por la que obtuvo el primer premio. Su título es expresivo: iilAbajo las murallas!!! Memoria sobre las ventajas que reportaría Barcelona, y especialmente su industria, de la demolición que circundan la ciudad. Su actitud entroncaba con la opinión ciudadana favorable a su derribo, porque significaban, al igual que la Ciudadela, la opresión por parte del gobierno central y era un obstáculo para el ensanche de la ciudad en claro proceso de industrialización ${ }^{7}$. Tres años después formaría parte de la Junta encargada de dirigir la operación de derribo de las citadas murallas.

Su última participación en el mundo del periodismo político la encontramos en 1841 en su colaboración en el diario El Popular, defensor de las ideas de soberanía nacional, tolerancia y progresismo.

Cuando Barcelona se insurrecionó en 1842 y fue bombardeada por Espartero, Monlau, al ser médico castrense, realizó una negociación con el objeto de poner fin a la situación y lograr la evacuación de hospitales, colegios y cárceles.

Al iniciarse el período moderado con Narváez fue separado de la cátedra de Literatura e Historia de la Unversidad y trasladado al Hospital Militar de Valencia. Aquí escribió una de sus obras Remedios del pauperismo, por la que la Sociedad Económica Matritense le concedió un accésit y premio extraordinario. Dicha obra se publicó en el periódico de la Sociedad El Amigo del País en 1856 y también en Valencia en la imprenta de D. Mariano de Cabrerizo.

En 1848 obtuvo la cátedra de Psicología y Lógica del Instituto de San Isidro en Madrid y años más tarde, en 1850, fue profesor de Psicología y Lógica de la Escuela Normal.

Fueron muchos sus artículos y obras sobre la higiene pública participando en varios congresos internacionales sobre esta materia, cuya cátedra regentó en la Universidad Central de Madrid hasta 1854. Entre sus obras, merece especial mención la titulada Higiene Idustrial, distinguida con el premio de Medalla de Oro en 1856 por la Academia de Medicina y Cirugía de Barcelona. También elaboró varios informes para el gobierno sobre la prostitución madrileña y sus causas.

Creada la Escuela Diplomática en 1856 fue nombrado catedrático de Gramática Histórico-comparada de Lenguas Romances. Fue elegido académico de la Real Academia Española de la Lengua en 1858, ocupando la silla "D». Este mismo año dirigió El Monitor de la Salud de las familias y de la salubridad de los pueblos.

Por R.O. de 1 de noviembre de 1863 es nombrado catedrático de

7 JUTGLAR, . o.c., pág. 20. 
término en el escalafón de Enseñanza Superior sección Diplomática. Junto con otros profesores, efectuó una inspección en el Archivo de Simancas, elaborando una memoria de los resultados obtenidos en diciembre de 1863. Entre 1867 y 1868 dirigió el Museo Arqueológico de Madrid. Finalmente fue catedrático en 1868 de Higiene Pública y Epidemología para el Doctorado, aunque por poco tiempo. Murió en Madrid en 1871.

D. Emilio Castelar, que sucedió a Monlau en la Academia Española de la lengua, al tomar posesión de su asiento lo elogió con las siguientes palabras: «Sucedo, en silla, ilustrada por Navarrete, a un sabio, que así poseía las ciencias de la naturaleza como las artes de la palabra; y si puedo sucederle, no puedo en manera alguna sustituirle» ${ }^{8}$.

\section{EVOLUCION DE SU PENSAMIENTO POLITICO.}

El doctor Monlau evolucionó a lo largo de su vida en sus ideas políticas. En su juventud participó de las tendencias del liberalismo exaltado y del progresismo y difundió el pensamiento socialista utópico sansimoniano. Tras su participación en el pronunciamiento de 1840 , se presentó en 1841 a las elecciones en la candidatura democrática. A partir de este año y de su estancia en Valencia, entre 1844 y 1846 , sus posiciones se hacen más conservadoras rechazando las ideas socialistas utópicas. La sociedad se basaría en la libertad individual, la propiedad y la familia, principios que atacarían las ideas socialistas:

«Todos los sistemas socialistas adoptan por divisa la palabra solidaridad (...). Lo único en que se diferencian entre sí los adeptos del socialismo, es que los unos atacan principalmente la propiedad (los comunistas); y otros a la familia y toda disciplina moral (los fourieristas); y los otros (los sansimonianos) anulan al individuo por entero, quitándole hasta la conciencia de sí mismo, haciendo del panteismo una religión, confundiendo en un mismo culto la materia y el espíritu... Estas diversas sectas se confunden, porque la destrucción de cualquiera de los tres principios que hemos sentado sería fatalmente la ruina de los otros dos» ${ }^{9}$.

En tal sentido era deber del Estado tutelar la libertad de los pueblos, a los que consideraba siempre menores de edad. $Y$ en las disputas entre las doctrinas proteccionistas y librecambistas adoptó un tér-

${ }^{8}$ CASTELAR, E. Discursos leídos ante la R.A.E. en la recepción pública del Sr. D. Emilio Castelar el día 25 de abril de 1880. Madrid, pág. 1. Citado por MOLINER PRADA, C. o.c., pág. 47.

9 MONALU I ROCA Higiene del matrimonio, impt. M. Rivadeneyra, Madrid, 1865, págs. 9-10. Citado por MOLINER PRADA, C. o.c. pág. 53. 
mino medio. En su opinión las únicas doctrinas que mejoraban la especie humana eran las doctrinas higiénicas que tanto ayudó a difundir.

Desde el punto de vista científico-médico tradujo muchas obras de autores extranjeros y participó en los problemas médico-profesionales de la época, como en el intento de unificar las categorías profesionales, problemas de la asistencia rural, etc.

La obra del doctor Monlau constituye la primera y más firme base de la higiene en nuestro país como disciplina moderna. Pero no se agota en esta materia ni siquiera en la medicina. Su obra es polifacética y abarca todo tipo de manifestaciones científicas y culturales ${ }^{10}$.

\section{LA CUESTION OBRERA.}

Como ya hemos señalado el testimonio de Monlau acerca de la situación del proletariado a mediados del siglo XIX es del máximo interés, ocupando un lugar destacado en su obra higiénica la denuncia de sus condiciones de vida y de trabajo.

Las circunstancias que influyeron en Monlau en este sentido son varias. J. Ma López Piñero apunta las siguientes:

En primer lugar el conocimiento de una serie de datos médicosociales que contribuian a denunciar su trágica situación, como eran:

1) El aumento de las cifras de mortalidad y morbilidad en esta clase y su notable diferencia con el campesinado.

2) La mayor incidencia en la misma de ciertas enfermedades como la tuberculosis pulmonar, tifus, cólera, etc.

3) La disminución de la talla y vida media de los proletarios.

4) Su mayor inadaptación social (miserables, criminales, prostitutas, etc.)

En segundo lugar por su exaltación idílica del campo frente a la ciudad. Las cifras de mortalidad de los núcleos urbanos industriales ingleses con respecto a las zonas rurales eran espantosas.

En tercer lugar por las consecuencias sociales y económicas que provocaban el proceso de industrialización.

En cuarto lugar su preocupación es propia de la clase social a la que pertenecía, la burguesía liberal. Es un testigo nada más, sin participar del destino de la clase obrera.

En quinto lugar por la importancia que iba tomando en España el

${ }^{10}$ LOPEZ PIÑERO, J. Ma Medicina moderna y sociedad española. Siglos XVI-XX. Cátedra e Instituto de Historia de la Medicina. Valencia, 1976. "Cuadernos Valencianos de Historia de la Medicina y de la Ciencia, XIX, Serie A (Monografías) pág. 268. 
desarrollo industrial. Según los datos que toma del censo de 1860 la población industrial ascendía a 1.085.293 operarios frente a 2.354.110 jornaleros del campo ( 150.000 obreros y 25.000 mineros) ${ }^{11}$.

Finalmente habría que añadir el sentimiento de compasión que le despertaba la condición mísera del proletariado, que provocaba desorden social.

Todo ello le llevó a denunciar la dura realidad del proletariado español. Monlau deseaba que su testimonio fuese el detonante para que la administración y las «personas honradas y previsoras» se decidieran a remediarla ${ }^{12}$.

Las obras publicadas en este sentido fueron Remedios del pauperismo, Elementos de Higiene Pública e Higiene Industrial.

\section{A) Remedios del pauperismo.}

Dicha Memoria la presentó para optar al premio ofrecido por la Sociedad Económica Matritense en su programa del $1^{\circ}$ de mayo de 1845. Obtuvo el accésit y premio extraordinario de título de Socio sin cargas. En 1850 presentó otra Memoria, titulada De la supresión de la mendicidad y Organización de las Juntas de Caridad que se puede considerar como su complemento ${ }^{13}$.

La obra trata de las siguientes cuestiones: 1) ¿Qué es el pauperismo?, 2) ¿Qué clases de individuos lo constituyen?, 3) ¿Qué remedio aplican los pobres a su estado de indigencia?, 4) ¿Cuáles son los resultados del pauperismo?, y 5) ¿Qué remedios debe aplicar el Gobierno para combatir el pauperismo?.

1) ¿Qué es el pauperismo?.

Lo define como la enfermedad social que resulta de la multiplicación de los pobres y su origen se confunde con el de la sociedad:

«El pauperismo - afirma - es hasta una condición necesaria de la misma naturaleza del hombre, porque necesidad natural y social es la desigualdad de condiciones; y la desigualdad social de condiciones supone necesariamente la indigencia ${ }^{14}$.

Pero no hay duda de que el pauperismo es también una acusación contra la mala organización de la sociedad.

El pauperismo como fenómeno social no existe en las sociedades

1 LOPEZ PIÑERO, J.Ma o.c., págs. 269 y s.

12 MOLINER PRADA, C. o.c., pág. 69.

${ }^{13}$ Uilizamos la edición de 1986, publicada en Valencia, imprenta de D. Mariano de Cabrerizo. Biblioteca Nacional, Madrid, Ca 760-6.

${ }^{14}$ Remedios del pauperismo, pág. 8. 
en estado salvaje o casi salvaje, aumentando al compás de la civilización. Incluso es menor en los distritos agrícolas que en los industriales, estando siempre en relación con la riqueza de los pueblos ${ }^{15}$.

En defintiva su observación es que el pauperismo crece con el desarrollo industrial.

\section{2) ¿Qué clases de individuos constituyen el pauperismo?}

Pobre debe considerarse en su opinión todo individuo que se ve más o menos completamente privado de lo necesario para vivir. $Y$ las necesidades varían según el país, edad, estado o rango social, etc.:

"A medida que el hombre apropia a su mayor número de objetos; a medida que progresa la industria, la civilización y el lujo, el hombre tiene más necesidades, y es preciso ser más rico para no estar privado de lo estrictamente indispensable» ${ }^{16}$.

Dentro de la categoría de pobres sitúa tanto a los que no pueden o no saben, o no quieren trabajar.

En la categoría de los que no pueden trabajar incluye a los huérfanos, expósitos, viuda con hijos, viejos, adultos «mal conformados», enfermizos o débiles, lisiados o estropeados, enfermos y los que no encuentran trabajo.

En la categoría de los que no saben trabajar introduce a los hacendados y propietarios arruinados, banqueros y comerciantes en decadencia, los retirados y pensionistas que no cobran (clases pasivas) y los médicos, abogados y literatos sin ocupación. Con respecto a este último grupo señala el estado de mediocridad existente en su tiempo:

"Huyendo del trabajo del campo o de los talleres (que tienen por deshonrosol, fueron a engrosar las filas harto engrosadas ya de las carreras literarias; y no pudiendo sobresalir en ellas, ni hacerse un lugar entre la turba, han quedado obscurecidos en ella, llenos de necesidades impremeditadamente contraídas y privadas de todos los medios de satisfacerlas. ¡Ay del país que tantas capacidades bastardas o de reemplazo cuenta en su seno! ${ }^{17}$.

El grupo de los que no quieren trabajar lo formarían los vagos y holgazanes, los mendigos de profesión, los borrachos y jugadores, los libertinos, viciosos y mal ocupados y los mal retribuidos por su trabajo. Monlau es consciente al hablar de estos últimos del problema obrero, al que se refiere con estas palabras:

«(...) mas no se olvide que la insuficiencia con que generalmente retribuye la industria a los que, no teniendo renta ni capital, viven

\footnotetext{
${ }^{15}$ Remedios del Pauperismo, pág. 13.

${ }^{16}$ Remedios del Pauperismo, pág. 15.

${ }^{17}$ Remedios del pauperismo, pág. 17.
} 
del trabajo de sus manos, es hoy día una de las principales causas del pauperismo. En esta insuficiencia de jornal está encarnado el todavía no fallado litigio entre el capital y el trabajo; y en esta insuficiencia de jornal va involucrado el más grande y formidable de los problemas de economía social. El proletarismo, o sea el estado de los que no tienen más recurso que el producto de su trabajo mecánico, es otra enfermedad social muy afin del pauperismo, o más bien son dos grados de una misma dolencia» ${ }^{18}$.

3) ¿Qué remedios aplican los pobres a su estado de indigencia?

Unos mueren de indigencia, a pesar de estar «en la época de la filantropía y de las luces, en el apogeo de la titulada civilización», otros se suicidan o emigran, o se dedican a mendigar o en el caso de las mujeres a la prostitución, o se degradan cometiendo delitos y crímenes.

4) ¿Cuáles son los resultados del pauperismo?

El pobre, por su escasez de recursos está condenado a sufrir una degeneración física. Al mismo tiempo el pauperismo debilita al Estado: "I(...) disminuye la población, gasta las fuerzas físicas y morales de una parte de la misma, corrompe las clases todas, degrada la dignidad del hombre y la libertad del ciudadano, abrevia la dur: :ción de la vida, bastardea las generaciones, fomenta las epidem. $s$ y los contagios, impele a la prostitución y al crimen, provoca a los disturbios políticos, desacredita a los Gobiernos, pone en peligro las instituciones (...), y llegaría a producir el caos) ${ }^{19}$.

5) ¿Qué remedios debe aplicar el Gobierno para combatir el pauperismo?.

Una vez descritas las causas y la tipología de la pobreza expone los remedios que debe emplear el Gobierno para combatirla.

Remediar el pauperismo es proponer el mejor sistema de gobierno posible. Monlau opta por el progreso, matizando al mismo tiempo que a la par de la civilización industrial debe caminar la moral. El remedio del pauperismo se logrará cuando el Gobierno cree un bienestar general, permanente y regular, fundado en la base del trabajo.

Para ello se requiere la creación de un amplio mercado, fomentando las vías de comunicación, el comercio y las instituciones de crédito; educar a los hombres en el trabajo, fomentando el espíritu de asociación, y mejorar la producción y la suerte de los productores, repartiendo los frutos del trabajo de una manera justa y creando una «Providencia» social activa y vigilante ${ }^{20}$.

\footnotetext{
${ }^{18}$ Remedios del pauperismo, pág. 19.

${ }_{19}$ Remedios del pauperismo, pág. 26.

${ }^{20}$ Remedios del pauperismo, pág. 32.
} 
El remedio para los que no pueden trabajar es el de la beneficiencia pública: la creación de inclusas, hospicios y hospitales. Cuyos gastos deben figurar en el presupuesto anual del Estado.

Para los que no saben trabajar, el Gobierno debe disminuir su número mediante un vasto sistema de educación pública que moralice o instruya a todas las clases», grabando en el corazón de todos la indeclinable ley del trabajo" ${ }^{21}$. Debe fomentar las escuelas primarias para la niñez, las escuelas industriales para la adolescencia, las colonias agrícolas para los hombres y las escuelas científico-profesionales para los jóvenes con capacidad probada. Debe remediar el fraude, crear cajas de ahorro y montes de piedad.

Con el objeto de disminuir el número de menesterosos que no saben trabajar, propone que el gobierno cree dificultades para el acceso a las carreras facultativas:

«( ...) hágase de suerte que sólo emprendan dichas carreras los jóvenes de verdadera vocación y de reconocida suficiencia: establézcase un saludable rigor en los exámenes de entrada, de curso y grados: impóngase crecidos, aunque siempre equitativos, derechos de matrícula y de depósito; y tendremos conseguida una de las más importantes reformas" ${ }^{22}$.

El Gobierno debe poner especial cuidado en la educación de la mujer. Su papel en la sociedad es meramente pasivo:

«Sí, las mujeres están más expuestas a la miseria que los hombres. Su sexo, su debilidad y su delicadeza les cierran el acceso a un sin número de carreras: algunas sucumben en la lucha trabada con el infortunio; si son jóvenes, abandonan la virtud, si tienen edad, tal vez se suicidan. Con todo, en general, las ha dado Dios la virtud de la resignación. Las más de ellas soportan mejor que los hombres el espantoso suplicio de la miseria. Casadas, son todavía la esperanza del hogar doméstico; ellas reaniman con su dulzura el abatimiento del esposo; y ellas con su actividad de espíritu saben encontrar a veces recursos que se ocultaban a la desesperación de un padre» ${ }^{23}$.

Para los que no quieren trabajar propone un plan combinado de educación, beneficiencia y corrección. Debe suprimirse la mendicidad y se debe crear una especie de hospitales morales y colonias agrícolas (como la establecida en 1818 en Frederick's Oord en los Paises Bajos).

En resumen, sus remedios son ingenuos y moralizantes: aumento del trabajo y una mayor justicia en la distribución de los frutos. Ideas

\footnotetext{
${ }^{21}$ Remedios del pauperismo, pág. 35.

${ }_{22}$ Remedios del pauperismo, pág. 37.

${ }^{23}$ Remedios del pauperismo, págs. 38-39.
} 
que aparecen también en su obra De la supreción de la mendicidad.

\section{B) Elementos de Higiene Pública e Higiene Industrial.}

La primera obra se publicó en 1847 y tuvo varias ediciones posteriores en 1862 y 1871, y la segunda en 1856.

El doctor Monlau, discípulo de Seoane, puede considerarse como el primer higienista español, preocupado por la situación del proletariado. Cuestión a la que dedicó estas obras, aumentando el número de páginas al respecto en sus respectivas reediciones, así como la revista El Monitor de la Salud, publicada entre 1858 y 1864.

Monlau está muy influenciado por los higienistas británicos, cuyos estudios y datos estadísticos utiliza en sus trabajos.

En las citadas obras aparece con suma claridad y objetividad su denuncia sobre las circunstancias en las que se desarrollaba la vida del proletariado español. La descripción que hace de sus casas y viviendas nos recuerda la que hizo Engels sobre Manchester en su obra La clase trabajadora en Inglaterra. Su mala alimentación es otro punto de denuncia. Su dieta alimenticia se reducía a pan, vino, vegetales, patatas, bacalao, tocino, sardinas saladas y escabeche, careciendo de un producto básico como es la carne. La falta de limpieza personal y mala vestimenta entre los obreros comportaba un deterioro físico y moral, resultado de la mala organización industrial.

Esta dramática realidad se comprueba con los datos médicossociales que él aporta. Asi por ejemplo la clase obrera es víctima de las epidemias y enfermedades sociales (tifus, cólera, anemia fabril, etc). Al mismo tiempo la estatura media de los hombres de los distritos industriales es inferior a la normal. Las elevadas cifras de mortalidad obrera se debían a las privaciones que padecía este grupo social.

En su estudio sobre los ịnadaptados sociales, realizado a través de El Monitor de la Salud, tomando los datos relativos a 1859, demostró que más del $50 \%$ de este grupo eran proletarios. La miseria les inducía al alcoholismo, a la delincuencia o en el caso de las mujeres a ejercer la prostitución.

En sus obras denunció reiteradamente la explotación del trabajo femenino, el excesivo número de horas de trabajo de los adultos, recomendando un jornada laboral entre 10 y 12 horas y la supresión del trabajo nocturno, y el abuso del trabajo infantil en las fábricas. Así describe el trabajo de los niños en los telares: "Las criaturas se ven plagadas de cicatrices, de tumores y deformaciones asquerosas. La población de tales manufacturas suele ser endeble, raquítica: criada a la sombra y 
encorvada sobre el telar, marchítase como una planta sin sol» ${ }^{24}$.

Cuando trata el tema del salario obrero, reconoce su escasez. Sus planteamientos son típicos del liberalismo económico. La cuestión salarial únicamente se puede resolver entre el empresario y el obrero, «ex aequo et bono", sin ningún tipo de intervencion gubernamental. A lo sumo el Gobierno sólo puede intentar disminuir los precios de los comestibles mediante una acertada política económica ${ }^{25}$.

En su análisis no podía faltar señalar el hecho del elevado número de accidentes de trabajo que producía el desarrollo industrial. Y en este punto, a diferencia del doctor Joaquín Salraich, que los atribuía a la inexperiencia de los obreros, culpa de ellos a las máquinas ${ }^{26}$.

Con respecto a la cuestión del asociacionismo obrero Monlau manifestó su oposición. A pesar de que en 1842 había aconsejado a la Asociación de Tejedores que resistiera pacíficamente a ser disuelta, después se manifestó contrario a todo tipo de asociación. Mentalidad propia de un liberal burgués de la época.

El obrero, según el higienista catalán, es pobre, ignorante y de malos instintos. Por ello había que socorrerlo, instruirlo y moralizarlo ${ }^{27}$.

En Higiene Industrial propone las medidas que podia tomar el Gobierno en favor de la clase obrera. La Memoria la había escrito Monlau haciéndose eco de los premios de la Academia de medicina y cirujía de Barcelona, convocados en enero de 1855 . Dicha institución acordó en 1856 imprimirla y recomendarla al Gobierno como un trabajo importante en esta materia. También premiaría en 1857 la obra del doctor Joaquín Salarich Higiene del tejedor.

Partiendo de las penosas condiciones físicas y morales en las que vivían las clases obreras de Inglaterra y Francia, analiza la de España: «La población obrera está plagada del vicio escrofuloso, es menos vigorosa que la agrícola, tiene menos talla, vive menos, etc., etc. ${ }^{28}$. Los datos que toma de Inglaterra relativos al año 1831 son clarificadores: la muerte causa cerca de una cuarta parte más de estragos en las poblaciones manufactureras que en las rurales.

Entre las medidas que él propone destacan las siguientes:

${ }^{24}$ Elementos de higiene pública. Barcelona, 1847, vol. II. pág. 545.

${ }^{25}$ Elementos de higiene pública, pág. 147.

${ }^{26}$ LOPEZ PIÑERO, J. Mà o.c. pág. 277; JUTGLAR, A. o.c. pág. 54.

${ }^{27}$ Higiene Industrial. ¿Qué medidas higiénicas puede dictar el Gobierno a favor de las clases obreras?. Madrid, imprenta de M. Rivadeneyra, 1856, pág. 66. (Utilizamos el ejemplar de la Biblioteca de la Universidad Central, Facultad de Medicina de Madrid. A. Jutglar la reproduce íntegramente en su libro, págs. 56-143).

${ }^{28}$ Higiene industrial, pág. 7. 
1) Descentralizar las fábricas y talleres.

Llevar las fábricas grandes y talleres a los pueblos rurales, creando colonias fabriles, ayudaría mucho a mejorar la situación y salud de los obreros. Con este fin el Gobierno debería primar a aquellas empresas que aceptaran esta proposición que redundaría en el bién común.

Monlau insiste una vez más en que el deterioro físico y moral de la clase obrera (condiciones de habitación, alimento, vestidos, fatigas y costumbres) es mayor que el de los campesinos ${ }^{22}$.

Sujetar la construcción de los talleres y de los edificios-fábricas a las condiciones de salubridad covenientes, y mandar inspeccionar los mismos edificios, bajo el punto de vista higiénico, depués de construidos o mientras sirvan para el objeto que fueran construidos.

El aspecto higiénico de las fábricas era de suma importancia, sobre todo la buena ventilación.

3) Mandar consturir casas-modelos con habitaciones adecuadas para los obreros y sus familias; y fomentar la construcción de casas análogas por cuenta de los particulares.

Tras señalar las medidas tomadas por los gobiernos de Inglaterra, Bélgica, Francia, Alemania y Holanda, hace referencia a la real orden de 9 de septiembre de 1853 del Gobierno español, relativa a arbitrar medios para construir casas para pobres con las condiciones de salubridad, comodidad y baratura, que hasta entonces no habían dado ningún resultado positivo.

4) Construir lavaderos públicos económicos o gratuitos. Abrir establecimientos o casas de baños, con iguales condiciones, para las clases obreras.

Una vez más se queja de la situación española, más atrasada que la de los paises europeos. Así por ejemplo el decreto gubernamental de 15 de junio de 1853 disponiendo la construcción de una casa de lavado y baños para pobres en Madrid había quedado en un mero proyecto.

La falta de limpieza predisponía a contraer epidemias y enfermedades y por consiguiente era la causa del aumento de la mortalidad: «En Madrid muere anualmente 1 habitante por cada 29, en Barcelona 1 por cada 36, y en Londres, con su inmensa población y riguroso clima, no muere más que 1 por cada $42{ }^{\prime 3}{ }^{30}$.

5) Proporcionar la abundancia y baratura de los alimentos, bebidas y condimentos más necesarios.

${ }^{29}$ Higiene Industrial, págs. 9-10.
${ }^{30}$ Higiene personal, pág. 26. 
La mala alimentación obrera, sobre todo la escasez de carne, era una realidad. Para remediarla, había que aumentar el precio del jornal del obrero, o hacer disminuir el precio de los comestibles. Como ya se ha señalado anteriormente, la cuestión salarial escapaba a los asuntos del Gobierno. Monlau mantenía los puntos del liberalismo econonómico, la cuestión salarial era competencia sólo del empresario y del obre$\mathrm{ro}^{31}$. Sí en cambio era factible que el Gobierno proporcionara abundancia de subsistencia, fomentando la agricultura, facilitando las comunicaciones y la reforma tributaria.

6) Perseguir sin descanso, y castigar severamente, las falsificaciones y adulteraciones de los artículos más usuales de comer, beber y arder.

El Código Penal debería ser más duro castigando tal tipo de delitos y la información pública sería uno de los mejores métodos de lucha contra el fraude.

7) Vigilar incesantemente las tabernas, bodegones, posadas y demás casas o puestos de donde se ha de comer, o se venden alimentos preparados o bebidas.

Así describe las fondas o cafés frecuentados por los obreros:

«Carne pasada, bacalao o escabeche podrido, salazón pasada, pan adulterado, vino emponzoñado, fruta verde o pasada, embutidos malsanos, aceite rancio o mezclado con sebo, chocolate sin cacao, agua de cualquier sustancia más o menos inofensiva por cafe, carbón mojado, desaseo, inmundicia $(. .).)^{32}$.

8) Dictar una ley sobre el trabajo de los niños de ambos sexos en las fábricas. Las disposiciones a tomar serían las siguentes: 1) no admitir al trabajo a ningún niño o niña sin una declaración del Médico inspector de que el respectivo trabajo las perjudicara a su crecimiento o desarrollo; 2) fijar la duración máxima del trabajo a seis horas diarias para los niños de diez a doce años, y a diez horas para los de doce a dieciseis; 3) prohibir absolutamente el trabajo de noche; 4) vigilancia continuada de los niños que trabajasen; 5) establecimientos separados en sus trabajos, y 6) disposiciones especiales para los que trabajasen en las minas.

9) Evitar, y en su caso remediar, los accidentes y desgracias que ocasionan a veces las máquinas.

A tal objeto los reglamentos deberían obligar a los fabricantes a tomar medidas drásticas y cuando se produjera alguna victima la asistencia médica debería estar asegurada lo mismo que su subsistencia, si quedaba inválido.

10) Evitar la competencia del trabajo de los establecimientos pena-

${ }^{31}$ Higiene Industrial, pág. 29.

${ }^{32}$ Higiene Industrial, pág. 33. 
les y de beneficiencia con el trabajo de las fábricas y talleres libres.

En los establecimientos de beneficiencia no deben elaborarse más artículos que los destinados al consumo de la misma cosa.

11) Abrir paseos y jardines de recreo, «tívolis», etc., para la clase obrera, en los cuarteles o barrios donde viven por lo común los jornaleros.

12) Establecer casas-cunas y salas de asilo para las criaturas de los obreros.

13) Establecer escuelas primarias para los niños y las niñas de los obreros. Dichas escuelas, sólo para niños obreros, no debieran ser plenamente gratuitas.

14) Establecer escuelas dominicales para obreros adultos.

Sus preocupaciones principales en los días festivos deberían ser tres: el cumplimiento de los deberes religiosos, el aseo y cuidado del cuerpo y el cultivo de la inteligencia. Con este fin asistirá el obrero a las escuelas dominicales, totalmente gratuitas, donde se le enseñará las primeras letras y los rudimentos de la Moral cristiana y social, Higiene y Economía doméstica. Sólo así adquiriría la madurez necesaria para entender la problemática de su mundo.

En este punto Monlau vuelve a reproducir los esquemas mentales de la burguesía bienpensante de la época, manteniendo unos postulados inspirados en el liberalismos individualista:

"(...) se enaltecerá a sus propios ojos, porque verá ensancharse el círculo de sus escasos conocimientos; y su inteligencia, hoy al parecer ruda e indócil, a la vuelta de poco tiempo comprenderá sin dificultad: - que las creecias religiosas, y no los sistemas filosóficos, son las que satisfacen el espíritu y consuelan el corazón; - que no hay felicidad posible fuera del camino de la virtud; - que la desigualdad de los bienes de la fortuna está tan en la naturaleza como la desigualdad de talento, de talla, de robustez o de fuerzas físicas; - que sin.jerarquías no hay orden ni sociedad posibles; que la templanza y la moderación en todo es la condición de la buena salud; - que es un absurdo ridículo querer fijar un mínimum de jornal y un máximum de trabajo; - que la fórmula esencial del progreso económico es producir cada día más, cada día más pronto y cada día más barato; - que las máquinas contribuyen a la solución de ese problema; y que en esa solución nadie está más interesado que el mismo obrero; - que las crisis industriales son fatalmente inevitables, dependientes del desequilibrio entre la producción y la demanda, están relacionadas además con las calamidades públicas, siendo tanto más frecuentes y trascedentales cuanto mayor es un país el desarrollo de su industria; - que el capital es tan libre y repetable como el trabajo, porque de trabajo, y nada 
más que de trabajo acumulado, se compone el capital; - que el trabajo del obrero no puede correr las eventualidades del capital del fabricante, y que la asociación mercantil de éste con el obrero, asociación que como equitativa y lisonjera se pinta, sólo es posible, sólo puede ser beneficiosa, en determinadas industrias, en ciertos casos y bajo ciertas condiciones siempre libérrimamente estipuladas entre el capitalista y el operario; - que las coaliciones de obreros para hacer subir el precio del jornal, son recursos ya gastados, estériles y ridículos; - que el aumento forzado del precio del jornal es insostenible, y que mientras dura tal aumento, queda de hecho anulado por un aumento paralelo en el precio de los artículos que ha de consumir el obrero; - que las agresiones brutales, los crímenes que alguna vez han manchado de sangre el recinto mismo de las fábricas o de los talleres, son puras manifestaciones de una ira salvaje e impotente...; - que hay, en fin, principios eternos de moral a cuyas consecuencias están indeclinablemente sujetos asi el fabricante como el obrero» ${ }^{33}$.

15) Mandar y componer, y distribuir gratis, una cartilla higiénica para uso de los obreros de cada arte o industria. En ella se haría referencia a nociones generales de higiene.

16) Ofrecer y adjudicar premios anuales a los autores de cualquier método o descubrimiento que contribuya a disminuir los peligros o la insalubridad de ciertas artes o industrias.

17) Establecer Cajas de Ahorros en todos los pueblos de alguna importancia fabril o que abundan en población obrera.

18) Fomentar y proteger el establecimiento de Sociedades de Socorros mutuos.

Dichas asociaciones socorrerían al obrero en caso de enfermedad o de imposibilidad para el trabajo. El número de individuos de cada sociedad no debía pasar de 100. Los socios honorarios ascenderían a 25; éstos pagarían las cuotas sin recibir asistencia alguna y quedaban encargados de administrar y distribuir los fondos de la sociedad.

19) Facilitar la asistencia médica gratuita y socorros domiciliarios, a las familias obreras.

${ }^{33}$ Higiene Industrial, págs. 49-51. 
20) Abrir una información general acerca de la situación o de las condiciones físicas y morales de las clases obreras, y formar la estadística de la industria fabril española.

Si en el caso de Francia o Inglaterra el Estado contaba con datos reales, en España no sucedia así. Cualquier medida del Gobierno debía de apoyarse en una estadística fabril: «(...) sin datos no se puede resolver ningún problema, $y$ en España no poseemos dato alguno o no se resuelve nada, o todo lo resolvemos mal (...) propongo como medida preliminar e indispensable la formación de la estadística industrial de España, con todos los datos apetecibles sobre el número y las condiciones del personal y del material» ${ }^{34}$.

\section{CONCLUSION}

Tal como se ha podido comprobar, el doctor Monlau supo captar y describió magistralmente los efectos nocivos del proceso de industrialización, pero en modo alguno se sintió partícipe del destino de la clase trabajadora, como acertadamente apunta J. Ma. López Piñero ${ }^{35}$.

Su óptica es propia de la clase social a la que él pertenece, la de la burguesía. Su pensamiento es típicamente liberal. Como ha escrito A. Jutglar su filosofía es la de los "bienpensantes» de entonces, lejos de la búsqueda de un igualitarismo social y cerca de las teorías del positivismo contiano o del funcionalismo spenceriano. Los pobres son vistos como débiles mentales sobre los que no es posible ejercer ningún tipo de labor que les ayude a mejorar, y por tanto, los acomodados no se sienten responsables de las desgracias del prójimo ${ }^{36}$.

Sin embargo, a pesar de todo, su denuncia de la situación obrera contrasta con la postura miope o reaccionaria de muchos médicos contemporáneos que intentaron disimular la realidad y descargar a la clase burguesa de responsabilidades. Al mismo tiempo no cabe duda de que su testimonio contribuyó a que fuera conocida la realidad obrera en su época.

Algunas de las medidas propuestas por Monlau eran muy acerta-

${ }^{34}$ Higiene Industrial, pág. 65.

${ }^{36}$ LOPEZ PIÑERO, J.Mà, o.c. págs. 270-271.

${ }^{36}$ JUTGLAR, A. o.c., págs. 46-47. 
das, como la descentralización de la industria, la formación de una estadística industrial en España, la creación de Asociaciones de Socorros Mutuos, la lucha contra el fraude alimentario, etc. Su aportación fundamental es como higienista, a través de sus obras se comprueba la situación higiénica española de mediados del siglo XIX. Al mismo tiempo quiso que su mensaje fuera el detonante para que la administración pusiera el remedio oportuno. Por todo ello, su obra constituye uno de los hitos más importantes en la historia de la medicina española del siglo $\mathrm{XIX}^{37}$. Sus numerosos trabajos sobre medicina legal, higiene, sanidad y psicología así lo confirman.

${ }^{37}$ MOLINER PRADA, C. o.c. págs. 209-210. 


\title{
LA I REPUBLICA Y LA MILICIA NACIONAL: ORGANIZACION DEL BATALLON DE VOLUNTARIOS DE LA REPUBLICA DE ALICANTE *
}

\author{
ROSA ANA GUTIERREZ LLORET
}

Universidad de Alicante

En la introducción a su libro, Juan S. Pérez Garzón ha escrito: «La Revolución burguesa se realizó en España. Y la Milicia nacional fue su instrumento"'. La Milicia Nacional fue una de las instituciones más importantes en el proceso de consolidación del capitalismo y de la sociedad burguesa en la España del siglo XIX. Constituyó la fuerza armada de la burguesía en cada coyuntura revolucionaria hasta 1874, fecha en que, una vez finalizado el proceso revolucionario, la burguesía conservadora prescinde de tal organización, que por su componente popular podía cuestionar el sistema constitucional y su dominación de clase. 1873 es un año clave en la historia de la Milicia nacional, pues en su transcurso y bajo una nueva forma de régimen - la República - se pr:cedió a su organización por última vez. En septiembre de ese mismo año el restablecimiento de la reformada ordenanza del 14 de julio de 1822 para la formación de la Milicia nacional introducía modificaciones substanciales en su organización y composición. Finalmente desde 1874 comienza un período de deterioro de la Milicia nacional que culminará en su definitiva disolución.

El objetivo de este trabajo ha sido realizar un análisis del Batallón de los Voluntarios de la República de la ciudad de Alicante. Su composición socioprofesional, organización, estructura interna y funcionamiento, y su participación en los sucesos cantonales, son algunos de los aspectos que hemos tratado.

La localización de una documentación en el Archivo Municipal de Alicante sobre el alistamiento y organización de los Voluntarios de la República nos ha permitido iniciar esta investigación ${ }^{2}$. La documentación se dividía en varias carpetas que trataban cada una de ellas aspectos diferenciados sobre la Milicia nacional de los años 1873 y 1874 . La

- En este artículo adelantamos algunas investigaciones que estamos realizando para nuestra tesis doctoral sobre el republicanismo alicantino en el siglo XIX, que bajo la dirección del Dr. D. Salvador Forner está en curso de elaboración.

1 PEREZ GARZON, J.S. Milicia Nacional y Revolución burguesa. El prototipo madrileño 1808-1874. Madrid, 1978, p. XXV.

${ }^{2}$ Archivo Municipal de Alicante. Voluntarios Nacionales 1873-74. Sala Histórica, Arm. 16 (En lo sucesivo utilizaremos la abreviatura A.M.A.) 
primera de ellas hace referencia a la creación del Batallón de los Voluntarios republicanos, tras la proclamación de la I República, organización y estructuración del mismo en varias compañías, y mecanismos de elección de los mandos del Batallón y de las compañías.

En la segunda encontramos una información exhaustiva sobre la composición de los Voluntarios a través de la consulta del padrón general de alistamiento de los milicianos y con los padrones parciales de alistados pertenecientes a cada una de las nueves compañias efectivas ${ }^{3}$. Los datos que nos proporcionan estas listas nominativas de voluntarios son de enorme interés para iniciar una investigación sociológica de los alistados y en cierta manera, una aproximación a la composición social y niveles profesionales del partido republicano - creemos que no es aventurado ni desvirtuamos demasiado la realidad si opinamos que la mayor parte de los voluntarios de la República militaban o participaban de la ideología del partido republicano- ${ }^{4}$. En estas listas consta el número de alistados en cada compañía, edad, profesión y la calle donde residían.

Una tercera parte del legajo la constituyen una serie de documentos referentes a los problemas surgidos en la milicia con la intentona cantonal de julio de 1873 y que tienen como consecuencia la reorganización de las fuerzas ciudadanas, consistente en la eliminación sistemática de los miembros de ésta sospechosos de simpatizar con el federalismo radical y con el movimiento cantonal. A través de ellos podemos ver como se lleva a cabo una total reestructuración de la oficialidad republicana y la disolución de algunas compañías; una de las cuales, la tercera, lo fue en su totalidad, procediéndose más tarde a la formación de una nueva, en la que se observa una composición socioprofesional radicalmente distinta. Dentro de esta documentación también encontramos las actas de elecciones de los mandos de las compañías y del Batallón que se efectuaron, ya bajo la Ordenanza de 1822 puesta en vigor por decreto del 18 de Septiembre, en los últimos días de 1873 y

${ }^{3}$ Se formó una décima compañía de individuos de más de cincuenta años, Compañía de Veteranos de la República, de la que no se conserva padrón de alistamiento, probablemente porque no se efectuó dada la edad y características de sus miembros, en su mayor parte jubilados, y su menor efectividad.

${ }^{4}$ Algunos datos corroboran esta hipótesis. Lógicamente al producirse la proclamación del régimen republicano, el partido progresista, cuyos militantes y simpatizantes habian nutrido hasta ese momento junto con los republicanos la Milicia nacional, se retrayeron al no aceptar la nueva situación. De hecho, en las listas nominativas no aparecen miembros de las familias de la oligarquía burguesa local como Campos Domenech, Vassallo, Pacheco, Bas, Pascual de Bonanza, que como progresistas tuvieron una activa participacion en los movimientos revolucionarios de la primera mitad del siglo XIX. Además, la totalidad de los mandos y oficialidad del Batallón y de las compañías militan activamente en las filas republicanas. Por otra parte las cifras de los alistados están muy próximas a las que por referencias periodísticas de la época sabemos formaban la militancia republicana. 
primeros de 1874. Por último, hemos encontrado una dispersa y variada documentación sobre los voluntarios: forma de pago, suministros de accesorios y armamentos, dimisiones, ceses y nombramientos que nos permiten acceder a una mayor compresión del funcionamiento de la Milicia en este período.

\section{ORGANIZACION DEL BATALLON DE VOLUNTARIOS DE LA REPUBLICA DE LA CIUDAD DE ALICANTE.}

Tras la proclamación el 11 de Febrero de 1873 de la República española, la organización de los Voluntarios de la Republica se convertía en una necesidad. Los republicanos habian tomado parte activa en la creación de la Milicia nacional en los períodos revolucịonarios, de la primera mitad del siglo XIX, sobre todo durante el Bienio Progresista y la revolución del 68. Durante este último movimiento revolucionario en los Voluntarios de la Libertad había habido un claro predominio del elemento republicano, que se comprueba cuando en la elección de los mandos del. Batallón obtiene, por mayoría, el cargo de Comandante el destacado republicano Eleuterio Maisonnave. Además en octubre de 1869, al iniciarse la sublevación federal, una de las primeras medidas del Gobierno militar consiste en la disolución y desarme de la milicia ${ }^{5}$, lo que reafirma nuestra hipótesis de que en este cuerpo había una amplia mayoría republicana.

El 18 de Febrero de 1873 el Alcalde de Alicante convocaba el alistamiento de los Voluntarios de la República con arreglo a las prescripciones establecidas en el Decreto Orgánico de la fuerza ciudadana de los Voluntarios de la Libertad del 17 de noviembre de 1868. Según la convocatoria el objetivo a cubrir con su formación era mantener el orden público y hacer frente a las incursiones de las partidas carlistas que en ocasiones llegaban a aproximarse demasiado a la capital, en concreto la partida mandada por Aznar. En realidad, el verdadero objeto de la organización de la milicia era contar con una fuerza republicana armada, organizada y dispuesta a acudir en defensa de la República, en un momento en el que la inestabilidad política y el rechazo a la nueva forma de régimen eran evidentes.

5 A.M.A. Sala Primera, Arm. 52, leg. Indeterminado, año 1869. 
En los primeros dias de marzo se procedió al alistamiento de las fuerzas ciudadanas que contaban, según el padrón realizado a tal efecto, con 872 hombres. El procedimiento de organización consistía en realizar un alistamiento general, del que luego se borraba a una serie de individuos que lo solicitaban por diversas razones de indole personal como edad avanzada, ocupaciones o negocios y cambios de residencia. El total de alistados se repartía entre las distintas compañias a formar con un número similar de miembros.

En un primer momento se crearon ocho compañías para cubrir las seis zonas en que se dividió la capital, que correspondian de forma muy aproximada a los distritos electorales.

División de la capital en zonas a cubrir por las Compañias de Voluntarios.

Zonas a cubrir por la Milicia

1. Centro

2. San Francisco

3. Teatro

4. Carmen

5. San Antón

6. Instituto
Cuarteles urbanos y partidas rurales que comprenden

$4 \stackrel{\circ}{\circ} 5^{\circ}$ y $6^{\circ}$

Campello

Casas

Consistoriales.

$10^{\circ}$ y $2^{\circ}$

San Blas, Babel y

Rebolledo

San Francisco

3. y $8^{\circ}$

Los Angeles

Teatro

Carmen

$7^{\circ}, 9^{\circ}, 10^{\circ}$ y 11 웅

San Antón

$14^{\circ}$

Santa María. 
El total de alistados en la compañías es de 839 individuos a los que se añaden 49 que forman la oficialidad de las compañías y del Batallón, lo que nos da una suma total de 888 individuos, que nos indica que con posterioridad al alistamiento gener al se sumaron algunos miembros más. En principio se pensó en la formación de ocho compañías que integraban alrededor de cien hombres, cifra considerada como la más idónea para el funcionamiento de la compañía. Se destinaron para ello 817 alistados, y con el resto se organizó una nueva compañía, la novena o compañía agregada, que contó con 66 milicianos; siendo por ello la menor en número.

Poco después se organizó una décima compañía formada por milicianos de más de cincuenta años de edad. De ellos mismos surgió la iniciativa y para ello el 22 de febrero redactaban una instancia al Ayuntamiento en la que solicitaban formar parte en la milicia con el nombre de Compañía de Veteranos de la República:

"Que habiéndose reunido una mayoría de individuos de edad de cincuenta años, amantes de la verdadera causa del pueblo, han acordado formar una compañía de Veteranos de la República, esclusivamente (sic.) para prestar sus servicios a las órdenes de ese Ayuntamiento y por lo tanto suplican a V.S. se sirva dar la autorización necesaria para poder llevar a efecto los trabajos preparatorios de organización de dicha compañía...».

La petición iba acompañada de catorce firmas y fue bien acogida por la municipalidad aunque la comisión de Voluntarios de la Républica consideró que en primer lugar debería procurarse el armamento a los voluntarios más jóvenes por ser éstos «los primeros y más obligados a acudir al sitio del peligro en defensa de la República».

Una vez configuradas las compañías se procedió a su distribución entre los distritos en que se había dividido a la ciudad. Esto se realizó de la siguiente manera: 


\begin{tabular}{|c|c|c|c|c|}
\hline Distritos & Población ${ }^{6}$ & $\begin{array}{l}\text { Compañias } \\
\mathrm{n}^{\circ} \text {. de orden } \\
\text { en el Batallón }\end{array}$ & $\begin{array}{l}\text { n. hombres } \\
\text { en cada Cía. }\end{array}$ & $\begin{array}{l}\text { Total de } \\
\text { Voluntarios } \\
\text { por Distrito }\end{array}$ \\
\hline San Francisco & 3.155 & $\begin{array}{l}\text { 1. Cía } \\
\text { 9. Cía. (Agreg.) }\end{array}$ & $\begin{array}{r}102 \\
66\end{array}$ & 168 \\
\hline Teatro & 3.215 & $\begin{array}{l}\text { 2. Cía. } \\
\text { 3. Cía. }\end{array}$ & $\begin{array}{l}113 \\
109\end{array}$ & 222 \\
\hline Carmen & 3.845 & $\begin{array}{l}\text { 4. Cía. } \\
\text { 5. Cía. }\end{array}$ & $\begin{array}{r}101 \\
92\end{array}$ & 193 \\
\hline Centro & $3.014^{7}$ & 6. Cía. & 98 & 98 \\
\hline San Antón & 4.606 & $\begin{array}{l}\text { 7. Cía } \\
\text { 8. Cía }\end{array}$ & $\begin{array}{r}104 \\
99\end{array}$ & 203 \\
\hline Totales & $17.835^{7}$ & & & 884 \\
\hline
\end{tabular}

Los voluntarios republicanos quedaban así distribuidos en nueve compañías, que cubrian cinco distritos de la ciudad, con las que días después se formaba el Batallón de Voluntarios de la República. Como vemos en esta distribución, el distrito que contaba con más milicianos era el del Teatro, con 222 hombres; seguido del de San Antón, 203 hombres, y el del Carmen con 193. Es precisamente en estos distritos en donde el partido republicano contaba con más fuerza. Si comparamos los datos del cuadro anterior con los resultados de las elecciones municipales celebradas en enero de 1870, podremos observar que en aquellos distritos donde el republicanismo contaba con más fuerza el número de voluntarios organizados es mayor.

${ }^{6}$ Las cifras de población no incluyen las partidas rurales, sólo hacen referencia a las relativas a los cuarteles urbanos ya que la milicia se circunscribia exclusivamente al núcleo urbano tanto a nivel de organización como de actuación. Las cifras son las que constan en el Padron municipal de habitantes de 1873 (A.M.A.).

${ }^{7}$ Si comparamos esta distribución de las compañías por distritos con el cuadro anterior de zonas urbanas a cubrir por la milicia se ve que falta el distrito de Santa María. Existen varias posibilidades: que no contase con ninguna compañia de voluntarios, lo que es altamente improbable; o bien que fuese agregado por razones de organización del Batallón a otros distritos que podian ser por su proximidad el Centro (Casas Consistoriales) o San Antón. Esta última parece la posibilidad más probable pues, partiendo del supuesto de que en la distribución de las compañias se tendría en cuenta el lugar de residencia de los voluntarios por razones obvias de mejor funcionamiento y mayor rapidez en la reunión de la compañia, hemos podido comprobar que los miembros de la 6 . Cía residian en calles que pertenecian tanto al Distrito del Casas Consistoriales como al de Sta. María lo que nos permitiría aventurar que esta compañía controlaba las dos zonas (Centro e Instituto). Pero ante la imposibilidad de afirmarlo por la falta de datos, hemos preferido indicar sólo la población de los cuarteles $4^{\circ}, 5^{\circ}$ y $6^{\circ}$. que formaban la zona de Centro o Casas Consistoriales con lo cual en el total de población quedaría eliminada la referente a los cuarteles 12. y 13. (Instituto y Santa María), cuya población era de 1.901 habitantes. 
Elecciones Municipales. Enero $1870^{8}$

Distritos (Votos obtenidos por el candidato más votado).

Republicano

Constitucional

(progresista).

San Francisco

523

407

Teatro

526

412

Carmen

440

321

Centro (Casas Consistoriales)

299

396

San Antón

530

324

Los votos obtenidos por los candidatos republicanos son sensiblemente superiores a los de sus oponentes constitucionales en los distritos de San Antón y el Teatro, que son los que contaban con un mayor número de milicianos, seguidos por San Francisco y el Carmen. También comprobamos como en el distrito del Centro (Casas Consitoriales) - donde se concentra la burguesía comercial y las clases acomodadashay un predominio del voto conservador y la candidatura republicana es derrotada por el partido progresista, y es, precisamente, este distrito el que contará en 1873 con el número menor de voluntarios organizados. Podemos deducir de ésto que la distribución numérica de la milicia republicana está en clara relación con la mayor o menor influencia del partido republicano en la zona urbana correspondiente.

\section{MANDOS, OFICIALES Y ELECCIONES DEL BATALLON}

Estructura orgánica del Batallón de Voluntarios de la República:

Compañías Capitanes Tenientes Subtenientes Voluntarios Total

\begin{tabular}{crrrrr}
\hline $1 . \mathrm{a}$ & 1 & 2 & 2 & 97 & 102 \\
$2 . \mathrm{a}$ & 1 & 2 & 2 & 108 & 113 \\
$3 . \mathrm{a}$ & 1 & 2 & 2 & 104 & 109 \\
$4 . \mathrm{a}$ & 1 & 2 & 2 & 96 & 101 \\
$5 . \mathrm{a}$ & 1 & 2 & 2 & 87 & 92 \\
$6 . \mathrm{a}$ & 1 & 2 & 2 & 93 & 98 \\
$7 . \mathrm{a}$ & 1 & 2 & 2 & 99 & 104 \\
$8 . \mathrm{a}$ & 1 & 2 & 2 & 94 & 99 \\
9. & 1 & 2 & 2 & 61 & 66 \\
\hline Totales & 9 & 18 & 18 & 839 & 884 \\
\hline
\end{tabular}

${ }^{8}$ Archivo de la Diputación Provincial de Alicante. Sección de Elecciones y censo electoral., leg. 377. 
Las compañías contaban con unos oficiales bajo cuyo mando se estructuraban militarmente; el capitan era el responsable de la actuación de la compañía, seguido de dos tenientes y dos subtenientes. En la primera compañía de San Francisco, primera en organizarse, se crearon también unos mandos intermedios que consistian en cinco sargentos (un sargento primero y cuatro sargentos segundos), un cabo furriel, cuatro cabos primeros y cuatro cabos segundos. En las restantes compañías no aparecen ya estas categorias.

La elección de los capitanes y oficiales se efectuaba por votación democrática de los voluntarios de cada compañía, para cuyo efecto se reunían en las Casas Consistoriales de la ciudad bajo la presidencia del Alcalde o un Teniente de Alcalde y los concejales que formaban la Comisión de la Milicia Nacional. Las elecciones se celebraron a principios de marzo $y$ los resultados fueron los siguientes:

\begin{tabular}{cll}
\hline Compañías & $\begin{array}{c}\text { Capitanes elegidos en Marzo de } 1873 \\
\text { Capitan }\end{array}$ & Profesión \\
\hline 1. Cía & José Cervera Flechero & Propietario \\
2. Cía & Manuel Sáez Moreno & Contratista \\
3a Cía & Vicente Alcaraz & Jornalero \\
4. Cía & José Charques & Músico \\
5. Cía & Bartolomé Pons & Carpintero \\
6. Cía & Vicente López & Sombrerero \\
7. Cía & Roman Bono Guarner & Industrial \\
8. Cía & José Marco Pérez & Carpintero \\
9. Cía & Gregorio Vallejos & Empleado \\
\hline
\end{tabular}

Como se observa en el cuadro adjunto $\mathrm{n}$.1, la actividad profesional predominante entre los oficiales de las compañias de Voluntarios de la República es la ligada al sector comercial que incluye corredores, tratantes y comerciantes. Le siguen los grupos de empleados, jornaleros, carpinteros e industriales. Los demás tienen múltiples oficios, la mayoría encuadrados en el sector artesanal: hojalatero, chocolatero, sombrerero, platero, sastre, etc.

El 17 de Marzo de 1873 se procedió a la elección de los jefes y ayudantes del Batallón. En la votación tomaron parte 347 voluntarios y los resultados fueron los que siguen:

\begin{tabular}{|c|c|c|c|}
\hline \multicolumn{2}{|c|}{ Comandante $1{ }^{\circ}$} & \multicolumn{2}{|c|}{ Comandante $2^{\circ}$} \\
\hline Candidato & Votos obtenidos & Candidato & Votos obtenidos \\
\hline \multirow{3}{*}{$\begin{array}{l}\text { Gaspar Beltrán } \\
\text { Manuel Blanquer } \\
\text { Jose Vicient }\end{array}$} & 301 & Juan Más Dols & 219 \\
\hline & 10 & Rafael Nogueras & 69 \\
\hline & 6 & Clemente Llallaves & 37 \\
\hline \multirow{2}{*}{\multicolumn{2}{|c|}{ Ayudante 1 : }} & Anacleto Rodriguez & 9 \\
\hline & & Ayudante $2^{\circ}$ & \\
\hline Candidato & Votos obtenidos & Candidato & Votos obtenidos \\
\hline Antonio del Espino & 251 & Eduardo Oarrich & 231 \\
\hline Ernesto Nogueras & 21 & Rafael Gallud & 57 \\
\hline José Martinez Pastor & 10 & Gregorio Vallejos & 13 \\
\hline
\end{tabular}




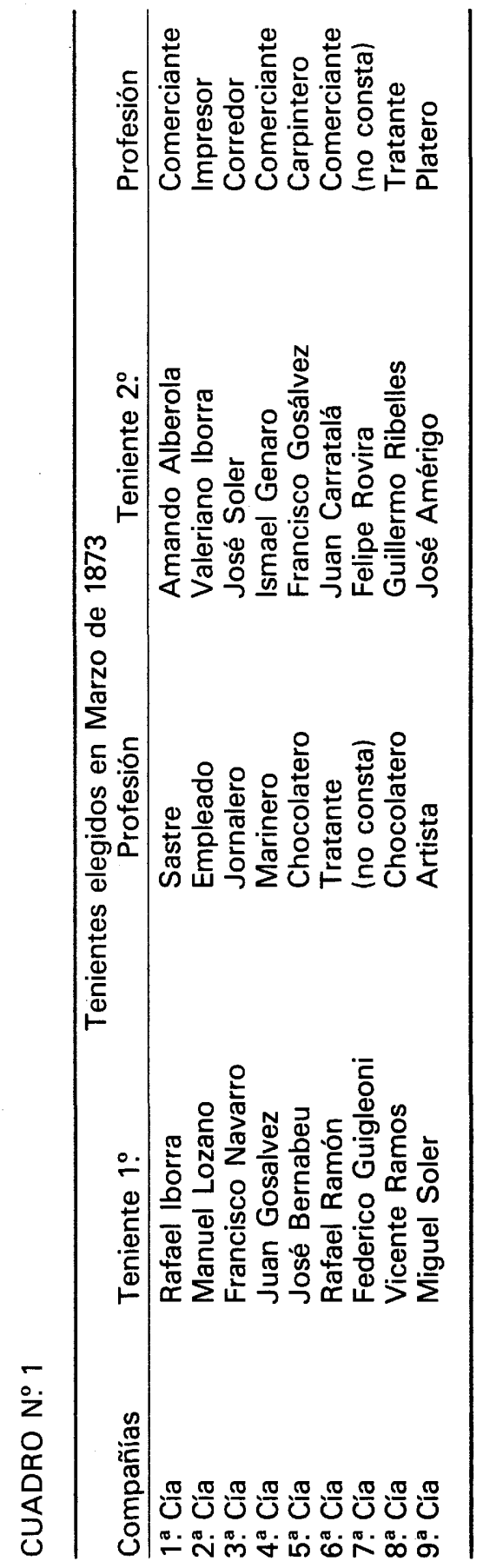

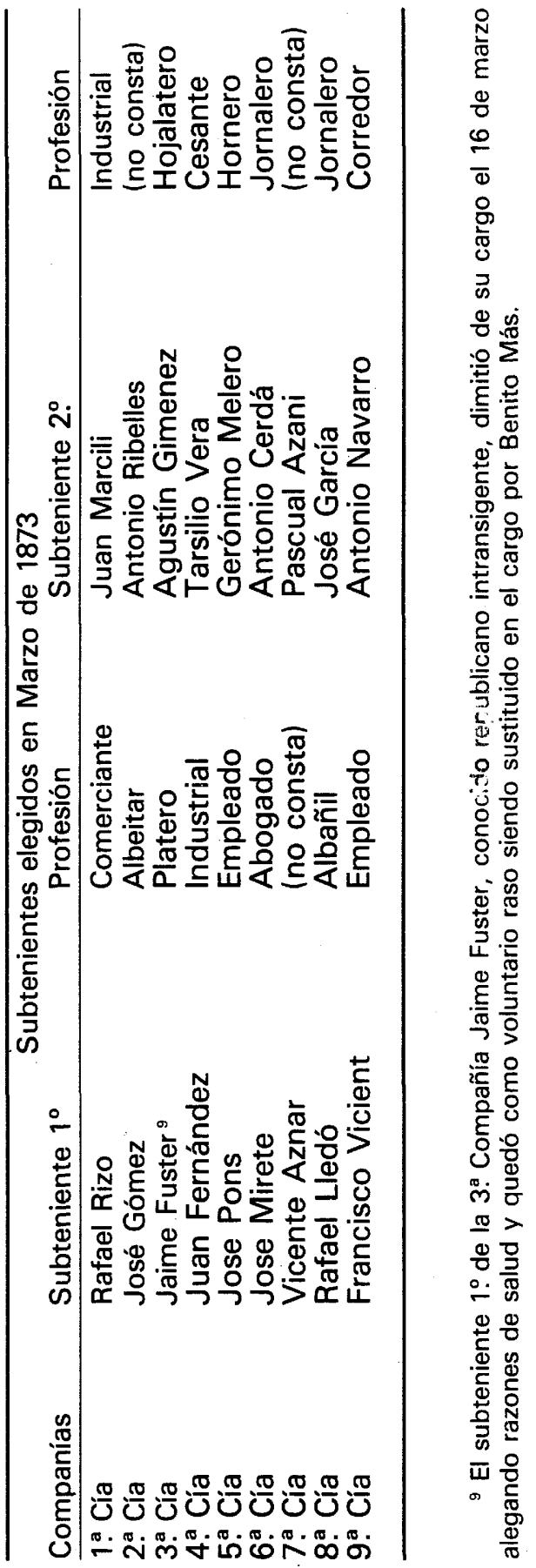


De esta manera, resultaron elegidos Gaspar Beltrán y Juan Más y Dols como Comandantes y Antonio del Espino y Eduardo Oarrichena como Ayudantes. Pero estos resultados no fueron aceptados por todos los miembros de la milicia; una minoría de voluntarios suscribieron una protesta al Alcalde, cuestionando en ella la validez de las elecciones por las presiones ejercidas por los oficiales sobre los hombres a su mando, a los que llevaron formados a votar, y por hacer entrega de las candidaturas en el mismo lugar de elección. Aunque la protesta se desestimó por falta de fundamentos legales, nos refleja la existencia de fricciones en el interior de la milicia nada más realizada su formación.

El principal objetivo de los Voluntarios de la República era contar con una fuerza armada republicana que en un momento dado pudiera hacer frente a los enemigos de la nueva forma de gobierno; pero, en realidad su función era mantener el orden público en la ciudad y repeler posibles ataques de las partidas carlistas. Los Voluntarios de la Libertad ya habían desempeñado funciones de policía urbana cuando en junio de 1869 formaban retenes y patrullas de vigilancia dentro del casco urbano. Estas funciones las siguieron desempeñando los Voluntarios de la República, a pesar de que en agosto de 1869 se había creado, por iniciativa del Ayuntamiento republicano, la guardia de policía urbana de Alicante, consistente en veintiún miembros, dependientes de la autoridad local ${ }^{10}$. Esta labor de policia del municipio consistía en desempeñar funciones de vigilancia, detención de personas que alterasen el orden público y custodia de edificios públicos como el Hospital de San Juan de Dios, las Casas Consistoriales o el Teatro Principal; este último contaba a finales de agosto de 1873 con un destacamento pertenenciente a la 6 . Compañía que, bajo el mando de Antonio Cerdá (Subteniente ${ }^{\circ}$. de dicha Cía), era conocido como la Guardia del Principal. Además, la estrecha vinculación de los Voluntarios a la municipalidad quedaba reforzada porque dependían directamente de la primera autoridad municipal, del Alcalde o Teniente de Alcalde que lo sustituyera.

El problema más grave que se le planteó al Ayuntamiento con respecto a la milicia fue el de sufragar los gastos que suponía la organización y funcionamiento de las compañías. Además, los voluntarios tenían derecho a cobrar por las labores de vigilancia y policía que desempeñaban pero la angustiosa situación financiera de la municipalidad, que contaba con un déficit crónico agravado tras la abolición del impuesto de consumos", dificultaba el pago de los voluntarios. Ante las quejas

${ }^{10}$ A.M.A. Sala Dirección. Leg. Indeterminado. Año 1869.

"A lo que se unió el fracaso del impuesto personal o de capitación y la inexistencia de fuentes de ingresos alternativos. Todo ello llevó a un sector de concejales republicanos a proponer en mayo de 1872 la reimplantación del impuesto de consumos, lo que produjo una fuerte oposición en amplios sectores del partido republicano y de la sociedad alicantina en general. Sobre este tema Vid. GUTIERREZ LLORET, R.A. Republicanos y liberales. La Revolución de 1868 y la / República en Alicante. Alicante. 1985 págs. 97-98. 
de éstos, el Ayuntamiento, no pudiendo afrontar este gasto, tuvo que recurrir a una suscripción particular. Finalmente, en el mes de agosto, E. Maisonnave solucionó el problema haciendo frente a los pagos por medio de una partida de 5.000 Ptas. que proveniente del Ministerio de Gobernación fue entregada por el Gobierno Civil para ser destinada al pago de haberes de los Voluntarios de la República.

\section{ANALISIS SOCIOLOGICO DE LOS VOLUNTARIOS DE LA REPUBLICA.}

\section{1. - Estructura socioprofesional.}

En los datos que a continuación exponemos sobre la actividad profesional de los voluntarios republicanos, se han excluído los referentes a mandos y oficiales, cuya ocupación profesional ya hemos comentado anteriormente. Del total de 839 milicianos, hemos desechado a 58 que no especificaban profesión, lo que nos da un total de de 781 voluntarios, cifra de casos con la que hemos elaborado la cuantificación profesional. En el manejo de esta documentación hemos encontrado algunas dificultades derivadas de la gran variedad de denominaciones que se utilizan, característica, por otra parte, muy usual en los padrones y listas municipales de la época.

Otro problema inherente a esta investigación ha sido el derivado de la necesaria delimitación conceptual de los términos profesionales empleados en las listas de voluntarios. El más común es el referente al termino jornalero, que se define en relación al sistema de retribución del trabajo - a jornal - pero sin indicativo de su carácter rural o urbano ${ }^{12}$, aunque expresa claramente su condición de asalariado. Otros términos pueden crear también confusionismo, como el de propietario, que indica que su fuente de ingresos proviene de las rentas de la tierra de su propiedad pero no especifica el carácter de terrateniente o mediano propietario y cultivador directo, aunque para este último concepto parece emplearse más bien el término de labrador. Por último dentro del conglomerado de profesiones artesanales podemos encontrar dificultades en la clasificación por la multitud de términos utilizados y su inserción en sectores de ocupación profesional de carácter más amplio. Las denominaciones utilizadas y los problemas de clasificacion que surgen en torno a ellas no son más que la expresión de una realidad socioeconómica en transformación, producida por el proceso de cambio

${ }^{12}$ Hemos incluido al numeroso grupo de jornaleros en el sector primario aunque somos conscientes de que combinaban las faenas agrícolas, de temporada, en la Huerta de Alicante o en comarcas colindantes, con trabajos ocasionales de carácter urbano como mozos de carga en los muelles, peones de obras, labores de limpieza y barrida de calles y otros similares. 
en las relaciones sociales y de producción; en resumen, del tránsito a una sociedad capitalista en la España decimonónica.

La complejidad de los datos evaludados es todavía mayor si intentamos una estructuración estrictamente sociológica. La propia dinámica social en la época que estudiamos, de transición y de cambio en las estructuras sociales, confiere a este intento mayor dificultad. Esta se da de forma más acusada en la categorización sociológica de las actividades artesanales pues en otras como propietarios o jornaleros, a pesar de los problemas que hemos señalado, no existe ninguno en lo referente a su clasificación social. Pero dentro de la pequeña producción artesanal se hace muy difícil la división entre propietarios del pequeño taller y los asalariados que trabajan para él. En ocasiones la adición a la profesión de los términos de aprendiz, oficial u operario nos indica el carácter de trabajador asalariado pero ésto sucede en un número muy reducido de los casos.

Por estas razones pensamos que en este trabajo sería más útil una clasificación de tipo económico, por sectores de producción, que social como una primera aproximación a los grupos sociales que integraron la milicia republicana.

Según se comprueba en el cuadro adjunto n. 2, en términos absolutos, el grueso de las profesiones del Batallón se integran en el sector secundario, en el que incluímos la industria y las actividades artesanales. Es necesario señalar que en este sector se incluyen casi exclusivamente profesiones artesanales; la única entidad fabril de cierta envergadura era la Fábrica de Tabacos, cuya población laboral no es interesante desde el punto de vista de este trabajo por estar constituída en su totalidad por mujeres. Más de la mitad de los milicianos del Batallón desarrollan actividades profesionales vinculadas al sector secundario $(53,64 \%)$. El resto se distribuye entre los otros dos sectores con un cierto equilibrio, que se inclina más favorablemente hacia el sector primario, con un $25,86 \%$, por el nutrido grupo de jornaleros que integran la milicia - el más numeroso con un porcentaje del $75,2 \%$ con respecto al sector y un 19,4\% respecto al total de miembros del Batallón - que al sector terciario (comercio y servicios) que representa un $20,47 \%$.

Dentro del sector secundario se agrupan diversas ramas de actividad, con gran variedad de denominaciones profesionales. Por este motivo hemos dividido al sector en varios subsectores, siendo el más destacado el de la construcción que incluye a 147 voluntarios $-35 \%$ del total del sector y un $18,8 \%$ del total del Batallón-, seguido por los subsectores de la madera (carpinteros, ebanistas, toneleros, etc.), y el de curtidos y afines (fibra vegetal) que representan dentro del sector un $18,8 \%$ y un $16,2 \%$ respectivamente. Dentro de estos tres subsectores destacan los grupos de albañiles - 127 miembros $186,3 \%$ del subsec- 


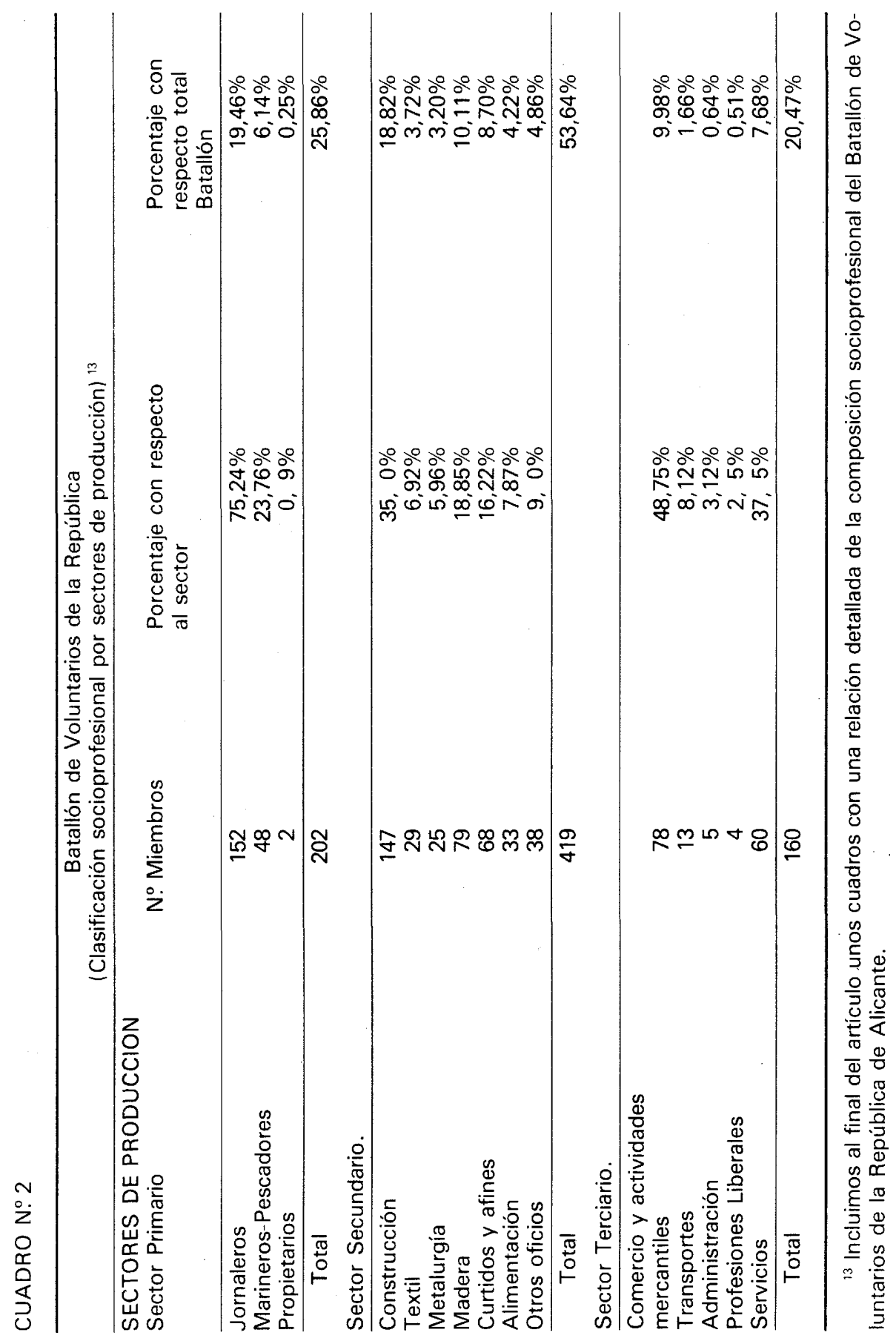


tor), los carpinteros -53 ( $67 \%$ del subsector) - y los zapateros -65 $(95,5 \%)-$. A un segundo plano quedarían relegados los subsectores del textil, alimentación y metalurgía con porcentajes más inferiores.

En el sector primario el predominio lo tienen los jornaleros, seguidos de los marineros y el ínfimo número de propietarios -2 en todo el batallón- que nos refleja el eminente carácter pequeño burgués y proletario de los Voluntarios de la República.

En último lugar, el sector terciario está también dividido en subsectores. El más importante es el relativo al comercio y actividades mercantiles $-48,7 \%$ - en el que destacan los empleados $-44,8 \%$ del subsector - y el de los comerciantes con un $17,9 \%$. Le sigue en número el subsector de servicios en el que hemos incluido gran cantidad de profesiones como barbero, tahonero, cortante, etc. Dentro de él predominan los grupos de cortantes y de barberos. Los grupos más reducidos dentro del sector terciario serían el de las profesiones liberales con un $2,5 \%$ y el de la administración en que sólo se han contabilizado cinco guardias municipales.

En este apartado de la ocupación profesional de los alistados, la documentación resulta bastante completa porque no sólo nos facilita una visión global del Batallón de Voluntarios sino que recoge también listas individuales de las profesiones de los miembros de cada compañía, que nos permite una investigación muy interesante sobre la composición socioprofesional de las compañías en relación con los barrios de donde procedían los alistados. Estos datos son de gran valor para comprender el comportamiento de algunas de las compañías durante la intentona de insurrección cantonal de septiembre de 1873.

Las listas encontradas ofrecen la siguiente composición socioprofesional:

Compañias de Voluntarios de la República

Composición socio-profesional ${ }^{14}$

Sectores de Producción

\begin{tabular}{clrrr}
\hline Compañias & Distritos & Sector 1\% & Sector . $^{\circ}$ & Sector 3. \\
\hline 1. Cía & San Francisco & $26,8 \%$ & $56,7 \%$ & $15,4 \%$ \\
2. Cía & Teatro & $27,8 \%$ & $53,6 \%$ & $18,5 \%$ \\
3. Cía & Teatro & $9,1 \%$ & $71,4 \%$ & $19,3 \%$ \\
4. Cía & Carmen & $7,7 \%$ & $64,9 \%$ & $27,2 \%$ \\
5. Cía & Carmen & $27 \%$ & $62,3 \%$ & $10,5 \%$ \\
6. Cía & Centro & $48,7 \%$ & $31,4 \%$ & $20,2 \%$ \\
7. Cía & S. Antón & $16,1 \%$ & $69,8 \%$ & $13,9 \%$ \\
8. Cía & S. Antón & $54,9 \%$ & $40,6 \%$ & $4,3 \%$ \\
9. Cía & San Francisco & $5,4 \%$ & $16,3 \%$ & $78,1 \%$ \\
\hline
\end{tabular}

${ }^{14}$ Véase en el apéndice relación detallada de la composición profesional de cada compañía. 
De los datos que nos ofrece el cuadro anterior se deduce que en la mayoría de las compañías predomina el sector artesanal a excepción de la octava compañía - distrito de San Antón-y la del Centro. En el primer caso es debido al gran número de milicianos jornaleros $(50$ alistados), en el segundo destaca una gran cantidad de marineros, al incluir el distrito de Centro el Arrabal Roig, tradicional barrio de los pescadores y marineros.

La tercera compañía - distrito del Teatro - es la que recoge mayor número de alistados dedicados al sector secundario con un porcentaje del $71,4 \%$ seguida por las compañías séptima - San Antón-, cuarta y quinta - Carmen - con unos porcentajes superiores al $60 \%{ }^{15}$.

Los grupos más numerosos de la milicia - jornaleros y albañilesse concentran en los distritos de San Antón, Carmen y el Teatro, lo que reafirma la idea de la ubicación de las clases asalariadas en esta zona de la ciudad. En el cuadro siguiente podemos ver claramente su distribución:

\begin{tabular}{|c|c|c|c|}
\hline \multicolumn{4}{|c|}{$\begin{array}{l}\text { Batallón de Voluntarios de la República } \\
\text { Grupos de iornaleros y albañiles }\end{array}$} \\
\hline Distritos & Compañías & Jornaleros & Albañiles \\
\hline Teatro & $\begin{array}{l}2^{\mathrm{a}} \\
3^{\mathrm{a}}\end{array}$ & $\begin{array}{r}27 \\
8\end{array}$ & $\begin{array}{l}29 \\
13\end{array}$ \\
\hline Total & & 35 & 42 \\
\hline Carmen & $\begin{array}{l}4 . a \\
5 .\end{array}$ & $\begin{array}{r}5 \\
22\end{array}$ & $\begin{array}{l}12 \\
21\end{array}$ \\
\hline Total & & 27 & 33 \\
\hline San Antón & $\begin{array}{l}7 \stackrel{a}{a} \\
8 \stackrel{a}{a}\end{array}$ & $\begin{array}{l}13 \\
50\end{array}$ & $\begin{array}{l}32 \\
14\end{array}$ \\
\hline Total & & 63 & 46 \\
\hline $\begin{array}{l}\text { Totales: } \\
\text { Totales } \\
\text { Ratallón. }\end{array}$ & & 125 & 121 \\
\hline
\end{tabular}

En las compañías de estos tres distritos se integra la mayor parte de los efectivos y en especial es en las compañías del barrio de San-

${ }^{15}$ En nuestra tesis doctoral, dedicamos un capítulo al análisis de la estructura socioprofesional de Alicante a lo largo del s. XIX. La consulta de los padrones municipales y de otras fuentes de documentación nos permite realizar una distribución geográfica de las actividades productivas que nos indican los barrios de San Antón y del Carmen, así como las estribaciones del Teatro como los lugares tradicionales de asentamiento de la mayor parte de los pequeños talleres artesanales y de las clases asalariadas. 
Antón donde aparecen los porcentajes mayores de jornaleros y albañiles alistados en la milicia. El sector terciario tiene una representación similar en la mayor parte de las compañías. Los mayores porcentajes de alistados integrados profesionalmente en este sector los recoge la cuarta - Carmen - con un $27,2 \%$ y la sexta - Centro - con un $20,2 \%$, que es la que cuenta con un mayor número de miembros que ejercen actividades relacionadas con el mundo del comercio, que se asentaba geográficamente en la zona centro de la ciudad - distrito Casas Consitoriales-.

De los datos comentados hasta ahora hemos eliminado a la novena compañía que por sus características, última que se formó cuando ya estaban organizadas las otras compañías, presenta una composición socioprofesional muy diferente de las restantes. Por este motivo hemos preferido tratarla por separado. En primer lugar es la que cuenta con menos efectivos, sólo 61 individuos, lo que nos hace pensar que se organizó con el resto de hombres del alistamiento general, una vez efectuado el reparto entre las ocho compañías con un número aproximado de cien miembros cada una ${ }^{16}$. En ella y en relación con el distrito urbano que le corresponde - San Francisco - hay un predominio absoluto del sector terciario con el $78,1 \%$, apareciendo alistados en ellas gran número de empleados $-19-$ y comerciantes $-6-{ }^{17}$. También destaca el hecho de que sólo aparezca un miembro de profesión jornalero y ningún albañil, por lo demás es la única compañía en donde aparecen dos propietarios ${ }^{18}$.

\section{2. - Distribución por edad.}

Al quedar reflejada en los padrones de alistamiento la edad de los milicianos, hemos podido establecer una distribución por edad de los Voluntarios de la República. A continuación elaboramos un cuadro en donde queda reflejada la división de los voluntarios - tanto oficiales como milicianos rasos - en grupos de edad.

${ }^{16}$ El Decreto de Organización de los Voluntarios de la libertad de 17 de noviembre de 1868, al que estaba sujeta la organización de la milicia republicana, señalaba la formación de un Batallón con ocho compañías y un total de 800 hombres. Como los voluntarios de la República en Alicante rebasaban escasamente esta cifra, se debió pensar que era innecesario crear un nuevo Batallaón por eso se agregó la novena al ya existente. Pero por referencias documentales sabemos que en fecha posterior, tras la reorganización que contemplaba el decreto del 18 de septiembre de 1873, se llegó a la formación de un segundo Batallón compuesto por dos compañías.

${ }^{17}$ Entre los comerciantes aparecen Anselmo Cutayar, procedente de una acomodada familia dedicada a actividades mercantiles y Luis Penalva, conocido comerciante y representante de una casa francesa de exportación de vinos.

${ }^{18}$ Los propietarios son Manuel Dols y Rafael Dols emparentados con el conocido comerciante Juan Más y Dols. 
BATALLON DE VOLUNTARIOS DE LA REPUBLICA

Distribución en Grupos de edad ${ }^{19}$.

\begin{tabular}{lccrc}
\hline & Oficiales & Alistados & Total & Porcentajes \\
\hline De 15 a 20 años & & 76 & 76 & $9,10 \%$ \\
De 21 a 30 años & 13 & 436 & 449 & $53,77 \%$ \\
De 31 a 40 años & 18 & 184 & 202 & $24,19 \%$ \\
De 41 a 50 años & 6 & 79 & 85 & $10,17 \%$ \\
De 51 a 60 años & 1 & 15 & 16 & $1,91 \%$ \\
De 61 a 70 años & & 7 & 7 & $0,83 \%$ \\
\hline Total & 38 & 797 & 835 & \\
\hline
\end{tabular}

Como conclusión de estos datos, podemos señalar que el mayor número de alistados se encontraba entre los veinte y los treinta años $-53,7 \%$ - , es decir más de la mitad de los miembros del Batallón, seguido por el grupo de edad más cercano, de treinta a cuarenta años con el $24,1 \%$. En conjunto hay un predominio de los voluntarios jóvenes, incluso dentro de la propia oficialidad del Batallón. Los voluntarios de más edad preferían alistarse en la décima compañía, Veteranos de la República.

Otro dato que constatamos es la participación de los voluntarios menores de veinte años $-9,1 \%$ del total de alistados eran menores de esa edad - a pesar de que el Decreto orgánico de la fuerza ciudadana de los Voluntarios de la Libertad de 17 de noviembre de 1869, bajo el cual se organizaron los Voluntarios de la República, señalaba en su artículo 6 . la edad mínima de veinte años como requisito para ser admitido en el alistamiento. Esto responde al interés que demostró siempre el partido republicano por la participación de la juventud en la vida política y en la causa republicana ${ }^{20}$.

La novena compañía también presenta unas características diferenciadas con respecto a las otras, al igual que sucedía con su composición socioprofesional, pues está integrada por los milicianos más jóvenes. La totalidad de sus 60 miembros estan comprendidos en el grupo de edad de 15 a 30 años. También la edad de los oficiales oscilaba entre los 21 y 30 años.

${ }^{19}$ Véase cuadros de la distribución por edad de los alistados y oficiales del Batallón en el apéndice donde se dividen por compañias.

${ }^{20}$ En enero de 1869, recien constituido el partido republicano, se organizó en Alicante un club de juventud republicana presidido por Juan Ramos. Véase el diario $\mathrm{La}$ Revolución, 31 de Enero de 1869. 

DE LOS VOLUNTARIOS DE LA REPUBLICA.

La tendencia federal no gozaba de gran influencia en el partido republicano de Alicante. Los grupos federales habían sufrido tras la sublevación de 1869 una gran represión por parte del gobierno y, además, se habían visto marginados dentro de la organización del propio partido. Eleuterio Maisonnave, representante del sector más conservador del republicanismo alicantino, inició desde ese momento una campaña en pro de los postulados moderados ${ }^{21}$ y su enorme prestigio en el partido le permitió conseguir una posición hegemónica y hacerse con el control de los órganos de dirección, marginando a los partidarios del federalismo. Pero en la milicia este sector del republicanismo local contaba con una cierta fuerza, la ideología federal había arraigado con firmeza entre las masas populares, pequeña burguesía radical, artesanos y obreros que como hemos visto en páginas precedentes eran la base sociológica de las Compañías de Voluntarios de la República.

Maisonnave y los sectores burgueses del partido eran conscientes del peligro que suponía armar a estos grupos radicalizados, pero en el momento en que se formó el nuevo gobierno, la consolidación de la República pasaba necesariamente por la formación de compañias republicanas armadas. No obstante se tomaron medidas para reforzar el control del sector moderado sobre la milicia; el que en las elecciones de mandos y oficiales de las compañías estos republicanos obtuvieron mayoría lo pone de manifiesto.

A comienzos del verano la situación ha variado radicalmente. El estallido de la sublevación internacionalista en Alcoy y la insurrección cantonal hacían temer a los «republicanos de orden» que la milicia se convirtiese en un foco de agitación política. La escasa importancia numérica del núcleo federal alicantino contuvo el estallido de un movimiento cantonal propio pero la llegada a fines de julio de la fragata cantonal "Victoria», al mando de Antonio Gálvez, precipitó la proclamación del cantón de Alicante, que, a pesar de ser debida a las presiones de los cantonales de Cartagena, no fue rechazada por la milicia. Es más, el hecho de que, nada más conocerse la aproximación al puerto de la fragata, se produjera la salida de la ciudad del Gobernador Civil y del Brigadier Militar junto con las fuerzas del ejército existentes ${ }^{22}$ parece in-

${ }^{21}$ Su postura se pone claramente de manifiesto con la creación de períodicos portavoces del más acentuado moderantismo como El Correo de España (1869) y La República Española (1870), y en su posición a favor de la Declaración de la Prensa.

22 Por ello el Gobernador Civil fue expedientado y cesado, y el Brigadier sometido a Consejo de Guerra, según acuerdos del Gobierno del 20 y 21 de Jülio. Archivo de la Presidencia del Gobierno. Actas del Consejo de Ministros. 
dicar que más bien se temía una masiva adhesión de los voluntarios a la causa cantonal.

La retirada de Gálvez, una vez ha comunicado al Ministro de la Gobernación la formación del nuevo cantón ${ }^{23}$, creó en la milicia una situación de divisón y el enfrentamiento de ésta con las autoridades locales. La retirada del alcalde republicano Manuel Santandreu decidió a los capitanes de las compañías de voluntarios a formar una Junta de Salud Pública que se hizo cargo inmediatamente del poder local con el objeto de restablecer el orden público ${ }^{24}$.

Maisonnave no estaba muy confiado con la milicia alicantina. Aunque la integración en la Junta de republicanos moderados era una garantía y él había defendido calurosamente en las Cortes la fidelidad de los voluntarios al poder legalmente constituido de la República ${ }^{25}$, en realidad era consciente de la división que existía en el seno de la milicia alicantina. Por ello se decidió a enviar a un delegado especial y a incrementar las fuerzas militares, carabineros y guardia civil, alli destacadas.

El delegado del Gobierno, Lorenzo Abizanda, traía ordenes expresas de Maisonnave de proceder a la reorganización de los Voluntarios de la República. Esta consistía en la eliminación de los voluntarios sospechosos de profesar la ideología federal y ver con simpatía el movimiento cantonal. Bajo este presupuesto, el 2 de agosto de 1873 veía luz pública un bando que consideramos necesario reproducir integramente:

Bando del Delegado del Gobierno.

Lorenzo Abizanda y Abizanda. Delegado especial del poder Ejecutivo en esta Provincia y encargado del Gobierno Civil de la misma.

\section{HAGO SABER:}

La actitud de desobediencia á la Autoridad local y á sus Jefes inmediatos en que se hallan colocados algunos voluntarios de la República, sostiene y alimenta la alarma que tanto perjuicio ocasiona á esta provincia y principalmente á su capital. Resuelto á que la fuerza ciudadana sea prenda de orden y elemento de libertad y en manera alguna causa de perturbación y semillero de discordias, estoy decidido á despojarla de todo lo que á ella es hetereogéneo.

En su consecuencia, y vista la conducta que en estos dias vienen observando algunos voluntarios no acudiendo al llamamiento repetido de sus Jefes y Oficiales para prestar el servicio que el Sr. Alcalde tenía dispuesto de acuerdo con las Autoridades superiores de la provincia, y llevando

23 PUIG CAMPILLO, A. El cantón Murciano, Cartagena, 1932, p. 178.

${ }^{24}$ Episodios internacionales y cantonales en 1873 por un testigo ocular. Alicante, 1878 , p. 33

${ }_{25}$ Diario de Sesiones de las Cortes Constituyentes de la República Española. (D.S.C.), 21 de julio de 1873. 
su osadía hasta hacer alarde de su desobediencia y de su identidad de miras con los insurrectos de las provincias limitrofes:

DISPONGO:

1. El Batallón de Voluntarios de la República de esta capital, se reorganizará inmediatamente, y con arreglo á las prescripciones del Decreto Orgánico de 17 de Noviembre de 1868, bajo la base de los jefes, oficiales, clases e individuos que han prestado servicio en los días 30 y 31 de Julio y 1 . del actual.

2. Quedan disueltas las Compañías 3. y 5. que en absoluto la una, y en la mayoría de sus oficiales e individuos la otra, han dejado de prestar servicio, a pesar del reiterado llamamiento que se les ha hecho.

3. Quedan expulsados de las filas todos aquellos voluntarios sin distinción de compañías, que sin causa justificada han dejado de presentarse á prestar servicio en los referidos días.

4. Todos los individuos, clases y oficiales de las compañias $3^{a}$ y $5^{a}$, así como los comprendidos en la disposición anterior, entregarán dentro del término de 3 horas, las armas y municiones que tengan en su poder, y el correaje que no sea de su exclusiva propiedad.

5. Todos los individuos que sin ser voluntarios posean armas de fuego sin las correspondiente licencia para usarla, las entregarán en el mismo improrrogable plazo. Estas armas serán devueltas á los interesados, tan luego como se provean de aquel documento.

6. Serán penados con arreglo al Código todos los que dentro del plazo prefijado hayan dejado de obedecer las prescripciones de este Bando. 7. La entrega de las armas, municiones y demás efectos, se verificará por lo que respecta á los que han pertenecido a la fuerza ciudadana, en los domicilios de los capitanes, y éstos por su parte lo harán en la Casa Consistorial, y en cuanto á las demás, en el propio edificio municipal, en el Cuartel de la Guardia Civil y Gobierno de la provincia. Como quiera que cuando se repartió el actual armamento dejó de recogerse el anterior, queda á cargo de los expresados Capitanes recojerlo ahora, asi como la dotación de municiones correspondientes al mismo que debe obrar en el poder de los individuos.

8. Las personas que deseen alistarse en las filas de los Voluntarios de la República, podrán hacerlo desde luego, acreditando reunir las condiciones exigidas por el artículo $6^{\circ}$. del Decreto ya citado.

9. El Alcalde de la Capital queda encargado de la ejecución de este Bando en cuanto se refiere a la recolección de armas y municiones de los voluntarios expulsados y de la reorganización de la fuerza ciudadana. Del patriotismo de este leal y sensato vecindario me prometo que todos los republicanos de buena fe prestarán su concurso al dignísimo señor Alcalde popular para llevar a cabo con acierto la reorganización de la fuerza ciudadana de la Capital que ahora como nunca debe ser la garantía de la República y el baluarte en que se estrellen las maquinaciones y atentados de los enemigos del reposo público, que lo son también de la prosperidad de esta población.

Alicante, 2 de Agosto de $1873^{26}$.

${ }^{26}$ A.M.A. Voluntarios Nacionales 1873-74. Sala Histórica Arm. 16 Se conserva también copia del bando en el mismo Archivo, Bandos, Sala Arm. 21. 
La reorganización suponía la expulsión de todos los alistados que no se presentaron a los requerimientos del delegado, al tomar posesión éste del cargo de gobernador civil. Se conminaba a los expulsados a la entrega inmediata de armas, municiones y correajes, y se procedia a un nuevo alistamiento para completar la reestructuración de las compañías. Esta afectó en su totalidad a la 3. compañía - Distrito del Teatro-, que fue completamente disuelta y organizada de nuevo, y parcialmente a la 5 . compañía - Distrito del Carmen - de la que fueron cesados el capitán ${ }^{27}$ y todos los oficiales. En el resto de las compañías se produjeron también algunas expulsiones.

Con la puesta en vigor del bando por edicto del Alcalde Anacleto Rodríguez el 4 de agosto se consolidaba la separación de todos los federales de las compañías de voluntarios y se procedía al nombramiento de nuevos mandos y oficiales, adictos al sector más moderado del republicanismo local. Así quedaba configurada la oficialidad del Batallón a fines de agosto:

\section{Batallón}

Comandante 1:: Gaspar Beltrán.

Comandante 2:: Rafael Nogueras.

Ayudante 1:: José Amérigo.

Abanderado: Manuel Genaro

\begin{tabular}{clcl} 
Compañía & Capitanes & Compañia & Capitanes \\
\hline 1. Cía & Rafael lborra & 6. Cía & Rafael Ramón \\
2. Cía & José Gómez & 7. Cía & Federico Guigleoni \\
3. Cía & Amando Alberola & 8. Cía & Jose Marco \\
4. Cía & José Charqués & 9. Cía & J. Amérigo Jornet \\
5. Cía & Vicente Aznar & &
\end{tabular}

Los oficiales del Batallón fueron cambiados en su mayoría, sólo permanecieron en la nueva organización Gaspar Beltrán, como Comandante del Batallón; José Charqués, capitan de la 4. compañía; Federico Guigleoni, capitán de la 7 a compañía ${ }^{28}$ y José Marco, al mando de la 8 .

${ }^{27}$ Bartolomé Pons, capitán de la 5a compañía, era conocido como un federalista intransigente que habia criticado con dureza las posiciones «benevolentes» en el partido y como promotor de la primera sociedad cooperativa obrera de Alicante en 1870.

${ }^{28}$ Federico Guigleoni habia sustituido en el mando de la 7. compañia al anterior capitán, Román Bono, el 20 de mayo, al dimitir éste en razón de sus múltiples ocupaciones. 
compañía. Los tenientes y subtenientes fueron también sustituidos en su mayor parte. Lo más significativo fue la total disolución de la $3{ }^{a}$ compañia y la formación de otra nueva a las órdenes de Amando Alberola, uno de los hombres de confianza de Eleuterio Maisonnave en el partido republicano de Alicante.

Interesa ahora comparar la estructura socioprofesional de la compañía disuelta y la organizada en su sustitución:

Tercera Cía

Tercera Cía

(Formada en Marzo 1873) (Formada en Agosto 1873)

Sector Primario

\begin{tabular}{rrrrr}
\hline Jornaleros & 8 & & \multicolumn{3}{r}{13} & \\
Marineros & 1 & & 1 & \\
\hline Total: & 9 & $(9,1 \%)$ & 14 & $(16,2 \%)$
\end{tabular}

Sector Secundario

\begin{tabular}{lrrrrr}
\hline Construcción & 14 & \multicolumn{3}{c}{8} & \\
Textil & 4 & - & \\
Metalurgia & 6 & 1 & \\
Madera & 17 & 5 & \\
Alimentación & 4 & 3 & \\
Curtidos y afines & 16 & & 3 & \\
Otros oficios & 9 & & 34 & $(39,5 \%)$ \\
\hline \multicolumn{1}{r}{ Total: } & 70 & $(71,4 \%)$ & & 34
\end{tabular}

Sector Terciario

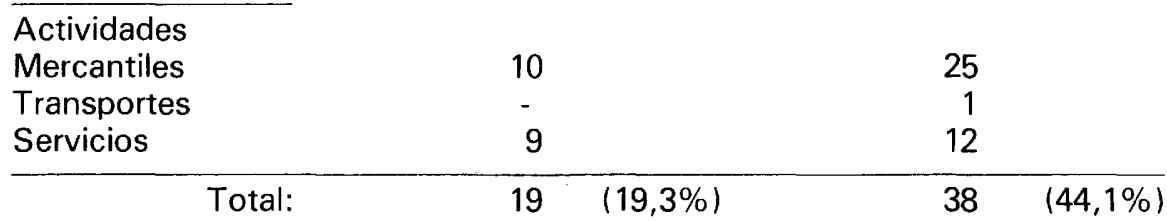

Lo más notorio es la importante reducción de alistados cuya profesión está comprendida en las actividades artesanales, que pasa de contar con un porcentaje del $71,4 \%$ en la primera compañía a un $39,5 \%$ en la segunda. Este descenso se efectúa en beneficio del sector servicios que sufre un significativo aumento, especialmente dentro de subsector del comercio. Los grupos artesanales eran más propicios a la ideología federal e incluso protosocialista, de hecho eran ellos los que habian sostenido la bandera del federalismo más exaltado dentro del partido, que otros sectores como los comerciantes que, en un satus social 
diferente, representaban una mayor garantía de orden y moderantismo.

También se constatan diferencias entre las dos compañías en lo referente a la distribución por edad. En los dos casos el grupo más representativo sigue siendo el comprendido entre los 21 y 40 años, pero en la nueva compañía el grupo de edad comprendido entre los 51 y 60 años sufre un notable incremento, del $6,8 \%$ que comprendía en el primer caso a un $19 \%$ en el segundo. Predominio de las ocupaciones relacionadas con el comercio - comerciantes, corredores, empleados-, descenso de los elementos pequeño burgueses y artesanales - albañiles, zapateros, carpinteros - y edad media más madura son las carcterísticas esenciales de la nueva compañía del Distrito del Teatro formada tras los sucesos cantonales:

La reorganización de los Voluntarios de la República se encuadra en un proceso más amplio, el de la eliminación del peligro que para la burguesía ya conservadora podía suponer el mantenimiento de la milicia armada. El instrumento que la burguesía había creado en su lucha revolucionaria contra el Antiguo Régimen podía volverse contra ella mis$\mathrm{ma}^{29}$. Con el gobierno de Castelar, su hombre de confianza, el alicantino Eleuterio Maisonnave, se encargaría desde el Ministerio de la Gobernación de dar los primeros pasos del proceso. En esos momentos la abolición definitiva de los cuerpos de voluntarios republicanos era impensable dada la situación de guerra que se vivía en la península y la oposición decidida de amplios sectores de la burguesía y del ejército a la República. Por otra parte la hegemonía ideológica del federalismo en la milicia era evidente. Era, por tanto, necesario desde la óptica conservadora de Castelar y Maisonnave proceder a una reorganización eficaz de estos cuerpos que eliminase de ellos a los elementos radicales. Así, el día 20 de agosto el Ministro solicitaba a la cámara de Diputados el tratamiento por vía de urgencia de un proyecto de Ley restableciendo la ordenanza del 14 de julio de 1822 sobre el régimen de la Milicia Nacional por considerar «la situación en que el país se halla, la completa desorganización en que se encuentran los Voluntarios de la República y la necesidad imprescindible de que el Gobierno se apoye preferentemente en ellos».

Días más tarde se presentaba dicho proyecto en las Cortes. En el preámbulo se insistía con vehemencia en la necesidad de dicha reorganización, señalando la obligatoriedad de dicha milicia: «haciéndose efectivo el deber que todo ciudadano tiene de contribuir al manteniemiento del orden y la defensa de los derechos de la Nación ${ }^{30}$ y otorgándose

${ }^{29}$ Nos parecen muy clarificadoras las tesis que al respecto mantien Juan S. PEREZ GARZON, op. cit. pág. 517 y ss.

${ }^{30}$ D.S.C. 30 de Agosto de 1873. Apéndice 1\% al n. 80. 
el ministerio de Gobernación la facultad de efectuar las modificaciones que consideran oportunas para una mayor eficacia de la milicia. Finalmente, el 2 de Septiembre la ley era sancionada por la Asamblea y decretada el día 18. Sus principales características eran el carácter obligatorio del servicio en la milicia para los que tuvieran: «propiedad, rentas, industria y otro modo conocido de subsistir», la significativa modificación introducida con respecto a la ordenanza del Trienio, ya no se trata de defender la Constitución sino de velar por «el orden público en el interior de las poblaciones», y la insistencia en la necesidad de la absoluta fidelidad al poder legalmente constituido. $Y$ para que este objetivo fuese realmente cumplido se creaba un sistema de fiscalización de la milicia que pasaba a depender de una serie de autoridades: Ministro de la Gobernación, Inspector General, Inspectores de Provincia y en último término del Alcalde ${ }^{31}$, que mermaban considerablemente la capacidad de autonomía y el carácter municipal y local de las fuerzas ciudadanas. Se intentaba evitar, así, que los voluntarios de la República se convirtieran en «instrumentos en manos de toda clase de perturbadores) ${ }^{32}$.

Estas modificaciones introducidas por Maisonnave provocaron la oposición de ciertos sectores de republicanos que, si bien consideraban necesaria la reorganización, criticaron el evidente carácter conservador de la Ley. El 2 de enero de 1874, en la última sesión que celebrarían las Cortes republicanas, el diputado Benítez de Lugo censuraba la actuación del Ministro en los siguientes términos:

«Votamos la ley de la Milicia Nacional con arreglo a la ordenanza de 1822, y con gran asombro mío he visto que esa Ley de la Milicia Nacional ha sido de tal manera reformada por el Ministro de la Gobernación, que yo casi no encuentro en ella una palabra de lo que dice la ordenanza. (...) las grandes variaciones que se han introducido en esta ordenanza; variaciones en cuya virtud en lugar de hacer una milicia popular, se crea una Milicia conservadora, separándose así, más y más, el Gobierno, como tiene por costumbre o por instinto, de todos los elementos revolucionarios».

El proceso se había iniciado, la abolición definitiva de la Milicia Naciona vendría de la mano de la Restauración.

${ }^{31}$ Ordenanza y Reglamento para el régimen de la Milicia Nacional, Imp. J.F. Carratala, Alicante. 1873.

${ }^{32}$ Circular, dictando reglas concernientes a la reunión de las fuerzas populares de los Voluntarios de la República, 1 de Octubre de 1873. Citada por PEREZ GARZON, J.S. op. cit. Apéndice Documental, pág. 609. 


\section{APENDICE DOCUMENTAL}

\section{COMPOSICION SOCIOPROFESIONAL DEL BATALLON DE VOLUNTARIOS DE LA REPUBLICA POR COMPAÑIAS *}

PRIMERA COMPAÑIA. - Distrito de San Francisco.

Total de voluntarios alistados: 97

Total de voluntarios que especifican profesión: 96

Profesiones de los voluntarios (clasificadas por sectores de producción): Sector Primario (Agrario): 26,8\%

Marineros ........... 16 Jornaleros

Sector Secundario (Industria y actividades artesanales): 56,7\%

Construcción

Albañil

Textil

Hilador

Sastre

Metalurgia

Hojalatero

Calderero

Alimentación

Chocolatero

Panadero

Confitero

\section{Madera}

4 Carpinteros ........... 7

Toneleros ............ 15

3 Curtidos

2 Zapatero ............. 7

Otros oficios

1 Cura

1 Impresor ........... 7

Pintor ............... 1

4 Embalador ............ 1

Sector Terciario (Comercio y servicios): $15,4 \%$

Comerciante .......... 1 Maquinista ........... 1

Dependiente .......... 1 Empdo. Estación ........ 2

Medidor ............. 2 Mozo de café $\ldots \ldots \ldots \ldots 2$

Peluquero ............ 1 Trapero .............. 1

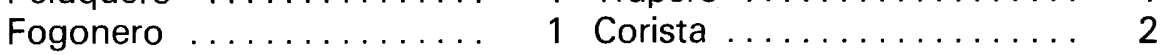

Barbero ............. 1

SEGUNDA COMPAÑIA. - Distrito del Teatro.

Total de voluntarios alistados: 108

Total de voluntarios que especifican profesión: 97

Profesiones de los voluntarios (clasificadas por sectores de producción): Sector Primario (Agrario): 27,8\%

Jornaleros ........... 27

* FUENTE: AMA, Sala Histórica, Arm. 16 Voluntarios Nacionales 1873-74. Elaboración propia. 
Sector Secundario (Industria y actividades artesanales): 53,6\%

Construcción

Albañil

Pavimentador

Cantero

Textil

Tintorero

Sastre

Sombrerero

Madera

Carpintero

Tornero

\section{Metalurgía}

29 Herrero .............. 2

1 Calderero 1

2 Alimentación

Panadero ............. 1

1 Horchatero ............ 1

1 Curtidos $y$ afines

2 Zapatero .............. 6

Alpargatero $\ldots \ldots \ldots \ldots \ldots 1$

1 Otros Oficios

1 Impresor $\ldots \ldots \ldots \ldots \ldots \ldots$.

Pintor .............. 1

Sector Terciario (Comercio y servicios): 18,5\%

Comerciante .......... 2 Barbero ............. 2

Carretero ............. 2 Empleado ............ 4

Maquinista ........... 2 Cortante $\ldots \ldots \ldots \ldots . . . \ldots$

Practicante $\ldots \ldots \ldots \ldots \ldots . \quad 1$ Tendero $\ldots \ldots \ldots \ldots . . \ldots$

TERCERA COMPAÑIA. - Distrito del Teatro.

Total de voluntarios alistados: 104

Total de voluntarios que especifican profesión: 98

Profesiones de los voluntarios (calificadas por sectores de producción):

Sector Primario: (Agrario): 9,1\%

Marineros

1 Jornaleros

Sector Secundario (Industria y actividades artesanales): $71,4 \%$

Construcción

Albañil

Pavimentador

Textil

Sastre

Tapicero

Sombrerero

Metalurgía

Herrero

Aperador

Alimentación

Chocolatero

Panadero
Madera

13 Ebanista

1 Carpintero .............. 11

Tonelero

1 Curtidos

2 Zapatero .............. 16

1 Otros Oficios Impresor ............ 2

4 Platero ................. 1

2 Pintor .............. 2

Dorador ............... 4

3

Sector Terciario (Comercio y servicios): 19,3\%

Corredor

4 Empleado 
Escribiente

2 Barbero

Cortante

Tendero

1 Músico

CUARTA COMPAÑIA. - Distrito del Carmen.

Total de voluntarios alistados: 96

Total de voluntarios que especifican profesión: 77

Profesiones de los voluntarios (calificadas por sectores de producción): Sector Primario: (Agrario): $7,7 \%$

Marinero

1 Jornaleros

Sector Secundario (Industria y actividades artesanales): $64,9 \%$

Construcción

Albañil

Cantero

Metalurgia

Herrero

Textil

Tejedor

Sastre

Alimentación

Panadero

Madera

Carpintero

\section{Curtidos y afines}

12 Zapatero

3 Alpargatero Otros oficios

1 Impresor .............. 1

Abaniquero ........... 1

1 Pintor ............... 2

1 Industrial ............. 1

Dulzainero ............ 1

4

13

Sector Terciario (Comercio y servicios): $27,7 \%$

Corredor

1 Cartero

Tratante

2 Cortante

Empleado

3 Barbero

Mozo

1 Músico

Guardia Municipal

4

QUINTA COMPAÑIA. - Distrito del Carmen.

Total de voluntarios alistados: 87

Total de voluntarios que especifican profesión: 85

Profesiones de los voluntarios (calificadas por sectores de producción): Sector Primario: (Agrario): $27 \%$

Marineros

1 Jornaleros

Sector Secundario (Industria y actividades artesanales): $62,3 \%$ Construcción

Albañil

Madera

Textil

21 Carpintero .............. 2

Sastre

Sillero

Cordonero

2 Alimentación

1 Panadero 
Colchonero

Metalurgia

Herrero

Hojalatero

Curtidos

Zapatero
1 Chocolatero ............ 1

Pastelero .............. 1

2 Otros oficios

3 Pintor .............. 2

Vaciador .............. 1

Sector Terciario (Comercio y servicios): 10,5\%

Empleado

1 Tratante

Barbero

2 Tahonero

Guardia Municipal

1 Tendero

SEXTA COMPAÑIA. - Distrito del Centro.

Total de voluntarios alistados: 93

Total de voluntarios que especifican profesión: 89

Profesiones de los voluntarios (calificadas por sectores de producción): Sector Primario: (Agrario): $48,7 \%$

Marineros

27 Jornaleros

Sector Secundario (Industria y actividades artesanales): $31,4 \%$

Construcción

Albañil

Metalurgía

Hojalatero

Madera

Carpintero

Calafate

Alimentación

Panadero
Textil

2 Sombrerero $\ldots \ldots \ldots \ldots \ldots 2$

Sastre .............. 3

2 Curtidos y afines

Zapatero ............. 3

9 Esterero .............. 1

1 Otros oficios

Tallista ............... 1

Sector Terciario (Comercio y servicios): 20,2\%

Corredor ............. 2 Empleado ............. 3

Tratante ............. 5 Cortante ............ 6

Factor

1 Barbero .............. 1

SEPTIMA COMPAÑIA. - Distrito de San Antón.

Total de voluntarios alistados: 99

Total de voluntarios que especifican profesión: 93

Profesiones de los voluntarios (calificadas por sectores de producción):

Sector Primario: (Agrario): 16,1\%

Marineros

1 Pescador

1

Jornalero 
Sector Secundario (Industria y actividades artesanales): 69,8\%

Construcción

Cantero

Albañil

Textil

Sastre

Tintorero

Tejedor

Madera

Carpintero

Tonelero

Curtidos

Zapatero
Metalurgía

4 Herrero

32 Aperador .............. 2

Alimentación

2 Panadero .............. 1

1 Horchatero ............. 1

1 Chocolatero ............. 1 Otros oficios

4 Impresor ............. 1

1 Pintor ............... 1

9

Sector Terciario (Comercio y servicios): 13,9\%

Carretero .............. 4 Empleado

Comerciante .......... 5 Jardinero

Corredor 1

OCTAVA COMPAÑIA. - Distrito de San Antón.

Total de voluntarios alistados: 94

Total de voluntarios que especifican profesión: 91

Profesiones de los voluntarios (calificadas por sectores de producción): Sector Primario: (Agrario): 54,9\%

Jornalero ............ 50

Sector Secundario (Industria y actividades artesanales): 40,6\%

Construcción

Albañil Alimentación

Cantero

14 Panadero

Pavimentador

8 Madera

Textil

1 Carpintero

Sastre Otros oficios

Curtidos

1 Pintor

Zapatero ............. 5

Sector Terciario (Comercio y servicios): 4,3\%

Maestro

1 Tendero

Tratante

1 Carbonero

NOVENA COMPAÑIA. - Distrito de San Francisco.

Total de voluntarios alistados: 61

Total de voluntarios que especifican profesión: 55 
Profesiones de los voluntarios (calificadas por sectores de producción): Sector Primario: (Agrario): $5,4 \%$

Propietario ............ 2

Jornalero $\ldots \ldots \ldots \ldots \ldots \ldots \quad 1$

Sector Secundario (Industria y actividades artesanales): 16,3\%

Madera

Carpintero

Alimentación

Panadero

Metalurgia

Aperador
Otros oficios

3 Encuadernador ........... 1

Artesano ............... 1

1 Pintor ............... 1

Industrial $\ldots \ldots \ldots \ldots \ldots \ldots$

Sector Terciario (Comercio y servicios): $78,1 \%$

Comerciante .......... 6 Cortante ............ 1

Agente de negocios ...... 1 Vendedor ............. 1

Corredor .............. 2 Mozo ............... 1

Empleado ............. 19 Peluquero ............. 5

Dependiente .......... 1 Barbero .............. 2

Medidor ............. 1 Estudiante ............ 2

Músico $\ldots \ldots \ldots \ldots \ldots \ldots .1$

TERCERA COMPAÑIA. - Distrito del Teatro. (Reorganizada en Agosto de 1873).

Total de voluntarios alistados: 89

Total de voluntarios que especifican profesión: 86

Profesiones de los voluntarios (calificadas por sectores de producción): Sector Primario: (Agrario): 16,2\%

Marinero ............ 1 Jornalero

Sector Secundario (Industria y actividades artesanales): 39,5\%

Construcción

Albañil

Cantero

Pavimentador

Marmolista

Metalurgia

Hojalatero

Alimentación

Hornero

Cafetero

Panadero

\section{Madera}

3 Carpintero .............. 9

3 Tonelero .............. 1

1 Serrador .............. 4

1

Curtidos

1 Zapatero .............. 3

Otros oficios

3 . Pintor 
Sector Terciario (Comercio y servicios): $44,1 \%$

Comerciante .......... 10 Vendedor ............ 1

Corredor ............. 1 Cortante ............ 6

Negociante .......... 1 Conserje ............ 1

Medidor ............. 5 Piloto .............. 1

Dependiente $\ldots \ldots \ldots \ldots .4$ Barbero ............. 1

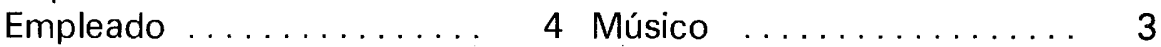

DISTRIBUCION POR EDAD DEL BATALLON DE VOLUNTARIOS

DE LA REPUBLICA DE ALICANTE*

\begin{tabular}{|c|c|c|c|c|c|c|c|c|c|c|}
\hline \multicolumn{11}{|l|}{ ALISTADOS: } \\
\hline Edades & 1. Cia & 2a Cía & 3. Cía & 4. Cía & 5. Cia & 6. Cia & 7. Cía & 8. Cía & 9. Cía & Total \\
\hline De 15 a 20 años & 9 & 4 & 14 & 7 & 8 & 4 & 8 & 8 & 14 & 76 \\
\hline De 21 a 30 años & 47 & 64 & 55 & 44 & 50 & 35 & 44 & 51 & 46 & 436 \\
\hline De 31 a 40 años & 22 & 26 & 22 & 18 & 19 & 27 & 29 & 21 & & 184 \\
\hline De 41 a 50 años & 17 & 10 & 7 & 6 & 9 & 9 & 12 & 9 & & 79 \\
\hline De 51 a 60 años & 1 & 1 & 3 & 4 & & 5 & & 1 & & 15 \\
\hline De 61 a 70 años & & 1 & 1 & & & 3 & 1 & 1 & & 7 \\
\hline Total: & 96 & 106 & 102 & 79 & 86 & 83 & 94 & 91 & 60 & 797 \\
\hline
\end{tabular}

MANDOS Y OFICIALES:

\begin{tabular}{|c|c|c|c|c|c|c|c|c|c|c|}
\hline Edades & 1. Cía & 2. Cía & 3: Cía & 4. $\mathrm{Cia}$ & 5. Cía & 6. Cía & 7. Cía & 8. Cia & 9. Cía & Total \\
\hline \multicolumn{11}{|l|}{ De 15 a 20 años } \\
\hline De 21 a 30 años & 2 & & 1 & 1 & 1 & 2 & & 1 & 5 & 13 \\
\hline De 31 a 40 años & 2 & 2 & 2 & 4 & 3 & 2 & & 3 & & 18 \\
\hline De 41 a 50 años & 1 & 2 & 1 & & & 1 & & 1 & & 6 \\
\hline De 51 a 60 años & & & & & 1 & & & & & 1 \\
\hline \multicolumn{11}{|l|}{ De 61 a 70 años } \\
\hline Total: & 5 & 4 & 4 & 5 & 5 & 5 & & 5 & 5 & 38 \\
\hline
\end{tabular}

* FUente: AMA Sala Histórica. Arm. 16 Voluntarios Nacionales 1873-1874 Elaboración propia. 
COMPOSICION SOCIOPROFESIONAL DEL BATALLON DE VOLUNTARIOS DE LA REPUBLICA POR COMPANIIAS *

\begin{tabular}{|c|c|c|c|c|c|c|c|c|c|c|}
\hline \multirow{2}{*}{$\frac{\text { Sectores Producción }}{\text { Profesiones }}$} & \multicolumn{10}{|c|}{ Compañías } \\
\hline & $1 \stackrel{a}{a}$ & $2 \mathrm{a}$ & 3. & $4:$ & 5 a & $6 a^{a}$ & $7 !$ & 8. & $9 a^{a}$ & Total \\
\hline \multicolumn{11}{|l|}{ Sector Primario } \\
\hline Jornalero & 10 & 27 & 8 & 5 & 22 & 16 & 13 & 50 & 1 & 152 \\
\hline Marinero & 16 & & 1 & 1 & 1 & 27 & 1 & & & 47 \\
\hline Pescador & & & & & & & 1 & & & 1 \\
\hline Propietario & & & & & & & & & 2 & 2 \\
\hline Total: & 26 & 27 & 9 & 6 & 23 & 43 & 15 & 50 & 3 & 202 \\
\hline
\end{tabular}

Sector Secundario

\begin{tabular}{|c|c|c|c|c|c|c|c|c|c|}
\hline $\begin{array}{l}\text { Construcción } \\
\text { Albañil } \\
\text { Cantero } \\
\text { Pavimentador }\end{array}$ & 4 & $\begin{array}{r}29 \\
2 \\
1\end{array}$ & $\begin{array}{c}13 \\
1\end{array}$ & $\begin{array}{r}12 \\
3\end{array}$ & 21 & 2 & $\begin{array}{r}32 \\
4\end{array}$ & $\begin{array}{r}14 \\
8 \\
1\end{array}$ & $\begin{array}{r}127 \\
17 \\
3\end{array}$ \\
\hline Total: & 4 & 32 & 14 & 15 & 21 & 2 & 36 & 23 & 147 \\
\hline
\end{tabular}

Textil

Colchonero

Cordonero

Hilador

Sastre

Sombrerero

Tapicero

Tejedor

Tintorero Total:

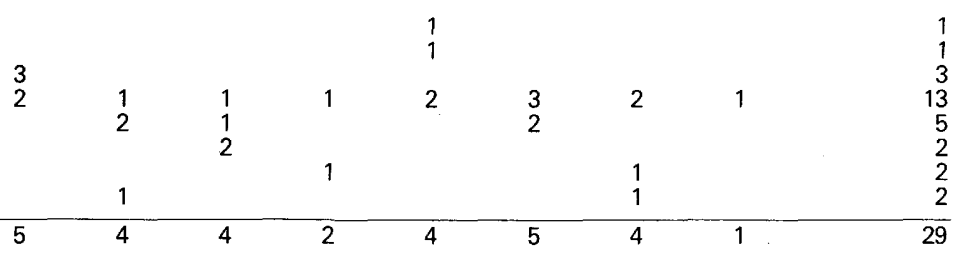

Metalurgía

Aperador

Calderero

Herrero

Hojalatero

Total:

\begin{tabular}{lllllllr}
1 & 1 & 2 & & & 2 & 1 & 5 \\
2 & 12 \\
1 & 2 & 4 & 1 & 2 & & 3 & 6 \\
\\
\hline 2 & 3 & 6 & 1 & 5 & 2 & 5 & 2
\end{tabular}

Madera

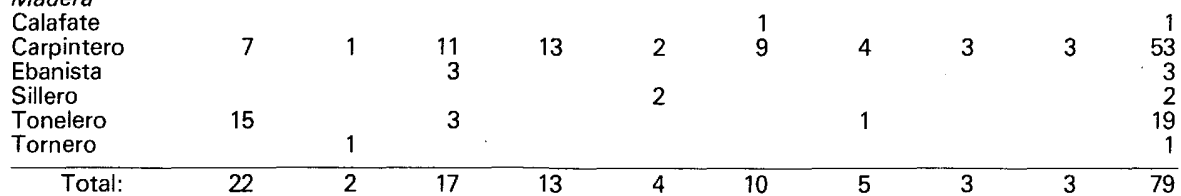

Curtidos $y$

afines

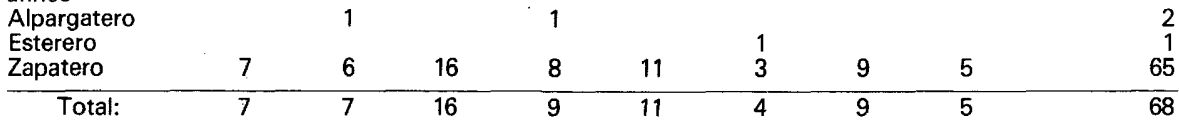

Alimentación

\begin{tabular}{|c|c|c|c|c|c|c|c|c|c|c|c|}
\hline $\begin{array}{l}\text { Confitero } \\
\text { Chocolatero } \\
\text { Horchatero } \\
\text { Panadero }\end{array}$ & $\begin{array}{l}1 \\
4 \\
1\end{array}$ & $\begin{array}{l}1 \\
1\end{array}$ & $\begin{array}{l}1 \\
3\end{array}$ & 4 & $\begin{array}{l}1 \\
1\end{array}$ & 4 & . & $\begin{array}{l}1 \\
1 \\
1\end{array}$ & 4 & 1 & 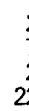 \\
\hline Total: & 6 & 2 & 4 & 4 & 5 & 4 & & 3 & 4 & 1 & \\
\hline
\end{tabular}

* FUENTE: AMA Sala Histórica. Arm. 16 voluntarios nacionales 1873-1874. Elaboración propia. 


\begin{tabular}{|c|c|c|c|c|c|c|c|c|c|c|}
\hline \multirow{2}{*}{$\begin{array}{c}\text { Sectores Productión } \\
\text { Profesiones }\end{array}$} & \multicolumn{10}{|c|}{ Compeñlas } \\
\hline & 19 & $2:$ & $3:$ & $4 !^{\circ}$ & $5:$ & $6 !$ & $7:$ & $8:$ & 9: & Total \\
\hline \multicolumn{11}{|l|}{ Otros Oficios } \\
\hline Abaniquero & & & & 1 & & & & & & 1 \\
\hline Artesano & & & & & & & & & 1 & 1 \\
\hline Dorador & & & 4 & & & & & & & 4 \\
\hline Dulzainero & & & & 1 & & & & & & 1 \\
\hline Encuadernador & & & & & & & & & 1 & 1 \\
\hline Embalador & 1 & & & & & & & & • & 1 \\
\hline Finquetero & & & & & & & 1 & & & 1 \\
\hline Industrial & & & & 1 & & & & & 1 & 2 \\
\hline Impresor & 7 & 1 & 2 & $j$ & & & 1 & & & 12 \\
\hline Pintor & 1 & 1 & 2 & 2 & 2 & & 1 & 1 & 1 & 11 \\
\hline Platero & & & 1 & & & & & & & 1 \\
\hline $\begin{array}{l}\text { Vaciador } \\
\text { Tallista }\end{array}$ & & & & & 1 & 1 & & & & 1 \\
\hline Total: & 9 & 2 & 9 & 6 & 3 & 1 & 3 & 1 & 4 & 38 \\
\hline
\end{tabular}

Sector Terciario

\section{Comercio \\ Agente de}

negocios

Comerciante

Corredor

Dependiente de

comercio

Empleado

Escribiente

Factor

Medidor

Tratante

Total:

1

2

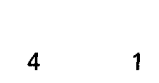

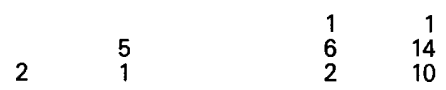

Transportes

Carretero

Cochero

Empleado de

estación

Fogonero

Maquinista

4

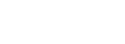

$\begin{array}{rrrrrrrrr}1 & 4 & 4 & 3 & 1 & 3 & 1 & 1 & 2 \\ & & 2 & & & & & 19 & 35\end{array}$

12

Total:

2

1

\begin{tabular}{rrrrrrrrr} 
& & 2 & 2 & 5 & & 1 & & 10 \\
\hline 4 & 6 & 10 & 6 & 3 & 11 & 7 & 1 & 30
\end{tabular}

Administración

Guardia Munici-

pal.

Total:

Profesiones

Liberales.

Estudiante

Maestro

Practicante

Total:

2

1

4

Servicios

Barbero

Carbonero

Cartero

Coristas

Cortante

Jardinero

Mozo de café

2

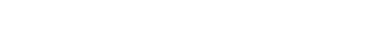

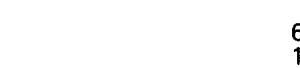

Músico

Peluquero

Tahonero

Tendero

Trapero

Vendedor

Total:

$\begin{array}{llll}1 & 2 & 3 & \\ 2 & 3 & 3 & \\ 2 & & & \\ 1 & & 1 \\ 1 & 2 & \end{array}$

\begin{tabular}{lll}
4 & 1 & 5 \\
\hline 4 & 1 & 5
\end{tabular}
5

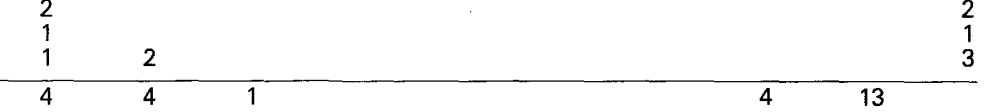





\section{ANARQUISTAS Y SINDICALISTAS EN LA PROVINCIA DE ALICANTE (1874-1917)}

FRANCISCO MORENO SAEZ

\section{LA REPRESION DEL MOVIMIENTO INTERNACIONALISTA $D E A L C O Y$}

Tras los sucesos ocurridos en Alcoy en 1873, popularmente conocidos con el nombre de «el petrolio» - y que han sido estudiados por diversos autores ' - se desató, en el marco político propiciado por el golpe de Estado de enero de 1874 y en los primeros años de la Restauración, una fuerte represión sobre la clase obrera que sumió en la clandestinidad a los sectores organizados en la Asociación Internacional de Trabajadores. Lógicamente, y dadas las repercusiones que había tenido el movimiento internacionalista de Alcoy, esa represión se agudizó allí y a lo largo de 1874 y 1875 aparecen, en la prensa de Alcoy y en la de Alicante, frecuentes noticias sobre la detención, a veces «en despoblado», de hombres y mujeres calificados de "cabecillas de la Internacional» y considerados «instigadores» y «agitadores» en los sucesos que le costaron la vida a Agustín Albors ${ }^{2}$. La labor represiva fue llevada a término por el subgobernador de Alcoy, nombrado al efecto, y por el comandante militar de la plaza, en un ambiente de verdadero terror, llegándose incluso a realizar un «auto de fe» con algunas proclamas de

1 Desde el estudio clásico de FEDERICO ENGELS, Los bakuninistas en acción. Informe sobre la sublevación española del verano de 1873 (en MARX-ENGELS, Revolución en España. Ariel. Barcelona. 1970) hasta el panfleto de RAFAEL COLOMA, La Revolución Intenacionalista alcoyana de 1873. Instituto de Estudios Alicantinos. Alicante. 1951, pasando por estudios parciales en las obras de JOSEP TERMES, Anarquismo y sindicalismo en España. La Primera Internacional. 1864-1881. Ariel. Barcelona. 1972, CLARA E. LIDA, Anarquismo y revolución en la España del siglo XIX, Siglo XXI. Madrid. 1972, o C.A.N. HENNESSY, La República Federal en España, Aguilar. Madrid. 1966. Y sobre todo, RAFAEL ARACIL - M. GARCIA BONAFE, Classe obrera i cantonalisme a Alcoi (1873), en "L'Avenç», n. 13, febrero de 1979, o MANUEL CERDA, Els moviments socials del País Valencià, Institució Alfons el Magnánim. Valencia. 1981.

${ }^{2}$ «Ha sido capturada en Alcoy Concepción Torregrosa Colau, complicada en los sucesos de aquella ciudad, y sobre la que pesan vehementes sospechas de haber sido una de los más furibundos instigadores que condujeron a las turbas a cometer todo género de excesos» en "El Constitucional». (Alicante), 20-V-1874 / «Por fuerzas de la Guardia Civil de la línea de Jijona... fueron capturados anteanoche y en despoblado, Bautista Reig Moltó y Francisco de Paula Sánchez, internacionalistas y otros de los que tomaron parte en los sangrientos acontecimientos de Alcoy en los días 10 y 11 de julio de 1873» en «El Constitucional», 20-V-1875. 
la A.I.T. en abril de $1874^{3}$. En consecuencia, fueron encausados gran número de obreros, aunque algunos destacados dirigentes de la A.I.T., tales como Severino Albarracín, Francisco Tomás, Vicente Fombuena y Vicente Santonja, lograron escapar. Durante tres años, la Justicia se dedicó a interrogar a testigos y reos, que ascendieron a más de setecientos, algunos acusados en rebeldía. Poco a poco, sin embargo, los presos fueron abandonando la cárcel y en 1876 quedaban encarcelados en la ciudad ciento cuarenta y dos obreros, que se redujeron a dieciseis en 1881, tras un sobreseimiento, y a seis únicamente a partir de 1883.

La causa llenó treinta mil hojas, se sucedieron los jueces especiales y, a partir de 1876, hubo en Alcoy un movimiento popular para tratar de resolver el problema, que afectaba a toda la ciudad: se buscó el concurso del conde de Bernar para gestionar la amnistía ${ }^{4}$ y la prensa local trataba periódicamente el tema, perdido en los meandros de la burocracia judicial, al tiempo que advertía que la cuestión «mientras dure, será un mal fermento para Alcoy $)^{5}$. En diciembre de 1887, el Juzgado alcoyano dictó sentencia absolutoria, por falta de pruebas, para todos los acusados, sentencia que fue acogida con alegría en la ciudad, llegando incluso el Ayuntamiento a asistir en pleno a un «Te Deum» en acción de gracias ${ }^{6}$. La sentencia fue confirmada en octubre de 1888 por la Audiencia de Valencia, aunque por distintos motivos: de los reos, "gran parte de ellos fueron comprendidos en un indulto, otros se incluyeron en el sobreseimiento que se dictó, algunos han fallecido, bastantes son de ignorado paradero y contra los restantes no han resultado cargos concretos». Según los cálculos efectuados a partir de la documentación de la causa judicial por Aracil y García Bonafé7, la mayoría de los procesados eran hombres de edades comprendidas entre los 23 y los 48 años, casados, habitantes de la comarca de l'Alcoiá-Comtat y pertenecientes, sobre todo, a los sectores papelero y textil de la industria alcoyana. Había entre ellos un gran porcentaje de analfabetos que, sin embargo, era inferior al existente entre la población en general.

Además de esta represión "selectiva» se ejerció otra, más difusa, sobre toda la clase obrera alcoyana - paradigma, para la prensa oficial

${ }^{3}$ «El Constitucional», 30-IV-1874.

${ }^{4}$ JULIO BERENGUER BARCELO, Historia de Alcoy, 3 vols. Alcoy. 1977.

5 «El Serpis» (Alcoy) 11-V-1878.

${ }^{6}$ "Revista de Alcoy», 7-I-1888.

${ }^{7}$ R. ARACIL - M.G. BONAFE, Clase obrera y revuelta social: la identidad del cantonalismo alcoyano de 1873, en «Estudios de Historia social» n. 7. Madrid. 1978. 
y la sociedad bienpensante, de masa revoltosa-. En el informe que se evacua en Alcoy con ocasión de la constitución de la Comisión de Reformas Sociales, en 1884, se denunciaba el hecho de que los obreros que protestaban de las condiciones de trabajo se veían obligados a emigrar porque «su nombre circula entre los fabricantes», que les negaban el trabajo, así como a todo obrero asociado. Entre los obreros que intervienen en la información oral predomina, claramente, el escepticismo ante la viabilidad de medidas reformistas: es más, se llega a decir que las escasas intervenciones que se producen de obreros se deben "a la falta de fé en el resultado de la información». Como hiciera Jaime Vera en el informe presentado en Madrid, los obreros alcoyanos con mayor conciencia de clase - por ejemplo, José Seguí, que había sido procesado por los sucesos de 1873 -manifestaban su personal convencimiento de que entre capital y trabajo «la armonía no puede existir por entero». Pese a la represión, seguía predominando en el proletariado alcoyano la tendencia apolítica de la antigua A.I.T., que se ponía de relieve en las palabras de otro obrero que aseguraba que capital y trabajo eran enemigos por naturaleza y que los gobiernos sólo podian dictar leyes favorables al primero, por lo que «la política es desventajosa para el obrero" ${ }^{8}$.

Así las cosas, resulta lógico que el movimiento de inspiración anarquista tardase en reconstruirse, a pesar de las medidas liberalizadoras de Sagasta en 1881, que habían permitido la creación de la Federación de Trabajadores de la Región Española, a la que, según Max Netlau, pertenecían en la década de los ochenta cinco sociedades obreras de Alcoy, una de Concentaina, otra de Alicante y otra de Elche ${ }^{9}$. Algunas fuentes hablan de la celebración de un Congreso comarcal de la Federación de Trabajadores de la Región Española que se habría efectuado en Alcoy en el verano de 1885, pero del cual no informa la prensa del momento. En 1889 - cuando ya se habia disuelto, tras los sucesos de "La Mano Negra», la Federación de Trabajadores de la Región Española, a la que sustituiría la Organización Anarquista de la Región Española - se celebró un mítin anarquista en la plaza de toros de Alcoy ${ }^{10}$. Lo que podemos asegurar, sin embargo, es que en esas fechas el movimiento obrero alcoyano, el único que había alcanzado un cierto

${ }^{8}$ COMISON DE REFORMAS SOCIALES, Información oral y escrita en virtud de la Real Orden de 5 de Diciembre de 1883. Madrid. 1889-1892.

${ }^{9}$ A la luz de nuestros datos, creemos que no es cierta la existencia de ninguna sociedad obrera afiliada a la Federación de Trabajadores de la Región Española en Elche, donde en los años ochenta únicamente existía el Círculo Obrero Illicitano, entidad interclasista e influída, en todo caso, por simpatizantes del PSOE.

${ }^{10}$ "Revista de Alcoy», 3-VIII-1889, según JULIO BERENGUER, o.c. 
grado de organización en toda la provincia, volvía a estar dirigido - por ejemplo, en algunas huelgas parciales en el textil, en mayo, julio y septiembre de 1889 - por los anarquistas, como se demostraría en 1890, con ocasión de la primera manifestación conmemorativa del Primero de Mayo.

\section{EL PRIMERO DE MAYO DE 1890}

Cuando se acercó esta fecha, en que el proletariado mundial había decidido exigir de los poderes públicos la jornada de ocho horas de trabajo, en recuerdo de los mártires de Chicago, la prensa reaccionaria se apresuró a recordar los sucesos de 1873 y aseguró que habían llegado a Alcoy «anarquistas de otras partes para soliviantar y mover los ánimos; se han repartido hojas clandestinas, de las cuales algunas han llegado a nuestra ciudad proclamando todos los horrores del más bárbaro socialismo" ". Algunas familias adineradas abandonaron la población y la clase obrera se mostraba dividida, pues algunos querían manifestarse el día 4 - de acuerdo con las consignas socialistas- y otros pretendian declarar la huelga general: "los fabricantes están inquietos, pues conocen el carácter violento de esta población obrera" "2. Al final $-y$ a diferencia de lo que ocurrió en otros lugares de la provincia, como Elche, Crevillente o Alicante, donde la celebración del Primero de Mayo se llevó a cabo de acuerdo con las directrices socialistas - se impusieron en Alcoy los dirigentes anarquistas y en la tarde del lunes 5 de mayo, tras una manifestación en demanda de la jornada de ocho horas en la que tomaron parte dos mil obreros, se proclamó la huelga general 13. La población - para la que habían partido el día 27 de abril la mayoría de las fuerzas de la Guardia Civil existentes en Alicante - fue ocupada militarmente, interviniendo también las tropas del Regimiento de Vizcaya. Corría por la población la siguiente hoja, firmada por Antonio Miralles Casanova, que sería detenido en el curso de la huelga cuando ondeaba en "El Molinar» la bandera "de la sociedad de anarquistas»: «(Si volvemos al trabajo) seremos el desprecio de las demás localidades que hoy sostienen la lucha. $Y$ después la burguesía nos trataría como merecemos, que es como hombres cobardes y sin constancia, y la miseria más espantosa pesará sobre nosotros. ¿Qué se diria de los trabajadores de Alcoy, que una vez principiada la

" «El Alicantino», 29-IV-1890.

12 "El Alicantino», 23-IV-1890, que toma la información de "El Imparcial».

13 "Revista de Alcoy», 10-V-1890. 
lucha nos pusiéramos a trabajar sin haber conseguido nuestra demanda de ocho horas por jornada, y más pedida por todos los obreros del Universo? Antes de llegar a este paso, que se abra la tierra y perezcamos todos en sus ruinas, y de esta manera salvaguardaremos nuestra dignidad de hombres y de trabajadores" ${ }^{14}$.

Tras algunas gestiones del Gobernador Civil - que se reunió con los presidentes de las Sociedades Obreras y les hizo diversas promesas ${ }^{15}-$ los trabajadores alcoyanos se mantuvieron firmes, pues apenas cuatrocientos de los miles de huelguistas se mostraron dispuestos a volver a las fábricas, a pesar del aumento de la miseria y de los empeños, más de doscientos diarios, en el Monte de Piedad. Al cabo de una semana de huelga, y al conocer el fracaso de la jornada en el resto de España y del mundo, los obreros alcoyanos regresaron al trabajo, sin lograr la jornada de ocho horas, pero habiendo demostrado su combatividad.

Ante el Primero de Mayo de 1891, «El Liberal» de Madrid publicaba una serie de artículos sobre la cuestión social y sobre las perspectivas que presentaba la fecha en las poblaciones industrializadas españolas. El corresponsal enviado a Alcoy describía las distintas tendencias existentes entre los obreros alcoyanos y, en relación a los anarquistas, decía:

«La Federación Alcoyana es el título que lleva la agrupación anarquista, que tiene un centro donde se congregan, divididos en agrupaciones, más de 400 colegas.

Es alma de esa agrupación José Seguí, hombre de cincuenta y cuatro años, de oficio tejedor, de poca instrucción, pero de una astucia finísima.

Seguí es muy conocido desde los sucesos ocurridos en esta población en 1873, a consecuencia de los cuales estuvo preso bastante tiempo en Alicante.

La Federación Alcoyana es partidaria de la huelga hasta conseguir la jornada de ocho horas, y su influencia la lleva a los trabajadores del ferrocarril de Gandía a Alcoy... el número de trabajadores se acerca a $2.000{ }^{16}$.

En 1893 se produjeron ciertos hechos relacionados con los anarquistas alcoyanos que demuestran el temor, infundado, que las organizaciones anarquistas provocaban en las autoridades: una noche del mes

14 «El Alicantino», 10-V-1890.

${ }^{15}$ «1/ Todos los patronos admitirán a los mismos obreros, con igual jornal y jornada que antes. $2 /$ Cuando en otras naciones se acepten las ocho horas, aquí también. 3/ Ningún patrono podrá despedir a nadie por represalias».

${ }^{16}$ «El Liberal» (Madrid), 20-IV-1891. 
de febrero la ciudad fue ocupada por tropas de Infantería y de la Guardia Civil, al conocer por confidentes las autoridades que los anarquistas de Alcoy y Cocentaina tenían el proyecto de alzarse en armas y promover un motín en el que incendiarían las notarías, los archivos y las Casas Consistoriales y volarían con dinamita edificios públicos y privados. La Guardia Civil registró las casas de «los más furibundos anarquistas" ${ }^{17}$. Al día siguiente, regresaron a sus lugares de procedencia las fuerzas de la Guardia Civil que habían llegado a Alcoy. Según la prensa adicta al régimen, el complot era auténtico y fue impedido por las acertadas medidas de las autoridades; según otros periódicos, no se trató más que ridículas habladurías ${ }^{18}$. De todos modos, se ejercía así una constante y eficaz presión sobre la organización obrera anarquista alcoyana, secundando con hechos la campaña de prensa con ocasión de los atentados terroristas efectuados, casi siempre a título individual, por determinados ácratas.

En el resto de la provincia, no parece que tuviesen mucha implantación los anarquistas entre 1890 y 1895 . La clase obrera de la capital alicantina estaba más bien influída por republicanos y socialistas. En 1892, ante los hechos de Jerez, el periódico católico «El Alicantino» se complacía en considerarlos consecuencias del liberalismo y las leyes desamortizadoras ${ }^{19}$, pero admitía que en Alicante no se habían producido las reacciones que en otros lugares: «entre los obreros alicantinos dominan temperamentos de prudencia y cordura que les honra y enalte(ce $\gg{ }^{20}$. Pero las autoridades vigilaban y ante la bomba del Liceo barcelonés - en la que aparece implicado el alcoyano Bautista Cervera - recoge "La Monarquía» el rumor de que el Gobierno Civil iba a revisar los reglamentos de las Sociedades Obreras existentes en la provincia "para ver si en algunas hay tendencias al anarquismo»"

En 1894, ante el auge del anarquismo andaluz, «El Alicantino» - que

17 "La Alianza Obrera» (Alcoy), 24-II-1893 / «El Serpis», 23-II-1893.

18 Para el alicantino "La Tarde», se trataba de un problema interno que había excitado a los anarquistas, que venían preparando un golpe de mano contra la burguesía. / Para "La Unión Republicana» (Alicante), 4-IV-1893, todo eran ridículas habladurías.

${ }^{19}$ "El Alicantino», 7-II-1892 / También, Socialismo y anarquismo, en «El Alicantino", 26-IV-1890: todo se vuelve contra los desamortizadores: "¿Qué diferencia hay entre los anarquistas y los demás liberales doctrinarios y oportunistas, sino un simple accidente de grado?».

${ }^{20}$ «EI Alicantino», 7-II-1892 / «El espíritu que anima a los obreros de esta población es hostil a las ideas anarquistas, y reprueban unánimemente los recientes sucesos de Jerez. («El Alicantino», 14-I-1892).

${ }^{21}$ "La Monarquía» (Alicante), 26-IX-1893 / Véase también Los sucesos de Barcelona o la libertad de la fiera, en "La Monarquía», 11-XI-1893. 
dedicó numerosos artículos al tema ${ }^{22}$ - tranquilizaba a sus lectores: «En Alicante debemos decir que los anarquistas, en el propio sentido de la palabra, no existen, pues no deben contarse como tales una docena de ilusos descreídos, que bien por la solapada propaganda del masonismo, bien por la mala educación que han recibido, se proclaman ateos y sueñan en reformar la sociedad. En Alicante no existiria esa docena de descontentos si volviese la prosperidad de otros días» ${ }^{23}$.

\section{LOS ANARQUISTAS EN EL TRANSITO DEL XIX AL XX}

Entre 1895 y 1906, y contrariamente a lo que han sostenido algunos autores ${ }^{24}$, el anarquismo no experimentó demasiados progresos ni en el campo, donde predominaba el catolicismo social, ni en las ciudades que contaban ya con algunos talleres, con la salvedad de Alcoy, donde los anarquistas tuvieron un importante papel en las huelgas textiles habidas en los últimos años del siglo XIX, especialmente en la del verano de 1895, en la que hubo enfrentamientos físicos con los esquiroles y numerosos detenidos. Al margen de esa organización alcoyana - que tampoco estaba tan definida como años atrás en un sentido anarquista - , creemos que apenas habría una docena de simpatizantes de las ideas libertarias en la capital de la provincia y algún pequeño grupo en Elda, y tal vez en Elche, pero sin la menor influencia sobre el conjunto de los trabajadores.

En el último lustro del siglo XIX, la persecución gubernamental contra el anarquismo - proyecto de Ley de represión del anarquismo y creación de la policía especial, torturas contra los presos anarquistas en Mont-

22 En «El Alicantino» pueden leerse varios artículos de este estilo: Los peligros anarquistas (16-II-1892), Los mandamientos del anarquismo (8-IV-1892), El proceso de los anarquistas (17-11-1894), Otra vez los anarquistas (18-11-1894), Los anarquistas (24-1I-1894), Misterio anarquista (13-III-1894), El anarquismo. Estudio sobre la cuestión social (15-I-1895): este último es una recensión de la obra del portugés Serga y Pimentel, que traduce Alvarez Sereix.

${ }_{23}$ "El Alicantino», 11-VII-1894 / El 8-VIII-1894 comenta los rumores - que juzga infundados - de la llegada a Alicante de ocho anarquistas «llevando siniestros propósitos».

24 JUAN ROMERO GONZALEZ, Orígenes del movimiento obrero valenciano en el tránsito del siglo XIX al XX. Del Cénia al Segura. Valencia. 1979. Pg. 263. Habla de incuestionables progresos del anarquismo en el campo, pero nos tememos que funciona aqui la frecuente extensión a todo el País Valenciano de lo que ocurría en Valencia y la comarca de l'Horta: no existe tal presencia anarquista en el campo alicantino. 
juich, etc. - provocó la solidaridad entre socialistas y republicanos alicantinos, que organizaron mítines de protesta en 1896 y $1897^{25}$.

A primeros de siglo, en 1902, los anarquistas habian lanzado, desde las páginas de "La huelga general» y "Tierra y Libertad», la idea de que la huelga general era, por así decirlo, la panacea universal para resolver de una vez por todas la injusta situación de la clase obrera. Cuando esta propuesta fue llevada a la práctica en Barcelona, las autoridades alicantinas volvieron a tomar precauciones y concentraron en Alcoy tropas del Regimiento de la Princesa, de Alicante, que se unieron a las alli estacionadas del Regimiento de Vizcaya: según la prensa, temían que el proletariado alcoyano, "tan sensible a las tácticas anarquistas», se uniese al paro general, cosa que no sucedió ${ }^{26}$.

Como es sabido, la huelga general provocó duros enfrentamientos entre el movimiento obrero anarquista y el socialista, pues ni la UGT ni el PSOE apoyaron el paro general. De ahí que uno de los ejes fundamentales de la propaganda socialista en esos años sea el intento de marcar diferencias con los ácratas, criticando determinadas actuaciones y propuestas ideológicas. En el semanario socialista alicantino «El Mundo Obrero" se encuentran numerosos ejemplos de esta polémica que, sin embargo, creemos era debida más bien al espíritu disciplinado de los dirigentes socialistas de la época que a una auténtica presencia anarquista entre el proletariado alicantino, de nuevo con la excepción de Alcoy. Se contraponían los atentados terroristas, la falta de cultura y la descabellada huelga general de los anarquistas a la prudencia y al carácter "científico» de la teoría socialista ${ }^{27}$.

${ }_{25}$ Mitin que organizan los socialistas en junio de 1896 contra el proyecto de ley contra el anarquismo («El Nuevo Alicantino», 28-VI-1896) / Artículos que sabemos publicaba el semanario socialista «El grito del pueblo», por alusiones en «El Nuevo Alicantino" / "La Federación» (Alicante), 16-V-1897: alusión a los tormentos de Montjuich / Incluso el moderado "El Graduador» (Alicante), 12-IX-1897, reconoce: «en un pais donde la justicia anda escasa y la moralidad no se conoce, tiene abono para que los anarquistas se multipliquen».

${ }^{26}$ "La Vanguardia» (Alicante), 4-III-1902.

${ }^{27}$ Frente a la Huelga general, que destroza a las sociedades de resistencia, que es fruto de la «ilusión, ignorancia, fanatismo», había que oponer la huelga por sectores, apoyada por otros compañeros que trabajasen: "El Mundo Obrero» (Alicante), 15-IX-1901. 9-II y 27-VII-1902. Había que propiciar la cultura de los obreros, pues las teorías anarquistas sólo hallarán «eco su estupidez en el corazón de alguna parte de los trabajadores mientras subsista la crasa ignorancia que predomina en el pueblo») (EI último fracaso, en «El Mundo Obrero», 2-VIII-1903). Se repudiaban, asimismo, los atentados personales, como algo inhumano y estéril: "Querer combatir el régimen social burgués o las instituciones que lo defienden llevando a cabo actos criminales contra las personas que los representan es tan torpe como estériles y contraproducentes son 
Incluso, en esos primeros años del siglo $X X$, los socialistas llegaron a disputar a los anarquistas su feudo alcoyano, donde lograron cierta implantación - si bien entre los obreros de sectores de la producción de menor importancia, pues en el textil parece que fue incontestable el predominio anarquista - : en «El Mundo Obrero» hay referencias al intento ácrata de hacer ingresar a las sociedades obreras alcoyanas en «la tan cacareada Federación Regional»" ${ }^{28}$, a la división existente en la clase obrera alcoyana - «hállanse hoy separadas en dos locales las cuatro únicas sociedades que existen ${ }^{29}-$, etc. Los socialistas predominaban en el Centro Obrero Instructivo y los anarquistas alcoyanos trataban de plantear en repetidas ocasiones controversias con los socialistas en torno a la huelga general y a los artículos que publicaban «El Mundo Obrero» y «El Corsario» ${ }^{30}$.

En el resto de la provincia, el movimiento obrero organizado que existía en los primeros años del XX estaba influído por los socialistas, especialmente el sector de la alpargata de Elche, donde se produjo en 1903 una huelga que iba a servir a los dirigentes de la UGT y del PSOE como ejemplo de las ventajas de las huelgas localizadas sobre la huelga general ${ }^{31}$. Los escasos núcleos anarquistas que existían en Elche, Alicante o Elda trataban de suscitar mitines de controversia con los socialistas ${ }^{32}$ y recibian algún apoyo de la prensa republicana $y$, especialmente, de "La Federación», órgano de los republicanos federales ${ }^{3}$.

sus resultados» (El último atentado, en «El Mundo Obrero», 24-IV-1904). En suma, para los socialistas alicantinos, los anarquistas tenían como único objetivo el dividir a la clase trabajadora y se llega a decir que «el anarquismo es el arma de que se aprovecha el jesuitismo ( $\mathrm{sic}$ ), para destruir el grandioso movimiento de concentración del proletariado consciente del Universo» (LEGNA, ¿Quiénes son y qué se proponen los anarquistas?, en «El Mundo Obrero», 28-VII-1901).

28 «El Mundo Obrero», 8-IX-1901.

${ }^{29}$ «El Mundo Obrero», 9-III-1902.

${ }^{30}$ "El Mundo Obrero", 3-VIII y 14-IX-1902 y 30-VIII-1903.

${ }^{31}$ Torpezas ácratas, en «El Mundo Obrero», 28-VI-1903.

${ }^{32}$ Así, en Elche, Fidel González retó a Verdes Montenegro, Pablo Iglesias y al dirigente socialista local Vives «para discutir lo funesta que es la politica para la clase trabajadora» («EI Mundo Obrero», 1-VI-1902) / En ese mismo mes, se pidió permiso para un mitin de Constancio Romeo, en la plaza de toros de Elche, sobre «Influencia perjudicial del PSOE en la clase trabajadora». (Folleto en el Archivo Municipal de EIche) / También polemizaron los ácratas con los republicanos («El Mundo Obrero», 14-VII-1901, alude a una polémica entre Tárrida del Mármol y los republicanos alicantinos Berenguer, Cabot y Sevilal.

33 "La Federación» ataca a los socialistas - que también trataban de desmarcarse de los republicanos - en defensa de Constancio Romeo y otros librepensadores cercanos al anarquismo, ataque que se agudizó al socaire del problema del anticlericalismo de esos años. 
En 1906 y a consecuencia del atentado de Mateo Morral contra el rey el 31 de mayo, se reprodujeron los ataques al anarquismo desde la prensa burguesa ${ }^{34}$ y fueron detenidos Nakens y Ferrer Guardia. En febrero de 1907 hubo una reunión en Alcoy - donde nuevas generaciones anarquistas, cercanas a las posiciones de Teresa Claramunt y Leopoldo. Bonafulla, iban sustituyendo a los antiguos militantes de los sucesos de 1873-, entre las sociedades obreras y las entidades políticas de izquierda, para organizar la campaña de protesta contra el proceso que iba a celebrarse contra Nakens y Ferrer. En esta campaña tuvo una intervención muy destacada el republicano radical Botella Asensi, que sería procesado por unos artículos en contra de Maura publicados en "Fraternidad», en los cuales se invitaba a los liberales a asistir al mitin que se llevó a cabo el día 7 de abril «para pedir no que se absuelva a los culpables, sino que no se condene a inocentes». En este mitin se pidió al Gobierno que «en el proceso incoado con motivo del crimen de la calle Mayor no se condene sin poseer pruebas materiales de la culpabilidad de los procesados» ${ }^{35}$. En esos momentos - sin duda, debido en parte a la campaña en favor de Nakens y Ferrer ${ }^{36}$ - se produjo en Alcoy un gran acercamiento entre anarquistas y republicanos; la iniciativa de los correligionarios de Botella Asensi de crear una Casa del Pueblo - que controlará el partido radical, al amparo de la posición de Botella Asensi en el Ayuntamiento alcoyano - fue bien acogida en los medios obreros cercanos a los anarquistas y con reticencias entre los socialistas, que al final cederán en su oposición y se integrarán en la comisión que prepara la Casa del Pueblo ${ }^{37}$. El periódico alicantino "Diario de Alicante», que envió a unos redactores a Alcoy para informar a sus lectores sobre la huelga textil del verano de 1907, aseguraba que el proletariado de aquella ciudad estaba dividido en cuatro opciones ideológicas: la católica, la socialista, la republicana radical y la anarquista. Advertía también de la existencia de numerosos agitadores «encargados de manejar a la masa obrera a su antojo, llevándola por descarriados caminos, con el pretexto de hacer su felicidad ${ }^{38}{ }^{38}$. Precisa-

34 Por ejemplo, «Heraldo de Alcoy», 19-VI y 4-VIII-1906 (La represión del anarquismol.

${ }_{35}^{35}$ "Fraternidad» (Alcoy), 13-IV-1907.

${ }^{36}$ La campaña había comenzado con un mitin celebrado el 13 de enero ( Fraternidad", 17-I-1907), en el que se leyó una hoja de Federico Urales, titulada Por la Justicia y por España / Véase también «Fraternidad», 9-II y 30-III-1907.

${ }^{37}$ El hecho de que Nakens y Ferrer fuesen dos campeones del anticlericalismo y. de la educación laica explica también la gran acogida que su proceso tuvo en las filas anarquistas / Véase también «Fraternidad», 30-III, 13 y 27-IV, 25-V , 6, 13 y 20-VII-1907.

${ }^{38}$ "Diario de Alicante», 7-VIII-1907. 
mente en esa huelga textil se acordó, tras una intervención del anarquista Claramunt en un mítin al que asistieron unos dos mil obreros, plantear la huelga general ${ }^{39}$.

Hemos de advertir que, salvo en estas ocasiones excepcionales, apenas tenemos información sobre la actividad y el desarrollo del anarquismo en la provincia de Alicante en estos años, no sólo por la falta de acogida que ante ellos muestra la prensa burguesa, sino sobre todo por la falta de prensa anarquista y de datos procedentes de las propias filas libertarias. Las monografías que Manuel Buenacasa recoge en su obra sobre el movimiento obrero español, apenas ofrecen datos sobre la provincia de Alicante ${ }^{40}$. Según este dirigente sindicalista, «pasados, idos los tiempos internacionalistas, llenos de impetuosidad y doctrinarismo, el Levante productor había caído en un sopor, en una abulia poco menos que renunciadora y suicida».

A finales de 1907 comenzó la agitación entre la oposición ante los rumores de que se preparaba por el Gobierno de Maura una ley contra el terrorismo, al amparo de las bombas que ponía, en esas fechas, el confidente y agente de la policía Rull ${ }^{41}$. La política de Maura estaba claramente dirigida contra el movimiento obrero organizado, pues al mismo tiempo que se presentaba la citada Ley contra el Terrorismo se discutía en el Senado un proyecto de ley sobre la huelga. Ante esta ofensiva legislativa, las izquierdas españolas reaccionaron vigorosamente: en abril de 1908 se celebraron mítines en Alicante contra la Ley de huelgas y la política de Maura ${ }^{42}$ y en mayo dió comienzo una fuerte campaña para frenar el proyecto de ley contra el terrorismo: ya en marzo se había organizado en Alcoy un mitin en la Escuela de Párvulos contra el sopechoso terrorismo de Barcelona ${ }^{43}$. A finales de mayo se recogieron firmas en Alcoy y Alicante para enviar al Congreso de los Diputados el siguiente texto:

"Los infrascritos, vecinos de..., ruegan al Congreso de Diputados rechace el proyecto de ley reformando la de delitos cometidos.

39 «Diario de Alicante», 15, 16 y 17-VIII-1907 / «El Demócrata» (Alicante), 18-VIII-1907.

40 "Ni Alcoy, ni Cullera, ni el Grao, ni Sueca, ni Alicante, ni las sierras de Cartagena... aparecen a nuestra vista aquí): MANUEL BUENACASA, El movimiento obrero español. Historia y crítica (1886-1926). París. 1966.

${ }^{41}$ Sobre Rull puede verse GILLES LAPOUGE - JEAN BECARUD, Los anarquistas españoles. Anagrama. Barcelona. 1972. Pg. 65.

42. «El Graduador», 15-IV-1908 / Para este diario (13-V-1908) «el terrorismo, tenemos la íntima seguridad de que se combate con medidas de cultura, más que con medidas de represión».

${ }^{43}$ "Fraternidad», 4-IV-1908. 
por medio de explosivos, estimando que infringe los principios constitucionales» ${ }^{44}$.

$Y$ en las primeras semanas de junio de 1908 se organizaron numerosos mítines contra el proyecto de ley: en Elche, el anarquista José Galiano solicitó el permiso para el mitin, que se llevó a cabo el 6 de junio ${ }^{45}$; en Alcoy asistió una enorme concurrencia, más de cuatro mil personas ${ }^{46}$. En Alicante se celebraron tres mítines, organizados respectivamente por los anarquistas, los socialistas y los republicanos, aunque colaboraron también los liberales dinásticos. No cuajó la propuesta de «Diario de Alicante» de organizar un mitin conjunto ${ }^{47}$. El día 7 se celebró en el Teatro Circo un mitin «respondiendo al gesto de indignación que en España entera se promueve contra el monstruoso y absurdo proyecto de ley de represión del terrorismo», que organizaron los anarquistas. La concurrencia «no es muy numerosa» - lo que indicaría, frente a los otros mítines, que tuvieron mayor eco, la escasa implantación de los anarquistas en la ciudad de Alicante-. Carlos Botella dio lectura a varias adhesiones. Intervinieron Juan Gomis, Valverde - que «pide que se apruebe el proyecto famoso para conseguir que el obrero sea de una vez hombre y conquiste por la fuerza los derechos que hoy mendiga humildemente»-, Aguilar - redactor del periódico ácrata valenciano «Humanidad Nueva»-, Aguado - en nombre de los anarquistas de Elche-, el anarquista catalán Solá y el republicano doctor Rico. Los asistentes aprobaron por unanimidad las siguientes conclusiones:

«1. - Los defensores de la democracia española esperamos sea pronto ley la proyectada contra el terrorismo.

2. - Sabemos conculca la Constitución, pero estimamos que aprobada ardería España por los cuatro costados, acabando con todas las leyes de excepción que cual el actual proyecto aten-

${ }^{44}$ «Fraternidad» y "Diario de Alicante», 30-III-1908 / En Alicante se recogen firmas en el Centro de Sociedades Obreras, el Círculo Republicano, el Centro de Escritores y Artistas y «Diario de Alicante».

${ }^{45}$ Puede verse la instancia en el ARCHIVO MUNICIPAL DE ELCHE, Legajo 50 / "La Correspondencia de Alicante», 9-VI-1908: al mitin asisten unas 3.000 personas y el orador Solá asegura que las autoridades y la policía catalanas eran los autores de las acciones terroristas.

46 "Fraternidad", 6-VI-1908 / Preside el obrero Francisco Martínez y hablan Eduardo Marhuenda (colaborador de «Fraternidad»), los obreros César Ruíz y Ramón Esplugues, el periodista Gonzalo Barceló, el socialista Salvador Palacios, Ricardo Gil, que lo hace en valenciano, y el líder republicano Botella Asensi. Al final, se adhieren a las conclusiones del mitin celebrado en Madrid.

${ }^{47}$ «Diario de Alicante». 3 y 5-VI-1908 / Ello, pese a la adhesión a la idea de «La Unión Democrática», "El Demócrata», «El Graduador», el Centro de Sociedades Obreras, la Juventud Alicantina, politicos liberales, socialistas y republicanos, etc. 
tan a nuestras libertades individuales reconocidas constitucionalmente.

3. - Aceptamos para anular las leyes todas de excepción el concurso de todos los elementos sociales que combaten a toda clase de gobierno que represente al actual régimen ${ }^{48}$.

Poco después se celebró en el Centro de Sociedades Obreras el mitin que organizaban los socialistas ${ }^{49}$ y otro, en el Teatro Principal, que organizaron republicanos y liberales: hablaron en este último el director de "Diario de Alicante» Emilio Costa, los republicanos E. Irles, Rafael Sevila y Juan Botella Asensi ${ }^{50}$ y los liberales dinásticos Ortega y Gasset y Francos Rodríguez. Las conclusiones aprobadas fueron las siguientes:

«1. - Protestar del intento que significa el proyecto de ley llamado del terrorismo.

2. - Proclamar la necesidad de que la España liberal, fuerte al estar unida, destruya la obra de los que quieren obligarle a retrasar el curso de su historia.

3. - Adherirse a la campaña que en toda España se realiza contra los propósitos del Gobierno» ${ }^{51}$.

Como es sabido, esta campaña tuvo éxito y Maura retiró el proyecto de ley del Parlamento ${ }^{52}$.

\section{DE "SOLIDARIDAD OBRERA» A LA CONFEDERACION NACIONAL DE TRABAJADORES}

En general, en estos primeros años del siglo los grupos anarquistas no tenían mucha influencia entre la clase obrera: Alcoy era la excepción, aunque el predominio anarquista sobre la clase obrera alcoyana estaba en cuestión por la presencia socialista, el influjo de los republicanos de Botella Asensi y, sobre todo, por la represión de las autoridades: así, en marzo de 1909 fueron detenidos bajo la acusación de ser anarquistas Enrique Catalá, Salvador Palacios y Camilo Monllor - y

${ }^{48}$ «Diario de Alicante», 8-VI-1908 / «El Graduador», 9-VI-1908. Al parecer, Solá era redactor de «Tierra y Libertad». Según la prensa, el local, castigado por el sol, restó mucho público («El Demócrata» y «La Correspondecia de Alicante», 8-VI-1908 / «Heraldo de Alicante», 8-VI-1908).

${ }^{49}$ «Diario de Alicante», 15-VI-1908 / «La Federación», 17-VI-1908.

${ }^{50}$ Cuyo discurso recoge integro «Fraternidad», 20-VI-1908.

${ }^{51}$ "Diario de Alicante», 12-VI-1908 / Más información en el «Heraldo de Alicante» y «El Demócrata», 12-VI-1908, "Diario de Alicante» 15-VI-1908 y "La Federación», 17-VI-1908.

${ }^{52}$ El triunfo, editorial de «El Demócrata», 1-VI-1908, comentando la retirada por el gobierno de este proyecto de ley tachado por todos los demócratas de reaccionario. 
al día siguiente, cuando acudian a llevarles comida, también fueron detenidos José Gironés y Camilo Nieto - , pero los obreros obtuvieron del alcalde que gestionase su libertad ${ }^{53}$. Los anarquistas "puros», sin embago, rechazaron hasta 1907 la actuación sindicalista y vegetaban, escasos en número, sin auditorio ni influencia sobre las masas ${ }^{54}$. La situación comenzó a cambiar con la fundación de "Solidaridad Obrera» en agosto de 1907.

Aunque, como ha demostrado Xavier Cuadrat ${ }^{55}$, "Solidaridad Obrera» se fundó en 1904, fue en el verano de 1907 cuando se procedió a su reorganización y extensión. En esos primeros años del siglo $X X$ hubo una gran interacción entre el movimiento obrero catalán y el francés: en 1902 el socialista Millerand entró en el gobierno de Waldeck Rousseau y en 1905 los diferentes partidos socialistas se fusionaron en la SFIO, que dirigía Jean Jaurés. En 1906 se celebró por la C.G.T. el Congreso de Amiens, donde triunfó la postura que propugnaba la independencia del movimiento sindical de todo partido político (la llamada "Carta de Amiens»). Este "sindicalismo revolucionario» habría de tener gran influencia en el movimiento obrero catalán, ejerciendo también un claro influjo sobre la C.N.T.

«El carácter economicista y pragmatico del sindicalismo explica la colaboración de socialistas, republicanos, antiguos anarquistas y nuevos sindicalistas en el seno de "Solidaridad Obrera», afirma Cuadrat. En efecto, aunque los ácratas intervinieron activamente en la formación de "Solidaridad Obrera», esta organización no llegó a adoptar un programa abiertamente libertario por la presencia de destacados socialistas, como Antonio Badia, y sectores puramente sindicalistas. El apoyo de Ferrer se limitó a financiar en parte el local y el periódico de «Solidaridad Obrera». En septiembre de 1908 se celebró el Congreso Obrero de Cataluña, donde se constituyó la llamada "Confederación Regional de Sociedades de Resistencia Solidaridad Obrera», con una participación importante de los socialistas catalanes - en tanto que la UGT apenas contaba con 6 secciones en Barcelona y ninguna en el resto de Cataluña-. Al calor de este Congreso surgieron, probablemente impulsados por los ácratas, intentos de reorganización de los Sindicatos en varias localidades españolas, concretamente en Gijón, Jerez, Montilla y Alcoy. No parece cierto, como asegura Pestaña, que estas sociedades obreras pidieran el ingreso en "Solidaridad Obrera», porque esta era una organización regional, pero se las consideró adheridas.

53 «Fraternidad», 20-III-1909.

${ }^{54}$ CESAR M. LORENZO, Los anarquistas españoles y el poder.

${ }^{55}$ XAVIER CUADRAT, Notas sobre el movimiento obrero catalán: los socialistas y "Solidaridad Obrera» (1907-1909), en «Revista de Trabajo». n. 46. Madrid. 1974. 
«Solidaridad Obrera» tuvo una destacada actuación en la Semana Trágica de Barcelona. En la provincia de Alicante, la agitación contra la guerra de Marruecos de 1909 contó también con la participación de los anarquistas, sobre todo en Alcoy - colaborando con socialistas y republicanos radicales, dirigidos éstos por Botella Asensi, que fue procesado por publicar un manifiesto y encabezar una manifestación de protesta-. Hubo varios heridos y numerosos detenidos, y una huelga general que duró cuatro días. Al final de esta protesta contra el envío de tropas a Marruecos cincuenta y cuatro alcoyanos fueron procesados por sedición o agresión a la fuerza pública ${ }^{56}$.

Tras la represión subsiguiente a la Semana Trágica, hubo un recrudecimiento de los conflictos sociales. En "Solidaridad Obrera» se recibían sugerencias de numerosas sociedades de localidades no catalanas en el sentido de extender a todo el estado esa organización sindical; de otro lado, los socialistas dudaban respecto a la táctica a seguir, ante la aparición de la Conjunción Republicano-Socialista. Por fin se celebró un Congreso Obrero Nacional, durante los días 30 y 31 de octubre y 1 de noviembre de 1910, en el Palacio de Bellas Artes de Barcelona, que daria lugar a la Confederación Nacional del Trabajo.

En este Congreso de constitución de la C.N.T. participaron algunas sociedades obreras alcoyanas: según Cuadrat ${ }^{5}$, Alcoy estuvo representada por Rogelio Cantó y Rafael Bernabeu, en nombre de los Tejedores Mecánicos y la «Unión del Arte Textil», aunque hay alguna confusión al respecto ${ }^{58}$. De la lectura de las actas del Congreso se desprende que Rogelio Cantó representaba a la Sociedad de Tejedores Mecánicos "La Unica» de Alcoy, y Rafael Bernabeu a la "Unión del Arte Fabril», en tanto que la Sociedad de Hiladores Mecánicos «La Constancia» de Alcoy figuraba entre las sociedades adheridas. No hemos

${ }^{56}$ JAUME PEREZ MONTANER, Els fets d'Alcoi i la guerra del Marroc, Comunicación al I Congreso de Historia del País Valenciano.

57 XAVIER CUADRAT, De la Confederación Regional Solidaridad Obrera a la CNT, en «Revista de Trabajo» n. 48 Madrid. 1974.

${ }_{58}$ En las actas del Congreso aparece repetidas veces Rogelio Cantó como representante de los Tejedores Mecánicos de Alcoy y partícipe en los trabajos de varias ponencias. Pero en la relación final, la única sociedad de Alcoy representada es "La Unión del Arte Fabril» y, además, aparece como miembro de alguna ponencia Rafael Bernabeu, representante de "La Unión del Arte Textil» de Alcoy. Según Cuadrat, se trataría de dos entidades distintas, pero creemos que era una sola. Se extraña también Cuadrat de que los Tejedores Mecánicos aparezcan entre los adheridos al Congreso. Creemos que ello sería posible, pese a la destacada actuación de su representante Rogelio Cantó, y sería una prueba de la actitud expectante de algunas sociedades obreras ante el Congreso. En suma, pensamos que hubo en el Congreso constitutivo de la CNT una sociedad alcoyana participante - «La Unión del Arte Textil» - y dos adheridas «Tejedores Mecánicos» e «Hiladores Mecánicos»-. 
podido identificar a Rafael Bernabeu, pero sabemos que Rogelio Cantó era uno de los líderes de los socialistas alcoyanos. Cuadrat señala la intervención en el Congreso de otros socialistas, como Puig o Jacinto Durán, que trataron de impedir la conversión de la Confederación Regional Catalana en Confederación Nacional ${ }^{59}$. Resulta algo extraño que Cantó fuese en representación de los Tejedores alcoyanos, dada su ideología, pero eran momentos en que anarquistas y socialistas colaboraban estrechamente, tras los hechos de la Semana Trágica y también hay que tener en cuenta que, antes del Congreso, no estaba aún clara la definición ideológica de ese sindicalismo que estaba a punto de surgir.

Rafael Bernabeu fue nombrado para la comisión revisora de actas y participó en una ponencia sobre el trabajo de la mujer, que fue aprobada por aclamación. Mayor intervención tuvo Rogelio Cantó: junto a J. Bueso, J. Benet, M. Mañé y otros representantes de Sevilla, Barćelona y Badalona, formó parte de la Quinta Ponencia, que estudió los siguientes temas: «Medios para conseguir la jornada de ocho horas. Salario mínimo»" ${ }^{60}$ "La huelga general, para que surta efectos de eficaz defensa del proletariado, ¿puede ser pacífica o ha de ser esencialmente revolucionaria?» ${ }^{61}$ y "Cuando estando una sociedad federada en lucha es atropellada por la policía o la fuerza pública, ¿qué actitud han de adoptar las demás secciones federadas?» ${ }^{62}$. En todas ellas, se evidenció

${ }^{59}$ Sin embargo, también sabemos que Cantó estuvo trabajando durante algún tiempo en Cataluña, en el textil. Creemos, aunque no podemos probarlo suficientemente, que Cantó era ya en esos momentos hombre de ideologia socialista. En 1911, la Agrupación Socialista de Alcoy envió a Cantó a Bañeres para organizar a los obreros papeleros, entonces en huelga contra el patrono Laporta («Fraternidad», 16-III-1918) / En «El Mundo Obrero», 3-IV-1920, Cantó recuerda a J. Bueso, con quien coincidió en el Congreso de la CNT de 1911, y dice: «A últimos del año 1911, y a consecuencia de la gran huelga que sostuvo el Arte Fabril de Tarrasa, me vine a Alcoy, ausentándome contra mi voluntad de la región catalana donde tan buenos amigos tenía». ¿Confundia Cantó el Congreso de 1911 con el de 1910?.

${ }_{60}$ Para lo primero, era necesario emprender una activa campaña de concienciación, pues la lucha por el salario mínimo era fácilmente superada por el alza contínua de los precios de las subsistencias. Se acordó que, cuando la conciencia de clase estuviese firme, se decretaria «por medio de la Confederación, la conquista de las ocho horas, a la cual han de contribuir todos los obreros».

${ }^{61}$ Se acordó que la huelga general habia de ser revolucionaria, porque «la huelga general pacífica es imposible que pueda ser duradera». Ahora bien, no podia usarse a la ligera: tenía que declararse en toda la nación, cuando la Confederación se hubiese consolidado, o cuando se produjese una guerra o cuando los obreros de una localidad o provincia se viesen obligados a proclamarla por la presión de la burguesía.

${ }^{62}$ La fuerza pública, según la ponencia, estaba al servicio del capital y no del pueblo. La neutralidad de los gobiernos era pura ilusión: de ahí que todos los medios para apoyar a los obreros atropellados fuesen lícitos - mitin, boicot, sabotaje, etc. - y no podian depender más que del entusiasmo y conciencia de clase existentes en cada momento. 
ya el carácter combativo y apolítico de la Confederación, aunque todavía con algunos matices, tales como el uso moderado de la huelga general, que no se debía emplear sino «para lograr una transformación total en el modo de producir y distribuir los productos».

También participó Cantó en la discusión de otro importante dictamen: "La emancipación de los trabajadores ha de ser obra de los trabajadores mismos. ¿Cuál es la única y verdadera interpretación que debe darse a esta frase?». La ponencia hacia alusión a los trabajadores intelectuales y señalaba los peligros de que se erigiesen en directores del movimiento obrero, aunque se mostraba dispuesta a acogerlos si sustituían su ideal de encumbramiento individual por el de la emancipación colectiva. Rogelio Cantó aseguró que «a su modo de ver, son más explotados hoy en día los obreros intelectuales que los obreros del terruño y del taller» y concluyó que "no puede considerarse obreros a los que ejercen de funcionarios en las instituciones burguesas, pero si a los que trabajaban desde su bufete, desde su biblioteca o desde su cuarto de estudio para el mejoramiento intelectual del obrero».

En cambio, no intervino Rogelio Cantó en la discusión fundamental del Congreso, sobre si «Solidaridad Obrera» debía pasar, o no, a ser una Confederación Nacional. La ponencia propuso que se constituyese una Confederación General del Trabajo con las entidades no acogidas a la U.G.T. y una vez constituída «se procure llegar a un acuerdo entre las dos Federaciones, a fin de unir a toda la clase obrera en una sola organización». Según otros, "Solidaridad Obrera» debía seguir a nivel regional e incluso apuntaban que la U.G.T. cambiaría con el ingreso de una Federación Catalana en ella. Negre negó la acusación de que la nueva organización estuviese compuesta por anarquistas, pues las decisiones se tomaban con neutralidad y formaban parte de ella «obreros de todos los matices». Al final, 84 votaron a favor de la constitución de una organización nacional, 14 en contra y 3 se abstuvieron. Lo que votaron Bernabeu y Cantó, lo ignoramos ${ }^{63}$.

Pese a las críticas a la U.G.T., la recién nacida C.N.T. no presentaba una ideología decididamente anarquista. Sin embargo, el descontento que en muchos lugares - Cataluña, la propia Alcoy - había en relación a las tácticas de la U.G.T. provocaría una gradual conversión de la C.N.T. en un sindicato influído por los ácratas y los sindicalistas apolíticos $^{64}$. En los momentos de la fundación, la ideología estaba to-

${ }^{63}$ Congreso de constitución de la Confederación Nacional del Trabajo. Anagrama. Barcelona. 1976.

64 ANTONIO BAR, Algunas puntualizaciones sobre la ideología del sindicalismo radical en España, en «Estudios sobre Historia de España: Homenaje a Tuñon de Lara». Madrid. 1981. Pgs. 191-200, y La CNT en los años rojos: del sindicalismo revolucionario al anarcosindicalismo. 1910-1928. Madrid. Akal. 1981, niega también el pre- 
davía poco definida y, desde luego, era mucho más moderada que la proclamada en la citada "Carta de Amiens». Las diferencias con el sindicalismo francés eran todavía bastantes grandes ${ }^{65}$. No hay que descartar, en el retraso en constituir un sindicato a nivel estatal, la importancia de la actitud de muchos anarquistas que, desde posiciones económicas anticuadas, temían que el paso de las sociedades de oficio a las grandes federaciones de industria se hiciese en detrimento de la «ortodoxia» libertaria ${ }^{6}$.

En la provincia de Alicante, comenzaron a partir de 1910 los anarquistas a tratar de lograr una mayor presencia entre la clase obrera. Seguían contando con el problema que suponía la vigilancia y la represión de las autoridades: así, en agosto de 1910 fue detenido en Alcoy y encarcelado en Alicante José Claramunt, «de ideas avanzadas» y procedente de Barcelona; le visitaron algunos republicanos, que telegrafiaron a Emiliano Iglesias y a otros políticos para obtener su libertad ${ }^{67}$. En Alicante, los anarquistas aprovecharon la hospitalidad que les prestaba el periódico republicano «El Pueblo» para rechazar las acusaciones contra ello. Bruno Ibáñez replicó a un artículo publicado en la prensa conservadora y titulado «El terrorismo en acción»: las bombas de Barcelona las ponía Rull y los anarquistas «somos precisamente los más activos defensores de la verdadera justicia y de cuanto esté dentro de la lógica». Carlos Botella, que con Juan Gomis ostentaba el liderazgo entre los ácratas alicantinos, terció en la polémica negando que los anarquistas pusieron bombas: "Han sido siempre los anarquistas los primeros quienes han lanzado su enérgica protesta ante la faz del mundo entero en contra de estos actos de barbarie, los cuales únicamente traen consigo sembrar el espanto y el dolor entre aquellos que sufren sus consecuencias» ${ }^{\circledR}$.

dominio de la ideología anarquista en el origen de la CNT, contra lo que se venía diciendo habitualmente. Asegura, en cambio, que la CNT es consecuencia directa de la introducción en España del sindicalismo revolucionario de origen francés, que pretendía una especie de "tercera vía» entre marxismo y anarquismo, y proclamaba su apoliticismo o neutralismo ideológico. La retirada de los socialistas de la CNT dejó el campo libre a los anarquistas para un trabajo ideológico, que fue penetrando - no sin reticencias y dando origen a la corriente anarcosindicalista - en esta central sindical, a partir de su vuelta a la legalidad en la primavera de 1914.

${ }^{65}$ En el sindicalismo francés, se recomendaba un uso más frecuente de la huelga general; al sindicalismo se le consideraba no sólo un medio, sino un fin, pues sustituiría al Estado como base de la organización de la sociedad; y, sobre todo, propugnaba la C.G.T. la constitución inmediata de Federaciones de Industria, mientras que la CNT defendía la organización «en artes y oficios».

${ }^{66}$ XAVIER PANIAGUA, La ideología económica de los anarquistas en Catáluña y el País Valenciano, en "Saitabi», n. 24. Valencia. 1974.

67 "El Pueblo Republicano» (Alicante), 13-VIII-1910 / "La Voz de Alicante», 17-VIII-1910: están detenidos los «agitadores» Claramunt y Luis Granados.

"68 "El Pueblo Republicano», 30-V y 3-VI-1910. 
De la lectura de "Tierra y Libertad»" se deduce la existencia de grupos anarquistas en Alcoy, Alicante, Elche, Monóvar, Elda y Cocentaina. En Alcoy, las ideas anarquistas se propagaban con rapidez y en julio de 1910 se había formado un grupo «Pro-prensa libertaria y sindicación revolucionaria» ${ }^{70}$. En Elche, el grupo "Ser o No Ser» propuso una reunión de sociedades obreras de la provincia de Alicante para ver de salir del estado "de postración» - sería una manera de proponer la nueva organización de la CNT - y en mayo de 1911, ante el aumento de compañeros, creó un nuevo grupo anarquista, llamado "Los Antijudas»" ${ }^{71}$. En Elda se constituyó en 1911 el grupo "Los Invencibles», con José Gil, para propagar las ideas anarquistas ${ }^{72}$. Se asegura que en Alicante las ideas anarquistas estaban fermentando más deprisa de lo esperado $^{73}$ : se habia conseguido cierto peso específico en alguna sociedad obrera, como la de los Pintores, que en mayo de 1911 organizó un mitin «contra el indigno proceder de la burguesía» y en petición de la libertad de los presos sociales ${ }^{74}$.

En Agosto de 1911, poco antes del Primer Congreso de la C.N.T. - que también se celebró en el Palacio de Bellas Artes de Barcelona-, Morato hizo balance en "Heraldo de Madrid» de las fuerzas de la nueva central sindical, tomando los datos de "Solidaridad Obrera»: en Levante había cinco entidades afiliadas a la C.N.T. con 1.022 afiliados (por el número de inscritos, ocupaba Levante la tercera posición, tras CataIuña y Andalucía). En la provincia de Alicante había una sociedad afiliada a la C.N.T. en Alcoy, otra en Alicante - donde al poco tiempo ingresó una segunda sociedad - y otra en Elche. Carlos Botella asiste en representación de Alicante al Primer Congreso de la C.N.T., que se celebró en los primeros días de septiembre de 1911, e intervino en la sesión de clausura ${ }^{75}$.

La C.N.T. fue, sin embargo, puesta fuera de la ley poco tiempo después, tras la huelga general que se produjo a partir del 16 de septiembre y que provocó graves disturbios en Cullera. Esta huelga tuvo

${ }^{69}$ "Tierra y Libertad», en su cuarta época, entre el 24-11-1910 y el 31-V-1911.

70 MILAGROS RODRIGUEZ, A los anarquistas de Alcoy, en "Tierra y Libertad", 19-V-1910 (Alcoy «no irá a la zaga en la cuestión social») / ANTONIO TOMAS, A la juventud anarquista de Alcoy, en «Tierra y Libertad», 8-VI-1910 (contra la degradación en las fiestas de Moros y Cristianos) / Véase también, de este semanario, el número del 6-VII-1910.

71 «Tierra y Libertad», 26-X-1910 y 31-V-1911.

12 "Tierra y Libertad", 1-II-1911.

${ }^{73}$ MANUEL OLCINA, Para los de Alicante, en "Tierra y Libertad», 6-VII-1910. El corresponsal en Alicante era Bruno Ibáñez.

${ }_{74}^{74}$ "El Liberal» (Alicante), 27-V-1911.

${ }_{75} \mathrm{M}$. TUÑON DE LARA, El movimiento obrero en la Historia de España. Taurus. Madrid. 1972. Pág. 495. 
epercusiones en Alcoy, donde socialistas y sindicalistas colaboraron en la organización de una huelga pacífica a partir del 20 de septiembre ${ }^{76}$. La prensa de Valencia publicó alarmantes y falsas noticias sobre incendios de fábricas y conventos y asalto al cuartel de Infantería de Alcoy que fueron desmentidas por la prensa local ${ }^{77}$. Las sociedades obreras alcoyanas desconvocaron el paro el 23 de septiembre, por considerar que «nuestra solidaridad queda cumplida desde el momento que la huelga de Bilbao ha terminado ${ }^{78}$. En Alicante, las autoridades tomaron precauciones y fueron detenidos los anarquistas Bruno lbáñez y Carlos Botella, upor sus ideas avanzadas y su entusiasmo por la causa del proletariado $)^{79}$.

Para poder seguir actuando, los anarquistas acudieron entonces a la fundación de Ateneos Sindicalistas: el primero había sido organizado en Barcelona en julio de 1909. En Alicante se fundó en noviembre de $1911^{80}$ y en Alcoy en febrero de $1912^{81}$. El Ateneo Sindicalista Obrero alicantino se integró, en un primer momento, en el Centro de Sociedades Obreras, donde también tenía su domicilio la Agrupación Socialista. Se proyectaba entonces la edificación de una Casa del Pueblo y se creó una comisión gestora: muy pronto comenzaron los enfrentamietos entre socialistas y anarquistas por el control de las sociedades obreras alicantinas. En la prensa apareció un escrito de algunas sociedades obreras - entre sus representantes aparecen los destacados anarquistas Juan Gomis y Carlos Botella - que denunciaban los que consideraban manejos de los socialistas: la comisión gestora había sido elegida a espaldas de algunas Sociedades Obreras, que no estaban conformes en que la Casa del Pueblo futura «sirva de albergue a un partido político que nada tiene que ver con los Sindicatos, y que, al final, sería quien se apoderaría de todo». A ello se oponían las sociedades de canteros, torneros, barberos, panaderos, pintores y aserradores mecánicos, que declaraban no odiar a los partidos políticos, pero reclamaban igualdad para todos los obreros, fuese cual fuese su ideología política. En suma, estas sociedades obreras influídas por los anarquistas se mostraban partidarias de que la Casa del Pueblo fuese un Centro exclusiva-

${ }^{76}$ "Diario de Alicante», "El Pueblo Republicano», "La Voz de Alicante» y "La Defensa» (Alcoy), 20-IX-1911 / «Fraternidad», 18-IX-1911.

${ }_{77}$ Una novela fantástica, en "La Defensa», 23-IX-1911.

${ }_{78}^{72}$ "La Defensa», 23-IX-1911.

${ }^{79}$ "El Pueblo Republicano", 21-IX-1911.

${ }^{80}$ "Periódico para todos» (Alicante), 28-XI-1911, da cuenta de la constitución del Ateneo Sindicalista Obrero alicantino: en su directiva figuran José Guijarro, Arnaldo Manón, José Jover y otros, pero están ausentes los líderes anarquistas más conocidos. / "Diario de Alicante», 27-XI-1912: el Ateneo Sindicalista celebra velada en su primer aniversario.

${ }^{81}$ El Ateneo Sindicalista de Alcoy presenta su reglamento al Gobierno Civil. («Diario de Alicante», 24-(I-1912). 
mente obrero ${ }^{82}$.

En noviembre de 1911 fueron clausuradas en Alcoy y Alicante algunas Sociedades Obreras, por mandato judicial del Juzgado de Instrucción de Barcelona ${ }^{83}$. Ante estas medidas represivas, los anarquistas organizaron, en la medida de sus fuerzas, varias actividades en favor de los presos sociales, impulsando la formación de comités Propresos y la organización de mítines en el mismo sentido: en Elche, los anarquistas organizaron el 10 de diciembre un mitin de protesta por el encarcelamiento de obreros al que invitaron a todos los trabajadores y a los «hombres altruistas»: "Queremos la libertad de los compañeros presos por cuestiones políticas y sociales, considerando como tales compañeros a los que en todas las naciones luchan por la emancipación obrera y declarando que para su acción no reconocen los límites de la geografía oficial» ${ }^{24}$. Y en enero de 1912 se constituyó el Comité Pro-presos en Elche, en el que tenían un destacado papel los grupos anarquistas "Ser o No Ser» - que será el más duradero-, "Rebeldes en acción» y «Anti-Judas» ${ }^{85}$. En Alicante se celebró, también en enero, un mitin Pro-Presos, que presidió el citado Carlos Botella y en el que intervinieron los anarquistas Aguado, de Elche, y Catalá, de Alcoy, y los republicanos Baldomero López Arias y Pascual Ors ${ }^{86}$.

Los grupos ácratas de la provincia - en Elda, Alicante, Alcoy y Elche - actuaban como podian, a través de los citados Comités ProPresos, en el seno de las Sociedades Obreras y a través de la prensa: en mayo apareció en Elche el periódico mensual - luego quincenal, aunque su vida sería muy corta - «Liberación», que se subtitulaba «perió-

82 «El Pueblo Republicano», 14 y 18-X-1911 / Más datos sobre la polémica entre anarquistas y socialistas en torno a la Casa del Pueblo, en "Periódico para todos», 23-VIII-1911; "La Unión Democrática», 3-VIII-1911; "Eco de Levante», 23-VIII, 18 y 23-X-1911; y «Diario de Alicante», 16-XI-1911 / También en Elche, la Sociedad de Zapateros "La Racional», impulsada.por los libertarios, se negó a ingresar en el Círculo Obrero Illicitano porque alli se albergaba el PSOE (Folletos, sin fecha, titulados Sociedad de Zapateros "La Racional" y A los trabajdores con alteza de miras, en el Archivo Municipal de Elche), lo que privaba a los ácratas de ejercer mayor influencia sobre los obreros de la localidad.

${ }^{83}$ La Sociedad de Canteros de Alicante, según «Eco de Levante», 17-XI-1911 / "La Montadora» de metalúrgicos y «La Lucha» de pintores, según «El Noticiero» y «Periódico para todos», 17-XI-1911 / En Alcoy, fue clausurada la «Sociedad Unión del Arte Fabril» («La Voz de Alicante», 16-XI-1911).

${ }^{84}$ Folleto en el Archivo Municipal de Elche.

85 "La Razón» (Elche), 7-ł-1912.

${ }^{86}$ «Eco de Levante», 29-I-1912 / «Periódico para todos», 27 y 28-1-1912 / «La Voz de Alicante», 29-I-1912, asegura que la concurrencia fue "escasa en grado irrisorio». Además de la libertad de los presos, se pedía también la derogación de la Ley de Jurisdicciones, la abolición de la pena de muerte y el fin de la persecución contra las sociedades obreras («La Unión Democrática», 28 y 30-I-1912). 
dico anarquista y de propaganda sindicalista» ${ }^{87}$. En los escasos números que se conservan, se pueden leer artículos sobre el auténtico significado del Primero de Mayo, colaboraciones de Soledad Gustavo, Anselmo Lorenzo y José Prat; frecuentes polémicas con los socialistas y propaganda de folletos como «La Imprenta y la Iglesia», o «Devocionario político» - «dedicado a los santos jefes del partido obrero español»-. En el mes de julio, "Liberación» daba la noticia de la constitución en Alicante de un nuevo grupo anarquista, que tomó el nombre de «Espartaco»" ${ }^{88}$.

En los primeros meses de 1912 continuó la polémica en el Centro de Sociedades Obreras de Alicante entre anarquistas y socialistas. Según un informe publicado a primeros de mayo en «Diario de Alicante»" el Primero de Mayo publicó el Ateneo Sindicalista Obrero un panfleto en el que se criticaba a los socialistas, que convocaron entonces una reunión en el Centro de Sociedades Obreras para expulsar al Ateneo Sindicalista Obrero. Ambas partes desfilaron por el Gobierno Civil «para pedir amparo a sus respectivos derechos», cosa sorprendente en el caso de los ácratas. La asamblea fue tumultuosa: los socialistas propusieron al Consejo de Delegados la expulsión del Ateneo y pareció prevalecer este criterio; los anarquistas propusieron que tanto el Ateneo Sindicalista como la Agrupación Socialista abandonasen el Centro de Sociedades Obreras ${ }^{90}$. Los socialistas dieron tres días al Ateneo para abandonar el local, al tiempo que trataban de expulsar también a las Sociedades de Torneros y Panaderos, donde tenían gran influencia los ácratas. Los miembros del Ateneo Sindicalista se resistían a abandonar el local, alegando que estaba subvencionado por el Ayuntamiento para uso de todos los obreros, y los socialistas amenazaron con acudir a los tribunales. Poco después, la Sociedad de Torneros, Pulimentadores y Constructores de Camas pedía la expulsión, en una hoja que repartió, de la Agrupación Socialista y el Ateneo Sindicalista, «dejando al obrero libre de los políticos». Solicitaba del Gobernador Civil que, de acuerdo con la Ley de Asociaciones, hiciera salir del Centro Obrero a ambos bandos: «Trabajadores: el Centro de Sociedades Obreras debe ser para los obreros solos. ¡¡FUERA TODA POLITICA!! » ${ }^{91}$.

El asunto se resolvió con la marcha de los socialistas - a un local de la calle de Castaños y, posteriormente, a la Casa del Pueblo, en su

\footnotetext{
${ }^{87}$ Se conservan algunos números - once, entre el 1 de mayo y el 30 de noviembre de 1912- en el Archivo Municipal de Elche. Es quincenal a partir de julio.

88 "Liberación», 21-VII-1912.

89 Fraternidad obrera, en "Diario de Alicante», 3, 4 y 6-V-1912.

90 "Diario de Alicante» apoya esta solución: asi «quedarán en armonía los obreros y será una verdad llamarse el local Centro de Sociedades Obreras».

91 «Diario de Alicante», 9-V-1912.
} 
actual emplazamiento - y del Ateneo Sindicalista, que encontró acomodo en un Círculo Republicano ${ }^{92}$ " donde a partir de septiembre de 1912 llevaron a cabo diversas actividades, como charlas anticlericales y veladas literario-sociológicas ${ }^{93}$. La reapertura, en el mes de julio, de las sociedades de Canteros, Pintores y Metalúrgicos, que habían sido clausuradas tras la huelga de 1911, permitió a los anarcosindicalistas mejorar sus posiciones entre los trabajadores de la capital ${ }^{94}$.

A primeros de 1913 continuaron los anarquistas sus actividades en pro de la liberación de los presos económico-sociales. En Alcoy, la sociedad de zapateros organizó un mitin en la Escuela de Párvulos que resultó desanimado, a pesar de que se adhirieron todas las sociedades obreras ${ }^{95}$. El Ateneo Sindicalista de Alicante envió unas cuartillas -al no poder asistir - al mitin Pro-Presos que se celebró el 1 de enero de 1913 en Madrid y en el que intervinieron Mauro Bajatierra - que las leyó--, Salvador Seguí, Eduardo Barriobero, José Sánchez Rosa y Constancio Romeo ${ }^{96}$. Posteriormente, en noviembre, organizó una conferencia con participación del citado Barriobero - verdadero ídolo de los ácratas en estos años - y con presidencia de Carlos Botella: los ataques de Barriobero al clericalismo y al militarismo fueron muy aplaudi$\operatorname{dos}^{97}$.

En vísperas de la Guerra Mundial, los anarcosindicalistas continuaban su labor: denunciaban, mediante artículos en la prensa, conferencias o manifiestos con ocasión del Primero de Mayo, el peligro que suponían «esos que con el nombre de propagadores y defensores de los trabajadores, engañan a sus compañeros», los socialistas ${ }^{98}$; seguían

${ }_{92}$ «Diario de Alicante», 19-VII, 20-VIII y 13-IX-1912 / Resulta curiosa la hospitalidad de los republicanos con los anarquistas, cuando estaba vigente la Conjunción Republicano-Socialista.

${ }_{93}$ Conferencia sobre «Dios») del radical Fuentes («Diario de Alicante», 13-IX-1912); velada con textos «del sociólogo Anselmo Lorenzo» («Diario de Alicante», 19-XII-1912) y otras actividades ( «La Correspondencia de Alicante», 16-XII-1912). En enero de 1913 figuraban en su directiva José Guijarro, Manuel Esquembre, José Ribes y Vicente Oncina, entre otros («Periódico para todos», 4-I-1913).

${ }_{94}$ "Diario de Alicante», 8-VII-1912.

95 "Periódico para todos», 7-1-1913.

${ }_{96}$ "Periódico para todos», 8-I-1913.

97 "Periódico para todos», 8-XI-1913 / «Alicante Obrero», 6-XI-1913.

${ }^{98}$ Vicente Gomis, en «Diario de Alicante», 20-I-1913 / Manifiesto del Ateneo Sindicalista Obrero sobre «Origen e historia del Primero de Mayo» («La Unión Democrática», 29-IV-1913) / En un panfleto lanzado por los anarquistas de Elche el 1 de mayo de 1914, dirigido Al pueblo trabajador, compañeros hermanos de infortunio, se contrapone lo sucedido en 1886 en Chicago y la fiesta local, con gira campestre y entrega de peticiones a una autoridad que las recibía, año tras año, con total indiferencia. Al año siguiente, comparaban la celebración festiva preparada por los socialistas ilicitanos y la convocatoria anarquista del Congreso por la Paz en El Ferrol (Hojas en el Archivo Municipal de Elche). 
criticando la política y proponiendo la abstención en las elecciones ${ }^{99} y$, sobre todo, trataban de aumentar su peso específico entre la clase obrera organizada: estaban bien implantados en el textil alcoyano - la Sociedad de Tintoreros y Similares "La Emancipación» fue una de las pocas sociedades no catalanas que participó en el Congreso Nacional del Arte Fabril, celebrado en Barcelona, poco antes de la guerra mundial y en el cual se acordó la creación de la Federación Nacional del Arte Textil ${ }^{10}$, que pronto sería escenario de enfrentamientos entre socialistas $y$ anarquistas - ; dominaban el sector del calzado de Elda, donde la sociedad "La Racional» trataba de extender su influencia a Petrel ${ }^{101}$ y dominaban alguna de las sociedades obreras más combativas de la capital, como las de panaderos, pintores o metalúrgicos. "La Montadora», sociedad de los metalúrgicos alicantinos, convocó en mayo de 1914 un Congreso Nacional del oficio - que se celebró poco después en Alicante - en el que se consumó la separación de numerosas organizaciones de metalúrgicos de la Federación Nacional del oficio afecta a la U.G.T. y la constitución de una nueva Federación, adherida a la C.N.T. ${ }^{10}$.

La provinvia de Alicante era, en estos años, una de las que contaba con mayor implantación de las nuevas ideas anarcosindicalistas: como asegura Tuñón de Lara ${ }^{103}$, «la implantación regional de la primitiva C.N.T. se colige fácilmente de sus Congresos. En primer lugar, Cataluña (y particularmente Barcelona), luego Zaragoza, Valencia, Alicante, Alcoy, un núcleo muy importante en Gijón, otro en La Coruña y Vigo».

\section{ANARQUISTAS Y SINDICALISTAS ENTRE 1914 y 1917.}

En julio de 1914 se constituyó públicamente el secretariado nacional de la C.N.T., que volvía así a la legalidad. Poco después, ante el estallido de la Guerra Mundial, hubo cierta polémica entre los medios libertarios: la mayoría, desde «Tierra y Libertad» y «Solidaridad Obrera» ${ }^{104}$, sostuvieron la posición neutralista, de acuerdo con la tradicio-

${ }^{99}$ El semanario socialista «Trabajo», 24-V-1914, trata de convencerles de que voten publicando un texto de Malato, de "La bataille syndicaliste».

${ }^{100}$ Pueden leerse los Estatutos de la Federación Nacional del Arte Textil en «Boletín de Reformas Sociales", enero de 1914.

${ }^{101}$ Mitin en Petrel, en "Alicante Obrero», 8-VIII-1914, con los sindicalistas Vicente Gil, de Elda, Segundo García, de Alicante, y Antonio Loredo, de Barcelona.

102 «E Socialista», 15 y 16-IV-1814 / «Periódico para todos», 4-V, 23 y 30-VI y 1-VII-1914 / "Diario de Alicante», 30-VI y 1-VII-1914.

${ }^{103}$ M. TUÑON DE LARA, o.c. pg. 509.

${ }^{104}$ Como testimonia Pestaña, "Solidaridad Obrera» recibía dinero de la Embajada alemana, y en ese sentido, se hizo una intensa y documentada campaña contra la emigración a Francia. 
nal tónica antibelicista y antimilitarista de los ácratas; pero hubo un grupo, dirigido por Eleuterio Quintanilla y Ricardo Mella que sostuvo, en las páginas de "Acción Libertaria», una posición de apoyo a la "entente cordiale» y en contra del militarismo alemán. Como señalaba Angel Pestaña:

«lo chusco de todo esto, sin embargo, era que la mayoría de los que en Barcelona haciamos propaganda contra la guerra, y algunos de los que fuimos como delegados al Congreso de la Paz, de El Ferrol, trabajábamos para la guerra» ${ }^{105}$.

Entre los ácratas alicantinos predominó la posición neutral: así, Carlos Botella logró que el Congreso de Pintores en el que tomaba parte, en mayo de 1915, protestase por unanimidad de la suspensión por el Gobierno del Congreso de la Paz que había de celebrarse en El Ferrol, organizado por el Ateneo Obrero de aquella ciudad, de inspiración libertaria ${ }^{106}$. En el Congreso estuvieron representadas, por Antonio Loredo, las sociedades obreras de Elda, y se adhirieron - por estar de acuerdo "con los medios que acordaran para acabar con la guerra europea» - el Centro Obrero de Alcoy, la Sociedad de Oficios Varios de Alicante, el grupo "Juventud ácrata» de Elche, el grupo «Acción Social» de Alicante y la sociedad de Gabarreros del puerto de la capital ${ }^{107}$.

Con la enorme demanda de mano de obra que la neutralidad española en el conflicto europeo provocó, el papel de los sindicatos comenzó a subir. Con todo, en la C.N.T. no había todavía una política clara, por la existencia en su seno de dos tendencias básicas: la sindicalista pura y la anarquista, que recelaba de las grandes organizaciones donde peligraba, según ellos, la «pureza» de los principios. Gerald H. Meaker ha descrito así estas dos tendencias:

«El anarquismo expresaba una ética austera, una crítica casi total de la sociedad industrial burguesa y una nostalgia puritana de retorno a una era preindustrial e incorrupta; el sindicalismo, en cambio, evocaba la visión. más moderna de un mundo de obreros, racionalmente organizado, industrializado y productivo, pero expuesto al peligro de que el poder organizativo y las mejoras materiales se convirtieran en fines en sí mismos. El anarquismo, por su parte, hacía hincapié fuerte en la espontaneidad y localismo de la lu-

${ }^{105}$ ANGEL PESTAÑA, Lo que aprendi en la vida / Puede verse también la descripción que hace Victor Serge de la Barcelona de la época: «Todos éramos, más o menos, obreros de las fábricas de guerra. Paños, cueros, calzado, conservas, granadas, piezas para máquinas, todo, incluso fruta - naranjas olorosas de Valencia-, todo lo que habia en nuestras manos, todo lo que embalaban y manipulaban estaba destinado a la guerra" (G. LAPOUGE - J. BECAUD, o.c.).

106 "El Socialista», 21 y 22-V-1915.

${ }^{107}$ CARLOS FORCADELL, Parlamentarismo y bolchevización. Crítica. Barcelona. 1978. Págs. 368-370. 
cha revolucionaria; el sindicalismo implicaba una preocupación mayor por la preparación organizativa, por la planificación y por la dirección centralizada» ${ }^{108}$.

En la provincia de Alicante, en esos años, parece predominar todavía la actuación de los grupos anarquistas y el sindicalismo se encuentra aún poco desarrollado, con la excepción de Alcoy y Elda. La actuación de los grupos anarquistas se centró en la propaganda de los ideales libertarios y en la campaña en favor de los presos por motivos políticos y sociales. En agosto de 1914, el grupo anarquista de Alicante «Los Espartacos» organizó un mitin de propaganda en el Salón Moderno - «la tribuna será libre para cuantos quieran hacer uso de la palabra»-: se anuncia la visita de varios ácratas valencianos y, sobre todo, la del famoso propagandista libertario andaluz José Sánchez Rosa, al que acompañaba su hija Paca. El mitin lo presidió Carlos Botella e intervinieron también los alicantinos José Gomis y Manuel Esquembre. Sobre la asistencia, la prensa da noticias dispares: numerosa concurrencia, según algunos; menos de cien personas, según otros ${ }^{109}$.

En marzo de 1915 apareció en "Alicante Obrero" un llamamiento dirigido "a todos los anarquistas y sindicalistas de Elche» para tratar de reorganizar las escasas fuerzas allí existentes: el grupo "Ser o No Ser» y la "Juventud Acrata»" En septiembre de 1915 el mismo periódico - que con frecuencia abría sus páginas a la colaboración de los ácratas que firmaban sus artículos con pseudónimos tales como "Floreal», «Acracio del Orbe» O «L. de la Acracia» - testimoniaba la existencia de dos grupos ácratas en Elda, "Un tren en marcha» y "Los invencibles».

En febrero de 1915 se constituyó, en el Centro de Sociedades Obreras de la Avenida de Zorrilla de Alicante - donde se encontraban las sociedades obreras influídas por los sindicalistas, pues las cercanas a los socialistas se hallaban ya en la Casa del Pueblo-, una Comisión Pro-Presos, a iniciativa de la Sociedad de Oficios Varios «La Organiza-

108 GERALD H. MEAKER, Anarquistas y sindicatos. Conflictos en el seno de la CNT. 1917-1923. Akal. Madrid. 1978 / En julio de 1914, por ejemplo, el anarquista Antonio Loredo, en una charla que dió en Alicante, niega que sindicalismo y anarquismo sean lo mismo, pero se muestra partidario de la huelga general y el sabotaje, y enemigo del parlamentarismo («Las leyes pueden hacerse por medio de huelgas»): (Diario de Alicante», 11-VII-1914.

${ }^{109}$ "Periódico para todos», 8 y 10-VIII-1914 / «El Batallador» y «El Noticiero», 10-VIII-1914 / "Diario de Alicante», 8-VIII-1914 / "Alicante Obrero», 7-VIII-1914.

110 "Alicante Obrero", 26-III-1915 / En mayo de 1915, el grupo "Juventud Anarquista) de Elche lanzó un Manifiesto (Nosotros contra todos los politicos. Al pueblo trabajador, en el Archivo Municipal de Elche), con ocasión de un mitin maurista, para hacer profesión de fe antipolítica: «Somos los eternos combatidos, los siempre vilipendiados por toda laya de tiranos, por los que procuran por todos los medios conservar su imperio y su dominación sobre la masa y afirmar por la fuerza y la arbitrariedad de sus leyes, sus privilegios y prerrogativas». 
dora»"'. El Comité acordó iniciar la campaña «en pro de los desgraciados trabajadores que jimen dentro de las cárceles españolas por culpa de los mezquinos y desalmados gobernantes». Pidieron a todas las sociedades obreras que enviasen sus delegados al Comité, para que no se dijera que el asunto había sido manipulado por unos cuantos ${ }^{112}$.

El 17 de febrero, anunció el Comité un mitin Pro-Presos, con la participación de Eduardo Barriobero. La amnistía decretada en diciembre de 1914 apenas había alcanzado a algunos delitos de opinión y se consideraba una estafa para la clase obrera, al haberse excluído a los presos por cuestiones sociales, "los de Cullera, Benalgabón, Zaragoza y a cuantos tuvieron por necesidad que luchar y rebelarse contra un polizonte, burgués $u$ otro de esta calaña» ${ }^{113}$. En la convocatoria se invitaba a asistir al mitin a todos los hombres «amantes de la justicia», para conseguir la libertad de los presos - llegando, si fuera necesario, «a un paro general en España que obligara a los reaccionarios gobernantes a soltar de sus garras leoninas por la fuerza de la razón de la fuerza, la presa que hoy sostienen y que piensan devorarn-.

Al mitin asistió una «enorme concurrencia»; presidió Carlos Botella y los oradores evidenciaron posturas muy dispares. Por ejemplo, Barriobero abogó «por la unión de la falange de hombres honrados de la izquierda» imitando a la derecha que se unía para defender sus intereses; recordó que había presentado en el Parlamento una enmienda a la amnistía para que se incluyese a los obreros; se mostró partidario de «la abolición de la cárcel» al mismo tiempo que «aconseja a los obreros que estudien las excelencias del movimiento mercantil inglés, de dónde sacarán provechosas enseñanzas», y acabó su confuso y demagógico discurso afirmando que «es más partidario de la acción que de la palabra»" 11 .

En abril hubo nuevo mitin Pro-Presos: según los organizadores, el Gobierno no tenía un rasgo de nobleza y altruísmo, y por ello, sólo por medio de la prensa y de actos públicos se podría liberar a los que «lucharon por nuestros derechos de hombres", y hacer que "los malditos y enmohecidos goznes giren para abrir la puerta de la celda lúgubre $y$ den paso a un héroe defensor de los desheredados de la fortuna» ${ }^{115}$.

"1" «Periódico para todos», 10-II-1915. Componian el Comité V. Gomis, Segundo Garcia, Francisco Arenas y Bautista Casanova, entre otros.

112 «Periódico para todos», 9-11-1915.

113 "Periódico para todos», 17 y 27-II-1915.

114 «El Liberal», 28-II-1915 / "Periódico para todos», 1-III-1915 / También participó en el mitin José Llorens, "Fray Feliú», peligroso demagogo radical, que no debió de contribuir a la clarificación del acto / «El Socialista», 1-III-1915 / "La Unión Democrática», 2-III-1915.

115 «Periódico para todos», 10-IV-1915. 
En el mitin intervinieron Segundo García, Juan Gomis, Manuel Esquembre, Carlos Botella, José Ferrando y Manuel Ríos, que pronunciaron "discursos enérgicos y valientes», y propusieron emprender una gran campaña para libertar a los presos políticos ${ }^{116}$. En mayo de 1915 y a lo largo de 1916 siguieron organizando los anarquistas estas actividades.

Los anarquistas, desde las sociedades obreras en las que estaban implantados, colaboraron también en diversos actos que se organizaron en Alicante contra la carestía de las subsistencias y la crisis de trabajo, derivadas de la especulación surgida al calor del conflicto europeo, desde 1915. Pero pronto evidenciaron un deseo de desmarcarse de otras opciones como la republicana o la socialista. Por ejemplo, en febrero de 1915 se celebró un mitin unitario en la Plaza de Toros de Alicante.

«para pedir a las autoridades la resolución de la actual crisis de trabajo, que llega a ser insoportable y que se achaca a la guerra actual, que sólo sirve para que unos cuantos hagan su negocio mientras la miseria llega a la mayoría de los hogares: la guerra sólo es la excusa para el encarecimiento con el que hombres sin conciencia explotan al pueblo y roban a mansalva. Las autoridades se encogen de hombros o se dan por vencidas al primer obstáculo».

La actitud de los oradores fue muy diversa: los representantes de las Sociedades Obreras censuraron a autoridades e industriales, acusaron de cobardes a los obreros porque «ha sonado la hora de tomar por la fuerza en vez de pedir suplicando", el anarquista Segundo García aseguró que la solución era «ir a los almacenes donde se acaparan las subsistencias y tomar alli lo que se necesite», en tanto que el concejal republicano Pascual Ors aprovechó la ocasión para alabar la actuación de los republicanos en el Ayuntamiento y pedir la dimisión del Alcalde ${ }^{117}$. Inmediatamente se produjo una reacción en contra de las sociedades obreras influídas por los anarquistas, que retiraron su adhesión al mitin «por entender que fue un acto puramente político y personalista». Estas sociedades - los Canteros, "La Organizadora», etc. - aseguraban estar persuadidas «de que toda clase de política es mala dentro de las luchas económico sociales, no queremos servir de testaferros de redentores de oficio" " 18 y protestaban de los intentos "de encauzar a las masas inconscientes por derroteros perjudiciales, de ningún fin práctico ni positivo», manifestando que sus sociedades obreras estaban forma-

116 «Periódico para todos», 13-IV-1915 / «La Unión Democrática», 14-IV-1915.

117 «Periódico para todos», 8-II-1915 / «El Batallador», 5, 6, y 8-II-1915. En el mitin, la mesa estaba cubierta por un paño rojo y la inscripción «Proletarios de todos los paises, UNIOS».

${ }^{118}$ Sobre el mitin, en «Periódico para todos», 9-11-1915. Nota de la Sociedad de Canteros de Alicante. 
das por "obreros que detestan la política, sea la que fuere» ${ }^{119}$. Segundo García, orador en el mitin y destacado anarquista, lamentó en un arículo el giro dado al acto por la intervención de Ors e insistió en la necesidad de una acción directa:

«Compañeros: El pedir pan y trabajo teniendo salud perfecta y hermosa fuerza hercúlea para producir lo suficiente para nuestros hijos y nosotros, es detestable; esto ningún obrero consciente lo creerá lógico; pedir es propio de mendigos, nosotros no debemos, compañeros, de ser mendigos, sino hombres, capaces de derrumbar a todos los gobiernos, únicos causantes directos de la crisis que actualmente lamentamos» ${ }^{120}$.

Comenzaron, de otro lado, los intentos de consolidar la organización sindical, mediante charlas sobre las características de la C.N.T. y sus diferencias con los sindicatos socialistas: a finales de marzo de 1914 habló en el Centro de Sociedades Obreras alicantino Joaquín Elizondo, sobre "Orientación social»: expuso las ventajas del sindicalismo sobre la U.G.T. y se "declaró amigo de la violencia para alcanzar mejoras»" ${ }^{21}$. En octubre de 1915 hablaron en Alicante y Alcoy los propagandistas Ramón Insa, de Valencia, y el argentino Equisnain sobre «Organización obrera» y «La política y los obreros» ${ }^{12}$. En enero de 1916 la activa sociedad de panaderos "La luz del día» organizó otra conferencia parecida en el Centro de Sociedades Obreras de Alicante, con intervención de Satrústegui, de La Felguera, sobre "El malestar social» ${ }^{23:}$ : según los panaderos, había que multiplicar este tipo de actividades porque «la clase proletaria huye como alma que lleva el diablo de los Centros Obreros... una grande apatía hacia la organización reina entre los trabajadores... Los trabajadores de esta capital levantina van de fracaso en fracaso, y esto da margen a la burguesía para envalentonarse».

En Alcoy, la táctica anarcosindicalista predominaba en el sector textil. En el II Congreso de la Federación del Arte Textil, celebrado en Barcelona en marzo de 1915, el delegado alcoyano, Iborra - que intervino en el mitin final junto a Largo Caballero y Besteiro-, criticó desde sus posiciones anarquistas la actuación del secretario, el socialista Perlasia - a cuya retribución se opuso- - Hubo en ese Congreso una fuerte lucha entre los socialistas, que fracasaron en su intento de que la Federación ingresase en la U.G.T., y los anarquistas, que consiguieron enviar

119 JUAN GOMIS, Gato por liebre, en «Periódico para todos», 11-II-1915: "Los obreros no queremos compañeradas con políticos disfrazados de obreros».

${ }^{120}$ Ya esta resuelta la crisis en esta localidad, irónico artículo de SEGUNDO GAR-

CIA, en «Periódico para todos», 9-II-1915.

121 "Periódico para todos», 1-IV-1914 / «Alicante Obrero», 1 y 2-IV-1914.

122 "Alicante Obrero», 15-X-1915.

123 "Alicante Obrero», 7-|-1916. 
una representación del Congreso a la reunión de La Paz en El Ferrol ${ }^{224}$. Se acordó que el III Congreso de la Federación del Arte Textil de España se celebrase en Alcoy - pues, en junio de 1914, habían ingresado en ella todas las sociedades obreras alcoyanas del sector--, pero en diciembre el Comité, que residia en Mataró, propuso que se celebrase en Igualada, pues en Alcoy «las representaciones al mismo serían escasas, por residir el núcleo mayor de nuestras fuerzas organizadas en Cataluña» ${ }^{225}$. El secretario de la Federación seguía siendo el socialista Perlasia, quien en agosto de 1915 enviaba a "El Socialista» una nota en que, ante la propuesta hecha por la Federación del Arte Textil de Alcoy de promover un paro general en toda España contra la intransigencia patronal, se alababa la energía y combatividad de los alcoyanos, pero se consideraba inoportuno «lanzarse a la aventura de una huelga general de todo el ramo" ${ }^{26}$.

Habia, pues, claras diferencias entre el Comité Nacional y la Federación del Arte Textil alcoyana, claramente controlada por los anarcosindicalistas. La dirigía el ácrata Antonio Iborra y agrupaba a Selfactineros, Tejedores Mecánicos, Borreros y Tintoreros - que habian abandonado el Centro "El Progreso», dominado por los socialistas, y pronto dejarian la U.G.T. - , y otros oficios del textil ${ }^{127}$. Poco después, aprovechando la época de buenos negocios del sector por los pedidos del ejército francés, se lanzó una ofensiva para mejorar las condiciones de trabajo, que se extendió a localidades cercanas como Cocentaina y Bocairente ${ }^{128}$. Se llegó a una huelga general del sector que afectó a varios miles de obreros y aunque los resultados obtenidos no fueron espectaculares, funcionó bien la solidaridad entre los obreros y aumentó el prestigio y la afiliación al sindicato.

Con ocasión de la huelga, hubo fuertes enfrentamientos con los socialistas, que se remontaban a las interrupciones hechas por los ácratas en una charla de Andrés Saborit y Virginia González, en el mes de marzo, que provocaron un manifiesto de los socialistas retirándose de la vida política local y dándose de baja en las sociedades obreras de la manufactura de la lana - que, como hemos visto, estaban controladas por los libertarios-. Según los socialistas, se les acusó falsamente de ac-

124 «El Socialista», 25 y 26-III-1915 / «Alicante Obrero», 24-III-1915/ «El Popular» (Alicante), 26-III-1915 / A. BALCELLS, La mujer obrera en la industria catalana durante el primer tercio del siglo XX, en Trabajo industrial y organización obrera en la Cataluña contemporánea. Laia. Barcelona. 1974.

125 «El Socialista», 23-XII- 1915.

${ }^{126}$ "El Socialista», 7-VIII-1915.

127 "Fraternidad", 27-III-1915.

128 "Alicante Obrero», 1, 4, 5 y 7-X-1915. 
tuar como esquiroles en la huelga ${ }^{29}$ y la Federación del Arte Textil alcoyana, al terminar el paro, envió a la prensa provincial y nacional ${ }^{130}$ el acuerdo tomado por todas las sociedades obreras que componían la Federación de «no dar ingreso a ningún socialista, por haber traicionado el último movimiento, dándose de baja cuando estalló la huelga».

Una labor semejante llevaba en Elda la sociedad de zapateros «La Racional», que anunció la salida de un periódico titulado "Guerra Social» y trató de extender las ideas sindicalistas en Mónovar, Sax, Petrel y Villena, donde predominaba "el ambiente socialista» ${ }^{131}$. "La Racional» consiguió, aprovechando también la buena época por la que atravesaba el sector del calzado, que fabricaba para los ejércitos franceś e inglés, varias mejoras, en conflictos sociales y en una huelga general, en apoyo de las aparadoras, que solicitaban unificación de salarios y el reconocimiento por parte de los patronos de la sociedad obrera, en 1914 y 1915.

En Alicante, los anarquistas controlaron uno de los conflictos más duros de estos años: la huelga de los metalúrgicos, que contó con la solidaridad de sus compañeros de Alcoy, contra los propietarios de la fundición Aznar. "La Montadora», sociedad de los metalúrgicos alicantinos, organizó numerosos mítines para mantener la solidaridad y contó con el apoyo de otros oficios: la táctica era ya abiertamente de enfrentamiento sin matices con el capital y los oradores, muchos de ellos anarquistas, hablan de la necesidad de que el obrero esté dispuesto a morir en la calle en lugar de hacerlo al pié de su maquinaria, de que "el pan se busca y no se pide», de que hay que proclamar "la huelga general revolucionaria, único medio para combatir al odioso capitalismo», en suma, de la "acción directa»: de ahí que en alguna ocasión todos los oradores que tomaban parte en un mitin fuesen llamados a declarar ante el juez de instrucción ${ }^{132}$.

En todos estos conflictos eran frecuentes los enfrentamientos con los socialistas, produciéndose numerosas polémicas. "Alicante Obrero», un diario muy demagógico, sirvió de portavoz de las posiciones de los anarquistas, que publicaron varios artículos sobre la inutilidad de la política para resolver los problemas sociales, artículos que eran contestados por los socialistas y también por los republicanos ${ }^{133}$. Por su

\footnotetext{
129 SANTIAGO GADEA, De cara al enemigo. Contra una campaña difamadora, en «Trabajo» (Elche), 17 y $24-X-1915$.

${ }^{130}$ Se publicó en «Alicante Obrero» y en «Solidaridad Obrera».

131 "Alicante Obrero», 4-XII-1915.

132 "Alicante Obrero», 18-XII-1914.

133 ENRIQUE DUBOIS, La politica es una farsa, en "Alicante Obrero», 22-XII-1914 / Rafael Sevila Linares pide al obrero que confie en los políticos que le apoyan, en «La Unión Democrática», 24-XII-1915 / Para «Alicante Obrero», 29-I-1915, los políticos «son peor que los gitanos, engañan al que pueden, sea el que sea». Sus redactores se defi-
} 
parte, los socialistas utilizaban las páginas del semanario ilicitano «Trabajo» para criticar a los anarquistas ${ }^{134}$. Para los socialistas, el sindicalismo comenzaba ya a ser un claro peligro, como señalaba Largo Caballero en una conferencia que dió en Elche en 1915: «no hay que interpretar el socialismo con el sindicalismo, siendo el sindicalismo el que por no tener disciplina hace fracasar a las masas obreras... pues esos propagandistas de la acción directa se esconden en el momento oportuno y se humillan a la autoridad $\gg{ }^{135}$.

La vigilancia de las autoridades sobre los medios libertarios era constante. Veamos algunos ejemplos: en abril de 1915 se celebró en la Audiencia de Alicante un juicio contra Fernando Claramunt, «agitador libertario», por quebrantamiento de condena. Claramunt alegó que había creído que estaba afectado por la amnistía ${ }^{136}$. La prensa publicaba con frecuencia rumores sobre la presencia en Alicante de «peligrosos agitadores anarquistas», en ocasiones con cierto humor: "¡Recorcho! El Director General de Seguridad ha telegrafiado al señor Gobernador Civil de la provincia notificándole que el anarquista Francisco Miranda, que se hallaba en Barcelona, ha salido de aquella capital dirigiéndose a Alcoy para hacer propaganda. Con tal motivo se encarece la estrecha vigilancia del mencionado individuo" ${ }^{137}$. En noviembre de 1916 se dirigè Ceferino Gil al Gobierno Civil, a través de la prensa, para protestar de la vigilancia de que es objeto, al acabar de salir de la cárcel tras doce años de encierro: «¿Se puede ser ácrata? Las ideas no son un hecho delictivo» ${ }^{138}$. En ese mismo mes, el anarquista de Villena Enrique Guardiola ve prohibida por la Guardia Civil local su presencia en unos actos organizados por la clase obrera del lugar contra la carestía de las subsistencias, con la excusa de que «no podían tomar parte en dichos actos ni sindicalistas ni anarquistas» ${ }^{139}$.

nen asi: «No somos políticos, no somos socialistas, no somos anarquistas: somos obreros, somos como tú, explotados que producimos, y por tanto, deseamos, como nos pertenece, alimentar nuestros estómagos, después de alimentar nuestro cerebro y nuestro corazón», («Alicante Obrero», 17-II-1915) / En diciembre de 1915 hay una nueva polémica sobre el tema en "Alicante Obrero», entre ANTONIO CORREA, ¿Le conviene al obrero ser politico?, y J. BOTELLA, ¿Ser obrero quiere decir ser político?.

134 "Trabajo», 9-XI-1915 / En mayo de 1916 hay una polémica sobre el tema entre "Trabajo» y «La Libertad», donde Francisco Navarro pregunta a los socialistas: «¿Y en los calabozos cuántos correligionarios teneis pagando las consecuencias del actual régimen?» (14-V-1916).

135 "Trabajo», 2-V-1915.

136 "Diario de Alicante», 21-IV-1915.

${ }_{137}$ "Periódico para todos», 10-VII-1916.

138 "Alicante Obrero», 29-XI-1916.

${ }^{139}$ Denunciamos al Sr. Gobernador, en «El Luchador», 16-XI-1916 / «El Socialista», 26-XI-1916. Los concejales socialistas de Villena intervienen en favor de Guardiola, 
A lo largo de 1916 aumentó la actividad de los anarcosindicalistas en la provincia de Alicante. En la capital, la sociedad de Oficios Varios "La Organizadora» se convirtió en la punta de lanza del sindicalismo tratando de integrar a las sociedades del Centro Obrero de la Avenida de Zorrilla en la C.N.T.: propuso la publicación de un periódico ${ }^{140}$, convocó a los trabajadores de otros oficios para que se reorganizasen ${ }^{141} \mathrm{y}$ montó actos de propaganda societaria: "Las organizaciones obreras frente a los problemas actuales", charla de Antonio Loredo en febrero, y mítines de controversia en abril, a cargo de los también anarquistas Juan Gomis y Francisco Aguado, sobre la autonomía de los sindicatos obre$\operatorname{ros}^{142}$. Por otro lado, en muchas sociedades obreras se iba poniendo de manifiesto la necesidad de alcanzar un tipo de organización más amplio que la mera sociedad de oficio y de potenciar, por tanto, un sindicalismo más solidario: se constituyó asi en Alicante el llamado "pacto de unión», que comprendia a las sociedades "La Marítima», "La Terrestre» y "La Paz», de trabajadores del puerto, a los Carreros, a los Toneleros y Aserradores Mecánicos y a los Dependientes de Fábricas y Almacenes - germen de lo que seria, en 1919, el Sindicato Unico del Transporte en Alicante-; esta alianza tenía como misión fundamental actuar conjuntamente - sus miembros podían paralizar el tráfico comercial alicantino - en casos excepcionales, como se demostró con ocasión del apoyo mostrado por esas sociedades a los obreros marítimos de "La Naval» en su huelga del verano de 1916 contra las navieras.

Por iniciativa anarquista se celebraron también varios mítines en favor de los presos sociales. En el mes de febrero, la citada Sociedad de Oficios Varios propuso celebrar uno «en pro de los compañeros catalanes, por los atropellos de que vienen siendo víctimas por parte de la burguesía y autoridades" ${ }^{143}$. Poco después, la sociedad de zapateros «La Racional» de Elda propuso que se diese al mitin un alcance provincial, como así se hizo, para «ver si por este medio logramos arrancar de las argóstulas (sic) a tan. dignos compañeros... que su único delito ha sido defender a sus compañeros de sufrimientos» ${ }^{144}$. Al acto se adhirieron, además de los organizadores, varias sociedades obreras de Ali-

que dirige una carta abierta al Gobernador protestando de tales persecuciones. El teniente de la Guardia Civil alega «órdenes recibidas desde arriba». No cabe duda de que las autoridades veían con mucho más recelo la intervención de los anarcosindicalistas en la campaña contra la crisis de trabajo y la carestía de la vida, que la de los socialistas.

${ }^{140}$ "Periódico para todos», 9 y 10-II-1916.

141 "Periódico para todos», 9-III-1916.

142 "Periódico para todos», 6-IV-1916 / «El Luchador», 15-IV-1916.

143 "Alicante Obrero", 9-II-1916.

144 "Alicante Obrero», 17-11-1916 / «Periódico para todos» y «El Luchador», 18-11-1916. 
cante, la Federación del Arte Textil de Alcoy, los Albañiles de Novelda, las sociedades de Oficios Varios de Sax y Bocairente y el grupo «Paso a la anarquía» de Villena, es decir, la mayoría de las organizaciones de orientación anarcosindicalista de la provincia. Las intervenciones fueron muy radicales: el representante de la sociedad alicantina «La Defensa» asegura que los mítines no sirven para nada y que la sociedad que representa "opina que se debe recurrir a otros medios»; otro orador pide más acción y menos palabras; Marcelino Gil asegura que «el obrero debe pedir siempre con virilidad y no como hembra lo que le corresponde», el alcoyano lborra asegura que «todos los partidos políticos son funestos para la nación y en particular para el obrero» ${ }^{15}$. Como se puede advertir, este mitin pro-presos era, al mismo tiempo, una forma de afirmación de las tácticas de la C.N.T., lo que explicaría la reticencia de los socialistas alicantinos a intervenir en este tipo de actos, como se probaría en otro mitin, organizado por los panaderos alicantinos de la sociedad "La luz del día», en mayo, para solicitar el perdón de los condenados a muerte por los sucesos de Cenicero, «protestar del empleo de la fuerza armada en los conflictos públicos suscitados entre patronos y obreros» y «solicitar la abolición de la pena de muerte» ${ }^{146}$. Los socialistas no intervinieron ni se adhirieron al acto - al que asistie-

ron pocos obreros--, lo que provocó una polémica en la prensa local ${ }^{147}$. También lanzaron las Sociedades de tendencia anarcosindicalista una campaña de recogida de firmas en favor de la libertad de José Castellvi, que llevaba 22 años en la cárcel: en ambos Centros Obreros, en las estaciones, fábrica de tabacos y en el puerto se llegaron a recoger 2.132 firmas ${ }^{148}$.

En Alcoy, la Federación del Arte textil convocó en enero de 1916 un mitin para protestar de la carestía de la vida - se pidió una rebaja del cincuenta por ciento en las subsistencias y del veinticinco por ciento en los alquileres - y para pedir la libertad de los trabajadores detenidos en Barcelona ${ }^{149}$. Poco después, el 13 de febrero, celebró la Federación una asamblea local, con delegados de todas las Sociedades Obreras del Ramo, que volvió a demostrar el predominio de las tácticas anarcosindicalistas. Se debatió, en primer lugar, la conveniencia de causar baja en la Federación Nacional del Arte Textil, a la vista de las diferencias de táctica existentes: se acordó seguir en ella, pero «protestar de

145 "Periódico para todos», 21-II-1916 / «El Luchador», 18 y 21-II-1916 / "Alicante Obrero», 22-II-1916.

146 "Periódico para todos», 15-V-1916 / "Alicante Obrero», 16-V-1916.

${ }^{147}$ Los socialistas pidieron también el indulto de los presos de Cenicero, pero no se adhirieron al mítin por la campaña difamatoria que algunas sociedades obreras llevaban contra ellos.

148 "Periódico para todos», 12 y 24-VI-1916.

149 "Diario de Alicante», $y$ «El Socialista», 25-I-1916. 
la conducta observada por el Comité Nacional del Arte Textil y que sean sustituídos dichos individuos por otros». Luego se planteó si "sería de utilidad el formar una Federación local de todos los oficios» y se acordó trabajar en ese sentido, para conseguir un Sindicato Unico de Trabajadores, de la misma forma que se había conseguido unficar a la manufactura de lana. Otros acuerdos tomados fueron la realización de propaganda sindical por los pueblos limítrofes, el estudio de la reducción de la jornada nocturna, la protesta por la carestía de las subsitencias y la posible publicación de un periódico como órgano de la Federación ${ }^{150}$. En marzo, la Federación lanzó una huelga en el sector textil que afectó a unos ocho mil obreros ${ }^{151} \mathrm{y}$, a partir del verano, organizó diversos actos de protesta contra la carestía de la vida, la crisis de trabajo y el mantenimiento en prisión de trabajadores acusados de delitos sociales ${ }^{152}$. En el mes de diciembre apareció un semanario, "La Lucha», órgano de la Federación del Arte Textil: desde sus columnas, anarquistas y sindicalistas animaban constantemente a los obreros en general a trabajar por su emancipación y a incorporarse a las filas de los sindicatos ${ }^{153}$.

En cuanto a los anarquistas de Elda, su acción en el terreno laboral, - con participación de "La Racional» en diversas huelgas sectoriales, que no obtuvieron demasiados logros - se vio completada por una labor propagandística por localidades cercanas, en especial en Sax - donde consiguieron organizar a parte de los campesinos - y en Villena - donde sus esfuerzos fueron vanos, ante el control socialista sobre la clase obrera de esa localidad -, y también por una labor educativa y cultural, con una Escuela Racionalista y conferencias de divulgación ${ }^{154}$.

En mayo de 1916, una Conferencia Nacional de la C.N.T. reunida en Valencia acordó incrementar la campaña de agitación en toda España contra la carestía de la vida. Como la U.G.T. acordó lo mismo en su Congreso, se dieron diversos pasos tendentes a conseguir la unidad de acción de ambas centrales, que se plasmó en un acuerdo tomado en el verano de $1916^{155}$. La campaña culminó en la huelga general de

150 «Fraternidad», 19-II-1916.

151 «La Unión Democrática», 6-IV-1916.

${ }^{152}$ Ya en marzo, la Federación del Arte Textil organizó un acto de este tipo, insistiendo mucho en la libertad de los detenidos por los sucesos ocurridos «a causa de la crisis de trabajo y del encarecimiento de las subsistencias» («Alicante Obrero», 14-III-1916.

${ }^{153}$ El periódico, que se mantuvo hasta marzo de 1917, puede consultarse en el Archivo Municipal de Alcoy.

${ }^{154}$ Asi. Vicente Gil diserta sobre "Anatomía y Fisiología» en la Escuela racionalista («Alicante Obrero», 9-V-1916).

155 MANUEL BUENACASA, o.c., testimonia la participación de los obreros levantinos en esta campaña: "Y cuando llegó el verano de 1916, estos obreros se incorporaron a la lucha nacional, unidos al resto de los trabajadores españoles, en aquellos preludios de la revolución de agosto de 1917». 
diciembre de 1916 - que ha sido analizada por mí en otro lugar ${ }^{156}$ - y en ella colaboraron socialistas y anarcosindicalistas, aunque no faltaron reticencias y problemas. Para muchos obreros, el sindicalismo era mucho más útil en esos momentos que la táctica tradicional de la U.G.T. y se les aparecía «como una institución salvadora en que cada despojado, cada injuriado, cada víctima de la injusticia social hallará no apoyo compasivo, sino solidaridad positiva, verdadero compañerismo, fuerza necesaria para su satisfacción y justificación» ${ }^{157}$.

Ya en 1917 y con anterioridad a la huelga general, los anarquistas siguieron mejorando sus posiciones entre la clase obrera alicantina. En la capital, ninguna de las más de veinte sociedades obreras existentes estaba ya afiliada a la U.G.T., pero tampoco se acababan de decidir por incorporarse muchas de ellas a la C.N.T.: pese a los acuerdos existentes a nivel estatal, socialistas y sindicalistas se miraban con recelo ${ }^{158} \mathrm{y}$ no se llegó a un acuerdo para conmemorar el Primero de Mayo. En la prensa local se debaten las causas de la división existente entre los trabajadores de la localidad ${ }^{159}$ y lo que parece evidente es el recelo de los socialistas instalados en la Casa del Pueblo a dar entrada en ella a sociedades obreras - Panaderos, Carpinteros, Ferroviarios Andaluces, etc. - con predominio anarquista. Cuando, tras la huelga general de agosto de 1917, se fusionaron, en el mes de noviembre, los centros obreros de la ciudad, incorporándose todos a la Casa del Pueblo, no se trataba más que de una tregua, a pesar de la colaboración en actos en favor de la amnistía.

En otras localidades, como en Alcoy, también pareció reinar momentáneamente la concordia tras los sucesos de agosto y en la lucha común por la liberación de los presos sociales ${ }^{160}$. La represión por la huelga de agosto - que también afectó a los anarcosindicalistas, pese a su menor papel en los hechos, pues fue clasurado el Ateneo Sindica-

156 FRANCISCO MORENO SAEZ, La huelga general de 1917 en la provincia de Alicante. Anales de la Unversidad de Alicante. Historia contemporánea, n. 2. Alicante. 1983. Págs. 225-269.

157 "Alicante Obrero», 23-VIII- 1916.

${ }_{158}$ Así lo testimonia el diario republicano «El Luchador»: «En Alicante, por desgracia, lejos de prosperar en este sentido (la búsqueda de la unidad), se ahondan las diferencias, se miran las sociedades con recelo mutuo, y por ello se aprovechan los enemigos del obrero» («El Luchador». 10-V-1917).

${ }_{159}$ Pueden leerse las justificaciones del socialista Angel Martínez - argumentando con determinados recovecos del reglamento de la Casa del Pueblo - en «El Luchador», $12,13,15,16,18$ y $19-\mathrm{V}-1917$.

${ }^{160}$ Celebración de una imponente manifestación, con más de doce mil asistentes, para pedir la amnistia, en diciembre de 1917 («El Socialista», 7-XII-1917) / Nota conjunta de Agrupación Socialista y Ateneo Sindicalista, entre otras entidades, frente a los ataques a los presos por parte de "La Voz del Pueblo» («El Liberal», "Alcoy, 15-XII-1917). 
lista alcoyano y detenidos en Alicante, Elche, Sax, Alcoy y Elda significados militantes libertarios - unió a los obreros de las distintas tendencias. Sin embargo, a partir de entonces, los anarcosindicalistas - desde sus posiciones en el textil alcoyano, el sector del calzado de Elda y distintas organizaciones obreras de la capital - acabarían capitalizando el desencanto producido entre los obreros por la fracasada huelga de 1917. Se dió origen así a una organización sindical - vagamente inspirada en los principios del anarquismo - que veía aumentar día tras día el número de sus afiliados que no se cansaban de planear reivindicaciones y de mostrar su solidaridad con otros compañeros: de ahí que la C.N.T., en 1919, lograse en la provincia de Alicante una implantación muy sólida y con una gran participación de las bases, que sólo pudo ser desmontada por las autoridades merced a una durísima represión ${ }^{161}$.

161 Para los acontecimientos de 1917, que giraron en torno a la preparación y desarrollo de la huelga de agosto y a la lucha contra la represión subsiguiente, véase mi artículo, ya citado, La huelga general de 1917 en la provincia de Alicante. 



\title{
DATOS BASICOS PARA LA RECONSTRUCCION HISTORICA DE LA BURGUESIA DE ALICANTE DURANTE LA RESTAURACION (1875-1900)*
}

\author{
JAVIER VIDAL OLIVARES \\ Universidad de Valencia \\ JOAN-CARLES USO I ARNAL \\ Centro de Estudios Históricos de la Masonería Española (CHEME)
}

\section{INTRODUCCION}

Pese a las amplias lagunas que todavía persisten en la historiografía alicantina del siglo XIX, entre las que cabe destacar la ausencia de trabajos monográficos sobre desamortización, corrientes políticas y los sucesivos períodos revolucionarios (trienio constitucional, bienio progresista y sexenio revolucionario), dos investigaciones han resultado coincidentes en el final de siglo. Partiendo de dos temáticas sustancialmente distintas y desde supuestos también diversos, se han puesto en común algunas conclusiones, cifradas en el interés de iluminar aspectos, a nuestro juicio importantes, de la historia alicantina'.

En el pasado, la ciudad de Alicante tuvo dos constantes de singular relevancia para su posterior desarrollo político y social. Su carácter de urbe portuaria le colocaba en óptimas circunstancias para acceder a las corrientes culturales más avanzadas, procedentes del exterior. Al mismo tiempo, los flujos y el tráfico mercantil, impulsados secularmente por una activa colonia de comerciantes, facilitaban, no sólo la penetración de todo tipo de información sino también la acumulación de expectativas empresariales de variado signo. No es nuestra intención realizar aquí un análisis pormenorizado del impacto de estas dos variables en la conformación de la burguesía alicantina en el siglo XIX. Tan sólo se pretende hacer hincapié en dos de las coordenadas básicas en la que

Queremos agradecer expresamente a Candelaria Saiz Pastor (Consejo Superior de Investigaciones Científicas) las sugerencias y datos concretos que ha aportado a este trabajo y que nos han permitido mejorar sustancialmente la información de que disponíamos.

1 Javier Vidal tiene en prensa un trabajo en el que se aborda la problemática política, social y económica de Alicante durante la primera restauración, titulado Comerciantes y Políticos. Alicante 1875-1900. Joan-Carles Usó indaga en su Tesis Doctoral, en curso de elaboración, ta historia de la masonería alicantina contemporánea, a través del estudio de la logia "Constante Alona», sin duda, el establecimiento más importante que ha alumbrado la masonería en el Estado español. 
esta burguesía se insertó durante el período anterior al que aquí se plantea.

Teniendo en cuenta este marco básico, se ha confeccionado una lista de hasta quince nombres, que poseen un elevado número de aspectos en común y que, en conjunto, consiguieron adquirir un inusitado protagonismo en el seno de la sociedad alicantina durante el último tercio de la pasada centuria. Los personajes seleccionados van acompañados de sus respectivos apuntes biográficos - que no pretenden ser exhaustivos, sino meramente indicativos - y de los datos más significativos a nivel económico, político y social. En conjunto, representan el paradigma o tipo de aquellos grupos que mantuvieron o elevaron su posición social en distintas situaciones políticas - monarquía o república -, preservando su estatus e incluso aumentándolo. Tenderiamos asi a disponer de una nueva aportación a esa tarea más amplia que consistiría en recopilar los principales personajes que integraron la burguesía decimonónica en el País Valenciano².

\section{NOTAS BIOGRAFICAS}

ALBEROLA MARTINEZ, Amando ${ }^{3}$.

- Alicante, 13 de Marzo de 1844 - 21 de Marzo de 1900.

- Domicilio en Alicante, C/ San Ildefonso, n?9 y 11, C/ Luchana. n. 27 y C./ Maisonnave, no 49 y 51.

- Comerciante, asociado a Guillermo Campos Carreras en negocios de carbones minerales ingleses y españoles, coke, etc. (C./ Quiroga).

- Propietario de grandes depósitos de maderas nacionales y de importación (Rusia, Suecia, Noruega, Austria, América, etc.).

- Miembro de la Cámara de Comercio de Alicante, Vocal de la Sección industrial desde su fundación y representante de dicha Cámara en la Asamblea de Cámaras de Comercio de Zaragoza.

- Presidente del Colegio Pericial Mercantil.

- Miembro del Consejo de administración de la sociedad construc-

${ }^{2}$ Un trabajo pionero en este sentido es el que llevaron a cabo Anacleto Pons y Justo Serna para la ciudad de Valencia. Véase PONS I PONS, Anacleto y SERNA ALONSO, Justo: "Elitismo y dominación de clase en Valencia (1856-1858)», Saitabi, v. XXXIV, Valencia, 1984, pp. 153-167. Varios de los personajes analizados por estos autores ya habian sido investigados anteriormente por Telesforo Marcial, en especial el grupo que dirigía el Marqués de Campo. Véase MARCIAL HERNANDEZ, Telesforo: Ferrocarriles y capitalismo en el País Valenciano (1843-1879), Valencia, 1983.

${ }^{3}$ Véase también ALBEROLA, G.: "Amando Alberola Martínez», El Luchador, Alicante, 16 de Febrero de 1918. 
tora «Los Diez Amigos», edificadora del barrio de Benalúa de Alicante.

- Presidente del Consejo de administración de la sociedad «Los Nueve», explotadora del tranvía de Alicante.

- Vocal del Consejo de administración de la Caja especial de Ahorros de Alicante (1888) y accionista de la misma (1890).

- Socio n. 52 de la Real Sociedad Económica de Amigos del País de Alicante (fecha de admisión, el 4 de Febrero de 1881).

- Iniciado como masón en la logia "Alona» de Alicante el 16 de Abril de 1877, con el nombre simbólico de Calvo Asensio ${ }^{4:}$ Primer Vigilante (1884) y Venerable Maestro (1886-1892) de dicha logia ${ }^{5}$; poseedor del grado $33^{6}$.

- Miembro del capítulo "Lucentino» (fecha de admisión, el 10 de Abril de 1884) y Presidente de dicho capítulo en 1892'.

- Miembro de la cámara de Caballeros Kadosch «Alicantina» desde su fundación, en 1892, con el cargo de Caballero de la Elocuencia ${ }^{\text {. }}$.

- Miembro del Partido Republicano Centralista de Alicante y Presidente del Comité de dicho partido en 1896, coincidiendo en su dirección con Ernesto Villar Miralles.

- Concejal de Ayuntamiento de Alicante durante los bienios 1890-91

${ }^{4}$ El hecho de adoptar los masones, en el acto de su iniciación, un nombre simbólico, que es el que en adelante utilizarán en sus trabajos masónicos, es un costumbre totalmente institucionalizada en el Estado español y que no se encuentre en otros países. Este nombre simbólico es un dato que puede contribuir a desvelar ciertos aspectos ideológicos de la masonería española y de sus miembros. Sobre el origen de esta costumbre véase FERRER BENIMELI, José A.: Masonería española contemporánea (v. 1), Madrid, 1980, p. 33.

${ }^{5}$ En las logias, las principales funciones recaen, por orden jerárquico, en el Venerable Maestro, Primer Vigilante y Segundo Vigilante (Dignatarios Luces Superiores), Orador, Secretario y Tesorero (Dignatarios y Oficiales de Primera Clase) y Expertos, Archivero-Guarda Sellos y Tesorero (Oficiales de Segunda Clase). Estos cargos vienen a estar cubiertos en casi todas las logias; después, si los trabajos de la logia lo requieren se puede nombrar toda una serie de cargos, que constituirán los Oficiales de Tercera Clase. Véase ARUS, Rosendo y FRAU. Lorenzo: Diccionario Eciclopédico de la Masonería, México, 1977.

${ }^{6}$ El número de grados en la masonería varía según el Rito - conjunto de reglas establecidas, tanto para la liturgia como para la propia estructura organizativa - que ésta siga. En concreto, el Rito Escocés Antiguo y Aceptado - el más generalizado - es el que seguían todas las logias mentadas en este trabajo y posee 33 grados subdivididos en cuantro escalafones: Masonería azul o simbólica (del 1. al 3\%.), Masonería roja o capitular (del $4^{\circ}$ al 18. ), Masonería negra o filosófica (del $19{ }^{\circ}$ al $30 \%^{\circ}$ ) y Masonería blanca o sublime (del $31 \%$ al 33. )

${ }^{7}$ El capitulo es la agrupación de masones (pertenecientes a una o varias logias regulares) que puede constituirse exclusivamente a partir del grado 4 .

${ }^{8}$ La Cámara de Caballeros Kadosch es la agrupación de masones (pertenecientes a una o varias logias regulares) que puede constituirse exclusivamente a partir del grado 30 . 
(Comisión de aguas), 1895-97 y 1897-99 (Comisión de aguas).

- Diputado provincial.

- Calificado de «consecuente republicano», "gran demócrata» y «gran filántropo».

AUSO MONZO, Manuel.

- Alicante, 8 de Diciembre de 1814 - 25 de Enero de 1891.

- Domicilio en Alicante, C/. Castaños, n: 22 y C/. Mártires.

- Estudios iniciales de Lengua latina en el Colegio de los PP. Franciscanos.

- Estudios de Filosofía en el Seminario de Orihuela y de Medicina en el Colegio Imperial de San Isidro de Madrid y en la Universidad de Valencia.

- Doctor en Medicina y Cirugía (1845) por la Universidad de Barcelona.

- Profesor de Historia Natural en el Instituto Provincial de Segunda Enseñanza de Alicante (1845); catedrático en propiedad de dicha plaza desde 1851, desempeñándola por espacio de cuatro años.

- Médico, defensor del sistema homeopático.

- Presidente del Círculo de Artesanos de Alicante (1866).

- Fundador, en 1868, de la Sociedad de Estudios Psicológicos de Alicante.

- Socio Fundador (1877) y accionista (1890) de la Caja especial de Ahorros de Alicante.

- Socio n: 2 de la Real Sociedad Eonómica de Amigos del País de Alicante (fecha de admisión, el 25 de Septiembre de 1859).

- Iniciado o afiliado como masón en la logia «Alona» de Alicante el 8 de enero de 1884, con el nombre simbólico de Hus; poseedor del grado 9.

- Colaborador en La Revolución, El Graduador, Gaceta Homeopática, El Agente de Alicante, E Criterio Espiritista, La Revelación, La Revista Espiritista, La Humanidad y otras publicaciones científicas y de divulgación.

- Autor, entre otros trabajos, de la Conferencia celebrada el 25 de Enero de 1880 en el Salón del Consulado de esta ciudad, Alicante, 1881 y del Programa de Historia Natural y de Fisiología e Higiene, Alicante, 1884.

- Poseedor de la Cruz de Beneficiencia de Tercera Clase (1860) y de la Encomienda de Isabel la Católica (1871). 
- Alicante, 20 de Enero de 1846 - ?

- Domicilio en Alicante, C/. Mayor, n: 34.

- Comerciante, dedicado al sector de la ferretería.

- Contribuyente industrial con 668 ptas. en 1889.

- Iniciado como masón en la logia "Alona» de Alicante el 18 de Junio de 1877, con el nombre simbólico de Maldonado; Arquitecto Revisor (1877).

- Afiliado a la logia "Constante Alona» de Alicante el 12 de Abril de 1880; plancha de quite ${ }^{9}$ el 11 de Octubre de 1880, para volver a la logia "Alona».

- Tesorero (1886), Primer Vigilante y miembro de la Comisión de Hacienda (1888), Primer Vigilante (1890) y Venerable Maestro (1892-93) de la logia "Alona».

- Censado el 7 de junio de 1901 como Venerable Maestro de la logia "Constante Alona»; poseedor del grado 30.

- Miembro del capítulo «Lucentino» (fecha de admisión, el 6 de Abril de 1890).

- Miembro de la cámara de Caballeros Kadosch «Alicantina» desde su fundación, en 1892, con el cargo de Segundo Teniente Gran Maestro.

- Miembro del Partido Republicano.

- Concejal del Ayuntamiento de Alicante durante los bienios 1894-95 y $1895-97$.

BONO GUARNER, Román.

- ? - Albacete, 29 de Agosto de 1896.

- Destacado industrial, propietario de "La Industria Alicantina» (fábricas de chocolate y pastas finas).

- Contribuyente industrial con 2.750 ptas. y territorial con 1.500 ptas. en 1889.

- Suscriptor del empréstito de 1896 con 250 obligaciones $=125.000$ ptas.

- Miembro del Consejo de administración del Ferrocarril de Alicante a La Marina.

- Contador de la Junta del Círculo de Artesanos de Alicante (1866).

- Socio fundador 1877 y accionista (1890) de la Caja especial de Ahorros de Alicante.

${ }^{9}$ La plancha de quite equivale a la certificación de baja (voluntaria y provisional, temporal o definitiva) de un masón en una logia. 
- Tesorero de la Liga de Contribuyentes de Alicante y su provincia (1895).

- Socio n: 8 de la Real Sociedad Económica de Amigos del País de Alicante (fecha de admisisón, el 8 de Noviembre de 1880).

- Alistado en la Brigada de Artillería de la Milicia Nacional (1873).

- Miembro del Partido Liberal.

- Concejal, Teniente de Alcalde, del Ayuntamiento de Alicante en 1896.

\section{CAMPOS CARRERAS, Guillermo.}

- ? - Alicante, 5 de Junio de 1936.

- Comerciante de tejidos e importador de salazones, asociado a Amando Alberola Martinez en negocios de carbones minerales ingleses y españoles, coke, etc (C/. Quiroga).

- Contribuyente industrial con 2.000 ptas. y territorial con 500 ptas. en 1889.

- Suscriptor del empréstito de 1896 con 150 obligaciones $=75.000$ ptas.

- Miembro del Círculo de Artesanos de Alicante (1866).

- Presidente de la Cámara de Comercio de Alicante.

- Socio n: 60 de la Real Sociedad Económica de Amigos del País de Alicante (fecha de admisión, el 20 de Enero de 1884).

- Teniente de la Milicia Nacional (1856).

- Miembro del Partido Republicano.

- Cónsul de Chile, Portugal y Brasil.

- Gran filántropo, fundador de la Asociáción Alicantina de Caridad.

\section{CARRATALA CERNUDA, Gregorio.}

- Comerciante.

- Contribuyente industrial con 580 ptas. en 1889.

- Suscriptor del empréstito de 1896 con 20 obligaciones $=10.000$ pesetas.

- Socio fundador (1877) y accionista (1890) de la Caja especial de Ahorros de Alicante; Vocal (1877) y Presidente (1891) del Consejo de administración de la misma.

- Miembro del Partido Liberal.

- Concejal del Ayuntamiento de Alicante durante los bienios 1890-91 y 1891-93. 
- Alicante, 1861-1926.

- Doctor en Medicina y licenciado en Farmacia.

- Suscriptor del empréstito de 1896 con 60 obligaciones $=60.000$ pesetas.

- Vicepresidente de "La Electra Alicantina S.A.» 1900.

- Iniciado como masón en la logia "Constante Alona» de Alicante el 4 de octubre de 1880, con el nombre simbólico de Lavoisier; Censor (1881) de dicha logia; plancha de quite el 14 de Marzo de 1881.

- Miembro del Partido Liberal.

- Concejal del Ayuntamiento de Alicante durante el bienio 1891-93.

- Alcalde del Ayuntamiento de Alicante en 1893, 1897 y 1901.

\section{GUARDIOLA PICO, José ".}

- Alicante, 8 de Septiembre de 1837 - 17 de Agosto de 1909.

- Domiciliado en Alicante, C/. San Francisco, n: 69.

- Arquitecto provincial hasta Noviembre de 1868; arquitecto de la diócesis de Orihuela y arquitecto municipal desde 1865 hasta 1905 (con algunas interrupciones).

- Miembro del Círculo de Artesanos de Alicante (1866).

- Socio fundador (1877) y accionista (1890) de la Caja especial de Ahorros de Alicante.

- Miembro de la Real Academia de Bellas Artes de San Fernando.

- Socio n: 51 de la Real Sociedad Económica de Amigos del País de Alicante (fecha de admisión, el 8 de Noviembre de 1880).

- Iniciado como masón en la logia "Alona» de Alicante el 22 de Marzo de 1877, con el nombre simbólico de Herrera; poseedor del grado 18.

- Miembro del capítulo "Lucentino» (fecha de admisión, el 6 de Abril de 1890).

${ }^{10}$ Véase también MONTERO PEREZ, F.: «José Gadea Pro» El Correo, Alicante, 18 de Mayo de 1926 y RHASIS: "José Gadea Pro», El Luchador, Alicante, 3 a 6 de Septiembre de 1935.

"Véase también JOSE DE ALICANTE: "José Guardiola Picó». Peña Alicante, n? 13. Barcelona, 1929; VARELLA BOTELLA, Santiago: «La obra urbanistica de José Guardiola Picó», Revista del Instituto de Estudios Alicantinos, n. 29, Alicante, 1980, pp. 43-54 y del mismo autor "La obra arquitectónica de José Guardiola Picó», Revista del Instituto de Estudios Alicantinos, n. 30, Alicante, 1980, pp. 63-87. 
- Irradiado ${ }^{12}$ de la logia "Alona» y del capítulo "Lucentino», el 29 de Agosto de 1893, por falta de asistencia y pago.

- Alistado en la Compañía de Ingenieros de la Milicia Nacional (1873).

- Miembro del Partido Republicano.

- Concejal del Ayuntamiento de Alicante durante el bienio 1897-99.

- Autor de dos proyectos en la Exposición de Bellas Artes de Alicante de 1884, patrocinada por la Real Sociedad Económica de Amigos del País de Alicante: uno para una iglesia del popular barrio de Benalúa y otro para un edificio destinado a escuelas; autor también de la actual plaza de toros, el Asilo de Nuestra Señora del Remedio, el campanario de la colegiata - hoy concatedral- de San Nicolás de Bari y otras muchas entidades oficiales y establecimientos benéficos de Alicante.

LEACH GIRO, Juan.

- ? - Barcelona, 8 de Abril de 1903.

- Domicilio en Alicante, C/. San Fernando.

- Nieto del poderoso comerciante Juan Giró.

- Socio en gran parte de los negocios emprendidos por Manuel Agustín Heredia, gran empresario malacitano, principal impulsor de la industrialización de Málaga.

- Comerciante, comisionista, exportador de vinos (C/. Bilbao) y frutos al por mayor y propietario de almacenes de frutos coloniales y depósitos de hierro al por mayor.

- Banquero a través de la firma Leach Giró y Cía.

- Suscriptor del empréstito de 1896 con 225 obligaciones $=112.500$ pesetas.

- Presidente de la Cámara de Comercio de Alicante (1890), Presidente de su Sección industrial y Vocal de su Sección comercial.

- Socio fundador (1877) y accionista (1890) de la Caja especial de Ahorros de Alicante, Director gerente (1877), Secretario (1877) y Vocal (1891) de su Consejo de administración.

- Accionista, con 21 acciones (sobre un total de 850), de la Sucursal del Banco de España en Alicante (1888).

- Socio n. 13 de la Real Sociedad Económica de Amigos del País de Alicante (fecha de admisión, el 8 de Noviembre de 1880) y Presidente de la misma.

- Miembro del Partido Republicano.

${ }^{12}$ La irradiación equivale a la expulsión de un masón de la logia y, en definitiva, de la Orden. Evidentemente, esta forzosa desvinculación impide al masón afectado acceder al derecho de la plancha de quite.

${ }^{13}$ Véase también LLORCA PILLET, J.: «Don Juan Leach Giró», Idealidad, Alicante, Enero de 1963. 
- Alcalde del Ayuntamiento de Alicante en 1874.

- Cónsul de los Estados Unidos de América.

\section{LINARES SUCH, Francisco}

- Alicante, ? - Sax, 1932.

- Domicilio en Alicante, C/. Maisonnave, n: 9.

- Comerciante, propietario de almacenes y depósitos de maderas y carbones minerales.

- Contribuyente industrial con 450 ptas. y territorial con 277,04 ptas. en 1889.

- Vocal de la Junta de gobierno de la Liga de Contribuyentes de Alicante y su provincia (1895).

- Contador del Consejo de administración de «La Electra Alicantina S.A.» (1900).

- Socio no 115 de la Real Sociedad Económica de Amigos del País de Alicante (fecha de admisión, el 15 de Abril de 1889).

- Masón, miembro de las logias «Alona» y «Constante Alona» de Alicante; con el nombre simbólico de Shakespeare; Secretario de la logia "Constante Alona» (1879-1880); poseedor del grado 3; plancha de quite el 25 de Octubre de 1880.

- Miembro de la Asociación de Escritores y Artistas de Alicante.

- Colaborador en Las Germanías y otras publicaciones periódicas alicantinas.

- Miembro de la Junta provincial del Partido Republicano Federal de Alicante (1886).

- Concejal del Ayuntamiento de Alicante durante los bienios 1891-93 y 1894-95 (Comisión de aguas).

\section{LOMA CORADI, Blas de}

- Cádiz, 1825 - Alicante, 11 de Septiembre de 1902.

- Poeta y dramaturgo.

- Profesor de Lengua inglesa en el Instituto Provincial de Segunda Enseñanza de Alicante (1860-1887) y primer Director y profesor en la Escuela de Comercio de Alicante (1887-1900).

- Suscriptor del empréstito de 1896 con 53 obligaciones $=26.500$ pesetas.

- Administrador-Jefe de la Fábrica de Tabacos de Alicante.

- Miembro del Círculo de Artesanos de Alicante (1866).

- Presidente del primer Ateneo Científico y Literario de Alicante (1886).

- Consejero del Banco de España y accionista, con 25 acciones 
(sobre un total de 850), de la Sucursal del Banco de España en Alicante. - Socio n: 3 de la Real Sociedad Económica de Amigos del País de Alicante (fecha de admisión, el 30 de Septiembre de 1859) y Presidente de la Sección de Literatura y Bellas Artes de dicha sociedad (1890).

- Alistado en ta Compañía de Caballería de la Milicia Nacional (1856).

- Miembro del Partido Liberal.

- Concejal del Ayuntamiento de Alicante durante los bienios 1887-89, 1890-91 y 1895-97.

- Considerado el decano de la prensa alicantina, colaboró, entre otras, en las siguientes publicaciones periódicas: El Agente de Alicante (1852-54), El Comercio de Alicante (1858-69), Revista de Instrucción Pública (1860-69), Album Literario (1863), El Lucentino (1866), La Instrucción (1866-68), La Tertulia de Alicante (1872-73), La Educación (1874-75), La Velada (1876), La Juventud Literaria (1899), El Noticiero (1899), etc.

- Autor de: Entrada en España de la Reina María Victoria (1871); Páginas en verso (1874); En la temprana muerte de la preciosa niña Matilde Pobil y Chichieri, en colaboración con Rafael Campos Vassallo (1874); Juan. Poema de aldea en cuarenta y un cuadros (1877); Adiós a la Señorita María Vivanco (1879); La poética de los niños o nociones rudimentarias de versificación destinadas a las Escuelas de Primera Enseñanza (1879); Ciencia y Arte de enseñar. Colección de manuales del maestro. Manual sexto: Enseñanza de la Gramática. Manual séptimo: Enseñanza de la Aritmética. Manual octavo: Enseñanza de la Geografía (1883); España en el siglo XX (1883); Al siglo XIX. Oda (1883 ?); Escuela de Comercio de Alicante. Memoria y Discursos de don ... y don Mateo Alonso del Castillo en la Inauguración de dicha Escuela (1888) etc.

- Caballero de la Medalla de Oro de la Cruz de la Rioja por mérito de guerra y poseedor de la Gran Cruz de Comendador de Carlos III.

MAISONNAVE CUTAYAR, Eleuterio ${ }^{14}$.

- Alicante, 6 de Septiembre de 1840 - Madrid, 5 de Mayo de 1890.

${ }^{14}$ Véase también ALBEROLA, G.: Don Eleuterio Maisonnave, Madrid, 1920; "Biografia de Eleuterio Maisonnave Cutayar», El Luchador, Alicante, 27 y 30 de Abril de 1929 y 4 de Mayo de 1929; GUTIERREZ SALMERON, A.: "Maisonnave», "El Luchador», Alicante, 8 de Mayo de 1918; JOSE DE ALICANTE: «Eleuterio Maisonnave Cutayar», Peña Alicante, n. 14, Barcelona, 1929; LLORCA PILLET, J.: «Eleuterio Maison- 
- Domiciliado en Alicante, C/. Prim y en Madrid.

- Licenciado en Derecho por las Universidades de Valencia y Madrid.

- Propietario.

- Fundador y Vicepresidente (1866) del Círculo de Artesanos de Alicante, catedrático de Geografía e Historia en dicha sociedad y redactor de sus Bases y Reglamento y de su Memoria.

- Socio fundador (1877) y accionista (1890) de la Caja especial de Ahorros de Alicante y redactor de su Memoria y Estatutos.

- Socio corresponsal n. 227 de la Real Sociedad Económica de Amigos del País de Alicante (fecha de admisión, el 8 de Noviembre de 1880).

- Iniciado como masón en la logia "Alona» de Alicante el 11 deJunio de 1876, con el nombre simbólico de Pericles; Venerable Maestro Honorario de dicha logia; poseedor del grado 33.

- Miembro del capítulo "Lucentino» (fecha de admisión, el 5 de Marzo de 1878).

- Miembro de la Gran Comisión de Justicia del Gran Oriente de España (fecha de proclamación, el 20 de Diciembre de 1884); Diputado por el distrito de Alicante a la Gran Logia Simbólica del Gran Oriente de España (1884 y 1866); Ilustre y Poderoso Gran Comendador y primer Presidente de la Cámara Consultiva del Gran Oriente de España.

- Activo preparador de la revolución de Septiembre de 1868, miembro del Cuerpo de Voluntarios de la Libertad (1868) y Comandante de la Milicia Nacional (1869).

- Republicano, figura destacada del partido presidido por Emilio Castelar.

- Alcalde del Ayuntamiento de Alicante en 1869, 1870 y 1872.

- Diputado y Presidente de la Comisión de Actas de las Cortes Constituyentes de 1873 y redactor de la Memoria presentada el 2 de Enero de 1874 a las Cortes Constituyentes.

- Ministro de Estado y Gobernación en el gabinete de Emilio Castelar y autor del proyecto que disolvió el Cuerpo de la Milicia Nacional (1873).

- Gobernador Civil de Alicante.

- Diputado a Cortes por Alicante en 1879, 1881 y 1886.

- Fundador, en Alicante, de El Derecho y el Deber (1869) y La República Española (1870); colaborador en varios periódicos alicantinos como Fígaro, El Correo de España y, sobre todo, El Gra-

nave Cuatayar», Idealidad, Alicante, Marzo de 1962; QUILIS MOLINA, R.: "La andariega estatua de don Eleuterio Maisonnave Cutayar», Idealidad, Alicante, Junio de 1965; RICO, M.: Boceto del Excmo. Sr. don Eleuterio Maisonnave Cutayar, Alicante, 1890; y SELLES, S.: «Maisonnave», El Luchador, Alicante, 5 de Mayo de 1913. 
duador (a través del cual mantuvo, a lo largo de 1877, una notable polémica con Basilio Martínez a propósito del pantano de Montnegre); director, desde 1886, de El Globo de Madrid.

- Autor de Comentarios de Derecho Mercantil (1865) Y de Contrato de Cambio (1867).

\section{PENALVA MUÑOZZ, Luis.}

- ? - Alicante, 30 de Marzo de 1912.

- Domicilio en Alicante, C/. Navas, n. 51 y C/. San Fernando.

- Empresario teatral.

- Hombre de negocios, comerciante muy acaudalado y comisionista de vinos al por mayor venido de Cataluña, asociado a la firma francesa "Moulle et Jeune», exportadora de vinos, con bodegas en el puerto de Alicante, Grao de Valencia, Castellón de la Plana, Villena, Benicarló, Criptana, Haro y Burdeos, sede de la casa madre francesa.

- Propietario de unas 1.000 hectáreas en Villena.

- Banquero.

- Suscriptor del empréstito de 1896 con 200 obligaciones $=100.000$ pesetas.

- Accionista (1890) y Vocal del Consejo de administración (1891) de la Caja especial de Ahorros de Alicante.

- Presidente de la Junta de gobierno de la Liga de Contribuyentes de Alicante y su provincia (1895).

- Iniciado como masón en la logia "Los Puritanos» de Alicante el 2 de Mayo de 1878, con el nombre simbólico de Marco Aurelio; Orador de dicha logia (1880); poseedor del grado 4.

- Miembro del Partido Republicano.

- Concejal del Ayuntamiento de Alicante durante los bienios 1890-91 y 1891-93.

\section{TEROL MALUENDA, Rafae/ ${ }^{15}$}

- Alicante, ? - 1902.

- Domicilio en Alicante, C/. San Francisco, n: 45.

- Comerciante y propietario, emparentado con Antonio Maigmon, Canciller del Consulado de Francia en Alicante a finales del siglo XIX.

\section{brero de 1894.}

${ }^{15}$ Véase también «Don Rafael Terol Maluenda», El Graduador, Alicante, 4 de Fe- 
- Socio n. 23 de la Real Sociedad Económica de Amigos del País de Alicante (fecha de admisión, el 8 de Noviembre de 1880).

- Iniciado como masón en la logia "Constante Alona» de Alicante en 1882, con el nombre simbólico de Mateo; plancha de quite, por no estar conforme con la marcha de la logia, el 4 de Julio de 1887.

- Miembro fundador (1888) de la logia «Esperanza» y del capítulo «Esperanza en Alicante; Venerable Maestro Honorario de la logia (1888 y 1890) y Maestro de Ceremonias del capítulo (1890) poseedor del grado 30 .

- Jefe local del Partido Liberal Fusionista.

- Presidente de la Diputación provincial de Alicante (1883).

- Alcalde del Ayuntamiento de Alicante durante el bienio 1887-89.

- Diputado a Cortes por el distrito de Alicante en 1893, 1898 y 1901.

\section{VILLAR MIRALLES, Ernesto.}

- Alicante, 1849 - Novelda, 1916.

- Compositor y musicológo, sucesor, en la dirección al frente de la Orquesta del Teatro Principal de Alicante, de su tío y maestro, Francisco Villar Modonés.

- Miembro del Cuerpo Pericial de Aduanas durante once años (año de ingreso, 1871).

- Suscriptor del empréstito de 1896 con 5 obligaciones $=2.500$ ptas.

- Fundador y Director, en Alicante, de la Sociedad de Cuartetos de Música Clásica.

- Director y Maestro de la capilla de música de la colegiata de San Nicolás.

- Profesor de la Escuela Normal de Magisterio de Alicante.

- Miembro de la Cámara de Comercio de Alicante y Contador de su Sección industrial.

- Miembro de la Real Academia de Bellas Artes de San Fernando.

- Socio corresponsal n:342 de la Real Sociedad Económica de Amigos del País de Alicante (fecha de admisión, el 25 de Noviembre de 1885).

- Masón, miembro fundador (1883) de la logia «Padilla» de Vinaroz $^{16}$.

${ }^{16}$ Ignoramos otros datos al respecto - fecha de iniciación, grad., nombre simbólico, etc. - , pero es seguro que perteneció al la logia «Padilla» de Vinaroz. Véase USO I ARNAL, Joan-Carles: La masonería castellonense contemporánea (1874-1939), Tesis de Licenciatura inédita dirigida por D. Joan Brines Blasco, Valencia, 1982. 
- Vicepresidente del Comité republicano centralista de Alicante (1896), coincidiendo en la dirección de dicho Comité con Amando Alberola Martínez.

- Concejal del Ayuntamiento de Alicante durante los bienios 1894-95 y 1895-97.

- Responsable de una abundante producción musical, en la que destacan, sobre todo, obras religiosas, himnos, etc.

- Autor de la Memoria del Centro de Instrucción y Recreo «El Estudio", desde su instalación hasta el 9 de noviembre de 1870 (s.a.), Impresiones (1890), Alicante artístico-musical (1893), El bello arte de la música (1894), Homenaje a Clavé (1894), Compendio de legis/ación escolar (1905) y otros muchos trabajos literarios sobre temas musicales.

\section{A MODO DE CONCLUSION.}

Los denominadores comunes más significativos de los personajes que hemos reunido evidencian el alto grado de cohesión interna existente. Diez militaban dentro del campo republicano; trece ejercieron cargos públicos en distintos niveles de la administración, desde Ministerios al Ayuntamiento, pasando por la Diputación provincial; once pertenecían a la Real Sociedad Económica de Amigos del País de Alicante, e igual número extraían sus ingresos del ejercicio de la profesión mercantil; diez estuvieron vinculados a las diversas logias masónicas que se establecieron en la ciudad, llegando a poseer grados y cargos relevantes en algunos casos particulares. La virtual presencia en iniciativas empresariales o financieras se cumple en ocho casos, sea como miembros fundadores de la Caja especial de Ahorros de Alicante, en 1877, sea como compradores de deuda pública, singularmente de los empréstitos emitidos con ocasión de las guerras coloniales a finales de siglo. Finalmente, cierto número había nutrido las filas de la Milicia Nacional, instrumento a través del cual habían intervenido en la consolidación del dominio de la burguesía durante el siglo XIX. Cuando este cuerpo se vislumbró como peligroso a los ojos de esta misma burguesía, por su elevado componente popular, se decretó su abolición definitiva en 1873, siendo Ministro de la Gobernación en el gabinete de Emilio Castelar, precisamente uno de nuestros personajes biográficos, Eleuterio Maisonnave ${ }^{17}$.

${ }^{17}$ Sobre la Milicia Nacional como instrumento del proceso revolucionario burgués, véase PEREZ GARZON, Juan Sisinio: Milicia Nacional y Revolución Burguesa. El prototipo madrileño (1808-1874), Madrid, 1978. La disolución de los Voluntarios de la República en 1873 por Eleuterio Maisonnave en p. 516. Las distintas listas de milicianos nacionales de Alicante se las debemos a Candelaria Saiz Pastor. 
Por lo que hace referencia al marco político en el seno del cual el conjunto de la burguesía ejerció su papel de liderazgo político, sabemos que, electoralmente, la ciudad de Alicante durante el último tercio del siglo XIX estuvo dominada por las corrientes republicanas ${ }^{18}$. Sin embargo, tanto liberales como conservadores confluyeron en sus intereses de clase con los republicanos, en un pacto que salvaba sus objetivos económicos y políticos, y otorgaba el ejercicio del poder a un reducido número de personas. Se conformaba así una oligarquía o clase dominante que detentaba el control de las instituciones consideradas como factores clave para conseguir dominar hegemónicamente el poder político ${ }^{19}$. Tanto el Ayuntamiento como otros centros de decisión - Cámara de Comercio, Real Sociedad Económica de Amigos del País, etc. - fueron instituciones desde las que la burguesía desempeñó su doble tarea de dominio político y de expansión ideológica, preservando, de este modo, sus objetivos económicos y sociales.

Pero hay que destacar otro punto de gran importancia. Esta oligarquía o clase dominante podía serlo en tanto en cuanto se mantuviera como grupo económicamente privilegiado. Un sector de este grupo disfrutaba de una posición social basada en negocios que rendían beneficios amplios y al calor de la gran expansión de la producción y exportación de vinos durante el último tercio del siglo XIX, con lo que acumularon capitales nada desdeñables que le permitían consolidar más su posición política ${ }^{20}$.

No ostante, las evidencias y datos con que contamos, pese a su

${ }^{18}$ Véase PEÑA GALLEGO; Fernando: Elecciones legislativas en la provincia de Alicante durante la época de la Restauración (1875-1902), Alicante 1979.

${ }^{19}$ A Propósito de la caracterización de esta forma de control del poder político, los historiadores valencianos han ido avanzando algunas hipótesis, a través de conceptos y denominaciones distintas. Para PONS, A. y SERNA, J.: op. cit.; p. 155, estos grupos gozaban de una, así calificada, clase de servicio integrada por elementos no desafectos totalmente sino parcialmente a la clase dominante que detentaba el poder político local de Valencia. En cambio, Alicia Yanini (véase «Parlamentarios valencianos: los diputados (1876-1901)", Cahiers de L'Université, no 1, Pau, 1982, pp. 83-97) prefiere la denominación de élite local, subsidiaria de la oligarquía que ocupaba la cúspide del poder. Para el caso de Alicante, el pacto tácito a que nos hemos referido parece indicar que los republicanos no integraban la clase dirigente pero participaban de la dominante. Véase VIDAL OLIVARES, Javier: "Burguesía y negocios: la especulación en el sector servicios de la ciudad de Alicante a fines del siglo XIX (1880-1900)",, Anales de la Universidad de Alicante. Historia Contemporánea, n. 2, Alicante, 1983, pp. 159-181.

${ }^{20}$ Sobre este punto véase el trabajo de CARNERO ARBAT, Teresa: «Economía y poder político en el País Valenciano (1870-1914)", Debats, n.7, Valencia, 1984, pp. 16-25. 
importancia, no dejan por ello de ser fragmentarios. Hay que acudir a fuentes todavía no explotadas que permitan una reconstrucción sistemática de las actividades, negocios, inversiones y propiedades de que gozaban estos grupos. Unicamente después de lograr un mayor y profundo conocimiento de los perfiles económicos y socio-políticos de este sector social se podrían elaborar interpretaciones globales más atinadas que las que ahora disponemos y que lograran explicar actitudes que hasta ahora permanecen en la oscuridad. 


\title{
APROXIMACION AL ESTUDIO CUANTITATIVO Y SOCIO-PROFESIONAL DE LOS MIEMBROS DE LA LOGIA "CONSTANTE ALONA» DE ALACANT (1878-1890)*
}

\author{
JOAN-CARLES USO I ARNAL \\ Miembro del Centro de Estudios Históricos de la Masonería Española (CEHME)
}

El presente trabajo, tal y como refleja su título, pretende establecer una primera aproximación al análisis cuantitativo y socio-profesional de los miembros de la logia "Constante Alona» de Alacant, entre 1878 y $1890^{\prime}$.

Los diversos aspectos tratados parecen actualmente superados, al menos, metodológicamente; no obstante, en el caso concreto de la "Constante Alona», cobran especial importancia, precisamente en función del taller masónico a que hacen referencia.

En efecto, conviene destacar que, a juicio de todos los especialistas en la materia, la logia "Constante Alona» es el establecimiento más relevante de todos los que ha alumbrado la masonería española hasta la actualidad.

Por otra parte, el largo período de su actividad - que se extendió

* Comunicación presentada en el «ll Symposium de Metodología Aplicada a la Historia de la Masonería Española», celebrado en Salamanca del 2 al 5 de Julio de 1985.

${ }^{1}$ Este período supone el marco cronológico sobre el que se centra mi investigación de Tesis Doctoral - actualmente en proceso de elaboración - sobre la logia alicantina "Constante Alona». Dicho periodo comienza en 1878 con la fundación del taller y concluye en 1890 con el cese de la publicación de La Humanidad, órgano de difusión de la logia, y que, de algún modo, marca los años de mayor auge y prosperidad de la «Constante Alona».

En este sentido, a tenor de la información ofrecida por Santiago Córcoles en su artículo "Logia Constante-Alona, los masones de Alicante», Información, Alicante, 30 de Abril de 1985, p. 9 y por Manuel Perales Pérez - miembro destacado de la logia que existe en la actualidad en Alacant, también con el nombre de "Constante Alona», adscrita a la Masoneria Mixta Internacional «El Derecho Humano» - en el programa regional valenciano Aitana, emitido el 22 de Mayo de 1985, quienes fijan la fundación de la logia "Constante Alona» en el año 1865, se hace necesaria una puntualización. Tanto Santiago Córcoles como Manuel Perales no citan ninguna fuente que corrobore esta fecha; ahora bien, la documentación conservada en el Arhivo Histórico Nacional de Salamanca: Sección Masonería no ofrece ninguna duda al respecto. Según el Libro de Actas de Grado 1․, de 1878 a 1882 (Legajo 576-A, Expediente 3), las primeras tenidas o reuniones de la logia, de carácter preparatorio, se celebraron los días 20, 21, 22 y 23 de Noviembre de 1878, y su Carta Constitutiva (Legajo 574-A, Expediente 1) fue expedida por el Grande Oriente de España con fecha de 25 de Noviembre de 1878. 
ininterrumpidamente ${ }^{2}$ desde 1878 hasta 1939 - y el hecho de haber estado adherida al Grande Oriente de España, Gran Oriente Nacional de España y Gran Oriente Español sucesivamente, nos pueden ofrecer una visión bastante amplia y completa de los avatares de la masonería española contempránea, particularmente de los problemas surgidos siempre en torno a las Obediencias o Grandes Orientes.

También es preciso poner de relieve la circunstancia de que la logia "Constante Alona» es uno de los talleres masónicos que afortunadamente conserva una mayor cantidad de material documental ${ }^{3}$, bibliográfico y periodístico, especialmente rico y valioso en contenido. En este sentido, no podemos olvidar que los miembros de la logia editaron como medio propio de difusión la revista La Humanidad ${ }^{4}$, que vió la luz pública entre el 10 de Enero de 1883 y el 30 de Noviembre de 1890.

Por último, podemos adelantar que las connotaciones políticas y socioeconómicas, al igual que el perfil tanto masónico como profano de sus miembros, contribuyen a aumentar el interés y significación de esa logia, auténtica pieza fundamental para entender el mosáico masónico español del último tercio del siglo XIX y del siglo XX hasta el final de la Guerra Civil.

Como base documental para intentar esta aproximación al estudio

${ }^{2}$ Es importante poner de relieve este hecho, según se afirma textualmente en una circular emitida por la logia "Constante Alona», con fecha de 22 de Noviembre de 1898 (A.H.N.S.M., Legajo 575-A, Expediente 2), ya que a partir de 1895 toda la masonería española entró, durante bastantes años, en una profunda crisis - a la que también se alude en el citado documento - al ser acusada de fomentar el independentismo en las colonias, lo que originó la disolución de la mayor parte de los talleres y de los altos poderes masónicos.

${ }^{3}$ La documentación correspondiente a la logia "Constante Alona», está localizada integramente en el Archivo Histórico Nacional de Salamanca: Sección Masonería, en los siguientes legajos:

574-A, expediente 1

575-A, expediente 2

$576-A$, expediente 3

$577-A$, expediente 4

578-A, expediente 5

579-A, expediente 6

580-A, expediente 7

Existen además numerosos expedientes personales correspondientes a miembros del taller.

${ }^{4}$ Sobre el órgano de difusión de la logia "Constante Alona», véase USO I ARNAL, Joan-Carles: "La Humanidad» (1883-1890): una revista masónica en el Alicante de la Restauración, comunicación presentada en el «ll Symposium de Metodología Aplicada a la Historia de la Masonería Española», celebrado en Salamanca del 2 al 5 de Julio de 1985. 
cuantitativo y socio-profesional de sus miembros, entre 1878 y 1890 , contamos particularmente con cinco cuadros lógicos, que corresponden a los años 1882, 1883, 1886, 1888 y 1890 respectivamente ${ }^{5}$ y, en menor grado, con una lista de miembros con derecho a voto para las elecciones internas del taller de $1885^{6}$.

Se trata de un material documental de primer orden, si bien presenta un doble incoveniente. En primer, lugar el cuadro lógico más antiguo data de 1882, con lo que este trabajo difícilmente puede contemplar los cuatro primeros años de actividad del taller. En segundo lugar, hemos de advertir que la logia "Constante Alona» contó con muchos miembros que no aparecen reflejados en las citadas fuentes ${ }^{7}$. A pesar de todo, tenemos la convicción de que ambas deficiencias pueden alterar en bien poco las conclusiones que de esta comunicación se obtengan.

Hechos estos preliminares, el número total de miembros pertenecientes a la "Constante Alona», según esta documentación, queda como sigue:

\begin{tabular}{|c|c|c|}
\hline 1882 & 57 & miembros \\
\hline 1883 & 131 & 》 \\
\hline 1885 & 133 & » \\
\hline 1886 & 143 & $»$ \\
\hline 1888 & 87 & $»$ \\
\hline 1890 & 78 & » \\
\hline
\end{tabular}

${ }^{5}$ A.H.N.S.M. Legajo 574-A, expediente 1.

${ }^{6}$ Ibídem. Este listado sólo contiene el nombre de los masones, agrupándolos en miembros «electores elegibles» y miembros «electores no elegibles»; no aporta ningún dato sobre su edad, profesión, naturaleza, domicilio, etc, por lo que resulta de escasa utilidad.

${ }^{7}$ Hemos podido constatar este hecho al investigar los Libros de Actas del taller, descubriendo un gran número de masones que no están incluidos en los cuadros lógicos. Por otra parte, no podemos olvidar que la documentación de la «Constante Alona», pese a ser una de las más abundantes y enjundiosas que se encuentran en el A.H.N.S.M., es una documentación indirecta, es decir, reconstruida a partir de la documentación de otros talleres masónicos. 


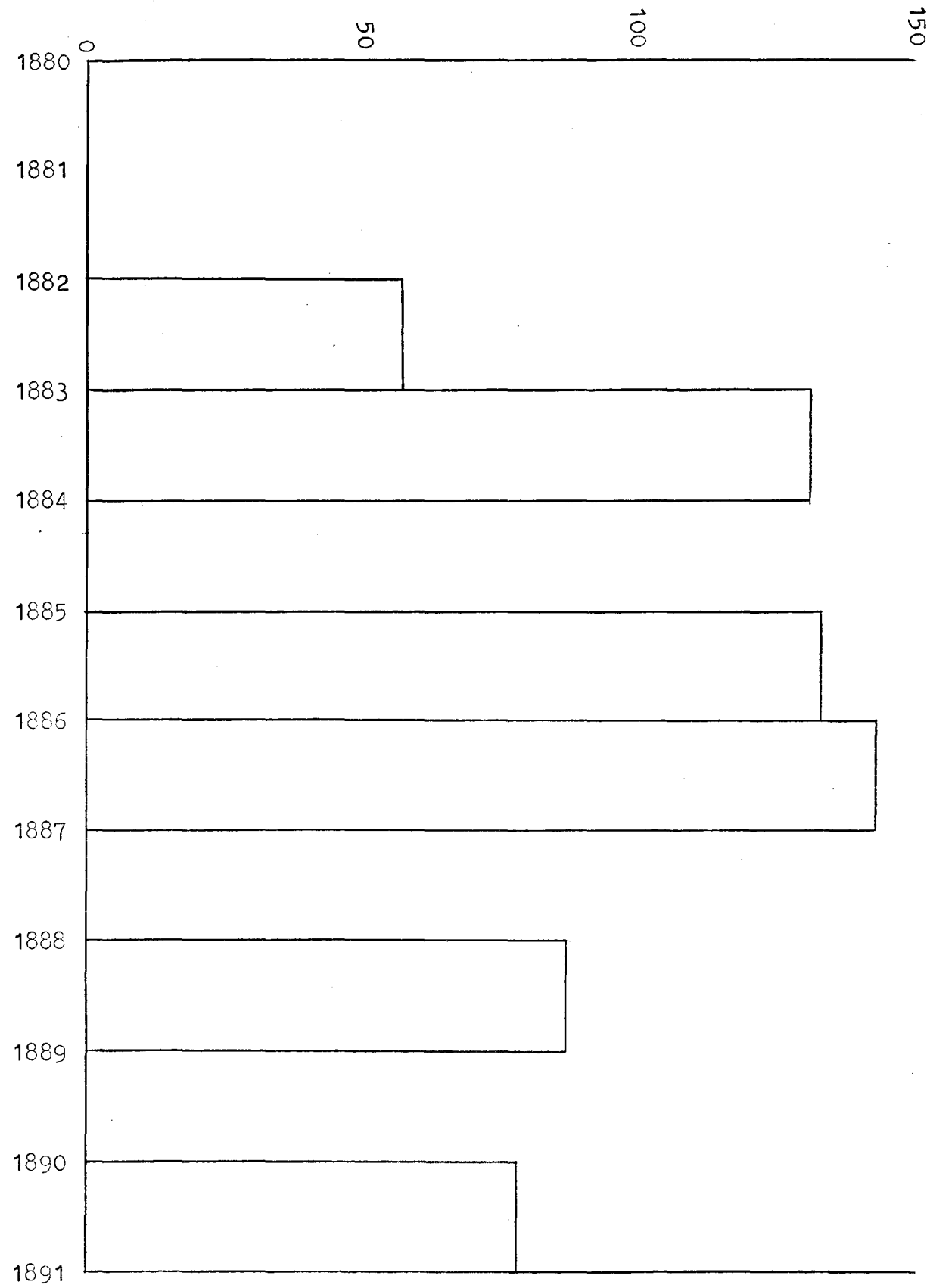


Como, a simple vista, podemos observar, se trata de un logia muy numerosa, que siguió una línea claramente en ascenso hasta el año 1886. En realidad, la logia "Constante Alona», constituida hacia finales de noviembre de 1878, a partir de una escisión interna producida en el seno de la logia "Alona» ${ }^{8}$, lo que provocó su disolución temporal, debió contar ya desde un primer momento con un número de masones relativamente superior al habitual en cualquier nuevo levantamiento de columnas. De hecho, no sólo procedían de la "Alona» sus fundadores, sino que, durante un periódo que podemos dar por conluido a fines de $1883^{\circ}$, fueron varios los miembros de la "Alona» que pidieron su afiliación en la "Constante Alona ${ }^{10}$. Del mismo modo, a lo largo de este período señalado, bastantes masones originarios de otras logias alicantinas "pasaron también a engrosar las filas del taller.

A destacar, en la evolución de este taller, el espectable aumento registrado entre 1882 y 1883, año en que el número de miembros llegó a duplicarse, y el no menos espectacular descenso producido entre 1886 y 1888.

El crecimiento entre 1882 y 1883 , que se vió continuado, si bien de un modo más proporcionado, hasta 1886, coincidió con los años de máximo esplendor de la logia "Constante Alona», bajo los auspicios del Grande Oriente de España. Sin duda, esta etapa de auge estuvo estrechamente relacionada con el «carácter eminentemente expansivo y democrático ${ }^{12}$ que imprimió a sus trabajos el Grande Oriente de España, especialmente bajo la dirección de Práxedes Mateo Sagasta y Antonio Romero Ortiz. Este hecho, unido a la «intransigencia del Grande Oriente Nacional y el extrañamiento de las logias establecidas en España bajo la autoridad del Grande Oriente Lusitano Unido de Portugal» ${ }^{13}$, fue el que determinó el crecimiento de las logias bajo la obediencia del Grande Oriente de España, hasta el punto de que durante estos años «el número de masones alcanzó cifras desconocidas en España» ${ }^{14}$.

En concreto, por lo que respecta a la logia «Constante Alona», el

${ }^{8}$ Se hace referencia a estos problemas de la logia "Alona» en el A.H.N.S.M. Legajo 576-A, expediente 3. Libro de Actas de Grado 1․, actas de 20 de noviembre y 2 de diciembre de 1878.

${ }^{9}$ La logia "Alona» volvió a la vida activa masónica el 6 de enero de 1884.

${ }^{10}$ Respecto a este punto, se hace necesario señalar que casi todos estos masones volvieron a afiliarse a la logia "Alona» cuando retornó a la actividad masónica.

1 Nos referimos a las logias "Los Puritanos", "Crisol» y "Numancia», todas de Alacant.

12 FERRER BENIMELI, José A.: Masonería española contemporánea, Madrid, 1980 , vol. 2, p. 5.

${ }^{13}$ Ibidem, p. 9.

14 Ibídem. 
incremento de sus efectivos masónicos a costa del Grande Oriente Nacional es un hecho que hemos constatado documentalmente ${ }^{15}$, sobre todo en 1880 . Todos estos masones reconocieron en la irregularidad del Grande Oriente Nacional la causa principal de su decisión de afiliarse en el taller.

Por otra parte, el aumento de miembros en la logia, particularmente mientras ocupó el cargo de Gran Maestro del Grande Oriente de España Antonio Romero Ortiz, puede tener un punto de referencia válido en la confianza de que disfrutó este célebre masón por gran parte de los alicantinos, quienes lo habian tenido - por espacio de tres mesesen 1856 como gobernador civil y quienes lo votaron en sucesivas ocasiones para diputado a Cortes en varias legislaturas ${ }^{16}$.

Del mismo modo, la pérdida de efectivos entre 1886 y 1888 correspondió al período de anarquía que se abrió en el seno del Grande Oriente de España tras la dimisión de su Gran Maestro, Manuel Becerra - sucesor de Antonio Romero Ortiz - , y las irregularidades administrativas llevadas a cabo por su Gran Secretario, Juan Utor Fernández, que «originaron nuevas escisiones y tal desconcierto que acabó prácticamente con la disgregación del Supremo Consejo y del Grande Oriente de España ${ }^{17}$. Incluso cabe dentro de lo posible que el desconcierto y el escepticismo creado, si no al nivel general sí particular, fuera mayor entre los miembros de la "Constante Alona», para quienes Juan Utor Fernández, al menos durante mucho tiempo, gozó de gran predicamento ${ }^{18}$.

Lo cierto es que la anarquía reinante en los altos poderes masónicos del Grande Oriente de España afectó también a los miembros de la "Constante Alona», parte de los cuales, tras agrios enfrentamientos, decidieron separarse de la logia y fundar, en febrero de 1888, un nuevo taller ${ }^{19}$.

Por lo que respecta sobre la naturaleza de los componentes de la 1882.

${ }^{15}$ A.H.N.S.M. Legajo 576-A, expediente 3. Libro de Actas de Grado 1. de 1878

${ }^{16}$ Otras razones que, sin duda alguna, también debieron influir decisivamente en el incremento de miembros en el Grande Oriente de España, en general, y en la logia "Constante Alona», en particular, durante las Grandes Maestrías de Sagasta y Romero Ortiz, fueron, en primer lugar, el mero prestigio personal $y$, en segundo lugar, la sincera convicción de que bajo estas dos destacadas figuras el Grande Oriente de España iba a desarrollar sus trabajos masónicos en un clima de verdadera unidad, fraternidad y seriedad.

17 FERRER BENIMELI, J.A.: op. cit., p. 9.

18 Juan Utor Fernández visitó la logia "Constante Alona» en diciembre de 1883. Los miembros del taller le dispensaron una calurosa acogida y lo nombraron por unanimidad Venerable Honorario, según queda reflejado en el A.H.N.S.M. Legajo 576-A, expediente 3. Libro de Actas de Grado 1\%, actas de 27 y 28 de diciembre de 1883.

${ }^{19}$ Nos referimos a la logia «Esperanza». Ver el A.H.N.S.M. Legajo 583-A, expediente 2. Cuadro lógico de 10 de marzo de 1888. 
logia, sólo nos aportan datos los cuadros lógicos de 1882 y 1883.

Según el cuadro de 1882 el origen de los 57 miembros con que contaba la «Constante Alona» era el siguiente:

\begin{tabular}{ll}
\hline 34 de Alacant & (I'Alacantí, Alacant) \\
4 de Cartagena & (Murcia) \\
2 de Fortuna & (Murcia) \\
2 de Murcia & (Murcia) \\
2 de Sant Joan d'Alacant & (I'Alacantí, Alacant) \\
2 de Villafranqueza ${ }^{20}$ & (I'Alacantí, Alacant) \\
1 de Agost & (I'Alacantí, Alacant) \\
1 de Alcoi & (I'Alcoià, Alacant) \\
1 de Motilla del Palancar & (Cuenca) \\
1 de Mutxamel & (I'Alacantí, Alacant) \\
1 de Napoli & (Italia) \\
1 de Palma de Mallorca & (Baleares) \\
1 de Parma & (Italia) \\
1 de Polopos & (Granada) \\
1 de Retortillo & (Soria) \\
1 de Rojales & (El Bajo Segura, Alacant) \\
1 de Valladolid & (Valladolid) \\
\end{tabular}

Por su parte, según el cuadro lógico del año 1883 podemos establecer la siguiente clasificación sobre el lugar de nacimiento de sus 131 miembros:

\begin{tabular}{ll}
\hline 61 de Alacant & (I'Alacantí, Alacant) \\
5 de Madrid & (Madrid) \\
4 de Cartagena & (Murcia) \\
4 de Fortuna & (Murcia) \\
4 de Palma de Mallorca & (Baleares) \\
4 de Sant Joan d'Alacant & (I'Alacantí, Alacant) \\
3 de Villafranqueza ${ }^{21}$ & (I'Alacantí, Alacant) \\
3 de Xixona & (I'Alacantí, Alacant) \\
2 de Almansa & (Albacete) \\
2 de Benidorm & (la Marina Baixa, Alacant) \\
2 de Mazarrón & (Murcia)
\end{tabular}

${ }^{20}$ Actualmente este municipio está incorporado al de Alacant.

21 Ibidem. 


\begin{tabular}{ll}
2 de Mutxamel & ('́Alacantí, Alacant) \\
2 de Pedralba & (Els Serrans, València) \\
2 de Sax & (El Alto Vinalopó, Alacant) \\
2 de Villagarcia ${ }^{22}$ & (Pontevedra) \\
1 de Alcalá de los Gazules & (Cádiz) \\
1 de Alcoi & (l'Alcoià, Alacant) \\
1 de Almoradí & (El Bajo Segura, Alacant) \\
1 de Altea & (la Marina Baixa, Alacant) \\
1 de Cádiz & (Cádiz) \\
1 de Castejón de las Armas & (Zaragoza) \\
1 de Durango & (Vizcaya) \\
1 de Estella & (Navarra) \\
1 de Huercal-Overa & (Almeria) \\
1 de Ito & (Cuenca) \\
1 de Losaso & (Italia) \\
1 de Llessui 23 & (Pallars Sobirà, Lleida) \\
1 de Monòver & (les Valls del Vinalopó, Alacant) \\
1 de Motilla del Palancar & (Cuenca) \\
1 de Motril & (Granada) \\
1 de Murcia & (Murcia) \\
1 de Ontinyent & (la Vall d'Albaida, València) \\
1 de Puertollano & (Ciudad Real) \\
1 de Relleu & (la Marina Baixa, Alacant) \\
1 de Retortillo & (Soria) \\
1 de Rojales & (El Bajo Segura, Alacant) \\
1 de Sant Vicent del Raspeig & (l'Alacantí, Alacant) \\
1 de Santiago & (La Coruña) \\
1 de Sevilla & (Sevilla) \\
1 de Tibi & (I'Alcoià, Alacant) \\
1 de València & (I'Horta, València) \\
1 de Valladolid & (Valladolid) \\
1 de la Vila Joiosa & (la Marina Baixa, Alacant) \\
& \\
\hline
\end{tabular}

Atendiendo a la información de estos cuadros, podemos ver que muchos masones eran foráneos, hecho que ya hemos observado en anteriores estudios referidos a otras comarcas del País Valencià ${ }^{24}$. En el

\footnotetext{
${ }^{22}$ Aunque el documento no especifica más, hemos optado por creer que se trata de Villagarcía de Arosa.

${ }^{23}$ Actualmente este municipio esta incorporado al de Sort.

${ }^{24}$ Esta cuestión aparece tratada, referida, sobre todo, a Castelló de la Plana - que en ciertos aspectos guarda algún que otro paralelismo con la ciudad de Alacant - , en mi Tesis de Licenciatura La masonería castellonense contemporánea (1874-1939), dirigida por Joan Brines Blasco, València, 1982.
} 
primer cuadro, de 57 miembros, $34(59,64 \%)$ eran de Alacant y 23 $(40,35 \%)$ nacidos fuera. En 1883, el número de masones foráneos, sobre un total de 131, era de $69(52,67 \%)$, llegando a superar al de autóctonos, que se cifraba en $61(46,56 \%)$. Así pues, la presencia de miembros foráneos, mientras que en 1882 no llegaba al $50 \%$ del total, en 1883 constituía más de la mitad de los efectivos humanos de la logia.

No obstante, si en vez de agrupar a los masones en autóctonos y foráneos, los distribuimos entre alicantinos - agregando los nacidos en todas las localidades alicantinas a los naturales de la capital- y nacidos fuera del ámbito de las comarcas alicantinas obtenemos unas cifras y unos porcentajes notablemente modificados. En 1882 los miembros alicantinos sumarían $42(73,68 \%)$ y los no alicantinos tan sólo 15 $(26,31 \%)$. En 1883 la diferencia sería entre $86(65,64 \%)$ y $44(33,58 \%)$, con un saldo favorable para los alicantinos.

Con todo, una información muy importante sobre esta cuestión es la contenida en el cuadro lógico de 1883 , que nos facilita la siguiente clasificación de los lugares de residencia de los masones, a los que nos hemos permitido añadir la distancia en kilométros a la capital ${ }^{25}$ :

\begin{tabular}{llr}
\hline 118 en Alacant & (l'Alacantí, Alacant) & \\
2 en Almoradi & (El Bajo Segura, Alacant) & $42 \mathrm{kms}$. \\
2 en Benidorm & (la Marina Baixa, Alacant) & $42 \mathrm{kms}$ \\
2 en Monòver & (les Valls del Vinalopó, Alacant) & $36 \mathrm{kms}$ \\
2 en S. Joan d'Alacant & (l'Alacantí, Alacant) & $8 \mathrm{kms}$ \\
1 en Almería & (Almería) & $431 \mathrm{kms}$ \\
1 en Denia & (la Marina Alta, Alacant) & $101 \mathrm{kms}$ \\
1 en Rojales & (El Bajo Segura, Alacant) & $40 \mathrm{kms}$. \\
1 en S. Fulgencio & (El Bajo, Alacant) & $39 \mathrm{kms}$ \\
1 en Sax & (El Alto Vinalopó, Alacant) & $50 \mathrm{kms}$.
\end{tabular}

${ }^{25}$ El dato está tomado de la Reseña estadítica de la provincia de Alicante, Presidencia del Gobierno, I.N.E., Madrid, 1969. 
Como fácilmente se puede observar, en 1883, de un total de 131 integrantes con que contaba la "Constante Alona», $118(90,07 \%)$ vivían en Alacant y únicamente $13(9,92 \%)$ residian fuera de la ciudad.

En realidad, todos estos datos no vienen sino a corroborar el hecho de que el despegue demográfico registrado por la capital alicantina en el último cuarto de siglo $X X^{26}$ fue un proceso basado casi exclusivamente en una fuerte corriente de inmigración.

Para finalizar este aspecto sobre la naturaleza de los miembros de la logia cabe destacar la presencia de tres masones italianos. Tampoco se trata de un hecho insólito a tenor del carácter cosmopolita y de «ciudad abierta» que tradicionalmente ha rodeado Alacant, sobre todo en función de su puerto de mar.

Podemos completar este análisis cuantitativo sobre los miembros del taller ofreciendo algunos datos sobre su edad. Para ello hemos elaborado dos pirámides de edad, con la información obtenida a través de los cuadros lógicos de 1882 y 1883, que nos facilitarán la visualización de esta parte del análisis. Según esto, la edad media que permite establecer el cuadro de 1882 es de casi 38 años y medio; en 1883 esta media de edad se ve reducida a poco más de 35 años, lo cual no carece de lógica si tenemos en cuenta el masivo aumento de miembros registrado de un año a otro. A título comparativo, podemos adelantar la media de edad de un cuadro lógico posterior, de $1891^{27}$, que es ligeramente superior a los 38 años. Como se puede apreciar, la edad media de los masones no varía mucho, simplemente durante los años de mayor incremento de miembros es menor que en los años en que desciende o se estabiliza su número. Por otra parte, según aparece reflejado en las pirámides, en 1882 los grupos de edad con más individuos son el de 31 a 35 años y el de 36 a 40 años, ambos con la misma cantidad; estos dos mismos grupos son también en 1883 los que cuentan con mayor número de masones, destacando por la cantidad de miembros y por ser inferior a la edad media de ese año el grupo de 31 a 35 años.

Por último, para completar todo lo anteriormente expuesto y ofrecer un aspecto del análisis socio-económico de los miembros de la logia "Constante Alona», hemos elaborado una relación, lo más rigurosa posible, de las profesiones conocidas, con el número de masones ocupado en cada una de ellas ${ }^{28}$, así como su porcentaje respecto al total

${ }^{26}$ Tengamos en cuenta que según los censos de población, Alacant contaba en 1877 con 34.926 hab., en 1887 con 40.115 hab. $y$ en 1900 con 50.142 hab.

27 A.H.N.S.M. Legajo 574-A, expediente 1.

${ }^{28}$ Para la confección de esta relación hemos tenido que salvar algunas dificultades de un modo un tanto arbitrario. Así, al aparecer una serie de masones con distinta profesión según se trata de un cuadro lógico u otro; hemos tenido que optar por una de ellas. Del mismo modo, nos han quedado dos individuos que, por aparecer sola- 

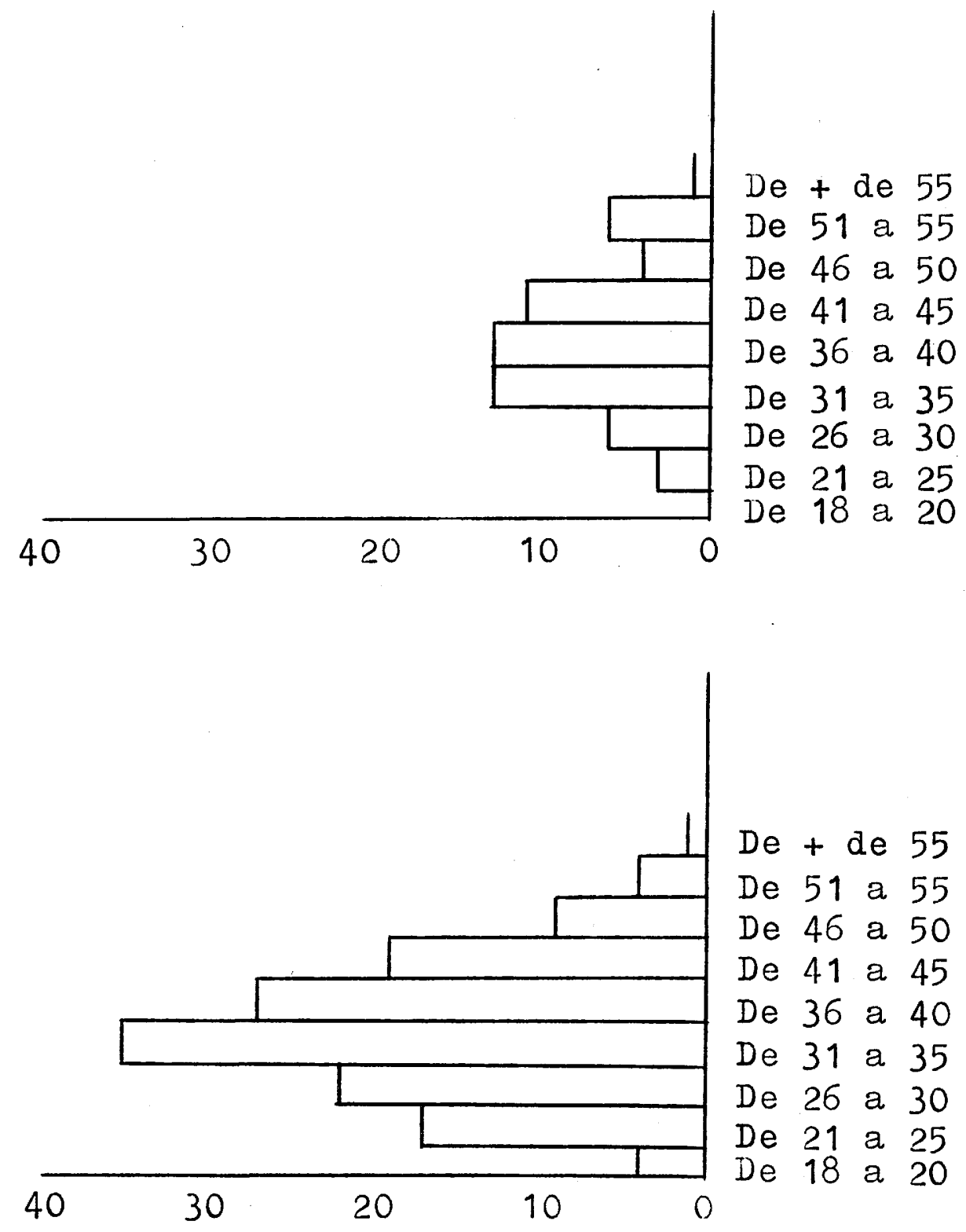
mente en el listado de miembros de 1885, ignoramos su profesión.

de individuos contabilizados.

\begin{tabular}{|c|c|c|c|}
\hline Comerciantes & 48 & $\doteq$ & $18,39 \%$ \\
\hline Empleados ${ }^{29}$ & 43 & $=$ & $16,47 \%$ \\
\hline Militares ${ }^{30}$ & 12 & $=$ & $4,59 \%$ \\
\hline Propietarios & 11 & $=$ & $4,21 \%$ \\
\hline Maquinistas ${ }^{31}$ & 9 & $=$ & $3,44 \%$ \\
\hline Artistas & 8 & $=$ & $3,06 \%$ \\
\hline Industriales & 7 & $=$ & $2,68 \%$ \\
\hline Médicos & 6 & $=$ & $2,29 \%$ \\
\hline Toneleros & 6 & & \\
\hline Marinos & 5. & $=$ & $1,91 \%$ \\
\hline Plateros & 5 & & \\
\hline Viajantes & 5 & & \\
\hline Zapateros & 5 & & \\
\hline Abgados & 4 & $=$ & $1,53 \%$ \\
\hline Dependientes de comercio & 4 & & \\
\hline Telegrafistas & 4 & & \\
\hline Carpinteros & 3 & $=$ & $1,14 \%$ \\
\hline Ebanistas & 3 & & \\
\hline Estudiantes & 3 & & \\
\hline Farmacéuticos & 3 & & \\
\hline Profesores Instrucción & 3 & & \\
\hline Sastres & 3 & & \\
\hline Agentes de Aduanas & 2 & $=$ & $0,76 \%$ \\
\hline Armeros & 2 & & \\
\hline Barberos & 2 & & \\
\hline Dentistas & 2 & & \\
\hline Guarnicioneros & 2 & & \\
\hline Herreros & 2 & & \\
\hline Hojalateros & 2 & & \\
\hline Jornaleros & 2 & & \\
\hline Peluqueros & 2 & & \\
\hline Periodistas & 2 & & \\
\hline
\end{tabular}

${ }^{29}$ En este grupo hemos incluido a dos individuos que aparecen bajo el epígrafe de "empleados F.C.» y a uno que aparece bajo el de "empleado de Tels.», los tres del cuadro lógico de 1888.

${ }^{30}$ En este grupo hemos incluido un «Oficial de Admo. Mlitar» del cuadro lógico de 1882; un "militar reitrado» del cuadro lógico de 1886 y un "Teniente del Ejército» del cuadro lógico de 1890.

${ }^{31}$ En este grupo hemos incluido un «maquinista de la Armada» del cuadro lógico de 1882. 
Pintores

Profesores de Música

Agentes de negocios

Albañil

Arcombor Aduanas

Cafertero

Caldedero

Cantante

Carabinero

Catedrático

Condestable

Contratista

Director de Fábrica de Gas

Director de orquesta y compositor

Escritor

Escultor

Fotógrafo

Gimnasta

Hornero

Ingeniero

Joyero

Lampista

Librero

Marmolista

Panadero

Pericial Aduanas

Piloto

Practicante

Practicante de la Armada

Practicante en medicina

Prestidigitador

Profesor Normal

Relojero

Representante

Sobrestante

Tablajero

Tipógrafo

Sin profesión idicada
2

1

1

1

1

1

1

1

1

1

1

1

1

1

1

1

1

1

1

1

1

1

1

1

1

1

1

1

1

1

1

1

1

1

1

$2=0,76 \%$

En conjunto, conforma un amplio espectro de burócratas, profesionales liberales e independientes y artesanos dedicados a satisfacer 
parte de los servicios y necesidades de Alacant. En realidad, esta generalización, unida al hecho concreto de predominar ostensiblemente sobre todos los demás grupos los comerciantes y los empleados, no hace sino confirmar el carácter mercantil y burocrático de la capital de l'Alacantí. En principio, este cuadro socio-profesional sólo viene a corroborar las conclusiones recogidas en los escasos trabajos que se han ocupado del tema dentro del marco del País Valenciá ${ }^{32}$.

Tras los dos grupos profesionales mencionados figura toda una serie de grupos, con muchos menos miembros, encabezada por los militares y los propietarios.

No obstante, siguiendo el ejemplo de Juan C. Gay Armenteros ${ }^{33}$, podemos destacar varios grupos profesionales - artistas, médicos, abogados, estudiantes, farmacéuticos, profesores de instrucción, periodistas, pintores, profesores de música, catedrático, director de orquesta y compositor, escritor, escultor, ingeniero, librero, profesor normal y tipógrafo - otorgándoles el calificativo y función dentro de la logia de «inteligentzia» o "élite intelectual». Del mismo modo, podemos agrupar otras profesiones - maquinistas, marinos, telegrafistas, agentes de aduanas, arcombor, aduanas, calderero, condestable, pericial aduanas, piloto, practicante de la armada e incluso alguna más - cuya razón de ser estaría claramente vinculada a la actividad portuaria de Alacant. Tanto en el primer caso $(41=15,70 \%)$ como en el segundo $(26=9,96 \%)$ comprobaremos que su número es bastante elevado, llegando incluso a superar con creces al de los militares y propietarios.

Podemos concluir todo lo expuesto destacando el peso fundamental que supone el puerto de Alacant, tanto por su importancia como enclave comercial como por su proximidad a Madrid ${ }^{34}$, auténtico epicentro de la vida política durante la Restauración. Un puerto y una actividad que configuran a esa mesocracia, esa clase social dinámica que es la burguesía comercial ligada a la exportación e importación, a esa, en

${ }^{32}$ A este respecto sólo podemos destacar la ponencia leida por Carmen Mellado Rubio y Concepción Ponce Aura en el Seminario dedicado al tema de "La maçonería contemporània al País Valencià», organizado por el Depto. de $\mathrm{H}$. Contemporánea de la Facultad de Geografía e Historia de la Universidad de Valéncia y celebrado el 8 de mayo de 1984 y mi tesis de licenciatura op. cit.

33 GAY ARMENTEROS, Juan C.: «Penuria y decadencia de la masonería jienense a finales del siglo XIX», Anuario de Historia Moderna y Contemporánea, /Granada/, nos. 2 y 3, 1975-1976, pp. 303-390.

${ }^{34} \mathrm{Al}$ quedar inaugurado, en 1858 , el ferrocarril que une a Madrid con Alacant, el puerto de esta última se convirtió - a una distancia de $445 \mathrm{Kms}$. - en la salida más próxima al Mediterráneo de la capital del Estado. 
palabras de Javier Vidal Olivares ${ }^{35}$, «oligarquía mercantil y portuaria y... sus grupos subalternos», que advertimos ligada a la masonería alicantina y que es la auténtica protagonista de la historia de la ciudad de Alacant durante los siglos XIX y XX.

${ }^{35}$ VIDAL OLIVARES, Javier: «Burguesía y negocios: La especulación en el sector de servicios de la ciudad de Alicante a fines del siglo XIX (1880-1900)", Anales de la Universidad de Alicante. Historia Contemporánea, /Alicante/, n:2, 1983, pp. 159-181. 



\author{
CARLOS DARDE MORALES \\ Dto. de Historia Contemporánea. \\ Universidad de Santander.
}

\title{
INTRODUCCION.
}

El presente artículo pretender ser una contribución a un mejor conocimiento de las elecciones de diputados a Cortes durante la Restauración; en concreto de una de las celebradas conforme a la ley conservadora de 28 de diciembre de 1878 - vigente hasta 1890- que, como se sabe, en lugar del sufragio universal masculino establecido por los revolucionarios del 68, reconocía el derecho electoral, exclusivamente, a los varones mayores de 25 años que pagarán 25 ptas. anuales, con un año de antelación, por contribución territorial, ó 50 ptas. anuales, con dos años de antelación, por subsidio industrial, o acreditasen su capacidad de acuerdo con determinadas condiciones establecidas en la ley'.

Para conseguir una explicación profunda y detallada del resultado de las elecciones de aquellos años, y de todas las celebradas en España hasta 1931, es preciso tener en cuenta, sobre todo, lo que podamos llamar factores locales. Dado el grado de desarrollo político existente, un candidato conseguía triunfar en la elección no tanto gracias al contenido del programa de su partido, o la propaganda efectuada, como en virtud de sus vinculaciones personales en el distrito correspondiente o, en caso de ser "cunero», es decir, sin arraigo personal en el distrito, por la consiguiente puesta a su servicio de todos los mecanismos de poder locales en manos de quienes le apoyaban².

Sin embargo, hay determinadas cuestiones globales del proceso electoral - el censo, la actuación gubernamental, la actividad pública

Ag̀radezco a José Varela Ortega los comentarios sobre una primera redacción de este artículo. Naturalmente la responsabilidad sobre el contenido final del mismo es exclusivamente mía.

1 Gaceta de Madrid, 29 de diciembre, 1878.

${ }^{2}$ Una visión general que recoge las últimas aportaciones historiográficas, J.M. JOVER ZAMORA, "La época de la Restauración. Panorama político-social, 1875-1902" en M. TUÑON DE LARA (dir) Historia de España, vol. VIII: Revolución burguesa, Oligarquía y Constitucionalismo (1834-1923). Barcelona, 1981, pp. 269-406. Sobre la naturaleza del régimen político y la práctica de las elecciones, vid. J. VARELA ORTEGA, Los amigos políticos. Partidos, elecciones y caciquismo en la Restauración, 1875-1900. Madrid, 1977 y J. TUSELL, Oligarquía y Caciquismo en Andalucía, 1890-1923. Barcelona, 1976. 
desarrollada por los partidos o el volumen de la violencia ejercida sobre los electores públicamente denunciada, por ejemplo - que, sin proporcionar en la mayor parte de los caso la última clave explicativa del resultado electoral, son profundamente significativas de la naturaleza de la vida política y acerca de las cuales sabemos muy poco con precisión; en muchos casos, se siguen manejando los mismos tópicos utilizados por los regeneracionistas del siglo pasado.

Para la consideración de estos aspectos generales en las elecciones de 1886, que pretendemos llevar a cabo en las siguientes páginas, hemos contado con un valioso instrumento en el libro publicado por el periodista de El Correo, Modesto Sánchez Ortiz, y el abogado Fermín Berástegui, sobre aquellas elecciones que, junto con el Diario de Sesiones del Congreso y la prensa de Madrid, han sido las principales fuentes de nuestro trabajo $^{3}$.

\section{CIRCUNSTANCIAS HISTORICAS; LOS PARTIDOS PARTICIPANTES.}

Las elecciones de diputados a Cortes celebradas el 4 de abril de 1886, habian sido convocadas por el partido liberal, llamado al poder a raiz de la muerte de Alfonso XII, en noviembre de 1885 . Este acontecimiento había producido una importante conmoción política en el país: la monarquía había sido restaurada hacía sólo once años y aunque la situación creada estaba perfectamente prevista en la Constitución - la esposa del rey difunto, doña María Cristina de Habsburgo Lorena, debía hacerse cargo de la regencia durante la minoría de edad del futuro rey o reina - la misma gravedad del trance y la debilidad en que parecía quedaba la máxima institución del Estado - con un poder infinitamente superior al que le reconocían formalmente las leyes- en manos de una mujer joven, extranjera, con escaso tiempo de permanencia en España, poco popular y con fama de escasamente inteligente, habían hecho cundir la alarma. "La muerte del rey ha producido aquí - le escribía Menéndez Pelayo a Juan Valera, ministro de España en Washington por aquellas fechas - un singular estupor e incertidumbre. Nadie puede adivinar lo que acontecerá» ${ }^{4}$.

En esas circunstancias, Cánovas, que desde 1884 ocupaba la presidencia del Consejo de Ministros al frente del partido conservador, de-

\footnotetext{
${ }^{3}$ Modesto SANCHEZ ORTIZ y Fermán BERASTEGUI, Las primeras Cámaras de la Regencia. Datos electorales, estadísticos y biográficos. Madrid, 1886.

${ }^{4}$ J. VALERA y M. MENENDEZ PELAYO, Epistolario. Madrid, 1946, p. 239. Vid. M. FERNANDEZ ALMAGRO, Historia politica de la España contemporánea. Madrid, 1968, vol. 2, pp. 9-21. Conde de ROMANONES, Sagasta o el politico. Madrid, 1930, pp. 162-163 y Doña María Cristina de Habsburgo Lorena. Madrid, 1930, p. 53.
} 
cidió dimitir y aconsejar a la regente que llamara a los liberales a gobernar. "Nació en mí - diría Cánovas meses más tarde en el Congreso el convencimiento de que era preciso que la lucha ardiente en que nos encontrábamos a la sazón los partidos monárquicos (...) cesara de todos modos y cesara por bastante tiempo. Pensé que era indispensable una tregua y que todos los monárquicos nos reuniéramos alrededor de la Monarquía (...) Y una vez pensado ésto (...) ¿qué me tocaba hacer a mí? ¿es que después de llevar entonces cerca de dos años en el gobierno y después de haber gobernado la mayor parte del reinado de Alfonso XII, me tocaba a mí dirigir a los partidos y decirles: porque el país se encuentra en esta crisis no me combatais más; hagamos la paz alrededor del trono; dejadme que me pueda defender y sostener?. Eso hubiera sido absurdo $y$, además de poco generoso y honrado, hubiera sido ridículo. Pues que yo me levantaba a proponer la concordia y a pedir la tregua, no había otra manera de hacer creer en mi sinceridad sino apartarme yo mismo del poder» ${ }^{5}$.

Cánovas hizo saber a Sagasta su decisión - que éste aceptó- en una reunión que, por mediación del general Martínez Campos, tuvieron en la sede de la Presidencia del Consejo, y que ha recibido equivocadamente el nombre de "pacto de El Pardo». Este entendimiento, como indica $R$. Carr, oponiéndose a la interpretación que le dieron los críticos de la Restauración «no puede presentarse como la partida de nacimiento del constitucionalismo bastardeado». El turno de los partidos sobre la base del acatamiento a la voluntad del monarca y de las elecciones «fabricadas» desde el ministerio de la Gobernación, ya había comenzado en 1881 y el acuerdo de 1885 no entrañaba en sí mismo nada contrario a la pureza del régimen parlamentario ${ }^{6}$.

La decisión de Cánovas tuvo, sin embargo, una consecuencia imprevista para el partido que dirigía: la escisión de Romero Robledo, el "gran elector» de los conservadores, enfrentado desde hacía tiempo con Francisco Silvela por el número dos del partido, para quien resultaba incomprensible el abandono voluntario del poder. La escisión de Romero debilitó considerablemente la organización conservadora: «siguen en pié sus columnas y pilares - decía El Imparcial- pero la casa yace en ruinas y para ser habitable tendrán que edificarla de nuevo»?.

Por el contrario, a los liberales la ocasión no podía haberles cogido

${ }^{5}$ A. CANOVAS DEL CASTILLO, Diario de Sesiones del Congreso, legislatura 1886, n: 44, p. 796.

'Sobre el supuesto "pacto de El Pardo», vid. M. FERNANDEZ ALMAGRO, op. cit. vol. 1, p. 444 y J.L. COMELLAS, Cánovas. Madrid, 1965, p. 291. R. CARR, España, 1808-1939. Madrid, 1969, p. 347. 1886.

${ }^{7}$ Diario de Sesiones del Congreso, leg. 1885-86, n. 6. El Imparcial, 5 de enero, 
en mejor momento. En junio de 1885, mediante una llamada «ley de garantías», elaborada por Alonso Martínez y Montero Rios, como representantes de fusionistas y demócratas, respectivamente, habian puesto fin a un complejo proceso de integración, de más de diez años de duración, cuyo resultado fue, en frase de Vicens Vives, la vuelta al «redil de la monarquía (de) las ovejas liberales descarriadas por la actuación de Isabel Il». Según Antonio Maura, que por entonces formaba parte del mismo, ningún partido en la historia parlamentaria de España había conseguido «tanta fuerza, tanto número y tal conjunto de prestigios» como reunía el liberal en 1885. Al margen del acuerdo, algunos demócratas monárquicos que habian pretendido que las reformas establecidas en la ley de garantías tuvieran rango constitucional siguieron dando vida a una disminuida Izquierda Dinástica bajo el liderazgo del general López Domínguez, sobrino del duque de la Torre. En enero de 1886, Sagasta intentó integrarlos en el partido liberal ofreciendo la embajada en París a López Domínguez, pero las peticiones de éste -37 diputados en las siguientes elecciones, además de diversos nombramientos para sus amigos, según El Liberal- fueron consideradas exorbitantes por los notables liberales y se fustró la unión ${ }^{8}$.

Los republicanos, por su parte, divididos en posibilitas, federales - pactistas y orgánicos - y demócratas progresistas, a pesar de haber mejorado su organización desde que vieron reconocida legalmente su existencia, no consituían, ni mucho menos, una posible alternativa ${ }^{9}$. Carlistas y socialistas, en ambos extremos del espectro político, sumamente débiles por diferentes razones, no participaron en las elecciones.

A raiz de un intento de sublevación republicana en el fuerte de San Julián, en Cartagena, el 10 de enero de 1886, que fue inmediatamente sofocado, los conservadores propugnaron el aplazamiento de las elecciones, porque el estado del país, decían, no aconsejaba la disolución de las Cortes. Según Francisco Silvela, Sagasta era también de esta opinión, aunque no tanto por la razón indicada, como por la «falta de homogeneidad»| de la que habría de adolecer la nueva mayoría, dada la escasa cohesión del partido liberal recientemente fundado. Pero - explicaba Silvela en una entrevista concedida al Journal des Debats los liberales «temiendo que cualquier incidente imprevisto pudiese devolver el poder prematuramente a los conservadores (...) han practicado vivas gestiones acerca de los Ministros, para inclinarles a que las elec-

8 J. VICENS VIVES, Historia social de España y América. Barcelona, 1961, t. IV, vol. II, p. 379. A. MAURA, Diario de Sesiones del Congreso, leg. 1886-87, n: 37, p. 635. El Liberal, 8-11 de enero, 1886. La Epoca, 11 de enero, 1886.

${ }^{9}$ Vid. C. DARDE MORALES, "Los partidos republicanos en la primera etapa de la Restauración, de 1875-1890» en J.M. JOVER ZAMORA Y AA. VV., El siglo XIX en España: doce estudios. Barcelona, .1974, pp. 433-463. 
ciones no se aplazasen más allá del mes de abril». Y esta última fue la opinión que prevaleció ${ }^{10}$.

\section{EL CENSO ELECTORAL Y SU DISTRIBUCION.}

El censo de que disponemos es el de 1884, que proporcionan Sánchez Ortiz Berástegui, integrado por 807.175 electores. El de 1886 fue el que resultó de las rectificaciones de este censo llevadas a cabo por los Ayuntamiento a fines de 1884 y 1885 . Como se sabe, el resultado de las rectificaciones anuales previstas por la ley, no fue el incremento del censo, como cabía suponer a causa del aumento de población y el crecimiento económico, sino su disminución progresiva, a consecuencia de la eliminación de errores y consiguiente depuración, aunque el resultado final, según parece, todavía estaba muy alejado de la realidad. Entre 1881 y 1884 el censo pasó de 846.961 electores a los citados 807.175: es decir, experimentó una pérdida en tres años de 39.786, el $4,8 \%$. No sabemos la variación que se produjo entre 1884 y 1886 aunque no debió ser tan importante: Sánchez Ortiz y Berástegui dan por válido el censo de 1884 sin más problemas y son muy escasas las referencias a este tema en la prensa".

En relación con la población española de 1886 que, según Sánchez Ortiz y Berástegui, era de 16.699.369 habitantes, el censo electoral suponía el $4,83 \%^{12}$. Dada la estructura demográfica expresada en el Censo de población de 1887, aproximadamente uno de cada cinco varones mayores de 25 años tenía derecho al voto. A pesar de la no exactitud de las cifras del censo y población total que manejamos, las magnitudes reales no estarían lejos de las expresadas.

Las unidades electorales básicas establecidas por la ley eran los dis1886.

${ }^{10}$ La Epoca, 11 de enero, 1886 y ss.; 26 de febrero, 1886. La Iberia, 14 de enero,

${ }^{11}$ Cuando nos referimos a cifras aportadas por SANCHEZ ORTIZ Y BERASTEGUI, ofrecemos el resultado de sumar las cantidades parciales que indican estos autores en el texto de la obra citada, no sus cifras globales, ni los resultados del final del libro que, en varias ocasiones, reflejan errores aritméticos o de imprenta. Censo de 1881 indicado por M.M. CUADRADO, Elecciones y partidos políticos de España (1868-1931). Madrid, 169, vol. 1, p. 243; el censo de 1886, cuyo volumen absoluto no ofrece, correspondía, según este autor - pp. 243-245- al 2,1\% del total de la población; ésto supone que en dos años se habría reducido en más del $50 \%$, lo cual no nos parece, en absoluto, verosímil.

${ }^{12}$ El volumen de la población española en 1886 era, en realidad, algo superior. Según el censo de 1877, ésta era de $16.634 .345 \mathrm{y}$, según el de diez años más tarde, 17.565.632. El porcentaje electoral en relación con la población de 1887 sería 4,59. Hemos adoptado, no obstante la cifra de población indicada por SANCHEZ ORTIZ y BERASTEGUI porque, al aparecer distribuida en cada distrito, nos permite establecer la comparación en cada uno de ellos con el censo electoral. 
tritos, formados por áreas de hasta 50.000 habitantes; los núcleos úrbanos que superaban esa cifra de población, elegían un número de diputados proporcional a sus habitantes, a razón de uno cada 50.000 o fracción; en este caso, los electores votaban por uno o dos candidatos menos que el total de diputados a elegir, para asegurar de esta forma la representación de las minorías. No obstante, algunas capitales de provincia, como Santander, por ejemplo, no veían íntegramente reconocida su personalidad urbana por la ley, al haber sido integradas en amplias áreas que incluian abundantes zonas rurales; es difícil no ver en ésto - una variación introducida por la ley conservadora - una maniobra para diluir el significado del voto de estos núcleos urbanos.

Aunque no podemos identificar estrictamente los distritos provinciales uninominales con población rural y los distritos formados por las capitales de provincia u otras áreas de más de 50.000 habitantes - Jerez de la Frontera y Cartagena - que elegían varios diputados, con población urbana, porque en los primeros estaban incluidos núcleos urbanos importantes - como Lorca, por ejemplo-y los segundos comprendían, como ya hemos indicado, numerosas secciones rurales, es indudable que unos y otros tenían una significación predominante rural o urbana, y así los denominaremos en adelante. La comparación entre ambos nos puede servir, grosso modo, al menos, para conocer como estaban representados en el censo distintos tipos de población.

De acuerdo con la estructura de la población española de la época - sólo el 10,01\% de la población vivía en 1887 en núcleos de más de 50.000 habitantes y más del $70 \%$ de la población activa estaba dedicada a la agricultura - la representación rural debía ser abrumadoramente mayor que la urbana. Así tenemos que la población total comprendida en los distritos que consideramos rurales era 11.753 .007 , el $70,38 \%$ de la población española, mientras que la incluída en los distritos urbanos era 4.946 .362 , el $29,62 \%$ restante. La distribución del censo venía, no obstante, a reforzar, aunque no excesivamente, el predominio de la población rural sobre la urbana. Los electores de los distritos rurales eran 605.446 , el $75 \%$ del censo, mientras que los de los distritos urbanos eran sólo 201.729 , el $25 \%$. El reparto de escaños también beneficiaba ligeramente a los distritos rurales: cada 43.389 habitantes de los distritos urbanos elegía un diputado, por $\mathbf{4 1 . 9 7 5}$ de los rurales (Cuadro n.1).

En cuanto a la distribución espacial del censo electoral, hay importantes variaciones tanto en los distritos como en las provincias y regiones. Los distritos con la máxima proporción de población electoral eran Sahagún (León) $11,7 \%$, Granada $11,6 \%$ y Amurrio (Alava) y Sueca (Valencia) $11 \%$; la mínima la tenían Ferrol (Coruña) y Gracia (Barcelona) $1,7 \%$, seguidos de Algeciras (Cádiz) y Santa Cruz de la Palma (Cana- 
rias) $2 \%$. Las provincias con un procentaje más elevado eran Alava $8,9 \%$, Guadalajara $8,3 \%$ y Soria $8,2 \%$; el menor lo registaban Cádiz 2,5\% y Canarias $2,7 \%$. Por regiones, tomando como modelo el actual mapa autonómico, aparecen en primer lugar La Rioja 7,1\%, seguida de CastillaLeón $6,7 \%$ y Navarra 6,2\%, y en los últimos Canarias 2,7\%, Murcia $3,2 \%$, Baleares 3,6\% y Andalucía 3,8\%. (Vid. Cuadro n. 2).

En el mapa n: 1 aparecen representados los porcentajes provinciales de población electoral. La distinción entre la mitad norte y la sur de la península, en líneas generales, es evidente, además del contraste entre Castilla y Andalucía, entre otros. Dadas las condiciones legales establecidas para ejercer el derecho al voto, claramente favorables a los propietarios de la tierra, ésta es la distribución espacial que cabía esperar.

Si consideramos el reparto de escaños entre las regiones, tomando como criterio la proporción habitantes/diputado, la región más favorecida era Aragón, con 40.331 habitantes por diputado, seguida de Castilla-León, 40.689 y Castilla-La Mancha 41.619; en el extremo contrario están Cantabria 48.311, Canarias, 47.255 y Madrid, 45.766. Este reparto no era especialmente discriminatorio para las regiones situadas en último lugar: si Cantabria o Canarias hubieran contado con un diputado más, habrían sido las mejor representadas del país. No existe una correlación significativa entre el índice de población electoral y la proporción habitante/diputado de las regiones ${ }^{13}$. Detrás de la distribución de los escaños cabe ver, en todo caso, el peso de la influencia de determinadas regiones, Aragón y Castilla, especialmente - o el escaso poder de otras como Cantabria o Canarias más que una intencionalidad política de carácter partidista. Aunque los conservadores fueron los autores de la ley electoral y; por tanto, de esta distribución, los liberales no la consideraron lesiva para sus intereses, ya que no la variaron en su reforma electoral de 1890 .

\section{PERIODO PREELECTORAL.}

\subsection{Actuación del gobierno.}

Nos ocupamos en este apartado de la actividad pública, discrecional, del gobierno directamente relacionada con el proceso electoral. Al margen de la misma, por su carácter privado, están, sin embargo, las acciones más importantes que realiza, tanto en el ámbito nacional - el "encasillado» - como en el provincial, a través de las presiones ejercidas por los gobernadores civiles sobre los electores.

${ }^{13}$ Coeficiente $r$ de Pearson - 0,398 ( $\left.N=17\right)$. 
En estas elecciones, como en todas las de la Restauración, el gobierno, al mismo tiempo que proclamaba su imparcialidad, actuaba principalmente a través de la remoción de jueces y Ayuntamientos para facilitar el triunfo de los candidatos adictos. El control de la administración local de justicia era, como ha escrito J. Varela Ortega, «la piedra angualr sobre la que descansaba la injerencia gubernamental», en cuanto garantizaba «la impunidad de los manejos electorales». Los Ayuntamientos, por su parte, eran los encargados de rectificar el censo y de organizar y dirigir el proceso electoral. En 1886 parece, no obstante, que la utilización de los resortes del poder fue menor que en otras ocasiones. Así, el ministro de la Gobernación, Venancio González, recomendaba a los gobernadores civiles, por circular de 9 de enero de 1886, velar por el libre ejercicio de los derechos de reunión, asociación y libertad de prensa, sin más límites que los establecidos en el Código penal, y usar con un criterio más restrictivo del que habian tenido sus predecesores del partido conservador, de la facultad que la ley les otorgaba de imponer multas gubernativas ${ }^{14}$.

Pero fue, sobre todo, en lo relativo a la suspensión de Ayuntamientos donde la actuación gubernamental fue relativamente menos coercitiva: frente a los más de 700 Ayuntamiento que Romero Robledo, como ministro de la Gobernación anterior, había suspendido en vísperas de las elecciones de 1884, los liberales sólo suspendieron 26 Ayuntamientos por autos judiciales y ordenaron celebrar elecciones, para renovar la mitad de sus componentes, en otros 216, de acuerdo con un dictamen del Consejo de Estado según el cual la situación de estos Ayuntamientos - y de 104 más - era ilegal desde $1884^{15}$. En 15 provincias no se removió a Ayuntamiento alguno; en 42 a menos de diez; y sólo en siete, a más de diez Ayuntamientos, hasta el límite de 21, cifra máxima de Ayuntamientos suspendidos que ostenta Badajoz, seguida de Tarragona con 20 y

14 J. VARELA ORTEGA, op. cit., pp. 405-406. Gaceta de Madrid, 9 de enero, 1886.

${ }^{15}$ El Imparcial, 9 de febrero, 1886. La Iberia, 18 de febrero, 1886. La ilegalidad provenía de que los Ayuntamientos que habían sustitụido a los suspendidos gubernativamente, habian declarado incapcitados a estos últimos, para que lo estuvieran al términos legal de la suspensión. La sentencia de la sección de la Gobernación del Consejo de Estado se refería al Ayuntamiento de Santa Amalia (Badajoz) pero podía aplicarse a los 320 Ayuntamientos donde se había producido un hecho semejante. Vid. SANCHEZ ORTIZ y BERASTEGUI, op. cit., p. 515. Al relacionar los Ayuntamientos repuestos en cada provincia, - datos con los que hemos elaborado el Cuadro n. 3- estos autores sólo señalan 20 casos de autos judiciales y 208 de suspensión gubernativa. 
Valencia con 18. Por regiones, destaca la mayor intervención gubernativa en Extremadura y la menor en las provincias vascongadas y castellanas (Cuadro n:3).

Las oposiciones reconocieron este cambio en la actitud del gobierno. "El señor Gonzalez - afirmaba el conservador La Epocano presta oídos a los candidatos, no los recomienda, no les sirve en sus arbitrarias exigencias, no suspende Ayuntamientos, no separa peatones y estanqueros, no intenta nada, en fin, de cuanto ha venido tolerándose hasta ahora, para desdicha de todos»; "en Gobernación - decía en otra ocasión - a sabiendas del Ministro, nadie falta a su deber». Y López Domínguez afirmaría en el Congreso que «la remoción de Ayuntamientos y Diputaciones provinciales, usual en otras épocas, no ha sido tan excesiva en ésta» ${ }^{16}$.

La relativa ausencia de coacción desde el poder central, no quería decir que ésta no se ejerciera desde otras instancias, sino, más bien, todo lo contrario. Según El Imparcial, existía el peligro de que al «romper el cetro con que el Gran Elector de la Puerta del Sol reinaba sobre el cuerpo electoral (...) los pedazos de ese cetro los recojan los caciques»; de que «al librar a los electores de la tiranía central», quedaran sometidos «como esclavos a la oligarquía de campanario». "Al cesar la corriente de sugestiones y violencias a que servía de vehículo el aparato telegráfico del Ministerio de la Gobernación, - continuaba - es urgente invalidar la acción abusiva de los caciques grandes y pequeños, así de los que desde Madrid dirigen los asuntos de una comarca, como de los que en el villorrio mangonean en el reparto de la contribución, en los expedientes de quintas y cuanto de un modo inmediato interesa al ciudadano». Pero aunque el gobierno intentó algo - por ejemplo, nombrando gobernadores que no fueran naturales de las provincias donde servían, para facilitar su independencia - «no es posible - se lamentaba $L a$ Iberia, periódico de Sagasta - cortar de raiz y en un sólo día y sólo por los esfuerzos de una voluntad, abusos inveterados y males cuyo contagio se ha extendido hasta el punto a que en España han llegado las corruptelas y los cubileteos electorales». En consecuencia, «la oligarquía de campanario» siguió actuando y más libremente que en otras ocasiones al no tener que competir con la influencia oficial. A las frecuentes protestas contra los manejos caciquiles por parte de las oposiciones, se unía, incluso, «el verdadero clamor de los ministeriales, que se encuentran con que los alcaldes, los ayuntamientos y hasta algunos empleados del gobierno se han lanzado

${ }^{16}$ La Epoca, 28 de enero, 1886; 8 de febrero, 1886. J. LOPEZ DOMINGUEZ, DSC, leg. 1886, n. $^{\circ}$, p. 713 . 
abiertamente a trabajar contra ellos» ${ }^{17}$.

En cualquier caso, parece que no cabe atribuir a la limitada actuación gubernativa el triunfo ministerial en las elecciones. Algunos liberales justificaban su neutralidad alegando que «en la mayoría de las corporaciones populares no existe la supuesta filiación política que las hace pasar por conservadoras o liberales; salvo excepciones muy contadas - afirmaban - los ayuntamientos y diputaciones tienen siempre marcada predilección por el gobierno, sea el que fuese». En el mismo sentido, decía el ministerial El Correo, «lo único que se ve más perceptible y esto no sorprenderá de fijo a nadie, es que la gran mayoría de los distritos prefieren con la mayor espontaneidad las candidaturas adictas». Según La Epoca, la explicación de este fenómeno, que también describe como algo común, radicaba en que el cuerpo electoral pensaba que «ayudando al que manda, se sirve sin riesgo", porque "falto de vigor, entregado a cálculos pesimistas fía más del favoritismo del primer joven que se le presenta llamándose ministerial y probando que lo es, que no en los esfuerzos del viejo adálid de una idea, o en el interés del que tiene en un distrito familia, hogar, propiedades, lazos de amistad antigua, motivos de gratitud (...) $)^{18}$.

3.2 Designación de candidatos; actividad de los partidos.

En teoría, la iniciativa para la designación de candidatos a diputado la tuvieron los comités locales o provinciales de cada partido, pero ésto, dada la escasa entidad que en numerosas localidades tenían los comités, equivalía en muchos casos a una autopresentación. Los anteriores parlamentarios también ejercieron un cierto control en la formación de las candidaturas; antes de la disolución de las Cortes conservadoras, eran frecuentes sus reuniones, por provincias, con este objetivo, llegando en el caso de los liberales asturianos a efectuar ellos mismos la designación. Los problemas que se plantearon fueron, sin embargo, muy diferentes en el partido en el gobierno y en los de oposición: mientras en aquel fueron muchos los que pretendieron obtener su representación, en éstos, los candidatos sabían que contaban con pocas posibilidades de éxito $y$, en consecuencia, sólo aquellos que tenían un considerable arraigo en un distrito, aventuraron su candidatura. «Ni un sólo conser-

${ }^{17}$ El Imparcial, 28 de enero, 1886. La Epoca, 7 de enero, 1886. La Iberia, 12 de febrero, 1886. Las protestas de las oposiciones son constantes en la prensa de ese carácter, especialmente EI Diario Español, de Romero Robledo. Quejas ministeriales en El Imparcial, 24 de marzo, 1886. 1886.

${ }^{18}$ El Imparcial, 9 de febrero, 1886; 14 de marzo, 1886. La Epoca, 10 de febrero, 
vador - afirmaba La Epoca - se ha presentado donde no tenga fuerzas propias» ${ }^{19}$.

La designación de candidatos del partido libera/ presentó abundantes problemas, como decimos; el partido se había formado hacía pocos meses y muchos comités de los grupos que lo componían seguían subsistiendo; en Madrid, por ejemplo, la integración de los tres comités liberales no se produjo hasta pocos días antes de las elecciones. $Y$ cada uno de estos comités tenía sus propios candidatos. «El Gobierno es una colección de mesnadas - escribía Castelar en una carta privada-. Quiere traer el grueso de sus tropas, Sagasta; su mesnada, Moret; el grupito parlamentario de militares saguntinos, Jovellar; sus celtas, Montero Rios; sus tercios, Navarro, en compañía de Gamazo; las huestes a cuya cabeza debe pedir la presencia del Congreso, Martos». Las visitas a Madrid, para tratar de obtener el favor oficial eran muchas veces consideradas imprescindibles. Los testimonios del trasiego de comisiones y candidatos son constantes en todo tipo de prensa. "No pasa día sin que las antesalas del despacho del $\mathrm{Sr}$. Sagasta se vean repletas de aspirantes a candidatos ministeriales para diputados a Cortes», decía El Diario Español. La Epoca daba cuenta de que «los postulantes de distrito - así se llaman los candidatos afectos al gobierno que no han entrado en la categoría de ministeriales - andan de Gobernación a la Presidencia en peregrinación constante. Todos aspiran a que en secreto se les diga: 'Usted será nuestro hombre; pero... váyase $\mathrm{V}$. al distrito'. Y nadie quiere ir al distrito sin que preceda el pregón ministerial». El Imparcial informaba que «tres comisiones de Valencia, dos de Barcelona, una de Burgos y un número considerable de diputados provinciales, alcaldes y caciques, andan estos días en procesión desde casa del Sr. Sagasta al despacho del ministro de la Gobernación, para tratar de las candidaturas para las próximas elecciones». Sobre ésto, López Domínguez diría críticamente en el Congreso: «los candidatos, en vez de buscar la confianza de los electores, venían aquí, a Madrid, a buscar y repartirse los distritos, o a disputárselos, apoyados respectivamente en las in-

${ }^{19}$ "A semejanza de lo hecho en la peninsula por su compañero de Gobernación, (el ministro de Ultramar) parece resuelto a que la iniciativa de las propuestas parta de los distritos de aquella isla (Puerto Rico) y no de la secretaría del ministerio) El Imparcial, 13 de marzo, 1886. Conde de ROMANONES, Biología de los partidos políticos. Madrid, 1892, pp. 123-125. Referencias a las reuniones de diputados y senadores en La Epoca y La Iberia, 7 de enero, 1886 y El Imparcial, 6 de febrero, 1886. La Epoca, 26 de marzo, 1886. 
fluencias de la situación ${ }^{20}$.

Ante semejante avalancha de peticiones, Sagasta y Venancio González - decía La Epoca «en honor a la verdad» - "contestan invariablemente que en las próximas elecciones no habrá candidatos ministeriales y que se sentarán en el Congreso los que por su propia influencia cuenten con más votos». Sin embargo, comentaba El Imparcial, "cuando los gobernadores civiles tengan terminado el cuadro de los que se presentan en sus respectivas provincias, el gobierno examinará la cuestión y se comunicarán las consiguientes instrucciones, porque sería inocente suponer que no ha de apoyar con su influencia a aquellos que se presentan como adictos a su política». No obstante, donde el enfrentamiento era entre ministeriales, «el gobierno ha adoptado como regla general (...) la declaración de que verá con igual gusto el triunfo de cualquiera de los dos adictos que luchan y de que por ninguno de ellos expresará predilección o simpatía». Lo cual, comentaba en otro número el mismo periódico, "está dando ocasión a los más curiosos y pintorescos incidentes entre los candidatos (...). Mientras el uno reclama una credencial como demostración de su fervor ministerial, otro gestiona las obras de una carretera o el nombramiento de un peatón o un alcalde de cárcel. Cuando llega al distrito una de estas credenciales, el comité, lleno de entusiasmo, proclama al remitente como el único y auténtico candidato, pero este acuerdo dura solamente hasta que el contrario envía otro nombramiento, con lo cual queda también aclamado». "El galimatías que rodea al ministro de la Gobernación y que le tiene mareado, - decía con intencionalidad política El Diario Españo/- demuestra que estamos al principio del gran barullo político que se nos prepara, porque ésto que ahora se ve en los despachos de los ministerios, se verá el día de mañana en el Congreso"s ${ }^{21}$.

El número total de candidatos presentados por el partido liberal fue 376, que optaron por 325 de los 394 escaños que estaban en juego en la península e islas metropolitanas, el 82,5\%. En 51 casos, por tanto, se enfrentaron candidatos liberales entre sí; las provincias donde lucharon en mayor número de distritos fueron Badajoz, en cuatro, y Granada, en tres. En todas las provincias hubo,

${ }^{20}$ Formación del comité liberal de Madrid bajo la presidencia de Núñez de Arce en El Imparcial, 25 de marzo, 1886. CASTELAR, Correspondencia (1868-1898). Madrid, 1908, pp. 186-187. El Diario Español, 15 de enero,1886. La Epoca, 19 de febrero, 1886. El Imparcial, 14 de febrero, 1886. J. LOPEZ DOMINGUEZ, DSC, leg. 1886, n: 51, p. 713.

${ }^{21}$ La Epoca, 14 de enero, 1886. El Imparcial, 14 de febrero, 1886; 9 de marzo, 1886. El Diario Español, 27 DE FEBRERO, 1886. 
al menos, un candidato liberal. Sólo en Guipuzcoa y Asturias los hubo en menos de la mitad de los distritos. Por el contrario, en todos y cada uno de los distritos de veinte provincias - Alava, Alicante, Badajoz, Cáceres, Canarias, Castellón, Ciudad Real, Córdoba, Granada, Guadalajara, Huelva, León, Logroño, Orense, Palencia, Salamanca, Soria, Toledo, Valencia y Zamora - se presentó, al menos, un candidato adicto al gobierno. En todas las demás provincias hubo candidatos liberales en la mitad o más de los distritos (Cuadro n: 4).

Tras la marcha de Romero Robledo, los conservadores se vieron obligados a rehacer toda su organización, comenzando por la creación de un nuevo Círculo en Madrid, ya que el establecido se alineó con los disidentes. Mientras se preparó el nuevo Círculo - del que formaban parte unos 400 socios que habían de pagar una cuota de 30 reales mensuales - la casa de Cánovas, que abría sus puertas a los correligionarios políticos los miércoles por la noche, sirvió de local social del partido en la capital, El conde de Toreno y Fernánddez Villaverde llevaban upersonalmente toda la correspondencia electoral». El número de comités que a fines de enero de 1886 se declaraban conservadores ortodoxos en todo el país era $736^{22}$.

Los candidatos presentados por el partido conservador fueron 121; el número de escaños por el que lucharon 115 , el $29,2 \%$ del total. En la provincia de Segovia optaron por todos los distritos, mientras que en Alava, Ciudad Real y Soria, no se presentaron en ninguno; en el resto de las provincias hubo, al menos, un conservador y en Asturias, Navarra, Vizcaya y Zamora, en la mayoría de los distritos.

Romero Robledo, al frente de los conservadores disidentes, también tuvo que prestar una atención preferente a la organización de su nuevo partido. Romero hacía gala en público y por escrito precisamente de aquello de lo que más le acusaban sus críticos: de no tener principios políticos específicos y definidos. "¿Qué va a decir en las provincias? (...) ¿Qué doctrinas predicará?», se preguntaba La Iberia ante la perspectiva de un viaje electoral de Romero Roble-

${ }^{22}$ Sobre el nuevo Círculo Conservador, decía la crónica de El Imparcial: «Eso sí, es genuína y ortodoxamente conservador todo lo que hay en el local anoche inaugurado: desde el conserje, los porteros y los ordenanazas, hasta los colores de los adornos que tienen las habitaciones. Alli todo es serio, grave, cuasi solemne, algo así como un senado de los primeros tiempos. Son anchas las mecedoras y anchos los divanes, enormes las colgaduras, negras las mesas, oscuras las alfombras y doradas las cornisas, lo cual conviene a la seriedad de la gente, no ya masa, que en los salones del Círculo Conservador (...)». "El Imparcial, 5 de febrero, 1886; 6 de enero, 1886. La Epoca, 7 de enero, 1886; 8 de febrero, 1886. La Iberia, 31 de enero, 1886. 
do. A lo que Romero contestaba en El Diario Español: «Lo primero que necesita una agrupación política es gente, después organización, propaganda, entusiasmo, fiebre; más tarde, la lucha por sostener sus candidatos, para defender aquellas ideas madre de su pensamiento, aquellas convicciones más profundas de su conciencia (...); luego surgen las necesidades del país: reorganizar la marina, hacer o deshacer los tratados, cambiar radical y esencialmente la organización y manera de existir del ejército (...); y entonces habrá capacidades e incapacidades para tales empeños, pero no faltarán nunca hombres para las soluciones dentro de la Monarquía, de los campos de la libertad, de la exigencia del orden. Esos hombres constituyen en aquel instante un partido, organizan un Gobierno, plantean una solución, resuelven una necesidad y han cumplido». Las palabras de Romero no se oponían abiertamente al vigente sistema de valores respecto a la vida política - según el cual, las ideas eran lo sustantivo de un partido, lo que justificaba su existencia-, pero resultaban claramente chocantes y provocativas al dejar las ideas en un segundo plano, colocando en el primero la eficacia de la organización y la calidad de la acción. En un documento del partido en Zaragoza, se decía "Queremos acción y movimiento, vivir en íntimo y frecuente contacto con nuestros correligionarios y no a una distancia desdeñosa, otorgarles debida participación en los negocios públicos $(\ldots)^{23}$.

En consecuencia, la actividad desplegada por los disidentes fue extraordinaria. El 15 de enero comenzó en El Diario Español la publicación de sus comités, que habría de durar hasta poco antes de las elecciones; figuran en esa relación 509 comités, la mayor parte pertenecientes a provincias andaluzas o levantinas - las regiones, en cuanto a existencia de comités de todos los partidos, más movilizadas del país-; en 19 provincias no aparece ningún comité. El mismo Romero permanecía todos los días hasta la madrugada en el Círculo madrileño del partido, donde contaban con «un censo perfectamente distribuido por distritos, barrios y calles, en el que constan todos los electores con su filiación política y en el que se anotan con cuidado todas las altas y bajas» ${ }^{24}$.

Con fines puramente electorales en principio, Romero Robledo acordò en marzo de 1886 una coalición con la lzquierda Dinástica de López Domínguez; el acuerdo fue refrendado por los exministros de ambos partidos $y$, más tarde, por las respectivas Juntas

${ }^{23}$ Vid. F. SILVELA, DSC, leg. 1885-86, n: La Iberia, 13 de febrero, 1886. El Diario Español, 17 de febrero, 1886; 5 de febrero, 1886.

${ }^{24}$ El Imparcial, 15 de marzo, 1886. 
Directivas. «Respecto al señor Romero Robledo - comentaba $E I$ Imparcial- esta consulta era ociosa, pues de sobra sabe todo el mundo que los húsares atacan sin discutir las órdenes de su jefe». Los candidatos presentados por los conservadores disidentes fueron 34 y por los izquierdistas, 16; a pesar de la coalición, miembros de ambos partidos se enfrentaban por la representación de las minorías en Coruña y Jaen, además de los jefes que lo hacían en Madrid; en conjunto optaron a 48 escaños, el $12,2 \%$ del total. La mayor presencia de candidatos disidentes la registraban Alicante, Coruña, Zaragoza y Málaga, provincia esta última donde también destaca la participación izquierdista ${ }^{25}$.

Los republicanos acordaron también una coalición electoral que abarcó al partido demócrata progresista y al federal pactista; los otros dos grupos - posibilistas de Castelar y federales orgánicos - no se sumaron a la misma: el primero por incompatibilidad con los federales y con los procedimientos de fuerza que representaba Ruiz Zorrilla; el segundo porque no fue convocado, pese a lo caul recomendó a sus seguidores que apoyaran a la coalición. En las bases de ésta se afirmaban los principios comunes al programa de los partidos que la suscribían y el procedimiento a seguir una vez instaurada la República. No obstante, el partido federal pactista de $\mathrm{Pi} \mathrm{y}$ Margall se creyó en la obligación de dejar bien claros los demás puntos de su programa en un manifiesto aparte ${ }^{26}$.

Los demócratas progresistas fueron quienes, entre los republicanos, se mostraron más activos, aunque sin llegar a lo que anunciaba El Liberal: «todas aquellas personas de autoridad e influencia - decia - irán a las provincias a verificar una campaña de activa propaganda que levante el espíritu público, a la manera que se hace en Inglaterra». No obstante, constituyeron una comisión de propaganda y organización, con 15.000 ptas. de presupuesto, que abrió una suscripción pública para sufragar los gastos electorales - el 7 de marzo había recaudado 1.860 ptas. - y redactó unas instrucciones para la renovación de los comités en todo el país. Los candidatos presentados por la coalición fueron 39, además de Pi y Margall, que lo hizo por acumulación de votos; en dos casos, representación de las minorías en Badajoz y Madrid, se enfrentaron entre si $^{\not}$.

${ }^{25}$ El Imparcial, 6 de marzo, 1886. Presentación pública de la coalición en el Círculo conservador disidente, vid. El Diario Español, 12 de marzo, 1886.

${ }^{26}$ El Imparcial, 12 de febrero, 21, 24 y 27 de marzo, 1886.

${ }^{27}$ El Liberal, 7 de enero, 1886. La Iberia, 29 de enero, 1886. El Imparcial, 23 de enero, 1886. No parece que la disciplina entre los coaligados fuera muy grande. Según La Unión, «en muchas provincias, los federales y los demócratas progresistas harán el mismo caso de lo acordado y resuelto en Madrid que de las coplas de Calainos. En Mallorca, por ejemplo, los demócratas progresistas se entienden perfectamente en mu- 
El partido posibilista estaba especialmente vinculado a la persona de Castelar; en Madrid ni siquiera contaba con un local propio, prestando sus servicios, en caso necesario, el domicilio del jefe o la redacción de El Globo. Castelar mantenía unas relaciones excelentes con Sagasta, pese a lo cual se quejaba del trato recibido en esta ocasión: «vamos a elecciones - decía en su correspondencia privada - . Se presenta muy mal este negocio. El Gobierno cuando vas a pedirle cualquier cosa te despacha trasteándote con la muletilla de su neutralidad». Presentó once candidatos, dos de ellos en Huesca. El partido federal orgánico presentó la candidatura de su jefe, Rispa Perpiñá, por Tarragona. En conjunto, los republicanos pretendieron obtener 49 escaños, el $12,4 \%$ del total; bastante repartidos por la geografía del país ${ }^{28}$.

Por último, fueron 25 los candidatos que se denominaban independientes, que se presentaron a la elección, enfrentándose entre sí en una ocasión.

Como hemos podido comprobar, en el período preelectoral, todos los partidos desplegaron una considerable actividad interna, en relación con la formación de las candidaturas: renovación de comités, reuniones de las Juntas Directivas, de los parlamentarios, coaliciones, gestiones cerca del poder, etc. La prensa consideraba la campaña electoral «de las más movidas de los últimos años». Sin embargo, las actividades externas, orientadas a obtener el voto del electorado, fueron muy escasas; sobre todo, las actividades de tipo masivo. En Madrid, sólo se celebró un mítin - el organizado por la coalición de conservadores disidentes e izquierdistas en el Teatro Real - además de las fiestas y bailes que se dieron en algunos Círculos. La prensa, los manifiestos impresos y las cartas drigidas a los electores, eran los principales vehículos y formas de propaganda ${ }^{29}$.

chos pueblos con los mismos conservadores (...). Los federales de Barcelona tampoco entienden de coaliciones y casi lo mismo sucede en Valencia, en Sevilla, en Málaga, etc. De modo que lo de la coalición está reducido, por ahora, a Madrid". Citado por El Imparcial, 25 de marzo, 1886.

${ }^{28}$ E. CASTELAR, op. cit., p. 186. No obstante, según La Epoca, 21 de enero, 1886, en Vera y Sorbas (Almería) el gobernador apoyaba a los posibilistas, en lugar de a los monárquicos; "no hay que decir como trinan los amigos del gobierno», comentaba.

${ }^{29}$ La Epoca, 26 de marzo, 1886. El Diario Español, 27 de marzo, 1886. Según este último periódico, 9 de marzo, 1886, por la estafeta de Correos establecida en el Congreso de los Diputados habían circulado de setenta a ochenta mil cartas de carácter electoral, antes de que fueran clausuradas las Cortes conservadoras. 
La designación de interventores, sobre la base de pliegos de firmas de electores - procedimiento que hacía muy fácil el fraude- se llevó a cabo siete días antes de la elección, el domingo 28 de marzo, sin ningún incidente. Este acto tenía gran importancia, sobre todo en los distritos donde había lucha electoral, por lo que suponía de control de las Mesas. En Madrid, destaca, sobre todo, el gran número de firmas reunidas por Romero Robledo, 1.273 - por 3.205 los liberales y sólo 491 los conservadores - cifra que superaría en casi 200 el número de votos que, a la semana siguiente, habría de conseguir en las elecciones, contra toda lógica. "Se duplican las firmas, se recogen entre los fallecidos, se prescinde de los que son verdaderos electores", se lamentaba Le Epoca ${ }^{30}$.

Las elecciones se celebraron el 4 de abril, también con la más completa tranquilidad aunque, en la víspera, circularon rumores de graves alteraciones del orden público. «El día ha sido oscuro y frío - decía $L a$ Epoca sobre la jornada en la capital - y oscura y fría la función electoral». Madrid mostró la animación habitual de los días festivos - «la Castellana rebosando carruajes y el Retiro como en los mejores días de primavera»-, pero "desde las ocho a las doce, varios colegios, en cuanto a electores, eran la imagen de la soledad (...). Las horas de mayor animación han sido las del mediodía hasta comenzar la tarde, en que otra vez volvió a decaer el siempre pacífico flujo de electores». Romero Robledo ubien pertrechado el pescante del coche de buenas cajas de tabacos» estaba en todas partes, llegando al extremo, tanto él como sus agentes, de «ir a buscar a su casa a los electores, que han conducido en su propio coche a los colegios» ${ }^{31}$.

La elección fue disputada por dos o más candidatos en 151 distritos rurales, el 53,9\% de los mismos; en 39 de los 52 distritos que hemos considerado urbanos hubo lucha, al menos, por alguno de sus escaños; el enfrentamiento se produjo en concreto por 60 de los 114 escaños correpondientes a los mismos, el $52,6 \%$ : una proporción, por tanto, de lucha electoral ligeramente inferior en los distritos urbanos que

${ }^{30}$ El Imparcial, La lberia, 28-29 de marzo, 1886. Romero acusaría más tarde a los liberales de haberse servido de 200 empleados de limpiezas y consumos del Ayuntamiento para que votarn, el 4 de abril, en nombre del mismo número de electores desconocidos y ausentes que figuraban en el censo de la capital, «rogándoles únicamente el mayor esmero posible en el traje». El Diario Español, 13 de abril, 1886. La Epoca de la misma fecha, identificaba esos 200 individuos con la diferencia entre las firmas presentadas y los votos obtenidos por los romeristas.

${ }^{31}$ La Iberia, 3 de abril, 1886. La Epoca, 4 de abril, 1886. 
en los rurales, contra lo que cabía suponer. En total hubo lucha por 211 escaños, algo más de la mitad de los que estaban en juego (Cuadro n:5).

Las provincias donde el enfrentamiento fue mayor fueron Cáceres y Huelva, por la totalidad de sus escaños, seguidas de Logroño, Madrid, Palencia, Segovia, Teruel y Zamora, por todos menos uno. La lucha fue menor en Valladolid y Lugo, por menos de la quinta parte de sus escaños (Cuadro n: 6).

Es interesante consignar aquellos distritos donde los candidatos de oposición no se enfrentaron con ningún liberal; esto suponía el reconocimiento por parte del gobierno de un dominio particular sobre el distrito en cuestión. En total fueron 27: 19 conservadores, 3 de la Izquierda Dinástica, 2 romeristas, 2 republicanos y un independiente. Destaca el arraigo conservador en Asturias y, en menor medida, en Murcia y Vizcaya; y la influencia de Romero Robledo y López Domínguez en Malága. La mayor parte de los beneficiarios de estos distritos indiscutidos eran políticos de profesión, 11, seguidos por los propietarios en el mismo distrito, 6 (Cuadro n. 7).

En cuanto a los resultados, los liberales obtuvieron 286 escaños, el $72,6 \%$ del total, seguidos por los conservadores con 62 , el $15,7 \%$; republicanos 21, el 5,3\%; la coalición de disidentes e izquierdistas, 16 , el 4,1\%; además de 3 independientes y 1 diputado carlista (Cuadro n. 4). Los liberales coparon todos los distritos de seis provincias - Ciudad Real, Guadalajara, Toledo, Palencia, Logroño y Huelva-. Por el contrario, en Guipuzcoa sólo obtuvieron uno de los cinco distritos en lucha. En todas las demás provincias obtuvieron la mayoría de los distritos, salvo en Asturias, Vizcaya, Segovia y Málaga, donde fueron minoría (Mapa $n$. 2). Los mayores triunfos para el partido conservador fueron en Vizcaya, donde obtuvieron la mayoría de los distritos, y en Asturias y Segovia con la mitad de los escaños (Mapa n: 3 ). Seis de los 16 escaños obtenidos por la coalición Romero Robledo-López Domínguez, correspondían a la provincia de Málaga. De los 21 escaños conseguidos por los republicanos, 8 pertenecian a los posibilistas - que obtuvieron dos en Huesca - y el resto a la coalición. Destaca el hecho de que en Oviedo los republicanos consiguieron los dos escaños de las mayorías. Pi y Margall no está incluido en los 21 republicanos citados, ya que obtuvo su acta por acumulación de votos emitidos a su favor en todo el país: en total, le fueron otorgados 21.244 votos, de los que 15,430 correspondían a 128 distritos donde no había habido lucha electoral ${ }^{32}$.

En resumen, puede hablarse en estas elecciones de un dominio ge-

${ }^{32}$ SANCHEZ ORTIZ y BERASTEGUI, op. cit., pp. 454-456. 
neralizado el partido liberal en todo el pais, con las contadas excepciones ya señaladas de los distritos conservadores en Asturias, dos de las provincias vascas - Vizcaya Y Guipuzcoa - , Segovia y Murcia; los de Málaga de la coalición Romero-López D., y los republicanos en Oviedo y Huesca. Además de distritos dispersos por todas las provincias - menos seis - donde triunfaron candidatos de oposición.

Es de señalar, que no fue precisamente en las provincias de menor arraigo liberal, según los resultados electorales, donde se produjo un mayor número de suspensiones de Ayuntamientos con anterioridad a las elecciones, ni donde la lucha electoral fue mayor, sino más bien, todo lo contrario: en Guipuzcoa, Vizcaya, Huesca y Segovia no fue removido ningún Ayuntamiento, y Huesca, Málaga y Asturias figuran entre las provincias con menor porcentaje de lucha electoral (Cuadros 3 y 6 ). Según estos indicadores, parece como si la oposición que salió de estas elecciones hubiera sido, en buena medida, previamente consenti$\mathrm{da}$, respetada o consensuada. Es también significativo, en este sentido, la proproción de candidatos derrotados de cada partido en relación con el número total de candidatos que presentaba: el $23 \%$ de los liberales; $48,8 \%$ de los conservadores; $59,6 \%$ de los republicanos; $68 \%$ de los disidentes e izquierdistas - que afectó especialmente a los partidarios de Romero Robledo, a pesar de sus esfuerzos organizativos - ; y $88 \%$ de los independientes. Una proporción creciente conforme era mayor el grado de apartamiento del partido en el poder o el peligro de desplazamiento de uno de los dos partidos participantes en el turno de gobierno.

Hemos podido calcular la participación electoral sólo de forma parcial, que que Sanchez Ortiz y Berástegui proporcionan exclusivamente los datos de votantes de todos los distritos uninominales, rurales y urbanos, pero no de los distritos con más de un escaño, con excepción de Oviedo y Lugo; los autores citados obtuvieron sus datos de las Actas recibidas en el Congreso, donde se consignaba el número de votos obtenidos por cada candidato, pero - dado el sistema adoptado para facilitar la representación de las minoría - de los votos obtenidos por los candidatos en los distritos plurinominales, no es posible deducir el número de votantes que habían participado en la elección. En las unidades consideradadas, según los datos oficiales, la participación electoral fue considerablemente alta, del $72,08 \%$. No tiene sentido comparar la abstención de distritos rurales y urbanos, al carecer de información sobre los más característicos de estos últimos. Mayor interés reviste la comparación, dentro de los límites impuestos por las estadísticas de que disponemos, entre los distritos con lucha y sin lucha electoral. Aunque la abstención media fue ligeramente superior en estos últimos - el $30,33 \%$ frente al $26 \%$ en los distritos con más de un candi- 
dato por escaño-, parece a todas luces una participación excesiva (Cuadro n.8).

Por provincias, destacan, por una parte, Guipuzcoa y Gerona con ínidices de abstención del 57 y el $40,7 \%$, respectivamente y, por otra, Canarias - excepto la capital entonces, Sta. Cruz de Tenerife-con el $19,2 \%$. La abstención del resto de las provincias osciló entre el 20 y el $40 \%$ (Mapa $n$ : 4). Hubo diez distritos donde el número de votos superó al censo electoral, de forma extrema en Puente del Arzobispo (Toledo) donde los votantes resultaron ser el $171,9 \%$ de la población electoral de derecho. Sánchez Ortiz y Berástegui explican estas circunstancias porque, dicen, el censo que manejan es el de 1884 y desde entonces las rectificaciones del censo pueden explicar las diferencias. Desde luego, no deja de resultar más que sospechosa una participación tan masiva: de los 10 distritos mencionados, hubo reclamaciones sobre el censo o el escrutinio, en los siete donde se registró lucha electoral (Cuadro $n^{\circ}$ 9). Por el contrario, los mayores índices de abstención los registraron Tolosa (Guipuzcoa) y Armurrio (Alava) con el 74,6 y $60,1 \%$, respectivamente, a causa de no haber en estos distritos candidatos tradicionalistas.

\section{EL FRAUDE ELECTORAL.}

El proceso que se seguía en el Congreso para la admisión de los diputados - consideración de las Actas junto con las protestas e impugnaciones que las acompañaban, y la consiguiente aprobación, declaración de nulidad o remisión al Tribunal de Actas Graves, en el caso de las seriamente dudosas - es una utilísima fuente para conocer el fraude electoral. En el caso de 1886, disponemos, además, de una relación completa de los incidentes por distritos, que Sánchez Ortiz y Berástegui obtuvieron de la documentación aneja a las Actas recibidas en el Congreso, que incluyen en su obra.

De los 332 distritos existentes en el país, hubo incidentes en 143, el $43,1 \%$. El Congreso declaró nula la elección de Vergara (Guipuzcoa) y envió al Tribunal de Actas Graves - compuesto por 24 diputados en representación proporcional de todos los partidos - las correspondientes a 12 elecciones, de las que sólo tres fueron declaradas nulas - las de Gracia (Barcelona), Almadén (Ciudad Real) y Corcubión (Coruña) - ; el resto fueron aprobadas, a pesar de las graves acusaciones que acompañaban a algunas de ellas, lo que dió origen a duras críticas en la prensa: «la impresión producida por el fallo del Tribunal de Actas Graves ha sido desastrosa», comentaba El Imparcial en ralación con la sesión en la que se consideró la elección de Sagunto (Valencia). El acta de Luar- 
ca (Asturias) quedó pendiente de aprobación (Cuadro n. 10) ${ }^{33}$.

La mayor parte de las protestas e impugnaciones se basaba en la inexactitud del censo, la violencia o engaños llevados a cabo el día de la elección, y la manipulación de las Actas en el período que transcrurría entre la redacción de la misma, al finalizar el escrutinio, y su recepción por el presidente de la Junta del Censo, período que en teoría, acababa a las diez de la mañana del día siguiente al de la elección. Así el acta de Almadén (Ciudad Real) fue anulada por la falsedad de las listas electorales ya que «la Junta del Censo (...) desobedeciendo lo ordenado por el juez de primera instancia de aquel partido (...) no incluyó en las listas electorales, cuando en diciembre de 1885 se rectificaron, a 62 nuevos electores y no excluyó de ellas a 50 de los que venían figurando en el censo y que habían perdido su derecho». Igualmente anulada fue el acta de Gracia (Barcelona) porque, según acta notarial, en la sesión tercera de este distrito sólo habian votado 46 personas $y$, sin embargo, al realizar el escrutinio, iban contabilizadas más de 150 papeletas cuando, "suscitándose un gran tumulto, desapareció el presidente con los individuos de la Mesa, arrojando un dependiente las papeletas en un brasero, donde se quemaron sin que fuese posible proceder a su recuento»; no obstante, en la Junta del Censo se recibió el acta de esta sección en la que se le adjudicaban a uno de los candidatos no ya los 150 votos, sino 298 (siendo el número de electores de la sección algo más de 300); en otros documentos, 16 electores de la misma sección afirmaban no haber tomado parte en la elección, y 29 partidas de defunción demostraban que otros tantos individuos, en contra de lo que proclamaban los resultados, no habían podido hacerlo ${ }^{34}$.

Entre los casos de falsificación evidente de Actas, que sin embargo fueron aprobadas por el Tribunal, al no considerar suficientes las pruebas presentadas en contra, destaca la de Bande (Orense): el candidato derrotado, un liberal apellidado González, afirmaba que las Actas de ocho secciones estaban escritas por la misma mano, en concreto por la de uno de los interventores del contricante, llamado Feijóo; presentaba además un acta notarial en la que siete individuos manifestaban «que antes de empezar la elección, les dijeron que habiéndose retirado de la lucha el señor Lisardo González, se abstuvieran de grandes trabajos y procurasen recoger las firmas del presidente e interventores, sin cubrir en las Actas los nombres de los candidatos y votos obtenidos por cada uno, porque estos huecos los cubrirían en Banden; por otra parte, las actas de varias secciones de este distrito, en lugar de depositarse en la estafeta de Correos más próxima, como establecía la ley electoral que

${ }^{33}$ El Imparcial, 28 de noviembre, 1886.

${ }^{34}$ DSC, leg. 1886, "Tribunal de Actas Graves», n.? 7, pp. 93-103 y n. 3, p. 40. 
debía hacerse, se llevaron a Bande, donde aparecian con el sello R.S. (Ramón Serantes), agente electoral de los conservadores Alvarez Bugallal. Los casos de Sagunto (Valencia) y Redondela (Pontevedra) son relativamente semejantes ${ }^{35}$.

Los ejemplos de cualquier irregularidad pueden multiplicarse. Por ejemplo, sobre falsificación de Actas, en Ferrol (Coruña) «la sección de Narón remitió a la Comisión del Censo dos Actas, una de las cuales, forzosamente, había de ser falsa (...). En la sección de Valdoviño aparece una nota que dice 'que aquella Acta es la sola verdadera y no otra que se les hizo firmar a los de la Mesa por los amigos del señor Becerra Armesto, auxiliados por una pareja de la Guardia Civil'». En Santullano (Oviedo) el republicano Pedregal adjuntaba la declaración del escribiente mismo a quien se había obligado a realizar la falsificación. En relación con defectos formales en la elección, en Rosario (Sta. Cruz de Tenerife) «hubo protestas por anunciarse la elección de dos diputados en lugar de tres»; en San Andrés y en Sauce (Sta. Cruz de la Palma), "fue protestada la votación por no haberse situado el colegio en el local designado de antemano por el Ayuntamiento, sino en una casa contigua»; en Sta. María de Teva (Tuy) «protestaron dos interventores por no haberse publicado con claridad el sitio en que se convocaba para la elección y porque la urna no tenía cerradura»; en Buenavista (Cervera) figuraba una protesta «porque las papeletas se guardaban en el cajón de una mesa, en lugar de urna»; lo mismo en Torres de Segre (Borjas) "por haber servido de urna un cajón informe»; y en San Feliú (La Bisbal) porque «en la elección, la Mesa cambió dos o tres veces desitio, llevándose, como era natural, la urna consigo» ${ }^{36}$.

Igualmente se relacionan amenazas de todo tipo: en Pego (Alicante) «un elector manifestó que se había amenazado a unos trabajadores con dejarlos sin trabajo en la carretera, si no votaban por Romero Robledo» y en Piña de Campos (Astudillo) «un cobrador de contribuciones ejerció coacción sobre los electores que no habían pagado la contribución, obligándoles a que votaran a don Lorenzo Garcia». No obstante las referencias a las autoridades o a la fuerza pública son relativamente escasas: la actuación de los Gobernadores civiles no fue objeto de mención en el Tribunal de Actas Graves más que en tres ocasiones: en Sagunto (Valencia) «dież de los alcades del distrito tienen declarado ante el Tribunal Supremo que el gobernador de Valencia les llamó exclusivamente para recomendarles la candidatura del señor Pachecon; en Gracia (Barcelona), según la declaración de uno de los candidatos, el gobernador tenía un especial empeño en el triunfo de su contrincan-

${ }^{35} / d e m$, n: 6, p. 78; n. 1, pp. 1-22 y n. 5, pp. 61-72

${ }^{36}$ SANCHEZ ORTIZ y BERASTEGUI, op. cit., pp. 253, 348, 234, 237, 367, 300 y 286. 
te y recomendó su candidatura en la mesa de la primera sección; por ultimo, en Bande (Orense) según el candidato conservador, «el gobernador de la provincia llamaba por medio de la Guardia Civil, con carácter urgente a los alcaldes, jueces municipales y algún diputado provincial de influencia en algunos Ayuntamientos, para recomendarles con insinuaciones cariñosas primero y con amenazas después, la candidatura ministerial». Sobre la fuerza pública, Sánchez Ortiz y Berástegui citan, entre otros casos, los de Plasencia (Cáceres) donde se pidió la anulación de la elección de Villanueva de la Vera upor haber sido desalojado el local por medio de la fuerza pública, quedando solos los de la Mesa, adictos todos a la candidatura del Sr. Cepeda, resultando al abrirse el local y hacerse el escrutinio que el Sr. Rodríguez Leal sólo tenía cinco votos, cuando era público y notorio que habían votado su candidatura mayor número de electores»; en Morón (Sevilla) "sacaron del local y llevaron a la cárcel a un elector antes de votari ${ }^{37}$.

No hay denuncias, por otra parte, de compra de votos por dinero.

El fraude electoral, en resumen, aparece como importante, aunque limitado, y sin que quepa atribuir a él, en la inmensa mayoría de los casos, el resultado de la elección: de acuerdo con las impugnaciones presentadas, no afectó, en absoluto, a más de la mitad de los distritos, y en aquellos donde hubo denuncias, estas se referían sólo a un pequeño número de sus secciones. Sin embargo, la proliferación de los casos de corrupción, en sus variadas formas, la lenidad con que son juzgados por el Congreso, e incluso la misma grosería con que son realizados, sin preocupación siquiera de guardar las formas, nos hablan de la considerable extensión de los procedimientos ilegales y de la connaturalidad con los mismos.

\section{CONCLUSIONES.}

Al analizar cada uno de los aspectos considerados en este artículo, hemos expuesto alguinas conclusiones, que pretendemos sintetizar ahora:

1. Como era previsible, dadas las condiciones establecidas para ser elector, la distribución del censo, desigualmente repartido entre la España norte y la sur, reforzaba, aunque no excesivamente, el predominio de la población rural sobre la urbana.

2. El reparto de los escaños también favorecía ligeramente a la población rural; un reparto relativamente equilibrado entre las distintas re-

${ }^{37}$ Ibídem, pp. 186, 357. DSC, leg. 1886, "Tribunal de Actas Graves», n: 1, p. 9; n: 6, p. 74; SANCHEZ ORTIZ y BERASTEGUI, op. cit., pp. 238 y 385. 
giones, aunque cabe reconocer diferencias entre ellas, atribuibles al grado de su influecia particular en la política del Estado y no a ningún principio político general o de partido.

3. El gobierno mediante su actuación pública discrecional - política de libertades y remoción de Ayuntamientos, pricipalmente-, no conculcó las reglas del sistema democrático; no cabe atribuir, como un factor fundamental, el triunfo ministerial a esta actuación. Su relativa neutralidad dió ocasión a una más intensa actividad de los caciques locales.

4. La designación de candidatos del partido en el poder, el liberal, planteó abundantes problemas, dado lo reciente de su integración y el interés de los jefes de grupo por llevar al Congreso el mayor número posible de amigos; en unos 50 casos no fue posible el acuerdo y se enfrentaron entre sí candidatos liberales. En menor proporción también se dieron estos enfrentamientos personales dentro de los partidos de oposición y en las coaliciones formadas con fines electorales, en las que no parece reinará una gran disciplina.

5. Intensiva actividad interna de los partidos en relación con las elecciones, pero muy escasa actividad externa.

6. Lucha electoral por algo más de la mitad de los escaños que, en la mayor parte de los casos, fue una lucha real, con resultados apretados, y ligeramente superior en los distritos rurales que en los lurbanos; 27 distritos fueron abandonados sin lucha por el gobierno a las oposiciones.

7. Triunfo generalizado del partido liberal, que obtuvo una abrumadora mayoría de diputados, en todo el país. Mayor arraigo conservador en Asturias, Vizcaya, Guipuzcoa, Segovia y Murcia; republicano en Huesca; y de la coalición de conservadores disidentes e izquierdistas en Málaga.

8. Abstención media entre el 20 y el $40 \%$ en la mayor parte de las provincias, que indica una participación popular sospechosamente alta, aunque hay que tener en cuenta lo relativamente reducido del censo. En diez casos, más que sospecha, evidencia de un inflamiento fraudulento del voto ante una participación superior al $100 \%$.

y 9 a El importante volumen de denuncias de prácticas fraudulentas - amañamiento del censo, coacciones, violencia y engaños ejercidos sobre los electores, manipulación de Actas- que afectan a algunas secciones del $43,1 \%$ de los distritos, y la escasa reacción ante las mismas, son expresivos de la tensión del fraude, aunque su influencia sobre el resultado electoral, en la mayor parte de los casos, no parezca determinante.

Una vez afirmado todo lo anterior, ¿qué cabe decir sobre el «encasillado", el procedimiento seguido por el ministro de la Gobernación para 
la «fabricación» de las elecciones?. La idea que del mismo nos transmite la historiografía de la Restauración es la de un plan para el reparto de todos los escaños entre los candidatos a diputados, en el que se reserva un cierto número para las oposiciones, con las que se establece un pacto. En la ejecución del plan que, se afirma, sólo podía llevarse a cabo sobre la base de la abstención masiva del electorado, era fundamental la actuación del gobernador civil, mediante el uso de las facultades que le reconocía la ley, por servir de correa de transmisión entre los designios del poder central y los núcleos locales de poder encargados de proporcionar los votos o, sin necesidad de los mismos, las Actas proclamando la elección de un candidato-, cambiando votos por favores. "Oligarquía y Caciquismo», en definitiva, según la expresión de Joaquín Costa.

Lo que hemos establecido para las elecciones de 1886, sin plantearse el núcleo de esta interpretación - que descansa en anális localespermite, a nuestro juicio, hacer algunas matizaciones sobre el procedimento:

1) el «encasillado», tal como indica el término - cada candidato en una cuadrícula - parece remitir a un plan perfectamente definido, elaborado por el partido en el gobierno, de acuerdo con los de la oposición, como si se tratara de organizaciones eficientes, con un control completo sobre sus miembros. Sin embargo, en 1886, no parece que sea éste el caso: más de 100 candidatos del partido en el gobierno se enfrentaron entre sí, sin contar con el reconocimiento de ministeriales; las oposiciones en un número considerable de distritos, no reconocieron el supuesto pacto y presentaron batalla al gobierno e, incluo, se enfrentaron entre sí.

2) Se dice que las elecciones eran un asunto del ministerio de la Gobernación más que de los electores, como si el papel de éstos fuera enteramente pasivo. Pero, en 1886, la lucha real en un gran número de distritos indica que no todo estaba decidido antes del dia señalado. Incluso, las mismas prácticas fraudulentas nos hablan de la necesidad, en determinados casos, de contrarrestar una cierta acción del electorado.

El «encasillado», por tanto, a la altura de 1886 , al menos, no era un plan minucioso y consensuado hasta el extremo. La historia de las elecciones es más variada, menos uniforme de lo que parece indicar este término; sus resultados no estaban siempre determinados por la decisión o la actuación del gobierno, ni siquiera por las de la dirección de los grandes partidos políticos: quedaba todavía un campo considerable para el ejercicio de las influencias personales, dentro de cada localidad, al margen de, o no enteramente bajo, la disciplina de las organizaciones de ámbito nacional. 
POBLACION TOTAL Y ELECTORAL DE ESPAÑA, 1886

\begin{tabular}{lccccccc}
\hline & pt. & $\%$ & $\begin{array}{c}\text { pe } \\
\text { (1) }\end{array}$ & $\%$ & $\begin{array}{c}\% \\
\text { (2) }\end{array}$ & dip & hab/dip \\
\hline $\begin{array}{r}\text { distritos } \\
\text { urbanos } \\
\text { distritos } \\
\text { rurales } \\
\text { total }\end{array}$ & 4.946 .362 & 29,62 & 201.729 & 25 & 4,07 & 114 & 43.389 \\
media & 16.699 .369 & 100 & 807.175 & 100 & 4,83 & 394 & 42.384 \\
\hline $\begin{array}{l}\text { Fuente: datos proporcionados por M. SANCHEZ ORTIZ y F. BERAS- } \\
\text { TEGUI, op. cit. }\end{array}$ \\
$\begin{array}{l}\text { (1) censo de 1884. } \\
\text { (2) en relación con el total de la población. }\end{array}$ \\
\hline
\end{tabular}

CUADRO N.2

POBLACION TOTAL Y ELECTORAL DE ESPAÑA, 1886. DISTRIBUCION REGIONAL

\begin{tabular}{lrrrrc}
\hline \multicolumn{1}{c}{ REGION } & \multicolumn{1}{c}{ PT } & \multicolumn{1}{c}{ PE } & \multicolumn{1}{c}{$\%$} & DIP & HAB/DIP \\
\hline La Rioja & 175.020 & 12.391 & 7,1 & 4 & 43.755 \\
Castilla-Leon & 2.156 .564 & 144.093 & 6,7 & 53 & 40.689 \\
Navarra & 316.899 & 19.660 & 6,2 & 7 & 45.271 \\
Aragón & 927.622 & 52.087 & 5.6 & 23 & 40.331 \\
Castilla-La Mancha & 1.248 .570 & 68.753 & 5,5 & 30 & 41.619 \\
Pais Vasco & 501.330 & 26.216 & 5,2 & 12 & 41.777 \\
Pais Valenciano & 1.378 .436 & 70.373 & 5,1 & 32 & 43.076 \\
Galicia & 1.898 .916 & 96.220 & 5,1 & 45 & 42.198 \\
Cataluña & 1.760 .596 & 78.069 & 4,4 & 42 & 41.918 \\
Cantabria & 241.555 & 10.501 & 4,3 & 5 & 43.311 \\
Asturias & 597.346 & 24.726 & 4,1 & 14 & 42.667 \\
Extremadura & 725.677 & 28.302 & 3,9 & 17 & 42.686 \\
Madrid & 594.968 & 22.860 & 3,8 & 13 & 45.766 \\
Andalucía & 3.148 .349 & 120.431 & 3,8 & 74 & 42.545 \\
Baleares & 291.934 & 10.502 & 3,6 & 7 & 41.704 \\
Murcia & 452.082 & 14.441 & 3,2 & 10 & 45.208 \\
Canarias & 283.532 & 7.550 & 2,7 & 6 & 47.255 \\
\hline TOTAL/MEDIA & 16.699 .396 & 807.175 & 4,8 & 394 & 42.384 \\
\hline Fuente: & & & & & \\
\hline
\end{tabular}

Fuente: idem. 
CUADRO N. 3

PROVINCIAS CON AYUNTAMIENTOS SUSPENDIDOS GUBERNATIVAMENTE O POR AUTO JUDICIAL

\begin{tabular}{lllll}
\hline \multicolumn{1}{c}{ ninguno } & de 1 a 4 & de 5 a 9 & de 10 a 14 & de 15 a 21 \\
\hline Alava & Alicante & Almería & Albacete & Badajoz \\
Avila & Baleares & Asturias & Barcelona & Tarragona \\
Burgos & Cádiz & Coruña & Cáceres & Valencia \\
Canarias & Castellón & Cuenca & Córdoba & \\
Cuadalajara & C. Real & Granada & & \\
Guipuzcoa & Gerona & Huelva & & \\
Huesca & Jaen & Logroño & & \\
Lérida & León & Málaga & & \\
Madrid & Lugo & Orense & & \\
Navarra & Murcia & Pontevedra & \\
Palencia & Santander Sevilla & & \\
Salamanca & Teruel & Toledo & & \\
Segovia & Valladolid Zaragoza & & \\
Soria & Zamora & & & \\
Vizcaya & & & & \\
\hline
\end{tabular}

Fuente: idem. 


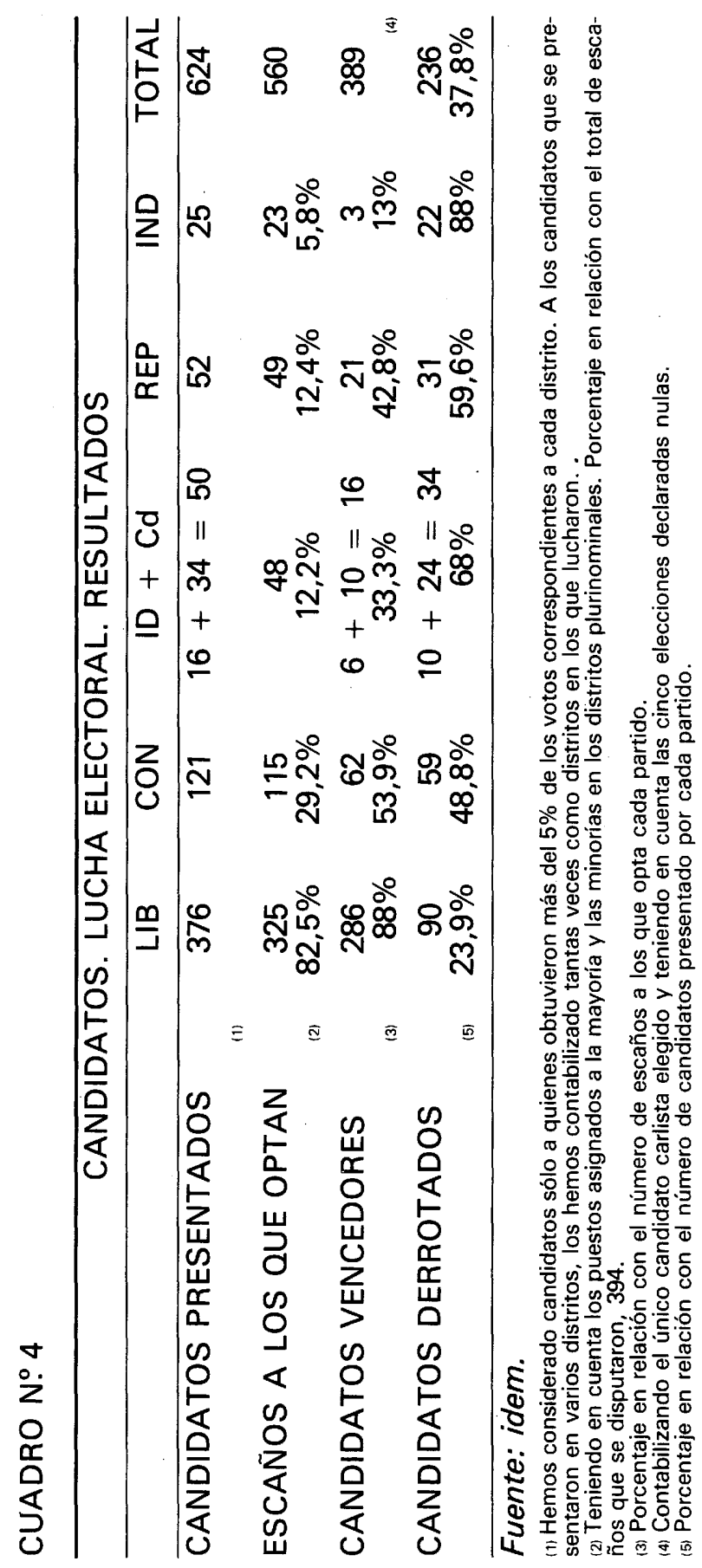


CUADRO N.5

ESCAÑOS POR LOS QUE HUBO LUCHA

\begin{tabular}{lll}
\hline De los distritos urbanos & Distritos rurales & Total \\
\hline 60 & 151 & 211 \\
$52,6 \%$ & $53,9 \%$ & $53,5 \%$ \\
\hline
\end{tabular}

Fuente: idem.

(1) Porcentaje en relación con el total de escaños de cada unidad (vid. Cuadro 1).

CUADRO N. 6

PROVINCIAS CON LUCHA ELECTORAL. PORCENTAJE DE ESCAÑOS

\begin{tabular}{|c|c|c|c|c|}
\hline del 0 al $19 \%$ & $20-39 \%$ & $40-59 \%$ & $60-79 \%$ & $80-100 \%$ \\
\hline $\begin{array}{l}\text { Lugo } \\
\text { Valladolid }\end{array}$ & $\begin{array}{l}\text { Avila } \\
\text { Cádiz } \\
\text { Huesca } \\
\text { Lérida } \\
\text { Málaga } \\
\text { Asturias } \\
\text { Salamanca } \\
\text { Sevilla } \\
\text { Tarragona } \\
\text { Toledo }\end{array}$ & $\begin{array}{l}\text { Alava } \\
\text { Albacete } \\
\text { Baleares } \\
\text { Burgos } \\
\text { Canarias } \\
\text { Castellón } \\
\text { Coruña } \\
\text { Cuenca } \\
\text { Granada } \\
\text { Guadalajara } \\
\text { Guipuzcoa } \\
\text { Jaén. } \\
\text { Navarra } \\
\text { Orense } \\
\text { Pontevedra } \\
\text { Soria } \\
\text { Vizcaya }\end{array}$ & $\begin{array}{l}\text { Alicante } \\
\text { Almería } \\
\text { Barcelona } \\
\text { Ciudad Real } \\
\text { Córdoba } \\
\text { Gerona } \\
\text { León } \\
\text { Logroño } \\
\text { Murcia } \\
\text { Santander } \\
\text { Segovia } \\
\text { Zaragoza }\end{array}$ & $\begin{array}{l}\text { Badajoz } \\
\text { Cáceres } \\
\text { Huelva } \\
\text { Madrid } \\
\text { Palencia } \\
\text { Teruel } \\
\text { Valencia } \\
\text { Zamora }\end{array}$ \\
\hline
\end{tabular}

Fuente: idem. 


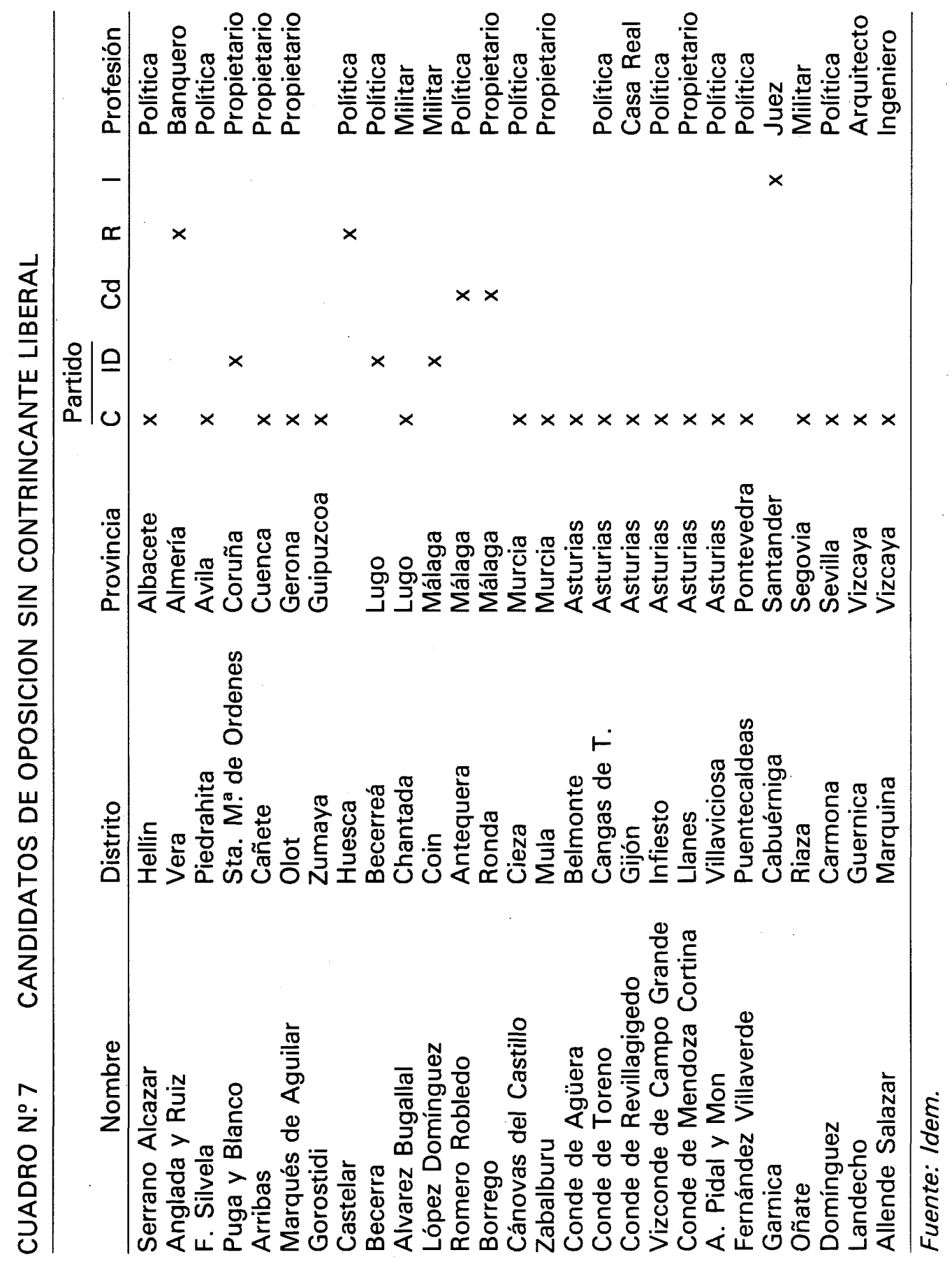


CUADRO N.8

\begin{tabular}{rcccc}
\hline \multicolumn{5}{c}{ PARTICIPACION ELECTORAL } \\
\hline & Pob. electoral & Votantes & Abstenciones & $\%$ \\
\hline $\begin{array}{r}\text { distritos } \\
\text { con lucha }\end{array}$ & 373.703 & 276.542 & 97.161 & 26 \\
$\begin{array}{r}\text { distritos } \\
\text { sin lucha }\end{array}$ & 298.375 & 207.867 & 90.508 & 30,33 \\
Total & 672.078 & 484.409 & 187.669 & 27,92 \\
\hline
\end{tabular}

Fuente: idem.

(1) Distritos uninominales, Oviedo y Lugo. 


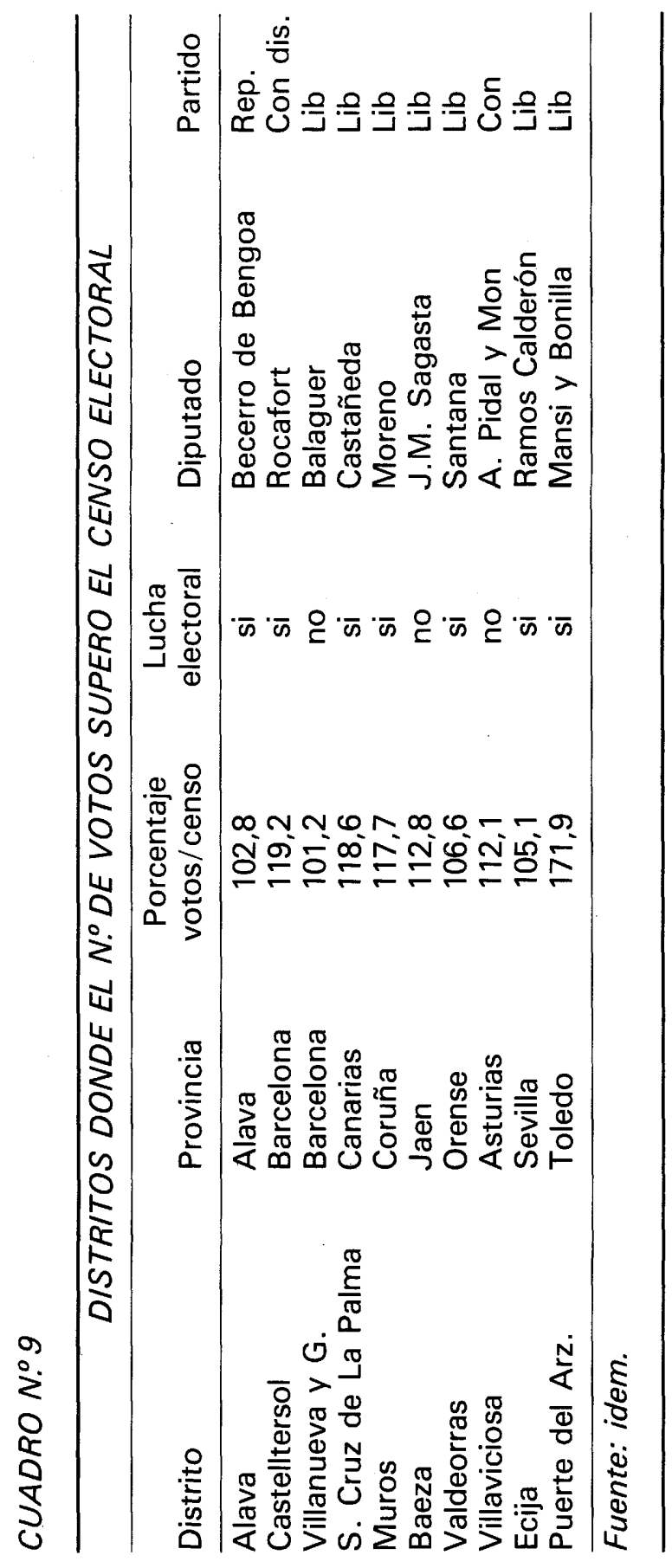


ACTAS NO APROBADAS O DECLARADAS GRAVES

Actas no aprobadas por el Congreso

Distrito Provincia

\begin{tabular}{lll}
\hline Luarca & Asturias & (pendiente de resolución) \\
Vergara & Guipuzcoa &
\end{tabular}

Actas graves

\begin{tabular}{lll} 
Distrito & Provincia & Resolución \\
\hline Sorbas & Almería & aprobada \\
Vera & Almería & aprobada \\
Gracia & Barcelona & anulada \\
Igualada & Barcelona & aprobada \\
Almadén & Ciudad Real & anulada \\
Coruña & Coruña & aprobada \\
Corcubión & Coruña & anulada \\
Velez-Málaga & Málaga & aprobada \\
Bande & Orense & aprobada \\
Redondela & Pontevedra & aprobada \\
Sagunto & Valencia & aprobada \\
Valmaseda & Vizcaya & aprobada \\
\hline
\end{tabular}

Fuente: idem. 
MAPA N. ${ }^{\circ}$ 1. POBLACION ELECTORAL

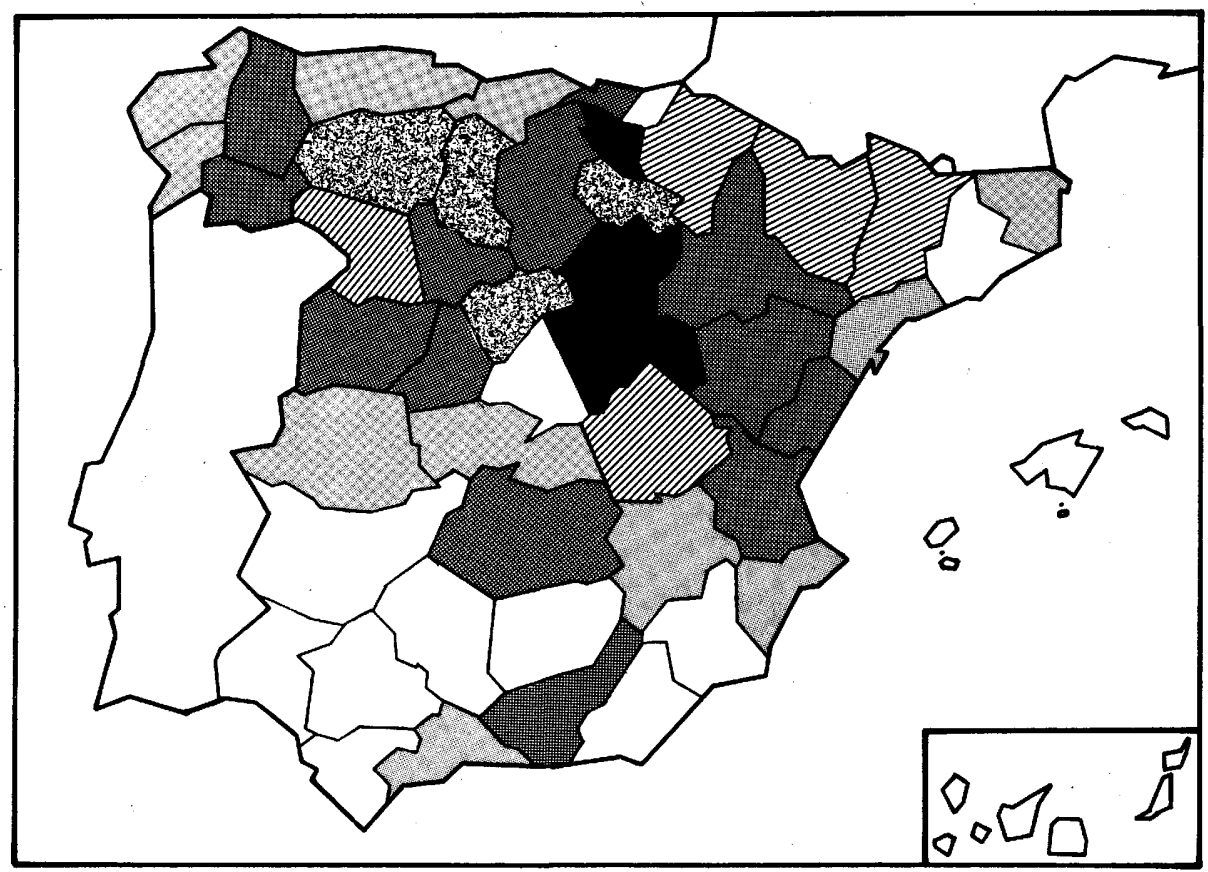

$\square \quad 2-3,9$

4 4-4,9

$5-5,9$
VIIIIII $6-6,9$

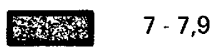

$8-8,9$ 


\section{MAPA N. ${ }^{\circ}$ 2. DIPUTADOS LIBERALES}

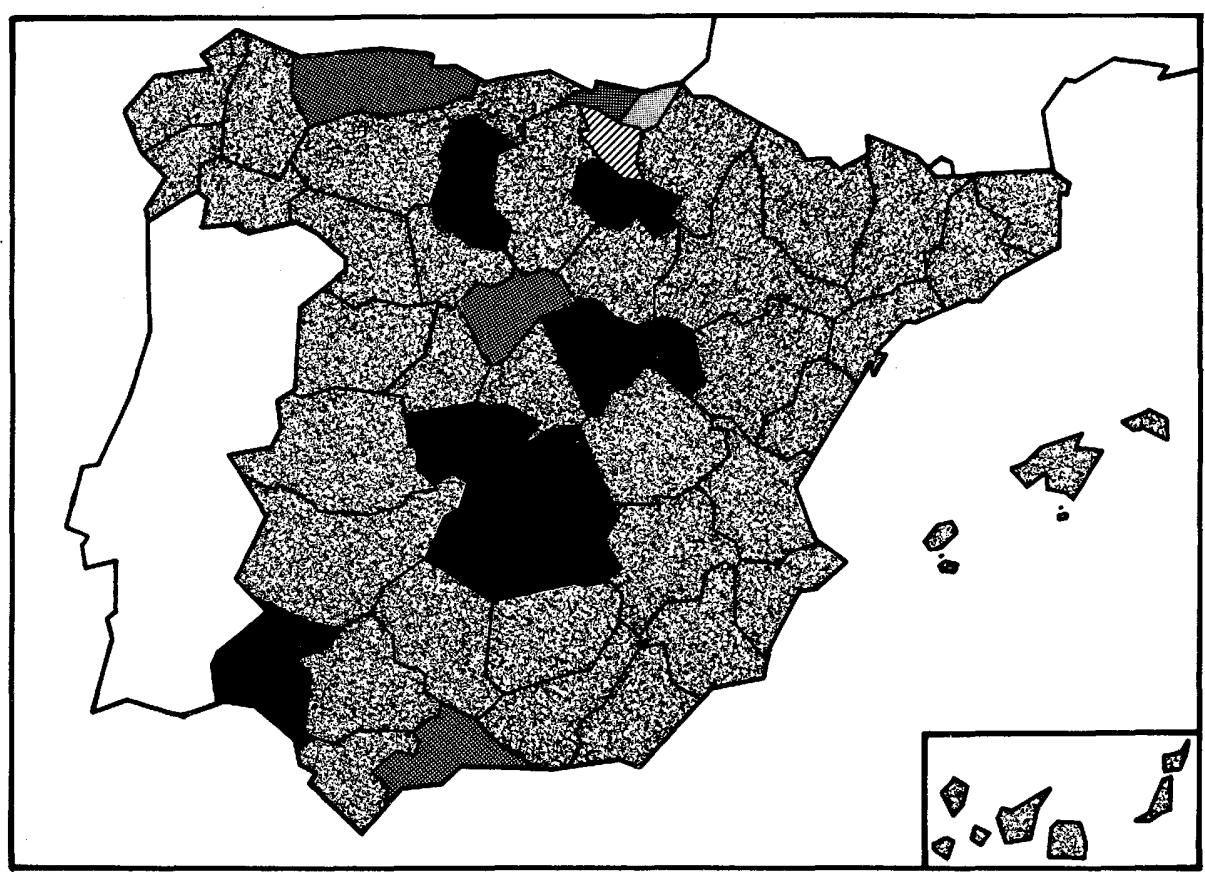

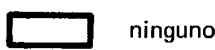

7. uno

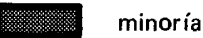

WIIII mitad

mayoría

totalidad 
MAPA N. ${ }^{\circ}$ 4. ABSTENCIONISMO

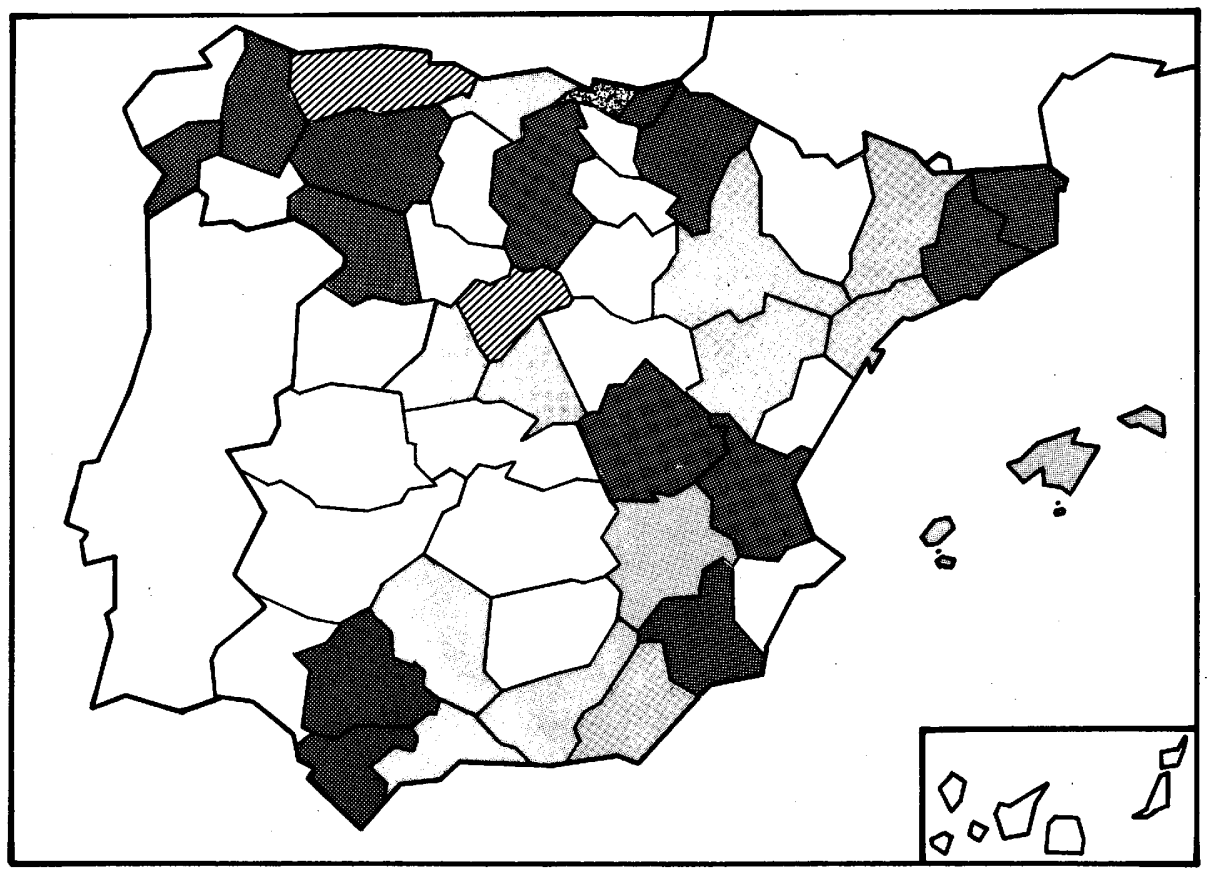

ninguno

WIIII mitad

uno

Fingoría

minoría

totalidad 
MAPA N..$^{\circ}$ 3. DIPUTADOS CONSERVADORES

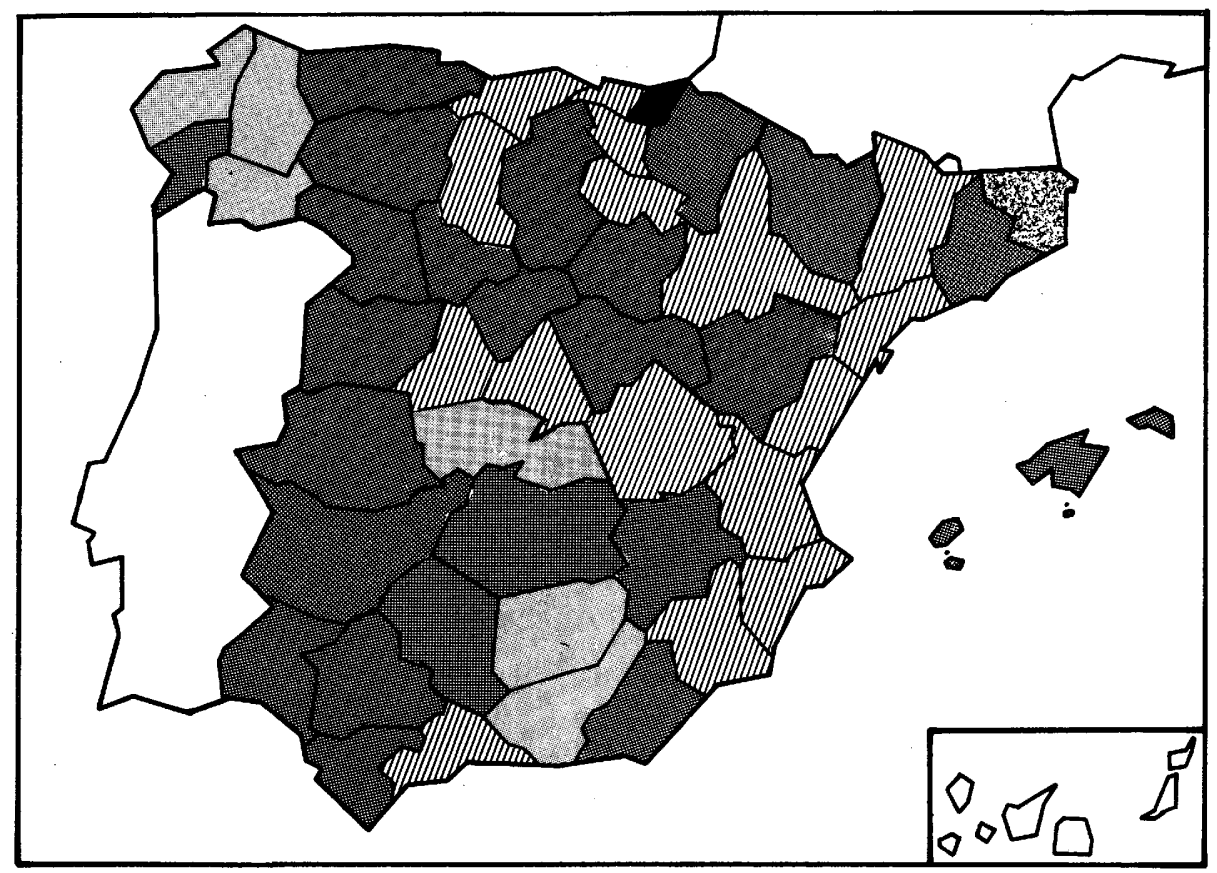

$\square$ menos del $10 \%$

WIIIA del 30 al 40

del 10 al 20

del 40 al 50

del 20 al 30

más del $50 \%$ 



\title{
EL REGENERACIONISMO DE LOS REPUBLICANOS FEDERALES.
}

\author{
GLICERIO SANCHEZ RECIO \\ Universidad de Alicante.
}

«Regeneracionismo» y "desastre del 98» son dos conceptos que se han presentado como íntimamente relacionados, de manera que el primero fuera consecuencia del segundo y éste, el revulsivo de aquel; de ahi la difusión de los términos «generación del 98» e, incluso, «gobierno regeneracionista del 1899» .

Sin embargo, esos dos conceptos deben someterse a un riguroso análisis y este trabajo pretende ser una aportación en ese sentido.

En primer lugar, el regeneracionismo, como ideario y planteamiento político, contaba ya con casi dos décadas de existencia. Varela Ortega ha expuesto ampliamente los objetivos de los trigueros castellanos, los medios políticos a utilizar y su absorción final por los partidos del sistema de la Restauración ${ }^{2}$.

Por otra parte, a lo largo de la década de los años noventa del siglo pasado, habian aparecido una serie de obras que continuaban la ya, en otras épocas, abundante producción de los «arbitristas». Los autores más representativos fueron L. Mallada, M. Picavea, V. Almirall y J. Costa ${ }^{3}$. Este último es el más significativo porque sus planteamientos tuvieron una base intelectual más profunda, partiendo, incluso, de los estudios de derecho consuetudinario, dentro de la escuela histórica

TUÑON DE LARA, M.: Costa y Unamuno en la crisis de fin de siglo. Pags. 26-45. Madrid 1974.

FERNANDEZ ALMAGRO, M.: Historia política de la España contemporánea. 1897-1902 (Vol. III). Págs. 223-229. Madrid 1970.

2 VARELA ORTEGA, J.: «El proteccionismo de los trigueros castellanos y la naturaleza del poder político en la Restauración» en Cuadernos económicos de I.C.E. No 6. Pags. 17, 39-40. Madrid 1978.

${ }^{3}$ MALLADA, L.: Los males de la patria y la futura revolución española. Selección, prólogo y notas de Francisco J. Flores Arroyuelo. Madrid 1969. La obra se habia publicado en 1890.

MACIAS PICAVEA, R.: El problema nacional. Hechos, causas y remedios. Introducción, enlace y notas de Fermin Solana. Madrid 1972. Se habia publicado en 1899.

ALMIRALL, V.: España tal como es. (La España de la Restauración). Prólogo de A. Jutgrar. Madrid 1972. Se habia publicado en 1886.

COSTA, J.: Colectivismo agrario en España. Doctrinas y hechos, Introducción y edición de C. Serrano. Zaragoza 1983. Esta obra se habia publicado en 1898.

- Oligarquia y caciquismo como forma actual de gobierno en España. Urgencia y modo de cambiarla. Introducción de Alfonso Ortí. Madrid 1975. Publicada en 1902.

- Oligarquia y caciquismo. Colectivismo agrario y otros escritos. (Antología). Edición y prologo de R. Pérez de la Dehesa. Madrid 1969. 
del derecho ${ }^{4}$, tratando de los métodos nuevos de la educación desde sus experiencias en la Institución Libre de Enseñanza, llegando hasta los problemas y los intereses de los campesinos del Alto Aragón, y apuntando a la formación de un partido político, que asumiera sus ideas y potenciara su práctica. Muy relacionado con este grupo estuvieron los escritores de la después llamada "generación del 98». Especial mención hay que hacer de Baroja, Maeztu y Azorín por ser quienes más se definieron ante los problemas de España, enumerando, incluso, una serie de medidas adecuadas para superarlos. Azorín, además, era una persona especialmente dotada para captar el contenido y la urgencia de la regeneración por su simultánea relación con Costa y con Pi y Margall ${ }^{4: k}$.

En tercer lugar, este movimiento se dará durante la profunda crisis de finales de siglo, en la que junto a los problemas financieros ${ }^{5}$ aparecen los de la industria y el comercio ${ }^{6}$ y la grave situación por la que pasaba la agricultura?. Es, precisamente, dentro de esta crisis econó-

${ }^{4}$ TUÑON DE LARA, M.: O. C. Pag. 90.

COSTA, J.: Oligarquía y caciquismo. Colectivismo agrario... Edición y prólogo de R. Pérez de la Dehesa. Pag. 10.

PEREZ DE LA DEHESA, R.: Política y sociedad en el primer Unamuno (1894-1904). Pags. 93-99 Madrid 1966. Se refiere al tema cuando trata de las relaciones de Costa con otros hombres de la "Generación del 98".

En el caso del País Valenciano se cuenta con la obra de Rafael Altamira «Derecho consuetudinario y economía popular de la provincia de alicante», que se publicó en 1905. Reeditaba en 1985, en Alicante, con introducción de A. Gil Olcina. RUIZ TORRES, P.: «Economía campesina y capitalismo agrario en el País Valenciano a finales del siglo XIX» en Estudios sobre historia de España (Homenaje a Tuñón de Lara). tomo I. Pags. 203-227. Madrid 1981.

4 his TUÑON DE LARA, M.: O.C. Págs. 139-153.

PEREZ DE LA DEHESA, R.: O.C. Págs. 97 y 126. Azorin, en 1902, en La Voluntad, después de reflejar un cierto deșánimo al tratar de la necesaria regeneración, escribía: "Esto es irremediable, 'Azorín, si no se cambia todo... Los unos son escépticos, los otros perversos... y así caminamos, pobres, miserables, sin vislumbres de bonan. za... arruinada la industria, malvendiendo sus tierras los labradores...» Edición de 1913. Editorial Renacimiento. Madrid.

5 TORTELLA, G. Y OTROS: La banca española durante la restauración. 2 vol. Madrid 1974.

${ }^{6}$ NADAL, J.: El fracaso de la revolución industrial en España. 1814-1913. Barcelona 1975

SARDA, J.: Politica monetaria y fluctuaciones de la economía española en el siglo XIX. Págs. 316-322. Barcelona 1970.

PRADOS, L. y TORTELLA, G.: Tendencias a largo del comercio exterior español (1714-1913). En Revista de Historia Económica. № 2. Pags. 353 y ss. Madrid 1983.

7 GARRABOU, R.: "La crisis agrária española de finales del segle XIX: Una etapa del desenvolupament del capitalisme». Recerques, n. 5. Págs. 163-216. Barcelona 1975.

CARNERO ARBAT, T.: Expansión vinícola y atraso agrario. 1870-1900. Madrid 1980.

AROSTEGUI, J.: Miseria y conciencia del campesino castellano (Memoria acerca de la información agraria en ambas Castillas). Introducción, notas y comentarios de textos por... Madrid 1977. 
mica donde hallarán sentido las aportaciones de los regeneracionistas, a falta de un planteamiento dirigido a la renovación de las estructuras del país. De este modo, el «desastre del 98» no supondría la consumación de la decadencia española sino que más bien habría sido la consecuencia de una "política cubana» equivocada, elaborada de espaldas a la realidad, que menospreció los sentimientos e intereses de los indígenas y de los criollos y minusvaloró el poderío norteamericano ${ }^{8}$, inflamando, en cambio, los sentimientos patrióticos de los españoles, pero, olvidándose de la falta de poder efectivo para mantener las colonias ${ }^{9}$.

Tampoco el regeneracionismo consistió en la asimilación de la anterior decadencia y en la adopción de medidas para superarla, aunque coyunturalmente fuera presentado de esta forma por el «partido de turno») (la Unión Conservadora de Silvela), para privar de los elementos renovadores y del futuro político al movimiento que había comenzado con la asamblea de la Cámara Agrícola del Alto Aragón. De ahí que el calificativo «regeneracionista» se aplique a lo largo del primer tercio del siglo $\mathrm{XX}$ a políticos de signo distinto y se asimile, en ocasiones, a la idea de «revolución desde arriba» ${ }^{10}$.

\section{EL PROGRAMA REGENERACIONISTA DE J. COSTA.}

No se expondrá aquí ampliamente el pensamiento de Costa, tarea

${ }^{8}$ Una de las escasas excepciones en el tratamiento del tema por la prensa española fue precisamente la de F. Pi y Margall expresada en El Nuevo Régimen. Semanario Federal. Ver los artículos: «Mi opinión» del 23 de enero de 1897. «Discurso pronunciado en el Centro Federal» del 17 de julio de 1897. "Las constituciones coloniales» del 4 de diciembre de 1897. "Cuba» del 8 de enero de 1898 "La guerra» del 14 de mayo de 1898.

FORNER, Ph. S.: La guerra hispano-cubana-americana y el nacimiento del imperialismo americano. 1895-1902. 2 vols. Madrid 1972.

JOVER, J.M.: "Caracteres de la política exterior de España en el siglo XIX» en Política, Diplomacia y Humanismo popular en la España del siglo XIX. Págs. 83-138. Madrid 1976.

TORRE, R. de la: «El noventa y ocho español». En Siglo XX Historia Universal 1 (Historia 16). Pags 79-90. Madrid 1983.

${ }_{9} \mathrm{Ph}$. S. Forner y R. de la Torre en la obra (vol. 1) y artículo citado apuntan algunas ideas tendentes a la revisión de este tema. Según R. de la Torre el gobierno español era consciente de su debilidad y el procedimiento elegido para su liquidación respondería a la urgencia con la que se quería terminar el problema de Cuba, aunque fuera a costa de su pérdida.

${ }^{10}$ CARR, R.: España. 1808-1939. Págs. 456-480; 552-558. Barcelona 1970.

TIERNO GALVAN, E.: Costa y el regeneracionismo. Barcelona 1961.

MAURICE, J. y SERRANO, C.: J. Costa: Crisis de la Restauración y el populismo (1875-1911). Madrid 1977. 
realizada con acierto por otros autores desde distintos puntos de vista ". Partiremos de un texto publicado en 1901 en el que aparecen sistematizados los distintos elementos para constituir «el programa del partido nacional», cuyo fin último sería realizar la revolución desde el poder ${ }^{12}$.

El programa, presentado de forma altisonante y apocalíptica, atribuye al partido las funciones de «... Llevar a cabo una total refundición del Estado Español sobre el patrón europeo que nos ha dado hecho la historia y a cuyo empuje hemos sucumbido; restablecer el crédito de nuestra nación ante el mundo... Fundar improvisadamente en la península una España nueva, es decir, una España rica y que coma, una España culta y que piense, una España libre y que gobierne, una España fuerte y que venza, una España, en fin, contemporánea de la humanidad... Tal es la magna... revolución que se impone... Y no pasemos en breve plazo de clase inferior a raza inferior, esto es vasallos que venimos siendo de una oligarquia indígena a colonos que hemos principiado a ser de franceses, ingleses y alemanes» ${ }^{13}$.

A continuación J. Costa enumera doce puntos a través de los cuales piensa que es posible realizar dicha revolución desde arriba ${ }^{14}$ :

1) Transformación del presupuesto del Estado, reduciendo el «de la España muerta o jubilada» y, por consiguiente, aumentando el «de la España naciente, de la España del porvenir». Creando, como medio para llevar a cabo la «nueva orientación política-financiera», «una caja especial autónoma o de varias, independientes del Ministerio de Hacienda, a cargo de cuerpos técnicos, para todos aquellos servicios e instituciones que significan adelanto y enriquecimiento de la nación». El presupuesto de la caja debe ser "la mitad siquiera de todo el presupuesto de ingresos».

2) El medio fundamental para crear la «España del porvenir» es la reforma de la educación. J. Costa comtempla no sólo el plan educativo; de acuerdo con el método de la pedagogía moderna, que atiende a la persona integral, sino también lo que es pevio, «la reforma de las instituciones docentes», mejorar y aumentar el número de escuelas, me-

"MAURICE, J. y SERRANO, C.: O. C., pag. 236. Hay una lista bibliográfica de estudios sobre el pensamiento de $\mathrm{J}$. Costa.

FERNANDEZ CLEMENTE, E.: Educación y revolución en J. Costa. Madrid 1969.

SABORIT, A.: Joaquin Costa y el Socialismo. Madrid 1970.

${ }^{12}$ COSTA, J.: Oligarquia y caciquismo... Edición y prólogo de R. Pérez de la Dehesa. Pags. 38-45.

-- Oligarquía y caciquismo.... Introducción de Alfonso Ortí. Pags. 236-243.

TUÑON DE LARA, M.: O.C. Págs. 92-98

${ }^{13}$ COSTA, J.: Oligarquía y caciquismo... Edición y prólogo de R. Pérez de la Dehesa. Pag. 38.

${ }^{14}$ Ver Nota 12. 
jorar y aumentar el número de maestros y elevar el nivel social de éstos. Habla, incluso, de un sistema de educación permanente. Trata de la destrucción de la vieja universidad, «fábrica de licenciados y proletarios de levita" y de la edificación de la nueva, "cultivadora seria de la ciencia, despertadora de las energías individuales, promovedora de las invenciones»; y potencia los estudios de los españoles en el extranjero. Termina refiriéndose a las experiencias de los norteamericanos en $\mathrm{Cu}$ ba y Puerto Rico y de las de Italia y Japón, paises que habian entrado con gran dinamicidad en el mundo moderno.

3) El abaratamiento de los artículos de primera necesidad mediante el aumento de la productividad, poniendo en práctica el plan hidráulico y la creación de instituciones docentes \{escuelas de Capataces y Gañanes), en donde se expongan y experimenten las técnicas de la agricultura moderna, y mediante la reforma y generalización de las instituciones financieras y del crédito agrícola, «a fin, todo, de que el labrador disponga del capital necesario para la transformación de los cultivos, remover tierras, arrancar viñas, comprar abonos, adquirir ganado». Todos estos medios no implicarán la desaparición de otros habituales para la reducción de los precios: supresión de impuestos, revisión de las tarifas, etc.

4) Facilitar la circulación por el interior del país «a la producción nacional», mejorando y aumentando el recorrido de los "caminos de herradura», con preferencia a «la construcción de carreteras».

5) «Suministro de tierra cultivable, con calidad de posesión perpetua y de inalienable, a los que la trabajan y no la tienen propia», mediante «la derogación de las leyes desamortizadoras en cuanto afectan a los concejos, y autorización a los ayuntamientos para adquirir nuevas tierras... con destino a repartirlas periódicamente al vecindario", la construcción de pantanos, acequias y uartefactos hidráulicos y arados de desfonde a vapor, para servicio de todos. "Apunta también la constitución de los «huertos comunales» y la «ley de expropiación forzosa por causa de la utilidad pública, como en Inglaterra». Para concluir diciendo: «Donde eso no baste, expropiación y arrendamiento o acensuamiento de tierras por el sistema de Floridablanca, Campomanes, de la Novísima Recopilación y de Flórez Estrada ${ }^{15}$.

${ }^{15}$ A estos proyectos se refiere J. Costa en Colectivismo agrario en España, edición de R. Pérez de la Dehesa, Págs. 53 y ss.: Existe también una relación entre los planteamientos de Flórez Estrada y Pi y Margall: Ver SANCHEZ RECIO, G.: «Los planteamientos socioeconómicos del partido democrático. La polémica entre Pi y Margall y Castelar en 1864» en Saitabi, Revista de la Facultad de filosofia y Letras de la Universidad de Valencia, N. XXVII, Págs. 123-144. 1977. Por otra parte, J. Fontana critica los planteamientos de Flórez Estrada. Ver FONTANA, J.: Cambio económico y actitudes políticas en la España del siglo XIX. Págs. 169-170. Barcelona 1973. 
6) Nueva legislación social: regulación del contrato de trabajo, seguro social o popular y socorro mutuo «por iniciativa y bajo la dirección del Estado», cajas de retiro para ancianos y de viudedad y horfandad, inspección del trabajo de las mujeres y de los niños, etc. ${ }^{16}$.

7) «Restablecer el crédito monetario de la nación... mediante la europeización de la agricultura, de la minería y del comercio, ... de la administración pública y de la política...».

8) Creación de un «poder judicial digno de su función» mediante el «expurgo», la reeducación del p̉ersonal existente, y «la formación de otro nuevo, que responda a las necesidades de la nueva situación y a los ideales del nuevo Estado».

9) Autonomía municipal, «régimen de los municipios por ordenanzas locales, de formación obligatoria, reformablès anualmente e intervenidas por el gobierno». "Generalización del sistema de consejo o democracia directa... o, en su defecto, del referendum». "Municipalización de los servicios públicos», y de creación por los municipios «de ciertas industrias o comercios en concepto de regulación o como monopolio». "Separar en absoluto la administración local de todo lo que sea política general de la nación, desaparición de las Diputaciones provinciales y creación de «organismos más amplios».

10) Sustitución del «liberalismo abstracto y legalista imperante, que ha mirado no más a crear y garantizar las libertades públicas» por un «neoliberalismo orgánico, ético y sustantivo, que atienda a crear y afianzar dichas libertades con actos personales de los gobernantes».

11) La ejecución de las anteriores ideas ha de realizarse de manera inmediata y simultánea, «porque son orgánicas entre si y cada una de ellas supone a las demás», forzosamente y por trámite sumarísimo, para superar el atraso, y por decreto «huyendo los procedimientos dilatorios y la sistemática obstrucción de las Cortes...»

12) Finalmente, renovar el personal político que llegó al poder con la Restauración, incluida «la representación actual del poder moderador» y formar "órganos nuevos» de opinión y de gobierno, con hombres aptos» para encarnar el presente minuto de nuestra patria y vencer su crisis, realizar el precedente plan de revolución y reprimir instantáneamente...».

Ante este programa de $\mathrm{J}$. Costa son muchos los problemas que

${ }^{16}$ Nuevos proyectos de legislación social estaban siendo elaborados por la Comisión de Obras Sociales, uno de los cuales, el de accidentes de trabajo, se convertía en ley en 1900. La previsión social se estaba llevando a cabo mediante asociaciones particulares. Ver HERNANDEZ FERRIS, R.: La Sociedad Cooperativa "EI Trabajo». 1880-1942. Memoria de Licenciatura, inédita. Facultad de Filosofia y Letras de la Universidad de Alicante. 1984. 
pueden plantearse: En primer lugar, es interesante destacar el esquema de razonamiento y exposición que utiliza. Se trata de una lucha de contrarios, que no aspira a un tercer elemento de síntesis, sino que se resuelve en sí misma con la imposición de uno sobre otro ${ }^{17}$, y del uso continuo de conceptos filosóficos y biológicos, símbolos y términos de carácter muy general y con una gran carga efectista como son los de "africanización-europeización», "Santiago de Cuba-Santiago de Galicia», «España muerta y jubilada-España naciente y del porvenir», «liberalismo abstracto y legalista-neoliberalismo orgánico, ético y sustantivo", etc., por los que si no consigue exponer con claridad sus ideas, si logra captar la atención del lector y del oyente y que se interese por su pograma.

Posteriormente, el significado del concepto de revolución, que él especifica y contrapone como «Revolución desde arriba» frente a la «revolución desde abajo» ${ }^{18}$. La "revolución desde arriba» tendría por objetivo la aplicación del anterior programa moderno y reformista; en cambio, la «revolución desde abajo», concepto que J. Costa no explica, llevaría consigo un efecto perturbador y destructivo de la sociedad ${ }^{19}$. La idea de la revolución en Costa está muy lejos de la revolución «orgánica» y se queda más próxima a la de revolución «política », que supone un simple cambio del equipo que ejerce el poder y en la aplicación de unas determinadas reformas ${ }^{20}$.

Las reformas previstas en el programa son eminentemente técnicas e implican una importante intervención del «nuevo Estado». Entre ellas son de destacar: a) La reforma de la educación y la función que se le concede en el proceso de transformación de la sociedad española, asuntos que Costa conocia pefectamente por su dilatada experiencia en la Institución Libre de Enseñanza ${ }^{21}$.

${ }^{17}$ Es éste un esquema dialéctico semejante al utilizado por Proudhon en sus obras. Ver SANCHEZ RECIO, G.: «La influencia de los pensadores y de los traductores franceses en F. Pi y Margallı. Anales de la Universidad de Alicante. Historia Contemporánea. N. 2, págs. 135-157. 1983.

18 TUÑNON DE LARA, M.: O.C. Pag. 97.

${ }^{19}$ El concepto de socialismo utilizado aquí por J. Costa, además de muy impreciso, es el adoptado por la burguesía en las décadas centrales del siglo XIX, aunque tampoco puede olvidarse del radicalismo de las organizaciones anarquistas en los años noventa del pasado siglo: MALUQUER DE MOTES, J.: El socialismo en España. 1883-1868. Barcelona 1977.

TUÑON DE LARA, M.: El movimiento obrero en la historia de España. Barcelona 1977 (Edic. Laia).

SABORIT, A.: O. C. Págs. 99 y ss.

${ }^{20}$ FONTANA, J.: O. C. Págs. 99-106.

${ }^{21}$ FERNANDEZ CLEMENTE, E.: O. C. Págs. 55 y ss..

GOMEZ MOLLEDA, Ma D.: Los reformadores de la España Contemporánea. Madrid 1966. 
b) Su preocupación e interés por el campesinado (pequeños propietarios y agricultores sin tierra); de ahí que arbitre varios medios para el acceso a la «posesión» de la tierra de los campesinos que no la tienen, para el cultivo de la misma y para el aumento de la productividad. Trata muy por encima de la expropiación forzosa, por lo que la estructura agraria permanecería inalterada.

c) La disponibilidad y la facilidad del crédito y una correcta aplicación del presupuesto a las necesidades reales de la nación.

d) Existe un cuarto elemento por omisión, la ausencia de cualquier referencia a la industria, a los grupos sociales y a los intereses con ella relacionados ${ }^{22}$.

Para llevar a cabo este programa había de ser previa la toma del poder, establecer las reformas políticas necesarias $y$, finalmente, se encomendaría la vigilancia de la correcta aplicación de las mismas a un «poder judicial digno de su función».

Sin embargo, lo anterior nos lleva a plantearnos un doble problema: La creación del medio adecuado para llegar a la toma del poder $y$, en segundo lugar, la naturaleza del poder político. Costa intenta conseguir lo primero mediante la constitución de un partido nacional, para lo cual pretende utilizar como base la Cámara Agricola del Alto Aragón, reunida en asamblea en noviembre de 1898, que lanzó un manifiesto el día 13, en el que aparecían las ideas del anterior programa; en febrero de 1899 se celebró en Zaragoza la Asamblea Nacional de productores, en la que participaron las Camaras Agricolas, las de Comercio e Industria, los Círculos Mercantiles, etc., de la que salió la liga $\mathrm{Na-}$ cional de Productores, con un programa mínimo para influir sobre el gobierno del Estado, abandonándose los anteriores planteamientos de partido. Finalmente, en 1901 se desintegraba este movimiento, entrando la mayoría de sus jefes en los partidos de turno ${ }^{23}$.

En cuanto a la naturaleza del poder político, es decir, a la concepción del Estado, el pensamiento de J. Costa es mucho menos preciso. Sólo habla del «neoliberalismo orgánico, ético y sustantivo», que permitirá una gran libertad de acción a los gobernantes, y de la expurgación del personal político que habia ejercido el poder desde el principio de la Restauración. Sin embargo, aquí se abren una serie de interro-

${ }^{22}$ TUÑ் DE LARA, M.: O. C. Págs. 97.

"La asamblea de produtores» en El Nuevo Régimen, 18 de febrero de 1899. A pesar de que el artículo no está firmado puede deducirse que pertenece a $\mathrm{Pi}$ y Margall por su estilo y por las ideas contenidas.

${ }^{23}$ CHEYNE, G.J.G.: Joaquín Costa, el gran desconocido. Págs. 131-142. BarceIona 1971.

TUÑON DE LARA, M.: O. C. Págs 186-206. 
gantes sobre la estructura y los poderes del Estado, el sistema de representación, etc., de los que J. Costa no trata ${ }^{24}$.

\section{LOS PLANTEAMIENTOS REGENERACIONISTAS DE PARTIDO REPUBLICANO FEDERAL.}

Los proyectos de regeneración no fueron exclusivos de un grupo de intelectuales y del programa de un partido nonato, sino que salpicaron también a los de los partidos del turno y a los de la oposición, y, más aún, en un momento en el que el cambio se hacía necesario, una vez quemado el gobierno de Sagasta por el resultado de la guerra de Cuba. De nuevo se presentaba la hora del partido conservador, que, ademas, tenía que resolver el problema de su dirección por haber desaparecido Cánovas. Es en esta coyuntura cuando se alza la voz de Silve$\mathrm{la}^{25}$, quien consigue ser aceptado como jefe del partido y aglutinar en torno a él a las personas más destacadas del mismo ${ }^{26}$, quienes en marzo de 1899 formaban el gobierno y convocaban posteriormente las elecciones, en las que obtendrian una amplia mayoría que les permitiría gobernar cómodamente. Este gobierno elaboró los primeros proyectos reformistas, el principal de todos ellos fue el de ajustar el presupuesto, a cargo de Villaverde, ministro de Hacienda ${ }^{27}$. También la oposición aprovechó la conyuntura para exponer su ideario, sus programas de reformas y presionar sobre el gobierno.

El partido republicano federal planteó sus intervenciones en una doble dirección política: una, de tipo didáctico y propagandístico, en reuniones, actos y mítines organizados por el propio partido, y otra, de carácter parlamentario, a través de sus miembros en el Congreso de los Diputados. Aqui estudiaremos los discursos pronunciados, en uno y otro casos, por el jefe del partido, F. Pi y Margall, y otros escritos publicados en El Nuevo Régimen entre 1898 y $1901^{\text {28. }}$. En los primeros se exponían los principios programáticos del partido, entre los que se incluia un amplio plan de reformas, similares a las propuestas por la Cá-

${ }^{24}$ Escribe Tuñón de Lara: «El gran vacio costiano fue siempre la cuestión del po der» (lb. pag. 98).

${ }^{25}$ TUNON DE LARA, M.: O. C. Pág. 69

FERNANDEZ ALMAGRO, M.: O. C. Págs. 208-215.

${ }^{26}$ FERNANDEZ ALMAGRO, M.: O. C. Págs. 219-226.

27 FERNANDEZ ALMAGRO, M.: O. C. Pág. 223.

TORTELLA, G. Y OTROS: La banca española durante la Restauración. Vol. I. Págs. 172-177.

VARIOS: El banco de España. Una historia económica. Págs. 295-297. Madrid 1970.

${ }^{28}$ El Nuevo Régimen. Semanario Federal. Madrid. El número 1. se publicó el 17 de enero de 1891. Semanario ligado estrechamente a la persona de F. Pi y Margall se convirtió en el órgano principal del partido republicano federal. 
gall tocaba el tema del regeneracionismo desde la perspectiva federal. El contenido de la misma puede considerarse como programático de la actividad política que desarrollaría hasta finales de 1901. Trató, en primer lugar, de la estructura federal del Estado, a la que, incluso, fundamentó filosóficamente, según sus principios habituales, y después de repasar las ventajas del sistema federal y de atacar al caciquismo como «sistemático falseamiento de la voluntad del pueblo», expuso su programa para la regeneración de España, enumerando, primero, los males de la patria:

«España es una de las naciones más atrasadas de Europa. Cuenta sólo 18.000.000 de habitantes; cuando Francia...; tiene apegada la agricultura a la rutina y escasamente admitidas las prácticas que hoy hacen de tierras estériles tierras fecundadas. Tiene reducidas la industria a corto número de poblaciones. Es de las que cuenta menos kilómetros de ferrocarril, y en los ferrocarriles menor movimiento de viajeros y de mercancias. Ni aún en vías ordinarias abunda, cuando tantas exige el fácil y barato transporte de nuestros productos para que puedan competir con los que de otras naciones nos vienen. Su escasa cultura, bien claramente la revela el hecho de que no sepa leer ni escribir siquiera el cincuenta por ciento de los españoles».

Ante este cúmulo de males enunciado, ofrece como soluciones «la instrucción y el trabajo», pero ambos elementos están íntimamente relacionados. El problema más grave que arrastraba el país era el de la hacienda pública:

"Vengamos ahora a lo más espinoso, a la Hacienda. Nunca se logra aquí nivelar los presupuestos. Los déficits se cubreri con deuda flotante del tesoro, y la deuda flotante pasa, periódicamente, a ser consolidada ... Cálculese que será ahora si hemos de tomar sobre nosotros la deuda de Cuba, que no bajará de tres mil millones de pesetas».

Ante esta situación sólo cabía una profunda transformación del presupuesto, que implicaba, a la vez, cambios políticos de importancia:

«Si hemos de fomentar la instrucción y el trabajo, hemos de transformar los presupuestos. No es posible que sostengamos ni la actual lista civil ni los sesenta y más millones de las clases pasivas, ni los cuarenta de las obligaciones eclesiásticas. No es posible que dejemos de reducir los capítulos de Guerra y Marina y el de la recaudación de rentas y contribuciones, fácil de rebajar por el sistema que os propongo».

En todas sus intervenciones públicas durante estos años Pi y Margall volvió sobre estos problemas, ampliando la relación de las refor- 
mara Agrícola del Alto Aragón y por la Liga Nacional de Productores, y en los segundos se respondía desde el punto de vista del partido a los proyectos del gobierno ${ }^{29}$.

\section{FEDERALISMO Y REGENERACIONISMO.}

El partido republicano federal a partir de 1874 estuvo formado por un pequeño grupo testimonial, dirigido ideológica y tácticamente por F. Pi y Margall, quién desde 1881 extendió su actividad pública al amparo de la ley de reunión de $1880^{30}$ y estuvo presente en el Congreso de los Diputados en la Legislatura de 1886 y a partir de la de 1891, por la promulgación de la ley del sufragio universal de 1890; sin embargo, el peso real del partido nunca estuvo al nivel de su altura ideológica. No se ha realizado todavía un estudio acerca del partido republicano federal, y no sabemos, por tanto, cual era su base electoral y su aceptación en la sociedad, ni conocemos el origen de los fondos con los que se financiaban sus campañas y sus medios de difusión. La presencia de sus miembros en el Congreso de los Diputados se consiguió desde 1891 a través de la coalición La Unión Republicana. Por otra parte, este pequeño partido republicano tenía perfectamente elaborados sus principios programáticos desde $1894^{31}$.

Respecto al tema que aquí nos ocupa, el regeneracionismo, los republicanos federales fueron conscientes del problema y, de manera semejante a los partidos del turno dinástico, introdujeron el regeneracionismo en su programa, más aún, como la República Federal se presentaba como alternativa del sistema establecido, el programa del partido aparecia como regenerador, sin que esto supusiera ningún cambio significativo en el mismo; de ahí que se hiciera un abundante uso de los términos «regeneración» y «degeneración» en los discursos y escritos.

En una conferencia pronunciada en el Círculo de la Unión Mercantil de Madrid, a finales de $1898^{3 "}$ sobre "la crisis de España», Pi y Mar-

${ }^{29}$ La actividad pública y política de Pi y Margall la hemos tratado más ampliamente en otro lugar: SANCHEZ RECIO, G.: Los discursos politicos de Pi y Margall durante la Restauración. Memoria de Licenciatura, inédita. Facultad de Filosofia y Letras de la Universidad Complutense de Madrid. 1973.

30 SANCHEZ RECIO, G.: "Aportación a la historia politica del País Valenciano. Viaje de propaganda federal de F. Pi y Margall en 1881». Item. Revista de Ciencias Humanas. Centros de Estudios Universitarios de Alicante. № 4, Págs. 95-102. 1978.

${ }^{31}$ En el mes de junio de ese año se celebró una asamblea federal en Zaragoza en donde se aprobó el programa del partido. Ver El Nuevo Régimen, 23 de junio de 1894 y 14 de diciembre de 1901.

PI Y MARGALL y PI Y ARSUAGA: La historia de España en el siglo XIX. Vol, VI. Págs. 892-904. Barcelona 1902.

32 El Nuevo Régimen, 3 de diciembre de 1898. 
mas que convenía realizar ${ }^{33}$. Especial importancia tiene el dicurso pronunciado en el Centro Federal de Madrid, el 4 de noviembre de 1899, dedicado, en su mayor parte, al tema de la instrucción y de la mujer, a través del cual aparecen claramente las ideas de los republicanos federales sobre la política educativa: la instrucción general debe ser común para los dos sexos, las escuelas, mixtas e igualdad total entre el hombre y la mujer; de ahí que juzguen indispensable algunas reformas relativas a la mujer ${ }^{34}$.

\section{LOS REPUBLICANOS FEDERALES FRENTE AL GOBIERNO DE SILVELA.}

El campo elegido para el combate fue el Congreso de los Diputados, en donde los republicanos federales estaban representados por varios diputados. Las ideas defendidas por Pi y Margall han sido expuestas fundamentalmente más arriba, aunque en sus discursos las concretara más y tratara de otras nuevas, aprovechándose de la conyuntura política.

Los republicanos federales fueron a las elecciones tácitamente aliados con los socialistas «aunque no hemos pactado alianza alguna», como diría Estévanez, candidato republicano federal, en el mitin celebra-

${ }^{33}$ Discursos de Pi y Margall en los que trató de las reformas a realizar:

- 7 de enero de 1899 en el Círculo Federal. El Nuevo Régimen, 14 de enero.

- 11 de febrero de 1899 en el Círculo Federal. El Nuevo Régimen, 18 de febrero.

- 1 de abril de 1899 en la Asociación de la Prensa. El Nuevo Régimen, 8 de abril.

- 6 de agosto de 1899 en el Nuevo Teatro. El Nuevo Régimen, 12 de agosto.

- 11 de febrero de 1900 en el Centro Federal. El Nuevo Régimen, 17 de febrero.

- 17 de noviembre en el Centro Federal. El Nuevo Régimen, 24 de noviembre.

- 11 de febrero de 1901 en el Círculo Federal El Nuevo Régimen, 16 de febrero.

${ }^{34}$ El Nuevo Régimen, 11 de noviembre de 1899. Por su importancia reproducimos algunos párrafos: «Para que la enseñanza produzca más resultados, es indispensable a mi juicio, que la instrucción general, lo que hoy comprenden la primera y la segunda enseñanza, sea común a los dos sexos. La mujer, como sabeis, es la que instruye y educa a los niños en los cuatro primeros años de la vida...

«En mi opinión las escuelas deberían ser todas para ambos sexos. No comprendemos que se les separe, cuando unidos podrian las hembras activar la energía intelectual de los varones y dulcificarles los sentimientos...

«A la mujer se le reconoce generalmente inferior al hombre, sin ver que esa inferioridad depende en gran parte de que no se le dé la instrucción que a los varones...

«Así yo entiendo que es indispensable reformar las leyes relativas a la mujer... «Tampoco le hace favor la sociedad. En el trabajo, generalmente hablando, no percibe nunca jornales tan altos como los de los varones, y tiene cerradas las puertas de un gran número de industrias...

«Tampoco goza la mujer de todos los derechos políticos. Se le permite que escriba... No que goce el derecho de sufragio...» 
do el 14 de abril de 1899 en el Círculo Federal, en el que también participó Pi y Margall, cuyo discurso estuvo dedicado en su mayor parte a tratar de las semejanzas programáticas de ambos partidos ${ }^{35}$.

Podría sintetizarse el ideario regeneracionistas de los republicanos federales con unas palabras de Pi y Margall pronunciadas en el Congreso de los Diputados, el 10 de julio de 1899, criticando el programa del gobierno: «Equilibrar los presupuestos no es regenerar la patria: no es abrir carreteras, ni construir ferrocarriles secundarios, ni canalizar los ríos, ni abrir las numerosas escuelas que el pueblo necesita» ${ }^{36}$. Sin embargo, la novedad principal era la de los recursos con los que deberían cubrirse los gastos necesarios para efectuar las anteriores obras: el presupuesto eclesiástico y la mayor parte de los haberes pasivos ${ }^{37}$. Más aún debería realizarse una emisión de papel «por una cantidad cuyos intereses y amortización pudieren cubrirse con lo que hoy importan esas dos secciones del presupuesto».

El programa republicano federal se completaba con la defensa de su sistema político, con el que se resolvía el problema de la descentralización administrativa, de la regionalización del Estado y de la autono-

35 El Nuevo Régimen, 15 de abril de 1899.

${ }^{36}$ El Nuevo Régimen, 15 de julio de 1899. Diario de Sesiones del Congreso de los diputados, 1899-1900; n. 32, pp. 789-792. Otros discursos de Pi y Margall pronunciados en esta legislatura fueron:

- 17 de julio de 1899. El Nuevo Régimen, 22 de julio Diario de Sesiones, N. 32, pp. 1020-1022

- 28 de julio sobre los «sucesos de Barcelona». El nuevo Régimen, 29 de julio de 1899. Diario de Sesiones, № 48, pp. 1446-1448.

-13 de noviembre de 1899. El Nuevo Régimen, 18 de noviembre, Diario de Sesiones, $N^{\circ} 60$, pp. $1817-1820$

- 20 de noviembre de 1899 sobre «los departamentos ministeriales». El Nuevo Régimen, 25 de noviembre Diario de Sesiones, N. 66, pp. 2047-2048

$-20,21$ de diciembre de 1899. El Nuevo Régimen, 23 de diciembre Diario de Sesiones, Nos. 91 y 92 , pp. 2.999-3.000, 3.037-3.038.

-8 de febrero de 1900. El Nuevo Régimen. 10 de febrero Diario de Sesiones. № 45. Extracto de la Gaceta.

-7 de marzo de 1900. El Nuevo Régimen. 10 de marzo Diario de Sesiones, № 144 , pp. 5.034-5.037.

- 12 de diciembre de 1900. El Nuevo Régimen. 15 de diciembre. Diario de Sesiones. 1900-1901. № 19 pp. 456-457.

${ }^{37}$ Decia Pi y Margall al respecto: "La Iglesia no necesita que el Estado la subvencione. Exige recompensa de los servicios que presta..."

«Soy también partidario de la reducción de los haberes pasivos... Nacen esos haberes de ciertos montepíos que se alimentaban con los descuentos de los funcionarios públicos. Desaparecieron los montepíos civiles en el año 1851 y los militares en 1857. Los que desde entonces entraron en la administración no tienen derecho al disfrute de pensión alguna, ya que no contribuyeron ni a la creación ni al mantenimiento de los montepios. Podrán subsistir, cuando más, los haberes de los que entonces estaban al servicio del Estado». 
mía de los pueblos. Desde esta perspectiva llevaría a cabo la defensa de los regionalistas catalanes (discurso del 28 de julio sobre los sucesos de Barcelona) ${ }^{38}$, en reconocimiento de lo cual sería nombrado mantenedor de los Juegos Florales de Barcelona de 1901.

Otro elemento importante del programa era la reforma y reducción del ejército y de la armada, fundándolo sobre la existencia de un pequeño núcleo de militares profesionales y una abundante y bien entrenada reserva (discurso del 17 de julio y del 20 y 21 de diciembre de 1899) ${ }^{*}$. En el primero de estos, muy alejado de la realidad, decía Pi y Margall que partía en su exposición del hecho «de que nos hemos curado totalmente de la manía colonial, después de los resultados de la guerra de Cuba y Filipinas y de la venta a Alemania de las Carolinas, las Marianas y las Palaos ${ }^{40}$. La reforma del ejército y de la armada supondría un importante ahorro en el presupuesto que debía destinarse a las obras de la modernización del pais.

En el mismo sentido exponía sus ideas sobre la reforma de la administración del Estado, partiendo de dos principios:

a) Separación de la política y de la administración: «Al paso que la política corresponde a los ministros, la administración ha de correr a cargo de los directores generales. Los directores generales han de salir siempre del fondo de la administración, jamás de la política, y han de responder en todo caso de sus resoluciones, nunca de los ministros».

b) La reducción del número de los ministros, que simplifica en tres: gobernación -interior, Estado -exterior- y Hacienda ${ }^{41}$.

Finalmente, en el discurso pronunciado el 12 de diciembre de 1900 , Pi y Margall hacía referencia al tema de la instrucción pública, criticando las bases de la reforma del gobierno sobre la enseñanza secundaria, en lugar de construir nuevas escuelas de enseñanza primaria y dotarlas mejor.

Pi y Margall continuó defendiendo estas mismas ideas en la legislatura de $1901^{42}$.

\section{${ }^{38}$ Ver la Nota 36.}

${ }^{39}$ Ver la Nota 36.

40 JOVER, J. Ma: O.C. Págs. 133-138.

GIMENEZ LOPEZ, E.: «Ejército y federalismo. Un proyecto de organización de ejército republicano en 1872». En Item. №. 2. Págs. 111-124. 1977.

${ }^{41}$ Discurso del 20 de noviembre de 1899 «sobre los departamentos ministeriales».

42 Discurso del 15 de julio de 1901. El Nuevo Régimen, 20 de julio. Diario de Sesiones del Congreso de los Diputados. 1901-1902. N. 29 pp. 610-613. 
$D E J$. COSTA.

A través de las páginas de El Nuevo Régimen, estrechamente ligado a la persona de $\mathrm{Pi}$ y Margall, se manifiesta la actitud de los republicanos federales y, particularmente, de su jefe hacia los proyectos reformistas de Costa. Estos no fueron vistos con simpatia por su imprecisión política y por la cortedad de sus perspectivas socioeconómicas y administrativas, aunque en algún momento se pusieran junto a las Cámaras de Comercio en contra del gobierno de Silvela, alegando la «burla» y el no cumplimiento de la palabra dada de llevar a cabo los proyectos de reforma elaborados por aquéllas, a pesar de que no fueran de total agrado para los republicanos federales ${ }^{43}$.

En términos generales, se critica la persona de Costa, aprovechando la actitud mantenida por éste, en la asamblea de Productores de Zaragoza:

«A nuestro modo de ver, el Sr. Costa, verbo de la referida Cámara Agrícola (la del Alto Aragón), va por mal camino. Abomina de los políticos sin distinción y se propone crear un partido; condena lo mucho que se habla en los Parlamentos, y no abre los labios que no pronuncie un discurso largo....»

$Y$ termina el artículo, afirmando:

«Es una verdadera ilusión creer que basta formular proyectos para que el país se regenere. Lo difícil no es concebirlos, sino imponerlos; y para imponerlos no hay más que dos caminos... ${ }^{44}$.

Rechazan también las relaciones del movimiento de las Cámaras y de la Liga con los gobiernos de la nación, primero, el de Sagasta y, después, el de Silvela. Los republicanos federales apoyaron a Sagasta en su no aceptación de las propuestas de las Cámaras de Comercio, acordadas en la Asamblea de Zaragoza, en noviembre de 1898, que se arrogaban una representación al margen del Parlamento, en un artículo equívocamente titulado "La Unión Conservadora» ${ }^{45}$. En cambio, critican la falta de firmeza en el mantenimiento de sus proposiciones frente al gobierno ${ }^{46}$ y la dureza empleada por éste en la represión del movi-

43 «Las Cámaras de Comercio». en El Nuevo Régimen, 25 de noviembre de 1899. Aunque el artículo no está firmado puede deducirse que su autor es Pi y Margall.

44 "La Asamblea de Productores» en El Nuevo Régimen, 18 de febrero de 1899.

${ }^{45}$ El Nuevo Régimen, 14 de enero de 1899. "La unión conservadora fue el nombre bajo el cual concurrió la mayor agrupación del partido conservador en las elecciones de la primavera de 1899, bajo la dirección de Silvela.

${ }^{46}$ El Nuevo Régimen, 25 de noviembre de 1899, artículo citado, y 23 de diciembre, artículo titulado "Las Cámaras y la Liga». 
miento ciudadano (negativa al pago de los impuestos y cierre de las tiendas) para repudiar la actitud del gobierno ${ }^{47}$.

En definitiva desde la órbita de los republicanos federales podría sintetizarse la trayectoria de los proyectos regeneracionistas de las Cámaras de Comercio y de la Liga de Productores con unas palabras de $\mathrm{Pi}$ y Margall, pronunciadas en el Centro Federal de Madrid, el 17 de noviembre de 1900:

"Todos recordareis que después de la pérdida de las colonias hubo en Zaragoza dos asambleas: la de las Cámaras de Comercio y de la Liga de Productores. Las dos propusieron gran número de reformas, y las llevaron al gobierno, a la Regente y a las Cortes. De todos recibieron promesas, pero promesas no cumplidas. Viendo que nada conseguían, recurrieron a medidas un tanto violentas... que el gobierno dominó suspendiendo las garantías constitucionales. Perdió el país la esperanza de mejores días, y de aquí la anemia que en la política observamos» ${ }^{48}$.

47 "Despujols» en El Nuevo Régimen, 25 de noviembre de 1899.

${ }^{48} \mathrm{Ver}$ la nota 33 . Casi estas mismas palabras las pronunciaba de nuevo en el Congreso de los Diputados pocos dias después, el 12 de diciembre (ver la Nota 36). 


\section{AGOTAMIENTO DEL CREDITO Y DIFICULTADES DE TRANSPORTE}

(Dos problemas de las relaciones comerciales republicanas entre particulares durante la guerra civil española 1936-1939)*

JOSE MIGUEL SANTACREU SOLER

Universidad de Alicante.

La España republicana llegó a ser, durante la guerra civil, un país de importantes ensayos revolucionarios. Ensayos teorizados a nivel general por Pascual Carrión ${ }^{1}$, Sam Dolgoff ${ }^{2}$, Gastón Leval ${ }^{3}$, Edward E. Malefakis ${ }^{4}$, Frank Mints ${ }^{5}$, José Peirats ${ }^{6}$ e incluso Hugh Thomas ${ }^{7}$ entre muchos otros; y analizados a nivel local por Aurora Bosch ${ }^{8}$ para el País Valenciano, Emiliano Colas ${ }^{9}$ y José Luis Gutiérrez ${ }^{10}$ para Castilla, Luis Garrido " para Andalucía, Josep. M. Muria ${ }^{12}$ y Albert Pérez Paró ${ }^{13}$ para Cataluña o Julián Casanova ${ }^{14}$ para Aragón.

Estos procesos revolucionarios parecía que iban a dar solución a la cuestión económica de la guerra civil, al menos esto es lo que deambulaba por las mentes de los revolucionarios; sin embargo, tropezaron con importantes problemas políticos y sociales dados a conocer, entre otros, por Joaquín Maurín ${ }^{15} \mathrm{o}$ Andrés Nin ${ }^{16}$. Ahora bien, estos problemas, consecuen-

- En este artículo se adelantan algunos resultados de la tesis que sobre la economia en la provincia de Alicante durante la guerra civil, realiza el autor bajo la dirección de D. Salvador Forner Muñoz y mediante el disfrute de una beca de investigación del Ministerio de Educación y Ciencia.

${ }^{1}$ La Reforma Agraria de la Segunda República. Barcelona 1973. Y Los latifundios en España. Barcelona 1975.

${ }_{2}^{2}$ The anarchist collectives: workes self-management in the Spanish Revolution, 1936-1936. Nueva York 1974.

${ }^{3}$ Colectividades libertarias en España. Madrid 1977. 1976.

${ }^{4}$ Reforma agraria y revolución campesina en la España del siglo XX. Barcelona

${ }^{5}$ L'autogestion dans /'Espagne révolutionnaire. Paris 1970.

${ }^{6}$ La CNT en la revolución española. París 1971.

7 "Colectividades anarquistas en la guerra civil española». En Estudios sobre la /l República y la guerra civil. Barcelona 1974.

8 Ugetistas y Libertarios. Guerra civil y revolución en el País Valenciano, 1936-1939. Valencia 1983. y Colectivistas (1936-1939). Valencia 1980.

${ }^{9}$ Colectividades de Castilla. Madrid 1937.

${ }^{10}$ Colectividades libertarias en Castilla. Madrid 1977.

${ }^{11}$ Los colectivistas agrarios de Andalucía: Jaén 1931-1939. Madrid 1979.

${ }^{12}$ La revolución en el campo de Cataluña. París 1937.

${ }^{13}$ Trenta mesos de col. lectivisme a Catalunya. Barcelona 1970.

${ }^{14}$ Anarquismo y revolución en la sociedad rural aragonesa 1936-1938. Madrid 1985.

${ }^{15}$ Revolución y contrarrevolución en España. París 1966.

${ }^{16}$ Los problemas de la revolución española. París 1971. 
cia de los enfrentamientos político-sociales entre el PC y la CNT, entre los pequeños burgueses y los proletarios, entre los campesinos y los obreros agrícolas, no fueron los únicos que entorpecieron la marcha económica del país y también de la vía revolucionaria. Los hubo que llegaron como resultado de la interacción de los acontecimientos bélicos y las realidades económicas. Hablo en concreto de las dificultades para establecer una relación comercial viva entre particulares, cooperativas, colectividades o sociedades dentro de la España republicana a lo largo de la guerra civil.

El primer efecto de las hostilidades entre los sublevados y antifascistas fue la cesación de muchos pagos contraidos con anterioridad al 20 de Julio de 1936 e incluso después. Gran parte de las industrias de la España republicana tenían importantes clientes en territorios ocupados por los rebeldes desde los primeros momentos; como el procedimiento de venta era, por lo general, el de letras a noventa días se encontraron con una masa de créditos incobrables ${ }^{17}$. Ello nos lleva al problema de los «impagados» y las "moratorias», asunto árduo y crucial en los primeros meses de guerra, como ha demostrado Josep María Bricall ${ }^{18}$.

En consecuencia y a causa de estos hechos «el agotamiento del crédito caracterizó al sector privado controlado por los obreros. Todos los tratos entre empresas se vieron reducidos a transaciones en metálicol) ${ }^{19}$.

Paralelo al agotamiento del crédito estuvo el problema de los transportes. Jackson ${ }^{20}$ hace un balance de las pérdidas de guerra en el sistema de transportes, prestando especial atención a los ferrocarriles. Nos dice que se destruyeron 1.309 locomotoras (el $41,6 \%$ del parque de julio de 1936), 30.000 vagones (el $40,3 \%$ del parque) y 3.700 coches de pasajeros (el $71,2 \%$ del parque). De otro lado, también realiza algunas apreciaciones sobre los daños en carreteras y puentes. Sin embargo, el problema no hay que centrarlo en las acciones bélicas que condujeron al deterioro de las vías de comunicación o de los medios de transporte, el control y la distribución de servicios también tuvo un importante papel en este cometido. Estos fueron los que determinaron a la postre si se concedía material para el transporte o no a un particular no vinculado con las industrias de guerra.

${ }^{17}$ TUÑON de LARA, M. La España del siglo XX, t. 3: La Guerra Civil (1936-1939). Barcelona 1981, 5. ed. p. 626.

${ }^{18}$ Política económica de la Generalitat (1936-1939), t. II: El sistema financer. Barcelona 1979. pp. 257-262.

${ }^{19} \mathrm{Cfa}$. de FRASER, R.: Recuérdalo tú y recuérdalo a otros. Historia oral de la guerra civil española, t. I. Barcelona 1979. p. 321.

${ }^{20}$ Entre la Reforma y la Revolución de 1931-1939. Barcelona 1980. p. 389. 
Según Tuñón de Lara y Ma Carmen García Nieto ${ }^{21}$ el control de los transportes por parte del gobierno se produjo, mediante el apoyo de las sindicales, nada más iniciarse la guerra. Lo cual nos lleva a suponer que sólamente tomando en consideración todos estos factores es posible explicar los problemas de las relaciones comerciales entre particulares durante la guerra civil española provocados por el transporte.

El agotamiento del crédito y las dificultades del transporte tienen una teorización como problema de las relaciones comerciales entre particulares, formulada gracias a los trabajos generales de Fraser, García Nieto, Jackson o Tuñón y al estudio económico de Cataluña de Bricall. Lo que ahora se impone es localizar un ejemplo completo y documentado que nos permita ilustrar las teorizaciones e introducir matices clarificadores al igual que hacen los estudios a nivel local del proceso revolucionario. Esta labor es la que abordamos a continuación.

\section{LA RELACION COMERCIAL DE 1938 ENTRE LA FEDERACION PROVINCIAL CAMPESINA* DE ALICANTE Y EL «FRENTE OBRERO DEL COTO MINERO॥ DE MINAS (ALBACETE)}

La FPC de Alicante, defensora del pequeño propietario frente a la Federación Regional Campesina de la CNT y afecta al Partido Comunista ${ }^{22}$, dentro de su política agraria, capítulo destinado a suministrar los abonos y semillas necesarios para la agricultura de sus afiliados en la provincia de Alicante, mantuvo contactos con diferentes productores de abonos, entre los que cabe citar a «Explotaciones Potásicas Colectivizadas» de Barcelona para obtener cloruro potásico de las minas de Cardona, Suria o Sallent, con la "Colectividad Cros S.A.» de Albacete para el sulfato de cal, con el frente Obrero del Coto Minero de Minas (Albacete) para el azufre, etc... todo ello a lo largo de 1937 y 1938.

De entre estas relaciones, atendiendo al volumen de documentación conservada, estudiaremos a continuación las que mantuvo la FPC de Alicante con el Frente Obrero del Coto Minero de Minas (Albacete) ya que su análisis nos permitirá indagar las bases mecánicas y financieras del intercambio.

En enero de 1938 el "Consejo de Empresa del Coto Minero» aceptó el pedido de 150 toneladas de azufre sublimado flor al precio de 1.400 $\mathrm{ptas} / \mathrm{tn}$. y 50 toneladas de azufre molido al precio de $1.250 \mathrm{ptas} / \mathrm{tn}$. formulado por la FPC de Alicante. El Consejo de Empresa no se compro-

${ }^{21}$ "La Guerra Civil». En Historia de España t. IX, Labor 2a reimp. 1983. p. 277. - La abreviatura para designar la Federación Provincial Campesina será: FPC.

${ }^{22}$ Vide. BOSCH, A. o.c.p. 117. (Ugetistas y Libertarios...) 
metió a determinados plazos de entrega pero sí que exigió que el pago se efectuase por delante de los envíos, mediante ingresos bancarios.

Debido a que la FPC no realizó los pagos adelantados que se le solicitaban, y tras varias advertencias, en febrero de 1938 el Consejo de Empresa del Coto Minero rompió el compromiso adquirido con la organización agrícola alicantina sin que aún se hubiese llevado a cabo ningún envío.

Esta ruptura obligó al secretario general de la FPC, Antonio Guardiola, a desplazarse a Minas personalmente para tratar de solucionar el problemas suscitado por el incumplimiento de la forma de pago. Guardiola logró que el pedido fuese otra vez aceptado; pero para ello tuvo que transigir en muchos aspectos - aceptó la forma de pago, se comprometió a proporcionar el saquerío, perdió la prioridad de turno que les concedía el anterior compromiso, etc. - y ofrecer algunos productos en contrapartida tales como géneros de papel o carbón.

En marzo de 1938 empezaron los envios de azufre hacia Alicante, envíos que, de forma discontínua y problemática, duraron hasta julio del mismo año. Concretamente, el 14 de julio de 1938 la FPC anuló el resto del pedido de azufre que tenía contratado y aún no se había servido, tal vez porque la temporada de su utilización agrícola ya expiraba y porque sólo quedaba por remitir el azufre molido, de menor interés, mientras que las $150 \mathrm{tn}$. de azufre sublimado flor ya se había recibido en Alicante, y con exceso ${ }^{23}$.

Más interesante que la exposición cronológica de las relaciones comerciales es, de cara a nuestros objetivos de estudio económico, el análisis detallado del sistema de intercambios: los pagos, los pedidos y el transporte. Todo esto nos servirá para ilustrar los dos problemas que nos interesa destacar de las relaciones comerciales republicanas entre particulares durante la guerra civil española, en concreto para la primera mitad de 1938, período al que afecta nuestra documentación.

\section{PAGOS.}

Sin lugar a dudas, la cuestión de los pagos es la más conflictiva y sistemática de las relaciones comerciales mantenidas entre las entidades que estudiamos. Como hemos visto ello fue la causa de que se rompieran momentáneamente las relaciones comerciales entre ambas, ya que la FPC no se ajustó a las exigencias del Consejo de Empresa

${ }^{23}$ AHN-Guerra Civil (Salamanca) Alicante PS leg. 15 carp. 6. Correspondencia del "Frente Obrero del Coto Minero» de Minas (Albacete), de «Eplotaciones Potásicas Colectivizadas» de Barcelona y de la "Colectividad Cros S.A.» de Albacete con la FPC de Alicante. 
del Coto Minero.

"Con referencia al pago, es nuestra norma se haga por mediación del Banco Español de Crédito de Hellín, en el que pueden abrir un crédito a favor de D. Bartolomé García por cantidades periódicas de 70.000 ptas. para ir cobrando del Banco las cantidades parciales, importe de las remesas, que se os bayan (sic) efectuando, pues de lo contrario no se os podrían hacer dichas remesas, dado el caso de que la forma propuesta por vosotros nos ocasionaría grandes gastos y pérdida de tiempo a la vez de entorpecernos la marcha que de cobros y facturaciones mucho nos retrasaría con perjuicio de todos» ${ }^{24}$.

Sólo cuando la FPC transigió ante el sistema de pagos propuestos por el citado Consejo de Empresa se materializaron los intercambios. Pero que la FPC transigiera no quiere decir que la fórmula propuesta por el Coto Minero de Minas se cumpliese a rajatabla.

"Con el fin de poder evitar contratiempos al presentarse con camiones a estas operaciones de carga de Azufre, os agradecemos que antes que nada tengais los ingresos correspondientes. ${ }^{25}$.

«En cuanto a vuestros ingresos, efectivamente aunque con algún retraso, hemos recibido el aviso del Banco Español de Crédito de Hellín de la transferencia que teneis hecha en la c/c. de Bartolomé García de ptas. $30.800,00$ las que os abonamos en cuenta» ${ }^{26}$.

Gracias a estos textos podemos observar que las cantidades periódicas ingresadas en el Banco Español de Crédito de Hellín por la FPC no fueron siempre de 70.000 ptas., como exigía el Comité de Empresa; aunque si bien las cantidades ingresadas no se ajustaron a lo convenido, la FPC tuvo que cumplir la norma de pago previo a los envíos ya que sin este requisito no salía de Minas ni un sólo cargamento de azufre.

Al igual que el Coto Minero de Minas tenía su c/c. en el Banco Español de Crédito de Hellín, la FPC de Alicante disponía de una cuenta corriente en el Banco Internacional de Industria y Comercio de Alicante. A través de la sucursal de Hellín de este Banco el Consejo de Empresa del Coto Minero cursaba la documentación relacionada con las remesas de azufre enviadas a Alicante;

....el Sabado pasado se os remesó un vagón de azufre Molido, cuya documentación se cursó al Banco Internacional de Industria

${ }^{24}$ Ibidem. Carta del "Consejo de Empresa del Coto Minero» a la FPC de Alicante, 17-01-1938.

${ }^{25}$ Ibídem. Carta idem. 25-06-1938.

${ }^{26}$ Ibídem. Carta idem. 30-06-1938. 
y Comercio de Hellín como de costumbre para que la haga seguir a vosotros ${ }^{27}$.

y cuando las operaciones comerciales entre ambas entidades concluyeron el citado Consejo de Empresa utilizó dicho Banco para ingresar la cantidad de dinero que el saldo bancario de la c/c. de Bartolomé García del Banco Español de Crédito de Hellín arrojaba en favor de la FPC.

$« .$. hoy procedemos a transferiros las 10.000 ptas, que resultan a vuestro favor para el ingreso en la $\mathrm{c} / \mathrm{c}$. que teneis en el Banco Internacional de Industria y Comercio de esa plaza» ${ }^{28}$.

Queda por analizar una cuestión. Saberios cómo se efectuó el pago del azufre, pero ¿qué sucedió con los géneros que envió la FPC a Minas?. Ya quedó dicho que estos géneros se ofrecieron como contrapartida, en aras de llegar a un acuerdo. Ello supuso que estas mercancías que envió la FPC al Coto Minero no se abonasen por anticipado sino que se recibiesen como pago previo del azufre, lo cual suponía que el precio de los mismos ingresaba como activo a favor de la FPC en la cuenta corriente del Banco Español de Crédito de Hellín que pertenecía al Consejo de Empresa del Coto Minero. Téngase presente que se trataba de una compensación, no de una relación comercial libre, lo cual explica las especiales condiciones de pago que tuvo que aceptar la FPC ya que lo que a ésta le interesaba era poder conseguir el azufre que necesitaban sus afiliados.

Frente a lo dicho, hay que matizar que también se efectuaron pagos de azufre al contado ${ }^{29}$; aunque fueron los menos y la vía normal de relaciones monetarias y documentales se desarrolló a través de los bancos ya citados. Ahora bien, fuese de una forma o de otra, el pago siempre se efectuaba antes de cargar el azufre en los medios de transporte.

«...en cuanto al camión que anuncias, desde luego puede venir para el transporte de azufre de 4 ó 5 toneladas que decíis, pero a base de traer el chaufer su importe según la cantidad y clase que cargue, pues ya conoceis su precio de 1.400 ptas. la tonelada de Flor, y 1.250 ptas. la tonelada de Molido, mediante factura que se entregará, a cuyo efecto puesto deceis (sic) traerá el camión algunos géneros, también vosotros entregareis la correspondiente factura para a la vez liquidar ésta con la del azufre» ${ }^{30}$.

El agotamiento del crédito en el sector privado controlado por los

${ }^{27}$ Ibídem. Carta idem. 18-07-1938.

${ }^{28}$ Ibídem. Carta idem. 7-09-1938. ptas.).

${ }^{29}$ Ibídem. Factura 16-04-1938 (pago en efectivo 8.400 ptas. y en géneros 894,35

30 Ibidem. Carta idem nota 24. 1-04-1938. 
obreros, como dice Ronald Fraser, está suficientemente ilustrado en este ejemplo de relaciones comerciales de la primera mitad de 1938. No hay duda de que si tuviésemos que destacar una característica del intercambio mantenido entre la FPC y el Coto Minero ésta sería la de las transaciones en metálico como garantía exlcusiva de unas buenas y sanas relaciones.

\section{PEDIDOS.}

Los pedidos, como quedó dicho, se centraron en el azufre: 150 tn. de azufre sublimado flor al precio de 1.400 pts./tn. y $50 \mathrm{tn}$. de azufre molido a $1.250 \mathrm{ptas} . / \mathrm{tn}$.

La FPC no tenía excesivo interés en el envío del azufre molido y las 50 tn. no llegaron a servirse nunca completas, el compromiso se anuló el 14 de julio, antes de que éstas fueran remesadas por el Coto Minero. A la contra, el azufre sublimado flor sí que era objeto de interés por parte de la FPC de Alicante. Así lo demuestran las constantes peticiones para que la dotación asignada de $150 \mathrm{tn}$. fuese ampliada. La respuesta del Coto Minero, en un principio, fue negativa:

«Ampliación: A esta por hoy no nos podemos comprometer como ya dijimos al compañero Guardiola en su visita, dada la circunstancia de tener vendidas todas las existencias y gran parte de lo que estamos fabricando, pues una vez cumplidos todos los compromisos adquirirdos, en su día se os facilitarán precios a como resulten, así como demás condiciones para poderlo adquirir» ${ }^{31}$.

Respuesta que pese a ser negativa, no cerró la posibilidad de tal ampliación; aunque sí que se reservó el derecho de aumentar el precio para un nuevo compromiso. Lo cierto es que ya a finales de abril de 1938, sólo un mes después de ser enviada la carta reproducida en el texto, el Consejo de Empresa del Coto Minero daba esperanzas a la FPC de que su demanda fuese aceptada en breve, cuando se hubiesen remesado las $150 \mathrm{tn}$. convenidas ${ }^{32}$, hecho que se produjo a finales de junio de 1938. En esta fecha ya se habían enviado a Alicante las $150 \mathrm{tn}$. contratadas de azufre sublimado flor, no obstante el Coto Minero siguió sirviendo los pedidos de azufre sublimado flor de la FPC; pero eso sí, a un nuevo precio: 1.800 ptas/tn. ${ }^{32}$. En tan sólo cuatro meses los precios habían subido en un $30 \%$.

Pese a seguir sirviendo las demandas de la FPC, el Consejo de Empresa del Coto no aceptó firmar ningún compromiso de cantidades a

31 Ibídem. Carta idem. 13-03-1938.

32 Ibídem. Carta idem. 30-06-1938. 
enviar, tal vez pensando en los posibles aumentos de precios o porque sus existencias eran, verdaderamente, precarias y porque tenian la intención de venderles el azufre molido.

«...hemos de significaros como las existencias de flor las tenemos agotadas, y como quiera que ahora sólo se dispone de la que se está fabricando (con la cual tenemos que atender a todos) por esta razón no podemos comprometernos a cantidad ni a plazo de entrega, pero no obstante haremos cuanto esté de nuestra parte para serviros lo que buenamente podamos, permitiéndonos haceros observar a la vez como el precio que ahora rige es el de 1.800 ptas. la tonelada sin saquerío" ${ }^{33}$.

La respuesta inmediata de la FPC fue que, a los pocos dias - el 14 de julio - , anuló el resto del pedido de azufre contratado que tenían desde marzo de 1938; aunque no pudieron evitar que el 16 de julio el Coto Minero les remitiese un vagón de azufre molido por el que la FPC mostraba tan poco interés y que daba la impresión de ser, más que una demanda en firme, un cebo compensatorio del azufre flor, al igual que las mercancías que la FPC envió al Coto Minero como contrapartida del azufre.

Las mercancías que la FPC utilizó para contentar al Consejo de Empresa del Coto Minero se centraron en unas pocas materias, muy preciadas en aquellas circunstancias. De un lado el "carbón" ${ }^{34}$, que por su volumen no fue servido a causa de las dificultades de transporte. De otro el «papel», que por su menor tamaño y necesidades de transporte sí que se envió; aunque no por completo. No hubo dificultades en cuanto a las remesas de papel de barba, cuartillas, sobres y papel estampillado, sí que las hubo con respecto a las libretas ya que de éstas la FPC no pudo encontrar existencias ${ }^{35}$. No olvidemos que los problemas para encontrar papel, ya en 1938, eran graves ${ }^{36}$. Tal vez por ello, pese a que la FPC no cumplió por completo las contraprestaciones, el Consejo de Empresa del Coto Minero se dió por satisfecho con lo obtenido.

Una cuestión que a primera vista parece no tener importancia y que, sin embargo, la tiene es la de los envases: el saquerío para remesar el azufre hacia Alicante.

A finales de 1937 la FPC ya había tenido una experiencia concreta y tajante con «Explotaciones Potásicas Colectivizadas» de Barcelona a

${ }^{33}$ Ibídem. Carta idem. 4-07-1938.

${ }^{34}$ Ibidem. Carta idem. 13-03-1938.

${ }^{35}$ Ibídem. Carta de la FPC de Alicante al Coto Minero. 30-05-1938.

${ }^{36}$ Nuestra Bandera (Organo del PC) Alicante «El problema del papel y los periódicos». 8-01-1938, p. 1. 
este respecto. El ingeniero jefe de la Sección I del Comité Permanente de Industria del Departamento de Economía de la Generalitat, servicio de potasas, especificó a la FPC que si ellos tenían que envasar el cloruro potásico sin que la FPC les hubiese remitido sacos el precio del cloruro aumentaría cuatro pesetas por saco ${ }^{37}$.

Algo similar sucedió con las relaciones entre el Coto Minero de Minas (Albacete) y la FPC de Alicante. En un primer momento, el Consejo de Empresa del Coto Minero aceptó la propuesta de la FPC en el sentido de que el saquerío estuviese incluido en el precio para los envíos de azufre sublimado flor - recordemos que este tipo de azufre es el que interesaba realmente a la FPC - mientras que se excluía para el azufre molido ${ }^{38}$. Sin embargo, al romperse el contrato por incumpliemiento de la forma de pago por parte de la FPC, hecho ya reiterado en este trabajo, las condiciones cambiaron y todo el saquerío tuvo que correr por cuenta de la FPC sin que los precios del azufre sufriesen alteración alguna ${ }^{39}$. Así, en abril de 1938 la FPC envió al Coto Minero 2.436 sa$\cos (1.951$ con capacidad para $100 \mathrm{~kg}$. y 485 más pequeños) mediante dos camiones para que fuese siendo envasado el azufre ${ }^{40}$.

Al finalizar las relaciones comerciales la FPC tuvo la pretensión de que se le abonase el saquerío de las remesas de azufre, a lo que se nego el Consejo de Empresa del Coto Minero diciendo:

"Muy de veras sentimos no poderos complacer en vuestras indicaciones respecto al abono del saquerío en las remesas que de Azufre se os han efectuado, por cuanto, debido a orden enconómico, dado el retraso en que obrasteis en hacer el ingreso correspondiente en el Banco para que quedara en firme nuestro contrato, tubimos (sic) que recurrir a otras operaciones para atender las imperiosas necesidades de ésta Industria, habiendo dejado sin efecto aquel, como ya se os decía en la nuestra del 25 de Febrero ppdo.; pero como quiera que después a unos días de haber surgido esto, se presentara en ésta el compañero Guardiola en ruego de que no se le dejara sin azufre, para la gran necesidad que le obligaba a adquirirlo, en consideración a la buena armonía que del año anterior nos unía, haciendo un gran esfuerzo y buscando convinaciones ( $\mathrm{sic}$ ) con la producción y compromisos adquiridos, accedimos a sus deseos sirviendo cuanto pudiéramos, sosteniendo el precio anteriormente convenido a condición de que ya con éste no entraba el saquerio, por lo que se le indicó tendrian que enviar los

${ }^{37}$ AHN-Guerra Civil (Salamanca) Alicante PS leg. 15 carp. 6. Carta de la Sección de Economía de la Generalitat a la FPC de Alicante. 13-11-1937.

${ }^{38}$ Ibídem. Carta del Consejo de Empresa del Coto Minero a la FPC. 17-01-1938.

39 Ibídem. Carta idem. 13-03-1938.

${ }^{40}$ Ibidem. Carta idem. 25-04-1938. 
envases para poder remesar en la forma que nos lo permitieran las circunstancias... Mañana se procederá al envío de todo el saquerío sobrante que tenemos de vuestra propiedad.... $\rangle^{42}$.

\section{TRANSPORTE.}

El tansporte del azufre se realizó de forma discontínua y problemática. El Consejo de Empresa del Coto Minero de Minas no se comprometió a ningún plazo de entrega debido a las dificultades que podían presentarse con el ferrocarril. Maticemos que algo similar sucedió a fines de 1937 con las condiciones de envío de coloruro potásico por parte de «Explotaciones Potásicas Colectivizadas» de Barcelona ${ }^{42}$.

No hay que olvidar que el gobierno, mediante decreto de 3 de agosto de 1936 del Ministerio de Comunicaciones y Transportes convalidado como ley el 19 de diciembre y el 26 del mismo mes de 1936, obtuvo la explotación provisional de los ferrocarriles; y que, mediante decreto del 21 de octubre de 1937 del refundido Ministerio de Transportes, Comunicaciones y Obras Públicas, creó la Red Nacional de Ferrocarriles a cargo del "Consejo Nacional de Ferrocarriles»" ${ }^{43}$.

Así, el Consejo de Empresa del Coto Minero manifestaba que el ferrocarril, con algunas excepciones, se centraba esencialmente en el transporte destinado a asuntos de guerra, descuidando los intereses particulares.

«Aunque está cerrada la facturación, dentro de la restricción desde hace unos cuatro días nos permiten al azufre hacer algunas facturaciones y para ello la estación nos facilita el material de que de antemano a ésta solicitamos dando el destino correspondiente según nuestro orden riguroso de los pedidos en turno; ahora bien se están dando casos de que estando por completo cerrada la facturación se han hecho facturaciones por Transportes Militares, pero esto ha sido a fábricas de pólvoras, oficinas del aceite, Sanidad y Farmacias militares en resumen por tratarse de Guerra que ya a particulares se hace imposible» ${ }^{44}$.

Esta circunstancia hizo que el primer envío de azufre tuviera que realizarse mediante dos camiones que la FPC mandó a Minas y que las remesas por ferrocarril sólo fuesen factibles cuando lograban encon-

${ }^{41}$ Ibídem. Carta idem. 7-09-1938.

42 Ibídem. Alicante PS leg. 15 carp. 2.

${ }^{43}$ Nuestra Bandera, op. c. "La explotación de los ferrocarriles por el estado». 28-10-1937 p. 2.

${ }^{44}$ AHN-Guerra CIVIL (Salamanca) Alicante PS leg. 15 carp. 6. Carta idem. nota 38. 13-03-1938. 
trar algún vagón disponible ${ }^{45}$.

Diversas gestiones y premuras con el ferrocarril por parte de los compradores de azufre y del Coto Minero lograron que a finales de abril el Control Nacional de Ferrocarriles comunicase al Consejo de Empresa del Coto Minero que, con arreglo a las disponibilidades de material ferroviario, se irían consignando vagones para el transporte del azufre particular, sin perjuicio de los asuntos de guerra ${ }^{46}$. A principios de mayo ya se materializó en vagones la promesa del Control Nacional, aunque con menores efectos de los deseados.

«...hemos de notificaros con respecto a material, como de 4 vagones que nos ha facilitado el f.c., dos han sido remesados a vosotros y los otros dos se han servido a otros dos compradores que igualmente que vosotros han hecho las mismas gestiones cerca del f.c., y también son los primeros en turno de sus pedidos en firme, ahora bien si tubierais (sic) facilidad para venir con camiones éste sería el mejor medio para abreviar en vuestras remesas, pues al paso que lleva el ferrocarril en servirnos el material esto observamos durará una eternidad, al no ser que después varie de modo de entendernos ${ }^{47}$.

A partir de esta fecha se sucedieron algunos envíos por ferrocarril; pero los largos intervalos entre envío y envío obligaron a que los propios interesados por el azufre, pertenecientes a diversas cooperativas afectas a la FPC de Alicante, se desplazasen con camiones propios a Minas en busca del azufre. Esto sucedía a finales de mayo y principios de junio de 1938, tal vez haciendo caso a la carta del Consejo de Empresa del Coto Minero.

«En cuanto al retraso de facturaciones tenemos que observaros como éste es debido a la falta de material que no se nos facilita como periódicamente se solicita, pues de disponer de caminones sería el mejor medio para hacerlo más rápido y oportuno evitando con esto tenernos que quedar con existencias estancadas» ${ }^{48}$.

En los CUADROS 1 y 2 puede observarse una muestra de la evolución de los envíos y su transporte. En ellos se ve cómo en un principio predominan las facturaciones hacia Alicante capital mediante el ferrocarril, hasta que a finales de mayo y, sobre todo, durante junio hay una eclosión de pequeños transportistas del norte de la provincia de Alicante que acuden a Minas en busca del azufre indispensable para sus viñedos esencialmente.

\footnotetext{
45 Ibídem. Carta idem. 25-04-1938.

${ }^{46}$ Ibídem. Carta idem. 29-04-1938.

47 Ibídem. Carta idem. 7-05-1938.

${ }^{48}$ Ibídem. Carta idem. 7-06-1938.
} 


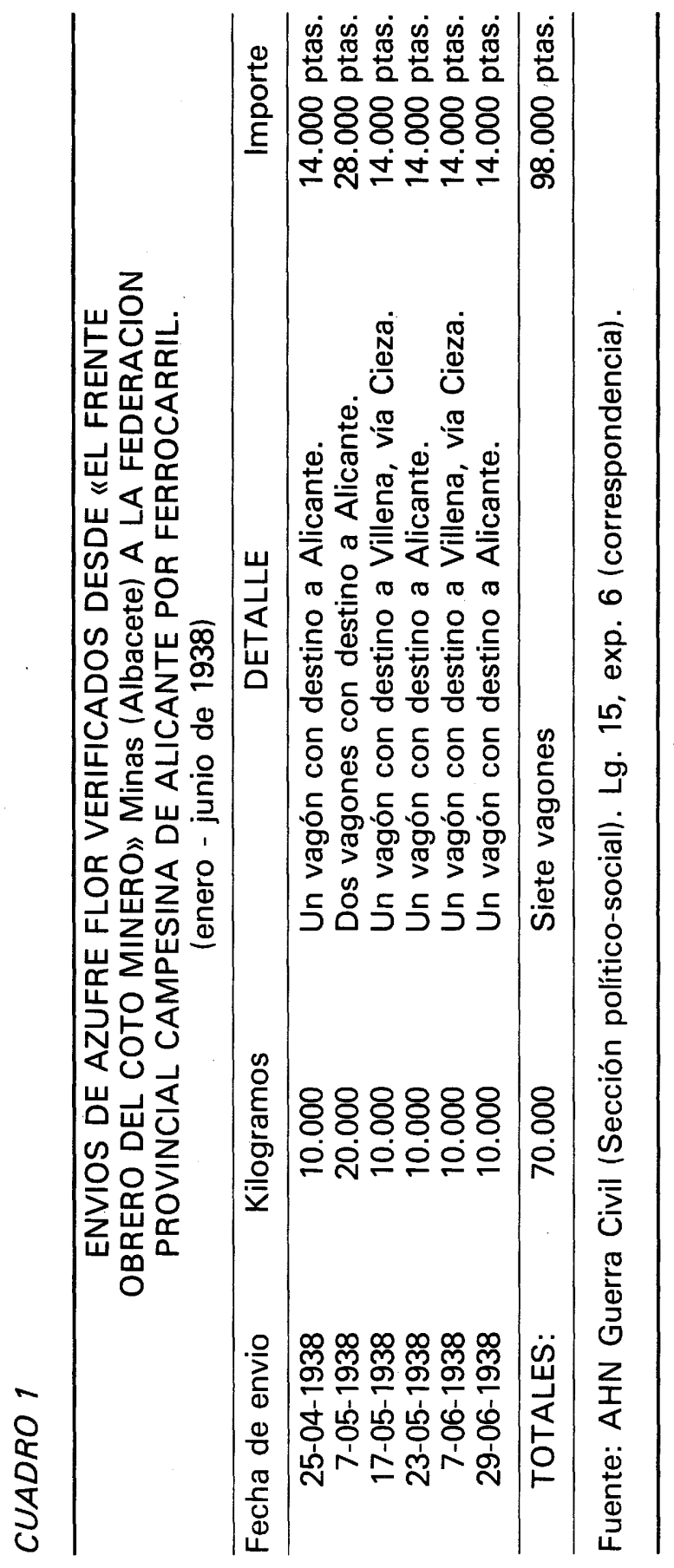




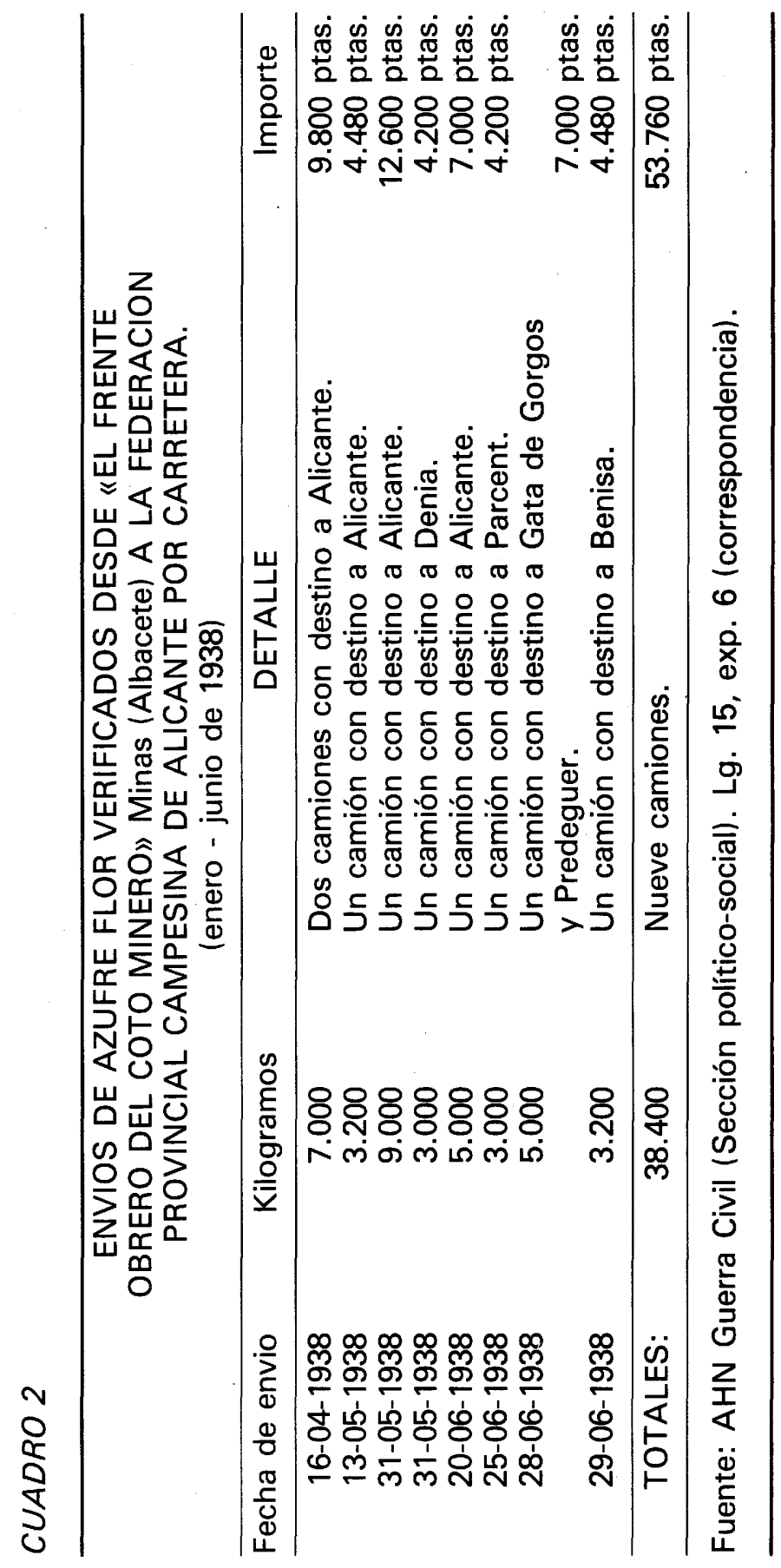


Lo más destacable del reparto del transporte es que si bien predomina el volumen de azufre enviado por ferrocarril con un $64,6 \%$ frente al $35,4 \%$ de azufre remesado por carretera, sin embargo, observando el número de camiones y el de vagones que efectuaron el transporte, el porcentaje se decanta a favor de los primeros con un $56,3 \%$ frente al $43,7 \%$ que representan los vagones. Ello es netamente indicativo de que el ferrocarril ofrecía mayores posibilidades de desplazar grandes cantidades de azufre; sin embargo, con el tiempo, tuvo que imponerse la utilización de los camiones por necesidad, pese a transportar menor volumen de azufre, ya que no siempre había material ferroviario disponible para los envíos.

Ahora bien, tengamos presente que el uso de los camiones tampoco estaba libre de trabas, el racionamiento y el aumento del precio de la gasolina junto a la escasez de camiones de particulares, que por lo demás precisaban de permisos para poder circular y salir de la provincia de Alicante ${ }^{49}$, matizaban la relativa viabilidad del transporte por carretera.

En conclusión, las relaciones comerciales entre particulares de la zona republicana durante la guerra civil española, y en concreto entre la FPC de Alicante y el "Frente Obrero del Coto Minero» de Minas (Albacete) durante la primera mitad de 1938, estuvieron condicionadas no sólo por el agotamiento del crédito, que hizo que todas las transacciones se efectuasen en metálico, ni por las dificultades de transporte, que motivaron retrasos e imposibilitaron el intercambio de ciertas mercancías, sino que también jugaron un papel importante la constante perspectiva de aumento de precios, que hacía inviable compromisos en firme; la necesidad de envases, que encarecía los productos; y la cuestión de las compensaciones para facilitar la consecución de contratos, que aún complicaba más el mundo del comercio. Si durante épocas de paz la venta y compra de productos es problemática, a lo largo de la guerra civil española entraron en juego una serie de circunstancias que aún dificultaron más estas operaciones.

${ }^{49}$ Bandera Roja, órgano de la UGT, Alicante 8-09-1937. (Sobre permisos de circulación de camiones a conceder por el Consejo Provincial). 


\title{
LA CONSTRUCCION POLITICA DE LOS NUEVOS ESTADOS MAGREBIES*
}

\author{
BERNABE LOPEZ GARCIA \\ Profesor Titular de Historia Contemporánea del Islam. \\ Universidad Autónoma de Madrid.
}

El primer problema que debe abordarse al analizar la historia de los estados independientes magrebíes es el de la fuente del poder, el origen de la autoridad, el sujeto de la soberanía, la cuestión, en suma, de la legitimidad. Lo que nos lleva a identificar y decribir las instituciones en las que se plasma la autoridad. Las constituciones definen las instituciones y delimitan, al menos en teoría, el ejercicio de los poderes ejecutivo y legislativo. Los textos constitucionales proclaman la soberanía popular que se ejerce por medio de instrumentos de representación política, los partidos, que se funden en algunos casos con la armadura estatal.

Existen sin embargo otras fuentes de poder, otros grupos de presión, otros organismos que interpretan la legitimidad, la asumen o la suplantan. El más importante de ellos es el Ejército, si bien su papel es diverso en unas y otras sociedades magrebíes.

La concatenación que existe entre estos cinco puntos - legitimidad, instituciones, constitucionalismo, partidos y Ejército - es la que me lleva a tratar de definir a través de ellos la formación política de los nuevos estados árabes norteafricanos.

\section{LEGITIMIDAD Y SOBERANIA.}

En los procesos de transferencia de poderes por parte de la antigua potencia colonial (Francia para Túnez, Marruecos, Argelia y Mauritania; Gran Bretaña y Francia en sustitución de Italia en Libia), está la clave del problema de la legitimidad. Los negociadores magrebies van a ser los futuros detentadores del poder y convinene analizar en qué medida la legitimidad que reconoce la potencia colonial se identifica con la que acepta como autoridad legítima la población. En los casos tunecino, marroquí y argelino, es el Movimiento Nacional el que a través de su resistencia se convierte en fuente de poder. Encarnado en un par-

- El tema de este artículo fue originalmente desarrollado como lección dentro de un curso sobre Historia Contemporanea Arabe impartido colectivamente en la Asociación de Amistad Hispano-Arabe de Madrid en 1983-1984. 
tido (el Neo-Destur tunecino), un Frente (EI F.L.N. argelino) o una institución (el Trono marroquí como emanación de su tradición). Estas tres entidades asumen la representación de la unidad política, del pueblonación. Pero mientras que los partidos pasarán de ser símbolo nacional a convertirse en estructura de encuadramiento y de consulta, el Trono marroquí desempeñará el papel de árbrito entre los distintos grupos surgidos de la lucha nacional sin perder su carácter de símbolo.

En Túnez, las negociaciones para la independencia fueron llevadas a cabo directamente por el representante del Bey Lamin Pacha, su jefe de gobierno, Tahar Ben Amar, en junio de 1955. El Bey es la autoridad legitimada por la tradición, la Historia, ya que la dinastía huseiní data de 1705. Pero junto a él, Francia va a reconocer con idéntica capacidad de negociar al representante del partido Neo-Destur, partido que durante décadas había tomado la dirección del movimiento nacional tunecino. Monŷi Slim, en nombre del Neo-Destur, firmará también el convenio con Francia de junio de 1955. Junto a la legitimidad histórica se encuentra, compitiendo con ella, la legitimidad aportada por una lucha nacionalista, por una resistencia política. Sin embargo, desde una perspectiva tunecina, el reconocimiento popular se va a inclinar más hacia la segunda legitimidad que a la aportada por la tradición '.

La actitud del Bey en los últimos años del colonialismo no puede calificarse de contraria a las reivindicaciones del movimiento nacional. Ya en 1951 había defendido la necesidad de una «soberanía nacional integral» y en 1952 había creado un consejo consultivo con representantes de las opciones políticas del pais, excluidos los comunistas. $\mathrm{Pe}$ ro su timidez no le procuró en ningún momento - al contrario que en el caso marroquí - la identificación con el pueblo. El movimiento nacionalista y su rama sindical la UGTT encabezan las luchas y consiguen el apoyo popular.

Las elecciones por sufragio universal masculino a la Asamblea Constituyente que tienen lugar el 25 de marzo de $1956^{2}$, dan un respaldo masivo a los candidatos del Frente Nacional, integrado por el Neo-Destur. Aunque casi no había opositores (la presencia de algunos comunistas o independientes en alguna circunscripción es casi anecdótica) la victoria del Partido es una confirmación por vía de las urnas del reconocimiento popular de su «legitimidad». El Bey se va a ver obligado a desig-

Sobre el origen de la legitimidad del poder en Túnez véase Roger LE TOURNEAU, Evolution politique de l'Afrique du Nord Musulmane. 1920-1961, Paris 1962. pp. 133-136; y Michel CAMAU, "Les institutions politiques des Etats Maghrébins postcoloniaux», en Introduction à l'Afrique du Nord Contemporaine, C.N.R.S. - C.R.E.S.M., Paris 1975, pp. 255-282.

${ }^{2}$ Sobre estas elecciones véase Charles DEBBASCH, La République Tunisienne, Paris 1962, pp. 42-44. 
nar a Habib Burguiba como jefe del Gobierno.

En la campaña electoral, el Frente Nacional había defendido un régimen de monarquía constitucional y democrática. Sin embargo, poco más de un año después, el 25 de julio de 1957, la Asamblea Nacional Constituyente, haciendo uso de los plenos poderes conferidos por el pueblo, declaró abolida la Monarquía y proclamada la República. La razón aducida va a ser la colaboración del Bey con el sistema colonial. La causa verdadera estriba sin embargo en la contradicción entre ambas legitimidades, entre ambas soberanías, la del partido y la beylical.

La Asamblea Nacional, emanación del Neo-Destur, había ido asumiendo algunas de las prerrogativas del soberano (elección del jefe del gabinete, definición de la política del Estado...) hasta decidir la supresión de la institución monárquica que no controlaba los resortes del poder, reducida durante la época colonial a una figura de ficción, meramente decorativa.

En el caso marroquí, la negociación para la independencia la va a llevar a cabo directamente el monarca con el presidente del Consejo francés, Antoine Pinay, el 6 de noviembre de 1955. Meses antes, las diferentes corrientes del movimiento nacionalista (Partido del Istiqlal y Partido Democrático de la Independencia; por supuesto los comunistas quedaban fuera) habían sostenido conversaciones de cara a la independencia con el gobierno francés, en Aix-les-Bains ${ }^{3}$.

El problema de la legitimidad presenta como en Túnez dos fuentes de poder: el Sultán, convertido ahora en Monarca, Mohamed V, y el movimiento nacionalista que encabezó la lucha por la independencia desde los tiempos del dahir beréber y del Manifiesto del Istiqlal. Pero hay, a diferencia del caso tunecino, algún elemento nuevo que desequilibra la balanza de poderes en beneficio del Sultán: el fundamento religioso de la institución del Trono lorigen cherifiano de la dinastía alauí, consideración del monarca como príncipe de los creyentes, máxima autoridad religiosa en nombre de la que se hace la plegaria del viernes) y el papel histórico desempeñado por Mohamed $V$ a través de su apoyo abierto al movimiento nacionalista y a quien el exilio. había transformado en figura carismática. Precisamente este exilio va a arrebatar a los partidos nacionales parte de su protagonismo al convertir al monarca

3 Para el proceso de independencia marroquí y la rivalidad en el ejercicio de la soberanía véase la obra de Charles-André JULIEN, Le Maroc face aux imperialismes, Paris 1978, así como la citada de R. LE TOURNEAU, pp. 245-251; ver también Abderrahim OUARDIGHI, La grande crise franco-marocaine, 1952-1956, Rabat 1976, segunda edición; Felix NATAF, L'independence du Maroc. Temoinage d'action 1950-1956, Paris 1975; así como el libro recopilativo de textos y documentos del P.C.M. de 1945 a 1958, Le Parti Communiste Marocain dans la lutte pour l'indépendence nationale, Paris s.d., especialmente las páginas 195-214. 
en símbolo nacional por el que se realizan las movilizaciones de masas, llegándose a identificar independencia y trono. Es aquí donde nace la subordinación de los partidos al Soberano y de ahí que las negociaciones las lleve a cabo Francia con el segundo.

Conseguida la independencia, no se va a recurrir a la soberanía popular para definir el sistema político. No se va a proceder a la elección por sufragio universal de una Asamblea constituyente como en Túnez, tan soberana que fue capaz de abolir la monarquía. En Marruecos las fuerzas políticas van a plegarse a la decisión del monarca de designar una Asamblea Consultiva en 1956, en la que los partidos comparten la representación con corporaciones económicas, profesionales, con sindicatos y confesiones réligiosas. Aunque la Asamblea consultiva, que presidirá el líder istiqlalí radical Mehdi Ben Barka, pretende asumir una función de control del gobierno, el Rey frenará estas iniciativas marginando al organismo y dejándolo languidecer en la inoperancia ${ }^{4}$. El comité Constitucional en 1960, que pretende sustituir a la Asamblea y que también es designado y no electo, va a sufrir un destino parecido.

De todas formas, aunque los partidos se van a resignar a este papel consultivo en los primeros años de la independencia, las tensiones entre ambas legitimidades presidirán el cuarto de siglo de vida del nuevo estado magrebí. Trono y partidos son asociados rivales en el ejercicio de la soberanía. Aunque el primero necesite a los segundos para asegurar un encuadramiento de la población y para que la represente en las instituciones políticas, la subordinación de los partidos al Trono es manifiesta, pués sólo a través de éste pueden acceder al poder, monopolizado por él.

En Argelia, la cuestión de la legitimidad, aunque guarda alguna similitud formal, se presenta de modo distinto. La inexistencia de un aparato estatal autóctono, por ficticio que fuese (institución beylical, Majzen) va a exigir partir de una nueva legitimidad, nacida de la lucha armada popular, tras la transferencia de poderes.

Los acuerdos de Evian del 19 de marzo de 1962 (y más tarde los del 17 de junio con la OAS) van a ser llevados a cabo en nombre del F.L.N., coalición de grupos y partidos que logrará aglutinar y movilizar al pueblo argelino durante los años de la lucha por la independencia.

La cuestión de la legitimidad en Argelia no estará resuelta en el momento de la transferencia de poderes. La falta de cohesión interna en el seno del F.L.N. y la ausencia de un programa político que fuese más allá de la independencia, llevaron una lucha por el poder en su seno que oponía esencialmente al Gobierno Provisional de la Revolución y

${ }^{4}$ Sobre la Asamblea Nacional Consultiva véase Pierre EBRAUD, «L'Asemblée Nationale Consultative marocaine", en Annuaire de l'Afrique du Nord, 1962, pp. 35-79. 
al Ejército de Liberación Nacional, (E.L.N.) sobre todo en su Estado Mayor integrado mayoritariamente por el grupo de los oficiales que ha coordinado la lucha desde las fronteras. En esa lucha por el poder se logrará imponer el E.L.N. que reclama la legitimidad revolucionaria, utilizando a un personaje con prestigio recién salido de prisión, Ahmed Ben Bella, que no logra sin embargo hacerse con todos los resortes del poder.

La coalición victoriosa al frente del F.L.N. está integrada por tres grupos dominantes: los benbellistas, los antiguos jefes de las wilayas con Zbiri a la cabeza y el "clan de Uxda» dirigido por Bumedian.

Pero a partir del golpe del 19 de junio de 1965, la legitimidad va a ser reclamada por un órgano colectivo, el Consejo de la Revolución, integrado por 26 miembros heterogéneos pero sobre los que domina el llamado "clan de Uxda» que forman en torno a Bumedian, Ahmed Medegri (convertido en Ministro del Interior), Abdelaziz Buteflika (Ministro de asuntos exteriores), Cherif Belkacem, Ahmed Kaid (Ministro de Finanzas) y Ahmed Benyili.

La nueva legitimidad en la Argelia independiente procede pues de la guerra de liberación y es depositada en el F.L.N., aunque tras él se esconde el Ejército, instrumento de la nueva legitimidad ${ }^{5}$.

El acceso a la independencia de Libia presenta unas características diferentes a los restantes países magrebíes.

Una estratificación social mal definida, una población escasa, una resistencia nacional con aspectos de localismo y no unificada, unos partidos casi inexistentes, una potencia colonial, Italia, que pierde durante la segunda guerra mundial el control del territorio y unas potencias aliadas que asumen el control militar de las distintas regiones, son algunos de los rasgos diferenciadores.

La transferencia de poderes en la región de Cirenaica producida en junio de 1949, va a constituir un ensayo de la independencia de todo el país que tendrá lugar el 24 de diciembre de 1951. El Emir Sayyid Muhammad Idris al-Mahdi al-Sanussi es proclamado rey de un estado federal. Pero contrariamente a lo que ocurre en Marruecos, el monarca no cuenta con suficientes apoyos entre la población. Algunas de las fuerzas políticas, como el Club Omar el Mujtar, expresará su oposición a la política del nuevo monarca, demasiado dependiente de Gran Bretaña. La legitimidad esgrimida por el rey proviene del prestigio religioso de la cofradía y del papel desempeñado en la resistencia en la década

${ }^{5}$ Sobre la cuestión de la legitimidad en Argelia véase Bruno ETIENNE «Le vocabulaire politique de légitimité en Algerie». en Elites, pouvoir et légitimité au Maghreb, CRESM-CNRS, Paris 1973, pp. 73-105; Mohamed DAHMANI, L'Algérie, Légitimité historique et continuité politique, Le Sycomore, Paris 1979; Bernard CUBERTAFOND, La République que Algérienne Démocratique et Populaire, PUF, Limoges 1979. 
de los años veinte. Sin embargo, el carácter otorgado de la independencia va a constituir uno de los motivos principales de oposición.

El caso libio se va a diferenciar también de los otros países magrebies por la ruptura del régimen surgido de la independencia. Mientras que los otros estados mantienen una cierta continuidad - aunque con alteraciones importantes como en el caso de Argelia - en Libia la revolución del primero de septiembre de 1969 va a significar un cambio brusco de trayectoria. La nueva legitimidad ostentada la encarna el Ejército a través de un Consejo del Mando de la Revolución, a la manera egipcia, que pretende lograr los objetivos de la unidad árabe, el dominio por el pueblo de los importantes recursos nacionales y la realización de la justicia social ${ }^{6}$.

\section{LA CONCENTRACION DE PODERES Y LAS INSTITUCIONES.}

Esta realidad del poder ha generado en cada caso una organización singular del Estado. Organización que tiene dos niveles, uno legal, aparente, plasmado en las instituciones ordenadas por las constituciones, y otro real, fáctico, confirmado por una práctica que no tiene por qué coincidir con la legalidad.

Los regímenes que se asientan en los países magrebíes parten del principio de la concentración del poder, a pesar de una apariencia jurídica demoliberal. Hay - las instituciones lo reflejan - una separación de funciones pero no de poderes ${ }^{7}$.

En los casos argelino y tunecino la organización del poder del Estado se centra en el partido único, que es delegado permanentemente de la soberanía del pueblo-nación y concentra todos los poderes. En la cumbre, las instancias del Partido y del Estado se confunden.

En Túnez, el partido monopoliza la escena política en la práctica aunque el ordenamiento jurídico no lo refleje. La Constitución tunecina de 1959 no hace ninguna referencia al papel del partido en la sociedad ni en la organización del Estado. Y sin embargo, en los primeros años de la independencia, Presidente del Partido y de la República coinciden, como ocurre con los Secretarios de Estado (Ministros), con los

${ }^{6}$ Sobre la legitimidad en la Libia pre y post-revolucionaria véase E.E. EVANSPRITCHARD, The Sanussi of Cyrenaica, Londres 1949; Hubert BRETON, "La Libye républicaine. Essai d'analyse d'un changement politique», en Annuaire de I'Afrique du Nord, 1969, pp. 360-373; asi como el libro colectivo La libye nouvelle, rupture et continuité, Paris 1975, publicado por el CRESM-CNRS, sobre todo los trabajos de Hervé BLEUCHOT, Rémy LEVEAU y Yolande MARTIN.

${ }^{7}$ Sobre este particular véase Michel CAMAU, "Caráctèr et rôle du constitutionnalisme dans les Etats Maghrébins», en Développements politiques au Maghreb, CNRSCRESM, Paris 1979, pp. 379-410. 
gobernadores y altos funcionarios, que son miembros de derecho del Comité Central del Neo-Destur. Por su parte, los gobernadores, como ocurría en nuestro país en la estructura del Movimiento, presiden el Comité Regional del Partido desde 1963.

El Consejo de la República, que asiste al Presidente y designa eventualmente su sucesor, estaba integrado por miembros del Gobierno y del Buró Político del Partido.

Esta situación fue modificada en el Congreso de Monastir de 1971, que trató de evitar la fusión-confusión, decidiendo que los Ministros y gobernadores no fuesen automáticamente miembros del C.C. y que los segundos no coordinasen al partido en las regiones. Pero la fusión no desaparece del todo, permaneciendo por encima del conjunto político la figura carismática de Habib Burguiba al frente del Estado y del Partido.

En Argelia, en el primer momento tras la independencia, el F.L.N. no era aún un partido formado sino el heredero de la organización político-militar que consigue la independencia. Durante el primer año, el F.L.N. se perfila como partido. También aquí sus instancias de dirección y las del Estado se confunden. Ben Bella reúne las funciones de Jefe del Gobierno y Secretario General del B.P. del F.L.N. La Consitución de 1963 convierte al partido en la clave del sistema. Según el artículo 24 es el encargado de definir la política de la nación y de inspirar la acción del Estado, controlando a la Asamblea Nacional y al Gobierno, siendo la institución que propone los candidatos únicos a los escaños de la Asamblea Nacional.

En congreso del F.L.N. de abril de 1964 consagra la fusión en la cumbre del partido con el Estado. Pero a partir del golpe militar de 1965, se establece una nueva forma de fusión: aparece la institución del Consejo de la Revolución, depositario de la autoridad soberana, que dirige el Estado y el Partido quedando por encima de ellos. Detenta las competencias que desempeñaban antes del golpe los órganos estatales $y$ partidarios pero los delega en instituciones designadas por él: el gobierno, que ejerce los poderes ejecutivo y legislativo hasta la puesta en práctica de la constitución de 1976; y el secretariado ejecutivo del F.L.N., responsable desde 1967 del aparato del Partido.

De este modo, el Consejo de la Revolución ejerce la tutela sobre el Partido y define la política y orientación del gobierno. Pertenecen al Consejo el jefe del Gobierno, Huari Bumedian, ministro además de Defensa, así como algunos Ministros y los principales jefes del Ejército, institución que en la práctica controla el Consejo y el poder.

Es más, a partir de 1967 el Consejo de la Revolución tiende a confundirse con el Gobierno, depurados algunos de sus elementos tras el intento de golpe del coronel Zbiri. El presidente del Consejo, Bumedian, asumirá la dirección del F.L.N. desde 1972, convirtiéndose en árbitro 
de las distintas facciones que se integran en el partido.

La constitucionalización del Régimen en 1976 hace desaparecer la institución del Consejo de la Revolución. En su artículo 98 se mantiene sin embargo la fusión del Partido y del Estado: "La dirección del país - dice el artículo - es la encarnación de la unidad de dirección política del Partido y del Estado. En el marco de esta unidad, es la dirección del Partido la que orienta la política general del País». Aunque el artículo 101 aclara en su primer párrafo que los órganos del partido y del Estado actúan en marcos separados aunque con objetivos idénticos, en su párafo tercero el mismo artículo matiza que la organización política del país está fundada en la complementariedad de tareas entre los órganos partidarios y estatales. El artículo siguiente prescribe que «las funciones determinantes de responsabildiad a nivel del Estado son detentadas por miembros de la dirección del Partido».

Esta segunda constitución argelina atribuye al F.L.N. la capacidad para proponer el candidato a la presidencia de la República, sancionado después por sufragio universal directo.

En Marruecos, la concentración de poderes no es el resultado de una lucha de facciones como en Argelia sino pervivencia de un modelo de gobierno inspirado en la tradición marroquí. Las instituciones consultivas, apenas si pueden palidecer un poder asumido de manera casi absoluta por el Monarca, convertido por la constitución de 1962 en la figura preponderante del sistema. Pero en Marruecos aparece otro elemento que ya vimos compitiendo con el Trono a la hora de ostentar la legitimidad del ejercicio del poder: los partidos, que integraron - algunos - el movimiento nacional y que contribuyeron al ascenso del primer soberano del Marruecos independiente. No lograrán sin embargo, ni siquiera en el breve período de experiencia parlamentaria de noviembre de 1963 a junio de 1965, ejercer una política de auténtico control sobre el ejecutivo vinculado a Palacio. Las tensiones entre el gobierno y la Cámara fueron resueltas por el estado de excepción en la última fecha señalada, a partir de la cual el rey Hassan II asume la presidencia del Consejo y ejerce las funciones ejecutiva y legislativa sin control alguno. Se vuelve así a la confusión de funciones anterior a 1963. Aunque en 1967 reaparece la figura del Primer ministro desgajada de la del soberano, la situación apenas cambia hasta la formación de un gobierno constitucional tras las elecciones de 1977, surgido de la mayoría en una Cámara de Representantes que vuelve a asumir la tarea legislativa.

En Libia, la concentración de poderes viene enmascarada tras la proclamación de la autoridad del pueblo por el coronel Qadafi en 1977. A pesar de la condena del sistema de representación política como su- 
plantador de la voluntad del pueblo ${ }^{8}$, el poder reside en la figura carismática del coronel y en el Secretario General del Congreso General del Pueblo, de carácter ejecutivo y no electivo, sólo teóricamente sometido al control de la macroinstitución que detenta la función legislativa: el Congreso Nacional General o Congreso General del Pueblo.

\section{LA IMPOSIBILIDAD DEL PARLAMENTARISMO Y LAS CONSTITUCIONES MAGREBIES}

Característica esencial del constitucionalismo del Magreb independiente es, como señala Michel Camau ${ }^{9}$, su tendencia a resumirse en su función de legitimación sin cumplir una función de previsión y de garantía. A pesar del «liberalismo» de su ideología jurídica (con amplias declaraciones sociales de derechos y libertades) mantienen una práctica del poder bien alejada de los principios ideológicos que la inspiran.

Dentro de este «liberalismo» en la apariencia constitucional puede destacarse el papel asignado a las Cámaras de Representantes, con teóricos poderes de control sobre el ejecutivo. Sin embargo, no es el modelo parlamentario el asumido por los nuevos regímenes magrebies al acceder a la independencia. Unicamente el caso marroquí se asemeja más a este modelo pero la práctica de años de estado de excepción y de ausencia de instituciones representativas dificultan el que califiquemos al esquema de gobierno marroquí como parlamentario. Sin lugar a dudas, es el caso libio el más alejado de un parlamentarismo, rechazado visceralmente como una fórmula de suplantación de la voluntad nacional.

La primera contitución magrebí (si dejamos a un lado la libia de 1951 que establecería un régimen de monarquía federal y representativa) va a ser la tunecina. Redactada por una Asamblea Constituyente y promulgada el primero de junio de 1959, establece un régimen presidencial inspirado en el modelo americano. El propio Burguiba reconocerá huir del modelo francés de la cuarta República, parlamentario típico, por la escasa estabilidad que asegura a la vida política y descubre la inspiración en el régimen americano que permite un poder fuerte y continuo, con un jefe de Estado con capacidad de iniciativa y de dirección, sin caer forzosamente en lo dictatorial ${ }^{10}$.

${ }^{8}$ «El pueblo no puede ser sustituído por nadie»; «la representación es una impostura», son algunas de las frases subrayadas en El Libro Verde. Véase edición española impresa en Saudade Artes Gráficas, sin fecha, páginas 10-11.

${ }^{9}$ Véase M. CAMAU, "Caráctèr et rôle..." citado, p. 381.

${ }^{10}$ Citado en Charles DEBBASCH, Ob. cit., p. 52. En este libro puede encontrarse un análisis de la constitución tunecina, estudiada también por Michel CAMAU en "Lévolution du droit constitutionnel en Tunisie», en Jahrbuch des Offentlichen Rechts 
De este modo, la Consitución tunecina de 1959 da los plenos poderes al Presidente, que ejerce el poder ejecutivo, que escoje a los miembros del gobierno, responsables ante él. Modificaciones posteriores del texto constitucional han permitido fórmulas de control del ejecutivo por la Asamblea, lo que originalmente no era posible.

El Presidente tiene la iniciativa de las leyes, puede devolver a la Asamblea leyes para su reexamen y cuenta con poderes suplementarios en momentos excepcionales. Elegido por sufragio universal, obtiene así la legitimidad de sus amplios poderes.

La Asamblea Nacional viene marcada ya por su forma de elección. Candidaturas únicas, propuestas por el partido Neo-Destur o P.S.D. (Partido Socialista Desturiano, nombre que adoptó el Neo-Destur desde 1964), aseguran de este modo la incondicionalidad de la Asamblea al Gobierno ". Así, la Cámara se convierte en un organismo de aprobación y como mucho, un mero órgano de control. Aunque la Cámara tunecina contase con iniciativa legislativa, compartida con el Presidente de la República, es significativo que la primera medida legal con origen en la propia Cámara fue la adoptada en 1981 prescribiendo la autodisolución de la misma a fin de poder proceder a elecciones anticipadas. Hasta ese momento, toda iniciativa había partido del ejecutivo.

Modificaciones posteriores han matizado las características de un régimen presidencialista como el tunecino. Se ha incorporado la figura de un Primer Ministro (función desempeñada hasta 1970 por el propio Presidente Burguiba), eventual sustituto del Presidente y con capacidad para designar su gabinete, si bien en un régimen patrimonialista como éste, en el que la personalización en torno al "Combatiente supremo» es extremada, no hay duda que la matización es sólo relativa.

La primera constitución marroquí, aprobada en referendum el 7 de diciembre de 1962, seis años después de la independencia, arranca sin el consenso de algunas formaciones políticas importantes. Lo que podría denominarse izquierda nacional preconizará el boicot al referendum

der Gegenwart, 20 (1971), pp. 319-374. Igualmente ver S. CHAABANE, «Le système constitutionnel tunisien à travers la réforme de 1976», en Développements politiques au Maghreb, pp. 311-344.

1 No siempre ha existido la fórmula de la candidatura única. En las elecciones a la Asamblea Constituyente y en las legislativas de noviembre de 1959 participaron algunos candidatos comunistas e independientes. En las de 1979 se permitió el doble de candidatos que de sedes a cubrir, pero dentro del mismo P.S.D. Por último, en noviembre de 1981 participaron cuatro formaciones políticas. Sobre el sistema electoral tunecino anterior a 1981 véase la obra de Michel CAMAU, Fadila AMRANI y Rafaâ BEN ACHOUR, Contrôle Politique et Régulations Electorales en Tunisie, CRESM, Túnez 1981. 
al rechazar la forma seguida para redactar el texto.

El reino de Marruecos se define como una «monarquía constitucional, democrática y social», a la vez estado musulmán soberano, parte integrante del Gran Magreb, que cuenta entre sus objetivos la realización de la unidad africana.

Se instituye el parlamentarismo como sistema de representación de los ciudadanos, siendo el único estado magrebí que adopta una fórmula semejante. Se prohíbe expresamente el partido único ${ }^{12}$, con la clara orientación de impedir las aspiraciones hegemonistas y exclusivistas del Istiqlal, mostrando de este modo las tensiones permanentes entre el Palacio y el Partido dominante.

La constitución de 1962 fue concebida, como señala Michel Rousset ${ }^{13}$, como un "medio de consagrar la victoria política que el rey consiguió en la carrera por el poder que se abrió al día siguiente de la independencia». El rey es considerado por el artículo 19, Emir de los Creyentes, símbolo de la unidad de la nación, garante de la perennidad y continuidad del Estado. Su figura es inviolable y sagrada y concentra numerosos poderes atribuidos en un régimen parlamentario al legislativo. Nombra y cesa al Primer Ministro y a los Ministros, preside el Consejo, dispone del derecho de voto sobre las leyes, obligando a una nueva lectura de las mismas, puede disolver la Cámara de Representantes sin el refrendo del Primer Ministro. Es el jefe supremo de las Fuerzas Armadas, ejerce el derecho de gracia y puede someter a referendum cualquier proyecto de ley ya deliberado por las cámaras. Puede, a semejanza de la primera autoridad tunecina, proclamar el estado de excepción y asumir todos los poderes.

La institución parlamentaria tiene sin embargo en la constitución marroquí de 1962 un papel secundario. Dividida en dos Cámaras, la de Representantes, elegida por sufragio universal para cuatro años y la de Consejeros, en la que la representación presenta un carácter indirecto y corporativo, ya que participan en la elección de sus miembros (para un mandato de seis años) los concejales de los municipios y las Cámaras agrarias, industriales, artesanales, así como los sindicatos.

La vigencia de la Constitución de 1962 concluye con la declaración del estado de excepción en junio de 1965. No volverá a ser puesta en

12 Es lo que se denominaba la «cláusula Guedira», por haber sido Ahmed Reda Guedira el introductor de dicha salvedad en la constitución de 1962. Sobre este particular véase John WATERBURY, Le Commandeur des Croyants. La Monarchie marocaine et son élite, PUF, Paris 1975, p. 170.

${ }^{13}$ Véase Michel ROUSSET, "Chanrgéments institutionnels et équilibre des forces politiques au Maroc. Un essai d'interpretation», en Développements politiques au Maghreb, p. 191. 
vigor. En julio de 1970, finalizando dicho estado de excepción, se procederá a un nuevo referendum constitucional por el que se aprueba un nuevo texto. En esencia es el mismo de 1962 pero con mayores prerrogativas para el soberano, acentuando también el carácter corporativo e indirecto de la representación. Sólo el tercio de la Cámara única va a ser elegido por sufragio universal. El rechazo de las formaciones políticas al texto de 1970 les va a llevar a preconizar el boicot al referendum, que consigue no obstante cifras oficiales de participación superiores al $93 \%$.

La Constitución de 1970 tuvo una corta duración, pues el intento de golpe del verano de 1971 movió al monarca a una reestructuración política de la mano de Karim Lamrani, por entonces ministro de Economía y Finanzas, encargado de formar un gabinete que no logró una conciliación con la oposición. Este objetivo fue perseguido también por la nueva Constitución de $1972{ }^{14}$, en la que se amplía la representatividad de la Cámara (dos tercios de sus miembros son elegidos por sufragio universal). Pero la oposición, agrupada en el Frente Nacional (al-Kutla al-Wataniya), rechazará un texto que acabará por acatar cuatro años más tarde a propósito de las elecciones municipales y legislativas.

El sistema argelino ha pretendido poner en práctica los principios de dirección colectiva o colegial de las instituciones y de la sociedad. Pero el poder personal, como en otras sociedades magrebíes, ha sido la tentación permanente del sistema. La Constitución de 1963, proclamada el 10 de septiembre, aparece dominada por el partido, según se ha dicho. El Presidente de la República es elegido por sufragio universal. La Asamblea no interviene en su elección pero puede, sin embargo, destituirlo, lo que constituye una innovación en derecho constitucional. Nombra a los Ministros, presentando su gobierno a la Asamblea que sin embargo no debe darle su confianza, rasgo típico del régimen presidencial. Acumula pues las funciones de presidente de la República y del gobierno, si bien el gabinete no existe jurídicamente como colectivo responsable. Como en los otros estados magrebíes, el presidente asume en circunstancias de crisis los poderes excepcionales.

La Asamblea Nacional es la otra institución estatal destacada por la Constitución. Comparte la iniciativa de las leyes con el Presidente de la República y ejerce teóricamente un doble control sobre el gobierno, el de las cuestiones orales o escritas y el del voto de censura a la perso-

${ }^{14}$ El texto de la Constitución de 1972, con anotaciones especificando sus diferencias con las anteriores de 1962 y 1970 puede encontrarse en mi libro Procesos electorales en Marruecos, (1960-1977), Centro de Investigaciones Sociológicas. Madrid 1979, pp. 107-123. Sobre el constitucionalismo marroquí véase Michel CAMAU, "L'évolution du droit constitutionnel au Maroc», en Jahrbuch des Offentlichen Rechts der Gegenwart, 21 (1972), pp. 383-529. 
na del Presidente, lo que entraña la disolución automática de la Asamblea.

El golpe del 19 de junio de 1965, que pretende el retorno a las fuentes de la revolución, depone al presidente de la República y Secretario general del Partido, disuelve la Asamblea e instituye un Consejo de la Revolución que asume el control de todos los poderes. La ordenanza número 65/182 del 10 de julio de 1965, integrada por siete artículos, va a servir de Constitución durante un largo período provisional que durará hasta 1976. La nueva Constitución de esta fecha, a la que me he referido, reconoce el papel político ejercido por el Ejército, «instrumento de la Revolución", que participa en el desarrollo del país y en la edificación del socialismo. El F.L.N. es el partido único cuya vinculación con las instituciones estatales vimos anteriormente. El Presidente de la República es responsable del nombramiento de los Ministros y puede designar a un Primer Ministro. Encarna la unidad de dirección política del Partido y del Estado, puede convocar refrendos para todas las cuestiones de importancia nacional y cuenta con los poderes excepcionales en caso de necesidad ya descritos en otras constituciones de la región.

El poder legislativo es ejercido por la Asamblea Popular Nacional, cuyos miembros son elegidos por sufragio universal directo a propuesta de la dirección del F.L.N. En las últimas elecciones se ha roto la tradición de la candidatura única, presentándose el doble de candidatos que de escaños, introduciendo un falso elemento competitivo o concurrencial en los procesos electorales. No puede, sin embargo, la Asamblea, como ocurría en el texto de 1963, provocar la dimisión del presidente ni ejercer la función de control sobre los ministros ${ }^{15}$.

La historia constitucional libia carece de la continuidad relativa de sus vecinos. El sistema parlamentario bicameral de la monarquía federal establecida por la Constitución de 1951 va a ser abolido por la proclamación constitucional del 11 de diciembre posterior al golpe de 1969. El Consejo del Mando de la Revolución asume todos los poderes dentro de una República Arabe democrática y libre. No se preven otras instituciones que este colectivo de once miembros en el que el coronel Qadafi se va perfilando como líder. En junio de 1971 se crea a la usanza egipcia un partido único, la Unión Socialista Arabe, sobre el que se pre-

${ }^{15}$ Sobre el constitucionalismo argelino véase el estudio de los textos de 1963 y 1965 publicado en el tomo I fascículo 1 del Corpus Constitutionnel, E.J. Brill, Leiden 1968 , pp. 163-202, en el que se incluyen ambos textos en su versión árabe y francesa. El libro citado de Bernard CUBERTAFOND incluye estudio de la Constitución de 1976, igualmente estudiada por J. LECA y J.C. VATIN, «Le système politique algérien (1976-1978)», en Develppements politiques au Maghreb, pp. 15-80. Un estudio global es el de Michel CAMAU, "L'évolution du droit constitutionnel en Algérie», en Jahrbuch des Offentlichen Rechts der Gegenwart, 23 (1974), pp. 239-334. 
tende asentar el sistema, asegurando un contacto permanente con el pueblo. Esta institución, reestructurada en 1975 siguiendo las directrices del tomo primero del Libro Verde, desembocará en la instauración de un régimen que quiere ser totalmente innovador, basado en el gobierno directo del pueblo, organizado en Comités Populares, Congresos populares de base, y asociaciones profesionales. Estas instituciones de base designan otras instancias intermedias que llegan hasta el mencionado Congreso General del Pueblo ${ }^{16}$.

\section{LOS PARTIDOS Y LA REPRESENTACION POLITICA.}

Me he referido al papel de los partidos únicos tunecino y argelino dentro de la gestión del gobierno. He hablado del pluralismo marroquí aludiendo a algunos de los grupos que lo integran. Por último, acabo de referirme a la Unión Socialista Arabe como fórmula que se pretende nueva para el encuadramiento popular.

Creo sin embargo necesario referirme ahora a los hitos cronológicos de las historias respectivas de dichos partidos.

En Túnez hay que aludir a la presencia en los primeros años de la independencia de un Partido Comunsita Tunecino que es ilegalizado en el marco de una persecución más general contra la izquierda en enero de 1963. Esta medida es adoptada inmediatamente después del reconocimiento por Burguiba del "socialismo moderado» como doctrina estatal y un año antes de la conversión del partido Neo-Destur en Partido Socialista Desturiano. Son los años de apogeo de la política económica socializante de Ahmed Ben Salah. El cambio de denominación no significa sin embargo ninguna modificación en su papel en la sociedad ni tampoco en el proceso de adhesión al mismo de demócratas que quieren ascender dentro del Estado, clases medias que pretenden proteger asi sus negocios, sindicalistas, ciudadanos que buscan alguna forma de ascensión social o política.

Cantera de cuadros, el P.S.D. va a ser también cantera de disidentes. Varias de las formaciones políticas que han ido emergiendo a lo largo de la última década en Túnez, proceden del cuerpo desturiano. El Movimiento de Unidad Popular va a ser fundado por el propio Ben Salah poco despues de su huída de la cárcel en la que se vio tras caer en desgracia de 1969. En marzo de 1975 se publica el manifiesto de M.U.P., que actúa abiertamente por un socialismo radical. Escindido

${ }^{16}$ Véanse los textos de las constituciones libias de 1951 y 1969 en Annuaire de I'Afrique du Nord, 1963 y 1969. Para un estudio de las instituciones actuales libias véase Hervé BLEUCHOT y Taoufik MONASTIRI, «Libye: l'évolution des institutions politiques (1969-1978)", en Développements politiques au Maghreb, pp. 141-188. 
a raiz de la convocatoria de elecciones legislativas libres en 1981, el sector en el exilio, vinculado al líder Ben Salah - que no ha aceptado la amnistía concedida por Burguiba - no va a participar mientras que un grupo del interior verá la luz con ese objetivo.

También el Movimiento de los Demócratas Socialistas procede del tronco desturiano. Su fundador, Ahmed Mestiri, ex-diputado, ex-Ministro y en tiempos discípulo aventajado del propio Burguiba. El Movimiento empieza algo más tarde que las disidencias de su líder que le acarrearon su salida definitiva del P.S.D. en 1971 y de la Asamblea Nacional en 1973. El grupo tiene su origen en una declaración firmada por un grupo de intelectuades a raiz del vigésimo aniversario de la independencia en marzo de 1976.

Otros dos grupos quedan lógicamente fuera del espectro desturiano: el P.C.T., legalizado el 18 de julio de 1981 y el Movimiento de la Tendencia Islámica, que no consiguió ni siquiera el reconocimiento de facto que los dos movimientos antes citados tuvieron en vísperas de las elecciones de 1981. Estas constituyeron el arranque de un proceso liberalizador del que fue responsable el primer ministo Muhammad Mzali. Proceso abortado de raiz al publicarse los resultados oficiales que arrojaron unos porcentajes de victoria del Frente Nacional (integrado por el P.S.D. y el sindicato U.G.T.T.) desacreditadores de la experiencia. M.U.P. y M.D.S. participaron con el consentimiento de ser legalizados si obtenían el $5 \%$ de los sufragios lo que, según las cifras oficiales, no se logró - según la oposición - por el fraude electoral.

La experiencia sin embargo constituyó, hasta el momento de la votación, casi un modelo democrático para el Magreb. En la campaña electoral se permitió el uso de la radio y la televisión a las formaciones políticas de oposición, lo que sin duda influyó para que en las municipales marroquies del 10 de junio de 1983 se autorizase a los seis principales partidos a usar estos medios de difusión ${ }^{17}$.

En Argelia hay que recordar la prohibición expresa del Partido Comunista Argelino y de todos los partidos el 29 de marzo de 1962. El apoyo del P.C.A. al F.L.N. - aunque manteniendo su autonomía- no impidió esta medida. Dicho partido ha sido sin embargo la única formación que ha pervivido en una ilegalidad consentida a todo lo largo de la existencia de la Argelia independiente. Convertido en Partido de Vanguar-

${ }^{17}$ Una visión del Túnez político actual puede encontrarse en la obra de Mohsen TOUMI, La Tunisie. Pouvoirs et luttes, Le Sycomore, Paris 1978. Sobre el P.S.D. véase el trabajo de Werner K. RUF, "Le socialisme tunisien. Consequences d'une experience avortée", en Introduction à l'Afrique du Nord Contemporaine, pp. 399-411. Sobre las elecciones de 1981 véase mi trabajo «Las elecciones tunecinas del 1 de noviembre de 1981», en Revista de Estudios Políticos, 25 (enero - febrero de 1982), pp. 193-220. 
dia Socialista, algunos de sus cuadros se encuentran incluso bien situados en altas esferas de la administración ${ }^{18}$.

Va a ser Marruecos lógicamente el país en el que la historia de los partidos presente unos caracteres más complejos. El reducido cuadro de partidos que existen en el momento de la independencia (Istiqlal, P.D.I., P.C.M.) va a sufrir una pronta ampliación. El propio Istiqlal se va a escindir reflejando así la diversificación social que se había integrado en el movimiento nacionalista. Junto a un nacionalismo burgés, alineado en torno a Allal el-Fassi y al propio partido del Istiqlal, va a dibujarse un nacionalismo radical y populista, que encabezará Mehdi Ben Barka. La oposición continua entre ambas tendencias, luego partidos, sólo va a quedar rota con la formación de la Kutla al-Wataniya a raiz de las elecciones que siguieron al referendum constiucional de 1970.

El Istiqlal va a ser intermitentemente un partido soporte del poder y un partido de oposición. Apoyando el referendum constitucional de 1962 desde el gobierno, sale del gabinete poco después al enfrentarse con sectores del mismo más fieles a Palacio y que acusan al Istiqlal de conservadurismo y oscurantismo. En la oposición va a participar en las legislativas de 1963 y en la oposición se va a mantener hasta las municipales de 1976. Pasando entonces a ocupar ciertas carteras de importancia política como la de Asuntos Exteriores ${ }^{19}$.

La Unión Nacional de Fuerzas Populares, esa formación radicalpopulista desgajada del Istiqlal, no va a perder nunca su papel de oposición a pesar de contar en algún momento con un ministro de Estado en el Gobierno. Lejos queda el momento en que el gabinete de Abdallah Ibrahim tuvo el gobierno en sus manos sirviendo, en 1960, de un instrumento más en la pugna de Palacio con el Istiqlal. Esta relativa ambigüedad puede verse también en 1965 cuando fue el único partido que apoyara la declaración por el soberano del estado de excepción. Error político que pagaría pocos meses después con la desaparición de su líder Ben Barka. Escindido en 1972, ha mantenido su línea tras Abderrahim Buabid en la Unión Socialista de Fuerzas Populares.

${ }^{18}$ Aparte los libros ya citados sobre la Argelia independiente, véase la obra de Jean LECA y Jean Claude VATIN, L'Algérie politique. Institutions et régime, A. Colin, Paris 1975. Un análisis político de interés lo constituye el trabajo de J.P. DURAND, «Exacerbation des contradictions sociales et resserrement des alliances politiques en Algérie», en Développements politiques au Maghreb, pp. 123-140.

${ }^{19}$ En las elecciones legislativas de 1984, tras las que ha vuelto a integrar la oposición, ocupó el cuarto lugar entre los partidos con el $15,33 \%$ de los votos. Sobre esta evolución reciente del Istiqlal véanse mis trabajos «La intervención administrativa y las elecciones locales marroquíes del 10 de junio de 1983», en Revista de Estudios Políticos, 36 (noviembre - diciembre de 1983), pp. 235-265 y "Las elecciones legislativas del 14 de septiembre de 1984 y la atomización política en Marruecos», en Revista Española de Investigaciones Sociológicas, 30 (abril - junio de 1985), pp. 245-290. 
Otros partidos han participado en la vida política marroquí incluso desde el gobierno. El más destacado de los históricos es el Movimiento Popular fundado en 1957 por Mahyubi Ahardan y el Dr. Abd el-Krim el-Jattib.

El Partido Comunista Marroquí, fundado en 1943, ilegalizado en 1960 por el Tribunal Supremo que lo declaró contrario al Islam, ha permacido bajo la dirección de Ali Yata en la cladestinidad, reapareciendo legalmente como Partido de la Liberación y del Socialismo entre junio de 1968 y agosto de 1969. Años más tarde, en el marco de la política liberalizadora de Hasan II a propósito de la recuperación del Sahara, se legalizó de nuevo como Partido del Progreso y del Socialismo en 1974.

Otros grupos de creación oficial deben citarse: el Reagrupamiento Nacional de los independientes, convertido por Ahmed Osman en partido a partir de la mayoría parlamentaria obtenida por los llamados «independientes» en la elecciones de 1977. Escindido en 1980, ha conservado la denominación en torno a su líder aunque convirtiéndose en una extraña oposición oficialista; el otro sector, conservando sus posiciones en el gobierno, ha fundado el Partido Nacional Demócrata. Por su parte, el primer ministro (hasta su sustitución por Karim Lamrani en noviembre de 1983) Maati Buabid, intentó perpetuarse en una nueva formación política vinculada al poder, la Unión Constitucional, con la que obtuvo una exigua mayoria en las controvertidas elecciones de 1983 y de $1984^{20}$.

Los procesos electorales mediante los que se consigue la representación política de los ciudadanos y la legitimación de las instituciones constitucionales, no son, en los países magrebies, un modelo de democracia. Unicamente en Marruecos puede hablarse de semiconcurrencialidad en los procesos, pero la falta de continuidad da inestabilidad al sistema electoral. Desde 1963 a 1977 no ha habido elecciones legislativas competitivas que sirvieran para instalar una Cámara de Representantes mínimamente democrática. Las de 1970 no merecen tal nombre. También en Túnez he hecho referencia a las elecciones semiconcurrenciales de 1981, aunque sus resultados evidenciaron el fraude. Para el

${ }^{20}$ La obra más significativa sobre los partidos marroquíes (dejando aparte la clásica y anticuada de Robert REZETTE, Les partis politiques marocains, A. Colin, Paris 1955) es la de Claude PALAZZOLI, Le Maroc politique, Sindbad, Paris 1974. Sobre el Istiqlal véase el libro de Attilio GAUDIO, Allal el Fassi ou l'histoire de I'/stiglal, A. Moreau, París 1972. Algunos documentos relativos a la U.N.F.P. pueden encontrarse en la obra de Mehdi BEN BARKA, Opción revolucionaria para Marruecos Ed. Cultura Popular, Barcelona 1967. Entre la escasa bibliografía española sobre el Marruecos político apenas puede citarse también el librito de Alberto MIGUEZ, Marruecos en la encrucijada, Castellote, Madrid 1973. Una breve interpretación del juego politico marroquí puede también encontrarse en Jean Jacques REGNIER, "Monarchie et forces politiques au Maroc), en Introduction à l'Afrique du Nord Contemporaine, pp. 341-358. 
Túnez anterior, la Argelia en toda su historia y la Libia anterior y posterior al Coronel, no cabe hablar de representación democrática.

\section{EJERCITO Y POLITICA.}

Como ocurre en la mayoría de los estados tercermundistas, ninguno de los nuevos estados magrebies hereda de la colonización un ejército bien organizado y entrenado. Sin embargo, Francia, por acción o reacción, va a estar presente en la constitución de los futuros ejércitos nacionales, participando en la formación de muchos de sus oficiales como en el caso marroquí o tunecino, o engendrando en su empecinamiento por conservar la Argelia colonial, un Ejército de Liberación Nacional. De todos modos, y el caso libio es también válido para esta afirmación, los ejércitos magrebíes no van a extraer su importancia de su papel en el campo estrictamente militar tras la independencia, sino de su función política - mayor o menor según los casos - en la vida doméstica de sus propios países.

En las distintas etapas de la historia de la Argelia porterior a 1962, el ejército ha encarnado la legitimidad revolucionaria, participando en la lucha por el poder primero, interviniendo activamente con el golpe de 1965 más tarde, controlando el Consejo de la Revolución, y configurándose, por último, tras 1976, como un auténtico poder reconocido por la Constitución ${ }^{21}$.

En Túnez, la historia de las Fuerzas Armadas parece vincularse más a sus funciones de defensa de las fronteras. Sin embargo, a partir de octubre de 1977 se les hace participar en la represión de huelgas en Ksar Hellal, inaugurando así una práctica con resultados dramáticos como la actuación del Ejército contra las manifestaciones obreras en la capital el 26 de enero de 1978 o las que recientemente (diciembre de 1983 - enero de 1984) han tenido lugar.

El Ejército tunecino se nutre del reclutamiento de los jóvenes, con excepción de los titulados universitarios. El cuerpo de oficiales lo integran sin embargo elementos de las clases medias que hasta las fechas citadas han demostrado su lealtad hacia el poder civil. La novedad de hacerle participar en la represión ciudadana entraña ciertos riesgos que deben sopesar los actuales dirigentes tunecinos. Estos se encuentran comprometidos en la tarea de modernizar al Ejército para lo que se ha llegado a sextuplicar su presupuesto de 1976 a 1978, destinándose la mayor

${ }^{21}$ Sobre el papel del Ejército argelino véase Abdelkader YEFSAH, Le processus de légitimation du pouvoir militaire et la conception de l'Etat en Algérie, Anthropos, Paris 1982. 
parte de éste al equipamiento ${ }^{22}$.

El papel del Ejército libio en su sociedad es aparentemente menos notorio que en el caso argelino a pesar de la subordinación del gobierno a instituciones como el Consejo del Mando de la Revolución, integrado, en su mayor parte, por altos militares (comandantes Yallud, ElHuni, Hawadi, el propio Qadafi). Sin embargo, desde la proclamación constitucional del 11 de diciembre de 1969 se asigna a las Fuerzas Armadas el papel de garante supremo de las instituciones revolucionarias. El papel desempeñado en la sociedad libia las hace partícipes del proceso de modernización en curso. No debe sin embargo menospreciarse la función que se les atribuye en el marco de las frecuentes tensiones fronterizas con sus vecinos que contradicen en parte la vocación unitaria árabe preconizada desde el primer momento por el estado libio ${ }^{23}$.

En Marruecos, la misma creación de las Fuerzas Armadas Reales en el momento inmediato a la independencia constituyó por sí mismo un acto político. Las F.A.R. van a ser encargadas de la tarea de neutralizar el Ejército de Liberación, guerrilla rural con arraigo en el Rif y zonas montañosas del Sur que desempeñó un papel importante a la hora de las negociaciones de Aix-les-Bains. Integraban este Ejército de Liberación unos diez o quince mil hombres mal organizados pero combativos que llegaron a representar un verdadero peligro para el equilibrio del régimen. De ahí que se atribuya a las F.A.R. la función de asimilar (o depurar) a los elementos de esta guerrilla. Esta tarea se encuentra ya cumplida en el verano de 1957 salvo para el Ejército de Liberación del Sur, que a petición de Ben Barka subsistirá hasta 1960, después de la recuperación de Tarfaya.

Pero el régimen marroquí va a asociar el Ejército a otras tareas políticas como la lucha antisubversiva, compromentiéndole en la condena de disidentes políticos como Ben Barka o el líder de la U.N.E.M. en 1963. También le va a hacer participar en la represión ciudadana en casos tan notorios como los sucesos de Casablanca de marzo de 1965, junio de 1981 y enero de 1984.

Pero un Ejército como el marroquí, formados sus cuadros en academias militares extrajeras (Saint-Cyr, Toledo), con encuadramiento de cooperantes franceses o de técnicos americanos, bien equipado militarmente, llega a convertirse en élite con aspiraciones políticas. Ciertos militares, a su vez, han iniciado un ascenso político a través de su participación en la vida civil. El caso de Ufkir es el más significativo y el que

${ }^{22}$ Véase Mohsen TOUMI, Ob. cit., p. 83.

${ }^{23}$ Véase Rémy LEVEAU, «Le système politique libyen», en La Libye nouvelle, pp. 83-100. 
pareció encerrar un proyecto político no por difuso menos real. Los golpes de estado de 1971 y 1972 lo demuestran. Estas intentonas obligaron al rey a someter más estrechamente al Ejército, depurado de sus elementos no leales. La guerra del Sahara va a proveer una salida exterior a las posibles tensiones que escondiera el Ejército tras su reestructuración. Pero evidentemente ha generado nuevos problemas. La muerte "accidentada» del general Dlimi en los palmerales de Marrakech en enero de 1983, días después de publicarse por una agencia de noticias americana la preparación de un nuevo golpe militar, no es sino la manifestación de estos nuevos problemas entre las F.A.R. y el monarca marroquí saldados en una posterior reestructuración ${ }^{24}$.

\section{CONCLUSION.}

Después de este recorrido por la historia de las instituciones que han conformado a los nuevos estados en el Magreb, cabe concluir que hemos asistido en los últimos treinta años al proceso de consolidación de los regímenes locales. Salvo el caso libio, expuesto a alteraciones profundas pese al apoyo exterior con que cuenta, los regímenes tunecino y argelino cuentan con un sistema estable, apoyado en una legitimidad que, sin llegar a ser estructural, permite una participación institucionalizada de sus ciudadanos. Los mecanismos constitucionales han funcionado en los momentos de crisis, revelando cierta solidez en las instituciones que cuentan con básicos apoyos internos. Incluso una sociedad como la tunecina, amenazada por diversos factores de desestabilización que proceden del exterior (Libia), de la presencia en su territorio de la sede de la O.L.P. (ataque israelí al cuartel general de esta organización en octubre de 1985) o de fuerzas interiores que rechazan en nombre del Islam la legitimidad del sistema (Movimiento de la Tendencia Islámica), enfoca con realismo el urgente problema de la sucesión de su líder carismático Burguiba.

La división en dos ejes estratégicos de la región (alianza argelinamauritano-tunecina de un lado y Unión Arabe Africana entre Marrue$\cos$ y Libia de otrol, en la que la guerra del Sahara desempeña un papel del primer orden, no impide un complejo problema de alineamiento internacional en el que no cabe la asociación automática de cada país a un bloque determinado. La búsqueda de un equilibrio en la región ha sido interés común de las superpotencias y la C.E.E, pero hoy se ve amenazado por la voluntad decidida de Washington de destruir al régimen libio. Y la rivalidad permanente entre Argelia y Marruecos, que aleja

${ }^{24}$ Sobre este tema véase el trabajo de J.C. SANTUCCI y J.J. REGNIER «Armée, pouvoir et légitimité au Maroc», en Elites, pouvoir et leǵitimité au Maghreb, pp. 141-182. 
la perspectiva de un Magreb unido, no pasa sin embargo de un verbalismo que esconde la mutua voluntad de ejercer un liderazgo en la zona. La rivalidad tiene causas económicas profundas, entre ellas la concurrencialidad de sus productos agrarios en los mercados europeos. Pero también políticas, derivadas de la mencionada consolidación de los regímenes locales, que buscan su supervivencia - en el marco de unas naciones-estados consolidadas - mucho antes que la integración en un conjunto regional al que dijeron aspirar en la primera etapa de su independencia. 



\section{RECENSIONES}

ANTONIO MOLINER PRADA 
La nueva historia económica en España, Edición de Pablo Martín Aceña y Leandro Prados de la Escosura. Madrid, Tecnos, 1985, 341 págs.

La historia ecónomica ha avanzado considerablemente en nuestro siglo gracias a la introducción de la estadística en los trabajos de contenido histórico-económico. Una primera corriente ha sido la denominada "historia serial», ligada a la escuela de los Annales, y está formada por historiadores economistas. Hacia los años cincuenta nace dentro del mundo anglosajón la denominada «historia cuantitativa», hecha por economistas historiadores. Su objetivo era hacer de la historia un campo de aplicación retrospectiva de la teoría económica más actual. La tercera tendencia y la más moderna es la «new economic history».

La «nueva historia económica» o Cliometría aplica los métodos modernos de teoría económica, estadística y econometría al estudio de la historia económica. Así satisface la vieja aspiración schumpeteriana de aproximar las ramas de la Historia, Teoría y Estadística'. Los nuevos historiadores económicos son más economistas que historiadores.

Los principios de esta nueva corriente fueron expuestos en 1957 en Estados Unidos por A.H. Conrad y J.R. Meyer en un famoso trabajo titulado "Teoría económica, inferencia estadística e historia económica». En él señalaban la necesidad de vincular la teoría económica a la historia, dando importancia capital a la cuantificación sistemática.

Pronto alcanzó gran difusión en Estados Unidos esta escuela. Sus seguidores revisaron la historia económica de este pais y pusieron al servicio de sus investigaciones las posibilidades inmensas de las nuevas tecnologías (informática, ordenadores, etc.). Sus trabajos se difundieron a través de la revista "Journal of Economic History".

Los resultados de estos trabajos han sido interesantes pero también conflictivos. Así por ejemplo las conclusiones del estudio de R.W. Fogel (Los ferrocarriles y el crecimiento económico norteamericano), afirmando que el desarrollo de los ferrocarriles no hubiera sido imprescindible para el crecimiento industrial de su país, o las de su trabajo junto con S.L. Engerman (Time on the Cross), intentando demostrar que el sistema esclavista americano no sólo era rentable económicamente sino que lo era más aún que la mano de obra libre y asalariada.

${ }^{1}$ La nueva historia económica en España. Prólogo, pág. 11. 
El profesor J. Fontana ha expuesto con claridad el reto que supone para el historiador actual la aplicación de modelos econométricos a la investigación histórico-económica. Pero el problema surge cuando el "cliómetra» pretende aplicar su método no a problemas concretos sino a estudios globales, a todos los ámbitos de la realidad histórica, como hace la «novísima» historia económica. Entonces poco es aprovechable ${ }^{2}$.

No hay duda de que la nueva escuela aporta rigor intelectual en la historia económica y ha estimulado el descubrimiento de nuevas fuentes, nuevos conocimientos y métodos. Incluso es positivo el uso de la especulación sobre alternativas históricas, pues sirve para determinar la eficacia de los costos en el pasado. Sin embargo su gran limitación es que analiza un fenómeno particular histórico, al que puede aplicarse la teoría económica, aislándolo de los demás , y que depende del valor de la prueba estadística ${ }^{3}$.

También en nuestro país hemos asistido en las últimas décadas a un auge espectacular de la historia económica. Los nombres de ilustres profesores como Carande, Vicens Vives, Sánchez Albornoz, P. Vilar, J. Nadal, J. Fontana, F. Ruiz Martín, G. Tortella y otros, lo atestiguan. La celebración de varios congresos sobre esta materia y el reciente nacimiento de la Revista de Historia Económica en 1983 confirman su importancia.

El libro que reseñamos es una novedad. Los trabajos que en él se presentan, aunque no son en sentido estricto de esta escuela (la «nueva historia económica»l, asumen sus contribuciones y las utilizan como marco de referencia. Realizados por economistas, profesores en muchas universidades españolas, permitirán a los historiadores comprobar los análisis económicos en el estudios de la Historia. Ya en 1984 se publicó en castellano una selección de textos de esta escuela (La nueva historia económica. Lecturas seleccionadas. Compilación de P. Temin, Alianza Editorial, Madrid, 1984).

El libro, como se indica en el Prólogo, cumple así dos objetivos: extender a la historia económica la moderna cuantificación estadística y econométrica y reinterpretar los hechos históricos a la luz del análisis económico.

Los artículos, tres de ellos reimpresos, están agrupados bajo tres

2 FONTANA, J. Historia. Análisis del pasado y proyecto social. Barcelona, 1982, págs. 195-199.

${ }^{3}$ HOBSBAWM, E.J. "Historia económica y social», en BARKER, P. Las ciencias sociales de hoy, México, 1979, págs. 112-122. Citado por PAGES, P. Introducción a la Historia, Barcelona, 1983, págs. 220-221. 
epígrafes: Atraso y crecimiento económico; La integración en la economía internacional, y El Estado en la economía. Enumeramos a continuación el objeto de cada uno de ellos.

Albert Carreras de Odriozola presenta en su trabajo un intento de aproximación al gasto nacional bruto y formación del capital en España durante el período 1849-1958. Calcula el gasto nacional bruto a través del consumo, la formación bruta del capital fijo y la diferencia entre las exportaciones y las importaciones. Las limitaciones de su estudio radican en la baja representatividad de las series seleccionadas para evaluar el consumo total y en el desconocimiento de los servicios tanto en el consumo como en las exportaciones.

El conocido grupo de Estudios de Historia Rural analiza la evolución de la superficie cultivada de cerales y leguminosas en España en el período 1886-1935. Su objetivo es, ante todo, conocer - con las limitaciones de las fuentes disponibles - la composición de la superficie cultivada de cereales y leguminosas, así como sus principales variaciones espaciales y temporales. El texto incluye también las cifras estadísticas en las que se apoya su investigación.

Pedro Fraile en «Crecimiento económico y demanda de acero: España (1900-1950)» defiende la hipótesis de que las tasas de crecimiento del producto nacional bruto, durante $1900-1930$, no fueron muy diferentes a las de otros países europeos. El desarrollo económico de esos años en España, aunque relativamente lento, generó en el caso de la siderurgia una demanda de manufacturas adecuada para un crecimiento económico industrial sostenido. Sin embargo, a diferencia de otros países europeos, la función de la siderurgia española como sector dirigente en la transición hacia un crecimiento industrial autosotenido nunca llegó a manifestarse.

Antonio Gómez Mendoza señala el papel que desempeñaron los ferrocarriles en la economía española entre los años 1855 y 1913. Sus conclusiones son diametralmente opuestas a las de Nadal y Tortella. Según estos autores la construcción de la red viaria, que empezó muy tarde, fue la "ocasión perdida» del fomento de la siderurgia en nuestro país. La ley de ferrocarriles de 1855 canalizó los recursos financieros hacia su construcción y los desvió del sector industrial y la franquicia arancelaria provocó la importación de hierros extranjeros, reduciendo así las posibilidades de la siderurgia nacional.

Sus conclusiones, en cambio, demuestran que debido al atraso español, en 1850 no se hubiera invertido capital extranjero a no ser por los actractivos que ofrecía la ley de 1855 y que la industria nacional no tenía la capacidad suficiente para afrontar la demanda de hierros, lo que hubiera retrasado aún más la construcción y elevado los costes. Al mismo tiempo la construcción de ferrocarriles resolvió el estrangulamiento de 
los transportes a mediados del siglo pasado. Según sus estimaciones hubiera sido necesario incrementar la capacidad de la industria siderúrgica doce veces en sólo diez años para poder cubrir la demanda ferroviaria en material fijo.

Leandro Prados de la Escosura contrasta en su artículo («Las relaciones reales de intercambio entre España y la Gran Bretaña durante los siglos XVIII y XIX ॥) la visión ampliamente aceptada en la historiografía española de una evolución adversa para nuestro país. Sus conclusiones cuestionan las hipótesis mantenidas por Fernández de Pinedo, Berend y Ranki y Sánchez Albornoz, acercándose a las tesis mantenidas por J. Nadal Farreras. Establece tres períodos: 19) 1714-1778, de estancamiento; 2 .) 1784-1879, de favorables precios relativos para las exportaciones, y 3.) 1879-1913, de intercambios desfavorables para España.

James Simpson estudia la producción de vinos en Jerez de la Frontera durante la segunda mitad del siglo XIX. Tras examinar el carácter de la agricultura jerezana, analiza los cambiós de los principales mercados de este vino. Antes de 1860 se incrementó la oferta de vinos, acompañada de una subida de los precios y de un posterior descenso, lo que indujo a los productores a intentar reducir los costes de producción. Situación que afectó de forma diferente a cosecheros, almacenistas y extractores.

Jaime García Lombardero describe los efectos de la protección arancelaria sobre la producción de cereales en España durante el período 1890-1910. Es claro que durante las dos últimas décadas del siglo pasado hubo una transformación del mercado nacional agrario. Sin embargo el aumento de la superficie sembrada fue absorbida en mayor proporción por cultivos de cereales, distintos del trigo y del maiz, y por las leguminosas. Por lo que el arancel proteccionista de 1891 no condujo a una extensión masiva y porcentualmente creciente del cutivo del trigo.

El trabajo de Sebastián Coll Martín («El coste social de la protección arancelaria a la minería del carbón en España, 1877-1925») se sitúa dentro de la corriente de la «nueva historia económica» de medir el ahorro social producido por la adopción de nuevos procesos de producción de bienes y servicios. Toda medida proteccionista, al imponer una fuerte barrera aduanera, implica una transferencia de renta de unos sectores a otros y un coste para el conjunto de la economía.

Sus conclusiones apuntan a que la existencia de protección arancelaria en este sector no parece tuvo relevancia para la renta nacional y su crecimiento a lo largo de este período, aunque suponía un reforzamiento de los defectos de la estructura fiscal española de estos años.

Pedro Tedde de Lorca presenta un trabajo sobre «El gasto público 
en España, 1875-1906: un análisis comparativo con las economías europeas». Dos factores, señala este autor, fueron !os que condicionaron el comportamiento del gasto público: la cuantia 1 a ztiva de la deuda y la imposibilidad de aumento de los gastos orc'ir ss. Lo cual impidió destinar recursos a otros fines, como servicios suciales o apoyo a la infraestructura económica. En esta etapa el sector público no pudo intervenir como impulsor de la modernización de la economía española.

Pablo Martín Aceña estudia la evolución del déficit público y la política monetaria durante la Restauración (1874-1923). Su objetivo es explicar cómo y en qué medida el déficit público incidió en la evolución monetaria y cómo interfirió en la instrumentalización y en los objetivos de la política monetaria. Al mismo tiempo presenta un análisis de los resultados presupuestarios de este período, aborda el tema de los efectos monetarios del déficit y estudia la relación entre el déficit público y la política monetaria durante estos años.

Carlos Barciela López analiza la intervención del Estado en la agricultura española entre 1936 y 1971. Dicha actuación, que fijaba los precios de los productos agrícolas, asignando los recursos productivos y controlando las producciones y el consumo, no consiguió los fines propuestos y fue un fracaso. Se basaba en una política improvisada con tintes autoritarios.

Finaliza el libro el trabajo de Francisco Comín sobre «La evolución del gasto del Estado en España, 1901-1972: construcción de dos teorías» (la ley de Wagner y del efecto desplazamiento de Peacock y Wiseman).

Este libro prueba, pues, el hecho de la difusión de las nuevas corrientes de la historiografía económica internacional en nuestro país y ofrece al historiador una serie de ensayos que permiten comprobar la utilidad de los análisis económicos en el estudio de la Historia.

ARTOLA, M.; TORTELLA, G.; BERNAL, A.M.; TOMAS Y VALIENTE, F.; MAINER, J.C. y otros, La España de la Restauración. Politica, economía, legislación y cultura. I Coloquio de Segovia sobre Historia Contemporánea de España, dirigido por M. Tuñón de Lara. Madrid, 1985, 545 págs.

Siguiendo la tradición de los Coloquios de Pau, se celebró en Segovia en abril de 1984 el I Coloquio sobre Historia Contemporánea de España, organizado por la Universidad Internacional Menéndez y Pelayo en colaboración con el Ayuntamiento de dicha ciudad. Dirigido por el prestigioso historiador M. Tuñón de Lara, su título era «Atraso económico y conflicto social: 1875-1914».

Fruto del coloquio es el presente libro que reseñamos en el que se recogen 20 de las 23 ponencias presentadas en él. La edición, bajo el 
cuidado del profesor J.L. García Delgado, está estructurada en cinco partes bien delimitadas: Sistema político, partidos y mentalidades; Industrialización y política económica; Aspectos de la cuestión agraria en la España contemporánea; El ordenamiento jurídico y la organización judicial, y Componentes de la escena cultural.

La ponencia de M. Artola, que encabeza la obra, sobre «El sistema político de la Restauración", pretende trazar y definir las características particulares del sistema canovista que configuraron el régimen de la Restauración así como señalar su defecto principal, la incapacidad de reconocer la importancia de los nuevos fenómenos sociales - socialismo y nacionalismo - y de reflejarla en las instituciones representativas.

A. Ma Calero Amor expone en «Los precursores de la Monarquía democrática» las corrientes de opinión y políticos que afirmaban la compatibilidad entre monarquía y democracia, cuando ambos aspectos se manifestaban antagónicos en la práctica. Destacan en primer lugar la corriente parlamentaria que inspiró la Constitución de 1869, en segundo lugar la corriente liberal que llevó a cabo las reformas políticas de los años 80 , protagonizada por los dirigentes más destacados del partido liberal y estimulada desde fuera por los republicanos posibilistas, $y$ en tercer lugar, ya en el siglo XX, la del partido reformista.

El significado político de Maura y el maurismo en el marco de la Monarquía de la Restauración, así como los límites y las contradicciones de la propuesta maurista de la "revolución desde arriba», son estudiados por Mercedes Cabrera («El conservadurismo maurista en la Restauración»).

Los estudios de Ma Cruz Mina («Elecciones y partidos en Navarra (1891-1923)») y de M. Victoria López Cordón Cordero («La mentalidad conservadora durante la Restauraciónı) cierran este primer apartado. En el segundo artículo la autora estudia ciertos tópicos del pensamiento español de la época a cuya formación y divulgación ayudó la Iglesia (la proclamación de la unidad inseparable de España y el catolicismo, la defensa de la armonía social o la batalla por el control de la educación, etc.).

Entre los estudios de tipo económico destaca el de G. Tortella sobre "La economía española a finales del siglo XIX y principios del XX». En él esboza la perspectiva económica de un país atrasado, encerrado en sí mismo, con una agricultura pobre, casi sin industria, que se ha de adaptar a unas nuevas circunstancias para iniciar un proceso de crecimiento. Su exposición trata de resolver preguntas claves que expliquen el atraso español así como su recuperación y reconversión lenta. Las relaciones comerciales de nuestro país con Francia e Inglaterra sirvieron para compensar en parte la pérdida de las colonias americanas. Lo que demostraría, en su opinión, que las relaciones económicas en- 
tre un país atrasado y los países avanzados no tienen por qué perjudicar a aquél.

Otros temas de índole económica son los estudios de M. González Portilla sobre "Las nuevas siderurgias vascas y los primeros sindicatos (cárteles) siderúrgicos (1886-1896)» (los nuevos altos hornos vizcaínos representaban el despegue definitivo de la industria siderúrgica española), el de P. Martín de Aceña «La política monetaria durante la Restauración (1874-1914)» y el de F. Comín "La política fiscal en España entre 1874 y 1914: algunas precisiones» (en el que describe las manipulaciones realizadas en las variables presupuestarias entre ambas fechas.

* Aspectos de la cuestión agraria en España incluye cinco trabajos del máximo interés. Antonio M. Bernal estudia «La llamada crisis finisecular (1872-1919)», señalando las características propias de nuestro país, donde la crisis fue más breve y menos intensa que en Europa y provocó manifestaciones de violencia campesina. Sus conclusiones superan el planteamiento reduccionista, que hacía coincidir por completo la crisis agraria con la cuestión triguera, quedando al mismo tiempo en entredicho las hipótesis que hacían recaer la responsabilidad de la crisis en el atraso.e inmovilismo del sector agrícola, planteándose al mismo tiempo si estamos ante una crisis coyuntural o estructural. Como condicionantes de la crisis sitúa la cuestión histórica de la propiedad de la tierra y sus costos sociales (miseria y conflictividad campesinas).

Jesús Sanz Fernández estudia en «La crisis triguera finisecular: los últimos años», la cuestión de los flujos comerciales de carácter interregional, del trigo y de la harina, abordando así el tema de la crisis triguera finisecular desde una nueva óptica.

Ricardo Robledo Hernández plantea en «La renta de la tierra en la crisis de fines del siglo XIX: variantes regionales», la evolución de la renta en el último tercio del siglo y principios del $X X$ en algunas regiones del interior, observando si otras de la periferia siguieron o no dicha evolución. A su vez insinúa algunas hipótesis en torno a la dinámica de la propiedad de la tierra en unas regiones y otras (menor intesidad y diferente cronología en el acceso del arrendatario castellano a la propiedad; mayor proletarización, a partir de los años de la gran depresión, actuando como mecanismo expropiador de la renta, en el área salmantina, etc.).

El estudio del caso valenciano es analizado por Ramón Garrabou ( «Sobre la modernidad de la agricultura valenciana en la segunda mitad del siglo XIX»). Aquí el crecimiento agrario durante la segunda mitad del siglo se alcanzó no a través de las innovaciones que habian revolucionado la agricultura inglesa sino por la vía de la especialización en plantas arbóreas y arbustivas en el secano y mediante la intesificación del trabajo y especialización en hortalizas, frutales, arroz, etc. $Y$ 
este crecimiento agrario valenciano descansó en gran parte en la explotación campesina.

Finaliza este apartado el estudio de Carlos Serrano titulado «Hacia la reforma agraria: Maeztu, Unamuno y la Meseta castellana (1898-1899)/).

El apartado cuarto, dedicado al ordenamiento jurídico y la organización judicial, incluye estudios de gran interés, sobre cómo nació y se elaboró el Código Civil vigente desde hace casi un siglo, "Los supuestos ideológicos del Código Civil: el procedimiento legislativo» de Francisco Tomás y Valiente, que fundamentaba el orden social sobre una concepción individualista de la propiedad; "El código de comercio de 1885» de E. Gacto Fernández y "Codificación procesal y estado de la administración de justicia (1875-1915)» de A. Fiestas Loza.

Finaliza el último apartado con varios estudios de algunos de nuestras mejores fuentes literarias: "Ortega: primeras armas (1902-1914)» de José Carlos Mainer, "El Europeismo de la España Moderna» de Raquel Asún y «Regeneracionismo y literatura en la revista Cultural Española (1906-1909)» de Maria Dolores Albiach.

Como se puede observar la multiplicidad de temas y ópticas recogidas en estos trabajos permiten conocer y abordar mejor el tema de la Restauración. Frente a la historiografía tradicional que señalaba sobre todo la estabilidad del régimen y la prosperidad económica, sólo modificada tras el desastre del 98, las investigaciones actuales insisten en la revisión crítica que algunos sectores minoritarios hicieron del sistema y en la crisis de final del siglo, que refleja los cambios experimentados en la formación social española durante el largo y complejo proceso del desarrollo del capitalismo.

El rigor académico y científico de las distintas comunicaciones presentadas en este coloquio hará sin duda fructificar otros estudios de carácter regional o general sobre esta etapa tan importante de nuestra historia. 


\section{MEMORIAS DE LICENCIATURA: \\ RESUMENES DE LAS MEMORIAS DE LICENCIATURA LEIDAS EN EL DEPARTAMENTO DE HISTORIA CONTEMPORANEA DE LA UNIVERSIDAD DE ALICANTE}

VALDES CHAPULI, Caridad: La Fábrica de Tabacos de Alicante: materiales para una historia social y económica.

Leída el 26 de abril de 1985. Director: Dr. Salvador Forner Muñoz. 

Desde comienzos del siglo XIX hasta nuestros días, La Fábrica de Tabacos de Alicante ha tenido una especial significación en la vida económica y laboral de la Ciudad de Alicante.

Dicha fábrica fue la tercera construida en España, tras la de Sevilla y Cádiz, y ha atravesado a lo largo de su existencia distintas etapas, como consecuencia tanto de los cambios ocurridos en el monopolio de la explotación del tabaco en España como de los cambios técnicos económicos por los que ha atravesado la misma.

La memoria de licenciatura de Caridad Valdés ha tenido como base el estudio de una importante documentación del Archivo Histórico Provincial y, sobre todo, de los propios fondos archivísticos de la Fábrica de Tabacos de Alicante, muy abundantes desde mediados del siglo XIX.

En el trabajo se estudia, en primer lugar, la evolución y el desarrollo histórico de la institución, con especial hincapié en las formas de fabricación del tabaco, evolución de la producción y organización del trabajo. En una segunda parte se analizan todos los apectos relacionados con el personal obrero de la Fábrica: evolución y composición del mismo y consecuencias de la progresiva maquinización en el volumen y características de la masa laboral. Por último, se estudian las condiciones sociales y económicas de los trabajadores, las formas y niveles de sindicalización y los sistemas de previsión y ayuda establecidos por el propio personal obrero, incluyéndose también un análisis de la evolución y características de la conflictividad laboral y social entre 1887 y 1936.

El estudio se complementa con una serie de apéndices documentales de gran valor informativo, constituyendo en su conjunto una aportación muy interesante para el conocimiento de importantes aspectos económicos y sociales de la vida local y de un sector tan importante de la población como el femenino, ya que la Fábrica de Tabacos de Alicante llegó a dar trabajo, a fines del siglo XIX, a más de 4.000 mujeres. 

